\title{
Failure Behavior of Pultruded GFRP Members Under Combined Bending and Torsion
}

\author{
Muhammad Asif Mahmood Qureshi \\ West Virginia University
}

Follow this and additional works at: https://researchrepository.wvu.edu/etd

\section{Recommended Citation}

Qureshi, Muhammad Asif Mahmood, "Failure Behavior of Pultruded GFRP Members Under Combined Bending and Torsion" (2012). Graduate Theses, Dissertations, and Problem Reports. 3575.

https://researchrepository.wvu.edu/etd/3575

This Dissertation is protected by copyright and/or related rights. It has been brought to you by the The Research Repository @ WVU with permission from the rights-holder(s). You are free to use this Dissertation in any way that is permitted by the copyright and related rights legislation that applies to your use. For other uses you must obtain permission from the rights-holder(s) directly, unless additional rights are indicated by a Creative Commons license in the record and/ or on the work itself. This Dissertation has been accepted for inclusion in WVU Graduate Theses, Dissertations, and Problem Reports collection by an authorized administrator of The Research Repository @ WVU.

For more information, please contact researchrepository@mail.wvu.edu. 


\title{
Failure Behavior of Pultruded GFRP Members Under \\ Combined Bending and Torsion
}

\author{
Muhammad Asif Mahmood Qureshi
}

\author{
Dissertation Submitted to the \\ Benjamin M. Statler College of Engineering and Mineral Resources \\ at West Virginia University \\ in partial fulfillment of the requirements \\ for the degree of
}
Doctor of Philosophy
In
Civil Engineering

\author{
Hota V.S. GangaRao, Ph.D., Chair \\ Udaya B. Halabe, Ph.D. \\ Roger Chen, Ph.D. \\ Jacky C. Prucz, Ph.D. \\ Robert C. Creese, Ph.D. \\ Bhyrav Mutnuri, MSME
}

Department of Civil and Environmental Engineering

\author{
Morgantown, West Virginia
}

2012

Keywords: Pultruded GFRP Composite Sections, Orthotropy, Torsion, Bending, Combined Loading, Strength-Failure, Buckling, Warping 


\begin{abstract}
Glass fiber reinforced polymer (GFRP) composite sections, manufactured through pultrusion process, are known for their high strength-to-weight ratio, corrosion resistance, low thermal conductivity, electric and magnetic transparency, low life cycle cost and ease of fabrication. They are being widely applied in infrastructure systems.

The load response of thin-walled GFRP composite sections is different from that of isotropic slender members. For instance, stress variation exists across the wall thickness and the FRP members are more prone to warping and local buckling including shear-lag. The literature survey revealed that the response of pultruded GFRP sections under combined bending and torsion has not yet been studied both in terms of the strength and stiffness.

Thru this research, the behavior of full scale sections was investigated under bending, torsion and combined bending and torsion. The shapes under investigation include circular, square and wide-flange with dimensions from 2" to 6" and lengths from 24" to 144". The analytical part is based on modified flexural and torsional theories for anisotropic materials.

Due to the absence of any formulation on combined bending and torsion of orthotropic sections, the formulae for isotropic sections were extended for orthotropic ones. Some finite element analysis models were also included to make a comparison.

The experimental work consists of (i) determining the laminate properties at coupon level through tension-tests, shear-tests, burnout-tests and microscopy, and (ii) investigating the behavior of full-length samples under 3-point bending, pure torsion and combined bending and torsion. Under torsion and combined loading, a dedicated apparatus was designed, fabricated, instrumented and calibrated at WVU-CFC Major Units laboratory. This apparatus is capable of incorporating samples of cross-sections up to 6 " $\times 6$ " and lengths up to 144 "; with the angle of twist measurement ranging from $+60^{\circ}$ to $-60^{\circ}$.

It was found from coupon tests that strength and modulus values are measurable with a reasonable range of accuracy, but fiber alignment and fiber volume fraction may vary along the cross-section. The bending behavior of full-length closed-sections was controlled by strength and that of wide-flange sections was due to flange-buckling. The torsional behavior of closed sections was also strength controlled, while the wide-flange section practically showed no torsional strength. The behavior under combined bending and torsion was influenced by principal stresses and maximum shear stresses under the effect of compressive bending and torsional shear stresses. On the $\mathrm{T} / \mathrm{T}_{\max }-\mathrm{M} / \mathrm{M}_{\max }$ interaction curve, some of the data-points agreed-well with the ideal curve, while the others lay beyond that. The reasons of deviation were investigated to be load rate, variations in fiber content and different types of losses in the apparatus.
\end{abstract}




\section{ACKNOWLEDGEMENTS}

Thanks and praises to God Almighty, the Lord of the two worlds, who enabled me to complete this research work. After that, I am indebted to all those who helped me in any form at any stage of my work.

I really value and regard the US education system and working environment; professionally advanced and efficient, socially comfortable and friendly.

Special thanks to Prof Dr Hota V.S. GangaRao whose accurate supervision and guidance played a key role in the completion of this project in a timely manner while maintaining a high standard. The last four and half years under his supervision have been a great opportunity of learning. He has been very kind and helpful in every regard.

I am also thankful to all of the committee members. Thanks to Prof Dr Udaya B. Halabe for his interest, guidance and practical tips. I had a great time in attending to his courses. Prof Dr Roger Chen has been very helpful and motivating in this research and in the course he taught. Prof Dr Robert Creese has been a source of inspiration for me. He gave me the sense of professionalism: maintain the quality of work without indulging into unnecessary complications. Prof Dr Jacky Prucz always gave useful pieces of advice on different aspects of this research. I am also thankful to him. Mr Bhyrav Mutnuri kept updating me on the practical aspects of design and manufacturing of pultruded sections.

The faculty, staff and students of the Constructed Facilities Center work with a true team spirit and being a part of this team is an honor for me. Dr P.V. Vijay and Dr Ray Liang always provided their help and guidance, whenever requested to. Mr Mark Skidmore also extended his help many times in the experimental work. Most of the experimental work was done at WVUCFC major units laboratory and it might not be possible without Mr Jerry Nestor. From fabrication of the apparatus to testing of each and every sample, his contribution and support has been invaluable. I am also thankful to Mr Abdullah Ibrahim for providing help in FEA modeling. 
I also appreciate the cooperation of all my colleagues. Many of them have graduated and the rest are on their way to graduation. My seniors Mr Aneesh Bethi, Mr Aymen Bataineh and Mr Manab Medhi were very helping and friendly. Then my colleagues Mr Sidda Lingish, Mr Vamsi Tolikonda, Mr Venugopal Chada, Mr David Dittenber, Mr Denny Dispennette, Mr Praveen Kumar and Mr Ken Donald have been very cooperative and friendly.

Last, but not least, I want to say thanks to all the administrative staff, for taking care of the issues I am not good at. Thanks to Lynne Jacobs for taking care of finances. Special thanks to Late Ms Kimberley of CEE Department and Ms Linda Cox of Students Services, who retired a few months ago. 


\section{Dedicated to}

- the endless and countless bounties and mercies of God Almighty

— the sacrifices, supplications and affection of my late parents

- the patience and cooperation of my wife Attia and children Safi and Fatima

— the well-wishes and support of my relatives and friends 


\section{TABLE OF CONTENTS}

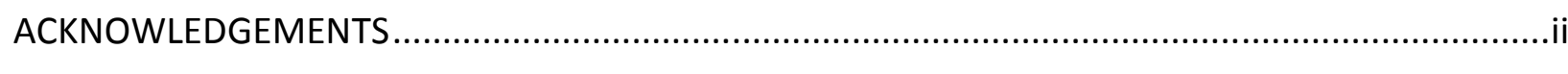

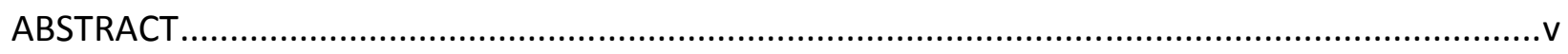

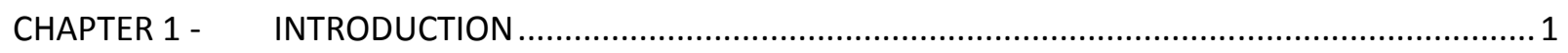

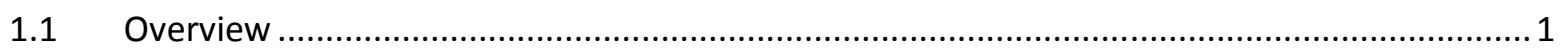

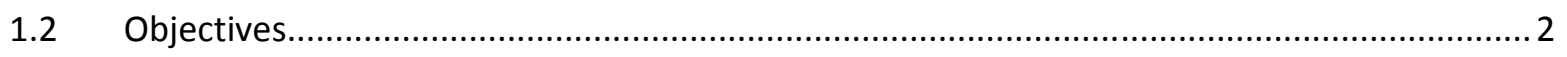

1.3 Scope

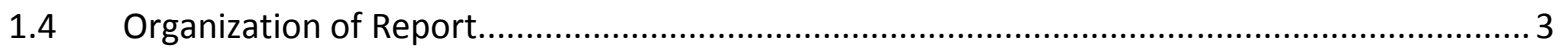

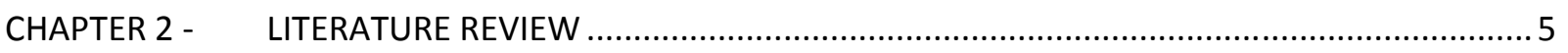

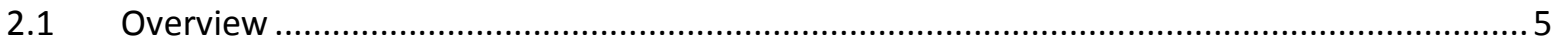

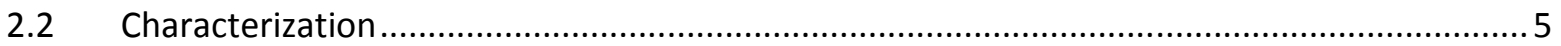

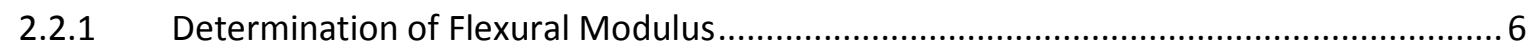

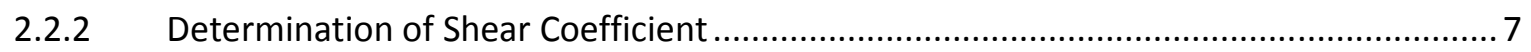

2.2.3 Determination of Shear Modulus …......................................................................... 7

$2.3 \quad$ Strength and Deformation Prediction................................................................................ 9

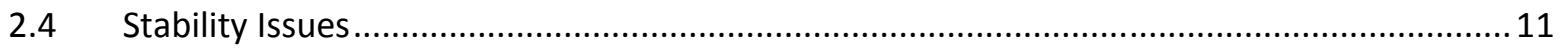

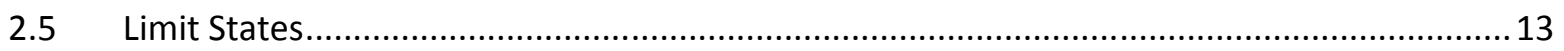

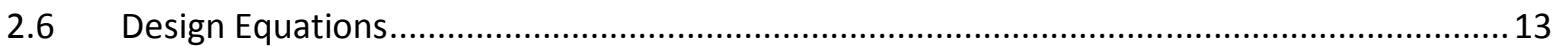

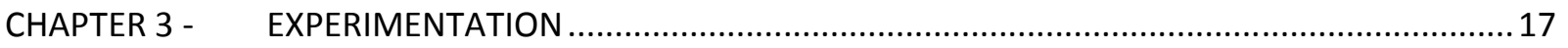

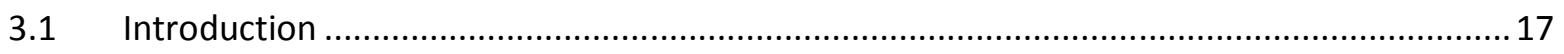

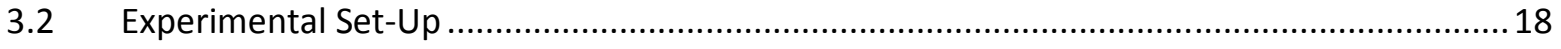

3.2.1 Experimental Set-Up for Laminate Properties .......................................................... 18

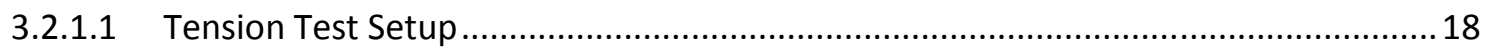

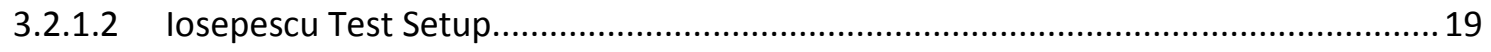

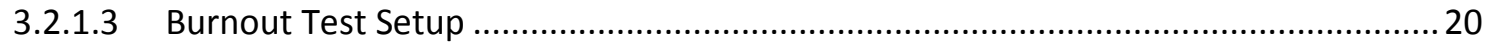

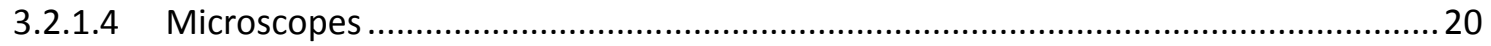

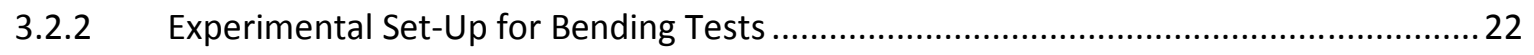

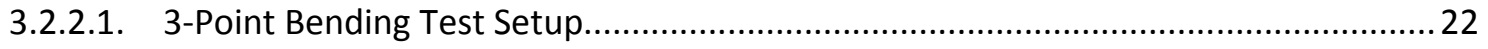

3.2.2.2. Setup for Other Types of Bending Tests ................................................................ 23

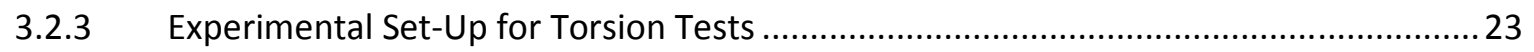

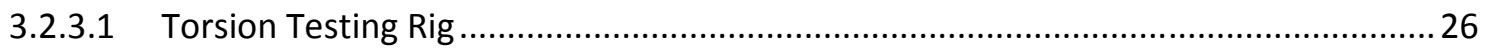




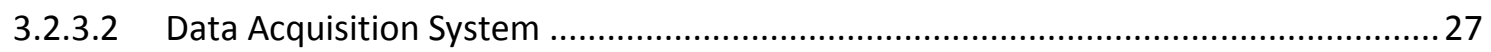

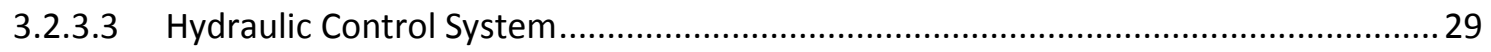

3.2.4 Experimental Set-Up for Combined Bending and Torsion ..............................................29

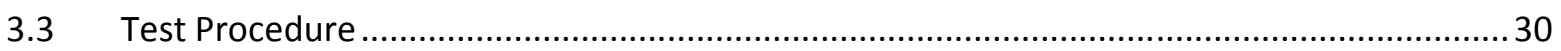

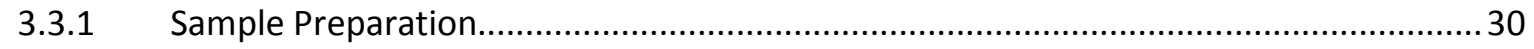

3.3.1.1 Sample Preparation for Laminate Properties …....................................................... 30

3.3.1.2 Samples Preparation for 3-Point Bending Tests .................................................... 33

3.3.1.3 Torsion Test Sample Preparation .......................................................................... 34

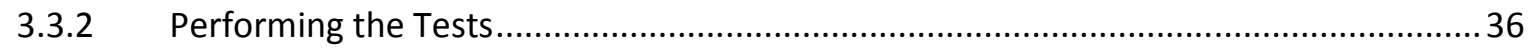

3.3.2.1 Performing the Tests for Laminate Properties......................................................... 36

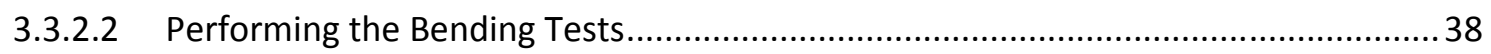

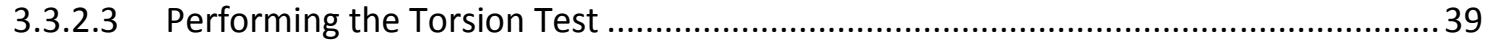

3.3.2.4 Performing the Combined Bending and Torsion Test............................................. 40

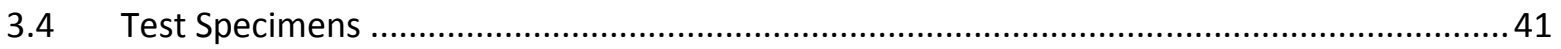

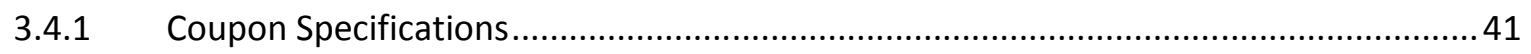

3.4.2 Specifications of Bending Test Samples................................................................... 41

S.4.3 Specifications of Torsion Test Samples .......................................................................... 42

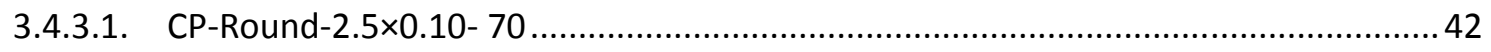

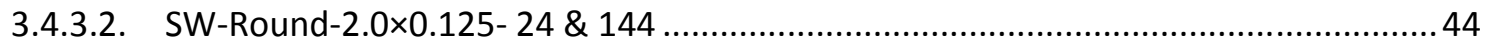

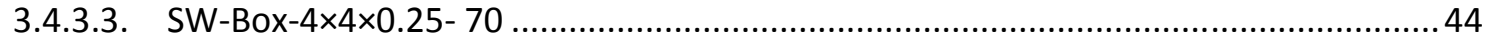

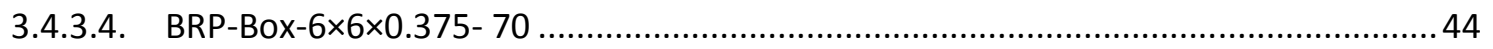

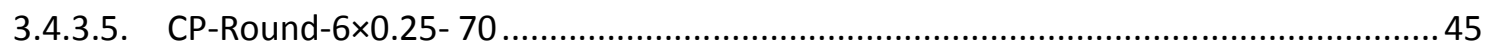

3.4.4 Specifications of Combined Bending and Torsion Test Samples ..................................45

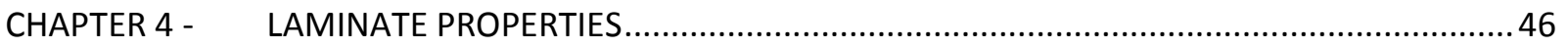

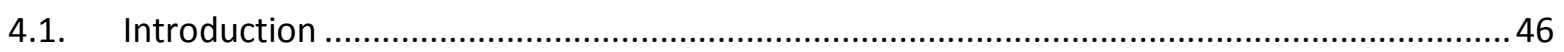

4.2. Problem Formulation: Classical Laminate Theory (CLT) ................................................ 46

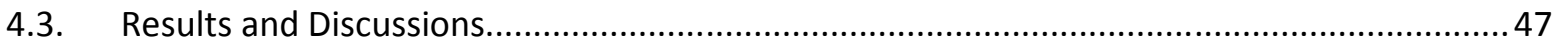

4.3.1 Coupon Tension Test Results ................................................................................. 47

4.3.1.1 BRP-Box-6×6×3/8-Longitudinal and Transverse Coupons ......................................... 47

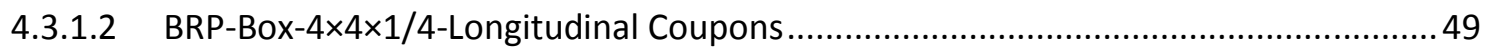

4.3.1.3 SW-Box-4×4×1/4-Longitudinal and Transverse Coupons ........................................5 50

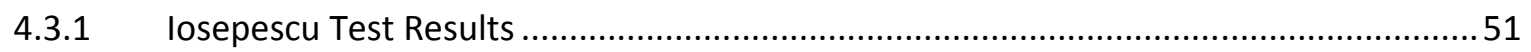




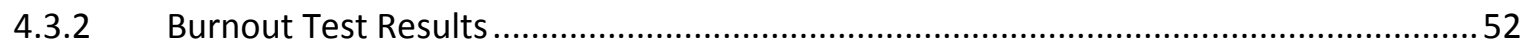

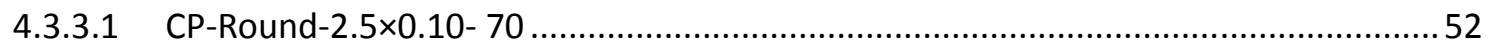

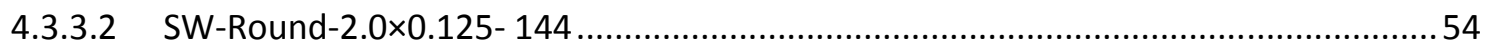

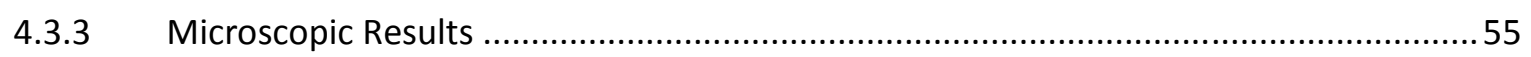

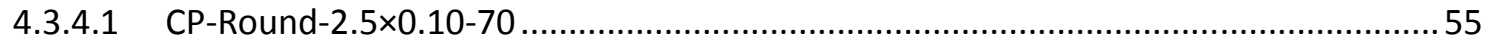

4.3.4.2 Micrographs of SW-Round-2.0×0.125/12L ........................................................... 57

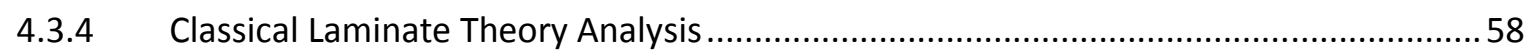

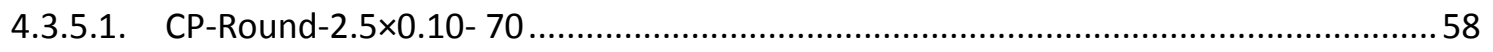

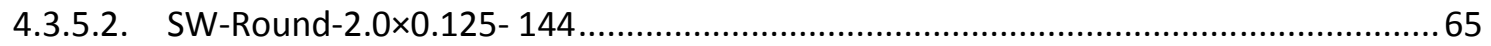

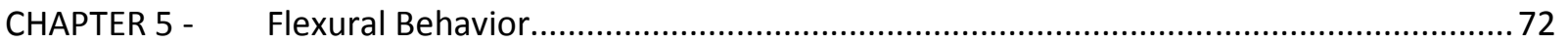

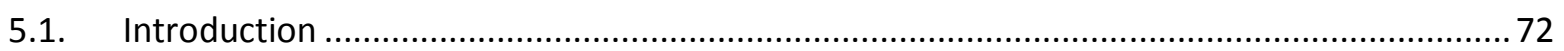

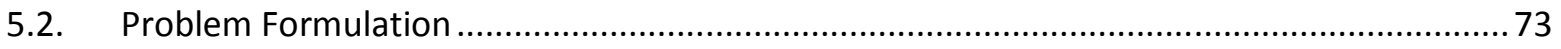

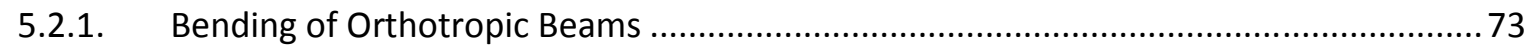

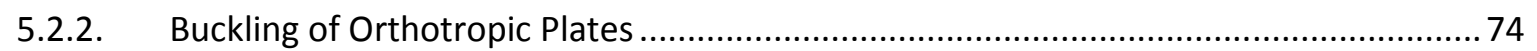

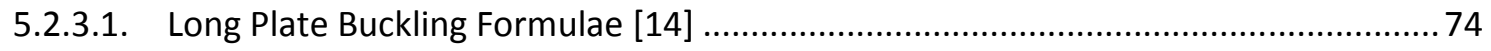

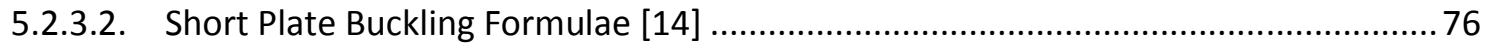

5.2.3. Design Equations of ASCE-LRFD Pultruded Sections Draft Manual ............................... 76

5.2.3.1. Nominal Strength Due to Material Rupture [1] .................................................... 77

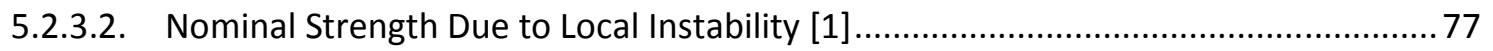

5.2.3.3. Nominal Strength Due to Lateral-Torsional Buckling [1] ........................................ 78

5.2.3.4. Nominal Strength Due to Material Rupture in Shear [1] ........................................ 78

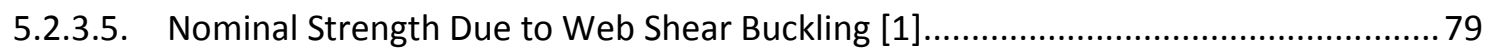

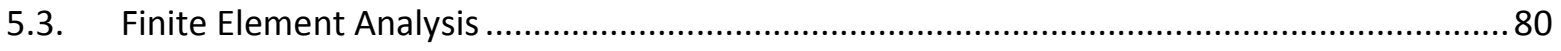

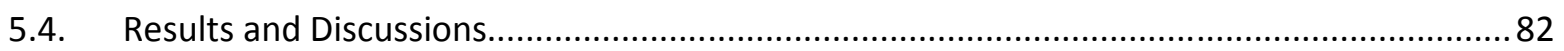

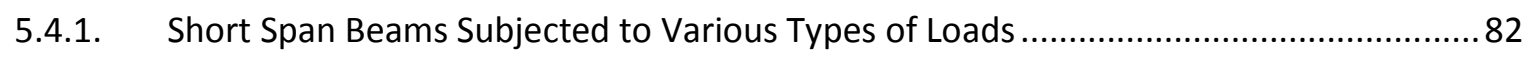

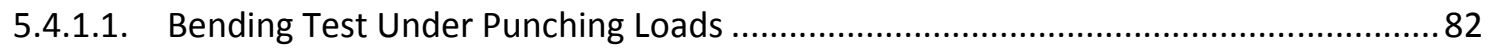

5.4.1.2. Bending Test Results With Loading Plate Longer Than Flange-Width ........................ 86

5.4.1.3. Bending Test Results With Uniformly Distributed Load .......................................... 87

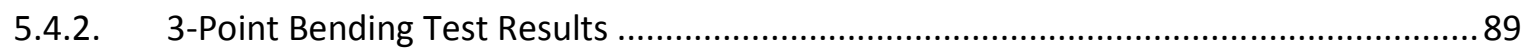

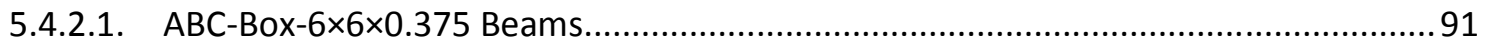

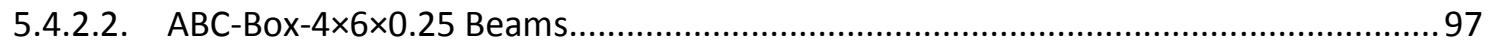

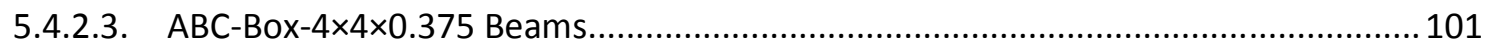




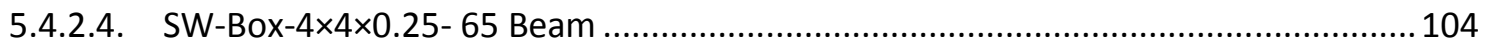

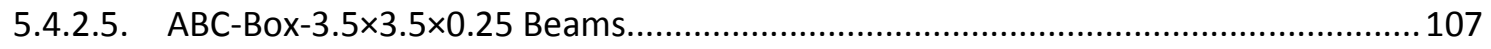

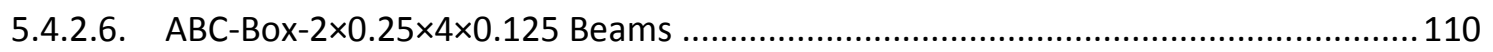

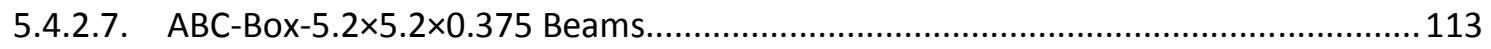

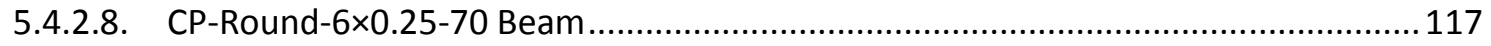

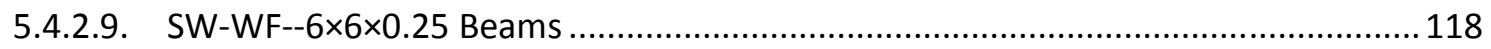

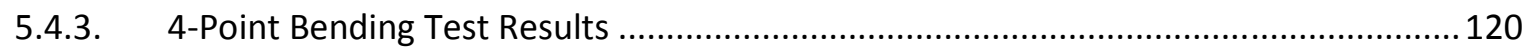

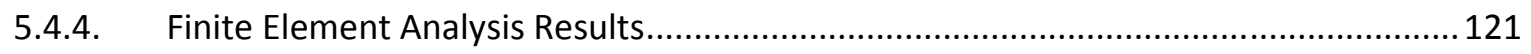

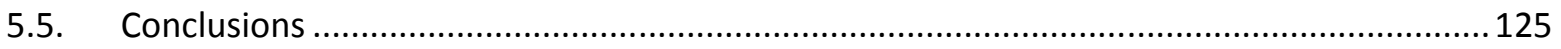

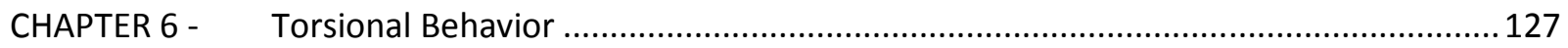

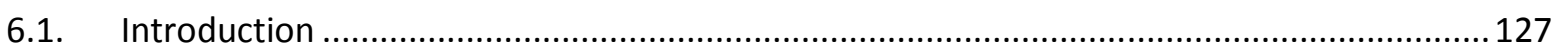

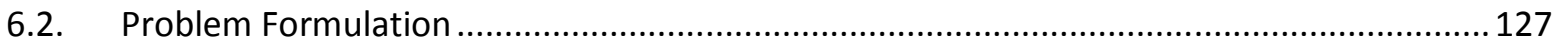

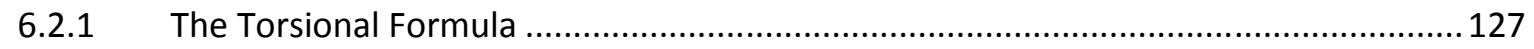

6.2.2 Simplified Classical Laminated Theory (SCLT) for Torsion ........................................ 129

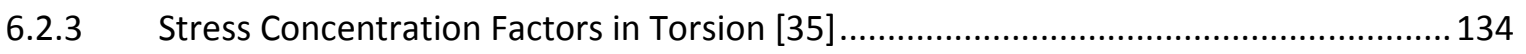

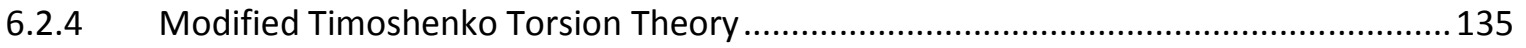

6.2.5 Design Equations of ASCE-LRFD Pultruded Sections Draft Manual [1] .........................138

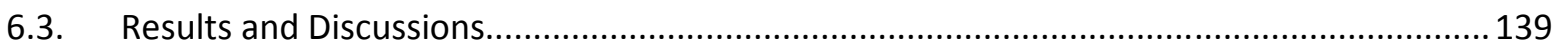

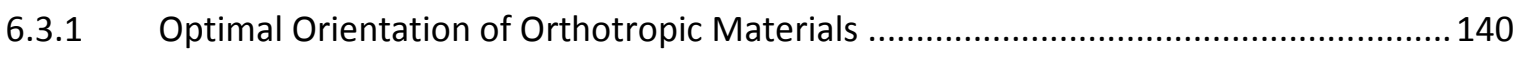

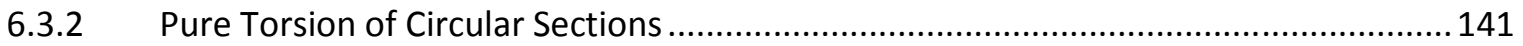

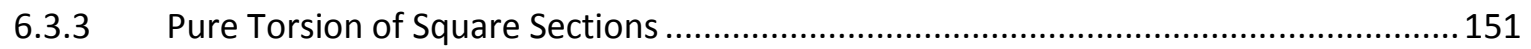

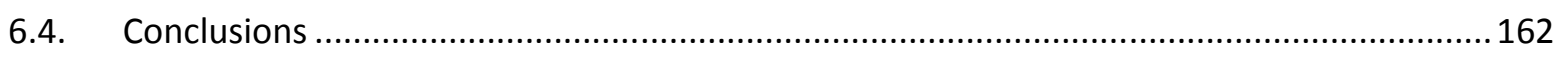

6.4.1 General Torsional Failure Behavior of Close-Shaped FRP Composite Members .......... 162

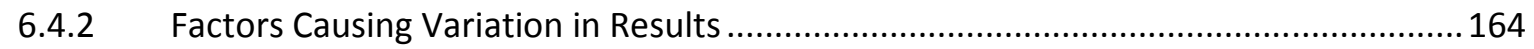

6.4.2.1. Inhomogeneous Material Structure of FRP Composites ........................................ 164

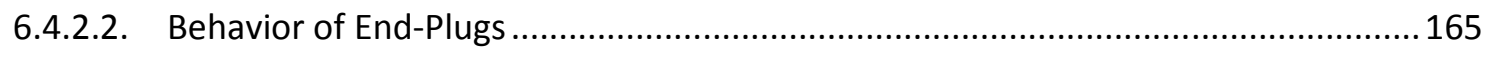

6.4.2.3. Frictional Losses in The Torsional Testing Rig .......................................................... 165

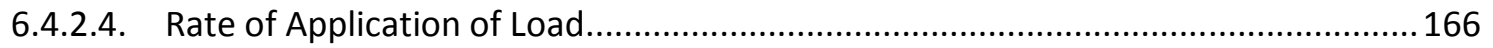

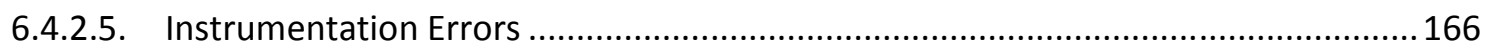

CHAPTER 7 - Behavior Under Combined Bending and Torsion................................................ 167

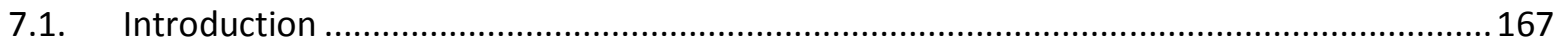

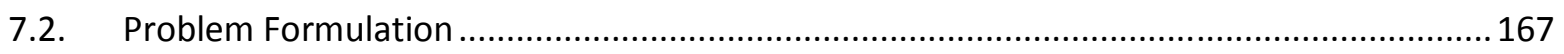


7.2.1 Strength Failure under Combined Bending and Torsion ......................................... 167

7.2.2 Buckling under Combined Bending and Torsion....................................................... 171

7.2.2.1 Orthotropic Sections Under Combined Bending and Torsion .................................. 171

7.2.2.2 Orthotropic Section Under Warping Effect............................................................... 175

7.2.2.3 Orthotropic Section Under Compressive Axial Load............................................... 177

7.2.2.4 Orthotropic Section Under Combined Flexural, Torsional and Axial Loading ..........178

7.2.2.5 Orthotropic Doubly Symmetric Sections Under Combined Flexural, Torsional and

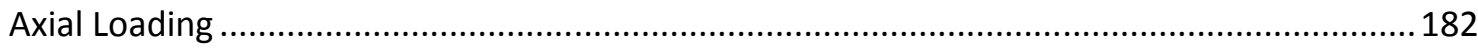

7.2.3 Design Equations of ASCE-LRFD Pultruded Sections Draft Manual [1] ........................ 184

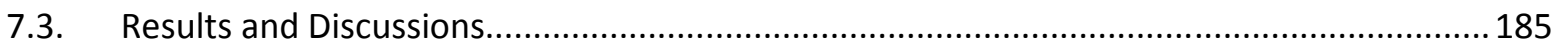

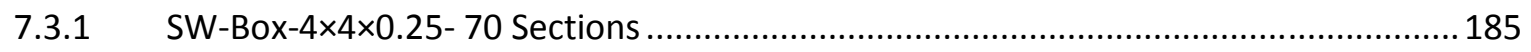

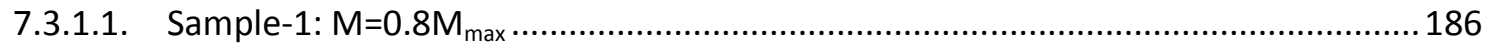

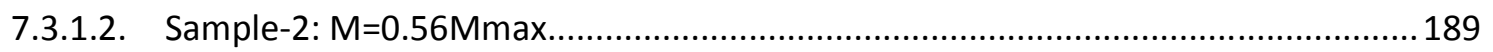

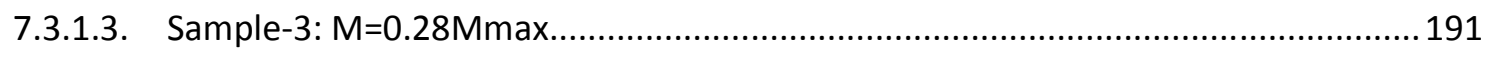

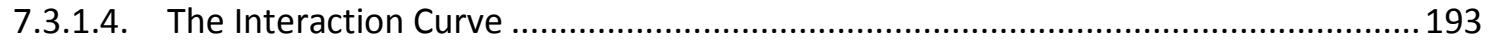

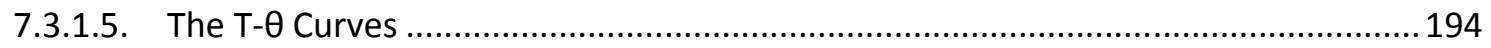

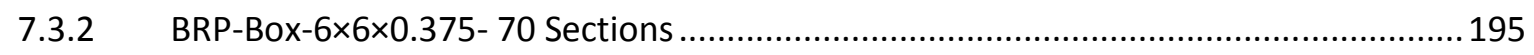

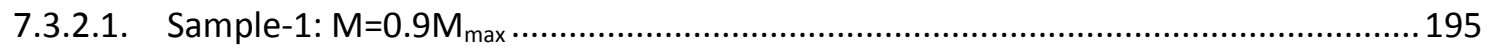

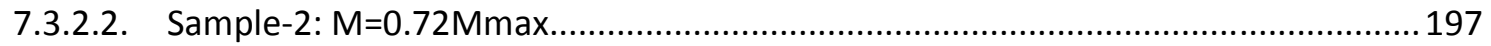

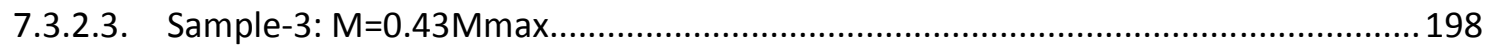

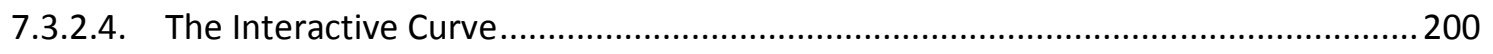

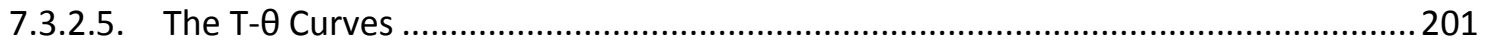

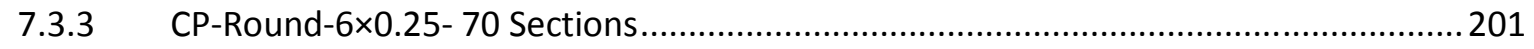

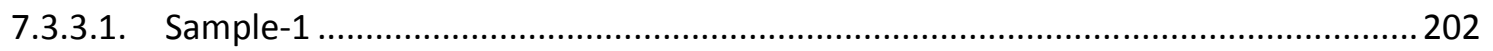

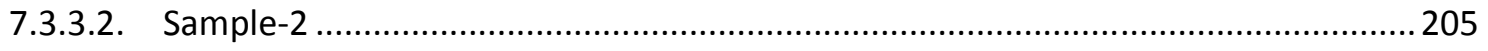

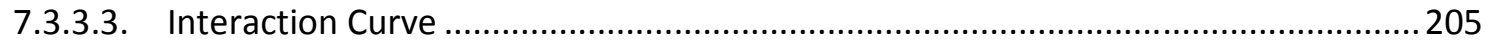

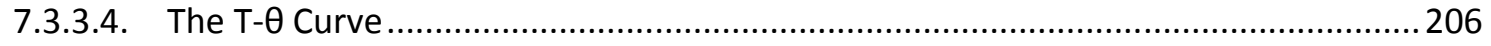

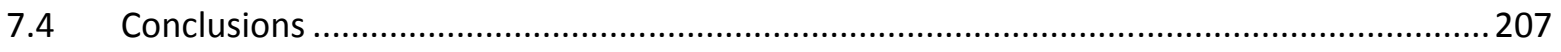

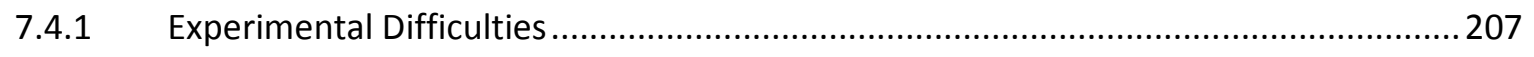

7.4.2 Response of Samples Against Combined Bending and Torsion ..................................208

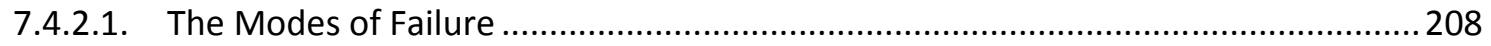

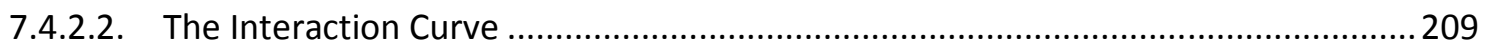




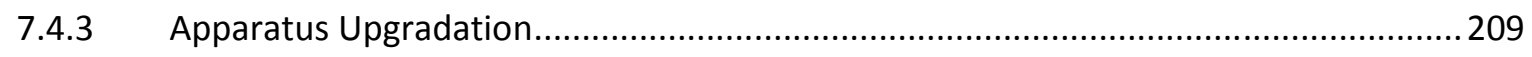

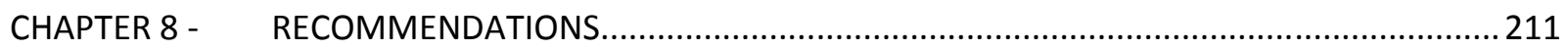

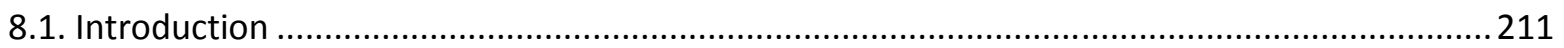

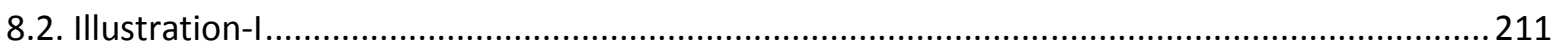

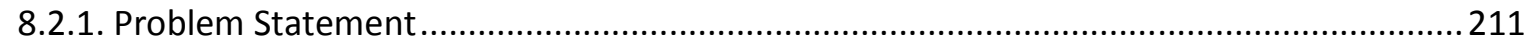

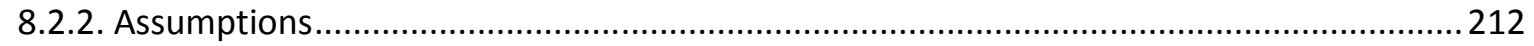

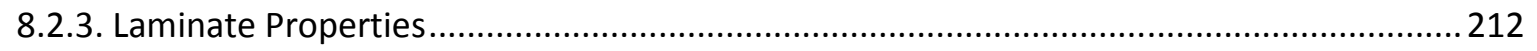

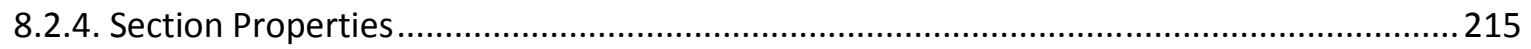

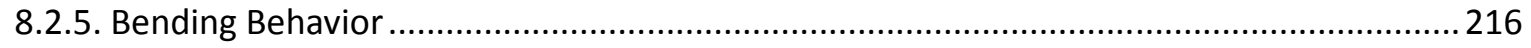

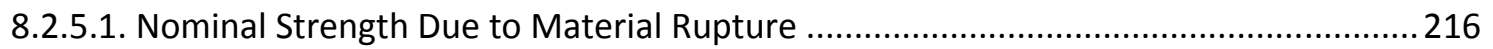

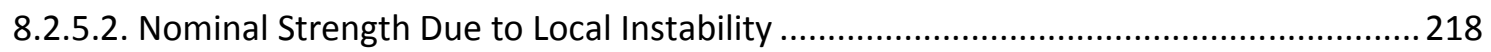

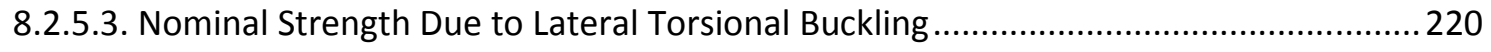

8.2.5.4. Nominal Strength Due to Material Rupture in Shear .................................................. 222

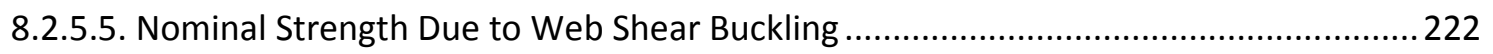

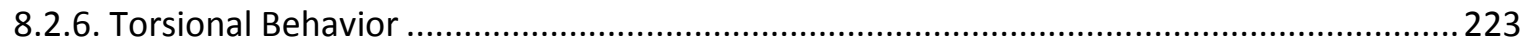

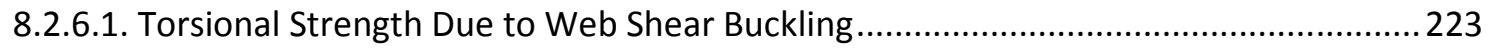

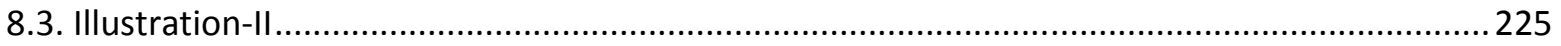

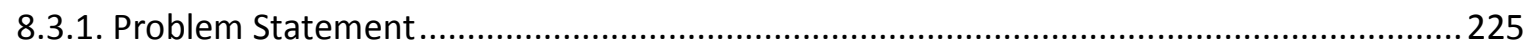

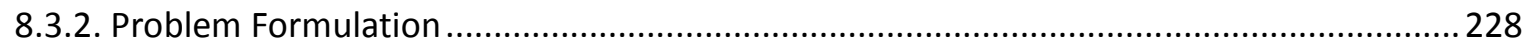

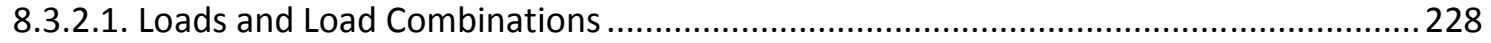

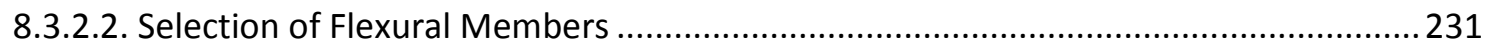

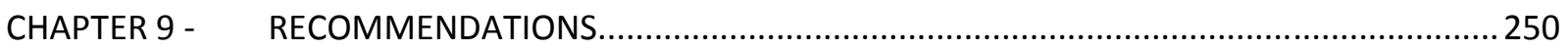

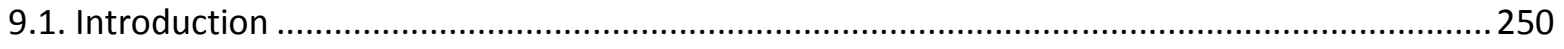

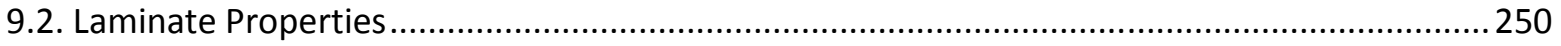

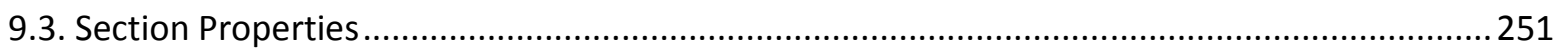

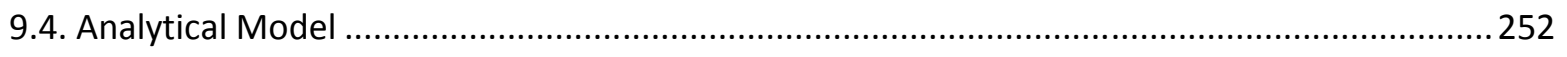

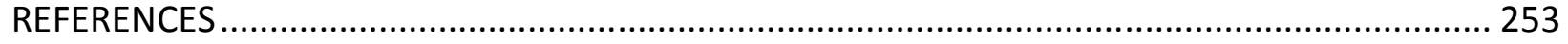

APPENDIX-A: Classical Laminate Theory (CLT) ............................................................... 256

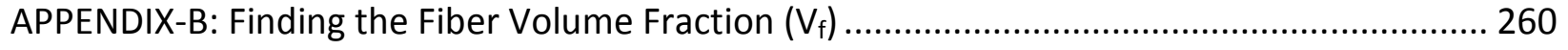

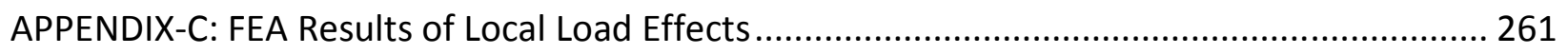




\section{LIST OF FIGURES}

Figure 3-1: Tension Test Setup for Longitudinal and Transverse Coupons ............................................ 18

Figure 3-2: Iosepescu Test Fixture s ........................................................................................... 19

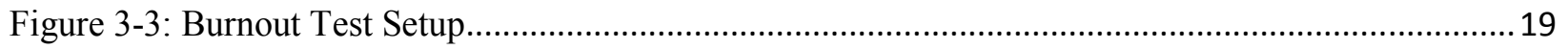

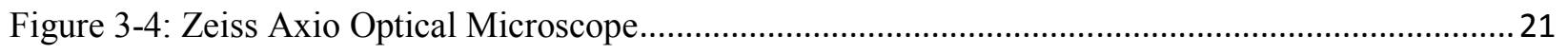

Figure 3-5: Hitachi S-4700 Field Emission Scanning Electron Microscope ........................................... 21

Figure 3-6: 3-Point Bending Test Setup at Bedford Plastics Inc. ........................................................ 22

Figure 3-7: 3 Load Scenarios of Bending Test of Short-Span Beams at Compression Side of Instron

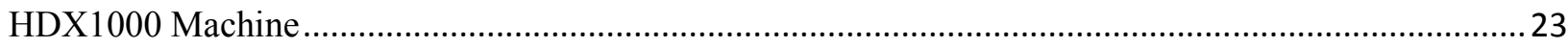

Figure 3-8: Schematic Diagram of the FRP Composites Torsion Testing Apparatus .............................. 24

Figure 3-9: Pictorial View of the FRP Torsion Testing Apparatus ....................................................... 25

Figure 3-10: Pictorial Views of the Torsional Testing Rig ............................................................... 26

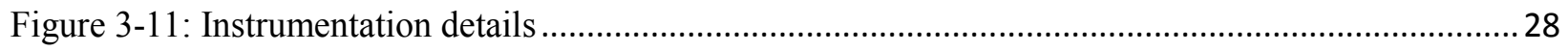

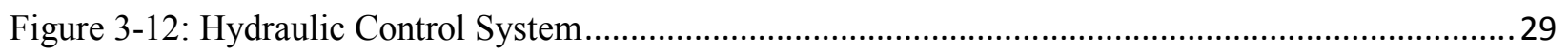

Figure 3-13: Experimental Set-Up for Combined Bending and Torsion ............................................... 30

Figure 3-14: End-Tabs of a Longitudinal Coupons ....................................................................... 31

Figure 3-15: End-Tabs of a Transverse Coupon ................................................................................ 31

Figure 3-16: Longitudinal and transverse Shear Test Samples with V-Notches ...................................... 32

Figure 3-17: Various Stages of SEM Sample Preparation.................................................................. 33

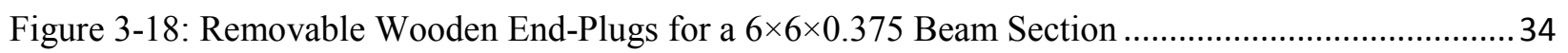

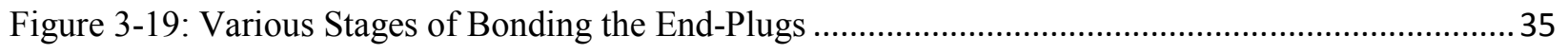

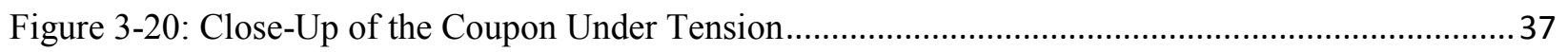

Figure 3-21: A Torsion Test Sample Ready for Testing .................................................................... 40

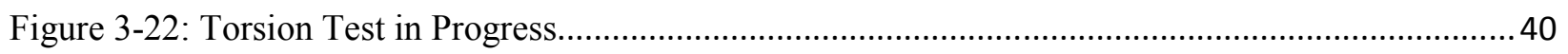

Figure 3-23: Manufacturer's Specifications of the CP-Round-2.5×0.1/6L Sample ................................. 43

Figure 3-24: Fiber Layout of the Inner Layer (VectorPly C-TTX 1800).................................................43

Figure 4-1: $\sigma-\varepsilon$ Curves with E values of BRP-Box- $6 \times 6 \times 3 / 8$ Longitudinal Coupons ................................ 47

Figure 4-2: $\sigma-\varepsilon$ Curves with E values of BRP-Box- $6 \times 6 \times 3 / 8$ Transverse Coupons .................................... 48

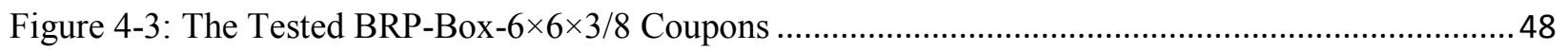

Figure 4-4: $\sigma-\varepsilon$ Curves with E values of BRP-Box- $4 \times 4 \times 1 / 4$ Longitudinal Coupons ................................. 49

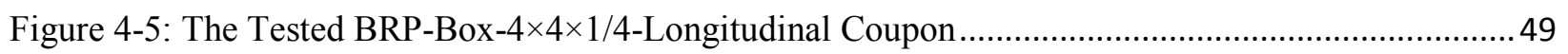

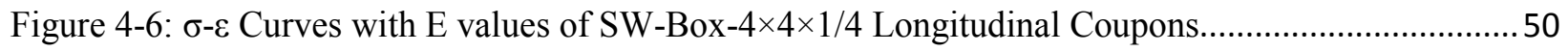

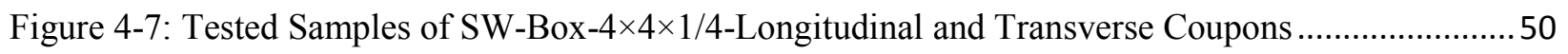

Figure 4-8: Burnout Test Results of CP-Round-2.5×0.10/6L Coupon ...................................................5

Figure 4-9: Fiber Architecture of the CP-Round-2.5×0.10/6L Specimen.............................................. 53

Figure 4-10: Burntout SW-Round-2.0×0.125- 144 Sample: Plies Separated and Weighed .......................55

Figure 4-11: Microscopic Views of the CP-Round-2.5×0.10/6L ........................................................5 56

Figure 4-12: Optical Micrographs of SW-Round-2.0×0.125/12L ........................................................5 57

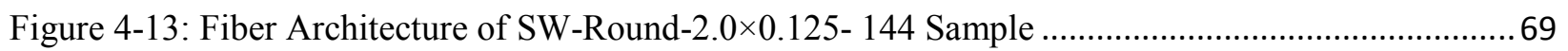

Figure 5-1: Notations of orthotropic beam sections used in Equation 5-4, 5-5 and 5-6 [14]...................73

Figure 5-2: Boundary conditions for the buckling loads on a long plate [14] ........................................ 75 
Figure 5-3: Buckled Shape of a Long Plate with Simple Supports [14] ................................................ 75

Figure 5-4: Boundary conditions for the buckling loads on a short plate [14] ........................................ 76

Figure 5-5: Unit Load Distributed at the Two Webs at Mid-Span ...................................................... 81

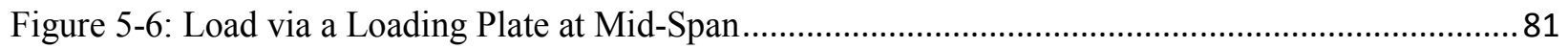

Figure 5-7: Samples Failed under Punching Load Without Elastomeric Pads ........................................ 84

Figure 5-8: Samples Failed under Punching Load With Elastomeric Pads .............................................. 84

Figure 5-9: Samples Failed with Loading Plate Longer Than Flange-Width ......................................... 86

Figure 5-10: Sample Failed under Uniformly Distributed Load (With Elastomeric Pads).......................87

Figure 5-11: Moment vs Deflection of 21"-25" Box Beams under Different Load Conditions..................8 88

Figure 5-12: Local Web Buckling as Short-Plate Buckling with Variable $\mathrm{L}_{\mathrm{y}}$......................................... 90

Figure 5-13: Graphs of ABC-Box-6×6×0.375- 65 Beam tested at CFC-WVU.......................................92

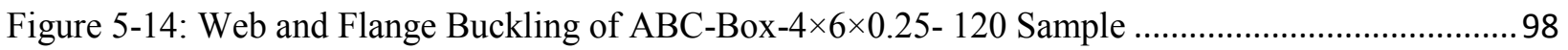

Figure 5-15: The ABC-Box-4×4×0.375- 168 Under 3-point Bending ................................................... 101

Figure 5-16: Plots of SW-Box-4×4×0.25- 65 Under 3-point Bending ................................................ 104

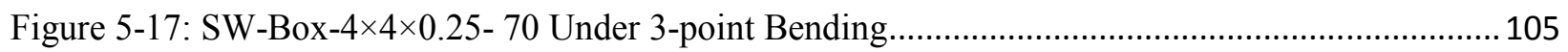

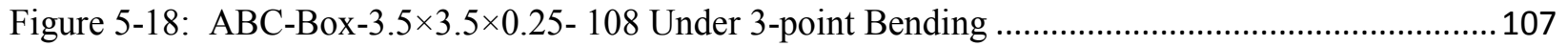

Figure 5-19 ABC-Box-2 $\times 0.25 \times 4 \times 0.125-96$ Under 3-point Bending ................................................. 110

Figure 5-20: CP-Round-6×0.25- 70 Under 3-point Bending ............................................................. 116

Figure 5-21: Graphs of CP-Round-6×0.25- 70 Under 3-point Bending: (a) Moment vs Strain at Mid-

Bottom, (b) Moment vs Central Deflection ............................................................................... 116

Figure 5-22: Notations of Bending Shear Stress in a Round Cross-Section.........................................118

Figure 5-23: Moment vs time plot of SW-WF- $6 \times 6 \times 0.25-70$ beam tested under 3-point bending .......... 119

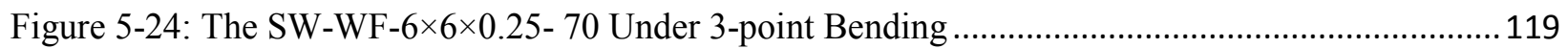

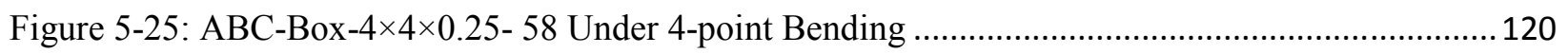

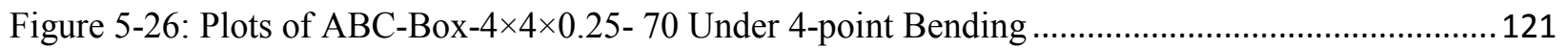

Figure 5-27: FEA Model of ABC-Box-6×6×0.375- 36 Sample with Nodal Load and 2-D Shell Element

Figure 5-28: FEA Model of ABC-Box-6×6×0.375- 36 Sample with Loading Plate and 3-D Brick Element

Figure 5-29: FEA Model of ABC-Box-4×4×0.375- 168 with Nodal Load and 2-D Shell Element......... 124

Figure 6-1: x-y: Load Axes/Off-Axes, 1-2: Material Axes/On-Axes [23] ............................................ 129

Figure 6-2: Area Enclosed by the Mid-line of the Cross-Section [23] …............................................130

Figure 6-3: General Form of Thin-Walled Curved Section with Orthotropic and Symmetric Layup,

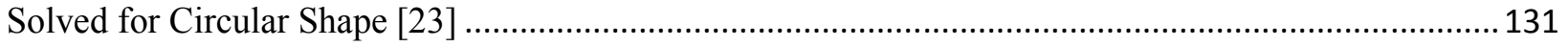

Figure 6-4: Dimensions of a Rectangular Cross-section [23] ............................................................. 132

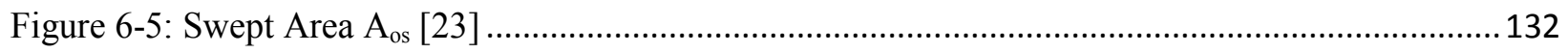

Figure 6-6: Warping Segments of a Rectangular Section [23] ......................................................... 133

Figure 6-7: Notations of Stress Concentration Formulas in Torsion of (a) Box-Sections, (b) Angle-

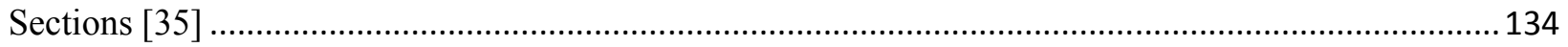

Figure 6-8: Torsional Shear Stress Distribution, (a) Saint Venant Torsion, (b) Restrained Warping Torsion

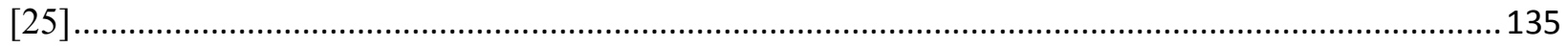


Figure 6-9: (a) Deformed Element at Bar Surface, (b) Shear Center O and Related Distances (c)

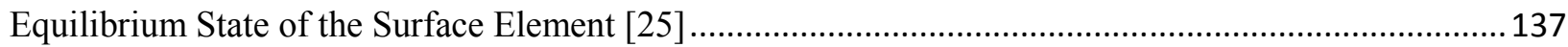

Figure 6-10: Graph between $\theta_{\exp }$ and TL of CP-Round-2.5 $\times 0.10-70$ Sample.................................... 143

Figure 6-11: Mode of Failure of CP-Round-2.5×0.10- 70 Sample ........................................................ 143

Figure 6-12: Graph between J $\theta$ and TL of SW-Round-2.0 $\times 0.118-24$ Sample ........................................ 145

Figure 6-13: Graph between J $\theta$ and TL of SW-Round-2.0×0.118- 70 Sample ..................................... 145

Figure 6-14: Graph between J $\theta$ and TL of SW-Round-2.0×0.118- 144 Sample .................................... 146

Figure 6-15: Failure of SW-Round-2.0×0.125/12L Sample Under Torsion............................................ 148

Figure 6-16: T vs $\theta$ Graph of CP-Round-6.0×0.25- 70 Sample........................................................... 149

Figure 6-17: T vs $\varepsilon_{ \pm 45}$ Graph of CP-Round-6.0×0.25- 70 Sample ....................................................... 149

Figure 6-18: Graph between J $\theta$ and TL of SW-Box-2.0×2.0×0.118- 70 Sample .................................... 152

Figure 6-19: Graph between J $\theta$ and TL of SW-Box-4×4×0.25-70 Sample .......................................... 153

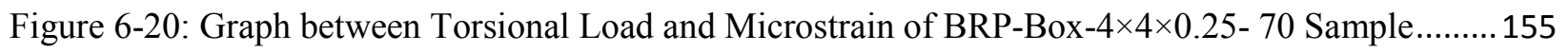

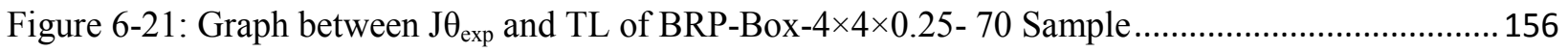

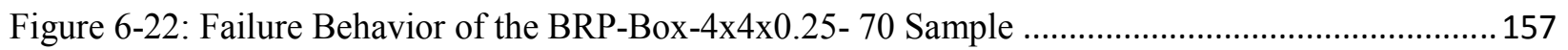

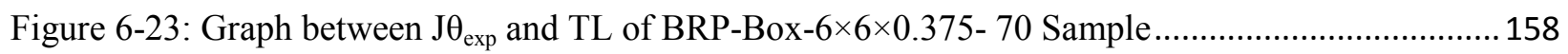

Figure 6-24: Tensile Versus Torsional Behavior of Fiber Reinforced Ploymer Matrix Composites ....... 163

Figure 6-25: Torsional-Strength Failure of Square Cross-Section Under Warping.................................. 163

Figure 7-1: State of Combined Bending and Torsional Stresses at an Area-Element (Ignoring Stress

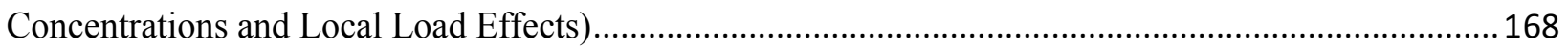

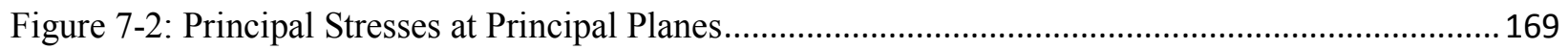

Figure 7-3: Arbitrary Open Section with Loacl and Glaobal Coordinates [5] ....................................... 170

Figure 7-4: Constituent Plate System of the Open Section [5] ......................................................... 170

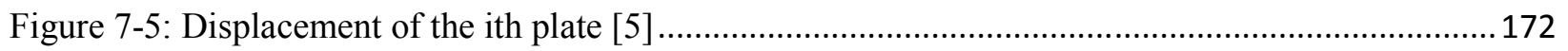

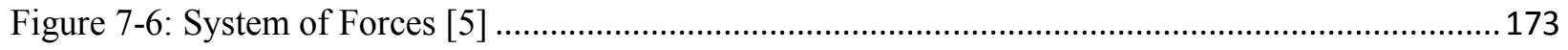

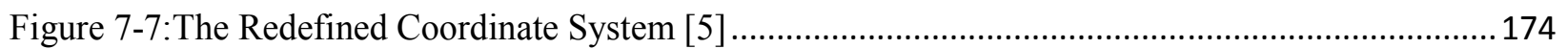

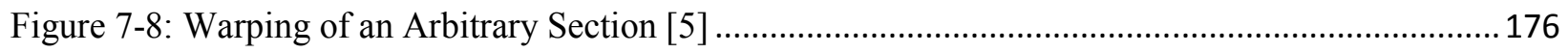

Figure 7-9: Buckled Form of an Axially Compressed Column [5] ...................................................... 177

Figure 7-10: A Doubly Symmetric Open Section [5] ................................................................... 181

Figure 7-11: Notations of orthotropic beam sections used in Equation 7-71 thru 7-81 [14] ................... 183

Figure 7-12: Ideal Interaction Curve of Combined Bending and Torsion ............................................ 185

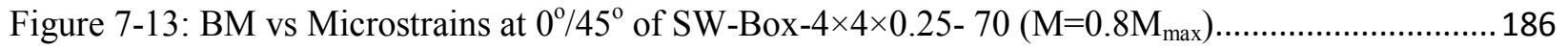

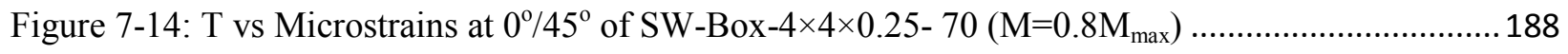

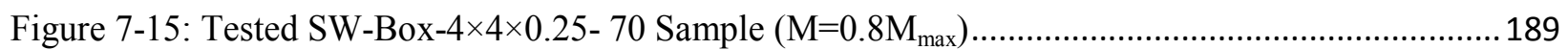

Figure 7-16: (a) M vs Microstrain, (b) T vs Microstrains of SW-Box-4×4×0.25- $70\left(\mathrm{M}=0.56 \mathrm{M}_{\max }\right) \ldots \ldots .190$

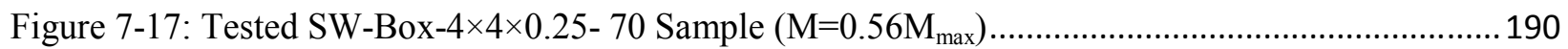

Figure 7-18: (a) M vs Microstrain, (b) T vs Microstrains of SW-Box-4×4×0.25- $70\left(\mathrm{M}=0.28 \mathrm{M}_{\max }\right) \ldots \ldots .192$

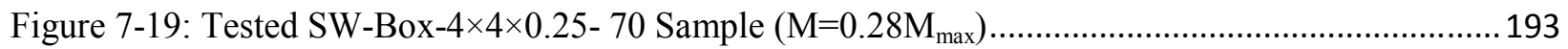

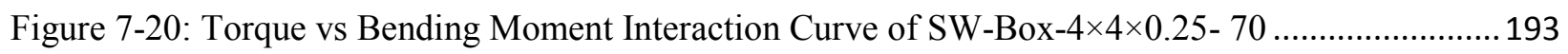

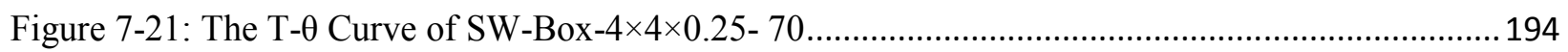

Figure 7-22: (a) M vs Microstrain, (b) T vs Microstrains of BRP-Box-6×6×0.375- $70\left(\mathrm{M}=0.9 \mathrm{M}_{\max }\right) \ldots . .196$

Figure 7-23: Strain Gage Locations at Top-Flange of BRP-Box-6 $\times 6 \times 0.375-70\left(\mathrm{M}=0.9 \mathrm{M}_{\max }\right) \ldots \ldots \ldots \ldots . . .196$ 


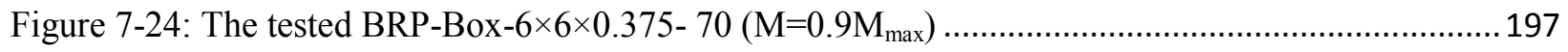

Figure 7-25: $\mathrm{T}$ vs Microstrains of BRP-Box-6 $\times 6 \times 0.375-70\left(\mathrm{M}=0.72 \mathrm{M}_{\max }\right)$......................................... 197

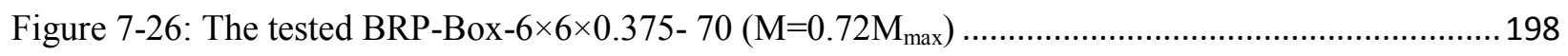

Figure 7-27: (a) M vs Microstrain, (b) T vs Microstrains of BRP-Box-6 $\times 6 \times 0.375-70\left(\mathrm{M}=0.43 \mathrm{M}_{\max }\right) \ldots 199$

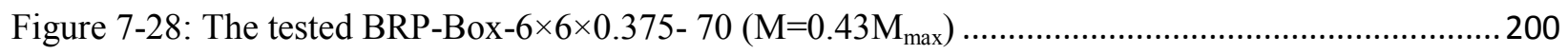

Figure 7-29: Torque vs Bending Moment Interaction Curve of BRP-Box- $6 \times 6 \times 0.375-70 \ldots \ldots \ldots \ldots \ldots \ldots \ldots . . . . . . . .200$

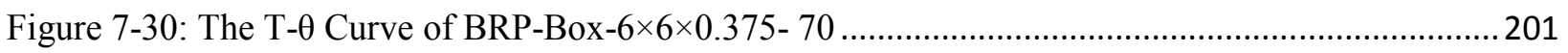

Figure 7-31: (a) M vs Microstrain, (b) T vs Microstrains of CP-Round-6×0.25- 70 (Sample-1) ............. 202

Figure 7-32: CP-Round-6×0.25- 70 Samples Tested Under Combined Bending and Torsion.................. 204

Figure 7-33: (a) M vs Microstrain, (b) T vs Microstrains of CP-Round-6×0.25- 70 (Sample-2) ............. 204

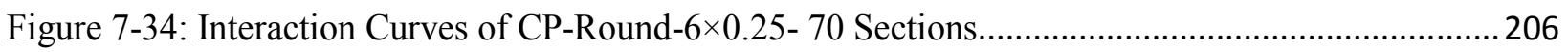

Figure 7-35: The T- $\theta$ Curve of CP-Round-6×0.25- 70 Sections Under Combined Bending and Torsion 207

Figure 9-1: Arrangement of Laminae in the Cross-section of a Box Beam............................................ 251

Figure B-1: SEM Line Method of finding fiber volume fraction .......................................................260 


\section{LIST OF TABLES}

Table 3-1: Specifications of Tension Test Coupons .............................................................................. 41

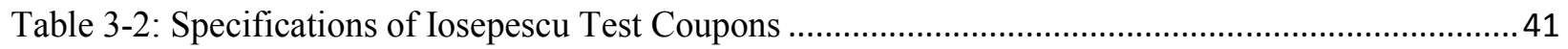

Table 3-3: Specifications of 3-Point Bending Test Samples ................................................................ 42

Table 3-4: Specifications of Other Bending Tests Samples................................................................. 42

Table 3-5: Manufacturer's Specifications of the Inner Layer (VectorPly C-TTX 1800) ..........................44

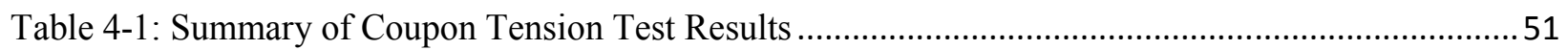

Table 4-2: Summary of Iosepescu Test Results................................................................................5 51

Table 4-3: Properties of Top/Bottom Layers (CTTX-1800) of CP-2.5×0.10/6L Sample...........................64

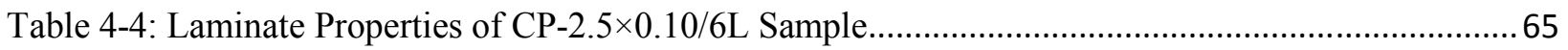

Table 4-5: Laminate Properties of SW-Round-2.0×0.125- 24 \&144 Samples ........................................ 70

Table 5-1: Values of Iortho for Different Beam Sections...................................................................... 82

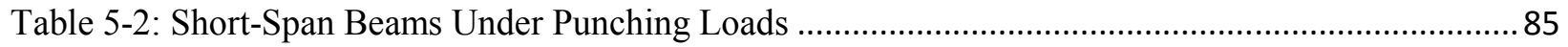

Table 5-3: Short-Span Beams With Loading Plate Longer Than Flange-Width ..................................... 85

Table 5-4: Short-Span Beams with Loading Plate Longer Than Flange-Width ..................................... 87

Table 5-5: 3-Point Bending Test Results of BRP-Box-6×6×0.375 Beams.............................................. 93

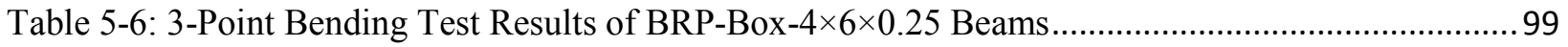

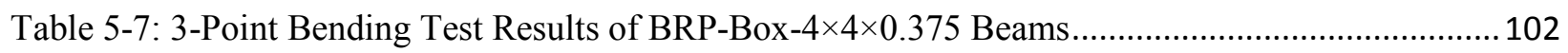

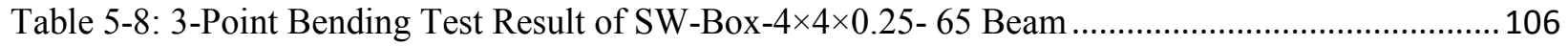

Table 5-9: 3-Point Bending Test Results of BRP-Box-3.5×3.5×0.25 Beams........................................ 108

Table 5-10: 3-Point Bending Test Results of BRP-Box- $2 \times 0.25 \times 4 \times 0.125$ Beams .................................. 110

Table 5-11: 3-Point Bending Test Results of BRP-Box-5.2×5.2×0.375 Beams..................................... 114

Table 5-12: 3-Point Bending Test Results of CP-Box-6×0.25 Beams.................................................. 117

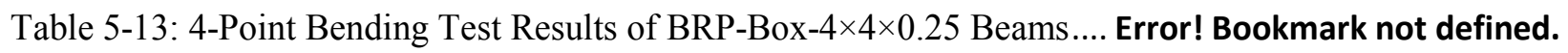

Table 5-14: 3-Point Bending Test Results of SW-WF-6×6×0.25 Beams ............................................... 119

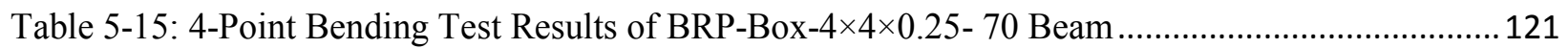

Table 6-1: Torsion Test Results of CP-Round-2.5×0.10- 70 Sample ............. Error! Bookmark not defined.

Table 6-2: Torsion Test Results of SW-Round-2.0×0.118 Samples.............. Error! Bookmark not defined.

Table 6-3: Torsion Test Results of CP-Round-6.0×0.25- 70 Sample ..................................................... 150

Table 6-4: Kts Values for BRP-Box Samples................................................................................... 151

Table 6-5: Torsion Test Results of SW-Box-2×2×0.118- 70 Sample.................................................... 152

Table 6-6: Torsion Test Results of Square Sections ....................................... Error! Bookmark not defined. 


\section{CHAPTER 1 - INTRODUCTION}

\subsection{Overview}

Composite materials consist of a matrix constituent that binds together continuous fibers and fabrics and result in stronger constituent(s). Thus, composites typically have a fiber phase that is stiffer and stronger than the matrix phase. The resulting composite material is superior to any of its constituent material because of proper balance of different internal forces by different constituents. In other words, the improved structural properties generally result from a loadsharing mechanism between the matrix and the fiber.

Unlike metals or pristine polymeric materials, composites are not isotropic. Their properties are direction dependent, hence making their design and analysis more involved. Composite materials are typically classified either on the basis of the type of matrix or that of the reinforcement form. The matrix of a composite material may be an organic material, a metal, or a ceramic material. The corresponding composites are given the names organic matrix composites (OMCs), metal matrix composites (MMCs) and ceramic matrix composites (CMCs). The matrix of an OMC may either carbon or polymer (thermoset or thermoplastic). The polymer matrix composites (PMCs) are the most widely used ones due to their ease of manufacture and fabrication, relatively low cost and higher mechanical properties. They find applications in defense, aerospace and infrastructure, etc.

Composite materials can either be classified on the base of resin material or reinforcement type. Carbon, glass, or aramid fibers are used in OMCs in a variety of forms of continuous and discontinuous reinforcements. All of these composites are considered to be very useful in aerodynamic, marine, automotive and civil structures. The reinforcements in MMCs and CMCs are typically of short forms, such as particles or whiskers, the materials usually being carbides or some other ceramics. 
The composite manufacturing processes primarily depend upon product-design and economics; hand lay-up, compression molding, filament winding, resin transfer molding, pultrusion process, prepreg lay-up, bag molding and autoclave processing being the typical examples. Pultrusion is a continuous production process employed to produce thin-walled members of uniform crosssection in large quantities. Bridge decks, panels, railings, gratings, structural sections such as round, square and rectangular tubes, wide flange, I, channel and angle sections are the typical products made through pultrusion.

The pultruded structural members, both of open and closed cross sections, are thin-walled members, i.e., the wall thickness is much less than the cross section which in turn is much less than the length. The orientation of the glass fiber dictates them to be orthotropic materials. When loaded under torsion or combined torsion and bending, they may undergo structural instability in addition to deformation. While the known forms of deformation being twisting and deflection, the instability may cause local or global buckling in addition to warping.

\subsection{Objectives}

This research is intended to investigate the structural response of pultruded FRP members of open and closed section under combined torsional and flexural loading. This will be accomplished through the following objectives:

I. Extensive literature review on pultruded FRP members through available books, research journal articles and world-wide web.

II. Problem formulation based on the thin-walled beam theory for orthotropic materials, theory of anisotropic plates and finite element analysis.

III. A rigorous experimentation on the full length members as well as on coupons.

IV. Analysis of the experimental results in the light of formulae derived.

V. Comparison of experimental results with the theory in items III and IV, simplification of theoretical relations and development of design equations.

VI. Suggestions for the future research to enhance the performance. 


\subsection{Scope}

I. The test-samples consist of thin-walled pultruded GFRP structural members of round, square and wide flange shapes with lengths varying from 2 to 12 feet and the cross sections ranging from $2 \times 0.15$ to $6 \times 6 \times 3 / 8$ inches.

II. The types of loading include bending, torsion and combined bending and torsion. The magnitude of load should be enough to break the component.

III. The structural response of the specimens includes twisting, deflection, local or global buckling and warping associated with torsional loads.

IV. Materials properties will be determined by testing the coupons cut from the full-scale samples.

\subsection{Organization of Report}

In order to understand the failure response of full-scale pultruded FRP members under combined bending and torsion, it is not only important to understand the laminate properties of such members, but also to understand the material behavior under bending and torsion separately. To effectively address all these issues, this dissertation report has been organized as under:

- A comprehensive literature review on various aspects of structural behavior of FRP composite material coupons and full-scale members are presented in Chapter 2.

- A complete detail of various types of experimental setup used in this research work are explained in Chapter 3.

- Experimental investigation and analysis of laminate properties is given in Chapter 4.

- Flexural behavior of different types of pultruded FRP members under a variety of load conditions has been explained in Chapter 5.

- Pure torsional behavior of round and square pultruded FRP members is given in detail in Chapter 6 .

- Combined flexural and torsional behavior of square and round pultruded FRP composite sections is given in detail in Chapter 7.

- Design procedure of pultruded FRP composite sections, based on LRFD Manual (Draft) is given in Chapter 8 . 
- Conclusions and future research recommendations are given in Chapter 9. 


\section{CHAPTER 2 - LITERATURE REVIEW}

\subsection{Overview}

A few things are evident from the literature survey of the structural response of pultruded GFRP materials. First, the information available about torsional loading is quite limited, unlike that about flexural loading and compressive axial loading. Second, there is no precedence of research on combined torsional and flexural loading. And third, there is lack of understanding about how to fully characterize the pultruded FRP materials due to practical difficulties in testing the fullscale members and also due to correlation drawbacks with test data from coupons.

In this chapter, the previous research work on pultruded GFRP members under flexural and/or torsional loading has been organized under following headings,

- Material characterization: Accurate analytical and experimental methods, both at microand macro-level for the determination of material properties of coupons and full-scale bars.

- Strength and Deformation Prediction: Theoretical development of strength and deformation prediction and experimental validation (coupons and full-scale bars).

- Stability Issues: Theoretical and experimental evaluation of local and global buckling, as well as, axial warping under torsion.

- Limit States.

- Design Equations.

\subsection{Characterization}

The pultrusion manufacturers typically provide material specifications in terms of nominal dimensions and moduli of elasticity and rigidity. However, information about fiber architecture is not disclosed. When the full-scale members and their coupons are tested under different load conditions, a considerable variation in properties is found. For example, the modulus of elasticity may have different values in tension, bending and torsional warping. Likewise, modulus of 
rigidity may have different value in torsion and bending [30]. The researchers have attempted to investigate the reasons of variation, as described below.

\subsubsection{Determination of Flexural Modulus}

L. C. Bank [2] used the Timoshenko beam theory [30] to find the flexural and shear moduli of pultruded FRP beams, as given below

$$
\begin{gathered}
E_{b} I \frac{\partial \emptyset}{\partial z}=M \\
\frac{\partial y}{\partial z}+\emptyset=\frac{Q}{A G_{b}}
\end{gathered}
$$

where $E_{b}$ denotes the section flexural modulus, $I$ is the second moment of area, $\varnothing$ is the bending slope, $\mathrm{z}$ is the axial coordinate, $\mathrm{M}$ is bending moment, $\mathrm{y}$ is the beam deflection, $\mathrm{Q}$ is the shear force, $A$ is the area of cross-section and $G_{b}$ is the section shear modulus. Here,

$$
G_{b}=K G_{\text {material }}
$$

with $\mathrm{K}$ as the shear coefficient.

Equations (2.1) and (2.2), when solved for a 3 points bending test, yield

$$
w=\frac{P l}{4}\left(\frac{l^{2}}{12 E_{b} I}+\frac{1}{A G_{b}}\right)
$$

where $\mathrm{w}$ is the midspan deflection, $\mathrm{P}$ is the midspan load and 1 is effective length. The second term on right hand side of equation (2.4) refers to the effect of shear on deformation.

Rewriting,

$$
\frac{4 A w}{P l}=\frac{1}{12 E_{b}}\left(\frac{l}{r}\right)^{2}+\frac{1}{G_{b}}
$$

By plotting a graph with $\frac{4 A W}{P l}$ along $\mathrm{y}$-axis and $\left(\frac{l}{r}\right)^{2}$ along $\mathrm{x}$-axis,

$$
\begin{aligned}
E_{b} & =\frac{1}{12 * \text { Slope }} \\
G_{b} & =\frac{1}{\text { Intercept }}
\end{aligned}
$$

3 -point bending tests were performed on GFRP pultruded wide-flange beams $(102 \times 102 \times 6.35$ $\mathrm{mm})$ and I-beams $(102 \times 51 \times 6.35 \mathrm{~mm})$ of polyester and vinylester matrix. The values of $\mathrm{E}_{\mathrm{b}}$ were found to be in the range of $22 \mathrm{GPa}$ and $\mathrm{G}_{\mathrm{b}}$ was found to vary from 0.75 to $1.23 \mathrm{GPa}$. 


\subsubsection{Determination of Shear Coefficient}

As stated by Bank [2], the total deflection in thin-walled FRP bars consists of deflection due to bending and that due to shear. The shear coefficient $\mathrm{K}$ is considered to be of main importance in the Timoshenko beam theory. For I-beams under major- and minor-axis bending loads, $\mathrm{K}$ is given by

$$
\begin{gathered}
K_{y}=\frac{\left(d_{w}+2 t_{f}\right)}{d_{w} t_{w}+2 b_{f} t_{f}} \\
K_{z}=\frac{2 b_{f} t_{f}}{1.2\left(d_{w} t_{w}+2 b_{f} t_{f}\right)}
\end{gathered}
$$

where $b_{f}, t_{f}$ and $d_{f}$ refer to breadth, thickness and depth of flange, while $b_{w}, t_{w}$ and $d_{w}$ represent the same values for web.

For orthotropic materials, $\mathrm{K}$ was first calculated effectively by Cowper [32, 33] from the equations of three-dimensional elasticity. Bank used the modified Timoshenko beam theory and modified Cowper's method to define a new parameter, modified shear coefficient $\left(\mathrm{K}^{*}\right)$, in terms of contour integrals of a number of parameters. The shear coefficient then can be expressed as,

$$
K=K^{*} \frac{E_{z}}{G_{S Z}}
$$

Where $E_{z}$ and $G_{s z}$ are in-plane longitudinal and shear moduli respectively.

The mathematical formulas were then derived to calculate the values of shear coefficient for rectangular, I and T shapes having different fiber orientations. A computer code was generated to find the tip-load response of graphite/epoxy and glass/epoxy cantilever I beams (100x100x2 mm) with a variety of fiber-layups. The shear deflection comprised $3.6 \%$ to $23 \%$ of the total deflection mainly due to the fiber lay-up; $\pm 45^{\circ}$ being corresponding to smaller values.

\subsubsection{Determination of Shear Modulus}

It is believed that the G value of a FRP member is influenced more by the matrix than the fibers. One way of finding the shear modulus of a section under transverse load is by using equation (2.7), which gave the values from 0.75 to $1.23 \mathrm{GPa}$ in the above case. However, manufacturer's 
specified value was not given. Roberts et al (2002, 2003) and Mottram (2004) researched on determination of shear modulus under transverse loading and torsional loading. They found the transverse shear modulus in the same way as above. To find out the torsional shear modulus of pultruded FRP bars, Roberts et al (2001) modified the torsional theory for isotropic materials, generally specified as that the total torque is the sum of Saint Venant torque and the warping torque[25]. The Saint Venant shear modulus $\mathrm{G}_{\mathrm{sv}}$ was found by using the following formula for uniform torsional tests,

$$
\theta_{a}=\frac{Q_{a}}{G_{s v} J}
$$

where $\theta_{a}$ and $Q_{a}$ represent the angle of twist and applied torque for the span ' $a$ ' and $J$ is the torsional constant.

To determine the warping torsional modulus $\mathrm{E}_{\mathrm{w}}$, the non-uniform torsion test was employed with both ends fixed and torque applied at the center; the corresponding formulae given by

$$
\begin{gathered}
\theta_{\text {net }}=\frac{Q}{G_{s v} J}\left\{a-\frac{\tanh \beta a}{\beta}\right\} \\
\beta^{2} \approx \frac{G_{s v} J}{E_{w} C_{w}}
\end{gathered}
$$

where $\theta_{\text {net }}$ is the net central rotation to fixed ends, $E_{w}$ is the warping torsional modulus and $C_{w}$ is the warping torsional constant.

The values of shear modulus under transverse loading and torsional loading exhibited a considerable difference. For example, for a $150 \times 150 \times 10 \mathrm{~mm}$ I-beam, the value of transverse shear was $2.55 \mathrm{GPa}$ and Saint Venant torsional shear modulus was around $4.8 \mathrm{GPa}$, in comparison to the manufacturer's specified value of $3.0 \mathrm{GPa}$.

Roberts et al (2002) attempted to explain the difference between the two values of shear in more than one ways. In analytical terms, if the laminate consists of 11 layers and the two outer layers have transverse shear modulus equal to five times that of the other layers, the value of Saint Venant shear modulus will be considerably higher than that of transverse shear modulus. However, Mottram (2004) disagreed with this assumption stating that "probably" the ratio of the two values cannot be more than 1.6 times. Roberts et al (2003) performed tension, torsion and Iosipescu tests at coupon level and found the values of the two shear moduli were in the range of 
3.1 3.8 GPa. They attributed the decrease in torsional shear modulus value to edge effect, i.e., fiber reinforcement in the vicinity of the edge was not able to withstand the torsional load.

For a better understanding, they modified the 3-point bending test about the major axis by fixing aluminum bars on each side and attaching transducers at the center of each bar. A third sensor was attached at the center of bottom. The test results showed that central deflection at the neutral axis was considerably less than that at the bottom center. The value of transverse shear modulus corresponding to the neutral axis deflection was $5.15 \mathrm{GPa}$, close to twice the previously determined value. They concluded, "Localized deformation at the supports has a significant influence on both deflections and apparent material properties". A careful analysis of this method shows that the aluminum strips were used to find representative deflection value, which would yield more realistic results. But the researchers should have mentioned the dimensions of the strips to make sure that they have not contributed towards the stiffening of the specimen.

\subsection{Strength and Deformation Prediction}

The flexural response of long span pultruded GFRP member is typically governed by local buckling of the compressive flange and is further discussed under stability issues. However, short span beam responses are dominated by in plane shear failures.

Mottram (1992) and other researchers used various forms of equation (2.4) to find the deflection under 3-point bending, which may be re-written as

$$
w=w_{\text {bending }}+w_{\text {shear }}=\frac{P l^{3}}{48 E_{b} I}+\frac{1}{4 A G_{b}}
$$

Bank et al and Nagaraj et al (1997) determined through series of experiments that shear deformation can constitute from $4 \%$ to $23 \%$ of the total deformation.

Design Manual by Creative Pultrusions Inc (2004) used the following formula for uniformly distributed loads,

$$
\Delta=\frac{5 w L^{4}}{384 E I}+\frac{w L^{2}}{8 A^{\prime} G}
$$


where $\Delta$ is deflection, $\mathrm{w}$ is udl, $\mathrm{L}$ is the span, $\mathrm{EI}$ is the flexural rigidity, $\mathrm{G}$ is modulus of rigidity and $A^{\prime}=K A_{w}$ with $K$ as shear coefficient and $A_{w}$ as shear area of profile. The values of $E$ and $G$ can be seen without any subscript because manufacturers typically use single values for various calculations.

The torsional response of pultruded GFRP members, discussed above was illustrated through equations (2.11), (2.12) and (2.13) by Roberts et al (2001).

Salim et al (2005) used the Vlasov's thin-walled beam theory to find the torsional deformation in anisotropic and orthotropic beams of thin walled cross-sections in terms of $[\mathrm{A}],[\mathrm{B}]$ and $[\mathrm{D}]$ matrices. They supported their analysis with tests on a square $(130 \times 130 \times 9.5 \mathrm{~mm})$ and a rectangular $(100 \times 200 \times 6.25 \mathrm{~mm})$ beam with known fiber lay-ups and found the results within less than $10 \%$ difference. But the fiber architecture of a manufacturer's supplied pultruded member is not generally known, hence the values of $\mathrm{A}_{\mathrm{ij}}$, $\mathrm{B}_{\mathrm{ij}}$ and $\mathrm{D}_{\mathrm{ij}}$ cannot be found in a straight forward manner.

Prachasaree (2005) worked on in-plane shear behavior of GFRP materials under torsion using:

$$
T=G J \bar{\theta}
$$

where GJ is the torsional rigidity and $\bar{\theta}$ is rate of twist ( $\mathrm{rad} / \mathrm{in})$ about the longitudinal axis. The values of GJ depend on the geometry and fiber architecture of the section and needs to be calculated for a given case. The analytical value of $\mathrm{G}$ was found by rule-of-mixtures with fiber volume fraction of $35 \%$ and was compared with the experimental and FEA values. For $6 \times 4$ inch cross-section box beam of 12 feet span, the difference ranged from $2.19 \%$ to $4.48 \%$. An analogous comparison of the in-plane strains showed a difference of more than $30 \%$ in experimental versus FEA values and around $10 \%$ in experimental versus theoretical values at flange near the supports. The difference in values away from the supports and on the web was relatively less. This variation can be attributed to couple of reasons. Typically, the end supports of the apparatus cannot provide a uniform and complete fastening grip and load transfers from flange to web. Also, the problem formulation does not take into account the stress concentration effects. 


\subsection{Stability Issues}

Mottram (1992) used the formula from Eurocode for lateral torsional buckling of I-beam made of orthotropic panels under central point loading,

$$
P_{c r}=\frac{8.56 \pi}{l^{2}}\left[E_{z . y y} I_{y y} G_{x y} J\right]^{0.5}\left[1+\frac{4 \pi^{2} E_{z . y y} I_{w}}{l^{2} G_{x y} J}\right]^{0.5}
$$

where $E_{z . y y} I_{y y}$ is the minor axis flexural rigidity, $G_{x y} J$ is the torsional rigidity $E_{z . y y} I_{w}$ is the warping rigidity

The experiment was performed on $102 \times 51 \times 6.3 \mathrm{~mm}$ I-beams of $1500 \mathrm{~mm}$ span, simply supported and centrally loaded. The buckling mode was found to be third in most of the cases and first in some of the cases. The buckling loads varied widely from 2.80 to $5.75 \mathrm{GPa}$. Mottram stated that the tests were very sensitive to imperfections, such as geometry, loading positions and material homogeneity. However, confusion existed in determining the value of $\mathrm{G}_{\mathrm{xy}}$. Therefore, it was hard to compare the experimental and theoretical values of the buckling load. It can be concluded that this research is very fundamental and does not explain precisely about the effect of each imperfection on the highly scattered results. Furthermore, one should investigate the causes leading to two different modes of buckling.

Bank [2] worked on local buckling and failure of pultruded fiber-reinforced plastic beams, stating that the failure mode should be local buckling of the flange under compression. They loaded $203 \times 203 \times 9.5 \mathrm{~mm}$ I-beams of $2743 \mathrm{~mm}$ span under 4-point loading, and effectively found out the local buckling stage corresponding to a nonlinearity observed in the strain gage readings. The following formulas were used for analysis purposes

$$
\sigma_{b}=\frac{M_{b} c}{I}
$$

where $\sigma_{b}$ and $M_{b}$ are the stress and moment corresponding to buckling, I is the second moment of area and $\mathrm{c}$ is the distance from neutral axis to the outermost location.

$$
E_{L}=\frac{M}{\kappa I}
$$

with 


$$
\kappa=\frac{\epsilon_{\text {ave }}}{c}=\frac{\left|\epsilon^{+}\right|+\left|\epsilon^{-}\right|}{2 c}
$$

where $\mathrm{E}_{\mathrm{L}}$ is the effective longitudinal modulus, $\mathrm{K}$ is curvature, $\epsilon^{+}$and $\epsilon^{-}$are measured at top and bottom of the beam.

$$
G=\frac{V Q}{\gamma I t}
$$

where $\mathrm{V}=\mathrm{P} / 2$, $\mathrm{Q}$ is the first moment of area of the section taken at the neutral axis, $\mathrm{t}$ is the wall thickness and $\gamma$ is the engineering shear strain reported by the shear rosette at the neutral axis.

On average, $\sigma_{b}=83.26 \mathrm{MPa}$ and $\epsilon_{b}=-3357 \mu \varepsilon$ for the FRP specimens tested under that program. The longitudinal modulus was around $26 \mathrm{GPa}$ and shear modulus was around $4 \mathrm{GPa}$. It is evident that this experiment and analysis was performed very elegantly since start till end and the results are quite satisfactory.

Roberts (2003) performed a theoretical and parametric study of the influence of shear deformation on the flexural, torsional and lateral buckling of pultruded FRP profiles using the mathematical relations:

$$
\begin{aligned}
& \text { Flexural Buckling } \quad P_{c r y}=\frac{\pi^{2} E_{b y} I_{y}}{L^{2}}\left\{1+\frac{P_{c r y}}{G_{t y} K_{y} A}\right\}^{-1} \approx P_{e y}\left\{1-\frac{P_{c r y}}{G_{t y} K_{y} A}\right\} \\
& \text { Torsional Buckling } \\
& \qquad P_{c r \theta}=P_{\theta}\left\{1+\frac{P_{c r \theta}}{G_{s} K_{s} A}\right\}^{-1} \approx P_{\theta}\left\{1-\frac{P_{c r} \theta}{G_{s} K_{s} A}\right\} \\
& \text { Lateral Buckling } \\
& M_{c r p s}=M_{c r o}\left\{1-\frac{E_{b z} I_{z}}{E_{b y} I_{y}}+\frac{E_{b z} I_{z}}{G_{s} A}\left(\frac{\pi}{L}\right)^{2}\right\}^{-\frac{1}{2}}
\end{aligned}
$$

With $\mathrm{x}$ - as the longitudinal axis, $\mathrm{y}$ - as the horizontal axis and $\mathrm{z}$ - as vertical axis, in equation (2.21), $\mathrm{P}_{\text {cry }}$ is flexural buckling load, $\mathrm{E}_{\text {by }}$ is the flexural modulus, $\mathrm{I}_{\mathrm{y}}$ is the second moment of area, $\mathrm{L}$ is the effective length, $\mathrm{G}_{\mathrm{ty}}$ is transverse shear modulus, $\mathrm{K}_{\mathrm{y}}$ is shear coefficient, $\mathrm{A}$ is the crosssectional area and Pey is the buckling load of a pin-ended bar excluding the influence of shear deformation. Equation (2.22) resembles equation (2.21) with $\theta$ representing torsion and $\mathrm{s}$ representing shear. In equation (2.23), $\mathrm{M}_{\mathrm{crp}}$ is the critical moment for lateral buckling, $\mathrm{M}_{\text {cro }}$ is lateral buckling moment excluding the influence of shear deformation and pre-buckling displacements. 


\subsection{Limit States}

No discussion about limit states of GFRP composite pultruded members could be found in the contemporary research material. However, Creative Pultrusions Inc, in their design manual, have provided the limit states of flexural members of open and closed cross-sections of various sizes. The sections considered were I, wide-flange, $\mathrm{C}$, square and rectangle, with sizes ranging from

$1 \frac{1}{2} \times 1 \frac{1}{2} \times \frac{1}{4}$ to $24 \times 4 \times \frac{15}{32}$ inch and lengths ranging from 4 to 40 feet in addition to specifying uniformly distributed load limits for simply supported beams having L/D ratios of 100, 150, 180, 240 and 360.

\subsection{Design Equations}

The design equations for pultruded FRP members are given in the ASCE LRFD Draft Manual for FRP structures. The required flexural strength $M_{u}$ is given by

$$
M_{u} \leq \lambda \phi M_{n}
$$

Where $\phi$ is the resistance factor for flexure depending upon the mode of failure, $\lambda$ is the time effect factor and $M_{n}$ is the nominal flexural strength. For tensile rupture, $\phi=0.65$ and for compressive rupture, $\phi=0.70$. Also,

$$
\begin{gathered}
M_{n}(\text { Tensile })=\min \left[\frac{F_{L, f}^{t}\left(E_{L, f}^{a v e} I_{f}+E_{L, w}^{a v e} I_{w}\right)}{y_{t, f} E_{L, f}^{a v e}}, \frac{F_{L, w}^{t}\left(E_{L, f}^{a v e} I_{f}+E_{L, w}^{a v e} I_{w}\right)}{y_{t, w} E_{L, w}^{a v e}}\right] \\
M_{n}(\text { Comp })=\min \left[\frac{F_{L, f}^{c}\left(E_{L, f}^{a v e} I_{f}+E_{L, w}^{a v e} I_{w}\right)}{y_{c, f} E_{L, f}^{a v e}}, \frac{F_{L, w}^{c}\left(E_{L, f}^{a v e} I_{f}+E_{L, w}^{a v e} I_{w}\right)}{y_{c, w} E_{L, w}^{a v e}}\right]
\end{gathered}
$$

where F, E, I and y represent strength, elastic modulus, $2^{\text {nd }}$ moment of area and distance from neutral axis to the extreme fiber, respectively. The superscripts/subscripts t, c, f, w and L stand for tensile, compressive, flange, web and longitudinal respectively.

$M_{n}$ of an I, C, T or box section due to local instability is given by

$$
M_{n}=f_{c r} \frac{E_{L, f}^{a v e} I_{f}+E_{L, w}^{a v e} I_{w}}{y_{c, e} E_{L, e}^{a v e}}
$$


where $f_{c r}$ is the critical buckling stress and the subscript e refers to the buckled element. The value of $f_{c r}$ can be found by using the section-specific formula from the table of formulas. $M_{n}$ of an I section due to lateral-torsional buckling is given by

$$
M_{n}=C_{b} \sqrt{\frac{\pi^{2} E_{L} I_{y} D_{J}}{L_{b}^{2}}+\frac{\pi^{4} E_{L}^{2} I_{y} C_{\omega}}{L_{b}^{4}}}
$$

Where $C_{b}$ is the moment modification factor commonly taken to be $1, D_{J}$ is the torsional rigidity of an open section, $C_{\omega}$ is the warping constant and $L_{b}$ is the length between points that are either braced against lateral displacement of the compression flange or braced against twist of the cross-section.

$$
\begin{gathered}
D_{J}=\sum_{i=1}^{n} \frac{1}{3} G_{L T}^{i} b_{i} t_{i}^{3} \\
C_{\omega}=\frac{t_{f} h^{2} b_{f}^{3}}{24}
\end{gathered}
$$

The required shear strength $V_{u}$ of a flexural member is given by

$$
V_{u} \leq \lambda \phi V_{n}
$$

$V_{n}$ for a section due to rupture in shear,

$$
V_{n}=F_{L T}^{v} A_{s}
$$

with standard notations and $\phi=0.65$.

$V_{n}$ for a section due to web shear buckling,

$$
V_{n}=f_{c r} h t_{w}
$$

with standard notations and $\phi=0.80$.

The procedure of finding $f_{c r}$ is to be followed from the ASCE LRFD Manual for FRP structures.

The other design procedures for FRP sections include design under flexural concentrated forces, design with holes, notches and openings, and design for serviceability.

The required torsional strength of a hollow circular or rectangular tube is given by

$$
T_{u} \leq \lambda \phi T_{n}
$$


where

$$
\phi=0.70
$$

When strength governs,

$$
T_{n}=F_{n} J
$$

When stiffness governs,

$$
\begin{gathered}
T_{n}=F_{c r} C \\
F_{n}=\gamma G_{L T} \\
F_{c r}=\min \left(\frac{0.236\left(E_{T}^{C}\right)^{5 / 8}\left(E_{L}^{C}\right)^{3 / 8}}{\left(\frac{R}{t}\right)^{3 / 2}}, \frac{0.733\left(E_{T}^{C}\right)^{5 / 8}\left(E_{L}^{C}\right)^{3 / 8}}{\left(\frac{R}{t}\right)^{5 / 4} \sqrt{\frac{L}{R}}}\right) \leq F_{L T}^{v}
\end{gathered}
$$

where $\gamma$ is the coupon specimen shear strain per unit length, $G_{L T}$ is the in-plane shear modulus of elasticity, $\mathrm{J}$ is the polar moment of inertia for circular tubes, $\mathrm{C}$ is the torsional constant for rectangular tubes and wide flange beams, $F_{c r}$ is the critical torsional buckling strength and $F_{L T}^{v}$ is the in-plane shear strength. Further calculation procedures are given in the manual.

The interaction of torsion, flexure and axial force is given below, which is yet to be verified experimentally.

$$
\frac{P_{u}}{P_{C}}+\frac{M_{u}}{M_{C}}+\left[\frac{T_{u}}{T_{C}}\right]^{2} \leq 1.0
$$

where,

$\mathrm{P}_{\mathrm{u}}=$ required axial tensile or compressive strength due to factored loads

$\mathrm{P}_{\mathrm{C}}=\lambda \phi_{t, c} P_{n}=$ available axial tensile or compressive strength

$\mathrm{M}_{\mathrm{u}}=$ required flexural strength due to factored loads

$\mathrm{M}_{\mathrm{C}}=\lambda \phi_{b} M_{n}=$ available flexural strength

$\mathrm{T}_{\mathrm{u}}=$ required torsional strength due to factored loads

$\mathrm{T}_{\mathrm{C}}=\lambda \phi_{T} T_{n}=$ available torsional design strength

$\phi_{\mathrm{t}}=$ resistance factor for tension $=0.65$

$\phi_{\mathrm{C}}=$ resistance factor for compression rupture and global buckling $=0.70$

$\phi_{\mathrm{C}}=$ resistance factor for local buckling $=0.80$ 
$\phi_{\mathrm{b}}=$ resistance factor for lateral torsional buckling and web crippling $=0.70$

$\phi_{\mathrm{b}}=$ resistance factor for local instability and web compression buckling $=0.80$

$\phi_{\mathrm{T}}=$ resistance factor for torsion $=0.70$ 


\section{CHAPTER 3 - EXPERIMENTATION}

\subsection{Introduction}

The objective of this research is to investigate the behavior of full-length thin-walled open- and closed-sections of pultruded glass-fiber reinforced polymer composite materials under combined bending and torsion. The comprehensive experimental program consists of three main stages: (i) investigation of the laminate properties, (ii) investigation of the behavior of full-length samples under 3-point bending and pure torsion separately, and (iii) investigation of the behavior of fulllength samples under various combinations of bending and torsion.

The laminate properties of the samples under investigations were found with the help of methods such as coupon tension tests, Iosepescu tests, burnout tests, optical microscopy and Scanning Electron Microscopy. Details of laminate properties are given in Chapter-4. The bending behavior of the full-scale specimens was investigated by 3-point bending tests. Most of these tests were performed at BRP Inc., with some additional testing done at WVU-CFC major laboratory unit. Details of bending behavior are given in Chapter-5.

Owing to a lack of research on torsion of composite beams, an intensive investigation was required. Therefore, an FRP Composites Torsional Apparatus was designed, developed and instrumented at WVU-CFC major units laboratory. The consequent details of pure torsional behavior of a variety of shapes and sizes of pultruded sections are given in Chapter- 6 .

Finally, the torsional apparatus was modified to incorporate a bending load in addition to the torsional load. A variety of shapes and sizes were tested under different combinations of bending and torsion, the results of which are presented in Chapter-7.

Described in the following sections are the experimental setups, sample preparation methods and step-by-step procedures of all types of tests conducted in this research. 


\subsection{Experimental Set-Up}

The experimental set-ups for laminate properties, 3-point bending tests, pure torsional tests and combined bending and torsional tests are given in the following sections.

\subsubsection{Experimental Set-Up for Laminate Properties}

The laminate properties are typically revealed at coupon level under tension tests, shear tests, burnout tests and microscopic tests.

\subsubsection{Tension Test Setup}

The longitudinal and transverse coupons cut from the full-length specimens were tested at the tension side of the 220 kip capacity Instron HDX1000 Machine, as shown in Figure 3-3 (a). However, the smaller samples, which could not be tested at the big machine, were tested at 22 kip Instron 8501 machine, as shown in Figure 3-3 (b).

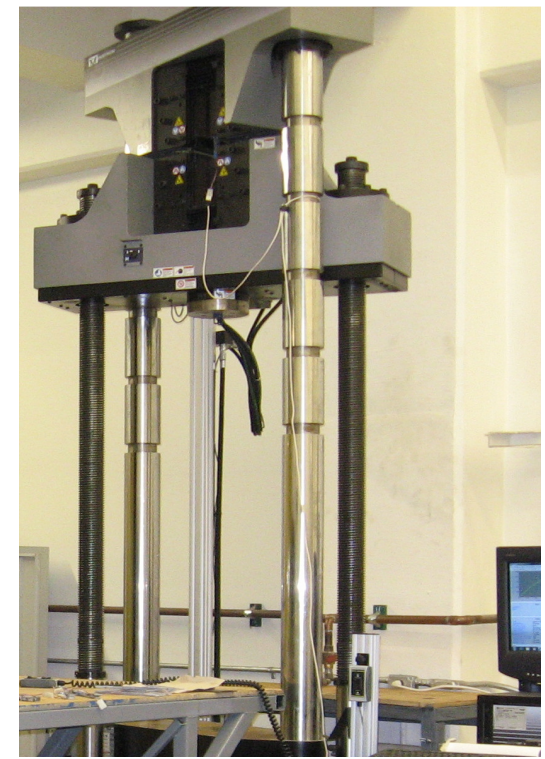

(a) Instron HDX1000 Machine

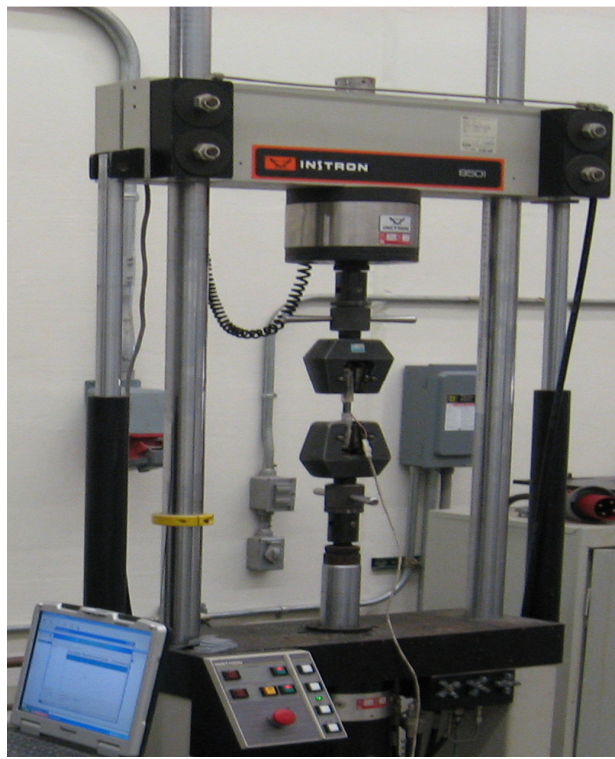

(b) Instron 8501 Machine

Figure 3-1: Tension Test Setup for Longitudinal and Transverse Coupons 


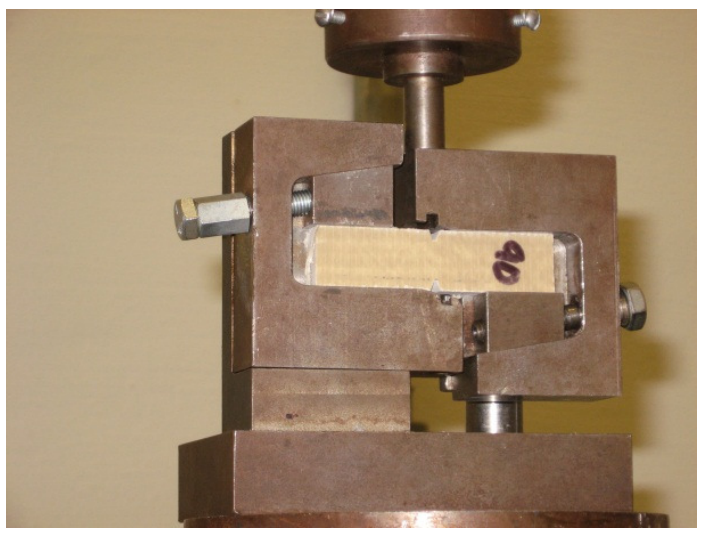

Figure 3-2: Iosepescu Test Fixture s

\subsubsection{Iosepescu Test Setup}

In order to apply shear loads on the coupons, they are inserted in a special type of fixture, which in turn is fitted into the two ends of the testing machine. A close-up of the Iosepescu test fixture is shown in Figure 3-2 with a coupon inserted therein. This fixture is attached to the Instron 8501 machine.

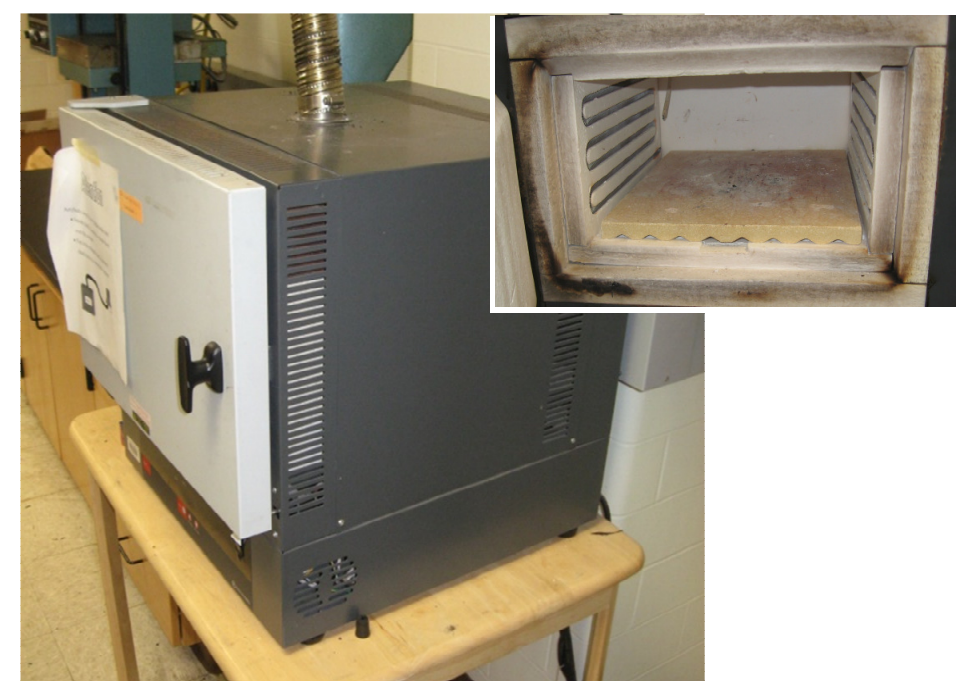

(a) Isotemperature Muffle Furnace, Model 550-58

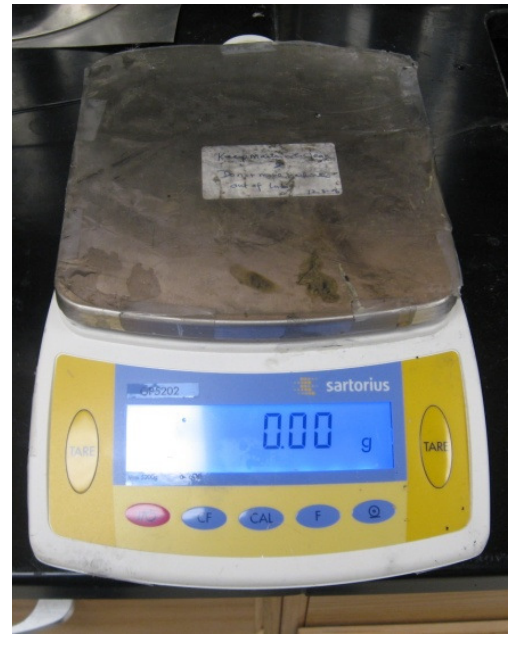

(b) Electronic Balance

Figure 3-3: Burnout Test Setup 


\subsubsection{Burnout Test Setup}

The burnout test is used to find out the fiber volume fraction of the sample of a fiber-reinforced composite material. The setup essentially consists of a furnace and a high precision electronic balance. The isotemperature muffle furnace, model 550-58 and the electronic balance, capable of measurement of 0.01 gram are shown in Figure 3-3 (a) and (b) respectively.

\subsubsection{Microscopes}

With the help of modern computerized microscopes, not only the samples can be viewed to a great magnification, but desired measurements can also be taken through the software. The microscopic examination of a GFRP composite sample is carried out to reveal the information about the fiber architecture. More specifically, it can be seen that what the number of plies is and how much is the thickness of each ply. Further, what is the diameter of fibers and in which orientation they are placed. The biggest advantage of a micrograph is that it can be used to find the fiber volume fraction. An optical microscope can be operated after some practice, but a scanning electron microscope is operated by specially trained staff. In the experimental program under consideration, samples were examined both under optical microscope and SEM. The Zeiss Axio optical microscope is shown in Figure 3-4 and Hitachi S-4700 field emission scanning electron microscope is shown in Figure 3-5. 


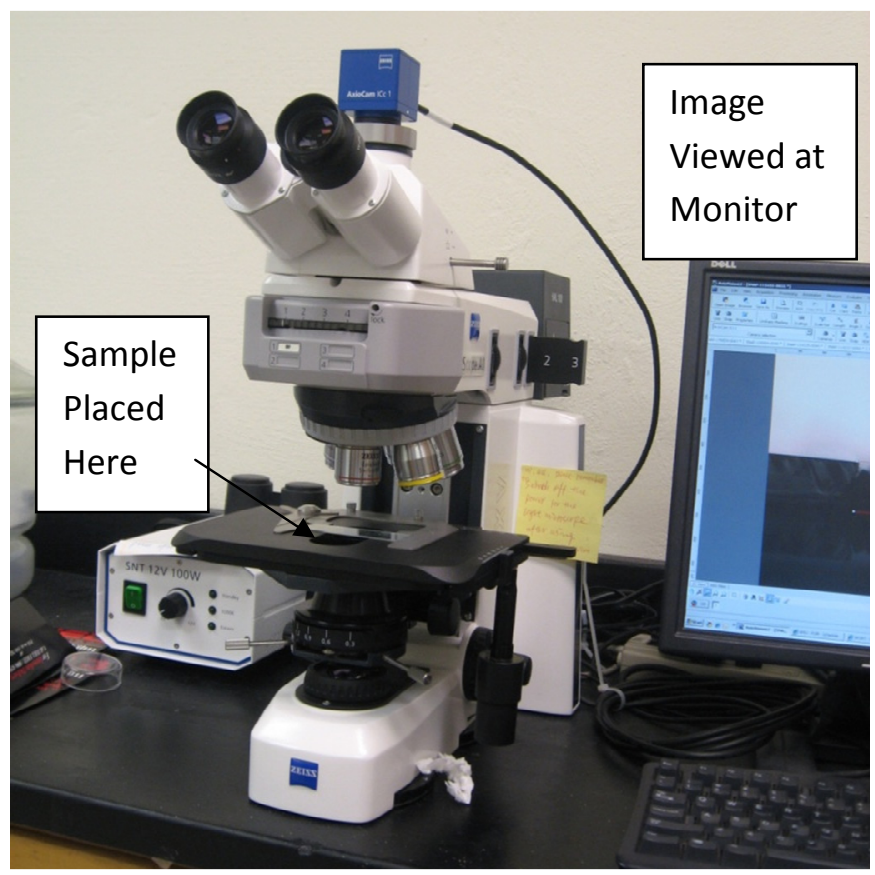

Figure 3-4: Zeiss Axio Optical Microscope

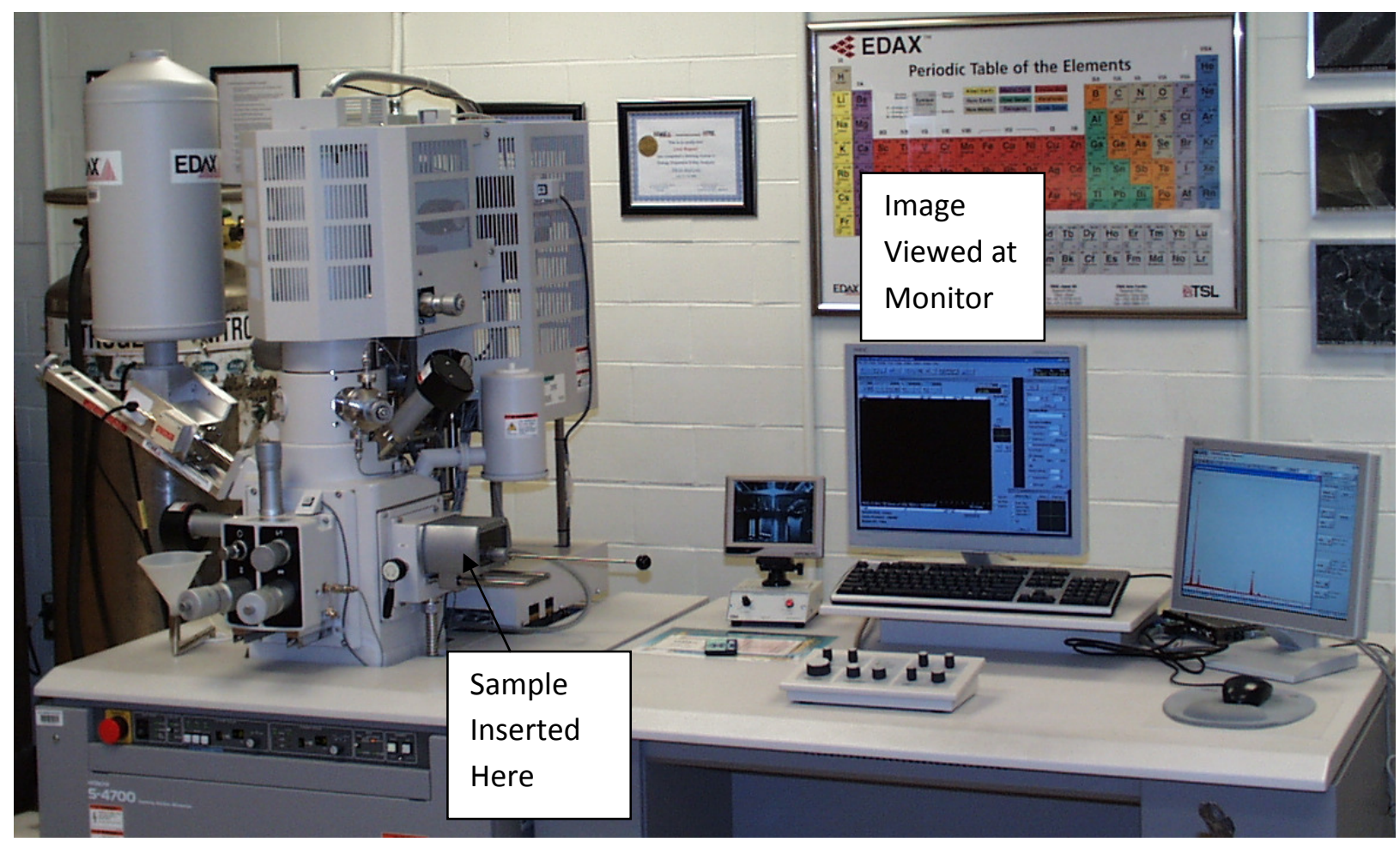

Figure 3-5: Hitachi S-4700 Field Emission Scanning Electron Microscope 


\subsubsection{Experimental Set-Up for Bending Tests}

Although the prime emphasis was on 3-point bending tests, yet some additional tests were also performed on short-span beams to better understand the flexural behavior under various load conditions.

\subsubsection{3-Point Bending Test Setup}

The full-length specimens were tested under 3-point bending at Bedford Reinforced Plastics Inc. by using the setup shown in Figure 3-6. The samples were supported at two roller supports, while the load was applied via a roller, attached at the end of a hydraulic ram. The diameter of the roller supports can be approximated as 1.5 inch and that of the loading roller is around 5 inch. The loading-roller with relatively bigger diameter and length helps minimize the local crushing of the testpiece at the point of application of load.

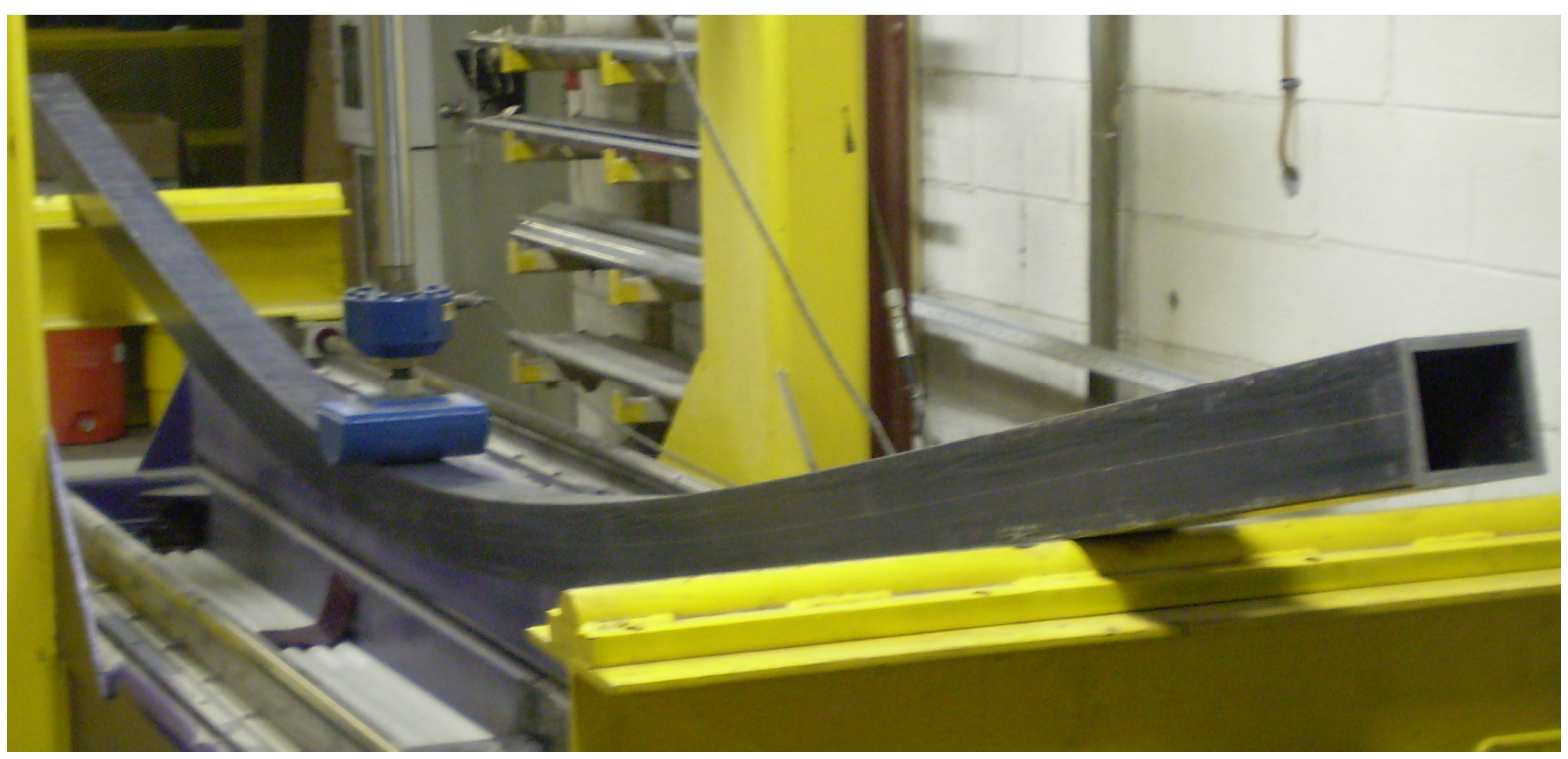

Figure 3-6: 3-Point Bending Test Setup at Bedford Plastics Inc. 


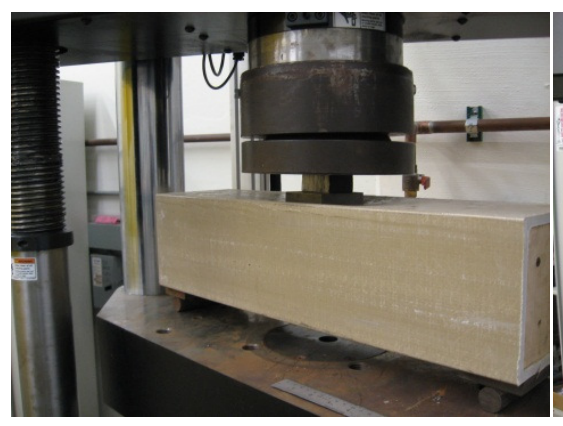

(a) Punching Load

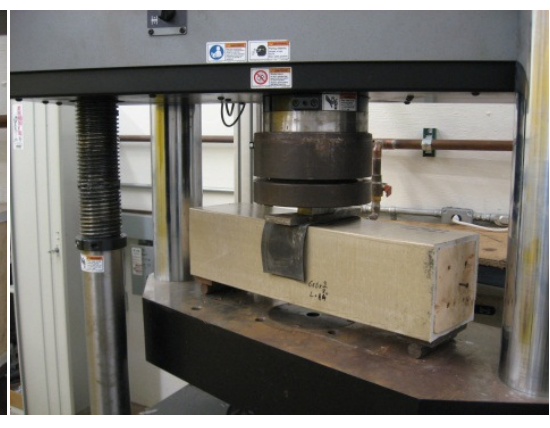

(b) $\mathrm{L}_{\text {plate }}>\mathrm{b}_{\mathrm{f}}$

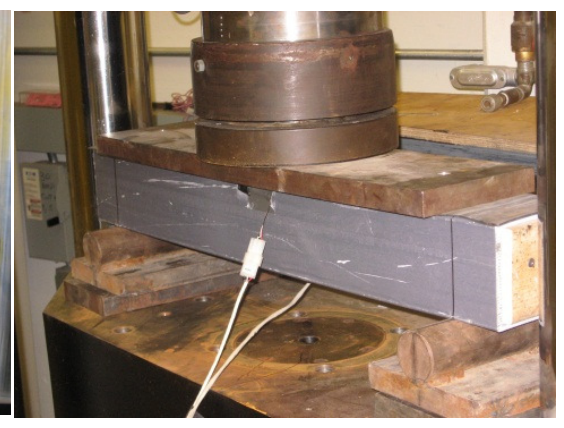

(c) UDL

Figure 3-7: 3 Load Scenarios of Bending Test of Short-Span Beams at Compression Side of Instron HDX1000 Machine

\subsubsection{Setup for Other Types of Bending Tests}

Additional bending tests were performed on 24 to 28 inch long square beams by using the compression side of the Instron HDX1000 Machine with load scenarios shown in Figure 3-7, i.e., (a) punching load without elastomeric pads, (b) loading plate longer than flange-width with elastomeric pad, and (c) loading plate longer and wider than the top face to exert a uniformly distributed load.

\subsubsection{Experimental Set-Up for Torsion Tests}

The FRP composites torsion test apparatus was designed, fabricated, instrumented and calibrated at WVU-CFC major laboratory unit. The schematic diagram of this apparatus is shown in Figure 3-8 and the pictorial view is shown in Figure 3-9. It essentially consists of an FRP torsion testing rig with suitable instrumentation and control system.

The salient features of the FRP composites torsion test apparatus are:

- The test samples of up to 6" $\times 6$ " cross-section and 144" length can be tested.

- The test samples can be subjected to torsion up to any degree of rotation. The measurement is however is limited to $\pm 60^{\circ}$. 


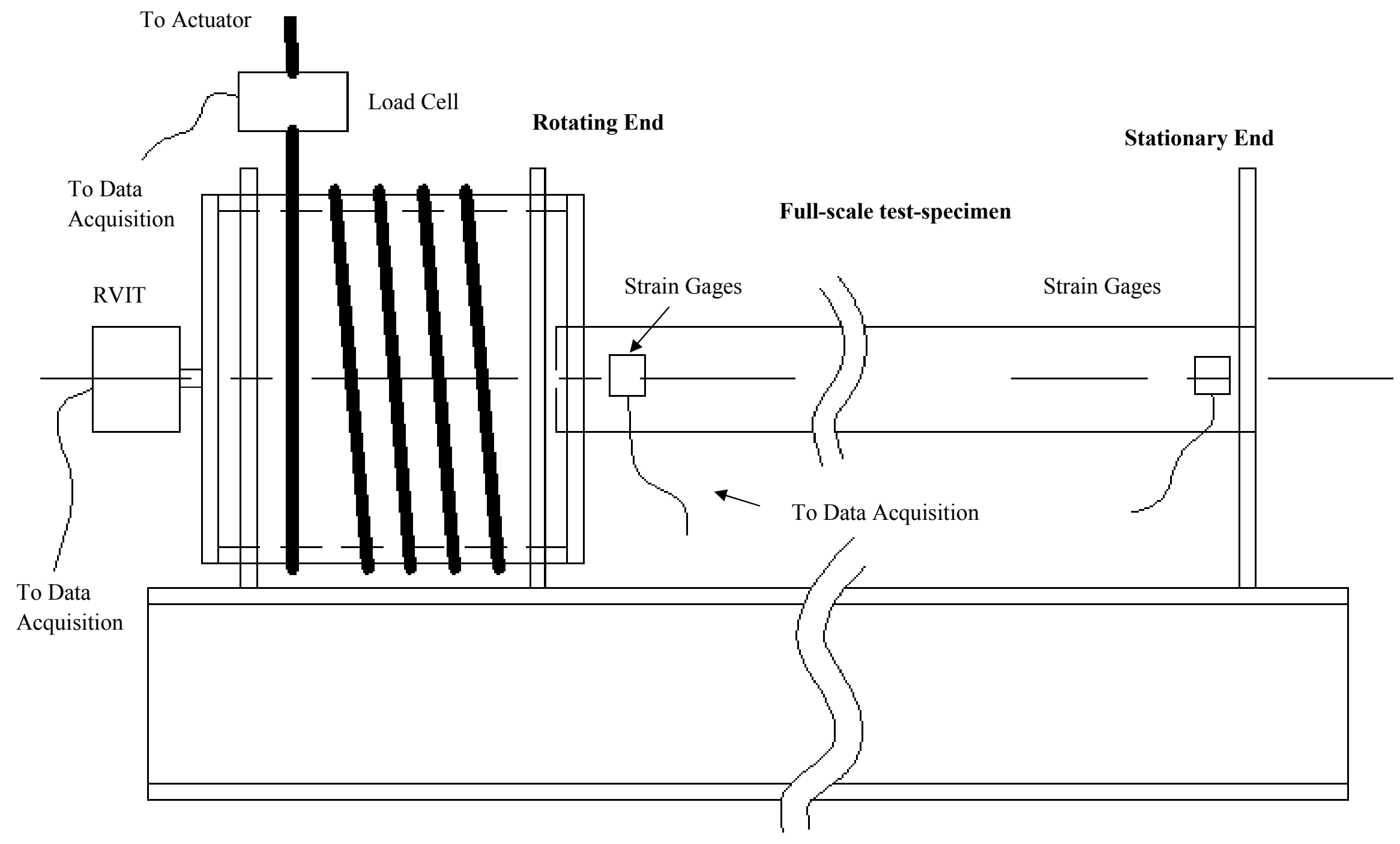

Figure 3-8: Schematic Diagram of the FRP Composites Torsion Testing Apparatus 


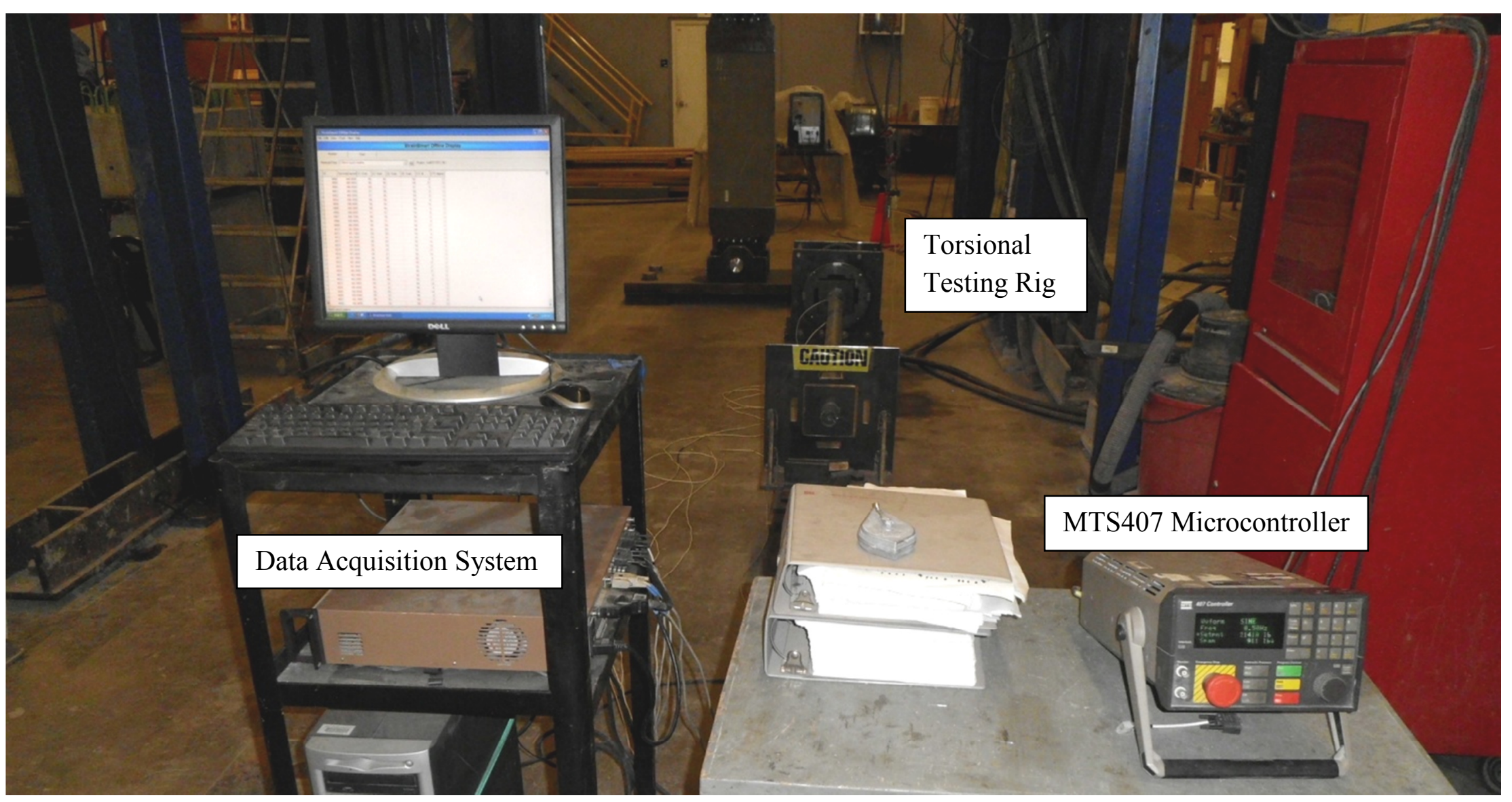

Figure 3-9: Pictorial View of the FRP Torsion Testing Apparatus 
- The test-samples can be mounted with both types of boundary conditions, i.e., simply supported and clamped.

- The floor-mounted design is user-friendly and safe.
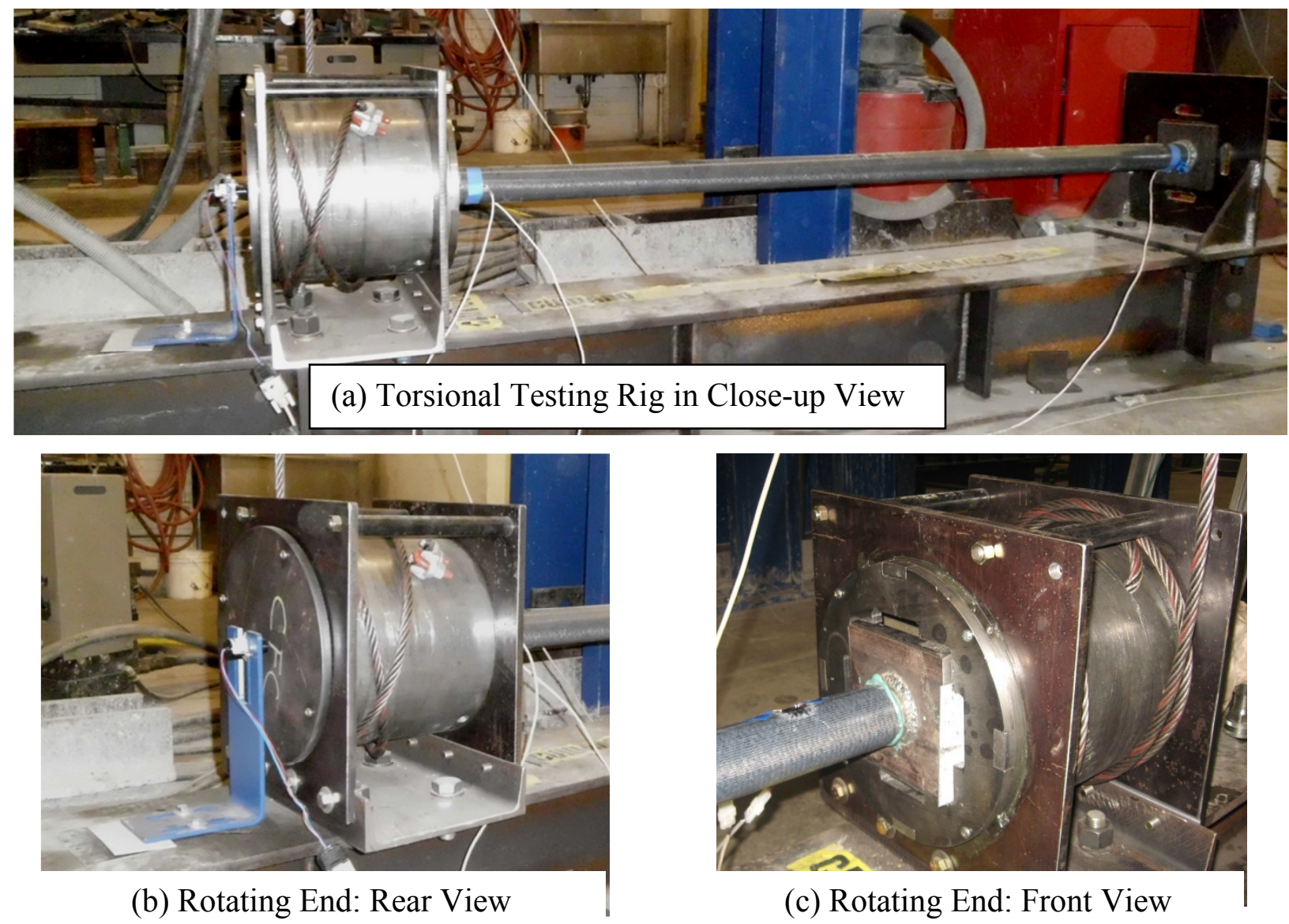

Figure 3-10: Pictorial Views of the Torsional Testing Rig

\subsubsection{Torsion Testing Rig}

The torsion testing rig is the heart of the whole apparatus. As can be seen in Figure 3-10, the rotating and the stationary ends are fitted atop a wide flange beam. The rotating end consists of a precise-diameter high-strength steel cylinder, rotatable in a frame consisting of two plates bolted on a channel section. The steel cylinder acts as a pulley and the frame acts as a bearing. The cylinder is rotated by a hydraulic actuator through a high strength cable. The pulling force is measured with the help of a load cell attached to the cable. The back face of the cylinder is 
covered by a circular plate which carries a rotary variable inductance transformer (RVIT) for rotation measurement. The front-face-plate of the cylinder has a $6.5^{\prime \prime} \times 6.5^{\prime \prime}$ slot to insert the fullscale test-specimen. The other end of the specimen is inserted inside a similar slot in the stationary end plate. The fastening mechanism depends upon the boundary conditions, i.e., fixed or simply supported.

\subsubsection{Data Acquisition System}

The data acquisition system necessarily consists of sensors attached to the apparatus/testpiece, connected to a data acquisition unit, linked to a personal computer.

\section{a) Sensors}

- Strain Gages: The $120 \Omega$ or $350 \Omega$ strain gages are mounted near the rotating and fixed ends of the testpiece at $45^{\mathrm{O}}$ to measure deformation under torsion.

- Load Cell: A 100 kip compression load cell is mounted in a purpose-built fixture in such a way that it can measure the tensile force. The load cell fixture is shown in Figure 3-11 (a).

- $\quad$ RVIT: A rotary variable inductance transformer is attached at the center of the back face of the rotating cylinder so as to measure its angle of twist. The range of this device is $\pm 60^{\mathrm{O}}$. The RVIT is shown in Figure 3-11 (b)

\section{b) Data Acquisition Unit}

The data acquisition unit comprises strain gage cards and high level cards. The strain gages and the load cell are connected to the strain gage cards while the RVIT is connected to a high level card. This unit is shown in Figure 3-11 (c) 


\section{c) Data Acquisition Software}

The data acquisition unit is linked to a personal computer on which StrainSmart ${ }^{\circledR}$ data acquisition software is installed. The data from the sensors, through the data acquisition unit, are acquired with the help of this software. The acquired data can be reduced and exported as an Excel worksheet. This provides a great ease in data processing.

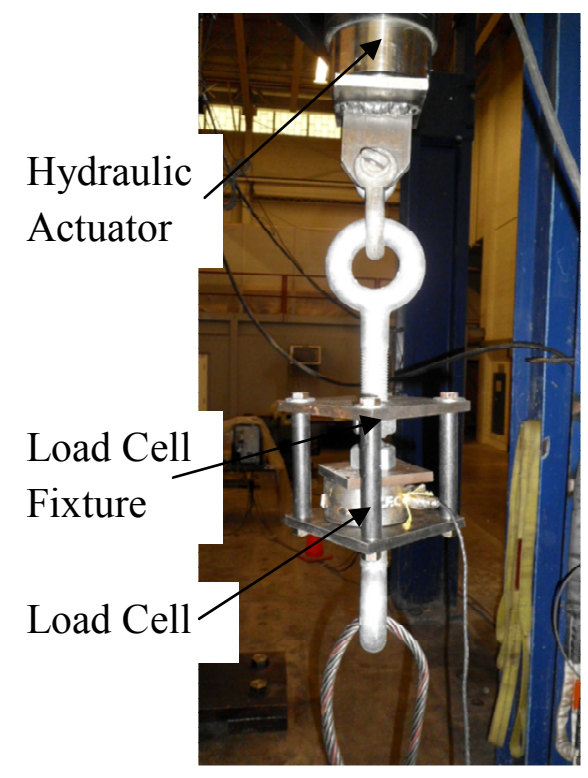

(a) Load Cell Fixture

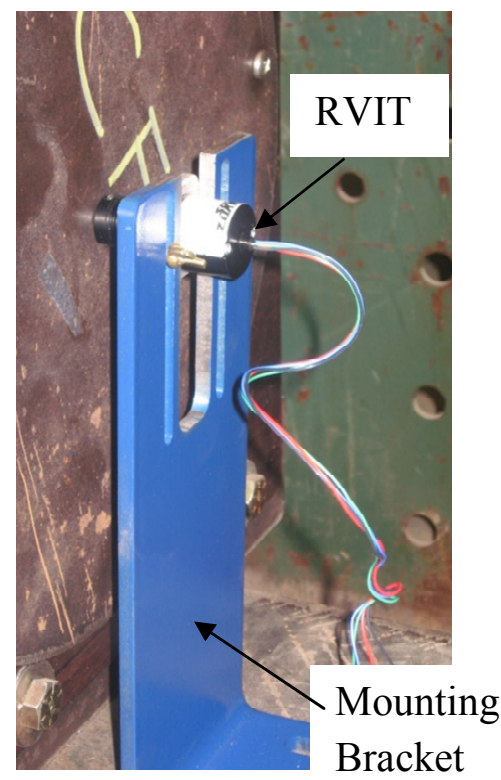

(b) Rotary Variable Inductor Transformer

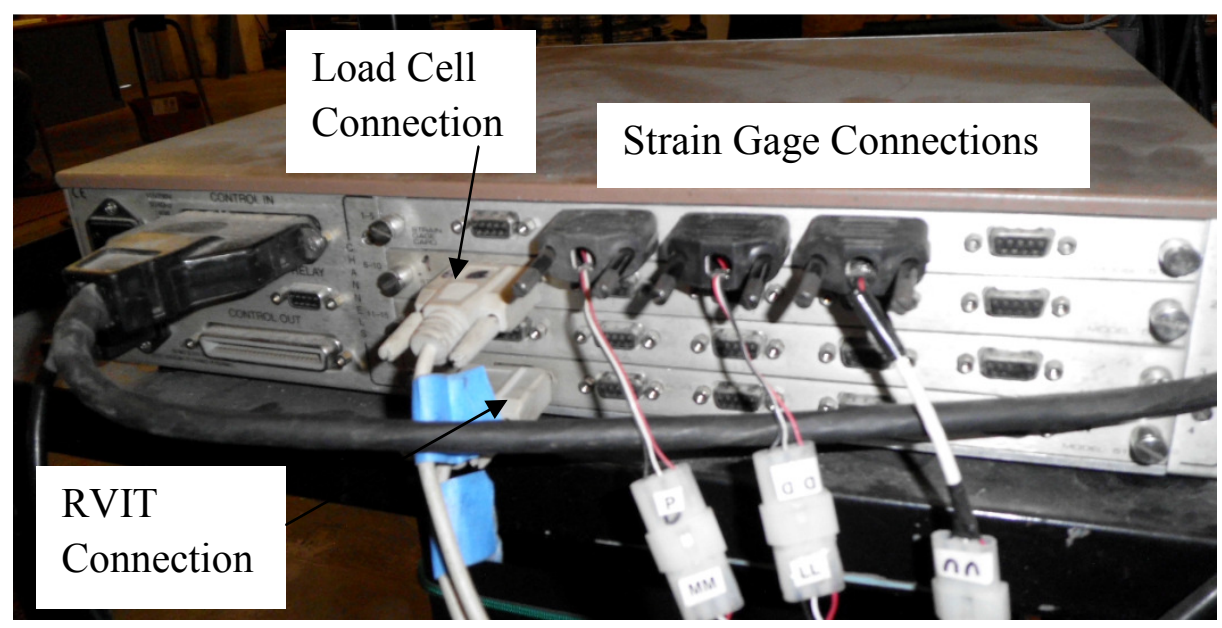

(c) Data Acquisition Unit

Figure 3-11: Instrumentation details 


\subsubsection{Hydraulic Control System}

The high strength cable, instrumented with the load cell, is attached to a hydraulic actuator. The actuator can be displaced to a maximum of 18 " and its displacement can be precisely controlled by MTS407 controller. The load rating of the actuator is 40 kips and that of controller is 100 kips. The hydraulic control system is shown in Figure 3-12.

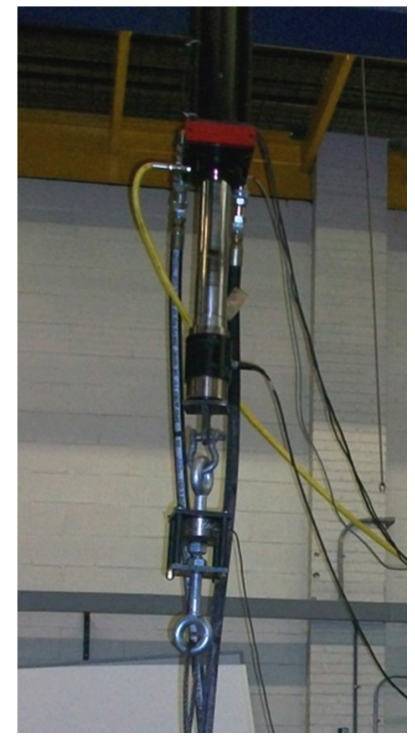

(a) Long-Stroke Hydraulic Actuator

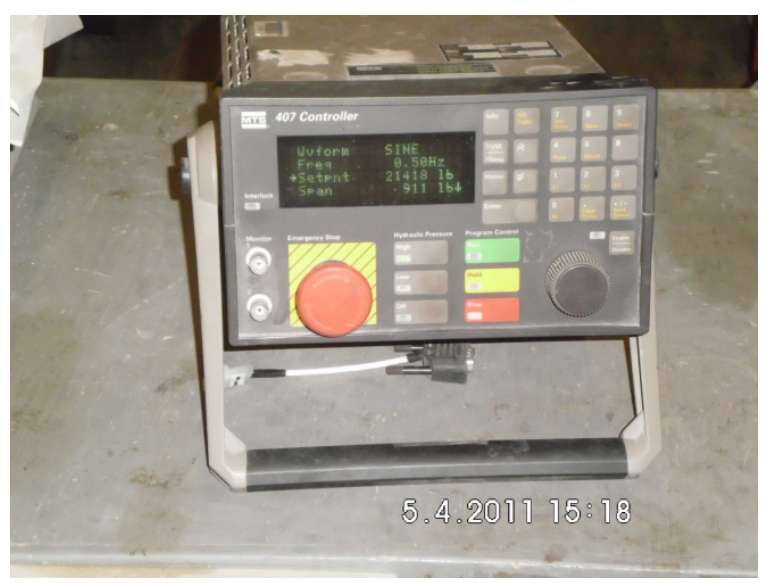

(b) MTS407 Microcontroller

Figure 3-12: Hydraulic Control System

\subsubsection{Experimental Set-Up for Combined Bending and Torsion}

The torsional test apparatus was modified for combined loading by bolting the rotating-end and the fixed-end on two separate pieces of wide-flange beam and leaving a gap in-between. A hydraulic actuator, equipped with a load-cell, was set in the middle of the gap to apply the bending load. After carefully mounting the sample, a bending load was applied first and then the torsional load was applied. All the other set-up essentially remained the same. The experimental setup for combined bending and torsion is shown in Figure 3-13. 


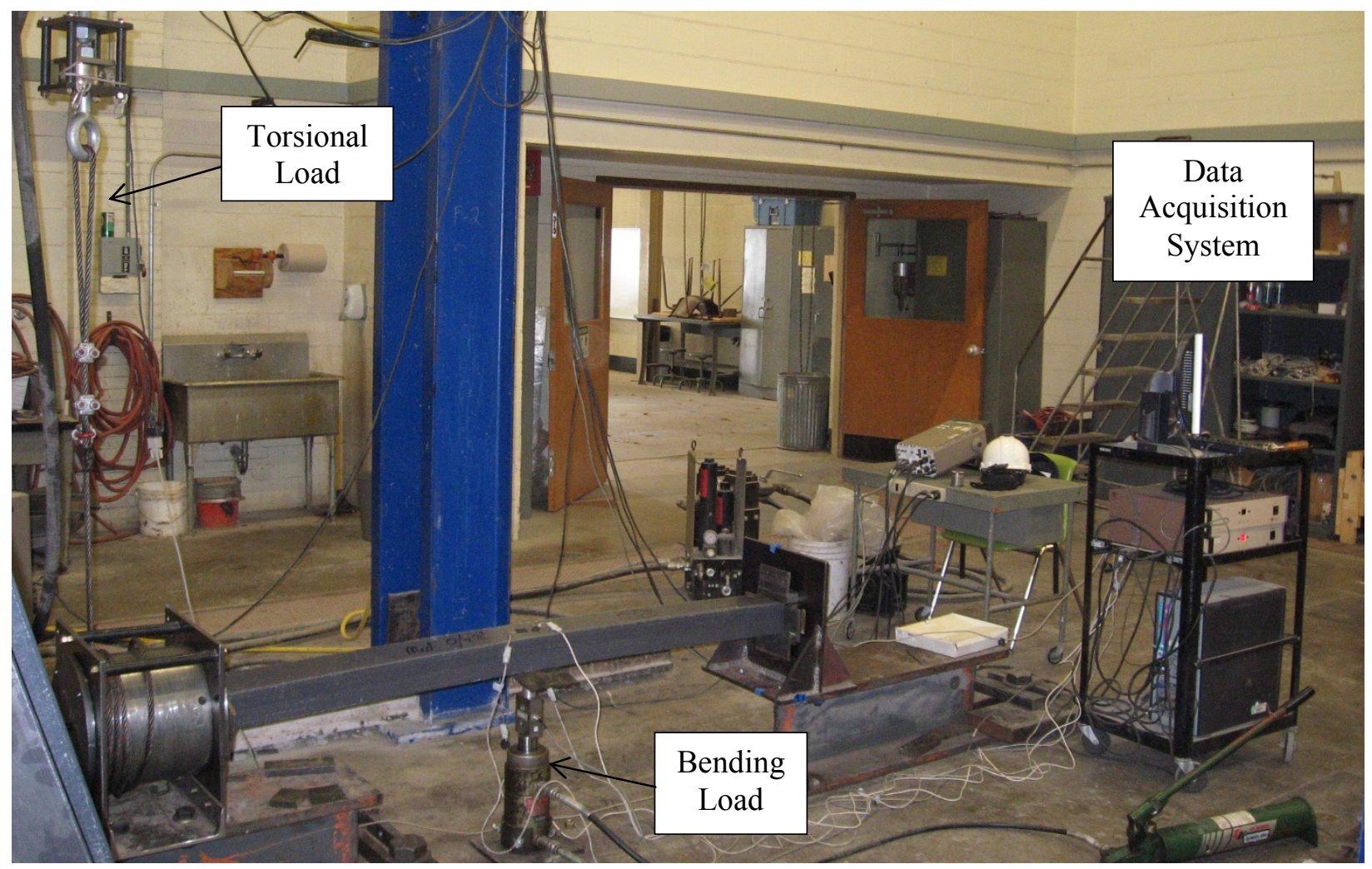

Figure 3-13: Experimental Set-Up for Combined Bending and Torsion

\subsection{Test Procedure}

The test procedure consists of sample preparation, mounting it in the testing machine, applying load and measuring response with the help of a data acquisition system, as explained below.

\subsubsection{Sample Preparation}

\subsubsection{Sample Preparation for Laminate Properties}

\section{a) Tension Test Coupons Preparation}

The minimum coupon size for the Instron HDX1000 machine is 12" with or without end tabs. But it is always preferable to bond the end tabs to provide a better grip and avoid stress concentrations. An end tab is a metallic piece, typically 3" long and as wide as the coupon itself. 
To prepare the end tabs, a number of small holes are drilled into the metal pieces. Then, the mating surfaces of the tabs and the coupon ends are roughened and degreased. A thin layer of the bonding material is spread on both sides of the roughened coupon end and the metallic tabs are placed on both sides. The whole assembly is clamped with medium pressure and left overnight for curing. The same process is repeated on the other end. The end-tab of a longitudinal coupon illustrated in Figure 3-14.

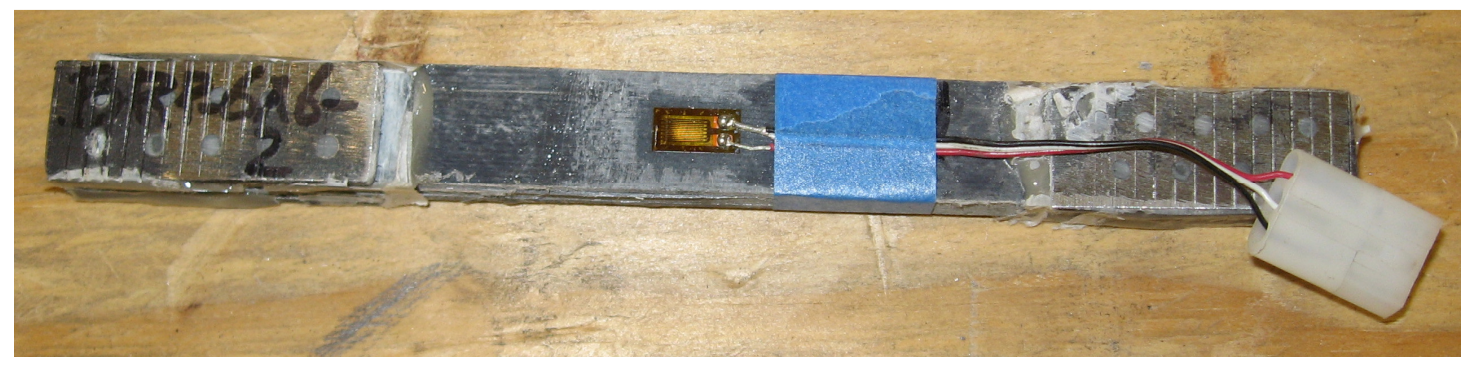

Figure 3-14: End-Tabs of a Longitudinal Coupons

The transverse coupons do not have enough length to be held in the testing machine. Hence, longer end tabs with a dummy strip are used, as shown in Figure 6.

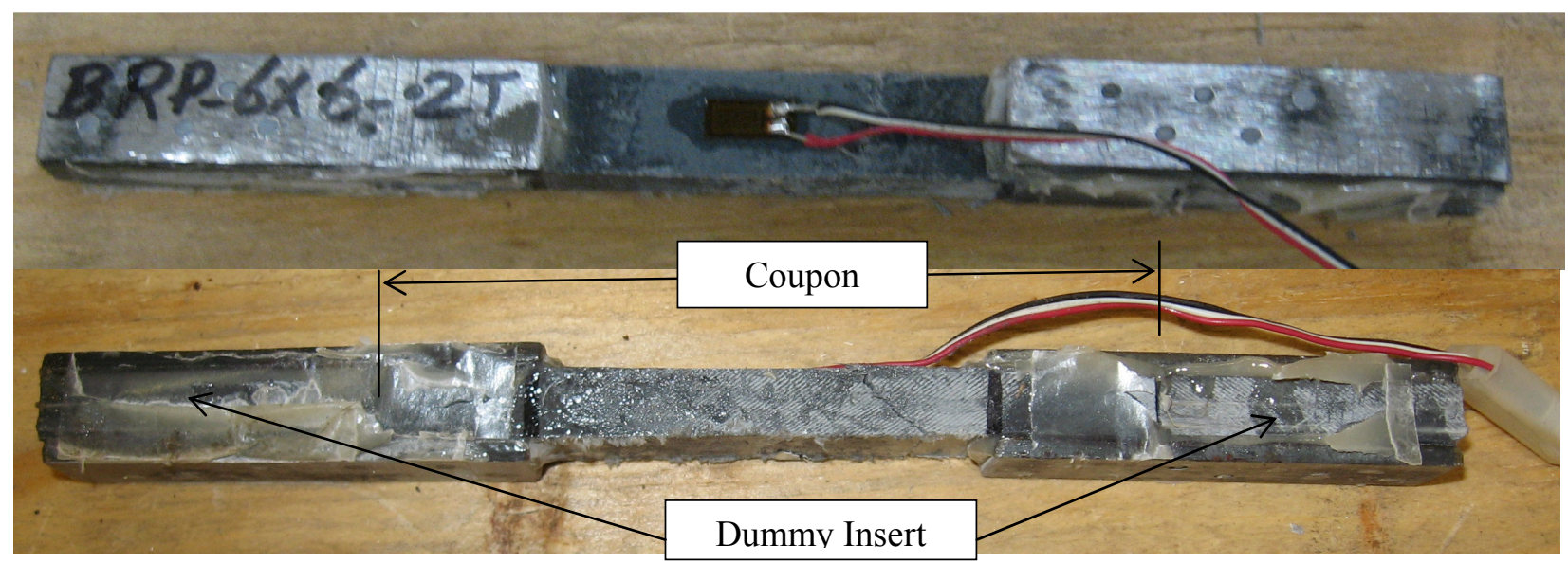

Figure 3-15: End-Tabs of a Transverse Coupon 


\section{b) Iosepescu Test Coupons Preparation}

To find the shear strength and modulus of rigidity, 4 " $\times 3 / 4$ " coupons are cut in the longitudinal and transverse direction of the sample. V-notches are then cut to a depth of $1 / 8$ " on both sides at mid-length. The prepared samples are shown in Figure 3-16.

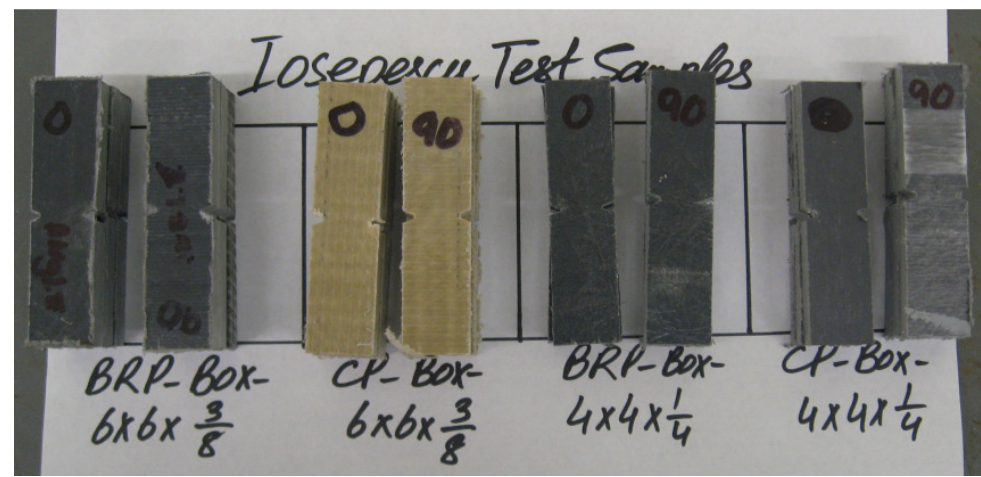

Figure 3-16: Longitudinal and transverse Shear Test Samples with V-Notches

\section{c) Burnout Test Coupons Preparation}

According to ASTM D 3171 test standard, the burnout test samples are cut as close to a size of 1 " $\times 1 "$ as possible.

\section{d) Scanning Electron Microcopy(SEM) Sample Preparation}

The standard steps of preparing the samples for scanning electron microscopy are as under:

I. Small pieces, of the order of a quarter of an inch, are cut from the full scale sample and their edges are trimmed with the help of a sharp knife.

II. 5 parts by weight of epoxy resin and 1 part by weight of hardener are mixed thoroughly together.

III. The sample container is sprayed with demolding agent, the FRP sample is placed edgewise at the bottom of the container and epoxy solution is poured to fill in the container.

IV. The samples are left overnight to get cured. 
V. Once the curing is done, the raw samples are removed from the containers and polished with the help of a polishing machine. A single sample is usually hand-held, while 3 to 5 samples are typically mounted in a sample holder.

VI. The hand-held polishing is more of a matter of personal judgment. First stage is done by a coarse sand paper of grit 320. In each of the subsequent stages, finer sand papers of grit 600 and 1200, respectively, are used to ultimately give a near-mirror finish. However, a high surface finish can be obtained only by using a bigger range of sand papers and mounting the samples in a sample holder.

The various stages of SEM sample preparation are shown in Figure 4.8.

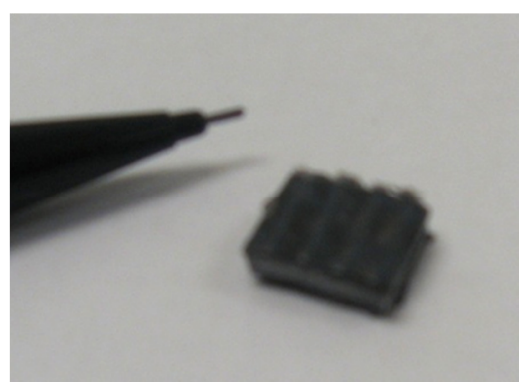

(a) The Cut Sample

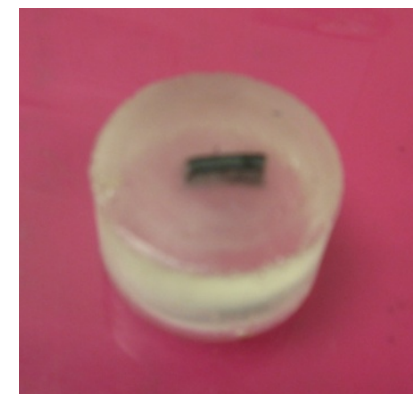

(c) Raw Sample

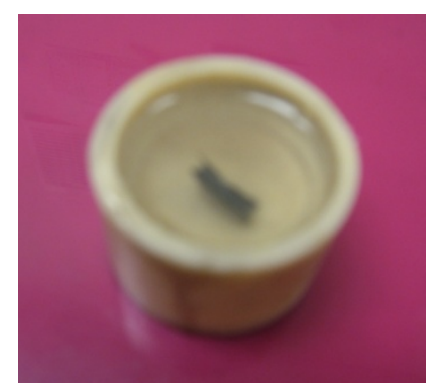

(b) Embedding Process

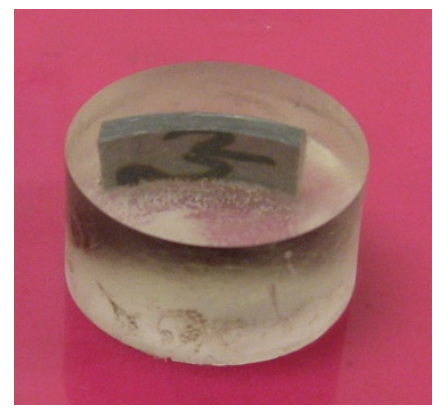

(d) Polished Sample

Figure 3-17: Various Stages of SEM Sample Preparation

\subsubsection{Samples Preparation for 3-Point Bending Tests}

In bending testing of full-length specimens, the contact line between the load and the specimen is a critical position, where local crushing may take place, especially for shorter spans. Therefore, it is advisable to place an elastomeric pad between the load and the testpiece. For the same reason, 
end-plugs should be inserted through both ends. A pair of removable wooden end-plugs for a $6 \times 6 \times 0.375$ beam section is shown in Figure 3-18.

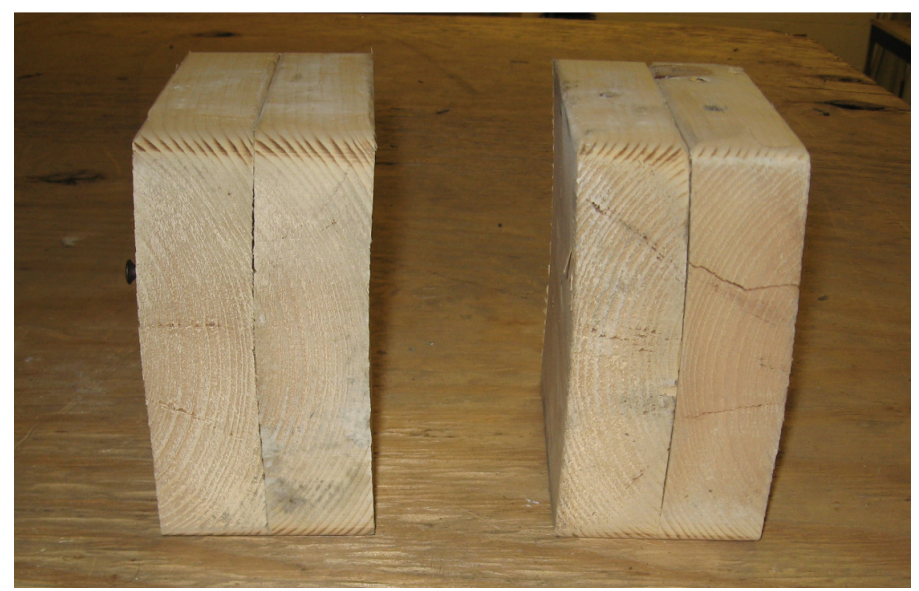

Figure 3-18: Removable Wooden End-Plugs for a 6×6×0.375 Beam Section

\subsubsection{Torsion Test Sample Preparation}

\section{a) Design of the End-Plugs}

The ends of the full-scale sample are held and loaded in the torsional testing rig, and need to be supported with the help of end-plugs due to two reasons: first, to transmit torsional load to the sample without end-crushing and second, to provide an appropriate shape to fit into the machine. The end-plugs of a round sample therefore consist of a square plate with a round plug welded at the center of its face such that the round part mates into the sample and the plate fits into the machine-end.

\section{b) Bonding the End-Plugs}

A high strength bond is required between the sample and the end-plugs. This is achieved through the following steps.

- The mating surfaces are roughened with the help of coarse sandpaper and are cleaned thoroughly of any debris with the help of compressed air. 
- High-strength bonding material, Pliogrip ${ }^{\mathrm{TM}}$, is available in the form of two barrels: having green and white materials. Equal quantities of the two are thoroughly mixed together on a clean surface.

- An even layer of the bonding material is applied at the mating surfaces.

- The end plug is mounted into the sample.

- An appropriate curing time, typically overnight, is provided for curing.

The step-by-step sample preparation procedure is shown in Figure 3-19.

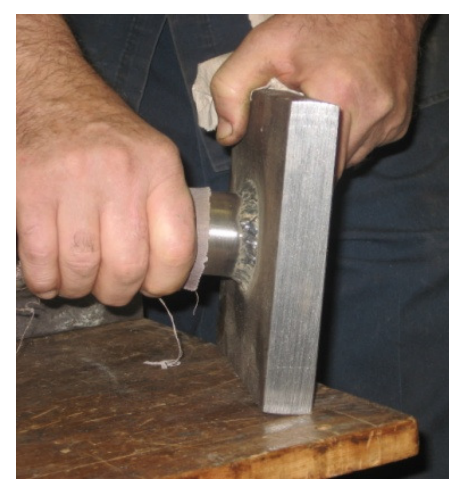

(a) Roughening the EndPlug Surface

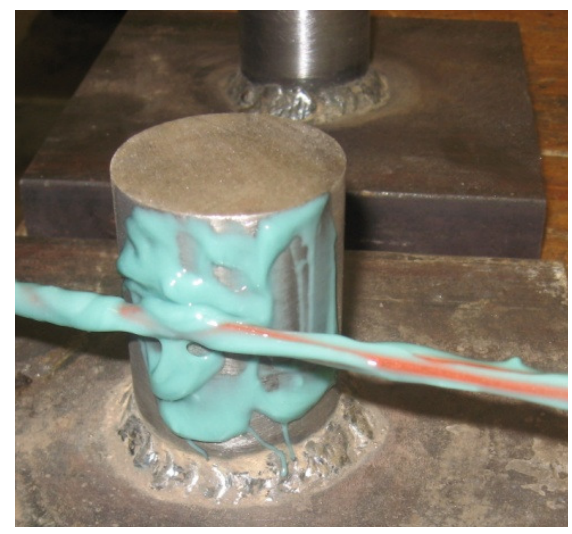

(d) Applying Bonding Material to the Roughened Surfaces

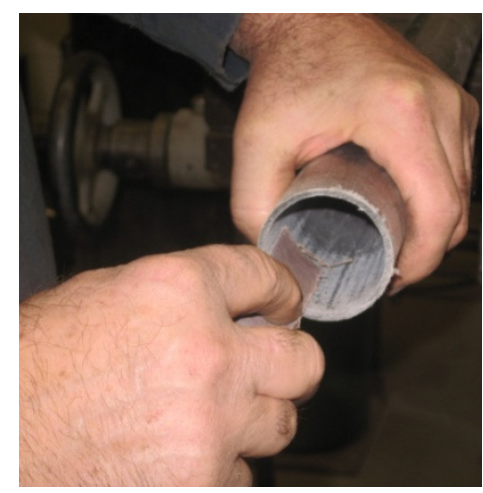

(b) Roughening the Inner Surface of Sample

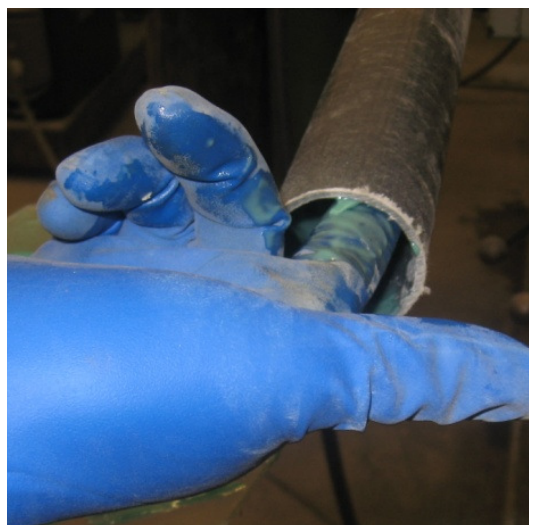

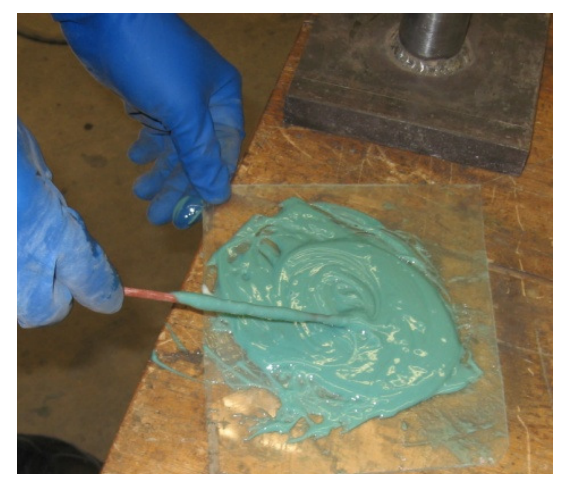

(c) Preparing the Bonding Material

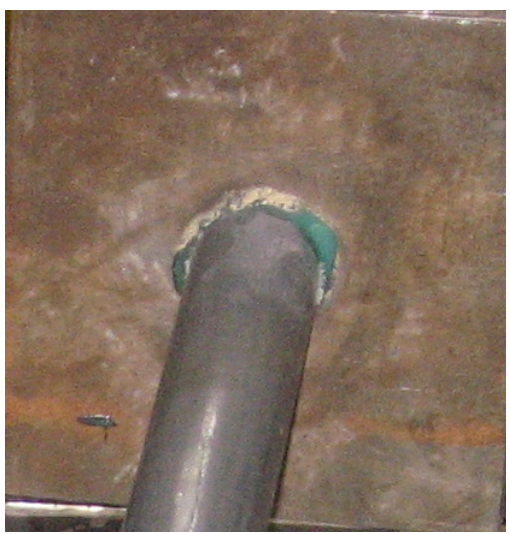

(e) Assembling the Parts

Figure 3-19: Various Stages of Bonding the End-Plugs 


\section{c) Installing the Strain Gages}

The basic shear strain relation is given by

$$
\gamma_{x y}=2 \varepsilon_{45^{o}}-\left(\varepsilon_{x}+\varepsilon_{y}\right)
$$

where $\mathrm{x}$ and $\mathrm{y}$ refer to longitudinal and transverse axes respectively. The values of $\varepsilon_{x}$ and $\varepsilon_{y}$ are experimentally found to be negligible. Also, it is more convenient to measure the strain at $\pm 45^{\circ}$. Hence, equation 4.1 is simplified as

$$
\gamma_{x y}=\left|\varepsilon_{45^{\circ}}\right|+\left|\varepsilon_{-45^{\circ}}\right|
$$

For a full-scale torsion sample, one pair of gages is applied near the fixed end at $\pm 45^{\circ}$ and the other near the rotating end at $\pm 45^{\circ}$; the gage length being the distance between both of the pairs. However, care must be taken that the gage position is at least 2" away from the end-plug. The net shear strain due to torsion will then be

$$
\gamma_{x y}=\left[\left|\varepsilon_{45^{o}}\right|+\left|\varepsilon_{-45^{o}}\right|\right]_{\text {rotating }}-\left[\left|\varepsilon_{45^{\circ}}\right|+\left|\varepsilon_{-45^{\circ}}\right|\right]_{\text {fixed }}
$$

Strain gage installation is a standard step-by-step procedure and is provided by all the manufacturers/ suppliers, hence needs not to be reported here.

\subsubsection{Performing the Tests}

\subsubsection{Performing the Tests for Laminate Properties}

\section{a) Coupon Tension and Iosepescu Tests}

The Instron HDX1000 machine and 8501 machine have different operating procedures, the sense however being the same. First of all, the sample is manually mounted in the jaws of the machine. Then the feed-rate is input to test-software, a typical value being $0.1 \mathrm{inch} / \mathrm{min}$. When test starts, load acts on the coupon till failure and is shown by a load extension curve on the monitor. At failure, the test stop automatically, while the data can be saved and copied as required. A closeup of the coupon tension test is shown in Figure 3-20. 


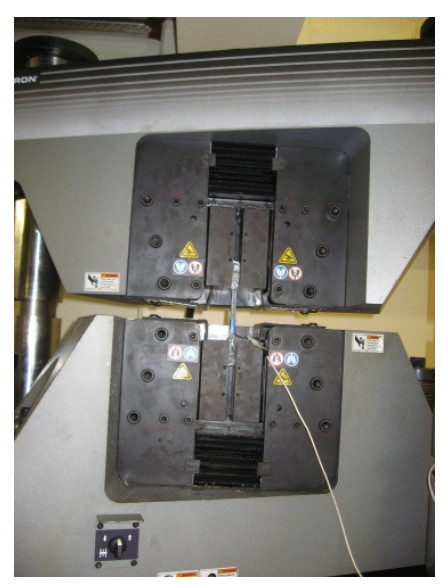

Figure 3-20: Close-Up of the Coupon Under Tension

In the Iosepescu test, sample is inserted in a fixture, which is manually mounted in the jaws of Instron 8501 machine, as shown in Figure 3-2. The feed-rate is $0.05 \mathrm{inch} / \mathrm{minute}$. The remaining procedure is essentially the same.

\section{b) Performing the Burnout Test}

As per ASTM D 3171 standard, following are the steps of burnout test to determine the fiber volume fraction.

I. Preheat the muffle furnace at $565^{\circ} \mathrm{C}$.

II. Accurately measure the length, width and thickness of the samples with the help of vernier calipers.

III. Measure the weight of empty crucibles at the electronic balance.

IV. Put the samples in the crucibles and measure the combined weight of samples with crucibles.

V. Place the weighed crucibles with samples in the preheated furnace for 3 hours to burnout all the polymer matrix while the fiber is left behind.

VI. Measure the weights of the burntout samples.

VII. Perform calculations to find the fiber volume fraction. 


\section{c) Microscopic Examinations}

As already stated, scanning electron microscopy is done by the relevant staff, but optical microscope can be operated after some practice. The sample is placed at its specified place and first the lowest magnification lenses are selected. Light is turned on to a medium intensity and the sample position is adjusted with the help of vertical/horizontal knobs. Then the software is clicked on to see the live image on screen, the focus of which is controlled by a knob. A better visualization can be achieved by varying the light intensity and magnification can further be enhanced by selecting the lenses of higher power. Once an appropriate view is found, snap is taken and the desired measurements are taken, followed by saving the micrograph as an image.

\subsubsection{Performing the Bending Tests}

In the 3-point bending test, the testpiece is placed at the roller supports and the load is applied at the mid-span via a hydraulic ram. The magnitude of load and position of the actuator are measured and recorded electronically. The feed rate of actuator is typically set at 0.1 inch/minute.

The bending tests with punching loads were performed on 2' long samples of 3" to 6" cross section square beams at the compression side of the Instron HDX1000 machine. A punching load was applied through a rigid metal piece of dimensions clearly smaller than the width of the top flange without an elastomeric pad. To see the effect of elastomeric pad, the same experiments were repeated by inserting elastomeric pads between the punching load and the top flange.

Then, the test procedure was repeated by a different load type, i.e., a rigid metal plate of length greater than the width of the top flange with elastomeric pad. This arrangement helps determine the compressive/crushing strength. Finally, to perform the tests with uniformly distributed loads, a rigid plate with length equal to the span length and width greater than the flange width was used. 
In all of the tests done at Instron machine, the sample ends were fitted by end-plugs and roller supported, the feed rate being $0.1 \mathrm{inch} / \mathrm{min}$.

\subsubsection{Performing the Torsion Test}

\section{a) Sample Mounting and Connecting to Data Acquisition System}

As already described, the plates of the end-plug fit into the end-supports of the testing machine. The type of fit depends upon the boundary conditions; the simply supported conditions are given by a loose fit and the fixed conditions are given by a tight fit by driving extra metal strips in the gaps. Then the cable wrapped around the cylinder of the rotating end is attached to the lower hook of the load cell fixture; the upper hook of which is attached to the hydraulic actuator. Finally, strain gages and load cell are connected to the data acquisition system as explained in section 3.2.1.2. The data acquisition system is turned on and the StrainSmart ${ }^{\circledR}$ software is used to start a new project. Before loading, it is important to make sure that all the sensors are connected properly. A sample ready for testing is shown in Figure 3-21.

\section{b) Loading the Sample and Acquiring the Data}

Once the set-up is ready, the StrainSmart ${ }^{\circledR}$ software is invoked to record the data. The hydraulic pump of the actuator is turned on and motion of the actuator is controlled by the microcontroller. Although no option is available to input a required feed rate (inch/min) to the microcontroller, yet attempt is made to keep the feed rate as constant as possible by manually operating it. The loading process is continued till failure of the sample. Data recording is stopped and the recorded data is reduced and saved as an Excel worksheet. The loading process is shown in Figure 3-22. 

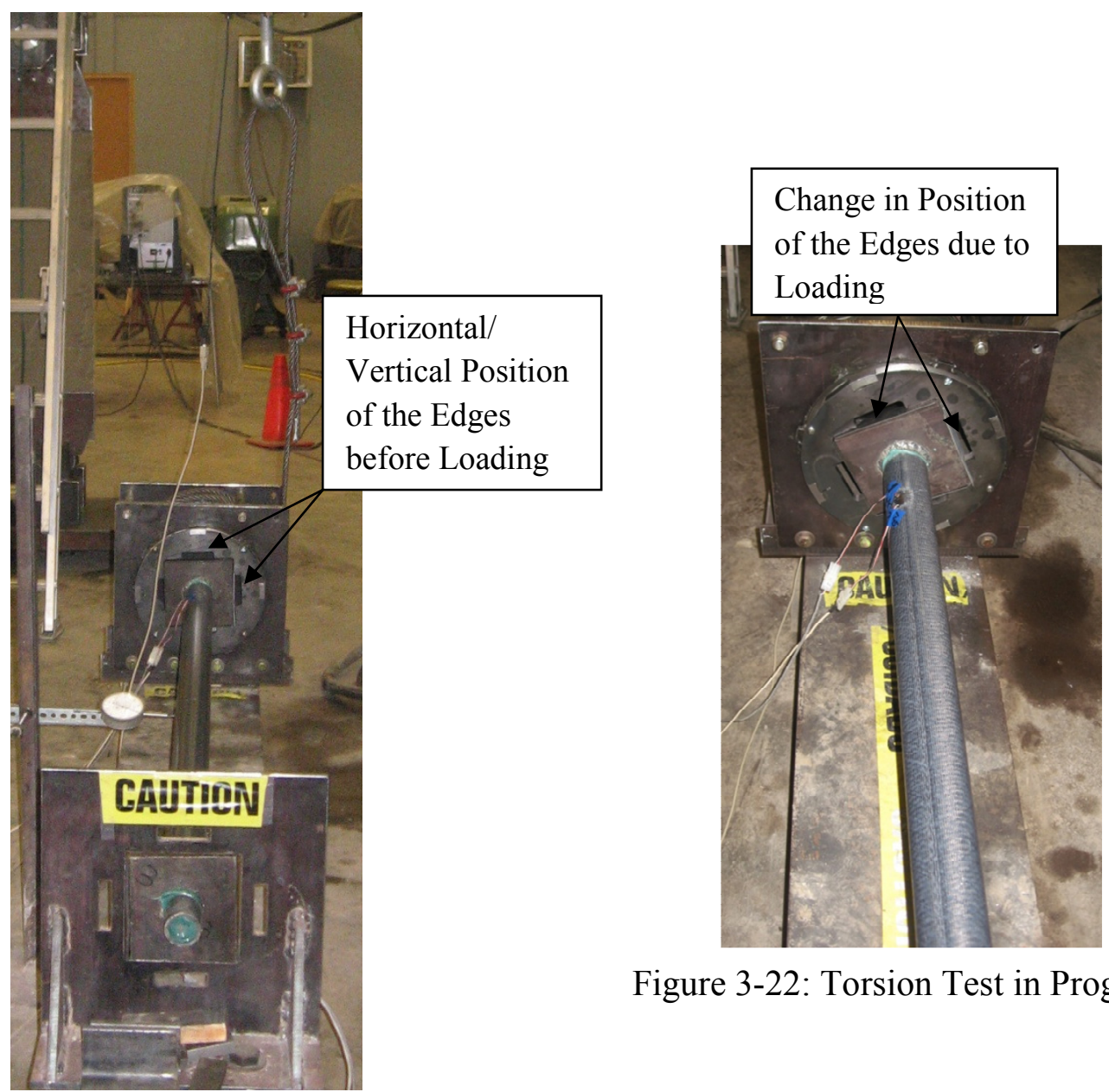

Figure 3-22: Torsion Test in Progress

Figure 3-21: A Torsion Test Sample Ready for

Testing

\subsubsection{Performing the Combined Bending and Torsion Test}

The test sample is mounted into the two ends of the apparatus with a loose fit to ensure the simply supported boundary conditions. It should be perfectly balanced and aligned; otherwise it may kick-out when load is applied. After connecting to the data acquisition system, the required amount of bending load is applied via a hydraulic actuator. Then the torsional load is applied till failure, exactly the same way as pure torsion and test data are recorded. 


\subsection{Test Specimens}

\subsubsection{Coupon Specifications}

The coupon specifications of tension tests and Iosepescu tests are given in Table 3-1 and 3-2 respectively.

Table 3-1: Specifications of Tension Test Coupons

\begin{tabular}{|c|c|c|c|c|c|}
\hline Parent Sample & Direction & $\mathbf{L}_{\text {total }}$ (inch) & $\mathbf{L}_{\text {effective (inch) }}$ & b (inch) & t (inch) \\
\hline BRP-Box-6×6×3/8 & Longitudinal & 8.00 & 3.75 & 0.75 & 0.375 \\
\hline BRP-Box- $6 \times 6 \times 3 / 8$ & Transverse & 8.00 & 2.50 & 0.75 & 0.375 \\
\hline BRP-Box-4×4×1/4 & Longitudinal & 8.00 & 3.75 & 0.75 & 0.250 \\
\hline BRP-Box-4×4×1/4 & Transverse & 8.00 & 1.15 & 0.5 & 0.250 \\
\hline SW-Box-4×4×1/4 & Longitudinal & 8.00 & 3.75 & 0.75 & 0.250 \\
\hline SW-Box-4×4×1/4 & Transverse & 8.00 & 1.25 & 0.5 & 0.250 \\
\hline
\end{tabular}

Table 3-2: Specifications of Iosepescu Test Coupons

\begin{tabular}{|c|c|c|c|c|c|}
\hline Parent Sample & Direction & L (inch) & w (inch) & t (inch) & V-notch Depth (inch) \\
\hline BRP-Box- $6 \times 6 \times 3 / 8$ & Longitudinal+Transverse & 3.00 & 0.75 & 0.375 & 0.125 \\
\hline CP-Box- $6 \times 6 \times 3 / 8$ & Longitudinal+Transverse & 3.00 & 0.75 & 0.375 & 0.125 \\
\hline BRP-Box- $4 \times 4 \times 1 / 4$ & Longitudinal+Transverse & 3.00 & 0.75 & 0.250 & 0.125 \\
\hline CP-Box- $4 \times 4 \times 1 / 4$ & Longitudinal+Transverse & 3.00 & 0.75 & 0.250 & 0.125 \\
\hline
\end{tabular}

\subsubsection{Specifications of Bending Test Samples}

The specifications of 3-point bending test samples are given in Table 3-3 and those of other bending test samples are given in Table 3-4. 
Table 3-3: Specifications of 3-Point Bending Test Samples

\begin{tabular}{|c|c|c|c|c|c|c|c|c|c|c|c|c|c|}
\hline \multirow{2}{*}{ Manufacturer } & \multicolumn{1}{|c|}{ Cross-Section (inch) } & \multicolumn{10}{|c|}{ Span (inch) } \\
\cline { 2 - 14 } & $\mathbf{b}$ & $\mathbf{t}_{\mathbf{f}}$ & $\mathbf{h}$ & $\mathbf{t}_{\mathbf{w}}$ & $\mathbf{L 1}$ & $\mathbf{L 2}$ & $\mathbf{L 3}$ & $\mathbf{L 4}$ & $\mathbf{L 5}$ & $\mathbf{L 6}$ & $\mathbf{L 7}$ & $\mathbf{L 8}$ & $\mathbf{L 9}$ \\
\hline $\mathrm{ABC}$ & 6 & $3 / 8$ & 6 & $3 / 8$ & 30 & 36 & 60 & 96 & 144 & 180 & & & \\
\hline $\mathrm{ABC}$ & 4 & $1 / 4$ & 6 & $1 / 4$ & 24 & 30 & 48 & 57.6 & 72 & 84 & 105.6 & 120 & 168 \\
\hline $\mathrm{ABC}$ & 4 & $3 / 8$ & 4 & $3 / 8$ & 48 & 84 & 120 & 168 & & & & & \\
\hline $\mathrm{ABC}$ & 3.5 & $1 / 4$ & 3.5 & $1 / 4$ & 36 & 60 & 108 & 144 & & & & & \\
\hline $\mathrm{ABC}$ & 2 & $1 / 4$ & 4 & $1 / 8$ & 42 & 72 & 96 & 144 & & & & & \\
\hline $\mathrm{ABC}$ & 1.5 & $1 / 4$ & 1.5 & $1 / 4$ & 30 & 45 & & & & & & & \\
\hline $\mathrm{ABC}$ & 5.2 & $3 / 8$ & 5.2 & $3 / 8$ & 48 & 84 & 120 & 168 & & & & & \\
\hline
\end{tabular}

Table 3-4: Specifications of Other Bending Tests Samples

\begin{tabular}{|c|c|c|c|c|c|}
\hline Manufacturer & $\mathbf{b}$ (inch) & $\mathbf{h}$ (inch) & $\mathbf{t}_{\mathbf{f}}$ (inch) & $\mathbf{t}_{\mathbf{w}}$ (inch) & $\mathbf{L}$ (inch) \\
\hline $\mathrm{ABC}$ & 3 & $1 / 4$ & 3 & $1 / 4$ & 28 \\
\hline $\mathrm{CP}$ & 4 & $1 / 4$ & 4 & $1 / 4$ & 28 \\
\hline $\mathrm{CP}$ & 6 & $3 / 8$ & 6 & $3 / 8$ & 24 \\
\hline
\end{tabular}

\subsubsection{Specifications of Torsion Test Samples}

\subsubsection{CP-Round-2.5 $\times 0.10-70$}

The specifications of the full-scale test-specimen, provided by Creative Pultrusions are given in Figure 3-16. The outer diameter is measured to be 2.5 ", wall thickness 0.1 " and the nominal length is 6'. The innermost layer is made of C-TTX 1800, manufactured by VectorPly Corporation, the specifications of which are given in Table 3-5 and fiber layout shown in Figure 3-17. However, the thickness of the middle layer and the outer layer are not given. 


\section{MM CARBDN TUEE CINGTRUCTIDN PART \# TU4D 1 DIE \# $6158-1$ c DATE: 3-1口-प6}

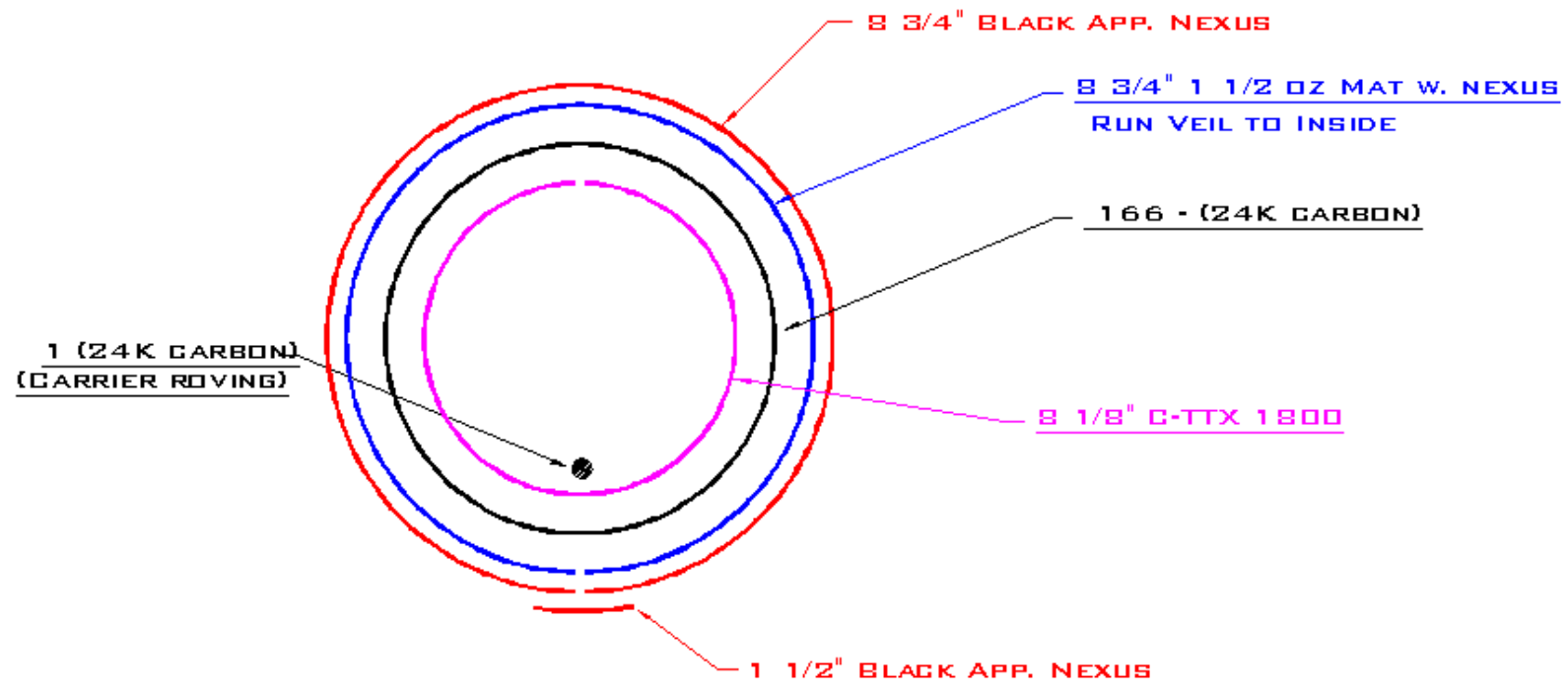

Figure 3-23: Manufacturer's Specifications of the CP-Round-2.5×0.1/6L Sample

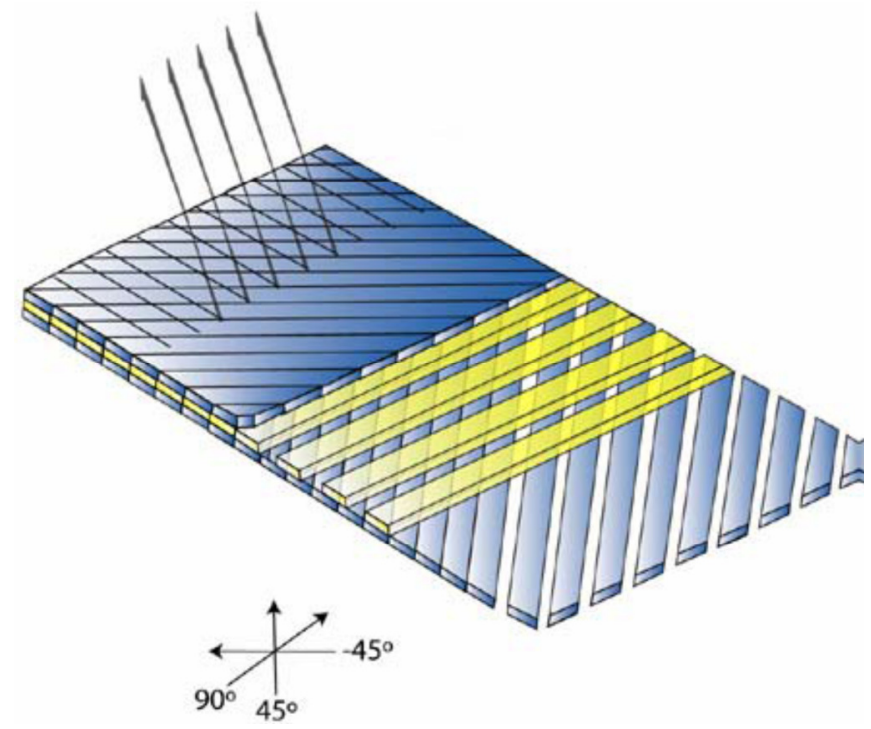

Figure 3-24: Fiber Layout of the Inner Layer (VectorPly C-TTX 1800) 
Table 3-5: Manufacturer's Specifications of the Inner Layer (VectorPly C-TTX 1800)

\begin{tabular}{|c|c|c|c|}
\hline \multicolumn{2}{|c|}{ Fiber Architecture } & \multicolumn{2}{|c|}{$\underline{\text { Laminated Properties }}$} \\
\hline Fiber Type & Carbon & Density & $1.53 \mathrm{~g} / \mathrm{cc}(93 \mathrm{lb} / \mathrm{cft})$ \\
\hline \multirow[t]{3}{*}{ Architecture } & 45/90/-45 Weft Triaxial & Fiber Content & $64 \%$ by weight \\
\hline & $\pm 45^{\circ}: 5.90 \mathrm{oz} / \mathrm{yd}^{2}\left(200 \mathrm{~g} / \mathrm{m}^{2}\right)$ & Thickness & 0.024 inch $(0.6 \mathrm{~mm})$ \\
\hline & $90^{\circ}: 5.57 \mathrm{oz} / \mathrm{yd}^{2}\left(189 \mathrm{~g} / \mathrm{m}^{2}\right)$ & Ex & $2.74 \mathrm{msi}(18.89 \mathrm{GPa})$ \\
\hline Dry Thickness & 0.035 inch $(0.89 \mathrm{~mm})$ & Ey & $6.63 \mathrm{msi}(45.71 \mathrm{GPa})$ \\
\hline \multirow[t]{3}{*}{ Total Weight } & $17.37 \mathrm{oz} / \mathrm{yd}^{2}\left(589 \mathrm{~g} / \mathrm{m}^{2}\right)$ & Gxy & $2.98 \mathrm{msi}(20.55 \mathrm{GPa})$ \\
\hline & & Ex,flex & $2.60 \mathrm{msi}(17.93 \mathrm{GPa})$ \\
\hline & & Ey,flex & $6.30 \mathrm{msi}(47.78 \mathrm{GPa})$ \\
\hline
\end{tabular}

\subsubsection{SW-Round-2.0 $\quad$ (0.125- $24 \& 144$}

The full-scale samples, provided by Strongwell Corporation, are of 2.0" outer diameter with a wall thickness of $1 / 8$ inch. The nominal length of one of the samples is 12' (Long-Sample) and that of the other one is 2' (Short-Sample). However, no manufacturer's specifications are available.

\subsubsection{3. $S W-B o x-4 \times 4 \times 0.25-70$}

These samples were provided by Strongwell Corporation with cross-section of 4 " $\times 4$ " $\times 0.25$ " and a nominal length of 6'. Effective length after excluding the end-plugs is 66". No manufacturer's specifications are available.

\subsubsection{BRP-Box $-6 \times 6 \times 0.375-70$}


The full-scale samples, provided by Bedford Reinforced Plastics, are of 6" $\times 6$ " square crosssection with a wall-thickness of $3 / 8$ inch, the nominal length being 6'. The effective length excluding the end-plugs is 66". No information about fiber-architecture is available. However, dimensions of the corner radii are available, as will discussed in Chapter-6, Figure 6-7.

\subsubsection{CP-Round-6 $\times 0.25-70$}

These samples, provided by Creative Pultrusions, consist of round cross-section of 6" diameter and 0.25 " wall-thickness with a nominal length of 70 " and effective length of 67 ". No sample specifications are available.

\subsubsection{Specifications of Combined Bending and Torsion Test Samples}

The three types of full-length samples tested under combined bending and torsion are:

- SW-Box- $4 \times 4 \times 0.25-70$

- BRP-Box-6×6×0.375- 70

- CP-Round-6×0.25- 70

as discussed under the torsion test samples. 


\section{CHAPTER 4 - LAMINATE PROPERTIES}

\subsection{Introduction}

Before investigating the behavior of pultruded GFRP composite beams under 3-point bending, pure torsion and combined bending and torsion, it is important to find their laminate properties in the desired directions. The laminate properties, found through a variety of tests, provide the reference values for any other type of test.

In this research work, the types of tests employed for laminate properties include optical microscopy, Scanning Electron Microscopy, burnout tests, coupon tension tests and coupon shear tests (Iosepescu tests).

\subsection{Problem Formulation: Classical Laminate Theory (CLT)}

Basics of classical laminate theory (CLT) are given in Appendix-A. As can be seen from Equations A-1 through A-5, the moduli of elasticity and Poisson's ratio can be expressed in terms of fiber and matrix properties if fiber volume fraction is known. The compliance and stiffness matrices can then be written in terms of moduli of elasticity and Poisson's ratios, as given by Equations A-8 through A-11. The on- and off-axis compliance matrices of a 2dimensional orthotropic laminate can be expressed as given by Equations A-13 through A-17. Finally, the $[A],[B]$ and $[D]$ matrices can be found as shown in Equations A-19 through A-24.

The comparison of experimental and analytical results of torsion tests, supported by optical and scanning electron microscopy, burnout tests and 3-point bending tests, is given in the following sections. 


\subsection{Results and Discussions}

\subsubsection{Coupon Tension Test Results}

\subsubsection{BRP-Box-6×6×3/8-Longitudinal and Transverse Coupons}

The stress strain curves along with the modulus of elasticity of the two longitudinal coupons are shown in Figure 4-1 (a) and (b). The fiber architecture of these beams consists of glass rovings in the longitudinal direction and continuous filament mat (CSM). A clearly linear trend till almost failure owes to the longitudinal glass rovings. The slight variation in the $\mathrm{E}$ value is not unexpected due to variation in fiber distribution in composite materials.

(a) BRP-Box-6X6X3/8-L1

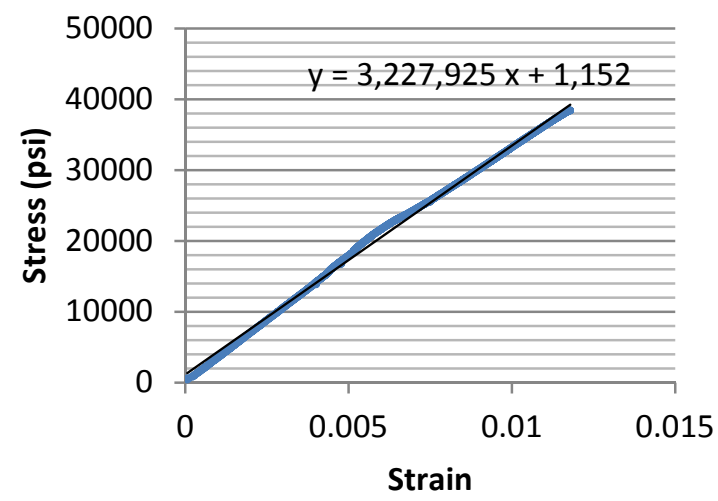

(b) BRP-Box-6X6X3/8-L2

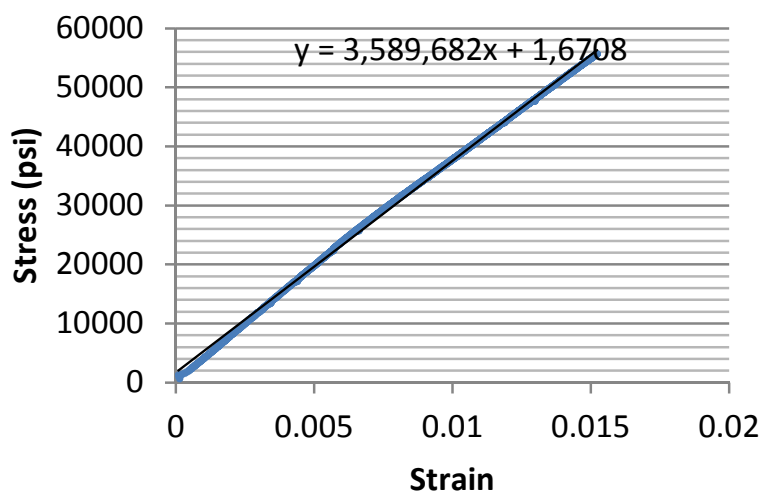

Figure 4-1: $\sigma-\varepsilon$ Curves with E values of BRP-Box- $6 \times 6 \times 3 / 8$ Longitudinal Coupons

The stress strain curves of the transverse coupons are shown in Figure 4-2 (a) and (b). As can be seen, the strength in this direction is around one-fourth of that in longitudinal direction. This is because only CSM contributes to the strength in this direction. As the curve is not linear till failure, the modulus of elasticity is determined corresponding to the linear part only. A further comparison is made with the modulus of elasticity till $40 \%$ load, the value being a little higher than that of the full linear portion of the curve. The 40\% load curves are shown in Figure 4-2 (c) and (d) respectively. 
(a) BRP-Box-6x6x3/8-T1

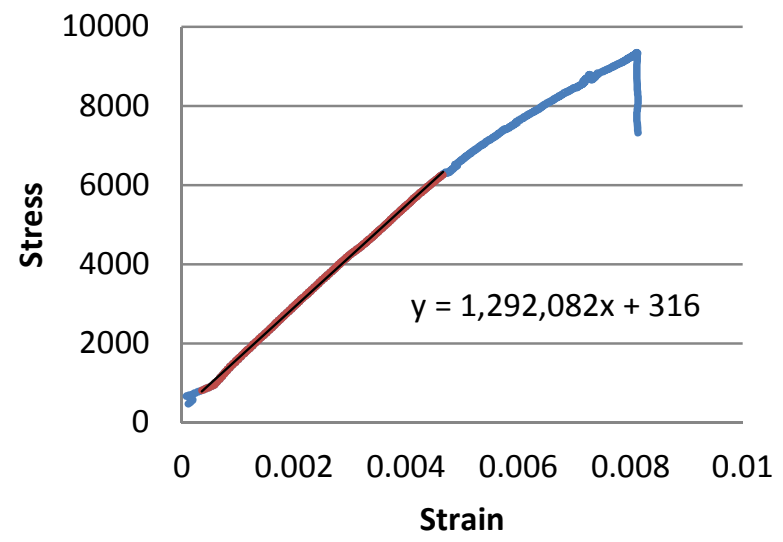

(c) BRP-Box-6x6x3/8-T1: 40\% Load

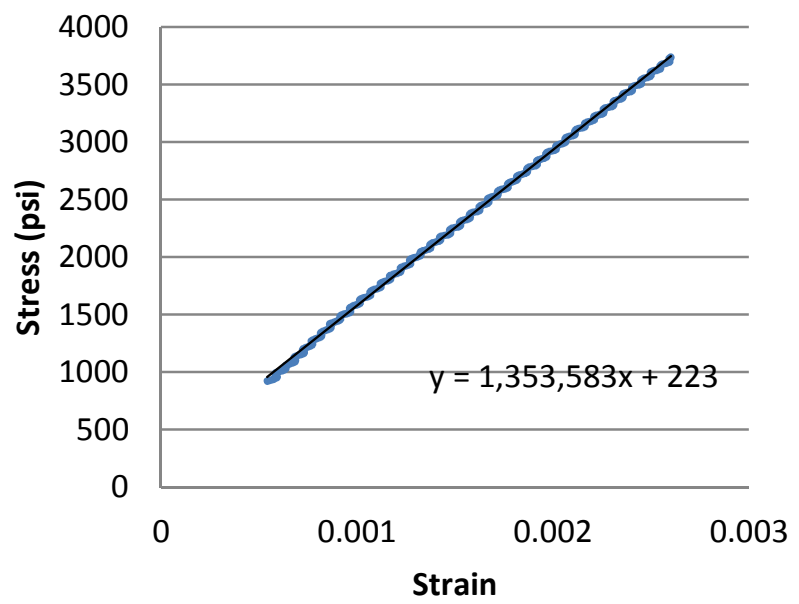

(b) BRP-Box-6x6x3/8-T2

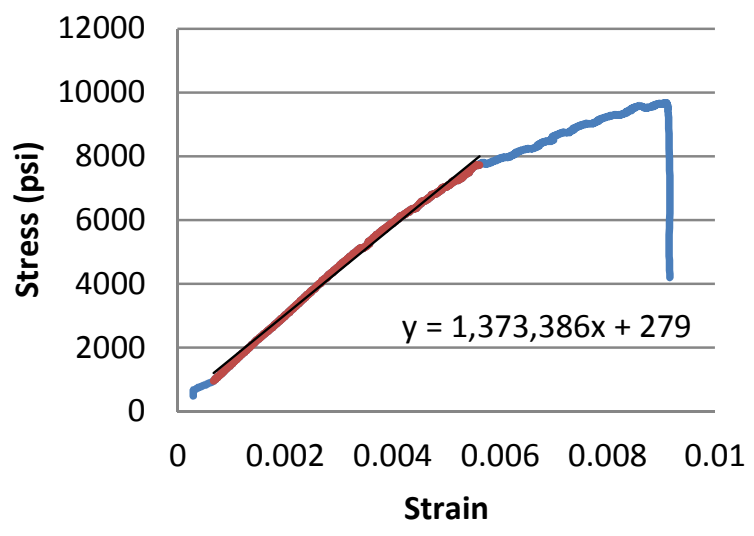

(d) BRP-Box-6x6x3/8-T2: 40\% Load

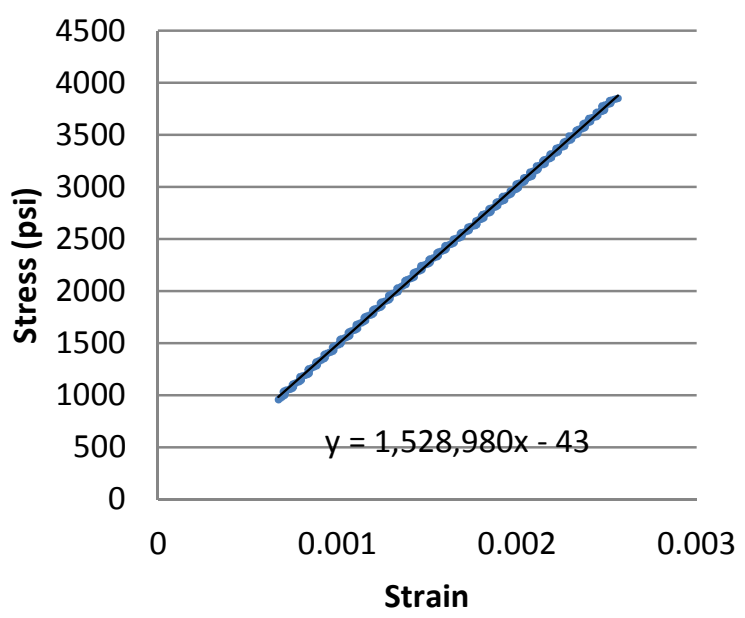

Figure 4-2: $\sigma-\varepsilon$ Curves with E values of BRP-Box- $6 \times 6 \times 3 / 8$ Transverse Coupons

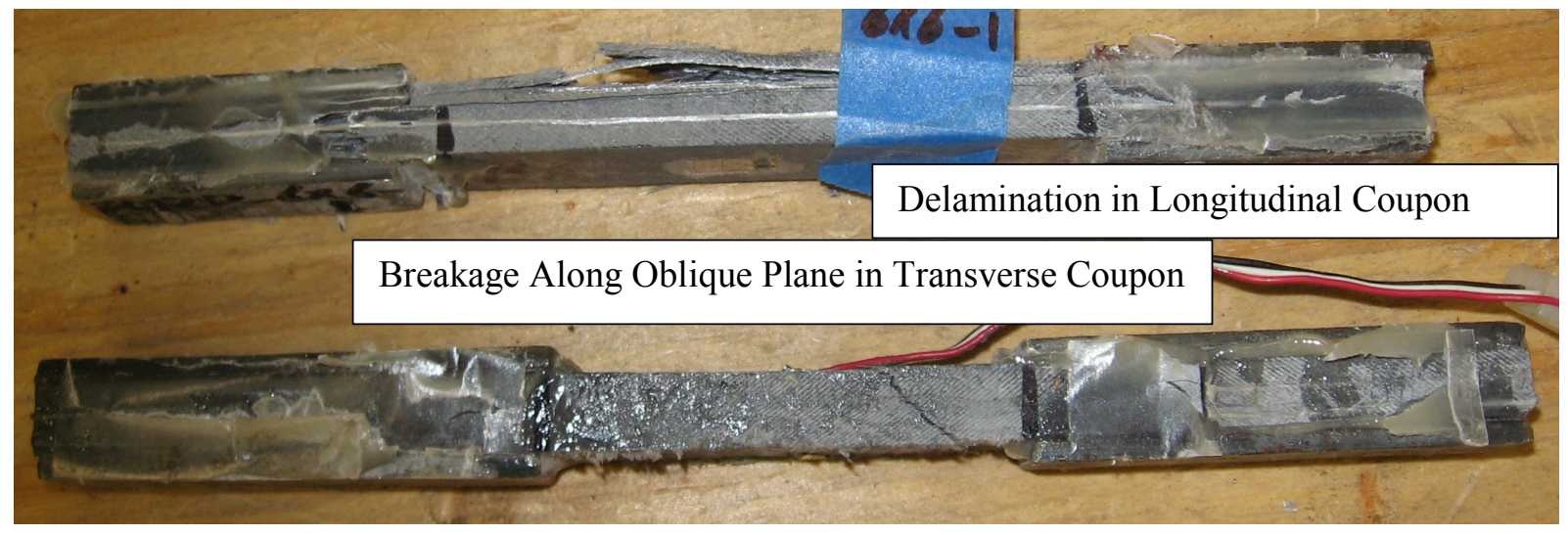

Figure 4-3: The Tested BRP-Box- $6 \times 6 \times 3 / 8$ Coupons 
The broken coupons (longitudinal and transverse) are shown in Figure 4-3. As can be seen, the longitudinal coupon failed due to delamination of the rovings in the longitudinal direction. The transverse coupon failed along an oblique plane because rovings have no effect in this direction.

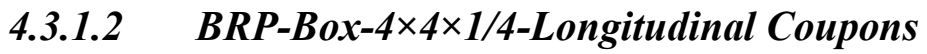

The stress-strain curves of the BRP-Box- $4 \times 4 \times 1 / 4$-Longitudinal Coupons and the E values are shown in Figure 4-4. The trend can be seen to be similar to that of the $6 \times 6 \times 3 / 8$ case, though the $\sigma_{\max }$ and $\mathrm{E}$ values are little higher. Overall, it can be assumed that the fiber architecture of these two beams sections is same.

BRP-Box-4x4x1/4-L1

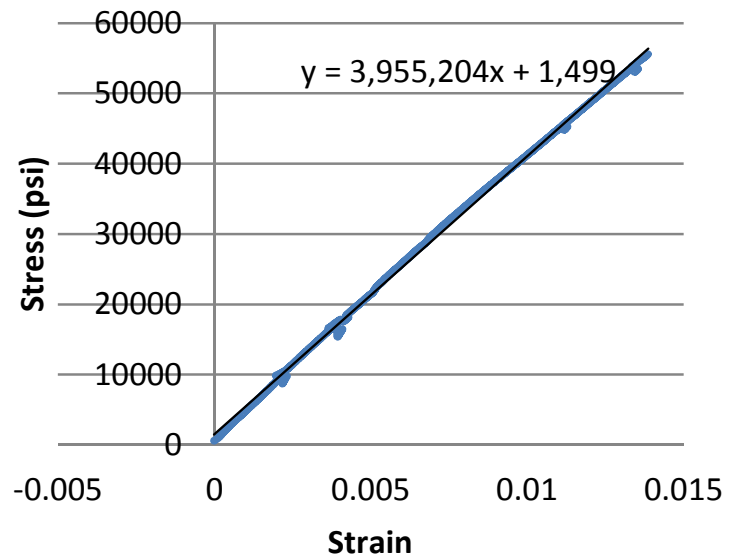

BRP-Box-4x4x1/4-L2

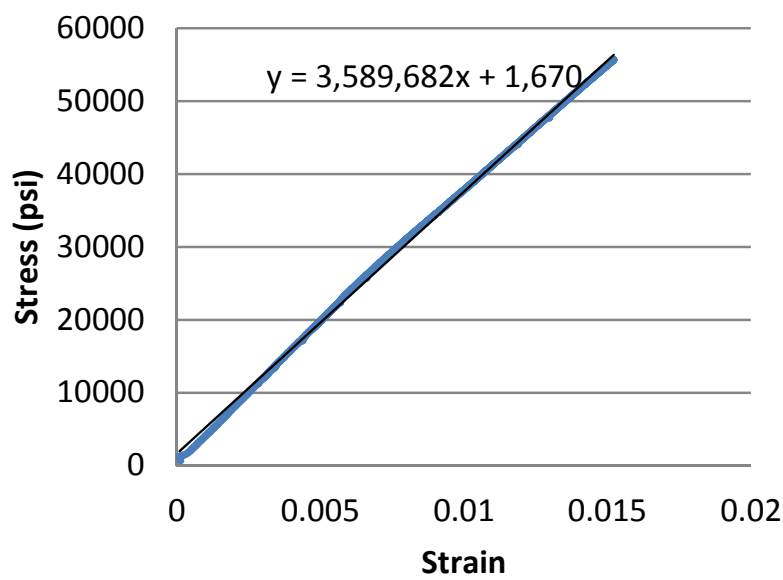

Figure 4-4: $\sigma-\varepsilon$ Curves with E values of BRP-Box-4×4×1/4 Longitudinal Coupons

The tested sample is shown in Figure 4-5, with a delamination mode of failure.

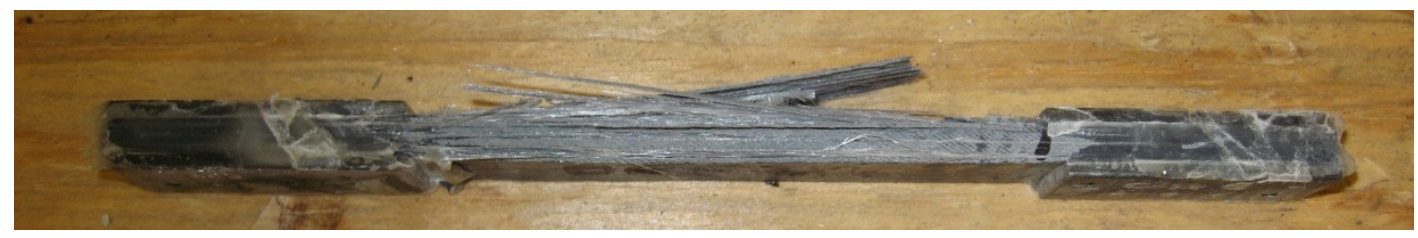

Figure 4-5: The Tested BRP-Box-4×4×1/4-Longitudinal Coupon 
The transverse coupons could not be tested due to practical difficulties associated to their small sizes.

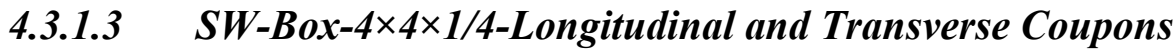

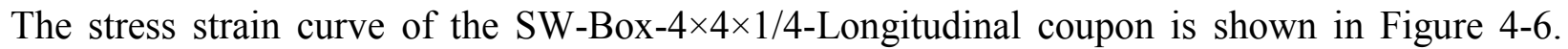
Although this coupon is from a different manufacturer, the effect of glass roving in the load carrying capacity in the longitudinal direction is evident. The higher values of $\sigma_{\max }$ and $\mathrm{E}$ refer to a higher fiber volume fraction than the BRP samples of the same dimensions. However, it would have been appropriate to have data from at least one more sample.

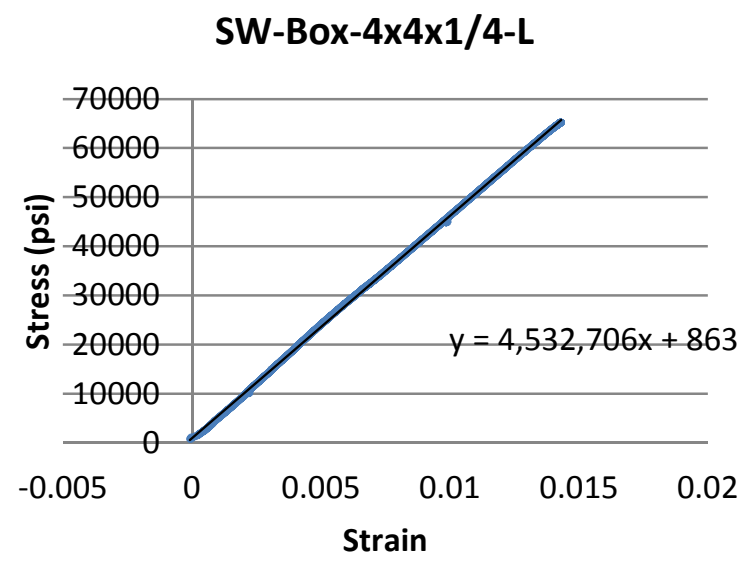

Figure 4-6: $\sigma-\varepsilon$ Curves with E values of SW-Box-4×4×1/4 Longitudinal Coupons

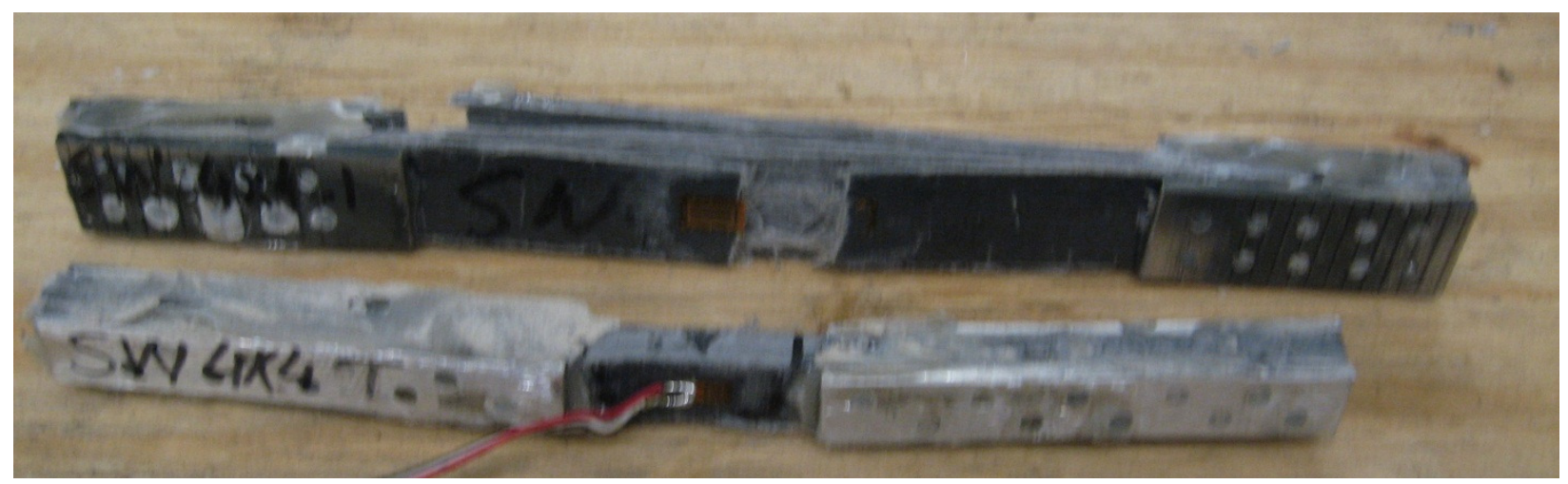

Figure 4-7: Tested Samples of SW-Box-4×4×1/4-Longitudinal and Transverse Coupons 
The transverse sample failed at $8328 \mathrm{psi}$ as compared to $65 \mathrm{ksi}$ in the longitudinal direction. However, the transverse modulus of elasticity could not be measured. The tested samples are shown in Figure 4-7. The longitudinal coupon failed due to delamination of rovings. The transverse sample failed near one of the end-tabs, possibly due to a weaker section there.

A summary of the coupon tension results is given in Table 4-1.

Table 4-1: Summary of Coupon Tension Test Results

\begin{tabular}{|c|c|c|c|}
\hline Coupon Specification & $\sigma_{\max }(k s i)$ & $\varepsilon_{\max (\mu \varepsilon)}$ & E (Msi) \\
\hline BRP-Box- $6 \times 6 \times 3 / 8-\mathrm{L} 1$ & 38.4 & 11786 & 3.2 \\
\hline BRP-Box- $6 \times 6 \times 3 / 8-\mathrm{L} 2$ & 45.5 & 16003 & 3.2 \\
\hline BRP-Box- $6 \times 6 \times 3 / 8-\mathrm{T} 1$ & 9.34 & 8109 & 1.29 \\
\hline BRP-Box-6×6×3/8-T1 @40\% Load & 3.7 & 2700 & 1.35 \\
\hline BRP-Box- $6 \times 6 \times 3 / 8-T 2$ & 9.67 & 9083 & 1.37 \\
\hline BRP-Box-6×6×3/8-T2 @40\% Load & 3.7 & 2500 & 1.53 \\
\hline BRP-Box-4×4×1/4-L1 & 55.6 & 13865 & 3.95 \\
\hline BRP-Box-4×4×1/4-L2 & 57.8 & 15900 & 3.59 \\
\hline SW-Box-4×4×1/4-L & 65.2 & 14302 & 4.53 \\
\hline SW-Box-4×4×1/4-T & 8.23 & - & - \\
\hline
\end{tabular}

\subsubsection{Iosepescu Test Results}

The shear strength values of the longitudinal and transverse coupons tested under Iosepescu tests are given in Table 4-2, with $\tau$ longitudinal higher than $\tau$ transverse due to contribution of glass rovings. It can be seen from Table 4-1 and 4-2 that shear strength is typically around one-fourth of the tensile strength. No strain data was recorded for these tests. 
Table 4-2: Summary of Iosepescu Test Results

\begin{tabular}{|c|c|c|}
\hline Coupon Specification & $\tau_{\text {longitudinal }}(\mathrm{ksi})$ & $\tau_{\text {transverse }}(\mathrm{ksi})$ \\
\hline BRP-Box- $6 \times 6 \times 3 / 8$ & 11.7 & 6.7 \\
\hline CP-Box-6×6×3/8 & 12.34 & 11.8 \\
\hline BRP-Box- $4 \times 4 \times 1 / 4$ & 11.8 & 8.0 \\
\hline CP-Box-4×4×1/4 & 10.0 & 7.4 \\
\hline
\end{tabular}

\subsubsection{Burnout Test Results}

\subsubsection{CP-Round-2.5 $\times 0.10-70$}

If a burnout test is intended to find $\mathrm{V}_{\mathrm{f}}$, sample dimensions should be 1 " $\times 1$ " as per ASTM D 3171 standard. As $\mathrm{V}_{\mathrm{f}}$ was already known in this case, a sample size of 4" $\times 1$ " was taken to get long unidirectional fibers from the middle-layer. The big sample size was facilitated in a mildsteel sheet container instead of a crucible. Following the standard test procedure and examining the burntout sample surprisingly revealed that the middle-layer consisted of uniaxial rovings of glass-fiber and top- and bottom-layers symmetrically consisted of triaxial $\left(+45^{\circ} / 90^{\circ} /-45^{\circ}\right)$ carbon fiber. Neither was there any uniaxial carbon fiber in the middle, nor any CSM at the top. The burnt sample is shown in Figure 4-8. As carbon fibers are very light weight and have the tendency to fly out with a small air blow, their triaxial directionality was lost during handling. 


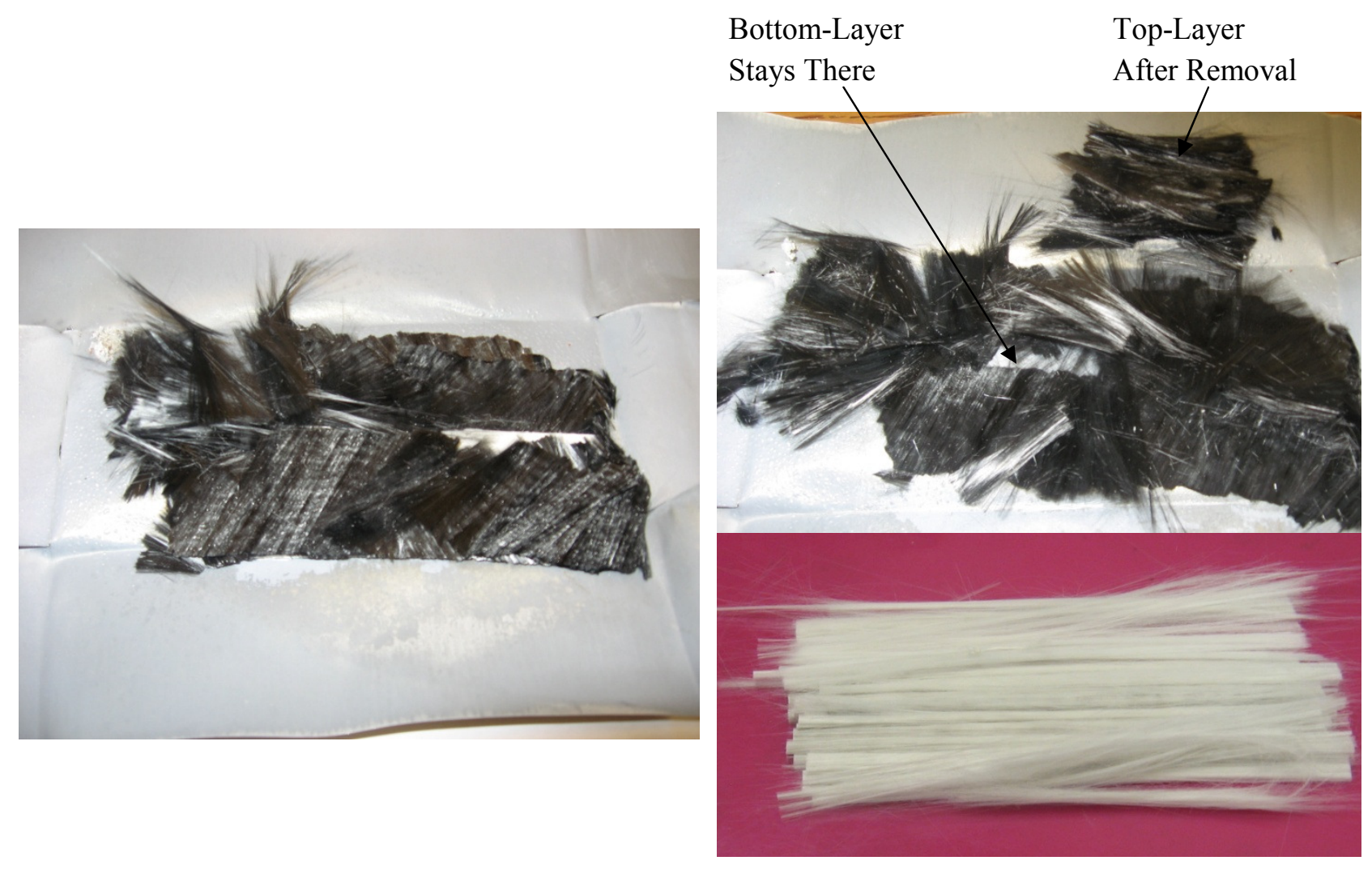

(a) Original Form: Glass Fiber Not Clearly Seen $\quad$ (b) Carbon- and Glass-Fibers Separated

Figure 4-8: Burnout Test Results of CP-Round-2.5×0.10/6L Coupon

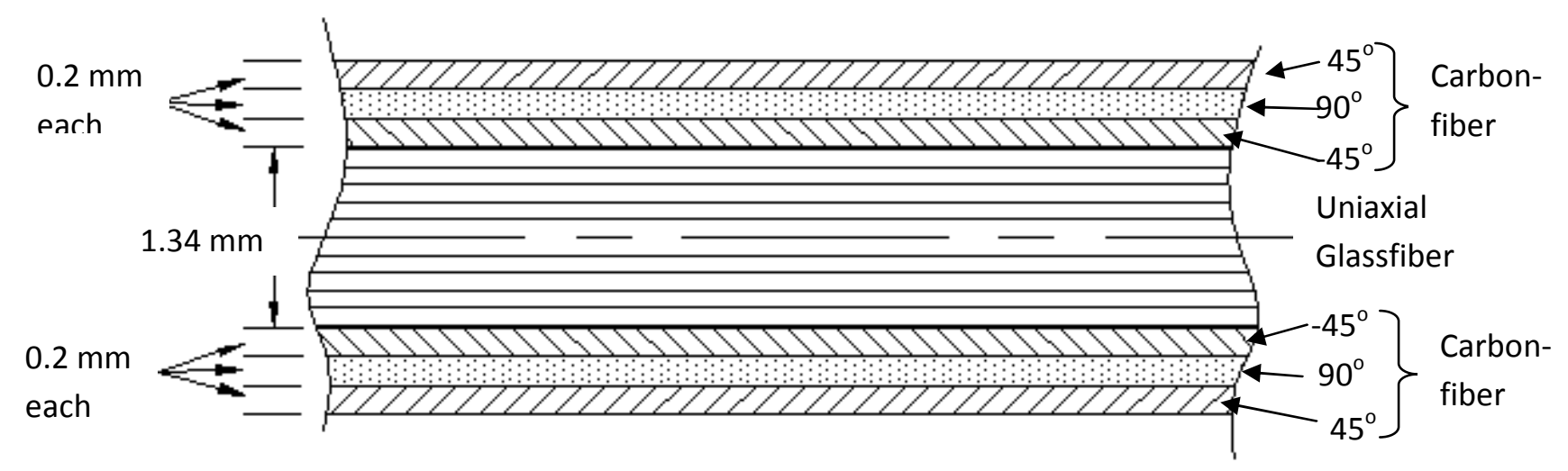

Figure 4-9: Fiber Architecture of the CP-Round-2.5×0.10/6L Specimen 


\subsubsection{SW-Round-2.0 $\quad$ (0.125- 144}

In case of CP-Round-2.5 $\times 0.10 / 6 \mathrm{~L}$ sample, the primary purpose of the burnout test was to reveal the ply-constituents, while $\mathrm{V}_{\mathrm{f}}$ was found through SEM image. Whereas, in this case, the burnout tests were conducted to determine the $\mathrm{V}_{\mathrm{f}}$ as per ASTM D 3171 standard. The samples were cut to an approximate size of 1 " $\times 1$ ". The dimensions were taken accurately with the help of a vernier calipers. Empty crucibles were weighed at the electronic balance to the accuracy of 0.01 gram, before placing samples in crucibles and weighing them. They were then placed in a pre-heated furnace at $560^{\circ} \mathrm{C}$ for three hours. The burnt samples were then weighed again. Then, top-, middle- and bottom-layers were carefully separated and weighed individually, as shown in Figure 4-10.

The fiber volume fraction was then found with the help of the following formula

$$
V_{f}=\frac{W_{f}}{\rho L S T}
$$

Where,

$\mathrm{W}_{\mathrm{f}}=$ weight of the fiber

$\rho=$ density of the glass fiber $=2.522 \mathrm{~g} / \mathrm{cm}^{3}$

$\mathrm{L}, \mathrm{S}, \mathrm{T}=$ length, arc-width and thickness of the sample respectively. Owing to a high curvature, arc-width was taken instead of line-width. For example, if $\mathrm{W}=2.41 \mathrm{~cm}, \mathrm{~S}=$ $2.51 \mathrm{~cm}$.

The experimental values of $\mathrm{V}_{\mathrm{f}}$ were calculated to be

$$
\begin{gathered}
V_{f}^{\text {top }}=0.30 \\
V_{f}^{\text {middle }}=0.67 \\
V_{f}^{\text {bottom }}=0.27
\end{gathered}
$$




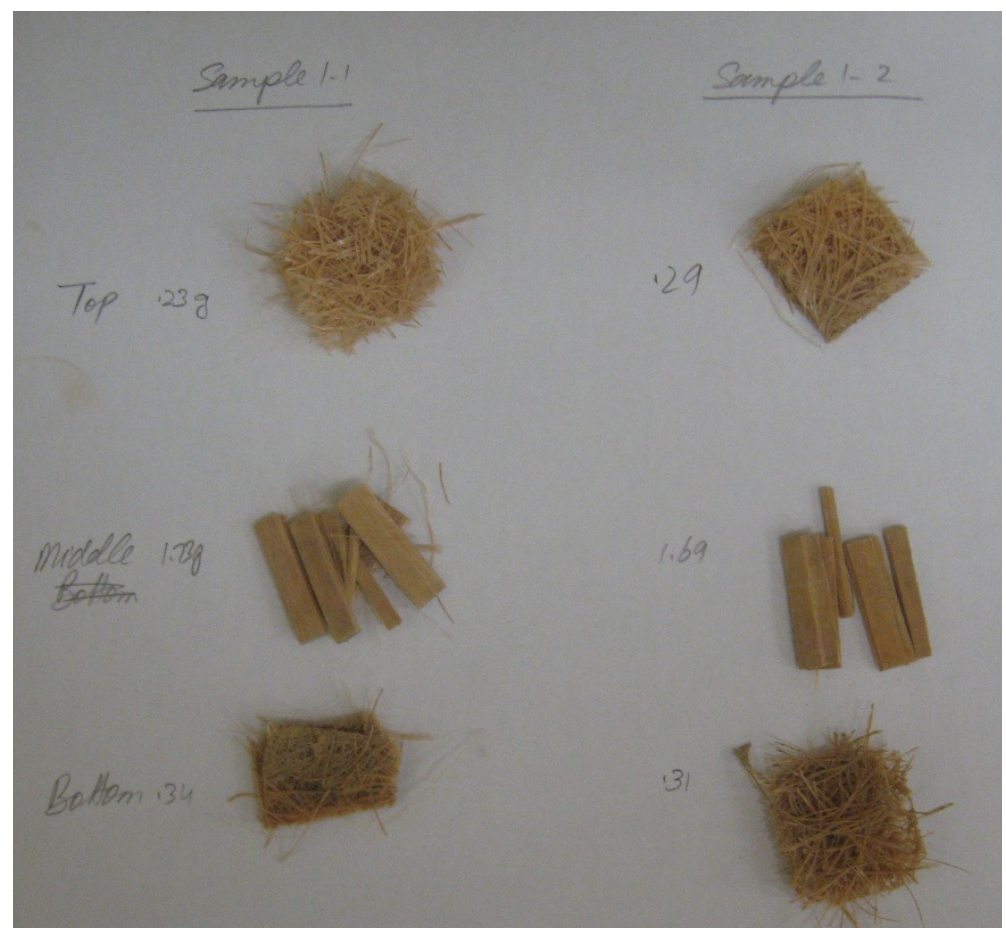

Figure 4-10: Burntout SW-Round-2.0×0.125- 144 Sample: Plies Separated and Weighed

\subsubsection{Microscopic Results}

\subsubsection{CP-Round-2.5×0.10-70}

The optical and scanning-electron micrographs are shown in Figure 4-11. The left hand side of the figure exhibits the top-, middle- and bottom-layer with electronically measured ply-thickness. As the ply-thickness keeps on varying, a large number of readings are taken and averaged. The top- and bottom-ply thickness is around $600 \mu \mathrm{m}$ and that of the middle-ply is around $1300 \mu \mathrm{m}$. The laminate thickness of $2500 \mu \mathrm{m}$ is in close agreement with the value found by vernier calipers, $0.1 \mathrm{inch}=2540 \mu \mathrm{m}$. However, from the manufacturer's specifications, it was expected that the top-layer with 1-1/2 oz CSM may have a thickness of around $250 \mu \mathrm{m}$, the middle-layer thickness being proportionately bigger. 


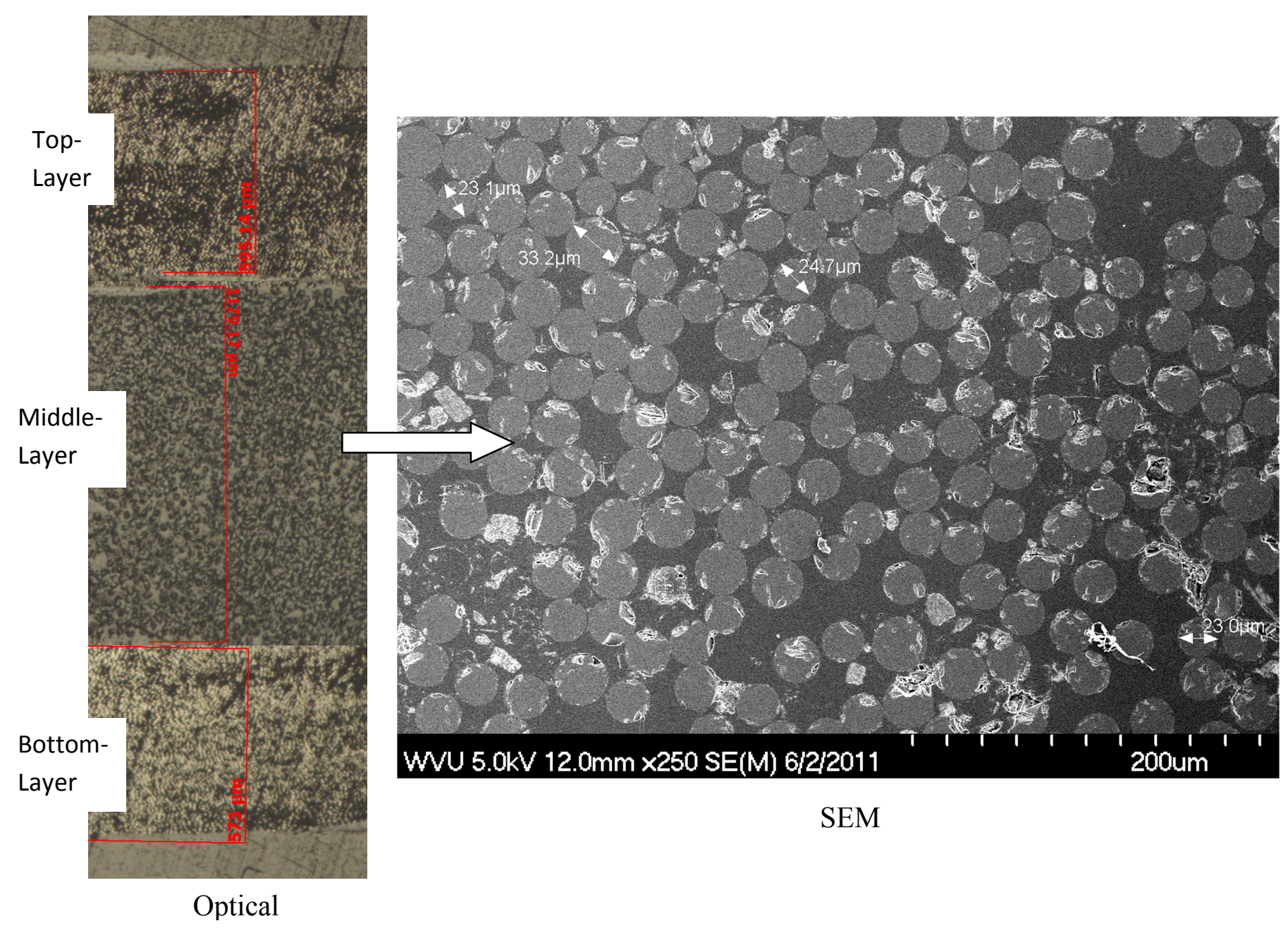

Figure 4-11: Microscopic Views of the CP-Round-2.5×0.10/6L

The right hand side of Figure 4-11 shows the scanning electron microscopic view of the middlelayer. The fiber diameters, measured electronically, range from 23 to $33 \mu \mathrm{m}$. This is again in contradiction to the manufacturer's specifications, because a carbon fiber in the middle-layer should have a diameter of the order of $7 \mu \mathrm{m}$. The SEM view offers a very effective mean of determining the fiber volume fraction $\left(\mathrm{V}_{\mathrm{f}}\right)$ either by area method or by line method. Employing the line method, $\mathrm{V}_{\mathrm{f}}$ of the middle-layer was found to be approximately $69 \%$, as explained in Appendix- B. 


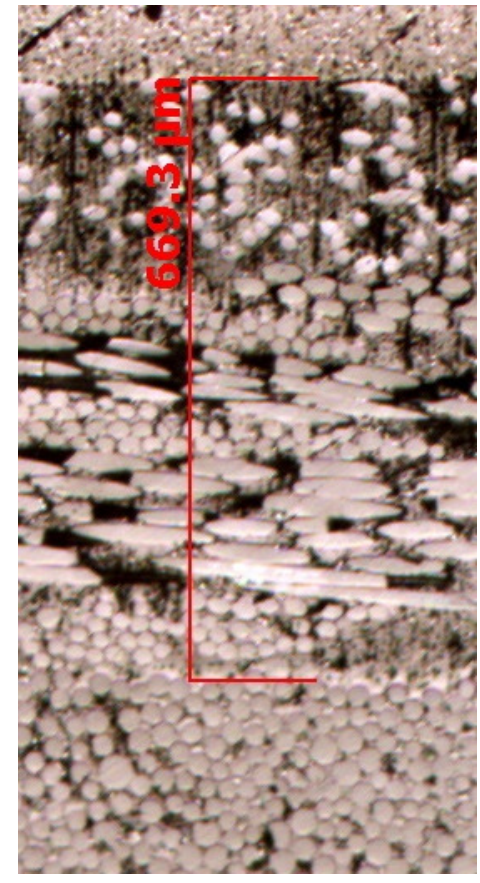

(a) Top-Layer (CSM)

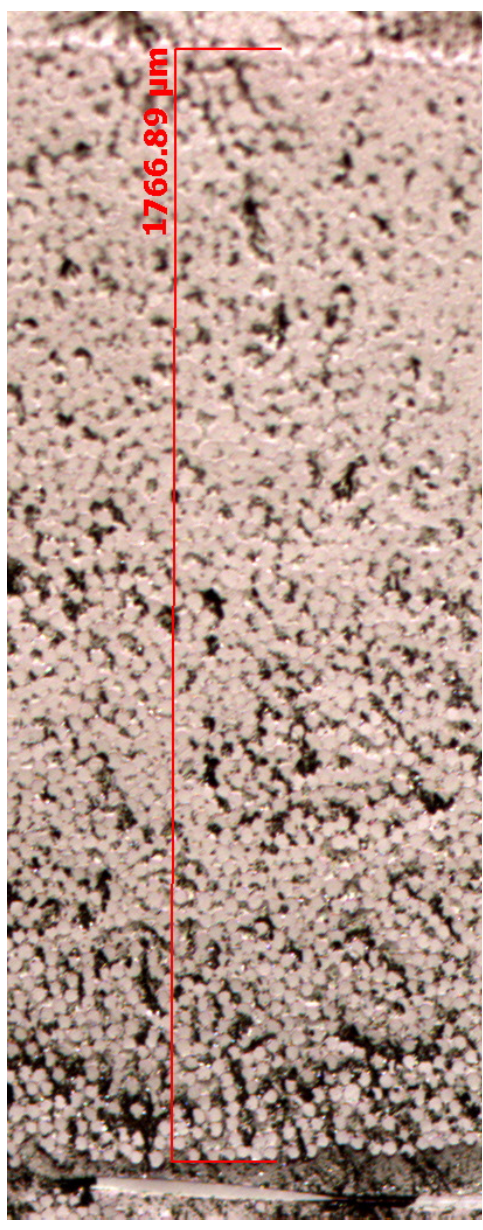

(b) Middle-Layer (Roving)

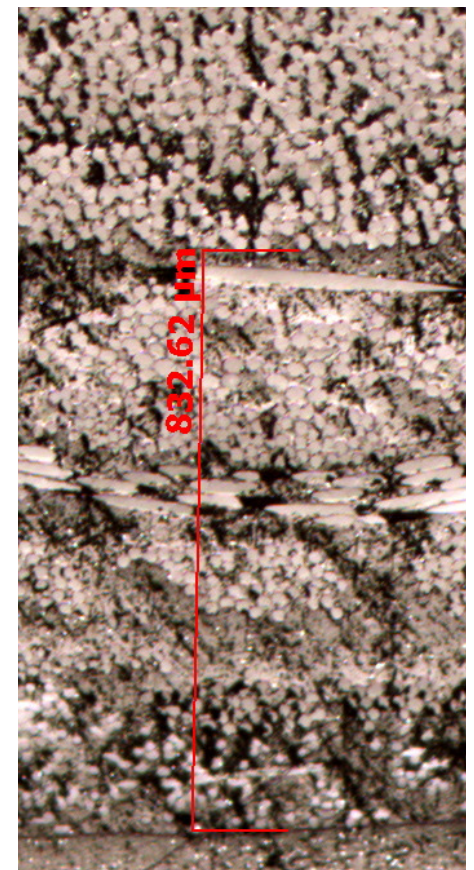

(c) Bottom-Layer (CSM)

Figure 4-12: Optical Micrographs of SW-Round-2.0×0.125/12L

\subsubsection{Micrographs of SW-Round-2.0 $\quad 0.125 / 12 L$}

Optical micrographs of the SW-Round-2.0×0.125/12L sample, as shown in Figure 4-12, were taken with the primary objective of electronically measuring the ply-thickness. As can be seen, the top- and bottom-plies are made of glass CSM, while the middle-ply is made of uniaxial glass rovings. For each ply, a large number of readings were taken and averaged to give the following values:

$$
\begin{gathered}
t_{k}^{\text {top }}=0.6 \mathrm{~mm} \\
t_{k}^{\text {middle }}=1.6 \mathrm{~mm}
\end{gathered}
$$




$$
t_{k}^{\text {bottom }}=0.8 \mathrm{~mm}
$$

\subsubsection{Classical Laminate Theory Analysis}

\subsubsection{CP-Round $-2.5 \times 0.10-70$}

In contrast to the Manufacturer's specifications, the cross-section is symmetric with triaxial carbon-fiber in the top- and bottom-layers and uniaxial glass-fiber in the middle-layer; the mathematical analysis of which is given as under:

\section{(a) Top/Bottom Layer (VectorPly CTTX-1800)}

For carbon-fiber, $E_{\mathrm{f}}=230 \mathrm{GPa}, \mathrm{v}_{\mathrm{f}}=0.2$ and $\rho_{\mathrm{f}}=1.77 \mathrm{~g} / \mathrm{cm}^{3}$

$$
V_{f}=\frac{\rho_{c}}{\rho_{f}} W_{f}=\frac{1.53}{1.77} \times 0.64=55.32 \%
$$

Where $\rho_{c}$ and $W_{f}$ are given in Table 4.1.

$$
G_{f}=\frac{E_{f}}{2\left(1+v_{f}\right)}=\frac{230}{2(1+0.2)}=95.833 \mathrm{GPa}
$$

Assuming vinylester matrix, $\mathrm{E}_{\mathrm{m}}=3.4 \mathrm{GPa}$ and $\mathrm{v}_{\mathrm{m}}=0.38$

$$
\begin{gathered}
G_{m}=\frac{E_{m}}{2\left(1+v_{m}\right)}=\frac{3.4}{2(1+0.38)}=1.232 \mathrm{GPa} \\
E_{1}=E_{f} V_{f}+E_{m} V_{m}=230 \times 0.5532+3.4 \times 0.4468=128.755 \mathrm{GPa} \\
E_{2}=E_{m}\left[\frac{1+\zeta \eta V_{f}}{1-\eta V_{f}}\right] \\
\eta=\frac{\left(E_{m} / E_{f}\right)-1}{\left(E_{m} / E_{f}\right)+2}=\frac{(230 / 3.4)-1}{(230 / 3.4)+2}=0.9569 \\
E_{2}=3.4\left[\frac{1+2 \times 0.9569 \times 0.5532}{1-0.9569 \times 0.5532}\right]=14.873 \mathrm{GPa}
\end{gathered}
$$




$$
\begin{aligned}
& v_{12}=v_{f} V_{f}+v_{m} V_{m}=0.2 \times 0.5532+0.38 \times 0.4468=0.28 \\
& G_{12}=G_{m} \frac{\left(1+V_{f}\right)+\left(1-V_{f}\right) G_{m} / G_{f}}{\left(1-V_{f}\right)+\left(1+V_{f}\right) G_{m} / G_{f}} \\
& G_{12}=1.232 \frac{(1+0.5532)+(1-0.5532) 1.232 / 95.833}{(1-0.5532)+(1+0.5532) 1.232 / 95.833}=4.115 \mathrm{GPa} \\
& v_{21}=\frac{E_{2}}{E_{1}} v_{12}=\frac{14.873}{128.755} 0.28=0.032 \\
& \Delta=1-v_{12} v_{21}=1-(0.28 \times 0.032)=0.9909 \\
& {[Q]=\left[\begin{array}{ccc}
\frac{E_{1}}{\Delta} & \frac{v_{12} E_{2}}{\Delta} & 0 \\
\frac{v_{12} E_{2}}{\Delta} & \frac{E_{2}}{\Delta} & 0 \\
0 & 0 & G_{12}
\end{array}\right]=\left[\begin{array}{ccc}
129.9317 & 4.2025 & 0 \\
4.2025 & 15.01 & 0 \\
0 & 0 & 4.115
\end{array}\right]} \\
& {[\bar{Q}]_{\theta}=\left[\begin{array}{lll}
\bar{Q}_{11} & \bar{Q}_{12} & \bar{Q}_{16} \\
\bar{Q}_{12} & \bar{Q}_{22} & \bar{Q}_{26} \\
\bar{Q}_{26} & \bar{Q}_{16} & \bar{Q}_{66}
\end{array}\right]} \\
& \bar{Q}_{11}=Q_{11} \cos ^{4} \theta+2\left(Q_{12}+2 Q_{66}\right) \sin ^{2} \theta \cos ^{2} \theta+Q_{22} \sin ^{4} \theta \\
& \bar{Q}_{12}=\left(Q_{11}+Q_{22}-4 Q_{66}\right) \sin ^{2} \theta \cos ^{2} \theta+Q_{12}\left(\sin ^{4} \theta+\cos ^{4} \theta\right) \\
& \bar{Q}_{22}=Q_{11} \sin ^{4} \theta+2\left(Q_{12}+2 Q_{66}\right) \sin ^{2} \theta \cos ^{2} \theta+Q_{22} \cos ^{4} \theta \\
& \bar{Q}_{16}=\left(Q_{11}-Q_{12}-2 Q_{66}\right) \sin \theta \cos ^{3} \theta+\left(Q_{12}-Q_{22}+2 Q_{66}\right) \sin ^{3} \theta \cos \theta \\
& \bar{Q}_{26}=\left(Q_{11}-Q_{12}-2 Q_{66}\right) \sin ^{3} \theta \cos \theta+\left(Q_{12}-Q_{22}+2 Q_{66}\right) \sin \theta \cos ^{3} \theta \\
& \bar{Q}_{66}=\left(Q_{11}+Q_{22}-2 Q_{12}-2 Q_{66}\right) \sin ^{2} \theta \cos ^{2} \theta+Q_{66}\left(\sin ^{4} \theta+\cos ^{4} \theta\right) \\
& {[Q]_{ \pm 45}=\left[\begin{array}{ccc}
42.4516 & 34.2217 & \pm 28.73 \\
34.2217 & 42.4516 & \pm 28.73 \\
\pm 28.73 & \pm 28.73 & 34.134
\end{array}\right]} \\
& {[\bar{Q}]_{90}=\left[\begin{array}{ccc}
15.01 & 4.2025 & 0 \\
4.2025 & 129.9317 & 0 \\
0 & 0 & 4.115
\end{array}\right]}
\end{aligned}
$$




\section{(b) Middle Layer (Uniaxial Glass-Roving)}

For glass-fiber, $\mathrm{E}_{\mathrm{f}}=72.345 \mathrm{GPa}$ and $\mathrm{v}_{\mathrm{f}}=0.22$

$$
G_{f}=\frac{E_{f}}{2\left(1+v_{f}\right)}=\frac{72.345}{2(1+0.22)}=29.65 \mathrm{GPa}
$$

Assuming vinylester matrix, $\mathrm{E}_{\mathrm{m}}=3.4 \mathrm{GPa}$ and $\mathrm{v}_{\mathrm{m}}=0.38$

$$
G_{m}=\frac{E_{m}}{2\left(1+v_{m}\right)}=\frac{3.4}{2(1+0.38)}=1.232 \mathrm{GPa}
$$

From SEM analysis,

$$
\begin{gathered}
V_{f}=0.69 \\
E_{1}=E_{f} V_{f}+E_{m} V_{m}=72.345 \times 0.69+3.4 \times 0.31=50.972 \mathrm{GPa} \\
E_{2}=E_{m}\left[\frac{1+\zeta \eta V_{f}}{1-\eta V_{f}}\right] \\
\eta=\frac{\left(E_{m} / E_{f}\right)-1}{\left(E_{m} / E_{f}\right)+2}=\frac{(72.345 / 3.4)-1}{(72.345 / 3.4)+2}=0.8711 \\
E_{2}=3.4\left[\frac{1+2 \times 0.8711 \times 0.69}{1-0.8711 \times 0.69}\right]=18.7677 \mathrm{GPa} \\
v_{12}=v_{f} V_{f}+v_{m} V_{m}=0.22 \times 0.69+0.38 \times 0.31=0.2696 \\
G_{12}=G_{m} \frac{\left(1+V_{f}\right)+\left(1-V_{f}\right) G_{m} / G_{f}}{\left(1-V_{f}\right)+\left(1+V_{f}\right) G_{m} / G_{f}} \\
G_{12}=1.232 \frac{(1+0.69)+(1-0.69) 1.232 / 29.65}{(1-0.69)+(1+0.69) 1.232 / 29.65}=5.518 \mathrm{GPa} \\
v_{21}=\frac{E_{2}}{E_{1}} v_{12}=\frac{18.7677}{50.972} 0.2696=0.0993 \\
\Delta=1-v_{12} v_{21}=1-(0.2696 \times 0.0993)=0.9737
\end{gathered}
$$




$$
[Q]=[\bar{Q}]_{0}=\left[\begin{array}{ccc}
\frac{E_{1}}{\Delta} & \frac{v_{12} E_{2}}{\Delta} & 0 \\
\frac{v_{12} E_{2}}{\Delta} & \frac{E_{2}}{\Delta} & 0 \\
0 & 0 & G_{12}
\end{array}\right]=\left[\begin{array}{ccc}
52.3736 & 5.2 & 0 \\
5.2 & 19.2845 & 0 \\
0 & 0 & 5.518
\end{array}\right]
$$

\section{(c) Deriving the ABD Matrices}

Rewriting the relations for $[\mathrm{A}],[\mathrm{B}]$ and $[\mathrm{D}]$ matrices,

$$
\begin{gathered}
{[A]_{3 \times 3}=\sum_{k=1}^{n}[\bar{Q}]_{k} t_{k}} \\
{[B]_{3 \times 3}=\sum_{k=1}^{n}[\bar{Q}]_{k} t_{k} \bar{z}_{k}} \\
{[D]_{3 \times 3}=\sum_{k=1}^{n}[\bar{Q}]_{k}\left(t_{k} \bar{z}_{k}^{2}+\frac{t_{k}^{3}}{12}\right)}
\end{gathered}
$$

$\bar{z}_{k}=$ distance from middle of laminate to middle of $\mathrm{k}^{\text {th }}$ lamina

For orthotropic laminates

$$
\begin{aligned}
& {[A]=\left[\begin{array}{ccc}
A_{11} & A_{12} & 0 \\
A_{12} & A_{22} & 0 \\
0 & 0 & A_{66}
\end{array}\right]} \\
& {[B]=\left[\begin{array}{ccc}
B_{11} & B_{12} & 0 \\
B_{12} & B_{22} & 0 \\
0 & 0 & B_{66}
\end{array}\right]} \\
& {[D]=\left[\begin{array}{ccc}
D_{11} & D_{12} & 0 \\
D_{12} & D_{22} & 0 \\
0 & 0 & D_{66}
\end{array}\right]}
\end{aligned}
$$

\section{$[\mathrm{ABD}]$ of CTTX-1800 Ply}

Form Figure 4-9, for the top- and bottom-layers,

$$
\begin{aligned}
& \mathrm{n}=\text { number of plies }=3 \\
& \mathrm{t}_{\mathrm{k}}=\text { ply thickness }=0.20 \mathrm{~mm} \text { each }
\end{aligned}
$$


Substituting the values of $\bar{Q}_{i j}$ and $\mathrm{t}_{\mathrm{k}}$ into equation 3.11 and solving yields the following results:

$$
\begin{aligned}
{[A]_{\text {CTT X-1800 }} } & =\left[\begin{array}{ccc}
19.982 & 14.5292 & 0 \\
14.5292 & 42.967 & 0 \\
0 & 0 & 14.4766
\end{array}\right] \times 10^{6}(\mathrm{~N} / \mathrm{m}) \\
{[A]_{\text {CTTX-1800 }}^{-1} } & =\left[\begin{array}{ccc}
6.636 & -2.244 & 0 \\
-2.244 & 3.086 & 0 \\
0 & 0 & 6.9077
\end{array}\right] \times 10^{-8}(\mathrm{~m} / \mathrm{N})
\end{aligned}
$$

For the symmetric $+45 / 90 /-45$ plies,

$$
[B]_{C T T X-1800}=\left[\begin{array}{lll}
0 & 0 & 0 \\
0 & 0 & 0 \\
0 & 0 & 0
\end{array}\right](N)
$$

Having $\bar{z}_{1}=0.2 \mathrm{~mm}, \bar{z}_{3}=-0.2 \mathrm{~mm}$ and $\bar{z}_{2}=0$ gives

$$
\begin{aligned}
{[D]_{C T T X-1800} } & =\left[\begin{array}{ccc}
0.7458 & 0.596 & 0 \\
0.596 & 0.82245 & 0 \\
0 & 0 & 0.5944
\end{array}\right](\mathrm{Nm}) \\
{[D]_{C T T X-1800}^{-1} } & =\left[\begin{array}{ccc}
3.1857 & -2.3086 & 0 \\
-2.3086 & 2.889 & 0 \\
0 & 0 & 1.6824
\end{array}\right](1 / \mathrm{Nm})
\end{aligned}
$$

\section{[ABD] of the Laminate}

Form Figure 4-9, for the whole laminate,

$$
\begin{aligned}
& \mathrm{n}=\text { number of plies }=7 \\
& \mathrm{t}_{1,2,3,5,6,7}=0.20 \mathrm{~mm} \text { each } \\
& \mathrm{t}_{4}=1.34 \mathrm{~mm}
\end{aligned}
$$

Substituting the values of $\bar{Q}_{i j}$ and $\mathrm{t}_{\mathrm{k}}$ into the corresponding equation and solving,

$$
[A]_{\text {Laminate }}=\left[\begin{array}{ccc}
110.146 & 36.026 & 0 \\
36.026 & 111.775 & 0 \\
0 & 0 & 36.347
\end{array}\right] \times 10^{6}(\mathrm{~N} / \mathrm{m})
$$




$$
[A]_{\text {Laminate }}^{-1}=\left[\begin{array}{ccc}
1.015 & -3.271 & 0 \\
-3.271 & 1.00 & 0 \\
0 & 0 & 2.751
\end{array}\right] \times 10^{-8}(\mathrm{~m} / \mathrm{N})
$$

From the symmetry of the laminate,

$$
[B]_{\text {Laminate }}=\left[\begin{array}{lll}
0 & 0 & 0 \\
0 & 0 & 0 \\
0 & 0 & 0
\end{array}\right](N)
$$

Having $\bar{z}_{1,7}= \pm 1.17 \mathrm{~mm}, \bar{z}_{2,6}= \pm 0.97 \mathrm{~mm}, \bar{z}_{3,5}= \pm 0.77 \mathrm{~mm}$ and $\bar{z}_{4}=0,[\mathrm{D}]$ is found from Equation 3.13 as

$$
\begin{gathered}
{[D]_{\text {Laminate }}=\left[\begin{array}{ccc}
49.605 & 29.5732 & 0 \\
29.5732 & 86.3936 & 0 \\
0 & 0 & 29.5347
\end{array}\right](\mathrm{Nm})} \\
{[D]_{\text {Laminate }}^{-1}=\left[\begin{array}{ccc}
0.02533 & -0.00867 & 0 \\
-0.00867 & 0.01454 & 0 \\
0 & 0 & 0.03386
\end{array}\right](1 / \mathrm{Nm})}
\end{gathered}
$$

\section{(d) Finding the Laminate Properties}

Based on the $[\mathrm{ABD}]$ matrix, the material and section properties are as under;

\section{Properties of CTTX-1800 Ply}

$$
\begin{gathered}
E_{x, \text { CTTX }-1800}^{\text {inplane }}=\frac{1}{h A_{11}^{-1}}=\frac{1}{0.6 \times 10^{-3} \times 6.636 \times 10^{-8}}=25.11 \mathrm{GPa}=3.64 \mathrm{msi} \\
E_{y, C T T X-1800}^{\text {inplane }}=\frac{1}{h A_{22}^{-1}}=\frac{1}{0.6 \times 10^{-3} \times 3.086 \times 10^{-8}}=54 \mathrm{GPa}=7.833 \mathrm{msi} \\
G_{x y, \text { CTTX-1800 }}^{\text {inplane }}=\frac{1}{h A_{66}^{-1}}=\frac{1}{0.6 \times 10^{-3} \times 6.9077 \times 10^{-8}}=24.13 \mathrm{GPa}=3.50 \mathrm{msi} \\
E_{x, \text { CTTX-1800 }}^{\text {flexural }}=\frac{12}{h^{3} D_{11}^{-1}}=\frac{12}{\left(0.6 \times 10^{-3}\right)^{3} \times 3.1857}=17.44 \mathrm{GPa}=2.53 \mathrm{msi}
\end{gathered}
$$




$$
\begin{aligned}
& E_{y, C T T X-1800}^{\text {flexural }}=\frac{12}{h^{3} D_{22}^{-1}}=\frac{12}{\left(0.6 \times 10^{-3}\right)^{3} \times 2.889}=19.23 \mathrm{GPa}=2.79 \mathrm{msi} \\
& G_{x y, C T T X-1800}^{\text {flexural }}=\frac{12}{h^{3} D_{66}^{-1}}=\frac{12}{\left(0.6 \times 10^{-3}\right)^{3} \times 1.6824}=33 \mathrm{GPa}=4.79 \mathrm{msi}
\end{aligned}
$$

Properties of the Laminate

$$
\begin{aligned}
& E_{x, \text { Laminate }}^{\text {inplane }}=\frac{1}{h A_{11}^{-1}}=\frac{1}{2.54 \times 10^{-3} \times 1.015 \times 10^{-8}}=38.79 \mathrm{GPa}=5.626 \mathrm{msi} \\
& E_{y, \text { Laminate }}^{\text {inplane }}=\frac{1}{h A_{22}^{-1}}=\frac{1}{2.54 \times 10^{-3} \times 1 \times 10^{-8}}=38.79 \mathrm{GPa}=5.626 \mathrm{msi} \\
& G_{x y, \text { Laminate }}^{\text {inplane }}=\frac{1}{h A_{66}^{-1}}=\frac{1}{2.54 \times 10^{-3} \times 2.751 \times 10^{-8}}=14.31 \mathrm{GPa}=2.076 \mathrm{msi} \\
& E_{x, \text { Laminate }}^{\text {flexural }}=\frac{12}{h^{3} D_{11}^{-1}}=\frac{12}{\left(2.54 \times 10^{-3}\right)^{3} \times 0.02533}=28.91 \mathrm{GPa}=4.19 \mathrm{msi} \\
& E_{y, \text { Laminate }}^{\text {flexural }}=\frac{12}{h^{3} D_{22}^{-1}}=\frac{12}{\left(2.54 \times 10^{-3}\right)^{3} \times 0.01454}=50.36 \mathrm{GPa}=7.30 \mathrm{msi} \\
& G_{x y, \text { Laminate }}^{\text {flexural }}=\frac{12}{h^{3} D_{66}^{-1}}=\frac{12}{\left(2.54 \times 10^{-3}\right)^{3} \times 0.03386}=21.62 \mathrm{GPa}=3.137 \mathrm{msi}
\end{aligned}
$$

Finally, the results have been summarized in Table 4-3 and 4-4 respectively

Table 4-3: Properties of Top/Bottom Layers (CTTX-1800) of CP-2.5×0.10/6L Sample

\begin{tabular}{|l|c|c|c|}
\hline Property & Manufacturer's Specifications & Analytical & Difference (\%) \\
\hline$E_{x}^{\text {inplane }}(\mathrm{msi})$ & 2.74 & 3.64 & 32.85 \\
\hline$E_{y}^{\text {inplane }}(\mathrm{msi})$ & 6.63 & 7.833 & 18.14 \\
\hline$G_{x y}^{\text {inplane }}(\mathrm{msi})$ & 2.98 & 3.50 & 17.45 \\
\hline$E_{x}^{\text {flexural }}(\mathrm{msi})$ & 2.60 & 2.53 & -2.7 \\
\hline
\end{tabular}




\begin{tabular}{|l|c|c|c|}
\hline$E_{y}^{\text {flexural }}(\mathrm{msi})$ & 6.30 & 2.79 & -55.7 \\
\hline$G_{x y}^{\text {flexural }}(\mathrm{msi})$ & - & 4.79 & - \\
\hline
\end{tabular}

Table 4-4: Laminate Properties of CP-2.5×0.10/6L Sample

\begin{tabular}{|l|c|}
\hline \multicolumn{2}{|c|}{ Laminate } \\
\hline Property & Analytical \\
\hline$E_{x}^{\text {inplane }}(\mathrm{msi})$ & 5.626 \\
\hline$E_{y}^{\text {inplane }}(\mathrm{msi})$ & 5.626 \\
\hline$G_{x y}^{\text {inplane }}(\mathrm{msi})$ & 2.076 \\
\hline$E_{x}^{\text {flexural }}(\mathrm{msi})$ & 4.19 \\
\hline$E_{y}^{\text {flexural }}(\mathrm{msi})$ & 7.30 \\
\hline$G_{x y}^{\text {flexural }}(\mathrm{msi})$ & 3.137 \\
\hline
\end{tabular}

\subsubsection{2. $\quad S W-R o u n d-2.0 \times 0.125-144$}

The SW-Round-2.0 $\times 0.125$ - 144 sample is a glass fiber reinforced polymer matrix (vinyl ester or polyester) composite material. The basic properties of the fiber and matrix are:

$$
\begin{array}{cc}
\frac{\text { GlassFiber }}{E_{f}=72.345 \mathrm{GPa}} & \frac{\text { Vinyl Ester/Polyester Matrix }}{E_{m}=3.4 \mathrm{GPa}} \\
v_{f}=0.22 & v_{m}=0.38 \\
G_{f}=\frac{1}{2(1+v)}=25.12 \mathrm{GPa} & G_{m}=\frac{1}{2(1+v)}=1.232 \mathrm{GPa} \\
\rho_{f}=2.522 \mathrm{~g} / \mathrm{cc} &
\end{array}
$$

The layer-wise analysis, based on classical laminate theory, is as under:

(a) Top-Layer (CSM)

$$
\begin{gathered}
t_{k}=0.6 \mathrm{~mm} \\
V_{f}=0.3 \\
E_{1}=E_{f} V_{f}+E_{m} V_{m}=72.345 \times 0.3+3.4 \times 0.7=24.08 \mathrm{GPa}
\end{gathered}
$$




$$
\begin{aligned}
& E_{2}=E_{m}\left[\frac{1+\zeta \eta V_{f}}{1-\eta V_{f}}\right] \\
& \eta=\frac{\left(E_{m} / E_{f}\right)-1}{\left(E_{m} / E_{f}\right)+2}=\frac{(72.345 / 3.4)-1}{(72.345 / 3.4)+2}=0.871 \\
& E_{2}=3.4\left[\frac{1+2 \times 0.871 \times 0.3}{1-0.871 \times 0.3}\right]=7.01 \mathrm{GPa} \\
& v_{12}=v_{f} V_{f}+v_{m} V_{m}=0.2 \times 0.3+0.38 \times 0.7=0.326 \\
& G_{12}=G_{m} \frac{\left(1+V_{f}\right)+\left(1-V_{f}\right) G_{m} / G_{f}}{\left(1-V_{f}\right)+\left(1+V_{f}\right) G_{m} / G_{f}} \\
& G_{12}=1.232 \frac{(1+0.3)+(1-0.3) 1.232 / 25.12}{(1-0.3)+(1+0.3) 1.232 / 25.12}=2.1524 G P a \\
& v_{21}=\frac{E_{2}}{E_{1}} v_{12}=\frac{7.01}{24.08} 0.326=0.095 \\
& \Delta=1-v_{12} v_{21}=1-(0.326 \times 0.095)=0.969 \\
& {[Q]=\left[\begin{array}{ccc}
\frac{E_{1}}{\Delta} & \frac{v_{12} E_{2}}{\Delta} & 0 \\
\frac{v_{12} E_{2}}{\Delta} & \frac{E_{2}}{\Delta} & 0 \\
0 & 0 & G_{12}
\end{array}\right]=\left[\begin{array}{ccc}
24.85 & 2.358 & 0 \\
2.358 & 7.23 & 0 \\
0 & 0 & 2.1524
\end{array}\right]} \\
& {[\bar{Q}]_{C S M}=\left[\begin{array}{ccc}
\bar{Q}_{11} & \bar{Q}_{12} & 0 \\
\bar{Q}_{12} & \bar{Q}_{11} & 0 \\
0 & 0 & \bar{Q}_{66}
\end{array}\right]} \\
& \bar{Q}_{11}=\frac{3}{8} Q_{11}+\frac{1}{4} Q_{12}+\frac{3}{8} Q_{22}+\frac{1}{2} Q_{66} \\
& \bar{Q}_{12}=\frac{1}{8} Q_{11}+\frac{3}{4} Q_{12}+\frac{1}{8} Q_{22}-\frac{1}{2} Q_{66} \\
& \bar{Q}_{66}=\frac{1}{8} Q_{11}-\frac{1}{4} Q_{12}+\frac{1}{8} Q_{22}+\frac{1}{2} Q_{66}
\end{aligned}
$$




$$
[Q]^{t o p}=\left[\begin{array}{ccc}
13.69 & 4.702 & 0 \\
4.702 & 13.69 & 0 \\
0 & 0 & 4.5
\end{array}\right] G P a
$$

(b) Middle Layer (Unidirectional Glass-Roving)

$$
\begin{aligned}
& t_{k}=1.6 \mathrm{~mm} \\
& V_{f}=0.67 \\
& E_{1}=E_{f} V_{f}+E_{m} V_{m}=72.345 \times 0.67+3.4 \times 0.33=49.59 \mathrm{GPa} \\
& E_{2}=E_{m}\left[\frac{1+\zeta \eta V_{f}}{1-\eta V_{f}}\right] \\
& \eta=\frac{\left(E_{m} / E_{f}\right)-1}{\left(E_{m} / E_{f}\right)+2}=\frac{(72.345 / 3.4)-1}{(72.345 / 3.4)+2}=0.8711 \\
& E_{2}=3.4\left[\frac{1+2 \times 0.8711 \times 0.67}{1-0.8711 \times 0.67}\right]=17.69 G P a \\
& v_{12}=v_{f} V_{f}+v_{m} V_{m}=0.22 \times 0.67+0.38 \times 0.33=0.2594 \\
& G_{12}=G_{m} \frac{\left(1+V_{f}\right)+\left(1-V_{f}\right) G_{m} / G_{f}}{\left(1-V_{f}\right)+\left(1+V_{f}\right) G_{m} / G_{f}} \\
& G_{12}=1.232 \frac{(1+0.67)+(1-0.67) 1.232 / 25.12}{(1-0.69)+(1+0.69) 1.232 / 25.12}=5.04 G P a \\
& v_{21}=\frac{E_{2}}{E_{1}} v_{12}=\frac{17.69}{49.59} 0.2594=0.0925 \\
& \Delta=1-v_{12} v_{21}=1-(0.2594 \times 0.0925)=0.976 \\
& {[Q]=[\bar{Q}]_{0}=\left[\begin{array}{ccc}
\frac{E_{1}}{\Delta} & \frac{v_{12} E_{2}}{\Delta} & 0 \\
\frac{v_{12} E_{2}}{\Delta} & \frac{E_{2}}{\Delta} & 0 \\
\hline & 0 & G_{12}
\end{array}\right]=\left[\begin{array}{ccc}
50.81 & 4.701 & 0 \\
4.701 & 18.125 & 0 \\
0 & 0 & 5.04
\end{array}\right] G P a}
\end{aligned}
$$




\section{(c) Bottom-Layer (CSM)}

$$
\begin{aligned}
& t_{k}=0.8 \mathrm{~mm} \\
& V_{f}=0.27 \\
& E_{1}=E_{f} V_{f}+E_{m} V_{m}=72.345 \times 0.27+3.4 \times 0.73=22 \mathrm{GPa} \\
& E_{2}=E_{m}\left[\frac{1+\zeta \eta V_{f}}{1-\eta V_{f}}\right] \\
& \eta=\frac{\left(E_{m} / E_{f}\right)-1}{\left(E_{m} / E_{f}\right)+2}=\frac{(72.345 / 3.4)-1}{(72.345 / 3.4)+2}=0.871 \\
& E_{2}=3.4\left[\frac{1+2 \times 0.871 \times 0.27}{1-0.871 \times 0.27}\right]=6.54 \mathrm{GPa} \\
& v_{12}=v_{f} V_{f}+v_{m} V_{m}=0.2 \times 0.27+0.38 \times 0.73=0.3314 \\
& G_{12}=G_{m} \frac{\left(1+V_{f}\right)+\left(1-V_{f}\right) G_{m} / G_{f}}{\left(1-V_{f}\right)+\left(1+V_{f}\right) G_{m} / G_{f}} \\
& G_{12}=1.232 \frac{(1+0.27)+(1-0.27) 1.232 / 25.12}{(1-0.27)+(1+0.27) 1.232 / 25.12}=2.0 \mathrm{GPa} \\
& v_{21}=\frac{E_{2}}{E_{1}} v_{12}=\frac{6.54}{22} 0.3314=0.0985 \\
& \Delta=1-v_{12} v_{21}=1-(0.3314 \times 0.0985)=0.9673 \\
& {[Q]=\left[\begin{array}{ccc}
\frac{E_{1}}{\Delta} & \frac{v_{12} E_{2}}{\Delta} & 0 \\
\frac{v_{12} E_{2}}{\Delta} & \frac{E_{2}}{\Delta} & 0 \\
0 & 0 & G_{12}
\end{array}\right]=\left[\begin{array}{ccc}
22.744 & 2.24 & 0 \\
2.24 & 6.76 & 0 \\
0 & 0 & 2.0
\end{array}\right]} \\
& {[\bar{Q}]_{C S M}=\left[\begin{array}{ccc}
\bar{Q}_{11} & \bar{Q}_{12} & 0 \\
\bar{Q}_{12} & \bar{Q}_{11} & 0 \\
0 & 0 & \bar{Q}_{66}
\end{array}\right]} \\
& \bar{Q}_{11}=\frac{3}{8} Q_{11}+\frac{1}{4} Q_{12}+\frac{3}{8} Q_{22}+\frac{1}{2} Q_{66}
\end{aligned}
$$




$$
\begin{gathered}
\bar{Q}_{12}=\frac{1}{8} Q_{11}+\frac{3}{4} Q_{12}+\frac{1}{8} Q_{22}-\frac{1}{2} Q_{66} \\
\bar{Q}_{66}=\frac{1}{8} Q_{11}-\frac{1}{4} Q_{12}+\frac{1}{8} Q_{22}+\frac{1}{2} Q_{66} \\
{[\bar{Q}]_{\text {Bottom }}=\left[\begin{array}{ccc}
12.624 & 4.368 & 0 \\
4.368 & 12.624 & 0 \\
0 & 0 & 4.128
\end{array}\right] G P a}
\end{gathered}
$$

\section{(d) Deriving the ABD Matrices}

[A], [B] and [D] for SW-Round-2.0 $\times 0.125-144$ sample can be found with the help of Equations 4-22, 4-23and 4-24 by using the values of $\bar{z}_{k}$ shown in Figure 4-14.

\begin{tabular}{|c|c|c|c|c|c|c|}
\hline \multirow{6}{*}{$\begin{array}{l}A \\
B\end{array}$} & 99606000 & 13840000 & 0 & -3083.64 & -1090 & 0 \\
\hline & 13840000 & 47313000 & 0 & -1090 & -3083.64 & 0 \\
\hline & 0 & 0 & 14000000 & 0 & 0 & -967.8 \\
\hline & -3083.64 & -1090 & 0 & 42.61 & 10.322 & 0 \\
\hline & -1090 & -3083.64 & 0 & 10.322 & 31.457 & 0 \\
\hline & 0 & 0 & -967.8 & 0 & 0 & 10 \\
\hline
\end{tabular}

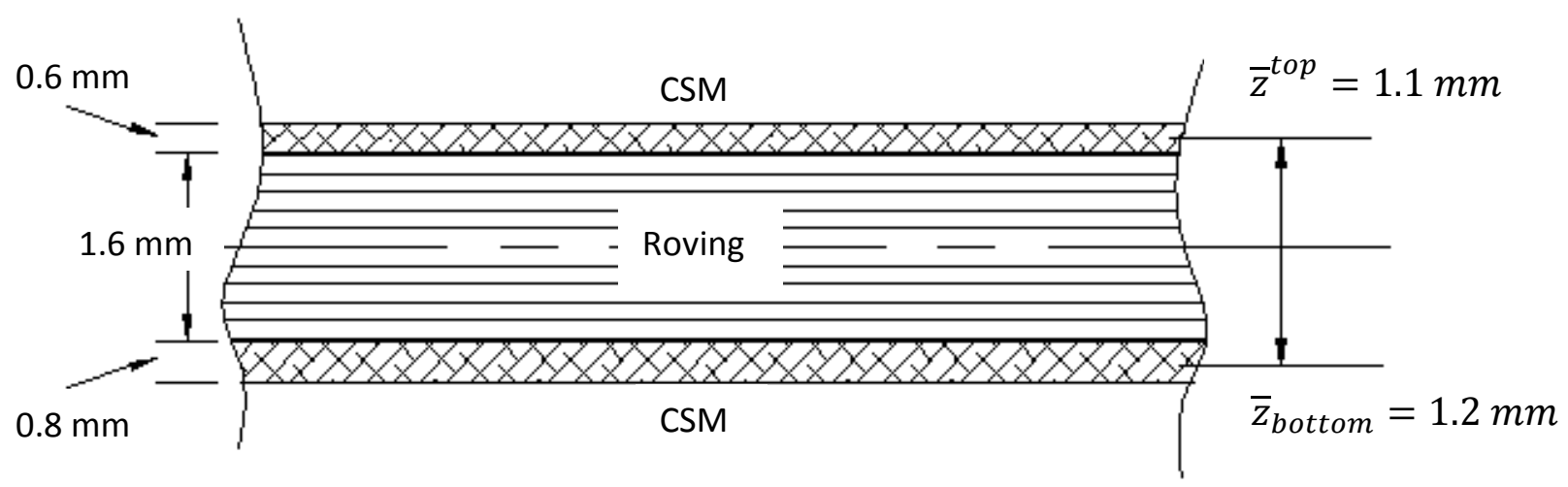

Figure 4-13: Fiber Architecture of SW-Round-2.0×0.125- 144 Sample 


$\left[\begin{array}{ll}A & B \\ B & D\end{array}\right]^{-1}=\left[\begin{array}{rrr|rrr|}1.0485 \mathrm{E}-08 & -3.0619 \mathrm{E}-09 & 0 & 7.23 \mathrm{E}-07 & -1.7394 \mathrm{E}-07 & 0 \\ -3.061 \mathrm{E}-09 & 2.2165 \mathrm{E}-08 & 0 & -1.7 \mathrm{E}-07 & 2.1221 \mathrm{E}-06 & 0 \\ 0 & 0 & 7.1909 \mathrm{E}-08 & 0 & 0 & 6.9594 \mathrm{E}-06 \\ \hline 7.2263 \mathrm{E}-07 & -1.6862 \mathrm{E}-07 & 0 & 0.025545 & -0.00837361 & 0 \\ -1.739 \mathrm{E}-07 & 2.1221 \mathrm{E}-06 & 0 & -0.00837 & 0.03473906 & 0 \\ 0 & 0 & 6.9594 \mathrm{E}-06 & 0 & 0 & 0.10067353 \\ \hline\end{array}\right.$

(e) Finding the Laminate Properties

$$
\begin{aligned}
& E_{x, \text { Laminate }}^{\text {inplane }}=\frac{1}{h A_{11}^{-1}}=\frac{1}{3 \times 10^{-3} \times 1.0485 \times 10^{-8}}=31.79 \mathrm{GPa}=4.61 \mathrm{msi} \\
& E_{y, \text { Laminate }}^{\text {inplane }}=\frac{1}{h A_{22}^{-1}}=\frac{1}{3 \times 10^{-3} \times 2.2165 \times 10^{-8}}=15.04 \mathrm{GPa}=2.18 \mathrm{msi} \\
& G_{x y, \text { Laminate }}^{\text {inplane }}=\frac{1}{h A_{66}^{-1}}=\frac{1}{3 \times 10^{-3} \times 7.19 \times 10^{-8}}=4.64 \mathrm{GPa}=0.672 \mathrm{msi} \\
& E_{x, \text { Laminate }}^{\text {flexural }}=\frac{12}{h^{3} D_{11}^{-1}}=\frac{12}{\left(3 \times 10^{-3}\right)^{3} \times 0.025545}=17.4 \mathrm{GPa}=2.52 \mathrm{msi} \\
& E_{y, \text { Laminate }}^{\text {flexural }}=\frac{12}{h^{3} D_{22}^{-1}}=\frac{12}{\left(3 \times 10^{-3}\right)^{3} \times 0.03474}=12.79 \mathrm{GPa}=1.855 \mathrm{msi} \\
& G_{x y, \text { Laminate }}^{\text {flexural }}=\frac{12}{h^{3} D_{66}^{-1}}=\frac{12}{\left(3 \times 10^{-3}\right)^{3} \times 0.1}=4.44 \mathrm{GPa}=0.64 \mathrm{msi}
\end{aligned}
$$

The summary of the results is given in Table 4-5.

Table 4-5: Laminate Properties of SW-Round-2.0×0.125- 24 \&144 Samples

\begin{tabular}{|l|c|}
\hline \multicolumn{2}{|c|}{ Laminate } \\
\hline Property & Analytical \\
\hline$E_{x}^{\text {inplane }}(\mathrm{msi})$ & 4.61 \\
\hline$E_{y}^{\text {inplane }}(\mathrm{msi})$ & 2.18 \\
\hline$G_{x y}^{\text {inplane }}(\mathrm{msi})$ & 0.672 \\
\hline$E_{x}^{\text {flexural }}(\mathrm{msi})$ & 2.52 \\
\hline$E_{y}^{\text {flexural }}(\mathrm{msi})$ & 1.855 \\
\hline
\end{tabular}


$G_{x y}^{\text {flexural }}(\mathrm{msi})$

0.64 


\section{CHAPTER 5 - Flexural Behavior}

\subsection{Introduction}

The flexural behavior of glass-fiber reinforced polymer composite beams of various crosssections, dimensions and spans was investigated under a variety of bending-to-failure tests. 3point bending tests were performed on square and rectangular cross-sections of $3 \times 3 \times 0.25$ inch to $6 \times 6 \times 0.375$ inch with spans of 24 inch to 180 inch, a wide-flange beam of $6 \times 6 \times 0.25$ inch crosssection and a round beam of $6 \times 0.25$ inch cross-section with span of 70 inch. A 4-point bending test was performed on a box beam of $4 \times 4 \times 0.25$ inch cross-section with a span of 58 inch.

For better understanding, additional bending testing with different load conditions was performed on $3 \times 3 \times 0.25$ inch, $4 \times 4 \times 0.25$ inch and $6 \times 6 \times 0.375$ inch beams of 21-25 inch span. The supports being roller-type, the load types included: (i) punching load with and without elastomeric pads, (ii) uniformly distributed load over the entire span, and (iii) the loading plate being longer than the beam width.

The experimental data were analyzed on the basis of classical laminate theory of orthotropic plates, supported by a finite element analysis. The two results were compared with each other, as well as, with the formulae of the ASCE-LRFD Manual.

It was found that in 3-point bending, the long-span beams failed under top-flange buckling and the short span beams failed under crushing of the web-flange corner, followed by the separation

of the two. For deeper and thinner cross-sections $\left(\frac{d}{t} \geq 24\right)$, web buckling was another mode of failure. The FEA results were in good agreement with those found by orthotropic plate theory, while the ASCE-LRFD Manual results provided lower bounds under flexure. 


\subsection{Problem Formulation}

The problem formulation based on classical laminate theory of bending of beams, buckling of orthotropic plates (web or flange) and design equations of ASCE-LRFD pultruded sections manual is described as under.

\subsubsection{Bending of Orthotropic Beams}

From basic mechanics of materials, bending moment and stress and shear stress under 3-Point bending of a beam is,

$$
\begin{aligned}
M & =\frac{P L}{4} \\
\sigma & =\frac{M c}{I} \\
\tau & =\frac{V Q}{I t}
\end{aligned}
$$

As shown in Figure 5-1 (a), for an orthotropic box section,

$$
\widetilde{E I_{y y}}=\frac{b_{f}}{\left(a_{11}\right)_{f}} \frac{d^{2}}{2}+\frac{2 b_{f}}{\left(d_{11}\right)_{f}}+\frac{2 b_{w}^{3}}{12\left(a_{11}\right)_{w}}
$$

For an orthotropic wide-flange section, as shown in Figure 5-1 (b),

$$
\widetilde{E I_{y y}}=\frac{b_{f}}{\left(a_{11}\right)_{f}} \frac{d^{2}}{2}+\frac{2 b_{f}}{\left(d_{11}\right)_{f}}+\frac{b_{w}^{3}}{12\left(a_{11}\right)_{w}}
$$

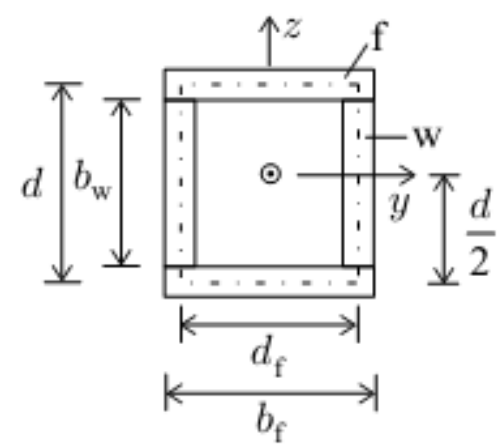

(a) Orthotropic box section

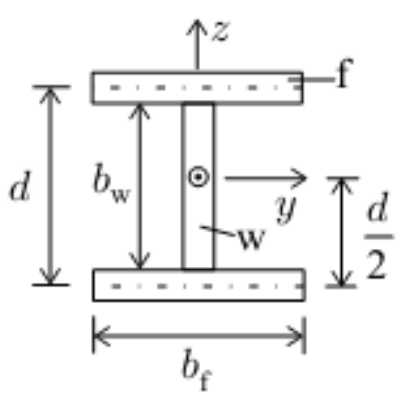

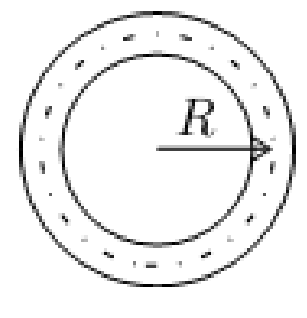

(b) Orthotropic wide-flange section (c) Orthotropic round section Figure 5-1: Notations of orthotropic beam sections used in Equation 5-4, 5-5 and 5-6 [14] 
And for an orthotropic round section as shown in Figure 5-1 (c),

$$
\widetilde{E I_{y y}}=\overbrace{E I_{z z}}=\pi\left(\frac{R^{3}}{a_{11}}+\frac{R}{d_{11}}\right)
$$

where $a_{11}$ and $d_{11}$ refer to the elements of inverse $[A]$ and $[D]$ matrices defined by Equations A22 and A-24.

Having known the modulus of elasticity from laminate properties, as described in Chapter-4, the

values of $\widetilde{I_{y y}}$ from Equation 5-4 through 5-6 refer to the orthotropic case and are different from the isotropic case, i.e.,

$$
\begin{aligned}
\sigma_{b, \text { ortho }} & =\frac{M c}{\widetilde{I_{y y}}} \\
\tau_{b, \text { ortho }} & =\frac{V Q}{\widetilde{I_{y y}} t}
\end{aligned}
$$

\subsubsection{Buckling of Orthotropic Plates}

Buckling of orthotropic plates can be formulated either as a short plate or as a long plate problem. A plate will behave as a long plate if

$$
\frac{L_{x}}{L_{y}}>3\left(\sqrt[4]{\frac{D_{11}}{D_{22}}}\right)
$$

where $L_{x}$ and $L_{y}$ refer to the length and width of the orthotropic plate respectively.

The top flange of a bent box beam is in compression and the bottom one in tension. For a symmetric loading, the two webs experience a linearly variable stress along the beam-depth (top to bottom). Then the buckling behavior can be formulated by using the following formulas.

\subsubsection{1. $\quad$ Long Plate Buckling Formulae [14]}

The related formulas of buckling of long orthotropic plates with symmetric layups are given below. 
For simply supported edges, as shown in Figure 5-2 (a), the buckling load per unit width is

$$
N_{x, c r}=\frac{\pi^{2}}{L_{y}^{2}}\left[2 \sqrt{D_{11} D_{22}}+2\left(D_{12}+2 D_{66}\right)\right]
$$

For the fixed edges, as shown in Figure 5-2 (b), The buckling load per unit width is

$$
N_{x, c r}=\frac{\pi^{2}}{L_{y}^{2}}\left[4.53 \sqrt{D_{11} D_{22}}+2.62\left(D_{12}+2 D_{66}\right)\right]
$$

For simply supported edges with linearly varying load, as shown in Figure 5-2 (c), the buckling value is

$$
N_{x, c r}=\frac{\pi^{2}}{L_{y}^{2}}\left[13.9 \sqrt{D_{11} D_{22}}+11.1\left(D_{12}+2 D_{66}\right)\right]
$$

(a) Simple Supports, Uniformly Distributed Load

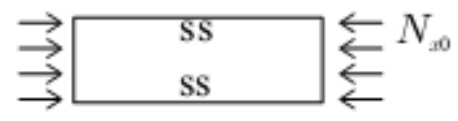

(b) Fixed Supports, Uniformly Distributed Load

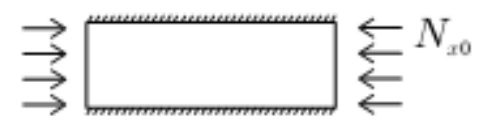

(c) Simple Supports, Linearly Varying Load

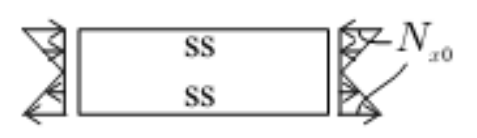

Figure 5-2: Boundary conditions for the buckling loads on a long plate [14]

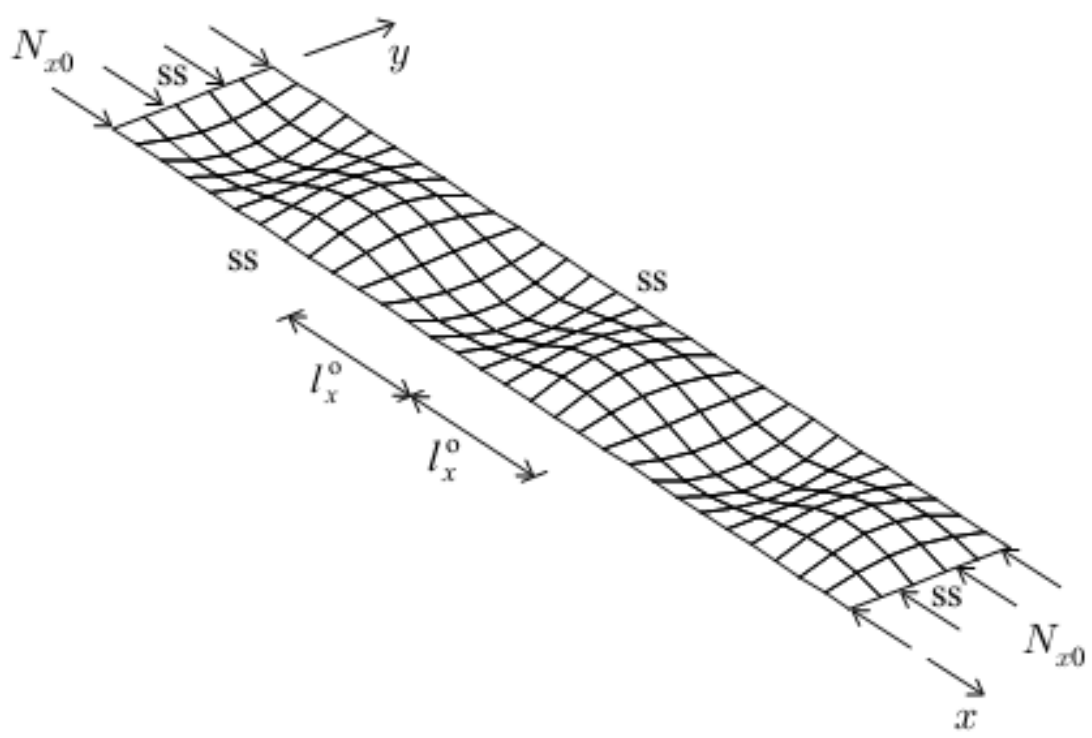

Figure 5-3: Buckled Shape of a Long Plate with Simple Supports [14] 
The buckled shape of a long plate with simply supported edges is shown in Figure 5-3, where $l_{x}^{o}$ refers to length of the half buckling wave.

\subsubsection{2. $\quad$ Short Plate Buckling Formulae [14]}

Taking $L_{x}$ and $L_{y}$ as length and width of a short orthotropic plate, the buckling load for the simply supported case, as shown in Figure 5-4 (a), is given by

$$
N_{x, c r}=\frac{\pi^{2}}{L_{y}^{2}}\left[D_{11} \frac{L_{y}^{2}}{l_{x}^{2}}+D_{22} \frac{l_{x}^{2}}{L_{y}^{2}}+2\left(D_{12}+2 D_{66}\right)\right]
$$

For a fixed supported short orthotropic plate, as shown in Figure 5-4 (b), the buckling load is given by

$$
N_{x, c r}=\frac{\pi^{2}}{L_{y}^{2}}\left[D_{11} \frac{L_{y}^{2}}{l_{x}^{2}}+5.139 D_{22} \frac{l_{x}^{2}}{L_{y}^{2}}+2.62\left(D_{12}+2 D_{66}\right)\right]
$$

where,

$$
\begin{gathered}
l_{x}=\frac{L_{x}}{i} \\
i=1,2,3 \ldots \ldots \ldots
\end{gathered}
$$

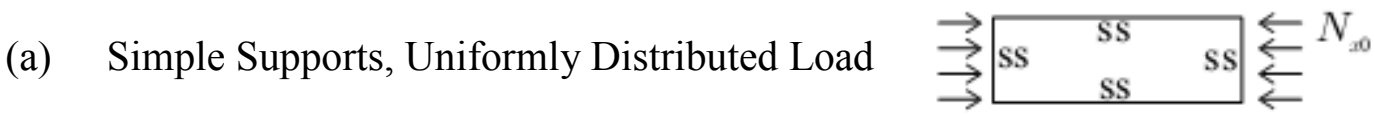

(b) Fixed Supports, Uniformly Distributed Load

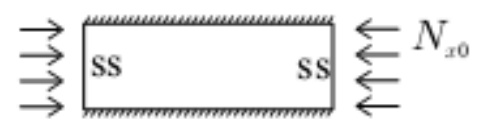

Figure 5-4: Boundary conditions for the buckling loads on a short plate [14]

\subsubsection{Design Equations of ASCE-LRFD Pultruded Sections Draft Manual}

The design equations of different failure modes of pultruded sections under bending load are given as under: 


\subsubsection{Nominal Strength Due to Material Rupture [1]}

The required flexural strength $M_{u}$ for a member subjected to bending due to transverse loads is given by

$$
M_{u} \leq \lambda \phi M_{n}
$$

where $\phi$ is the resistance factor for flexure depending upon the mode of failure, $\lambda$ is the time effect factor and $M_{n}$ is the nominal flexural strength. For tensile rupture, $\phi=0.65$ and for compressive rupture, $\phi=0.70$. Also,

$$
\begin{aligned}
& M_{n}(\text { Tensile })=\min \left[\frac{F_{L, f}^{t}\left(E_{L, f}^{a v e} I_{f}+E_{L, w}^{a v e} I_{w}\right)}{y_{t, f} E_{L, f}^{a v e}}, \frac{F_{L, w}^{t}\left(E_{L, f}^{a v e} I_{f}+E_{L, w}^{a v e} I_{w}\right)}{y_{t, w} E_{L, w}^{a v e}}\right] \\
& M_{n}(\mathrm{Comp})=\min \left[\frac{F_{L, f}^{c}\left(E_{L, f}^{a v e} I_{f}+E_{L, w}^{a v e} I_{w}\right)}{y_{c, f} E_{L, f}^{a v e}}, \frac{F_{L, w}^{c}\left(E_{L, f}^{a v e} I_{f}+E_{L, w}^{a v e} I_{w}\right)}{y_{c, w} E_{L, w}^{a v e}}\right]
\end{aligned}
$$

where F, E, I and y represent strength, elastic modulus, $2^{\text {nd }}$ moment of area and distance from neutral axis to the extreme fiber, respectively. The superscripts and subscripts $t, c, f, w$ and $\mathrm{L}$ stand for tensile, compressive, flange, web and longitudinal respectively.

\subsubsection{Nominal Strength Due to Local Instability [1]}

$M_{n}$ of an I, C, T or box section due to local instability is given by

$$
M_{n}=f_{c r} \frac{E_{L, f}^{a v e} I_{f}+E_{L, w}^{a v e} I_{w}}{y_{c, e} E_{L, e}^{a v e}}
$$

where $f_{c r}$ is the critical buckling stress and the subscript e refers to the buckled element. In box beams, for strong axis bending of flange and weak axis bending of the web,

$$
\begin{gathered}
f_{c r}=\frac{4 \pi^{2} t_{e}^{2}}{b_{e}^{2}}\left[\frac{\sqrt{\left(E_{L, e}^{c} E_{T, e}^{c}\right)(1+4.1 \xi)}}{6}+\left(2+0.62 \xi^{2}\right)\left(\frac{E_{T, e}^{c} \nu_{L, e}}{12}+\frac{G_{L T, e}}{6}\right)\right] \\
\xi=\frac{1}{1+\frac{4 E_{T, e}^{c} t_{e}^{3}}{5 k_{r} b_{e}}}
\end{gathered}
$$




$$
k_{r}=\frac{E_{T, a}^{c} t_{a}^{3}}{3 b_{a}}\left[1-\left[\frac{2 t_{e}^{2} b_{a}^{2} E_{L, a}^{c}}{11.1 b_{e}^{2} t_{a}^{2} E_{L, e}^{c}}\right]\left[\frac{\sqrt{E_{L, e}^{c} E_{T, e}^{c}}+E_{T, e}^{c} v_{L, e}+2 G_{L T, e}}{1.25 \sqrt{E_{L, a}^{c} E_{T, a}^{c}}+E_{T, a}^{c} v_{L, a}+2 G_{L T, a}}\right]\right]
$$

For weak axis bending of flange and strong axis bending of web,

$$
f_{c r}=\frac{11.1 \pi^{2} t_{e}^{2}}{12 b_{e}^{2}}\left[1.25 \sqrt{\left(E_{L, e}^{c} E_{T, e}^{c}\right)}+E_{T, e}^{c} v_{L, e}+2 G_{L T, e}\right]
$$

The subscripts " $e$ " and " $a$ " refer to the element and the adjacent element respectively. If flange is the element, the web is adjacent element and vice versa. The superscript " $c$ " stands for mode under compression. Typically, the properties in compressive direction can be taken as $90 \%$ of those in longitudinal direction. " $L$ " and " $T$ " refer to longitudinal and transverse directions.

\subsubsection{Nominal Strength Due to Lateral-Torsional Buckling [1]}

For a doubly symmetric closed rectangular section bent about its strong axis, $M_{n}$ due to lateraltorsional buckling is given by

$$
M_{n}=C_{b} \sqrt{\frac{\pi^{2} E_{L} I_{y} D_{J}}{L_{b}^{2}}}
$$

where,

$C_{b}=1$

(moment modification factor)

$D_{J}=4\left[\left(b_{f}-t_{w}\right)\left(h-t_{f}\right)\right]^{2}\left[G_{L T, f} \frac{t_{f}}{8 b_{f}}+G_{L T, w} \frac{t_{w}}{8 b_{w}}\right]$

(torsional rigidity of single-celled doubly-symmetric, thin-walled closed rectangular section)

$L_{b}=$ length between points that are either braced against lateral displacement of the compression flange or braced against twist of the cross-section.

\subsubsection{Nominal Strength Due to Material Rupture in Shear [1]}

The nominal shear strength due to shear rupture is given by 


$$
V_{n}=F_{L T}^{v} A_{s}
$$

Where $F_{L T}^{v}$ is the in plane shear strength of the section found from coupon testing and $A_{S}$ is the area under shear.

\subsubsection{Nominal Strength Due to Web Shear Buckling [1]}

The nominal shear strength of I-sections, back-to-back channels, single channels and box sections (square and rectangle) under bending about their strong axis is given by

$$
V_{n}=f_{c r} h t_{w}
$$

If

$$
2 G_{L T, w}+E_{L, w}^{c} v_{T, w} \leq \sqrt{E_{L, w}^{c} E_{T, w}^{c}}
$$

then

$$
f_{c r}=\frac{t_{w}^{2} k_{L T} \sqrt[4]{E_{L, w}^{c}\left(E_{T, w}^{c}\right)^{3}}}{3 h^{2}}
$$

where

$$
k_{L T}=8.1+5.0 \frac{2 G_{L T, w}+E_{L, w}^{c} v_{T, w}}{\sqrt{E_{L, w}^{c} E_{T, w}^{c}}}
$$

else

$$
f_{c r}=\frac{t_{w}^{2} k_{L T} E_{T, w}^{c}}{3 h^{2}} \sqrt{v_{L, w}+\frac{2 G_{L T, w}}{E_{T, w}^{c}}}
$$

where

$$
k_{L T}=11.7+1.4\left(\frac{\sqrt{E_{L, w}^{c} E_{T, w}^{c}}}{2 G_{L T, w}+E_{L, w}^{c} v_{T, w}}\right)^{2}
$$




\title{
5.3. Finite Element Analysis
}

The philosophy of the finite element analysis is to generate a fine mesh resulting in convergent solution under given analysis parameters.

The finite element analysis of bending behavior of GFRP composite beams tested under 3-point bending was done in ANSYS 13.0 with the following salient features:

$$
\begin{array}{ll}
\text { Element Type: } & \text { (i) Structural Mass - Shell - 3d4node181 } \\
& \text { (ii) Structural Mass - 3D Brick Element }
\end{array}
$$

\author{
Material Properties: Structural - Linear - Elastic - Orthotropic \\ Input Data: Moduli of Elasticity \\ Moduli of Rigidity \\ Poisson's Ratios \\ Data Source: Coupon Tension Testing
}

Mesh Size: Equal to Wall Thickness

Support Type: Simply Supported at Bothe Ends

Load Types: (i) Unit Load Distributed at Mid-Span at Web Edges (Figure 5-5)

(ii) Load via a Loading Plate at Mid-Span (Figure 5-6)

Output: $\quad \sigma_{\mathrm{x}}, \sigma_{\mathrm{y}}, \sigma_{\mathrm{z}}, \tau_{\mathrm{xy}}, \tau_{\mathrm{xz}}, \tau_{\mathrm{yz}}$ 


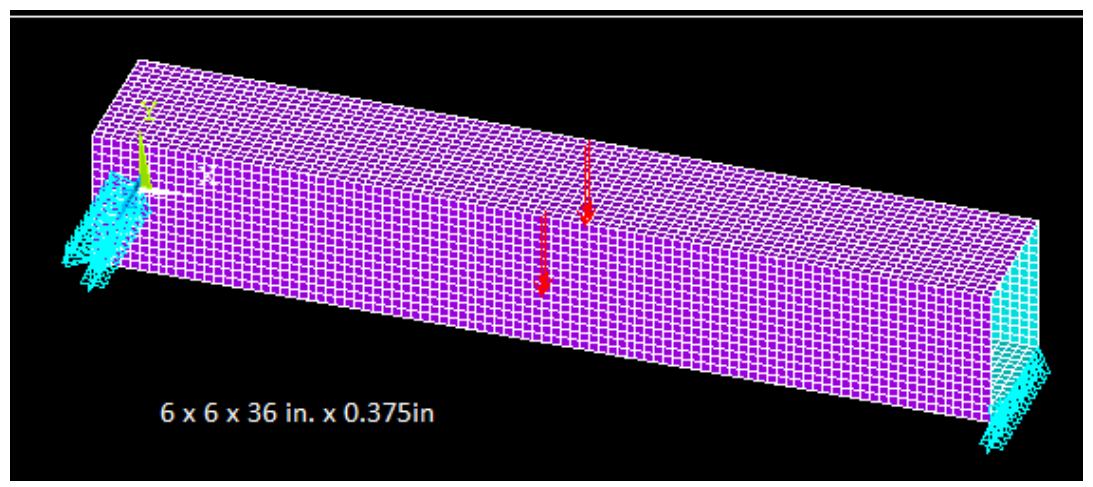

Figure 5-5: Unit Load Idealized as Point Loads Acting at Centerline on Webs

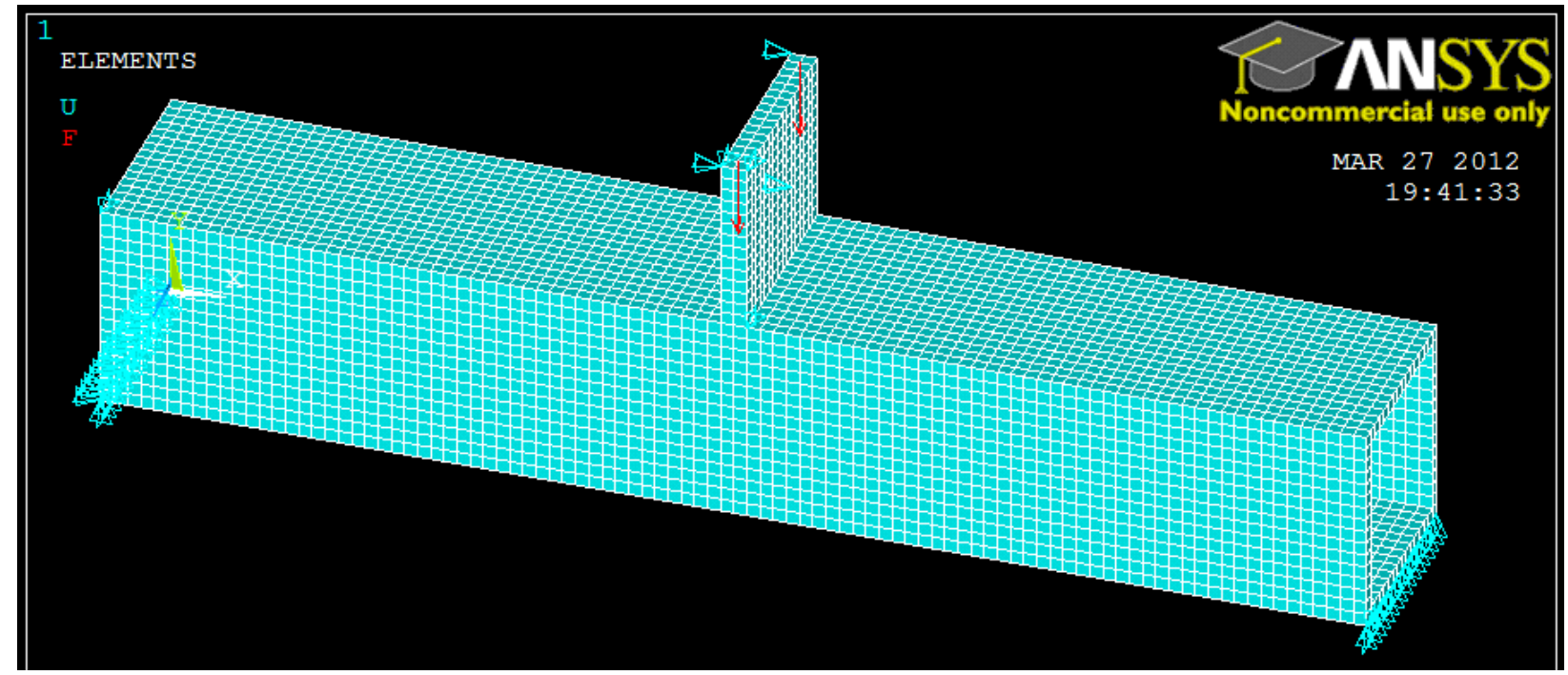

Figure 5-6: Load via a Loading Plate at Mid-Span 


\subsection{Results and Discussions}

The values of $I_{\text {ortho }}$, calculated from Equations 5-4 and 5-5, on the basis of laminate properties given in Chapter-4, are given in Table 5-1.

Table 5-1: Values of $I_{\text {ortho }}$ for Different Beam Sections

\begin{tabular}{|c|c|}
\hline Section (Manuf-Shape-Size") & $\begin{array}{c}\boldsymbol{I}_{\text {ortho }}\left(\text { inch }^{4}\right) \\
\text { Eqns } 5-4,5-5,5-6,5-7\end{array}$ \\
\hline ABC-Box- $6 \times 6 \times 0.375$ & 42.982 \\
\hline ABC-Box- $6 \times 4 \times 0.25$ & 22.735 \\
\hline ABC-Box-5.2×5.2×0.375 & 27.17 \\
\hline ABC-Box- $4 \times 4 \times 0.375$ & 11.574 \\
\hline ABC-Box $-4 \times 4 \times 0.25$ & 8.55 \\
\hline ABC-Box-3.5×3.5×0.25 & 5.52 \\
\hline ABC-Box $-3 \times 3 \times 0.25$ & 3.35 \\
\hline ABC-Box- $2 \times 0.25 \times 4 \times 0.125$ & 4.275 \\
\hline SW-Box-4×4×0.25 & 8.58 \\
\hline SW-WF- $6 \times 6 \times 0.25$ & 27.48 \\
\hline CP-Round- $6 \times 0.25$ & 18.257 \\
\hline
\end{tabular}

\subsubsection{Short Span Beams Subjected to Various Types of Loads}

To better understand the flexural behavior of various types of box beams, some beams with 20 to 25 inch span were tested under three different types of loading are given below:

\subsubsection{Bending Test Under Punching Loads}

Punching load refers to a case where a bending load acts through a rigid metal piece placed in the middle of the top flange such that the metal-piece dimensions are less than the width of the top flange. The test results under punching load for three different testpieces, with and without 
elastomeric pads, are given in Table 5-2. The failure patterns of tested samples are shown in Figures 5-7 and 5-8 respectively.

Important observations are as under:

- In all the three cases, a higher shear and bending stress corresponds to the punching load with elastomeric pad, compared with the case without elastomeric pad. Such increase is attributed to better load distribution resulting in enhanced load carrying capacity.

- Failure stresses under bending $\left(\sigma_{\mathrm{b}}\right)$, compression $\left(\sigma_{\mathrm{c}}\right)$, bending shear $\left(\tau_{\mathrm{b}}\right)$ and punching shear $\left(\tau_{\mathrm{p}}\right)$ are found to be far less than the values found from coupon testing, i.e., $\sigma=40$ ksi and $\tau=7-12 \mathrm{ksi}$. As the failure mode corresponds to punching shear, it is important to realize that apparent $\tau_{\mathrm{p}}$ does not truly represent the failure behavior because

i. In punching shear calculations,

$$
A_{s}=\text { perimeter } \times \text { thickness }=2 t(l+w)
$$

where $l$ and $w$ refer to the length and width of the punch and $t$ refers to the thickness of the top flange.

This formula works well if a plate is placed at rigid supports on all the four sides and the punch acts across the plate thickness. In our case, two supports are at the end and the web edges act as the other two supports, hence representing a case of multiple stresses of $\sigma_{\mathrm{b}}, \sigma_{\mathrm{c}}, \tau_{\mathrm{b}}$ and $\tau_{\mathrm{p}}$, the last one being most dominant.

ii. In pultruded sections, major strength contribution is from longitudinal fibers. Hence the area parallel to the fiber direction is not able to resist any considerable normal or shear stresses, because primary resistance is offered by the matrix.

iii. A high stress concentration factor exists along the punch edges.

- No close form solution for this kind of problem exists. However, the finite element analysis approach can be employed to show the failure behavior, as given in section 5.3. 

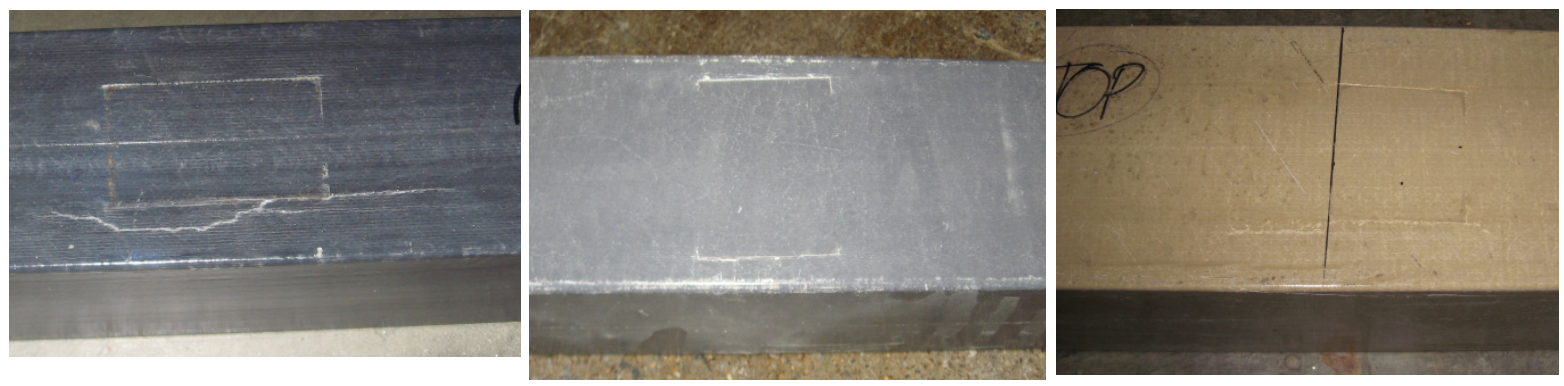

a) ABC-Box-3"×3" $\times 1 / 4 "-25 "$

b) CP-Box-4" $\times 4 " \times 1 / 4 "-25 "$

c) CP-Box-6" $\times 6 " \times 3 / 8 "-20 "$

Figure 5-7: Samples ailed under Punching Load Without Elastomeric Pads
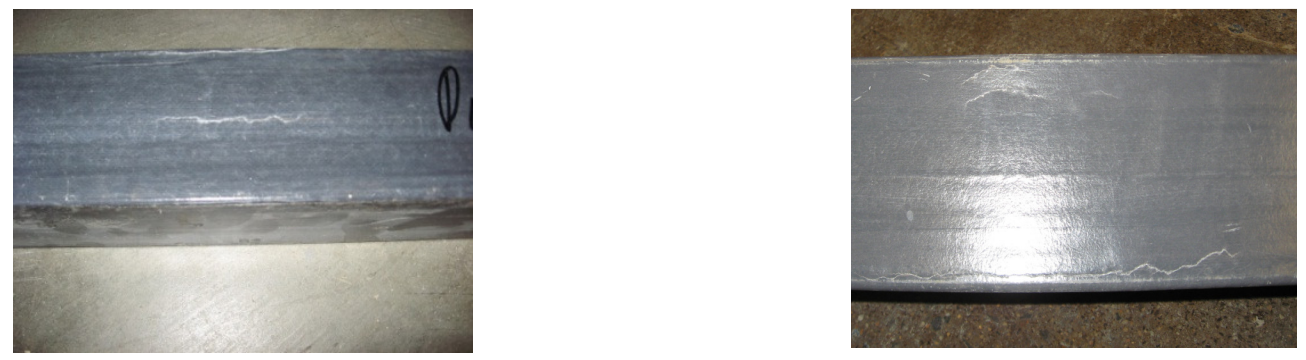

a) $\mathrm{ABC}-$ Box-3" $\times 3 " \times 1 / 4 "-25 "$

b) CP-Box-4" $\times 4 " \times 1 / 4 "-25$ "

Figure 5-8: Samples Failed under Punching Load With Elastomeric Pads 
Table 5-2: Short-Span Beams Under Punching Loads

\begin{tabular}{|c|c|c|c|c|c|c|c|c|}
\hline \multirow{2}{*}{$\begin{array}{l}\text { Sample Specifications } \\
\text { (Manuf-Shape-Size") }\end{array}$} & Punch Size & Elastom & M & $\sigma_{\mathbf{b}}$ & $\sigma_{c}=\mathbf{P} / \mathbf{A}_{c}{ }^{*}$ & $\tau_{\mathbf{b}}$ & $\tau_{\mathbf{p}}=\mathbf{P} / \mathbf{A}_{\mathbf{s}}$ & \multirow{2}{*}{ Mode of Failure } \\
\hline & $l " \times w " \times h "$ & eric Pad & (lb-in) & (psi) & (psi) & (psi) & (psi) & \\
\hline & & & Eqn 5-1 & Eqn 5-7 & & Eqn 5-8 & & \\
\hline ABC-Box-3×3×1/4- 25 & $2.44 \times 1.5 \times 1$ & No & 13390 & 5996 & 585 & 1317 & 1072 & Punching Shear \\
\hline ABC-Box-3×3×1/4- 25 & $2.44 \times 1.5 \times 1$ & Yes & 18403 & 8240 & 805 & 1810 & 1473 & Longitudinal cracks around punch area \\
\hline CP-Box-4×4×1/4- 25 & $3 \times 2.7 \times 0.625$ & No & 19455 & 4407 & 384 & 1391 & 1092 & Punching shear \\
\hline CP-Box- $4 \times 4 \times 1 / 4-25$ & $3 \times 2.7 \times 0.625$ & Yes & 25830 & 5851 & 510 & 1847 & 1450 & Longitudinal cracks around punch area \\
\hline CP-Box-6×6×3/8- 20 & $3 \times 2.7 \times 0.625$ & No & 34330 & 2411 & 848 & 1356 & 2410 & Punching shear \\
\hline CP-Box-6×6×3/8- 20 & $3 \times 2.7 \times 0.625$ & Yes & 53085 & 3729 & 1311 & 2097 & 3725 & Longitudinal Cracks at Edges \\
\hline
\end{tabular}

$* \mathrm{~A}_{\mathrm{c}}=1 " \times \mathrm{W} "$

Table 5-3: Short-Span Beams With Loading Plate Longer Than Flange-Width

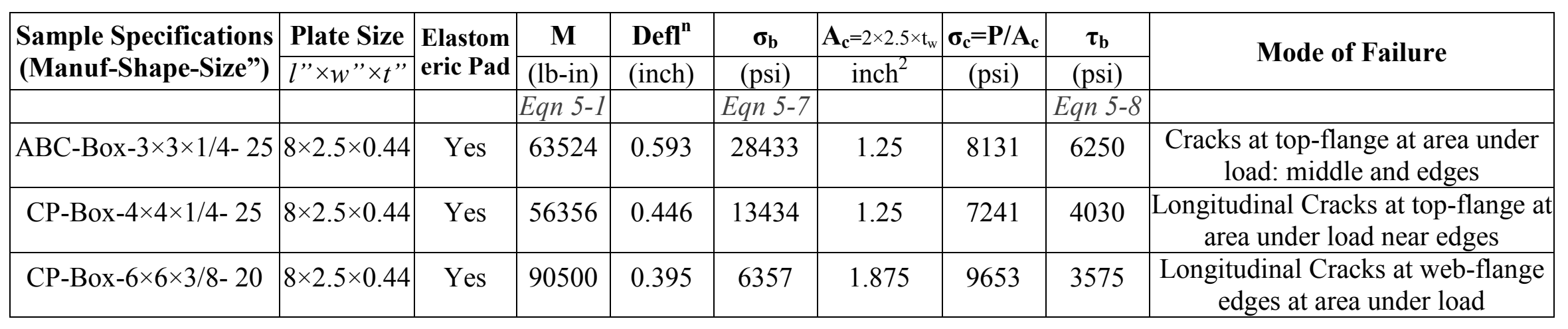




\subsubsection{Bending Test Results With Loading Plate Longer Than Flange-Width}

In this case, the loading plate was approximately 3 " wide, but the length was clearly more than the flange-width. This test arrangement helps make comparison with a typical 3-Point bending test, in which the load is applied through a roller-shape, whose contact area varies with amount of deflection, hence difficult to determine the exact contact area. The test results are summarized in Table 5-3 and the tested samples are shown in Figure 5-9.

a) ABC-Box-3" $\times 3 " \times 1 / 4 "-25$

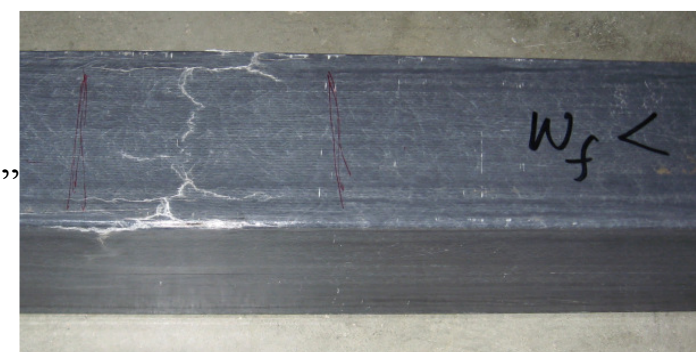

b) CP-Box-4" 4 "” $\times 1 / 4 "-25$

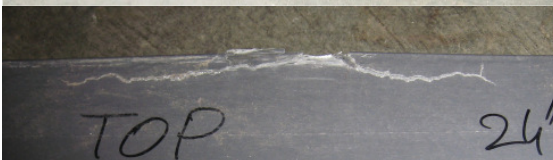

c) CP-Box-6" $\times 6 " \times 3 / 8 "-20 "$
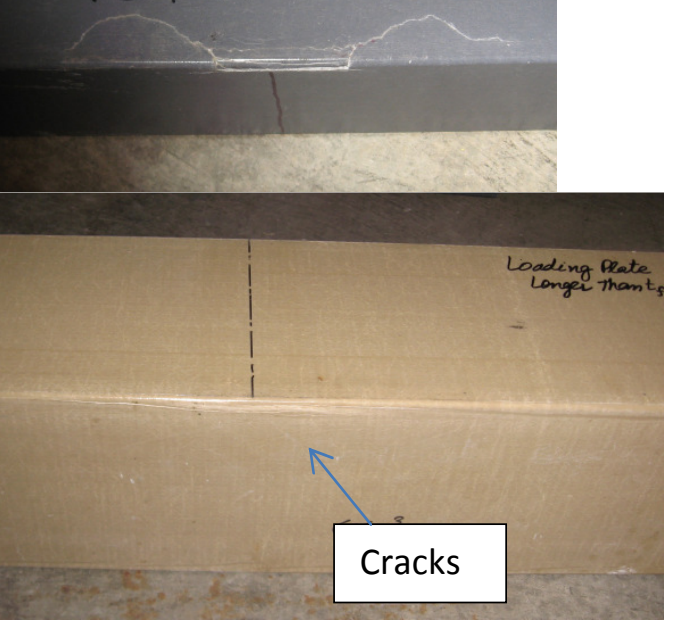

Figure 5-9: Samples Failed with Loading Plate Longer Than Flange-Width (With Elastomeric Pads)

Important observations are as under:

- ABC-Box-3" $\times 3$ " $\times 1 / 4$ "- 25 " sample represented a classical fiber buckling failure with a compressive bending stress of $27 \mathrm{ksi}$. By taking into account the stress concentration 
factor of 1.5 at the web-flange junction, this value is comparable to the axial strength of 40 ksi. For this sample, $\frac{L}{b_{f}}>8$.

- The CP-Box-4" $\times 4 " \times 1 / 4 "-25$ " sample showed failure due to crushing of the web-flange junction with a local compressive stress of $3.3 \mathrm{ksi}$. For this sample, $\frac{L}{b_{f}} \approx 6$.

- The CP-Box-6" $\times 6$ " $\times 3 / 8$ "- 20" sample exhibited yet another failure mode: longitudinal cracks at the web-flange junction with a local compressive stress of 9.6 ksi. For this sample, $\frac{L}{b_{f}} \approx 3.5$.

\subsubsection{Bending Test Results With Uniformly Distributed Load}

The uniformly distributed load was applied with the help of a rigid plate, having the same length as the effective length of the beam. The test results are given in Table 5-4. The top and bottom of the tested sample are shown in Figure 5-10.

Table 5-4: Short-Span Beams with Uniformly Distributed Load

\begin{tabular}{|c|c|c|c|c|c|c|c|c|}
\hline \multirow{3}{*}{\begin{tabular}{|c|} 
Sample \\
Specifications \\
(Manuf-Shape-Size")
\end{tabular}} & $\begin{array}{l}\text { Plate } \\
\text { Size }\end{array}$ & \begin{tabular}{|l} 
Elasto \\
meric
\end{tabular} & M & Defi ${ }^{\mathrm{n}}$ & $\sigma_{\mathbf{b}}$ & \multirow{3}{*}{$\begin{array}{l}\varepsilon_{\text {top- }} \\
\text { corner } \\
(\mu \varepsilon)\end{array}$} & \multirow{3}{*}{$\begin{array}{l}\varepsilon_{\text {side- }} \\
\text { corner } \\
(\mu \varepsilon)\end{array}$} & \multirow[t]{2}{*}{ Mode of Failure } \\
\hline & l" $\times w " \times t "$ & Pad & $(\mathrm{lb}$-in) & (inch) & (psi) & & & \\
\hline & & & $\begin{array}{c}E q n \\
5-1\end{array}$ & & $\begin{array}{c}E q n \\
5-7\end{array}$ & & & \\
\hline CP-Box- $4 \times 4 \times 1 / 4-25$ & $24 \times 6 \times 1$ & Yes & 48747 & 0.389 & 3272 & 1800 & 1872 & $\begin{array}{l}\text { 1. Longitudinal cracks at top- } \\
\text { flange near supports } \\
\text { 2. Local crushing at rollers }\end{array}$ \\
\hline
\end{tabular}
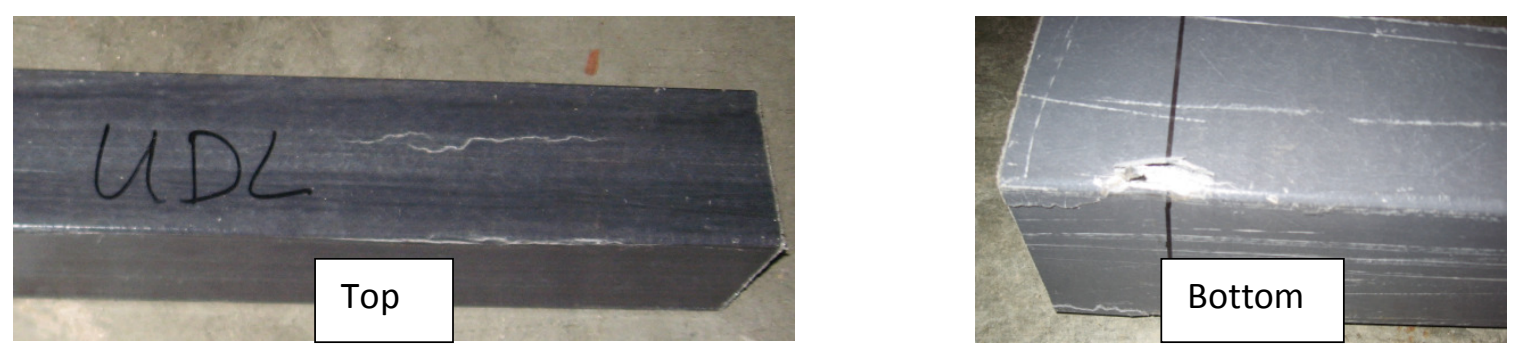

Figure 5-10: Sample Failed under Uniformly Distributed Load (With Elastomeric Pads) 
Following are the most important observations:

- Rigid steel plate, through which the uniformly distributed load (udl) was applied, stiffened the sample. Hence the sample failed near the end of the plate at the top and at roller supports at the bottom. In other words, this method of applying the udl did not prove to be satisfactory.

- Due to the same reason, the strains at the top-corner and the side-corner were very small and almost same in magnitude.

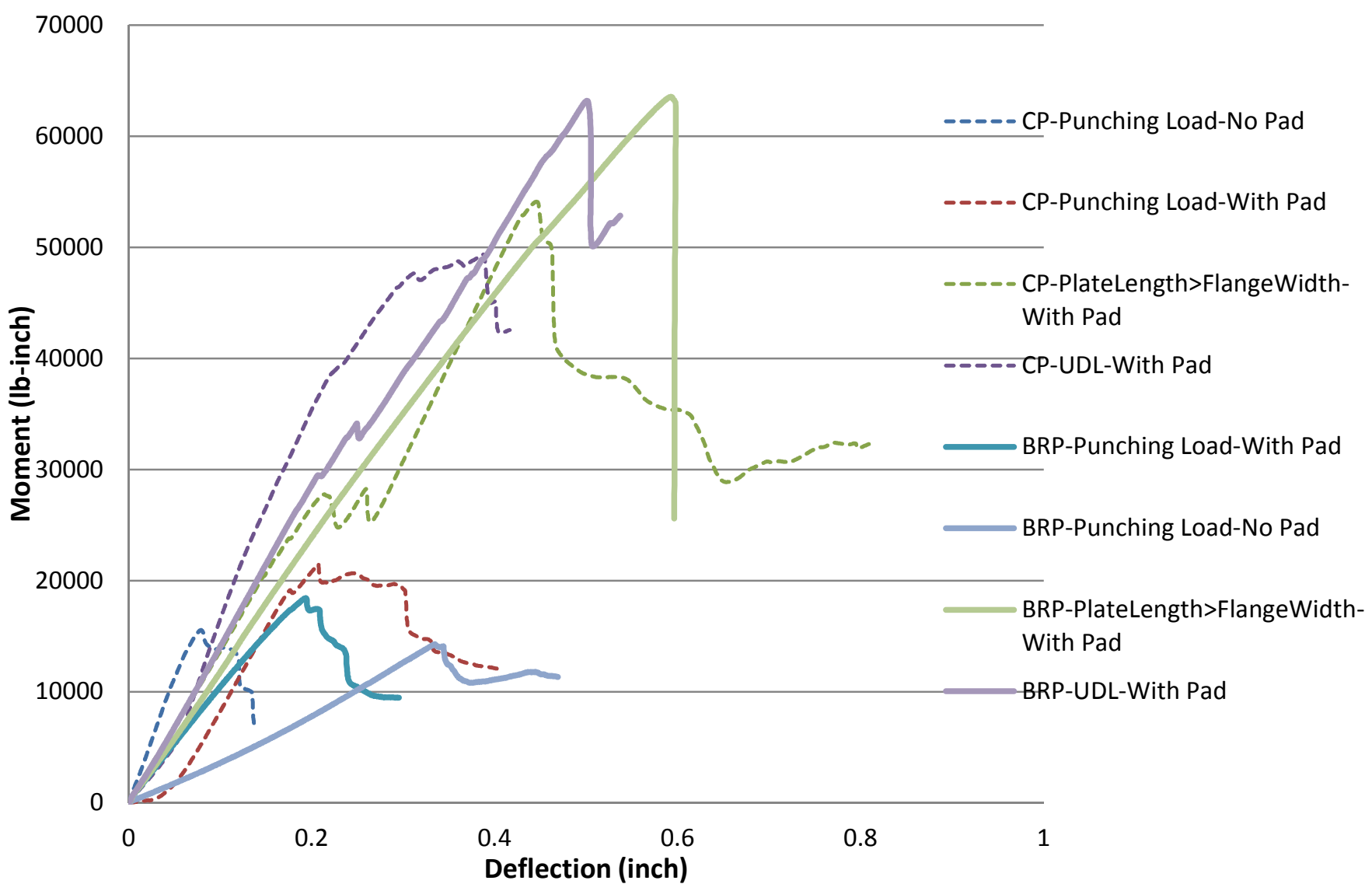

Figure 5-11: Moment vs Deflection of 21"-25" Box Beams under Different Load Conditions

The moment versus deflection plots of short span box beams under different loading conditions are shown in Figure 5-11. The deflection recorded from the Instron machine may not be a 
representative value because it corresponds to the loading side and is prone to local effects. However, a quick comparison can be made between the three loading types and the two types of beam sections, i.e.,CP-4" $\times 4$ " $\times 0.25$ " and ABC-3" $\times 3$ " $\times 0.25$ ". The punching loads with elastomeric pad are higher than those without pad, while the loads with steel-plate across the beam width including pad are much higher than the punching ones with pad.

\subsubsection{3-Point Bending Test Results}

Different beam cross-sections of varying spans were tested to failure under 3-point bending at ABC Inc. Additional testing was performed at CFC-WVU on $6 " \times 0.25$ " round, $6 " \times 6$ " $\times 0.25$ " wide-flange and $6 " \times 6 " \times 0.375$ " box sections of 6' nominal length. The sample specifications and test procedure are explained in Chapter-3.

The test samples exhibited a variety of modes of failure, depending upon the $\mathrm{L} / \mathrm{b}$ and $\mathrm{L} / \mathrm{t}$ ratios. The test data were analyzed using two different approaches:

i. The formulae of ASCE LRFD Pultruded Sections Manual by taking into account the strength and instability (local and lateral torsional)

ii. Assuming the box sections to be composed of four long plates, adjoining at the edges, and analyzing the failure behavior in terms of plate-buckling of either the flange under compression or web.

Flange Compression Buckling can be calculated by employing plate buckling formulas for uniformly distributed loads with simply supported and fixed edge conditions, i.e., Equations 5-9, 5-10, 5-12 and 5-13. The real behavior of the top-flange may be varying between simple and fixed conditions.

Web Buckling under Bending Stresses can be calculated with the help of plate-buckling formula for bending stresses with simply supported edges, i.e., Equation 5-11. The actual web-buckling load should be higher because of partial-fixity instead of simple support. 
It is worth mentioning that short-plate formulas (Equations 5-12 and 5-13) yield the same results as long-plate formulas (Equations 5-9 and 5-10).

Local Web Buckling can be determined by employing the short-plate buckling formulas, given in Equations 5-12 and 5-13, under the arrangement shown in Figure 5-12.

For an orthotropic laminate with the given load direction,

$$
\begin{gathered}
{[Q]=\left[\begin{array}{ccc}
E_{T} & v_{T} E_{L} & 0 \\
v_{T} E_{L} & E_{L} & 0 \\
0 & 0 & G_{T L}
\end{array}\right]} \\
{[D]=[Q] \frac{t_{f}^{3}}{12}}
\end{gathered}
$$

where subscripts $\mathrm{T}$ and $\mathrm{L}$ refer to transverse and longitudinal directions, respectively.
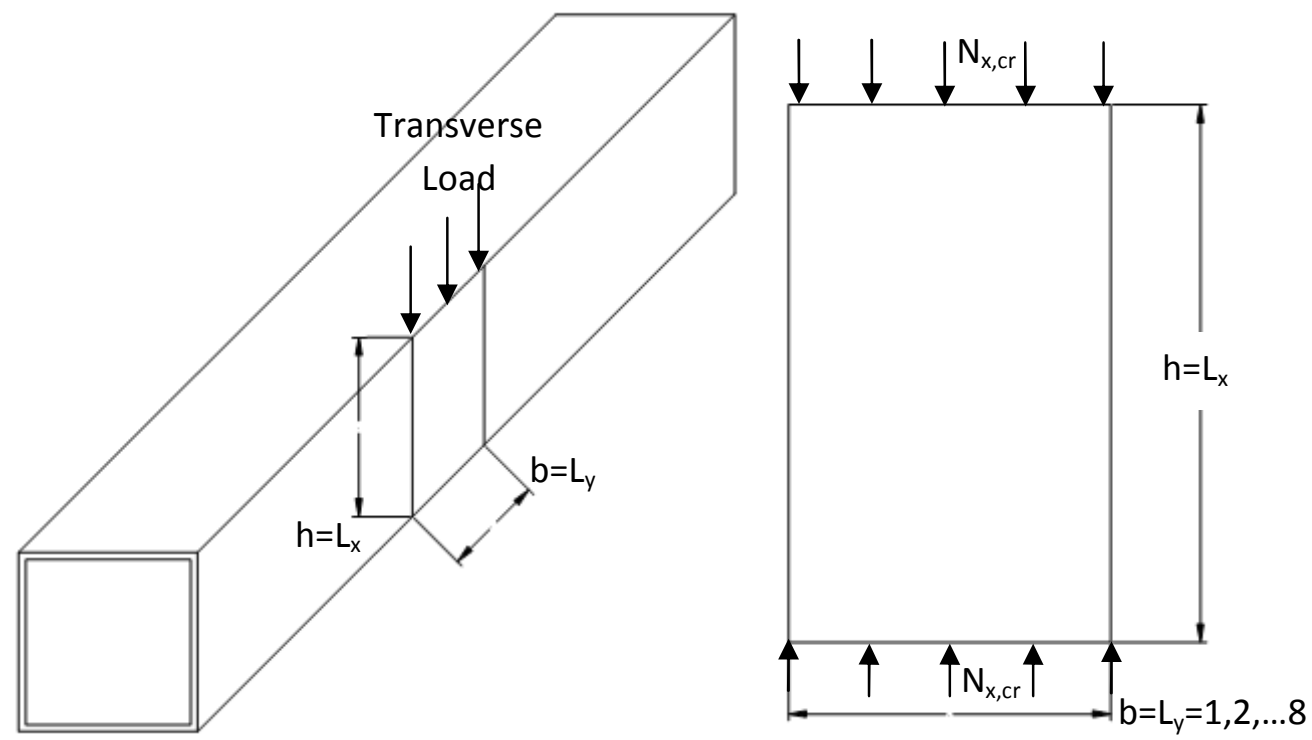

Figure 5-12: Local Web Buckling as Short-Plate Buckling with Variable $\mathrm{L}_{\mathrm{y}}$

This approach is different in two aspects:

(a) The contents of $[D]$ matrix in Equation 5-31 are different than those of a regular one because of interchanging the longitudinal and transverse directions. 
(b) The plate length $L_{x}$ is kept constant and the width $L_{y}$ is taken to be variable. This variation is due to the fact that the load is applied via a 5" diameter (approximately) roller, which had a minimum line contact at the time of load initiation but the contact area kept on increasing as the roller load increased.

The test results have been presented and discussed in the following sections.

\subsubsection{1. $\quad A B C-B o x-6 \times 6 \times 0.375$ Beams}

The 71" long sample was fitted with 3" long end-plugs, hence the effective length being 65". Two strain gages were attached at mid-span on the face opposite to loading, one at center and the other near the edge. The moment vs microstrains is shown in Figure 5-13 (a) and moment vs ratio of microstrains at edge and center is shown in Figure 5-13 (b). Both strains show a linear trend, except a slip in the strain value at center, which is a typical experimental error. Though the strain at the edge is higher than that in the center, the ratio between two is almost constant between 1.3 and 1.5. This ratio can be taken as strain concentration factor. As stress is directly proportional to strain, stress concentration factor can be taken to be equal to stress concentration factor. This factor provides a lower bound for the stress concentration under the given shape, load and boundary conditions owing to the following reasons

(a) Gage was placed away from the corner

(b) In reality, actual sample has a corner radius of curvature of around 1/16". 


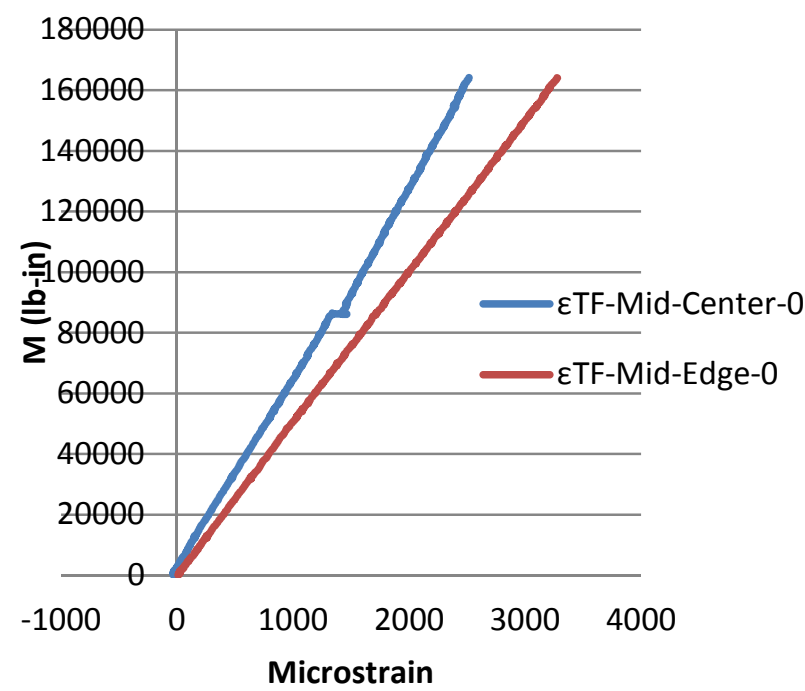

(a) Moment versus microstrains

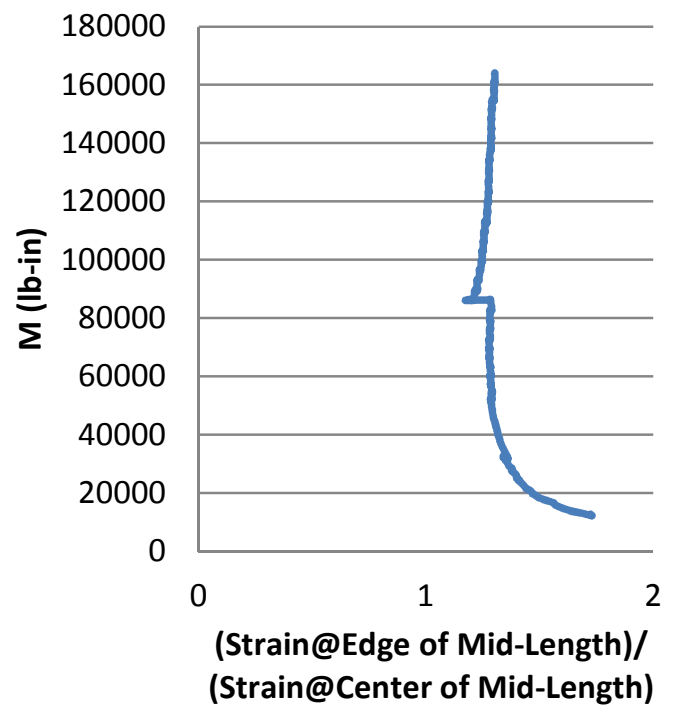

(b) Moment versus strain ratio at edge and center

Figure 5-13: Graphs of ABC-Box-6×6×0.375- 65 Beam tested at CFC-WVU

All the other ABC-Box- $6 \times 6 \times 0.375$ beams were tested to failure under 3-point bending without any end-plugs. The test data were analyzed on the basis of formulae of ASCE LRFD Manual (Draft) and orthotropic plate buckling formulae, the results of which are shown in Table 5-5 (a). Table 5-5 (b) refers to local web buckling under transverse load, given by Equations 5-30 and 531 and shown in Figure 5-12.

From Equations 5-14 and 5-15, failure strength is $18.7 \mathrm{ksi}$. Considering top flange as orthotropic long plate with simply supported edges, the buckling strength was found as $23 \mathrm{ksi}$. The other values such as local instability strength, lateral torsional buckling strength and buckling strength of web as orthotropic plate are considerably high due to a relatively higher wall thickness of $3 / 8$ inch; hence do not control the failure load magnitude. 
Table 5-5 (a): 3-Point Bending Test Results of ABC-Box-6×6×0.375 Beams

\begin{tabular}{|c|c|c|c|c|c|c|c|c|c|c|c|c|c|c|c|}
\hline \multicolumn{3}{|c|}{ Cross-section vs Span } & \multicolumn{5}{|c|}{ Experimental Values } & \multicolumn{4}{|c|}{ ASCE LRFD Manual } & \multirow{2}{*}{\multicolumn{4}{|c|}{$\begin{array}{l}\text { Top-Flange Buckling as Orthotropic } \\
\text { Long Plate }\end{array}$}} \\
\hline \multirow{2}{*}{$\mathbf{L}$} & \multirow{2}{*}{$\mathbf{L} / \mathbf{b}$} & \multirow{2}{*}{$\mathbf{L} / \mathbf{t}$} & \multirow{2}{*}{$\mathbf{P}_{\exp }$} & \multirow{2}{*}{$\mathbf{M}_{\exp }$} & \multirow{2}{*}{$\sigma_{\text {failure }}$} & \multirow{2}{*}{$\boldsymbol{\tau}_{@ \text { failure }}$} & \multirow{2}{*}{$\tau / \sigma$} & \multirow{2}{*}{$\begin{array}{c}\text { Strength } \\
\text { psi }\end{array}$} & \multirow{2}{*}{$\begin{array}{c}\sigma_{\text {Local- }} \\
\text { Inst }\end{array}$} & \multicolumn{2}{|c|}{ Lateral Torsional } & & & & \\
\hline & & & & & & & & & & \multirow{3}{*}{\begin{tabular}{|c|}
$\mathbf{M}_{\mathbf{n}}$ \\
$\mathbf{l b}-\mathbf{i n}$ \\
Eqn 5-22
\end{tabular}} & \multirow{3}{*}{\begin{tabular}{|c|}
$\boldsymbol{\sigma}$ \\
psi \\
Eqn 5-6
\end{tabular}} & \multirow{2}{*}{\multicolumn{2}{|c|}{ Simply Supported }} & \multirow{2}{*}{\multicolumn{2}{|c|}{ Fixed }} \\
\hline \multirow[t]{2}{*}{ inch } & & & Ibs & lb-in & psi & psi & $\%$ & \multirow{2}{*}{$\begin{array}{c}\boldsymbol{\sigma} \\
\text { Eqns } \\
5-14,15\end{array}$} & psi & & & & & & \\
\hline & & & & Eqn 5-1 & Eqn 5-6 & Eqn 5-8 & & & $\begin{array}{l}\text { Eqns } \\
5-6,17\end{array}$ & & & $\mathbf{N}_{\text {xcr }}$ & $\boldsymbol{\sigma}$ & $\mathbf{N}_{\text {xcr }}$ & $\boldsymbol{\sigma}$ \\
\hline $30^{1}$ & 5 & 80 & 11153 & 83647 & 5838 & 2189 & 37.5 & 18700 & \multirow{4}{*}{$\begin{array}{l}\text { Flange: } \\
44500\end{array}$} & $5.4 \mathrm{E}+06$ & 378531 & $\mathrm{lb} / \mathrm{in}$ & psi & $\mathrm{lb} / \mathrm{in}$ & psi \\
\hline $36^{1}$ & 6 & 96 & 12340 & 111060 & 7752 & 2422 & 31.2 & \multirow{2}{*}{$\begin{array}{l}\boldsymbol{V}_{\boldsymbol{n}, \boldsymbol{w e b}}^{\text {Rupture }} \\
\text { Eqn 5-23 }\end{array}$} & & $4.5 \mathrm{E}+06$ & 315442 & Eqn 5-9 & $N x, c r / t$ & Eqn 5-10 & $N x, c r / t$ \\
\hline $60^{2}$ & 10 & 160 & 12169 & 182535 & 12740 & 2389 & 18.7 & & & $2.7 \mathrm{E}+06$ & 189265 & 8620 & 23000 & 16668 & 44500 \\
\hline $65^{2}$ & 11 & 173 & 10100 & 164100 & 11454 & 1983 & 17.3 & 99560 & & $2.5 \mathrm{E}+06$ & 174706 & \multicolumn{4}{|c|}{ Web Buckling as Orthotropic Long Plate } \\
\hline $96^{3}$ & 16 & 256 & 9688 & 232512 & 16229 & 1902 & 11.7 & \multirow{2}{*}{$\begin{array}{l}\boldsymbol{V}_{\boldsymbol{n}, \boldsymbol{w e b}}^{\text {Buckling }} \\
\text { Eqn 5-24 }\end{array}$} & \multirow{3}{*}{$\begin{array}{l}\text { Web: } \\
70800\end{array}$} & $1.7 \mathrm{E}+06$ & 118291 & \multicolumn{2}{|c|}{$\mathbf{N}_{\mathrm{xcr}}(\mathrm{lb} / \mathrm{in})$} & \multicolumn{2}{|c|}{$\sigma(p s i)$} \\
\hline $144^{3}$ & 24 & 384 & 8261 & 297396 & 20757 & 1622 & 7.8 & & & $1.1 \mathrm{E}+06$ & 78861 & \multicolumn{2}{|c|}{ Eqn 5-11 } & \multicolumn{2}{|c|}{$N x, c r / t$} \\
\hline $180^{3}$ & 30 & 480 & 6966 & 313470 & 21879 & 1367 & 6.2 & 38920 & & $9.0 \mathrm{E}+05$ & 63088 & \multicolumn{2}{|c|}{75843} & \multicolumn{2}{|c|}{202250} \\
\hline
\end{tabular}

${ }^{1}$ Samples failed due to local flange and web crushing due to applied load

${ }^{2}$ Samples failed due to strength failure and buckling of the top flange due to compressive bending stresses, followed by the bending strength failure of the webs.

${ }^{3}$ Samples failed due to strength failure and buckling of the top flange due to compressive bending stresses, followed by the bending strength failure of the web. No Buckling 
Table 5-6 (b): Critical Transverse Load (lb/inch width) for Local Web Buckling of ABC-Box-6×6×0.375 Beams -Figure 5-12

\begin{tabular}{|c|c|c|c|c|c|c|c|c|c|c|}
\hline & & & \multicolumn{8}{|c|}{ Assumed Width Under Loading, b= $\mathrm{L}_{\mathrm{y}}$ (inch) } \\
\hline \multicolumn{3}{|c|}{ Edge Condition } & 1 & 2 & 3 & 4 & 5 & 6 & 7 & 8 \\
\hline \multirow{2}{*}{$\begin{array}{c}\text { Simply } \\
\text { Supported }\end{array}$} & $\mathrm{N}_{\mathrm{x}, \mathrm{cr}}(\mathrm{lb} / \mathrm{in})$ & Eqn 5-9 & 240,540 & 61,463 & 27,585 & 15,366 & 11,108 & 6,896 & 4,909 & 3,841 \\
\hline & $\sigma(p s i)$ & $N x, c r / t$ & 641,439 & 163,901 & 73,561 & 40,975 & 29,622 & 18,390 & 13,091 & 10,244 \\
\hline \multirow{2}{*}{ Fixed } & $\mathrm{N}_{\mathrm{x}, \mathrm{cr}}(\mathrm{lb} / \mathrm{in})$ & Eqn 5-10 & 465,781 & 116,445 & 52,774 & 29,685 & 18,631 & 13,194 & 10,624 & 8,120 \\
\hline & $\sigma(\mathrm{psi})$ & $N x, c r / t$ & $1,242,082$ & 310,520 & 140,731 & 79,161 & 49,683 & 35,183 & 28,332 & 21,654 \\
\hline
\end{tabular}


With $b / t=16$ and $L / b=5$ to 30 , the flexural behavior of these beams can be divided into three main categories, as described below:

1. Local Failure:

This behavior is dominant in short-span beams $\left(\frac{L}{b}<10\right)$ where the applied load creates a high local stress, though bending stresses are considerably small. It is somewhat comparable to the case of loading plate longer than the flange-width. For example the CP-Box-6×6×3/8- 20 sample withstood $6.4 \mathrm{ksi}$ as compared to $5.84 \mathrm{ksi}$ for 30 ” long and $7.75 \mathrm{ksi}$ for 36 " long samples of $\mathrm{ABC}$.

Ignoring the effect of flanges and assuming that half load is carried by each web, area under crushing for 1 " roller-contact width is

$$
A_{c}=t_{w}=0.375 \text { inch }^{2}
$$

and let us say

$$
\text { Load }=\frac{P}{2}=6000 \mathrm{lbs}
$$

Then

$$
\sigma_{c=} \frac{6000}{0.375}=16 k s i
$$

As the load acts on the web in transverse direction, it should be compared with transverse strength, given from coupon testing as,

$$
\sigma_{T}=9.5 \mathrm{ksi}
$$

The crushing stress is almost twice as the transverse strength. This may be due to: (i) although the contact area is assumed to be 1", load is distributed along the length of the web, (ii) the top- and bottom-flange provide a restraint at the web-flange junction hence enhancing the load carrying capacity. Although this approach gives an idea of the local crushing behavior yet it cannot be fully accurate because the contact area may vary from the assumed value. 
The bending shear at failure (2.2 to $2.4 \mathrm{ksi}$ ) is around 30 to $35 \%$ of shear stress at failure and 18 to $20 \%$ of the coupon shear strength $(11.7 \mathrm{ksi})$. Although the bending shear in short-span beams is higher than that in longer spans, yet it cannot be a cause of failure.

\section{Flexural Strength Failure and Flange Buckling}

In the beams with $10 \leq \frac{L}{b} \leq 20$, the top-flange is susceptible to two kinds of failure: flexural strength failure or flange-buckling. For $60 ", 65$ " and 95" spans, the bending stress ranged from 11.5 to $16.23 \mathrm{ksi}$, which after incorporating SCF of 2.0, exceeds the bending strength of $18.7 \mathrm{ksi}$. The flange-buckling strength should be a combination of simply supported and fixed edges, say around $30 \mathrm{ksi}$. Hence it can be said that the failure behavior is controlled by flexural strength limit state.

Although the applied loads are still comparable to those in short-span beams, a longer web helps better distribute them, reducing the chance of local crushing. The bending shear stresses are in the range of 12 to $19 \%$ of $\sigma_{\mathrm{f}}$. All the other buckling strength values are too large to control.

\section{Failure Behavior of Long-Span Beams}

For beams with $\frac{L}{b}>20, \sigma_{\text {failure }}$ with $\mathrm{SCF}=2.0$ is of the order of $40 \mathrm{ksi}$, much higher than flexural strength of $18.7 \mathrm{ksi}$ (Equations 5-14 and 5-15) and approximated compression flange buckling strength of $30 \mathrm{ksi}$. However, local instability strength, lateral torsional buckling strength and web-buckling strength as orthotropic long plate are still not reached.

Typically, a high bending deflection is associated with long-span beams. Hence, a limit state needs to be described for proper design. On the other side, since the applied loads to failure are smaller than the ones for short beams case, the chance of local crushing is remote. 
Other important observations are:

- The absence of instability is essentially attributed to a relatively high wall thickness, symmetric cross-section and closed-shape.

- The critical load for web-buckling was calculated in the Table 5-5 (b), assuming a varying width $\left(\mathrm{L}_{\mathrm{y}}\right)$ under loading to simulate the varying roller contact with increasing deflection. For a contact of 2 to 3 inch, the stress drops from $164 \mathrm{ksi}$ to $73 \mathrm{ksi}$ for simple supports and from $310 \mathrm{ksi}$ to $141 \mathrm{ksi}$ for fixed supports. In reality, however, the load is distributed along the web length. It can, however, be concluded that there is no chance of web-buckling due to the load acting in the transverse direction.

\subsubsection{2. $\quad A B C-B o x-4 \times 6 \times 0.25$ Beams}

The beam shape in this case is different from the previous one in two regards: less wall-thickness and web-width more than flange-width. The results of 3-point bending tests on various lengths are shown in Table 5-6 (a). From Equations 5-14 and 5-15, flexural strength is $25.8 \mathrm{ksi}$ and from Equations 5-6 and 5-17, local instability strength of the web is $30.5 \mathrm{ksi}$ due to smaller wallthickness and higher web-width. Buckling strength of the top-flange as orthotropic plate with partial fixity can be averaged out as $36 \mathrm{ksi}$. However, the lateral-torsional buckling strength is still not reached. Similarly, buckling strength of web as orthotropic long plate is also as high as 78 ksi.

Assuming $\mathrm{SCF}=2.0$, the failure behavior of this type of beams can be described as under:

- For beams with $\frac{L}{b} \leq 12, \sigma_{\text {faliure }}$ ranges from 9 to $21 \mathrm{ksi}$, which is less than the failure strength of $25.8 \mathrm{ksi}$, hence local crushing being the primary mode of failure. As the wallthickness is less than that of $6 \times 6 \times 3 / 8$ box beams, the effect of local crushing is dominant to higher $\mathrm{L}$ to $\mathrm{b}$ ratios.

- The beams with $12<\frac{L}{b}<20$, failed under strength failure. 
- $\sigma_{\text {faliure }}$ for beams with $\frac{L}{b}>20$ ranged from 33 to $49 \mathrm{ksi}$, i.e., well-above the failure strength of $25.8 \mathrm{ksi}$ and local instability strength of the web (30.5 ksi)

- The bending shear stress at failure ranged from 15 to $30 \%$ of $\sigma_{\text {faliure }}$ for shorter span beams and 5 to $10 \%$ of $\sigma_{\text {faliure }}$ for longer span beams. Similar to the case of $6 \times 6 \times 0.375$ beams, bending shear stress cannot be cause of failure.

- The critical loads and stresses for web-buckling under transverse load with variable contact width $\left(\mathrm{L}_{\mathrm{y}}\right)$ are shown in Table 5-6 (b). With simple supports the stress drops from $77.8 \mathrm{ksi}$ to $35.9 \mathrm{ksi}$ corresponding to a width changing from 2 to $3 \mathrm{inch}$. The values are almost double for fixed supports. It is clear that the samples are web-buckling safe.

The 120" long sample at failure is shown in Figure 5-14. Its failure stress with SCF=2.0 is 40 ksi. Comparing with $\sigma_{\text {strengh }}=25.8 \mathrm{ksi}$ and $\sigma_{\text {local-instability } @ w e b}=30 \mathrm{ksi}$, and observing Figure $5-14$, it is clear that the top flange underwent stress failure and at the same time, the web underwent local instability.

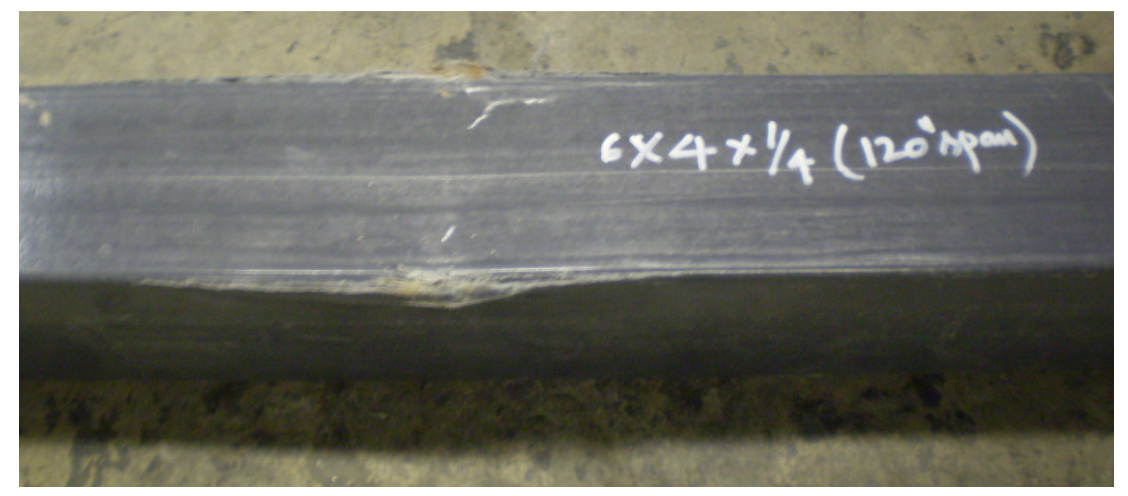

Figure 5-14: Web and Flange Buckling of ABC-Box-4×6×0.25- 120 Sample 
Table 5-7 (a): 3-Point Bending Test Results of ABC-Box-4×6×0.25 Beams

\begin{tabular}{|c|c|c|c|c|c|c|c|c|c|c|c|c|c|c|c|}
\hline \multicolumn{3}{|c|}{ Cross-section vs Span } & \multicolumn{5}{|c|}{ Experimental Values } & \multicolumn{4}{|c|}{ ASCE LRFD Manual } & \multirow{2}{*}{\multicolumn{4}{|c|}{$\begin{array}{l}\text { Top-Flange Buckling as Orthotropic } \\
\text { Long Plate }\end{array}$}} \\
\hline \multirow{2}{*}{$\mathbf{L}$} & \multirow{2}{*}{$\mathbf{L} / \mathbf{b}$} & \multirow{2}{*}{$\mathbf{L} / \mathbf{t}$} & \multirow{2}{*}{$\mathbf{P}_{\text {exp }}$} & \multirow{2}{*}{$\mathbf{M}_{\mathbf{e x p}}$} & \multirow{2}{*}{$\sigma_{\text {failure }}$} & \multirow{2}{*}{$\boldsymbol{\tau}_{@ \text { failure }}$} & \multirow{2}{*}{$\tau / \sigma$} & \multirow{2}{*}{\begin{tabular}{|c|} 
Strength \\
psi
\end{tabular}} & \multirow{2}{*}{$\begin{array}{c}\sigma_{\text {Local- }} \\
\text { Inst }\end{array}$} & \multicolumn{2}{|c|}{ Lateral Torsional } & & & & \\
\hline & & & & & & & & & & \multirow{3}{*}{\begin{tabular}{|c|}
$\mathbf{M}_{\mathbf{n}}$ \\
lb-in \\
Eqn 5-22 \\
\end{tabular}} & \multirow{3}{*}{\begin{tabular}{|c|}
$\boldsymbol{\sigma}$ \\
psi \\
Eqn $5-6$ \\
\end{tabular}} & \multirow{2}{*}{\multicolumn{2}{|c|}{ Simply Supported }} & \multirow{2}{*}{\multicolumn{2}{|c|}{ Fixed }} \\
\hline \multirow[t]{2}{*}{ inch } & & & lbs & lb-in & psi & psi & $\%$ & \multirow{2}{*}{$\begin{array}{c}\boldsymbol{\sigma} \\
E q n s \\
5-14,15\end{array}$} & \multirow{2}{*}{$\begin{array}{c}\text { psi } \\
\text { Eqns } \\
5-6,17\end{array}$} & & & & & & \\
\hline & & & & Eqn 5-1 & Eqn 5-6 & Eqn 5-7 & & & & & & $\mathbf{N}_{\mathbf{x c r}}$ & $\boldsymbol{\sigma}$ & $\mathbf{N}_{\mathbf{x c r}}$ & $\boldsymbol{\sigma}$ \\
\hline $24^{1}$ & 6 & 96 & 5783 & 34698 & 4578.6 & 1462.6 & 31.9 & 25800 & \multirow{5}{*}{$\begin{array}{c}\text { Flange: } \\
43080\end{array}$} & $2.4 \mathrm{E}+06$ & 321421 & lb/in & psi & lb/in & psi \\
\hline $30^{1}$ & 7.5 & 120 & 6178 & 46335 & 6114.1 & 1562.5 & 25.6 & \multirow{2}{*}{$\begin{array}{l}\boldsymbol{V}_{\boldsymbol{n}, \text { web }}^{\text {Rupture }} \\
\text { Eqn 5-23 }\end{array}$} & & $1.9 \mathrm{E}+06$ & 257137 & Eqn 5-8 & $N x, c r / t$ & Eqn 5-9 & $N x, c r / t$ \\
\hline $48^{1}$ & 12 & 192 & 6600 & 79200 & 10450.8 & 1669.2 & 16.0 & & & $1.2 \mathrm{E}+06$ & 160710 & \multirow{3}{*}{6130} & \multirow{3}{*}{24520} & \multirow{3}{*}{11900} & \multirow{3}{*}{47600} \\
\hline $57.5^{2}$ & 14.5 & 230.5 & 6713 & 96499.38 & 12733.6 & 1697.8 & 13.3 & 56000 & & $1.0 \mathrm{E}+06$ & 133925 & & & & \\
\hline $72^{2}$ & 18 & 288 & 6319 & 113742 & 15008.8 & 1598.2 & 10.6 & \multirow{2}{*}{$\begin{array}{l}\boldsymbol{V}_{\boldsymbol{n}, \boldsymbol{w e b}}^{\text {Buckling }} \\
\text { Eqn 5-24 }\end{array}$} & & $8.1 \mathrm{E}+05$ & 107140 & & & & \\
\hline $84^{3}$ & 21 & 336 & 6019 & 126399 & 16679.0 & 1522.3 & 9.1 & & \multirow{4}{*}{$\begin{array}{l}\text { Web: } \\
30500\end{array}$} & $7.0 \mathrm{E}+05$ & 91834 & \multicolumn{4}{|c|}{ Web Buckling as Orthotropic Long Plate } \\
\hline $105.6^{3}$ & 26.5 & 422.5 & 5507 & 145384.8 & 19184.3 & 1392.8 & 7.3 & \multirow[t]{3}{*}{12260} & & $5.5 \mathrm{E}+05$ & 73050 & \multicolumn{2}{|c|}{$\mathrm{N}_{\mathrm{xcr}}(\mathrm{lb} / \mathrm{in})$} & \multicolumn{2}{|c|}{$\sigma(p s i)$} \\
\hline $120^{3}$ & 30 & 480 & 5215 & 156450 & 20644.4 & 1318.9 & 6.4 & & & $4.9 \mathrm{E}+05$ & 64284 & Eqn 5 & -10 & Eqn & \\
\hline $168^{3}$ & 42 & 672 & 4424 & 185808 & 24518.3 & 1118.9 & 4.6 & & & $3.5 \mathrm{E}+05$ & 45917 & 194 & & 77 & \\
\hline
\end{tabular}

${ }^{1}$ Samples failed due to local flange and web crushing due to applied load

${ }^{2}$ Samples failed due to strength failure and buckling of the top flange due to compressive bending stresses, followed by the bending strength failure of the webs.

${ }^{3}$ Samples failed due to strength failure and buckling of the top flange due to compressive bending stresses, followed by the bending strength failure and local instability of the web. 
Table 5-8 (b): Critical Transverse (lb/inch width) Load for Local Web Buckling of ABC-Box-4×6×0.25 Beams -Figure 5-12

\begin{tabular}{|c|c|c|c|c|c|c|c|c|c|c|}
\hline \multirow{2}{*}{\multicolumn{3}{|c|}{ Edge Condition }} & \multicolumn{8}{|c|}{ Assumed Width Under Loading, b= $\mathrm{L}_{\mathrm{y}}$ (inch) } \\
\hline & & & 1 & 2 & 3 & 4 & 5 & 6 & 7 & 8 \\
\hline \multirow{2}{*}{$\begin{array}{c}\text { Simply } \\
\text { Supported }\end{array}$} & $\mathrm{N}_{\mathrm{x}, \mathrm{cr}}(\mathrm{lb} / \mathrm{in})$ & Eqn 5-9 & $77,796.90$ & $19,449.22$ & $8,968.57$ & $4,862.31$ & $3,433.10$ & $2,289.91$ & $1,589.08$ & $1,215.58$ \\
\hline & $\sigma(p s i)$ & $N x, c r / t$ & $311,187.59$ & $77,796.90$ & $35,874.27$ & $19,449.22$ & $13,732.41$ & $9,159.64$ & $6,356.33$ & $4,862.31$ \\
\hline \multirow{2}{*}{ Fixed } & $\mathrm{N}_{\mathrm{x}, \mathrm{cr}}(\mathrm{lb} / \mathrm{in})$ & Eqn 5-9 & $152,331.14$ & $37,447.80$ & $16,643.47$ & $9,361.95$ & $6,093.25$ & $4,160.87$ & $3,255.33$ & $2,763.85$ \\
\hline & $\sigma(p s i)$ & $N x, c r / t$ & $609,324.57$ & $149,791.22$ & $66,573.87$ & $37,447.80$ & $24,372.98$ & $16,643.47$ & $13,021.33$ & $11,055.40$ \\
\hline
\end{tabular}




\subsubsection{ABC-Box $-4 \times 4 \times 0.375$ Beams}

The results of 3-point bending tests on various lengths of ABC-Box- $4 \times 4 \times 0.375$ beams are shown in Table 5-7. As the wall-thickness of these beams is same as that of $6 \times 6 \times 0.375$ beams, the same laminate properties are assumed, yielding the same flexural strength of $18.7 \mathrm{ksi}$. On the other hand, as the width of web and flange is less, the local buckling strengths are higher, e.g., web strength against local instability is $70.8 \mathrm{ksi}$ for bigger section versus $184.5 \mathrm{ksi}$ for smaller section. The same is true for flange buckling strengths. However, the lateral torsional buckling behavior is length dependent. For example for $\mathrm{L} / \mathrm{b}$ value of 30 , the lateral torsional buckling strength of the smaller section is $59.6 \mathrm{ksi}$ versus $63 \mathrm{ksi}$ for the bigger section, the two values being closely comparable.

Assuming SCF=2.0, the sample with $\frac{L}{b}=12$ failed at $45 \mathrm{ksi}$. For other samples $\left(\frac{L}{b}>20\right), \sigma_{\text {failure }}$ ranged from 66 to $82 \mathrm{ksi}$. The same trend is observed in other beam-types, i.e., when $\frac{L}{b}>20$, $\sigma_{\text {failure }}$ is significantly higher than failure strength. The 168 " long tested sample $\left(\frac{L}{b}=42\right)$ is shown in Figure 5-15 with web-flange separation and web failure. For this sample, $\sigma_{\text {failure }}=40.8 \times 2.0 \approx 82 \mathrm{ksi}$, while $\sigma_{\text {lat-tor }}=42.5 \mathrm{ksi}$. It can be concluded that the top-flange failed first and load was transferred to the two webs which in turn failed due to a combination of lateraltorsional buckling and strength failure.

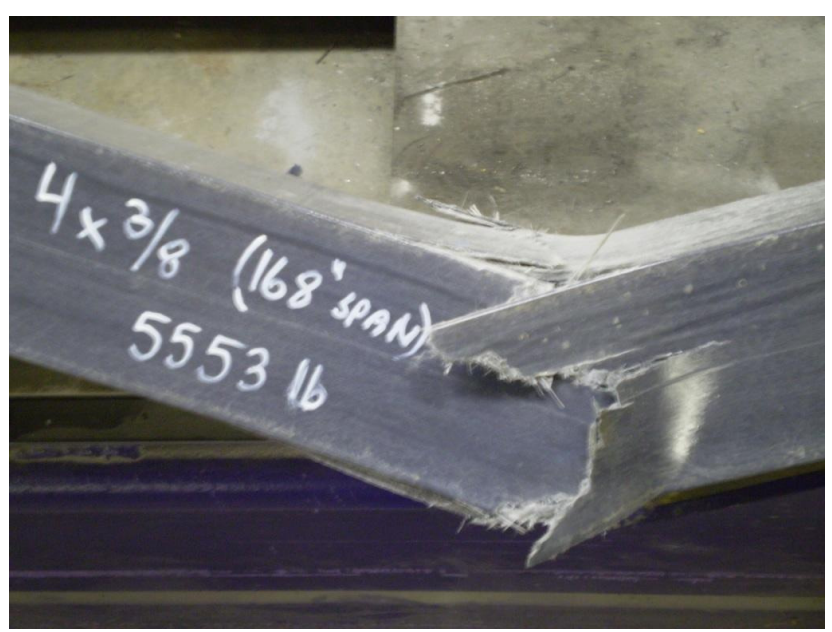

Figure 5-15: The ABC-Box-4×4×0.375- 168 Under 3-point Bending 
Table 5-9 (a): 3-Point Bending Test Results of ABC-Box-4×4×0.375 Beams

\begin{tabular}{|c|c|c|c|c|c|c|c|c|c|c|c|c|c|c|c|}
\hline \multicolumn{3}{|c|}{ Cross-section vs Span } & \multicolumn{5}{|c|}{ Experimental Values } & \multicolumn{4}{|c|}{ ASCE LRFD Manual } & \multicolumn{4}{|c|}{$\begin{array}{l}\text { Top-Flange Buckling as Orthotropic } \\
\text { Long Plate }\end{array}$} \\
\hline \multirow{2}{*}{$\mathbf{L}$} & \multirow{2}{*}{$\mathbf{L} / \mathbf{b}$} & \multirow{2}{*}{$\mathbf{L} / \mathbf{t}$} & \multirow{2}{*}{$\mathbf{P}_{\exp }$} & \multirow{2}{*}{$\mathbf{M}_{\mathbf{e x p}}$} & \multirow{2}{*}{$\sigma_{\text {failure }}$} & \multirow{2}{*}{$\boldsymbol{\tau}_{@ \text { failure }}$} & \multirow{2}{*}{$\tau / \sigma$} & \multirow{2}{*}{$\sigma_{\text {strength }}$} & \multirow{2}{*}{$\begin{array}{c}\sigma_{\text {Local- }} \\
\text { Inst }\end{array}$} & \multicolumn{2}{|c|}{ Lateral Torsional } & \multicolumn{2}{|c|}{ Simply Supported } & \multicolumn{2}{|c|}{ Fixed } \\
\hline & & & & & & & & & & $\mathbf{M}_{n}$ & $\boldsymbol{\sigma}$ & $\mathbf{N}_{\mathbf{x c r}}$ & $\boldsymbol{\sigma}$ & $\mathbf{N}_{\mathbf{x c r}}$ & $\boldsymbol{\sigma}$ \\
\hline inch & & & lbs & lb-in & psi & psi & $\%$ & psi & psi & lb-in & psi & lb/in & psi & lb/in & psi \\
\hline & & & & Eqn 5-1 & Eqn 5-6 & Eqn 5-7 & & $\begin{array}{c}\text { Eqns } \\
5-15,16\end{array}$ & $\begin{array}{l}\text { Eqns } \\
5-6,17\end{array}$ & Eqn 5-22 & Eqn 5-6 & Eqn 5-9 & $N x, c r / t$ & Eqn 5-9 & $N x, c r / t$ \\
\hline $48^{1}$ & 12 & 128 & 10875 & 130500 & 22549 & 3406 & 15.1 & \multirow{4}{*}{18660} & \multirow{4}{*}{$\begin{array}{c}\text { Flange: } \\
101345 \\
\text { Web: } \\
184451\end{array}$} & $8.94 \mathrm{E}+05$ & 149028 & 22500 & 60000 & 43500 & 116000 \\
\hline $84^{2}$ & 21 & 224 & 9049 & 190029 & 32834 & 2834 & 8.6 & & & $5.11 \mathrm{E}+05$ & 85159 & \multicolumn{2}{|c|}{$\mathbf{N}_{x c r, \text { web }}(\mathbf{l b} / \mathbf{i n})$} & \multicolumn{2}{|c|}{$\sigma_{\text {web }}(p s i)$} \\
\hline $120^{2}$ & 30 & 320 & 7540 & 226200 & 39084 & 2362 & 6.0 & & & $3.58 \mathrm{E}+05$ & 59611 & \multicolumn{2}{|c|}{ Eqn 5-10 } & \multicolumn{2}{|c|}{ Eqn 5-6 } \\
\hline $168^{2}$ & 42 & 448 & 5624 & 236208 & 40813 & 1761 & 4.3 & & & $2.55 \mathrm{E}+05$ & 42579 & \multicolumn{2}{|c|}{245700} & \multicolumn{2}{|c|}{655200} \\
\hline
\end{tabular}

${ }^{1}$ Sample failed due to strength failure of the top flange under compressive bending stresses.

${ }^{2}$ Samples failed due to strength failure of the top flange under compressive bending stresses, followed by the bending strength failure of the webs. The 120 " and 168 " long samples also experienced lateral-torsional buckling. 
Table 5-10 (b): Critical Transverse Load (lb/inch width) for Local Web Buckling of ABC-Box-4×4×0.375 Beams-Figure 5-12

\begin{tabular}{|c|c|c|c|c|c|c|c|c|c|c|}
\hline \multicolumn{4}{|c|}{} & \multicolumn{9}{c|}{ Assumed Width Under Loading, b=L (inch) } \\
\hline \multicolumn{3}{|c|}{ Edge Condition } & 1 & 2 & 3 & 4 & 5 & 6 & 7 & 8 \\
\hline \multirow{2}{*}{$\begin{array}{c}\text { Simply } \\
\text { Supported }\end{array}$} & $\mathrm{N}_{\mathrm{x}, \mathrm{cr}}(\mathrm{lb} / \mathrm{in})$ & Eqn 5-9 & 242,687 & 60,672 & 30,435 & 15,168 & 9,866 & 7,609 & 6,459 & 5,798 \\
\cline { 2 - 12 }$y(\mathrm{psi})$ & $N x$, cr/t & 647,164 & 161,791 & 81,160 & 40,448 & 26,311 & 20,290 & 17,224 & 15,462 \\
\hline \multirow{2}{*}{ Fixed } & $\mathrm{N}_{\mathrm{x}, \mathrm{cr}}(\mathrm{lb} / \mathrm{in})$ & $E q n 5-9$ & 466,794 & 117,232 & 52,103 & 30,772 & 20,633 & 13,026 & 9,526 & 7,693 \\
\cline { 2 - 11 } & $\sigma(\mathrm{psi})$ & $N x, \mathrm{cr} / \mathrm{t}$ & $1,244,783$ & 312,619 & 138,942 & 82,060 & 55,023 & 34,735 & 25,404 & 20,515 \\
\hline
\end{tabular}


Table 5-7 (b) refers to critical transverse load for local web-buckling, as explained in Figure 5-12 and given by Equations 5-30 and 5-31. In this case, $\frac{b}{t}=\frac{h}{t}=10.67$, which is smaller than the previous two cases. Hence, chances of web-buckling under transverse load are less. It is clear that for a web-width of 2 to 3 inches, local web-buckling stresses are very high, hence there is no chance of this kind of failure.

\subsubsection{4. $\quad S W-B o x-4 \times 4 \times 0.25-65$ Beam}

This sample was tested with a "loading-plate longer than flange-width with elastomeric pad" condition. The total length of 71 " reduced to the effective length to 65 " due two end-plugs, used to prevent any end-crushing. The coupon test showed higher strength and modulus values as compared to $1 / 4$ " thick BRP counterpart; the flexural strength being higher. With $L / b=16$, this is a case of intermediate span, the failure behavior thus not being comparable to that of CP-Box$4 \times 4 \times 1 / 4-25$ sample with the same boundary conditions for which the failure stress was $13.8 \mathrm{ksi}$ without accounting for SCF. Similarly, no comparison can be made with ABC-Box- $4 \times 4 \times 0.375$ samples, as the $\mathrm{L} / \mathrm{b}$ and $\mathrm{b} / \mathrm{t}$ values are different.
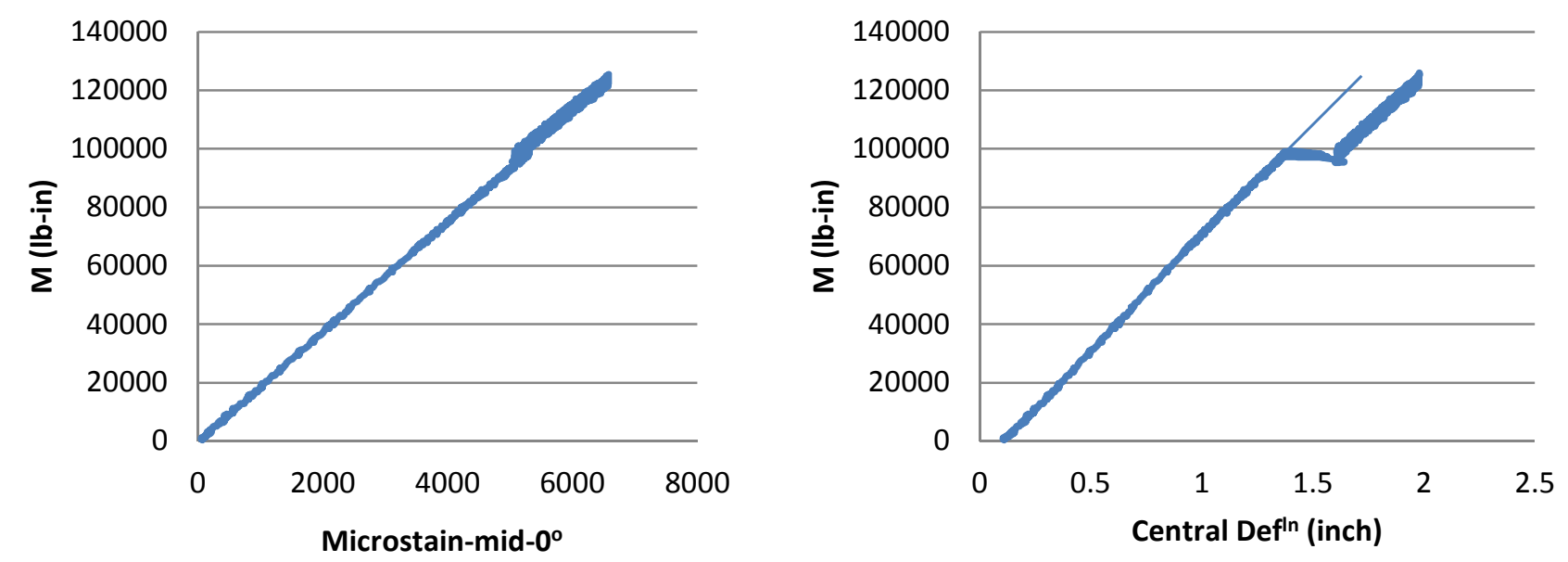

(a) Moment vs Microstrain at mid of Top Flange (b) Moment vs Deflection at mid of Bottom Flange Figure 5-16: Plots of SW-Box-4×4×0.25- 65 Under 3-point Bending 
Bending moment versus microstrain at the center of top flange, which is under tension, is shown in Figure 5-16 (a). The trend is seen to be almost linear till failure. This is primarily due to the fiber reinforcement in the longitudinal direction. The graph between moment and central deflection is shown in Figure 5-16 (b), which also verifies the linear behavior till failure. However, the slip shows some error in the connection of the LVDT with the beam. A more accurate value could be found by extending the initial straight line, i.e., around 1.7".

In terms of relation of deflection versus concentrated load at the center od a simply supported beam:

$$
\delta=\frac{P L^{3}}{48 E I}
$$

If $\mathrm{L}_{\text {effective }}$ is used,

$$
E \approx 2 m s i
$$

However, if length of the two end-plugs is also included

$$
E \approx 2.8 \mathrm{msi}
$$

As compared to $4.5 \mathrm{msi}$ found from coupon testing. It can therefore be concluded that $\mathrm{E}_{\text {tension }}$ is different than $\mathrm{E}_{\text {flexural }}$ for orthotropic materials.

From Table 5-8, $\sigma_{\text {failure }}=29 \mathrm{ksi} \times \operatorname{SCF}(=2.0)=58 \mathrm{ksi}$, i.e., almost double the bending strength. The local instability strength of the flange is $57 \mathrm{ksi}$ and buckling strength of the compression flange with partial fixity can be taken as $45 \mathrm{ksi}$. Hence the failure is a combination of (i) strength failure of the compression flange, (ii) buckling of the compression flange, and (iii) local instability. Web-buckling can be seen in Figure 5-17.

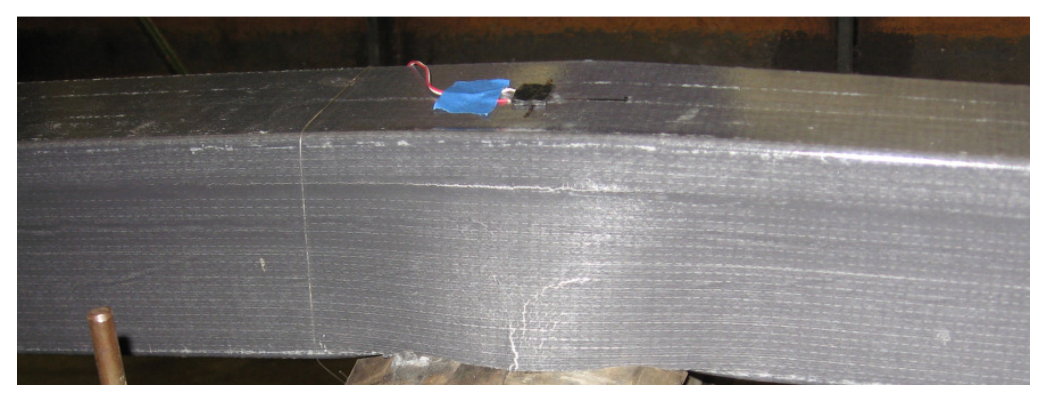

Figure 5-17: SW-Box-4×4×0.25- 70 Under 3-point Bending 
Table 5-11 (a): 3-Point Bending Test Result of SW-Box-4×4×0.25- 65 Beam

\begin{tabular}{|c|c|c|c|c|c|c|c|c|c|c|c|c|c|c|c|c|c|}
\hline \multicolumn{3}{|c|}{$\begin{array}{l}\text { Cross-section } \\
\text { vs Span }\end{array}$} & \multicolumn{5}{|c|}{ Experimental Values } & \multicolumn{4}{|c|}{ ASCE LRFD Manual } & \multicolumn{4}{|c|}{$\begin{array}{l}\text { Top-Flange Buckling as } \\
\text { Orthotropic Long Plate }\end{array}$} & \multirow{2}{*}{\multicolumn{2}{|c|}{$\begin{array}{c}\text { Web Buckling as } \\
\text { Orthotropic Long } \\
\text { Plate } \\
\text { Simply Supported }\end{array}$}} \\
\hline \multirow[t]{2}{*}{$\mathbf{L}$} & \multirow[t]{2}{*}{$\mathbf{L} / \mathbf{b}$} & \multirow[t]{2}{*}{$\mathbf{L} / \mathbf{t}$} & \multirow{2}{*}{$\mathbf{P}_{\text {exp }}$} & \multirow{2}{*}{$\mathbf{M}_{\text {exp }}$} & \multirow{2}{*}{$\sigma_{\text {failure }}$} & \multirow{2}{*}{$\boldsymbol{\tau}_{\text {@failure }}$} & \multirow[t]{2}{*}{$\tau / \sigma$} & \multirow{2}{*}{$\sigma_{\text {strength }}$} & \multirow{2}{*}{$\sigma_{\text {Local-Inst }}$} & \multicolumn{2}{|c|}{ Lateral Torsional } & \multicolumn{2}{|c|}{$\begin{array}{c}\text { Simply } \\
\text { Supported }\end{array}$} & \multicolumn{2}{|c|}{ Fixed } & & \\
\hline & & & & & & & & & & $M_{n}$ & $\boldsymbol{\sigma}$ & $\mathbf{N}_{\text {xcr }}$ & $\sigma$ & $\mathbf{N}_{\mathrm{xcr}}$ & $\boldsymbol{\sigma}$ & $\mathbf{N}_{\mathbf{x c r}}$ & $\sigma$ \\
\hline inch & & & Ibs & Ib-in & psi & psi & $\%$ & psi & psi & lb-in & psi & $\mathrm{lb} / \mathrm{in}$ & psi & Ib/in & psi & lb/in & psi \\
\hline & & & & Eqn 5-1 & $\begin{array}{r}E q n \\
5-6 \\
\end{array}$ & $\begin{array}{r}\text { Eqn } \\
5-7\end{array}$ & & $\begin{array}{c}\text { Eqns } \\
5-15,16\end{array}$ & $\begin{array}{l}\text { Eqns } \\
5-6,17\end{array}$ & $\begin{array}{l}\text { Eqn } \\
5-22\end{array}$ & $\begin{array}{r}E q n \\
5-6\end{array}$ & $\begin{array}{c}E q n \\
5-8\end{array}$ & $N x, c r / t$ & Eqn 5-9 & $N x, c r / t$ & Eqn 5-10 & $N x, c r / t$ \\
\hline $65^{*}$ & 16 & 260 & 7700 & 125125 & 29170 & 3363 & 11.5 & 30000 & $\begin{array}{l}\sigma_{\mathrm{f}}: 57200 \\
\sigma_{\mathrm{w}}: 70800\end{array}$ & $6.7 \mathrm{E}+05$ & 155840 & 7425 & 29700 & 14460 & 57840 & 65530 & 262120 \\
\hline
\end{tabular}

* The sample failed due to combination of strength failure, compression flange buckling and local instability

Table 5-12 (b): Critical Transverse Load (lb/inch width) for Local Web Buckling of SW-Box-4×4×0.25- 65 Beam -Figure 5-12

\begin{tabular}{|c|c|c|c|c|c|c|c|c|c|c|}
\hline \multirow{2}{*}{\multicolumn{3}{|c|}{ Edge Condition }} & \multicolumn{8}{|c|}{ Assumed Width Under Loading, $b=\mathrm{L}_{\mathrm{y}}$ (inch) } \\
\hline & & & 1 & 2 & 3 & 4 & 5 & 6 & 7 & 8 \\
\hline \multirow{2}{*}{$\begin{array}{c}\text { Simply } \\
\text { Supported }\end{array}$} & $\mathrm{N}_{\mathrm{x}, \mathrm{cr}}(\mathrm{lb} / \mathrm{in})$ & Eqn 5-8 & $77,598.63$ & $20,133.35$ & $9,185.67$ & $5,033.34$ & $3,103.95$ & $2,296.42$ & $1,891.34$ & $1,661.37$ \\
\hline & $\sigma(\mathrm{psi})$ & $N x, c r / t$ & $310,394.53$ & $80,533.40$ & $36,742.67$ & $20,133.35$ & $12,415.78$ & $9,185.67$ & $7,565.35$ & $6,645.50$ \\
\hline \multirow{2}{*}{ Fixed } & $\mathrm{N}_{\mathrm{x}, \mathrm{cr}}(\mathrm{lb} / \mathrm{in})$ & Eqn 5-9 & $149,125.06$ & $37,889.09$ & $17,378.80$ & $9,472.27$ & $6,977.77$ & $4,344.70$ & $3,043.37$ & $2,368.07$ \\
\hline & $\sigma(\mathrm{psi})$ & $N x, c r / t$ & $596,500.26$ & $151,556.34$ & $69,515.22$ & $37,889.09$ & $27,911.09$ & $17,378.80$ & $12,173.4$ & $9,472.27$ \\
\hline
\end{tabular}


The critical transverse loads for local web-buckling with varying web-width, following the methodology of Figure 5-12, are shown in Table 5-8 (b). It can be seen that for 3" width with simply supported boundary conditions, buckling stress is only $36.74 \mathrm{ksi}$, verifying the chances of local web-buckling.

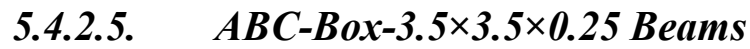

The $\mathrm{L} / \mathrm{b}$ values of the beams tested in this category ranged from 10 to 41 . As shown in Table 5-9 (a), the failure stress of the shortest sample $(16.5 \times 2=33 \mathrm{ksi})$ is comparable to the failure strength (25.8 ksi). From Table 5-3, the failure stress for ABC-Box- $3 \times 3 \times 0.25-25$ sample, with loading plate longer than flange-width, is $28.4 \times 2 \approx 57 \mathrm{ksi}$. With comparable $\mathrm{L} / \mathrm{b}$ values (10.2 and 8.33 ), the higher stress is due to a 2.5 " wide loading plate with elastomeric pad.

The values of the buckling strengths are higher than the Strongwell $4 \times 4 \times 0.25$ counterpart, given in Table 5-8, even with lower coupon properties. This is primarily dictated by the smaller web and flange dimensions. In addition, there is no major effect of bending shear and local crushing. The web-buckling strength due to transverse loading, shown in lower part of Table 5-9 (b), is also high enough and safe.

A 108 " long tested sample is shown in Figure 5-18. It failed at $31.8 \times 1.5=47.7 \mathrm{ksi}$, causing combined strength-failure and buckling of the top-flange, followed by the web failure.

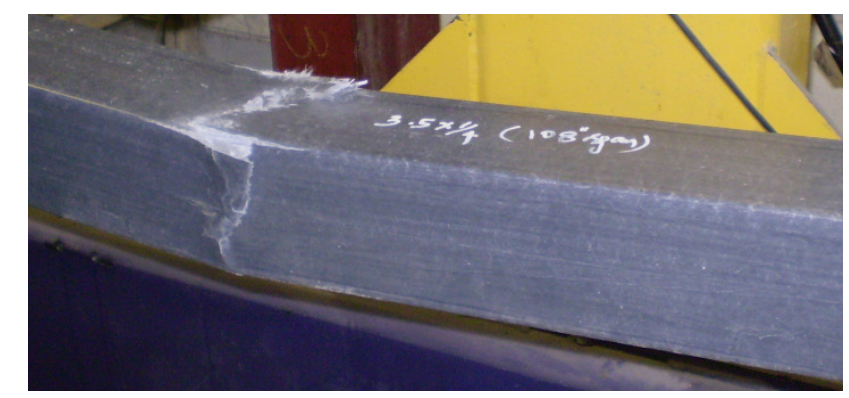

Figure 5-18: ABC-Box-3.5×3.5×0.25- 108 Under 3-point Bending 
Table 5-13 (a): 3-Point Bending Test Results of ABC-Box-3.5×3.5×0.25 Beams

\begin{tabular}{|c|c|c|c|c|c|c|c|c|c|c|c|c|c|c|c|}
\hline \multicolumn{3}{|c|}{ Cross-section vs Span } & \multicolumn{5}{|c|}{ Experimental Values } & \multicolumn{4}{|c|}{ ASCE LRFD Manual } & \multicolumn{4}{|c|}{$\begin{array}{c}\text { Top-Flange Buckling as Orthotropic } \\
\text { Long Plate }\end{array}$} \\
\hline \multirow{2}{*}{$\mathbf{L}$} & \multirow{2}{*}{$\mathbf{L} / \mathbf{b}$} & \multirow{2}{*}{$\mathbf{L} / \mathbf{t}$} & \multirow{2}{*}{$\mathbf{P}_{\exp }$} & \multirow{2}{*}{$\mathbf{M}_{\mathbf{e x p}}$} & \multirow{2}{*}{$\sigma_{\text {failure }}$} & \multirow{2}{*}{$\boldsymbol{\tau}_{@ \text { failure }}$} & \multirow{2}{*}{$\tau / \sigma$} & \multirow{2}{*}{$\sigma_{\text {strength }}$} & \multirow{2}{*}{$\sigma_{\text {Local-Inst }}$} & \multicolumn{2}{|c|}{ Lateral Torsional } & \multicolumn{2}{|c|}{ Long Plate:SS } & \multicolumn{2}{|c|}{ Long Plate:Fix } \\
\hline & & & & & & & & & & $\mathbf{M}_{n}$ & $\boldsymbol{\sigma}$ & $\mathbf{N}_{\mathbf{x c r}}$ & $\boldsymbol{\sigma}$ & $\mathbf{N}_{\mathbf{x c r}}$ & $\boldsymbol{\sigma}$ \\
\hline inch & & & Ibs & lb-in & psi & psi & $\%$ & psi & psi & lb-in & psi & lb/in & psi & lb/in & psi \\
\hline & & & & Eqn 5-1 & Eqn 5-6 & Eqn 5-7 & & $\begin{array}{c}\text { Eqns } \\
5-15,16\end{array}$ & $\begin{array}{l}\text { Eqns } \\
5-6,17\end{array}$ & Eqn 5-22 & Eqn 5-6 & Eqn 5-8 & $N x, c r / t$ & Eqn 5-9 & $N x, c r / t$ \\
\hline $36^{1}$ & 10 & 144 & 5800 & 52200 & 16549 & 2988.3 & 18.1 & \multirow{4}{*}{25800} & \multirow{4}{*}{$\begin{array}{c}\text { Flange: } \\
62000 \\
\text { Web: } \\
102000\end{array}$} & 635833 & 193649 & 8345 & 33380 & 16320 & 65280 \\
\hline $60^{2}$ & 17 & 240 & 4857 & 72855 & 23097 & 2502.4 & 10.8 & & & 381500 & 116190 & \multicolumn{4}{|c|}{$\begin{array}{l}\text { Web Buckling as Orthotropic Long } \\
\text { Plate: Simply Supported }\end{array}$} \\
\hline $108^{2}$ & 31 & 432 & 3714 & 100278 & 31791 & 1913.5 & 6.0 & & & 211944 & 64550 & $\begin{array}{r}\mathbf{N}_{\mathbf{x c r}} \\
E q n\end{array}$ & $\begin{array}{l}\text { b/in) } \\
5-10\end{array}$ & & $\begin{array}{l}\mathrm{si)} \\
\mathrm{cr} / \mathrm{t}\end{array}$ \\
\hline $144^{2}$ & 41 & 576 & 3137 & 112932 & 35803 & 1616.2 & 4.5 & & & 158958 & 48412 & & & 31 & 200 \\
\hline
\end{tabular}

${ }^{1}$ Strength failure of the top flange due to compressive bending stresses followed by the bending strength failure of the webs

${ }^{2}$ Strength failure and buckling of the top flange under compressive bending stresses followed by the bending strength failure of the web 
Table 5-14 (b): Critical Transverse Load (lb/inch width) for Local Web Buckling of ABC-Box-3.5×3.5×0.25 Beams -Figure 5-12

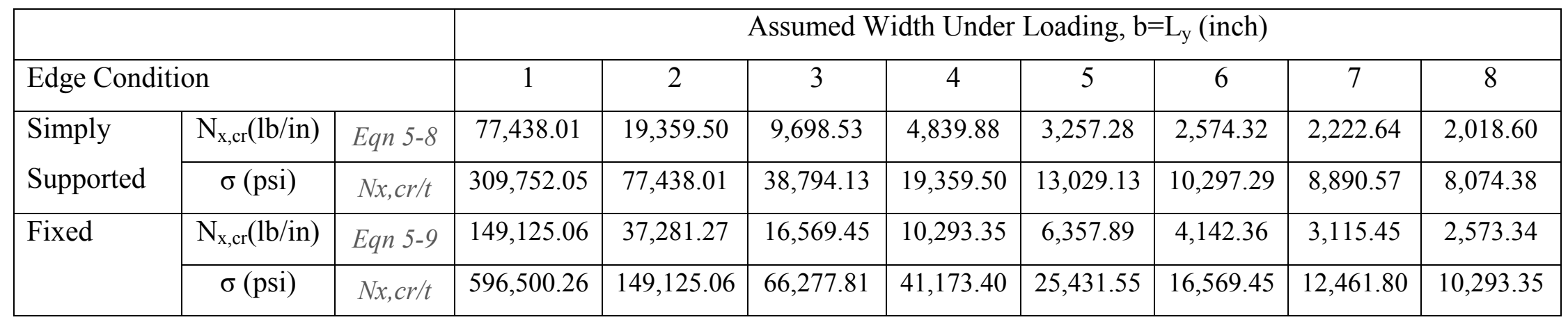




\subsubsection{6. $A B C-B o x-2 \times 0.25 \times 4 \times 0.125$ Beams}

The results of 3 -point bending tests on various lengths of ABC-Box- $2 \times 0.25 \times 4 \times 0.125$ Beams are shown in Table 5-10 (a). The flanges are $2 " \times 0.25$ " in cross-section and the webs are $3.5 " \times 0.125$ " in cross-section. The higher width and smaller thickness of the web makes it considerably more unstable than a symmetrical cross-section. Local instability strength (18.8 ksi) is therefore found to be the lowest of all. For shorter spans, the local crushing will also be higher due to thinner web. Due to the same reason, though the $\mathrm{L} / \mathrm{b}$ value for 42 " span is 21 , it took only $11.74 \times 2=23.5$ ksi for failure.

For longer spans, the lateral torsional buckling is considerably low, for example, $23.6 \mathrm{ksi}$ for 144" span. The shear to failure ranged from 5 to $18 \%$ corresponding to longest to shortest span. The critical load for web-buckling due to transversely applied load, as calculated in Table 5-10 (b), is the lowest of all the cases considered.

The tested BRP-Box- $2 \times 0.25 \times 4 \times 0.125-96$ samples are shown in Figure 5-19, which clearly refer to the strength failure of the top flange under compressive bending stresses.

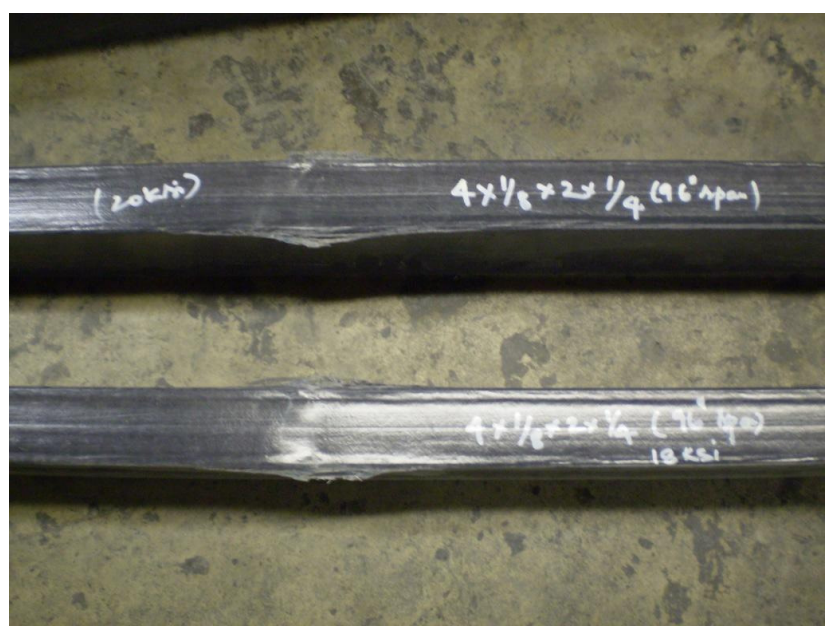

Figure 5-19 ABC-Box-2×0.25×4×0.125- 96 Under 3-point Bending 
Table 5-15 (a): 3-Point Bending Test Results of ABC-Box-2×0.25 $\times 4 \times 0.125$ Beams

\begin{tabular}{|c|c|c|c|c|c|c|c|c|c|c|c|c|c|c|c|}
\hline \multicolumn{3}{|c|}{ Cross-section vs Span } & \multicolumn{5}{|c|}{ Experimental Values } & \multicolumn{4}{|c|}{ ASCE LRFD Manual } & \multicolumn{4}{|c|}{$\begin{array}{l}\text { Top-Flange Buckling as Orthotropic } \\
\text { Long Plate }\end{array}$} \\
\hline \multirow{2}{*}{$\mathbf{L}$} & \multirow{2}{*}{$\mathbf{L} / \mathbf{b}$} & \multirow{2}{*}{$\mathbf{L} / \mathbf{t}$} & \multirow{2}{*}{$\mathbf{P}_{\exp }$} & \multirow{2}{*}{$\mathbf{M}_{\text {exp }}$} & \multirow{2}{*}{$\sigma_{\text {failure }}$} & \multirow[b]{2}{*}{$\boldsymbol{\tau}_{@ \text { failure }}$} & \multirow{2}{*}{$\tau / \sigma$} & \multirow{2}{*}{$\begin{array}{l}\text { Strength } \\
\text { psi }\end{array}$} & \multirow{2}{*}{$\begin{array}{c}\sigma_{\text {Local- }} \\
\text { Inst }\end{array}$} & \multicolumn{2}{|c|}{ Lateral Torsional } & \multicolumn{2}{|c|}{ Long Plate:SS } & \multicolumn{2}{|c|}{ Long Plate:Fix } \\
\hline & & & & & & & & & & $\mathbf{M}_{n}$ & $\sigma$ & $\mathbf{N}_{\text {xcr }}$ & $\sigma$ & $\mathbf{N}_{\mathrm{xcr}}$ & $\boldsymbol{\sigma}$ \\
\hline \multirow[t]{2}{*}{ inch } & & & Ibs & lb-in & psi & psi & $\%$ & \multirow{2}{*}{$\begin{array}{c}\boldsymbol{\sigma} \\
\text { Eqns } \\
5-14,15\end{array}$} & psi & lb-in & psi & lb/in & psi & lb/in & psi \\
\hline & & & & Eqn 5-1 & Eqn 5-6 & Eqn 5-7 & & & $\begin{array}{l}\text { Eqns } \\
5-6,17\end{array}$ & Eqn 5-22 & Eqn 5-6 & Eqn 5-8 & $N x, c r / t f$ & Eqn 5-9 & $N x, c r / t f$ \\
\hline $42^{1}$ & 21 & 168 & 2365 & 24832.5 & 11741 & 2097 & 17.9 & 25800 & \multirow{4}{*}{$\begin{array}{c}\text { Flange: } \\
137500 \\
\text { Web: } \\
18792\end{array}$} & 166167 & 80860 & 24500 & 98000 & 47600 & 190000 \\
\hline $72^{2}$ & 36 & 288 & 1897 & 34146 & 16145 & 1682 & 10.4 & \begin{tabular}{|l|}
$\boldsymbol{V}_{\boldsymbol{n}, \text { web }}^{\text {Rupture }}$ \\
Eqn 5-23 \\
\end{tabular} & & 96931 & 47168 & \multicolumn{4}{|c|}{$\begin{array}{l}\text { Web Buckling as Orthotropic Long } \\
\text { Plate: Simply Supported }\end{array}$} \\
\hline $96^{3}$ & 48 & 384 & 1747 & 41928 & 19824 & 1549 & 7.8 & 22125 & & 72698 & 35376 & $\begin{array}{r}\text { Nxcr } \\
E q n\end{array}$ & $\begin{array}{l}\text { (lb/in) } \\
5-10\end{array}$ & $\begin{array}{r}\boldsymbol{\sigma}( \\
N x, c\end{array}$ & $\begin{array}{l}\text { psi) } \\
r / t w\end{array}$ \\
\hline $144^{3}$ & 72 & 576 & 1386 & 49896 & 23591 & 1229 & 5.2 & $\begin{array}{c}\boldsymbol{V}_{\boldsymbol{n} \text {,web }}^{\text {Buckling }} \\
\text { Eqn 5-24 } \\
2230\end{array}$ & & 48465 & 23584 & 67 & & 54 & \\
\hline
\end{tabular}

${ }^{1}$ Combined failure modes of (i) Local flange and web crushing due to applied load, (ii) local web instability

2 (i) Strength failure of the top flange under compressive bending stresses followed by the strength failure of the web, (ii) local webinstability

3 (i) Strength failure of the top flange under compressive bending stresses, (ii) local web-instability, (iii) lateral-torsional buckling 
Table 5-16 (b):Critical Transverse Load (lb/incvh width) for Local Web Buckling ABC-Box-2×0.25×4×0.125 Beams

Figure 5-12

\begin{tabular}{|c|c|c|c|c|c|c|c|c|c|c|}
\hline & & & \multicolumn{8}{|c|}{ Assumed Width Under Loading, $b=\mathrm{L}_{\mathrm{y}}$ (inch) } \\
\hline \multicolumn{3}{|c|}{ Edge Condition } & 1 & 2 & 3 & 4 & 5 & 6 & 7 & 8 \\
\hline \multirow{2}{*}{$\begin{array}{c}\text { Simply } \\
\text { Supported }\end{array}$} & $\mathrm{N}_{\mathrm{x}, \mathrm{cr}}(\mathrm{lb} / \mathrm{in})$ & Eqn 5-8 & $9,672.59$ & $2,510.31$ & $1,144.94$ & 627.58 & 386.90 & 286.23 & 235.76 & 207.12 \\
\hline & $\sigma(\mathrm{psi})$ & $N x, c r / t w$ & $77,380.70$ & $20,082.49$ & $9,159.48$ & $5,020.62$ & $3,095.23$ & $2,289.87$ & $1,886.10$ & $1,656.99$ \\
\hline \multirow{2}{*}{ Fixed } & $\mathrm{N}_{\mathrm{x}, \mathrm{cr}}(\mathrm{lb} / \mathrm{in})$ & Eqn 5-9 & $18,588.66$ & $4,725.64$ & $2,168.31$ & $1,181.41$ & 870.25 & 542.08 & 379.63 & 295.35 \\
\hline & $\sigma(\mathrm{psi})$ & $N x, c r / t w$ & $148,709.28$ & $37,805.12$ & $17,346.50$ & $9,451.28$ & $6,962.02$ & $4,336.63$ & $3,037.01$ & $2,362.82$ \\
\hline
\end{tabular}




\subsubsection{ABC-Box-5.2×5.2×0.375 Beams}

These samples are different from others because of having fabric in their fiber architecture, hence enhancing the strength and modulus values. However, due to exact properties not being available, those of the $6 \times 6 \times 0.375$ samples have been used for the analysis purpose. 3-point bending tests on various lengths are shown in Table 5-11. As evident, due to symmetric crosssection and higher wall-thickness, there is no chance of instability.

Comparing with the bending behavior of $6 \times 6 \times 0.375$ sections given in Table 5-5, the results are found to be similar to each other. For example, for $L / b \approx 10$, failure stress for $6 \times 6 \times 0.375$ section is $12.7 \mathrm{ksi}$ and that for $5.2 \times 5.2 \times 0.375$ section is $11.85 \mathrm{ksi}$. This is also true for $\mathrm{L} / \mathrm{b}=16$, i.e., 16.23 ksi vs 15.34 ksi. However, the bending moment at failure for the bigger section will be notably higher than the small section. 
Table 5-17 (a): 3-Point Bending Test Results of ABC-Box-5.2×5.2×0.375 Beams

\begin{tabular}{|c|c|c|c|c|c|c|c|c|c|c|c|c|c|c|c|}
\hline \multicolumn{3}{|c|}{ Cross-section vs Span } & \multicolumn{5}{|c|}{ Experimental Values } & \multicolumn{4}{|c|}{ ASCE LRFD Manual } & \multicolumn{4}{|c|}{ Orthotropic Plate Buckling Formulas } \\
\hline \multirow{2}{*}{$\mathbf{L}$} & \multirow{2}{*}{$\mathbf{L} / \mathbf{b}$} & \multirow{2}{*}{$\mathbf{L} / \mathbf{t}$} & \multirow{2}{*}{$\mathbf{P}_{\exp }$} & \multirow{2}{*}{$\mathbf{M}_{\text {exp }}$} & \multirow{2}{*}{$\sigma_{\text {failure }}$} & \multirow{2}{*}{$\boldsymbol{\tau}_{@ \text { failure }}$} & \multirow{2}{*}{$\tau / \sigma$} & \multirow{2}{*}{$\sigma_{\text {strength }}$} & \multirow{2}{*}{$\sigma_{\text {Local-Inst }}$} & \multicolumn{2}{|c|}{ Lateral Torsional } & \multicolumn{2}{|c|}{ Long Plate:SS } & \multicolumn{2}{|c|}{ Long Plate:Fix } \\
\hline & & & & & & & & & & $M_{n}$ & $\sigma$ & $\mathbf{N}_{\mathrm{xcr}}$ & $\sigma$ & $\mathbf{N}_{\mathrm{xcr}}$ & $\sigma$ \\
\hline inch & & & lbs & lb-in & psi & psi & $\%$ & psi & psi & lb-in & psi & lb/in & psi & lb/in & psi \\
\hline & & & & Eqn 5-1 & Eqn 5-6 & Eqn 5-7 & & $\begin{array}{c}\text { Eqns } \\
5-15,16\end{array}$ & $\begin{array}{c}\text { Eqns } \\
5-6,17\end{array}$ & Eqn 5-22 & Eqn 5-6 & Eqn 5-8 & $N x, c r / t$ & Eqn 5-9 & $N x, c r / t$ \\
\hline $48^{1}$ & 9.23 & 128 & 10318 & 123816 & 11848 & 2382 & 20.1 & \multirow{4}{*}{18700} & \multirow{2}{*}{$\begin{array}{l}\text { Flange: } \\
59500\end{array}$} & 2129166 & 195945 & 12000 & 32000 & 23200 & 61900 \\
\hline $84^{2}$ & 16 & 224 & 7635 & 160335 & 15343 & 1762 & 11.5 & & & 1216666 & 111968 & \multicolumn{4}{|c|}{$\begin{array}{l}\text { Web Buckling as Orthotropic Long Plate: } \\
\text { Simply Supported }\end{array}$} \\
\hline $120^{3}$ & 23 & 320 & 6335 & 190050 & 18187 & 1462 & 8.0 & & \multirow[t]{2}{*}{$\begin{array}{l}\text { Web: } \\
98500\end{array}$} & 851667 & 78378 & \multicolumn{2}{|c|}{$\begin{array}{c}\text { Nxcr (lb/in) } \\
\text { Eqn } 5-10\end{array}$} & \multicolumn{2}{|c|}{$\begin{array}{l}\boldsymbol{\sigma} \text { (psi) } \\
N x, c r / t\end{array}$} \\
\hline $168^{3}$ & 32.3 & 448 & 4384 & 184128 & 17620 & 1012 & 5.7 & & & 608333 & 55984 & \multicolumn{2}{|c|}{112200} & \multicolumn{2}{|c|}{299200} \\
\hline
\end{tabular}

${ }^{1}$ Local flange and web crushing due to applied load

${ }^{2}$ Strength failure of the top flange under compressive bending stresses followed by the bending strength failure of the web

${ }^{3}$ Strength failure and buckling of the top flange under compressive bending stresses followed by the bending strength failure of the web 
Table 5-18 (b): Critical Transverse Load for Local Web Buckling (lb/inch width)-Figure 5-12

\begin{tabular}{|c|c|c|c|c|c|c|c|c|c|c|}
\hline \multicolumn{4}{|c|}{} & \multicolumn{9}{c|}{ Assumed Width Under Loading, b=L (inch) } \\
\hline \multicolumn{3}{|c|}{ Edge Condition } & 1 & 2 & 3 & 4 & 5 & 6 & 7 & 8 \\
\hline \multirow{2}{*}{$\begin{array}{c}\text { Simply } \\
\text { Supported }\end{array}$} & $\mathrm{N}_{\mathrm{x}, \mathrm{cr}}(\mathrm{lb} / \mathrm{in})$ & $E q n 5-8$ & 240,557 & 60,139 & 26,729 & 16,781 & 10,002 & 6,682 & 5,077 & 4,195 \\
\cline { 2 - 12 }$y(\mathrm{psi})$ & $N x, c r / t$ & 641,486 & 160,372 & 71,276 & 44,750 & 26,672 & 17,819 & 13,539 & 11,188 \\
\hline \multirow{2}{*}{ Fixed } & $\mathrm{N}_{\mathrm{x}, \mathrm{cr}}(\mathrm{lb} / \mathrm{in})$ & $E q n 5-9$ & 463,618 & 118,029 & 51,513 & 29,543 & 18,885 & 14,593 & 10,355 & 7,386 \\
\cline { 2 - 11 } & $\sigma(\mathrm{psi})$ & $N x, c r / t$ & $1,236,316$ & 314,743 & 137,368 & 78,781 & 50,359 & 38,915 & 27,612 & 19,695 \\
\hline
\end{tabular}




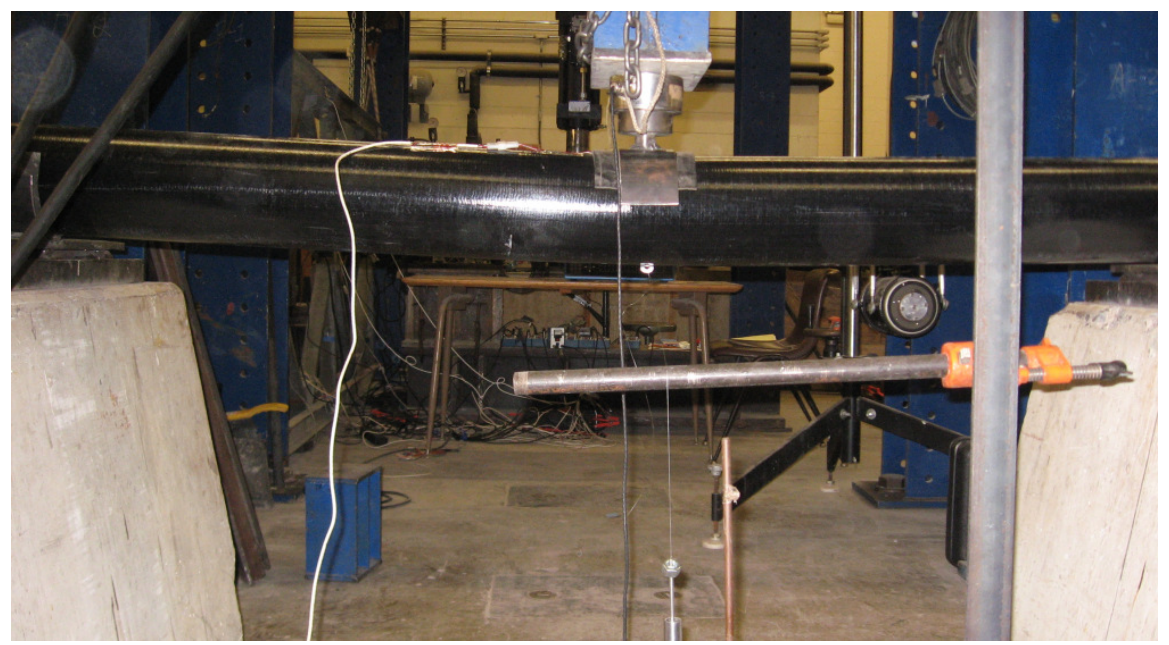

Figure 5-20: CP-Round-6×0.25- 70 Under 3-point Bending

(a)
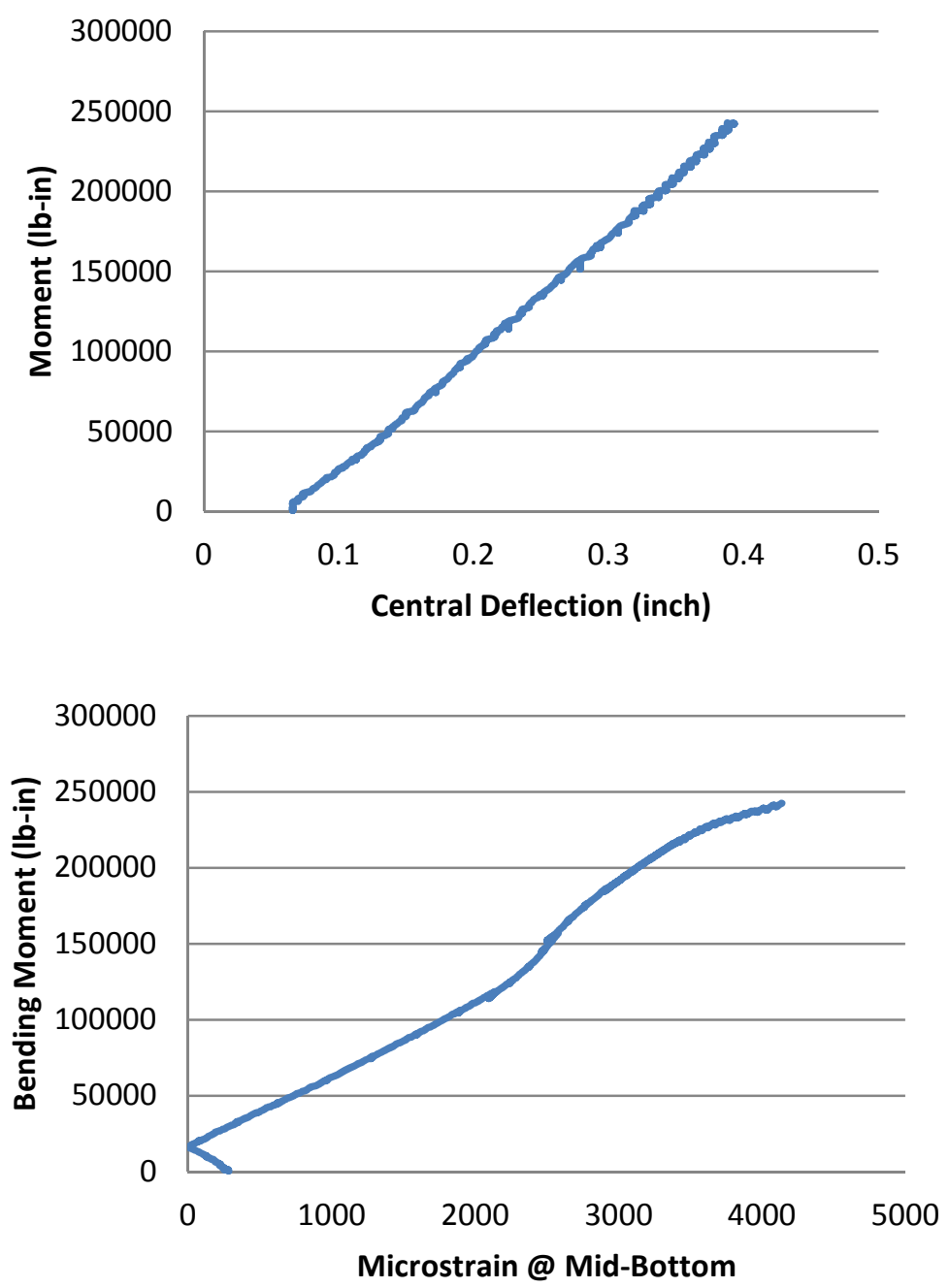

Figure 5-21: Graphs of CP-Round-6×0.25- 70 Under 3-point Bending: (a) Moment vs Strain at Mid-Bottom, (b) Moment vs Central Deflection 


\subsubsection{CP-Round-6 $\times 0.25-70$ Beam}

One CP-Round-6×0.25-70 beam was tested in 3-point bending, as shown in Figure 5-20. Owing to an anticipated local crushing at the area of application of load, a metallic disc, 3/4" wide, was inserted inside the tube to support that area. Although the purpose was served, yet the strain and deflection values cannot be considered as representative due to local reinforcement under the applied load. Therefore, Figure 5-21 (a) and (b) may not represent the true bending behavior of the sample.

On the other hand, it can be said with confidence that a local reinforcement of such type cannot add to the overall strength of the sample and only prevents premature crushing. Hence, the maximum moment and the corresponding stress values are correct. In Table 5-12, the experimental values of bending stress is found to be around $40 \mathrm{ksi}$, whereas the coupon tensile strength is $70 \mathrm{ksi}$. This is analogous to $\mathrm{SW}-\mathrm{Box}-4 \times 4 \times 0.25-65$ beam with $\mathrm{E}_{\text {bending }}=2.8 \mathrm{msi}$ and $\mathrm{E}_{\mathrm{L}}=4.5 \mathrm{msi}$, concluding that tensile behavior associated with bending represents a different scenario than pure tension.

Table 5-19: 3-Point Bending Test Results of CP-Box-6×0.25 Beams

\begin{tabular}{|c|c|c|c|c|c|c|c|c|c|}
\hline \multicolumn{2}{|c|}{ Cross-section vs Span } & \multicolumn{6}{|c|}{ Experimental Values } & \multicolumn{2}{c|}{ Coupon Values } \\
\hline $\mathbf{L}$ & $\mathbf{L} / \mathbf{d}$ & $\mathbf{L} / \mathbf{t}$ & $\mathbf{P}_{\exp }$ & $\mathbf{M}_{\text {exp }}$ & $\boldsymbol{\sigma}_{\text {failure }}$ & $\boldsymbol{\tau}_{@ \text { failure }}$ & $\boldsymbol{\tau} / \boldsymbol{\sigma}$ & $\boldsymbol{\sigma}_{\text {ultimate }}$ & $\boldsymbol{\tau}_{\text {ultimate }}$ \\
\hline inch & & & $\mathbf{l b s}$ & $\mathbf{l b}$-in & $\mathbf{p s i}$ & $\mathbf{p s i}$ & $\mathbf{\%}$ & $\mathbf{p s i}$ & $\mathbf{p s i}$ \\
\hline 70 & 11.7 & 280 & 13861 & 242564.5 & 39860 & 3069.3 & 7.7 & 72000 & $\begin{array}{c}\text { Cannot be found } \\
\text { due to curved } \\
\text { coupons }\end{array}$ \\
\hline
\end{tabular}

The bending shear stress at failure for a circular cross-section is found from the relation,

$$
\tau=V \sin \theta / \pi r_{m} t
$$

with the notations shown in Figure 5-22. 
As stated, the bending shear value does not have a coupon counterpart. This is due to the fact that the round shape of a cut coupon makes it unsuitable to be tested under shear.

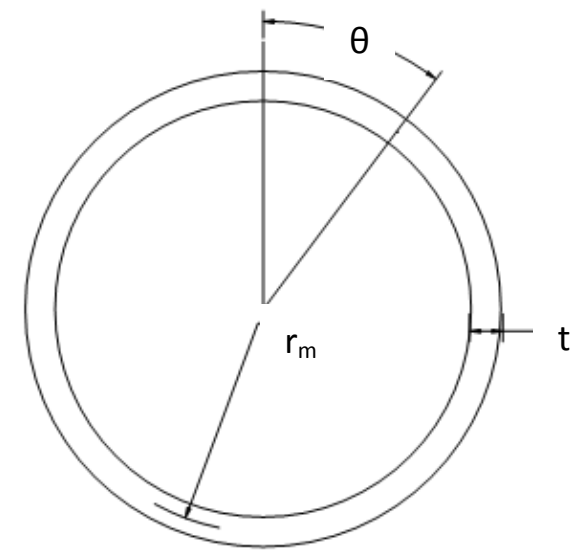

Figure 5-22: Notations of Bending Shear Stress in a Round Cross-Section

Another significant aspect of this section is that the round shape is perfectly symmetric and does not suffer from any type of buckling or warping.

\subsubsection{9. $S W-W F-6 \times 6 \times 0.25$ Beams}

The results of 3-point bending test of one SW-WF- $6 \times 6 \times 0.25-70$ sample are shown in Table 514, the moment vs time graph is shown in Figure 5-20 and the tested sample is shown in Figure 5-23. As can be seen, the flange buckling is the typical mode of failure of the open sections such as wide-flange ones. From the Table 5-14, the flange-buckling strength is only $3.8 \mathrm{ksi}$, whereas the sample failed at $14 \mathrm{ksi}$ (without stress concentration factor). The concept however gets clear from the graph, where a horizontal slip refers to deformation. After initial slip, the behavior remained linear upto $40 \mathrm{kip}$-inch with a minor deformation at $20 \mathrm{kip}$-inch, whereas, the $3.8 \mathrm{ksi}$ stress corresponds to $35 \mathrm{kip}$-inch moment. Although the sample kept on taking the moment beyond the failure of bottom-flange, applied load was resisted by the top flange and the web.

The nominal strength of this sample, as found from Equations 5-15 and 5-16, is $33.8 \mathrm{ksi}$ and the lateral-torsional buckling strength, as found from Equations 5-6 and 5-22, is 35.6 ksi. However, for all practical purposes, the sample will be considered as failed after the flange under compression is buckled (3.8 ksi) 
Table 5-20: 3-Point Bending Test Results of SW-WF-6×6×0.25 Beams

\begin{tabular}{|c|c|c|c|c|c|c|c|c|c|c|c|}
\hline \multicolumn{3}{|c|}{ Cross-section vs Span } & \multicolumn{5}{|c|}{ Experimental Values } & \multicolumn{4}{|c|}{ ASCE LRFD Manual } \\
\hline \multirow{2}{*}{$\mathbf{L}$} & \multirow{2}{*}{$\mathbf{L} / \mathbf{b}$} & \multirow{2}{*}{$L / t$} & \multirow{2}{*}{$\mathbf{P}_{\text {exp }}$} & \multirow{2}{*}{$\mathbf{M}_{\text {exp }}$} & \multirow[b]{2}{*}{$\sigma_{\text {failure }}$} & \multirow[b]{2}{*}{$\boldsymbol{\tau}_{@ \text { failure }}$} & \multirow{2}{*}{$\tau / \sigma$} & \multirow[b]{2}{*}{$\sigma_{\text {strength }}$} & \multirow[b]{2}{*}{$\sigma_{\text {Local-Inst }}$} & \multicolumn{2}{|c|}{ Lateral Torsional } \\
\hline & & & & & & & & & & $\mathbf{M}_{\mathbf{n}}$ & $\sigma$ \\
\hline inch & & & lbs & lb-in & psi & psi & $\%$ & psi & psi & lb-in & psi \\
\hline & & & & Eqn 5-1 & Eqn 5-6 & Eqn 5-7 & & $\begin{array}{c}\text { Eqns } \\
5-15,16\end{array}$ & $\begin{array}{l}\text { Eqns } \\
5-6,17\end{array}$ & $\begin{array}{l}\text { Eqn } \\
5-22\end{array}$ & $\begin{array}{c}E q n \\
5-6\end{array}$ \\
\hline 70 & 11.7 & 280 & 7361 & 128820 & 14000 & 2310 & 16.5 & 33800 & $\begin{array}{c}\sigma_{\mathrm{f}}: 3800 \\
\sigma_{\mathrm{w}}: 41300\end{array}$ & 326150 & 35600 \\
\hline
\end{tabular}

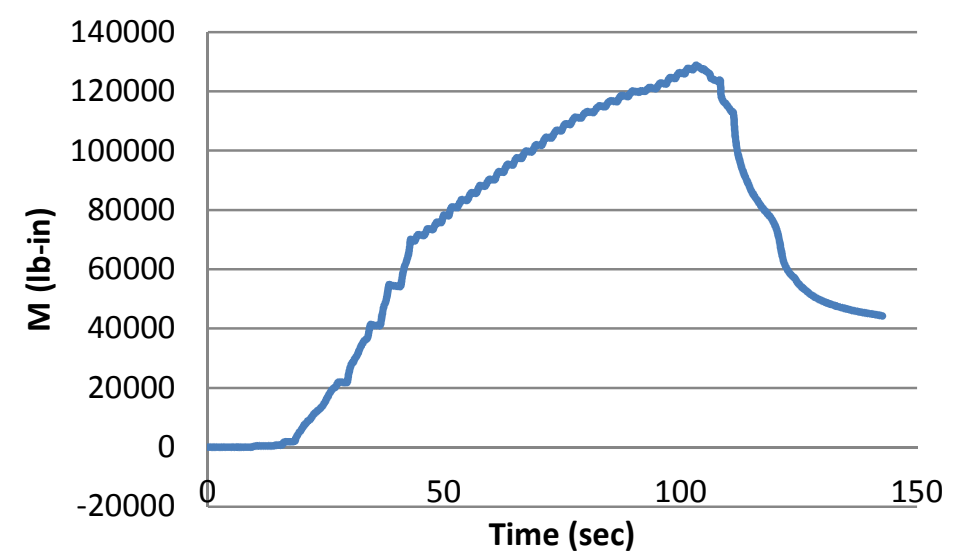

Figure 5-23: Moment vs time plot of SW-WF- $6 \times 6 \times 0.25-70$ beam tested under 3-point bending

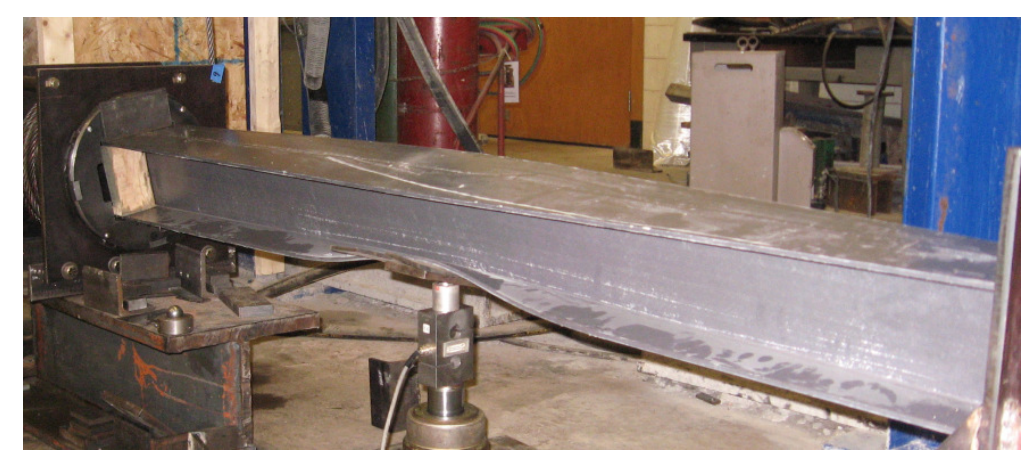

Figure 5-24: The SW-WF-6×6×0.25- 70 Under 3-point Bending 


\subsubsection{4-Point Bending Test Results}

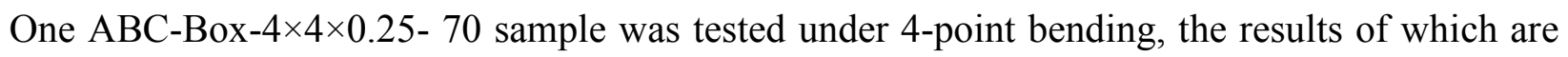
shown in Table 5-14. With $\frac{L}{b}=14.5$, this is an intermediate span beam $\left(10 \leq \frac{L}{b} \leq 20\right)$, which typically fails due to strength failure of the flange under compression, as can be observed in Figure 5-25. Assuming $\mathrm{SCF}=2.0$, stress at failure will be $19.2 \times 2=38.4 \mathrm{ksi}$, as compared to nominal strength of $25.8 \mathrm{ksi}$ (Equation 5-15 and 5-16). The local instability strength (47.3 ksi) and lateral-torsional buckling strength (142.4 ksi) are too high to control the failure behavior. It can also be seen that in 4-point bending case, the crack-length is much more than that in the 3 point bending due to the effect of two roller contacts.

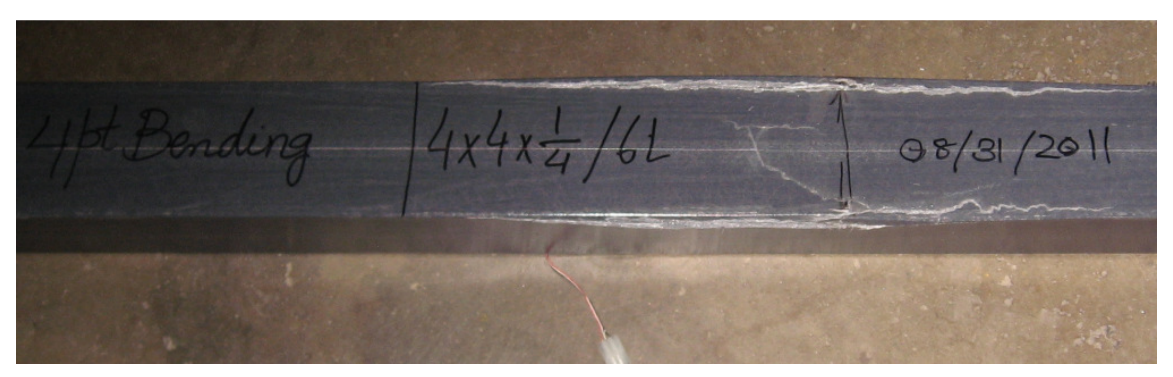

Figure 5-25: ABC-Box-4×4×0.25- 58 Under 4-point Bending

The moment versus microstrain graph of this test is shown in Figure 5-26 (a), which shows almost a linear trend till failure. The moment versus deflection graph is shown in Figure 5- 26 (b), also showing a linear trend till failure. 

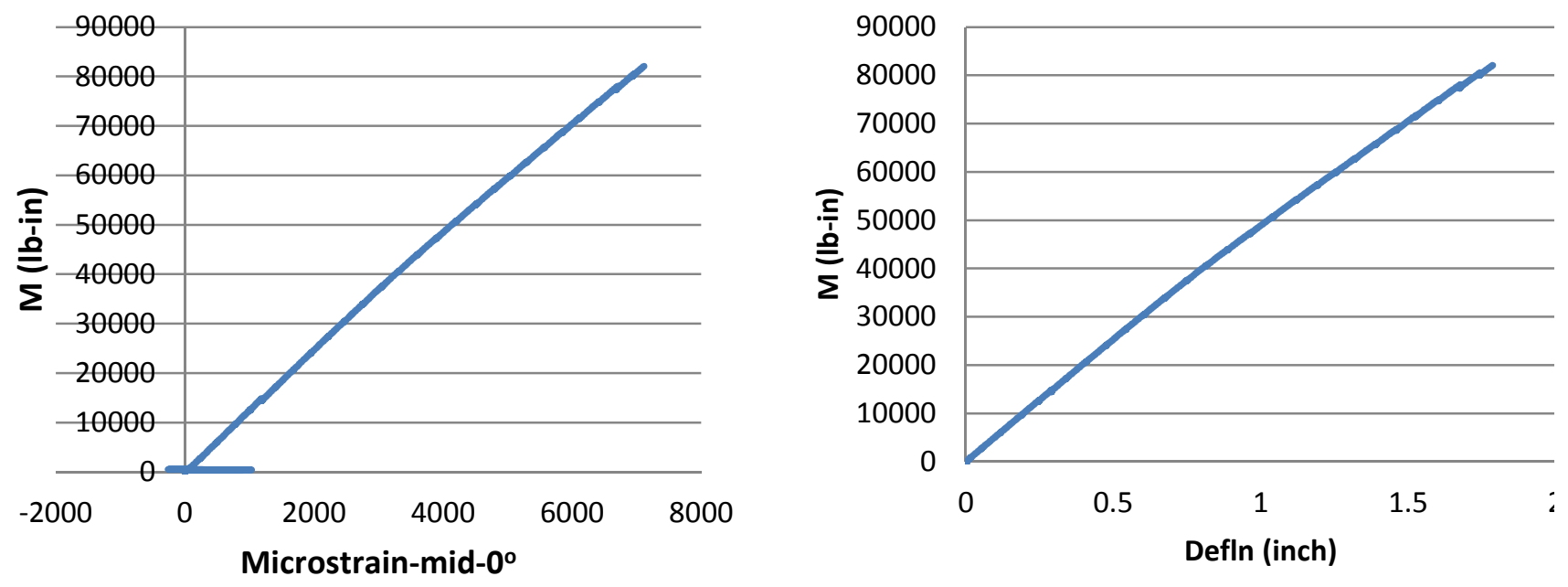

(a) Moment vs microstrain at mid of bottom-flange (b) Moment vs deflection at mid of bottom-flange

Figure 5-26: Plots of ABC-Box-4×4×0.25- 70 Under 4-point Bending

Table 5-21: 4-Point Bending Test Results of ABC-Box-4×4×0.25- 70 Beam

\begin{tabular}{|c|c|c|c|c|c|c|c|c|c|c|c|}
\hline \multicolumn{3}{|c|}{ Cross-section vs Span } & \multicolumn{5}{|c|}{ Experimental Values } & \multicolumn{4}{|c|}{ ASCE LRFD Manual } \\
\hline \multirow{2}{*}{$\mathbf{L}$} & \multirow{2}{*}{$\mathbf{L} / \mathbf{b}$} & \multirow{2}{*}{$\mathbf{L} / \mathbf{t}$} & \multirow{2}{*}{$\mathbf{P}_{\text {exp }}$} & \multirow{2}{*}{$\mathbf{M}_{\text {exp }}$} & \multirow{2}{*}{$\sigma_{\text {failure }}$} & \multirow{2}{*}{$\boldsymbol{\tau}_{@ \text { failure }}$} & \multirow{2}{*}{$\tau / \sigma$} & \multirow[b]{2}{*}{$\sigma_{\text {strength }}$} & \multirow[b]{2}{*}{$\sigma_{\text {Local-Inst }}$} & \multicolumn{2}{|c|}{ Lateral Torsional } \\
\hline & & & & & & & & & & $\mathbf{M}_{\mathbf{n}}$ & $\boldsymbol{\sigma}$ \\
\hline inch & & & lbs & lb-in & psi & psi & $\%$ & psi & psi & Ib-in & psi \\
\hline & & & & Eqn 5-1 & Eqn 5-6 & Eqn 5-7 & & $\begin{array}{c}\text { Eqns } \\
5-15,16\end{array}$ & $\begin{array}{l}\text { Eqns } \\
5-6,17\end{array}$ & $\begin{array}{l}E q n \\
5-22\end{array}$ & $\begin{array}{r}\text { Eqn } \\
5-6\end{array}$ \\
\hline 58 & 14.5 & 232 & 9650 & 82000 & 19200 & 4232 & 22 & 25800 & $\begin{array}{l}\sigma_{\mathrm{f}}: 47300 \\
\sigma_{\mathrm{w}}: 58500\end{array}$ & $6.1 \mathrm{E}+05$ & 142400 \\
\hline
\end{tabular}

\subsubsection{Finite Element Analysis Results}

As mentioned in Section 5.3, the FEA was performed with two types of elements and two methods of application of a unit load. The section considered was ABC-Box- $6 \times 6 \times 0.375$, with spans varying from 36 to 50 inch. The non-trivial results are discussed below 


\section{Comparison of Flanges Under Compression and Tension}

As already observed in the experiments, the flange under compression is more subject to the effect of applied load. The same is verified from the FEA model. For example, in 30" long sample, the ratio of compressive bending stress to tensile bending stress is 1.8. This phenomenon can be attributed to two major effects:

i. The compressive side is the one which is in contact with the applied load and experiences local effects.

ii. The compression side in a thin-walled section is always vulnerable to instability, such as, flange-buckling, local-instability or lateral torsional buckling.

\section{Effect of Method of Application of Load}

Although the most common method in FEA is to apply nodal loads, yet it is important to understand that this method is a source of error, as it gives rise to a great deal of local stresses, not only in $\mathrm{x}$-, but also in $\mathrm{y}$ - and z-directions.

\section{Effect of Type of Element}

A 2-dimensional shell element is easier to generate and analyze, but it is considerably less accurate than a 3-dimensional brick element. Therefore, the 2-D shell element will yield higher stress values than 3-dimensional brick element.

The combined effect of load type and element type can be seen in Figures 5-27 and 5-28. When the 36 " long sample with 2-D shell element was subject to unit nodal load, $\sigma_{\mathrm{x}}=4.272, \sigma_{\mathrm{y}}=4.683$ and $\sigma_{z}=3.0$ (Figure 5-27). When the same sample was modeled with 3D brick element with a loading plate under unit load, $\sigma_{\mathrm{x}}=2.361, \sigma_{\mathrm{y}}$ and $\sigma_{\mathrm{z}}$ being insignificant. 


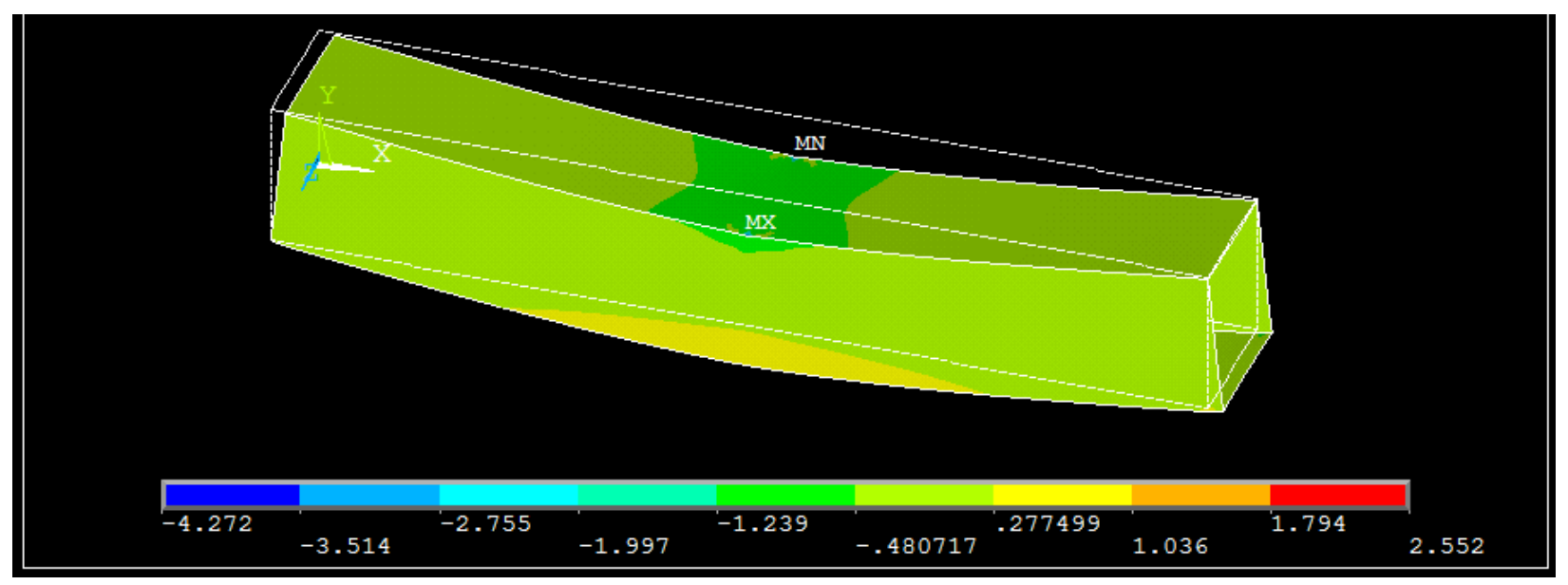

Figure 5-27: FEA Model of ABC-Box-6×6×0.375- 36 Sample with Nodal Load and 2-D Shell Element

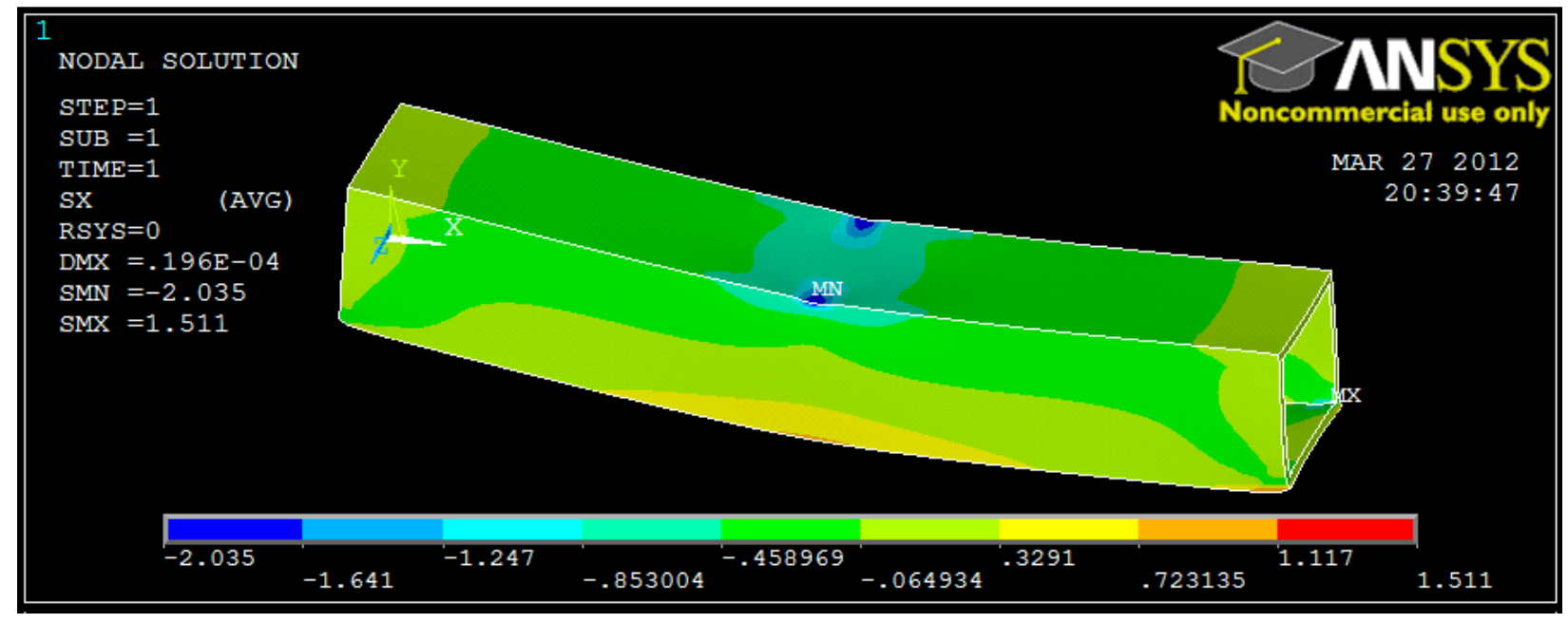

Figure 5-28: FEA Model of ABC-Box-6×6×0.375- 36 Sample with Loading Plate and 3-D Brick Element

\section{Effect of Test-Span}

An important aspect revealed from the FEA is that the longer the test span, the larger is the stress affected zone. For example, when a unit nodal load is applied at the mid-span of a ABC-Box$4 \times 4 \times 0.375-168$ sample, as shown in Figure $5-29, \sigma_{\mathrm{x}}$ is 8.743 , spreading over a considerable length of the top flange. This is in contrast to the ABC-Box- $6 \times 6 \times 0.375-36$ case, where the high stress zone was extremely small. 


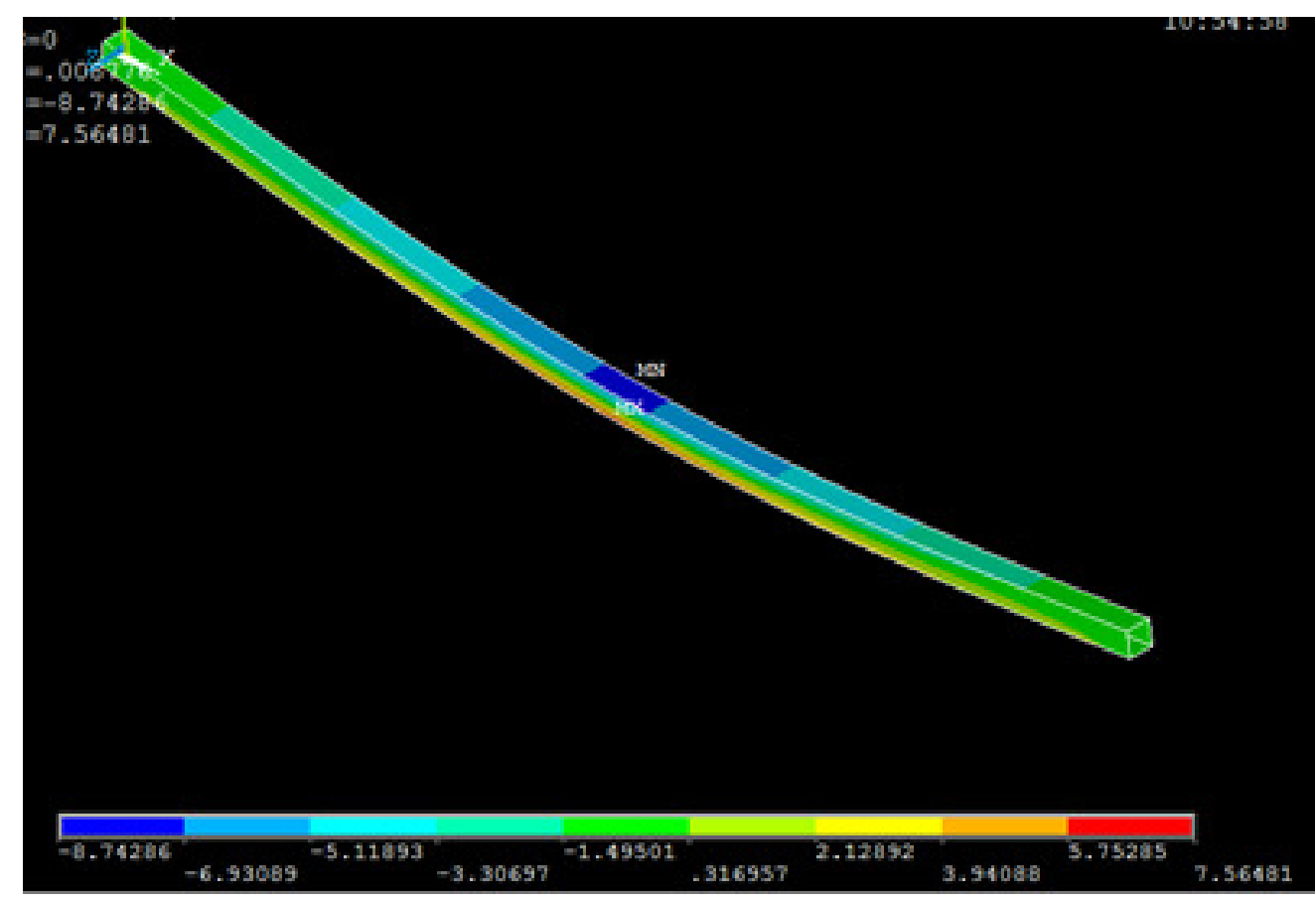

Figure 5-29: FEA Model of ABC-Box-4×4×0.375- 168 with Nodal Load and 2-D Shell Element

\section{Local Load Effect}

As suggested in Figure 5-12, applied loads tend to create local web buckling. For different beam sections, buckling load values are given in lower portions of Tables 5-3 through 5-13. The existence of such kind of local loads can also be verified by finite element analysis. As given in Appendix-C, a $6 \times 6 \times 3 / 8$ beam section of 36 " length was modeled with properties of BRP box beam and subjected to unit load at mid-span. Then a 3" wide central portion was selected and magnified to see the state of stress. The nodal points of right- and left-web are shown in Figure $\mathrm{C}-1$. As can be seen, node\#16990 is near the bottom with $\sigma_{\mathrm{y}}=-0.0257$, node\#16997 is above middepth with $\sigma_{\mathrm{y}}=-0.1614$ and node\#17002 is near the top with $\sigma_{\mathrm{y}}=-0.1991$. Hence it is shown that local stresses under applied loads $\left(\sigma_{\mathrm{y}}\right)$ positively exist, though not uniform in magnitude, as suggested in Figure 5-12. In fact, the suggested model is simplified for comparison purpose only, the exact formula for such local buckling being unknown. 


\subsection{Conclusions}

The bending behavior of the pultruded FRP composite beams of different cross-sections and spans was investigated under a variety of load conditions and simply supported boundary conditions, the summary of which is as follows:

\section{Effect of Cross-Section Type on Failure Behavior}

- Closed sections (square and round) typically fail due to strength failure. Their symmetric shape prevents them from any type of local or global instability. The bending behavior of rectangular sections with uniform wall-thickness is also somewhat similar.

- The wide-flange sections typically undergo flange-buckling at considerably low loads. However, a post-buckling strength is contributed by the web, as long as the direction of load and axis of the web are coincident. A small shift in the load direction can make the sample unstable.

- The rectangular sections with $t_{w}=\frac{1}{2} t_{f}$ typically have low strength against local instability of the web and lateral torsional buckling. Also, a relatively high bending load may cause local crushing of the web.

\section{Effect of Stress-Concentration on Failure Behavior}

- A strain concentration factor of 1.3 to 1.5 was found experimentally for one sample. Under ideal circumstances, it is taken to be equal to stress concentration factor. But one SCF value may not be applicable to all the cases, as it depends upon the cross-sectional dimensions and corner radii. Therefore, 1.3 to 1.5 is a lower bound for the SCF.

- The SCF plays a vital role in determining the failure behavior of flange under compression, which is most vulnerable to both strength failure and buckling. It can be better understood by assuming the top flange to be partially fixed along the two edges and subject to compression. Then, not only the strength of the flange is less in compression than in tension but also a stress concentration occurring along the edges is reducing the load carrying capacity. 


\section{Effect of Test-Span on Failure Behavior}

- For short-span box beams $\left(\frac{L}{b}<10\right)$, local crushing is the dominant mode of failure, i.e., the area of the test-specimen in contact with the load applicator will rupture under the load. The applied load does not induce much bending moment due to shorter moment arm, hence less bending stresses will be induced.

- The intermediate span box beams with $10 \leq \frac{L}{b} \leq 20$, fail under strength failure of the compression flange while stress concentrations are also accounted for.

- The long-span box beams with $\frac{L}{b}>20$ fail at bending stresses significantly higher than their nominal strength. The bending stresses depend upon bending moment, which in turn depends upon moment-arm $\left(\frac{L_{\text {effective }}}{2}\right)$, rather than magnitude of the applied loads. As the applied loads are much less than those in short-span beams, local load effects such as crushing under load are minimal. This allows little more load to be applied, which will create high bending moment due to long moment arm.

\section{Conclusions from the Finite Element Analysis}

- For the FEA modeling, a load applicator plate should be used instead of nodal loads, otherwise, higher stress values will result. Similarly, 3-D brick elements yield more accurate results than 2-D shell elements.

- In case of short span beams, high local stresses occur not only in longitudinal direction but also in the transverse directions. However, the spread of the high stress zone is very small.

- In case of long-span beams, high bending stresses take place over a considerable area under the applied load. All the other types of stress are however insignificant.

- In all the cases, bending shear stresses do not play any significant role in the failure behavior of FRP beams. 


\section{CHAPTER 6 - Torsional Behavior}

\subsection{Introduction}

The behavior of glass-fiber reinforced polymer composite beams of various cross-sectional shapes, dimensions and spans was investigated under pure torsional loads till failure. The test samples consisted of round sections of diameters of 2 " to 6" with wall thickness of 0.115 " to 0.25 " and spans of 2' to 12 '; square sections of 4 " $\times 4$ " $\times 0.25$ " and $6 " \times 6$ " $\times 0.375$ " with 6' span and a wide-flange section of $6 " \times 6 " \times 0.25$ " with 6" span.

The test data were analyzed on the basis of Simplified Classical Laminate Theory (SCLT) and design equations of ASCE-LRFD Manual of Pultruded Sections. It was found that the circular sections failed due to strength failure for all diameters and lengths, without any kind of local or global buckling. The square sections, on the other hand, experienced a stress concentration factor

of the order of 4 at the corners, causing the samples to fail. The results of SCLT analysis and ASCE-LRFD design equations were found to be in good agreement with the experimental results.

\subsection{Problem Formulation}

\subsubsection{The Torsional Formula}

The torsional formula in its general form is written as

$$
\frac{T}{J}=\frac{\tau}{\rho}=\frac{G \theta}{L}
$$

where $T$ is the applied torque, given by,

$$
T=P R
$$

with $P$ as the load and $R$ as the moment arm

$J$ is the polar moment of inertia, represented for a circular cross-section by

$$
J=\frac{\pi}{32}\left(d_{o}^{4}-d_{i}^{4}\right)
$$

with $d_{o}$ and $d_{i}$ being the outer and inner diameters respectively. 
$\tau$ is the shear stress, $\rho$ is the radial distance from polar axis, $G$ is the modulus of rigidity, $\theta$ is the angle of twist and $L$ is the length.

When a torque $T$ acts upon a member, the corresponding angle of twist can be measured either by means of a rotation measurement device, such as RVIT, or from the strains values found through strain gages by using the relation [34]

$$
\gamma_{x y}=\left|\varepsilon_{+45}\right|+\left|\varepsilon_{-45}\right|-\left|\varepsilon_{90}\right|
$$

The strain at $90^{\circ}$ is usually negligible under pure torsion, while the values at $+45^{\circ}$ and $-45^{\circ}$ are almost equal in magnitude, as found experimentally. Hence the above equation can be simplified as

$$
\gamma_{x y}=2\left|\varepsilon_{45}\right|
$$

By employing the stress-based method of finding the optimal orientation of orthotropic materials, it can be verified that the principal axes $\left(\theta_{1,2}\right)$ lie near $45^{\circ}$, as given by the mathematical relation [39],

$$
\tan \theta_{1,2}=\frac{-B E \pm \sqrt{B^{2} E^{2}-A^{2} B^{2}+A^{2} E^{2}}}{A(B-A)}
$$

If

$$
\begin{gathered}
c=S_{11}-S_{22} \\
d=\frac{S_{11}-2 S_{12}+S_{22}-S_{66}}{2}
\end{gathered}
$$

with $S_{i j}$ being the elements of compliance matrix (Equation A-11). Then,

$$
\begin{gathered}
A=c\left(\sigma_{2}^{2}-\sigma_{1}^{2}\right) \\
B=2 c \sigma_{12}\left(\sigma_{1}+\sigma_{2}\right) \\
D=d\left\{4 \sigma_{12}^{2}-\left(\sigma_{1}-\sigma_{2}\right)^{2}\right\} \\
E=4 d \sigma_{12}\left(\sigma_{1}-\sigma_{2}\right)
\end{gathered}
$$

If $\gamma_{x y}$ is known, the angle of twist will then be found as

$$
\theta=\frac{\gamma_{x y} L}{r_{o}}=\frac{2\left|\varepsilon_{45}\right| L}{r_{o}}
$$




\subsubsection{Simplified Classical Laminated Theory (SCLT) for Torsion}

Torsional behavior of closed FRP members under unrestrained warping was well explained by Prachasaree $[23,36]$. He introduced some simplifications in the classical laminate theory (CLT) [14] and named it simplified classical laminate theory (SCLT).

Referring to Equations A-5 and A-10, if $\varepsilon_{\mathrm{x}}$ and $\varepsilon_{\mathrm{y}}$ are taken to be zero and $1-v_{12} \nu_{21} \approx 1, \tau_{\mathrm{xy}}$ is found to be

$$
\tau_{x y}=\left[\frac{1}{(\cos 2 \theta)^{2}\left(\frac{1}{G_{12}}\right)+(\sin 2 \theta)^{2}\left(\frac{1}{E_{11}}+\frac{1}{E_{22}}+\frac{2 v_{21}}{E_{22}}\right)}\right] \gamma_{x y}
$$

where $\theta$ is the angle between material axis (1-2) and load axis (x-y), as shown in Figure 6-1, $\mathrm{E}_{11}$ and $E_{22}$ are the longitudinal and transverse moduli of the lamina, $G_{12}$ is the in-plane shear modulus and $v_{21}$ is the in-plane Poisson's ratio.

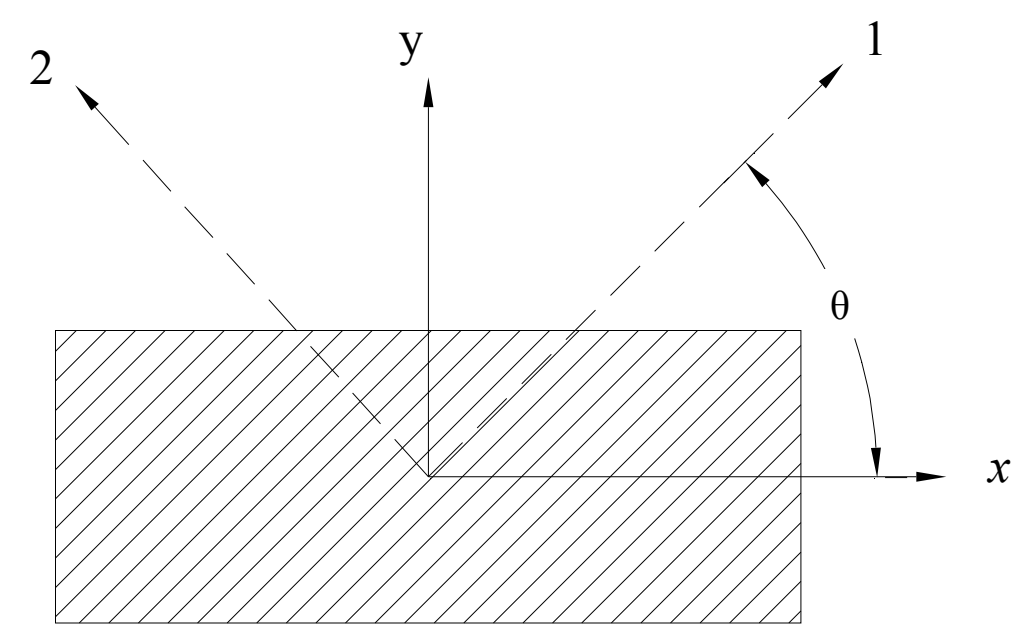

Figure 6-1: x-y: Load Axes/Off-Axes, 1-2: Material Axes/On-Axes [23]

Under SCLT, Equation 4-18 reduces to

$$
\left\{\begin{array}{l}
N_{x y} \\
M_{x y}
\end{array}\right\}=\left[\begin{array}{ll}
A_{66} & B_{66} \\
B_{66} & D_{66}
\end{array}\right]_{2 \times 2}\left\{\begin{array}{l}
\gamma_{x y o} \\
\kappa_{x y}
\end{array}\right\}
$$


For closed sections, $\mathrm{N}_{\mathrm{xy}}$ is significant and $\mathrm{M}_{\mathrm{xy}}$ is negligible, then

$$
\begin{gathered}
\kappa_{x y}=-\frac{B_{66}}{D_{66}} \gamma_{x y o} \\
N_{x y}=\left[A_{66}-\frac{B_{66}^{2}}{D_{66}}\right] \gamma_{x y o}
\end{gathered}
$$

The applied torque is then given by,

$$
T=2 A^{*} q
$$

and shear flow $\mathrm{q}$ is given by,

$$
q=\int \tau_{x y} d z=N_{x y}
$$

$\mathrm{A}^{*}$ and $\mathrm{q}$ are shown in Figure 6-2

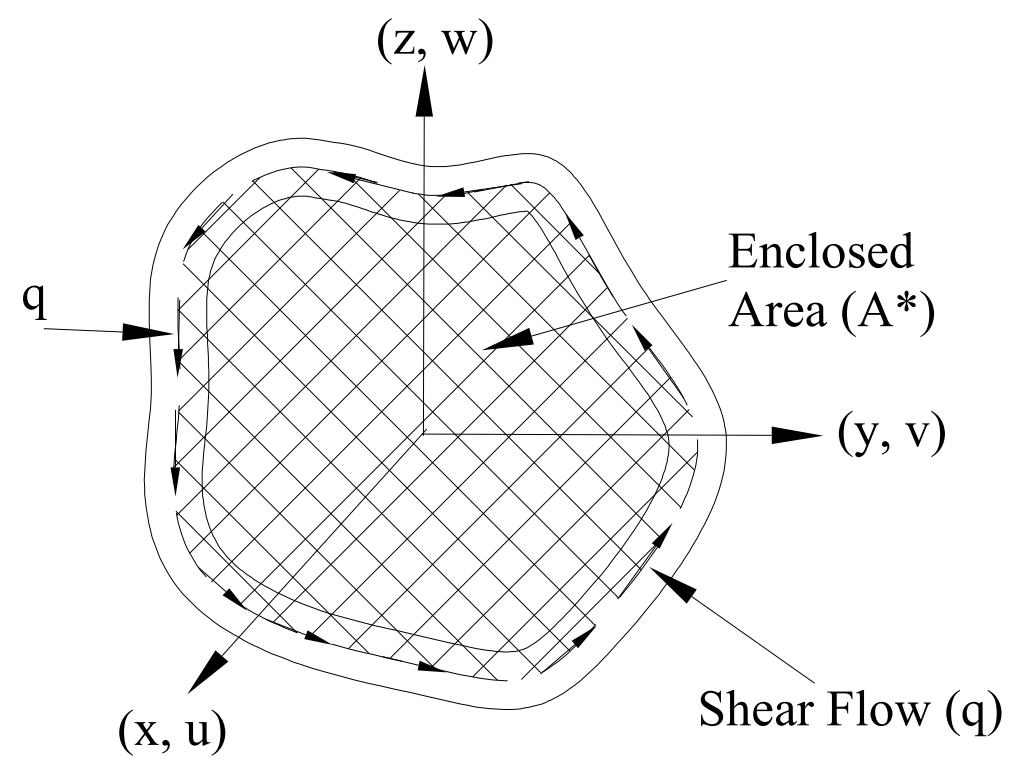

Figure 6-2: Area Enclosed by the Mid-line of the Cross-Section [23]

The torque is represented in terms of torsional rigidity $(G J)$ and rate of twist per unit length $(\bar{\theta})$ as,

$$
T=\{G J\} \bar{\theta}
$$




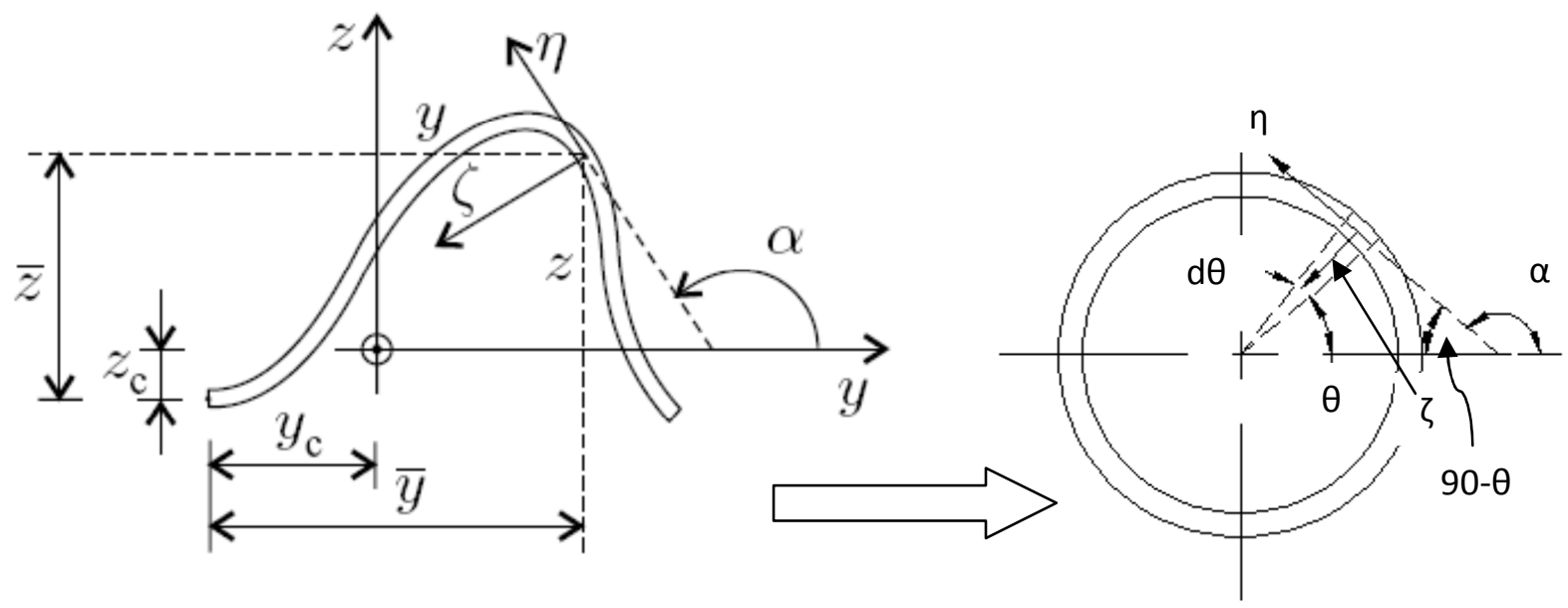

Figure 6-3: General Form of Thin-Walled Curved Section with Orthotropic and Symmetric Layup, Solved for Circular Shape [23]

The torsional stiffness for the general form of a thin-walled curved section having an orthotropic and symmetric layup, as shown in Figure 6-3, is given by

$$
\widetilde{G J}=\frac{4 A^{2}}{\oint A_{66}^{-1} d \eta}
$$

For a closed circular section,

$$
\widetilde{G J}=\frac{4 A^{2}}{A_{66}^{-1} \oint_{0}^{2 \pi} r d \theta}=\frac{2 \pi r_{e f f}^{3}}{A_{66}^{-1}}
$$

where $r_{e f f}$ is the mean of inner and outer radii.

For rectangular shapes,

$$
\begin{gathered}
\widehat{G J}=\frac{2 S_{f}^{2} S_{w}^{2}}{A_{66, f}^{-1} S_{f}+A_{66, w}^{-1} S_{w}} \\
J=\frac{4 A^{* 2}}{\frac{2 S_{f}}{t_{f}}+\frac{2 S_{w}}{t_{w}}}
\end{gathered}
$$

where $S_{f}$ and $S_{w}$ are shown in Figure 6-4. 


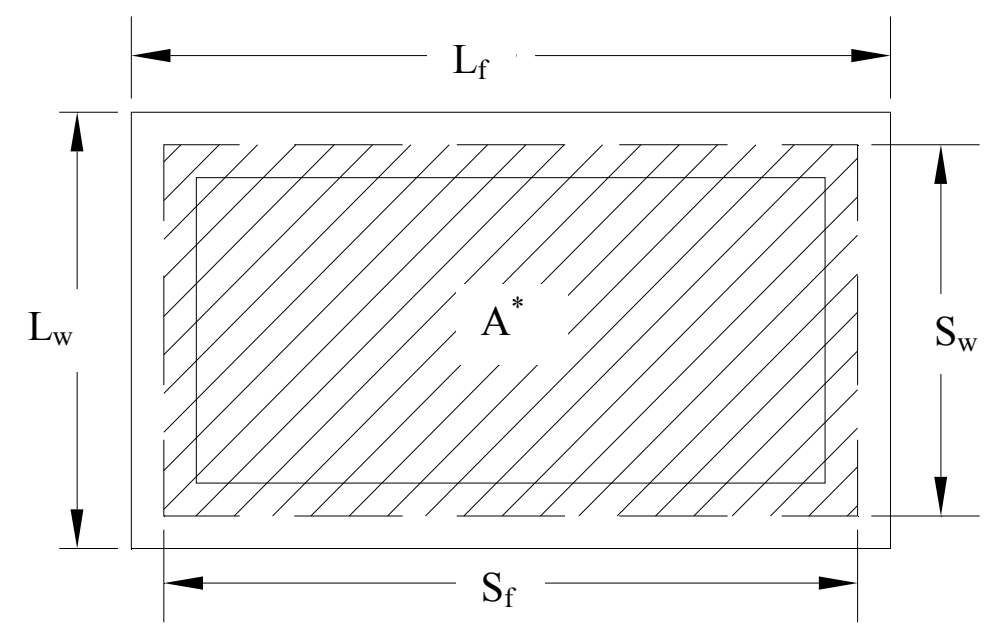

Figure 6-4: Dimensions of a Rectangular Cross-section [23]

The axial warping displacement of a segment of close-shaped FRP member from points o to $\mathrm{s}$ is given by,

$$
\left(u_{s}-u_{o}\right)=\frac{T}{2 A^{*}}\left[\int_{o}^{s} \frac{1}{\left[A_{66}-\frac{B_{66}^{2}}{D_{66}}\right]} d s-\frac{A_{o s}}{A^{*}} \oint \frac{1}{\left[A_{66}-\frac{B_{66}^{2}}{D_{66}}\right]} d s\right]
$$

where $A_{o s}$ is the area swept from o $t \mathrm{~s}$ about the center point, as shown in Figure 6-5.

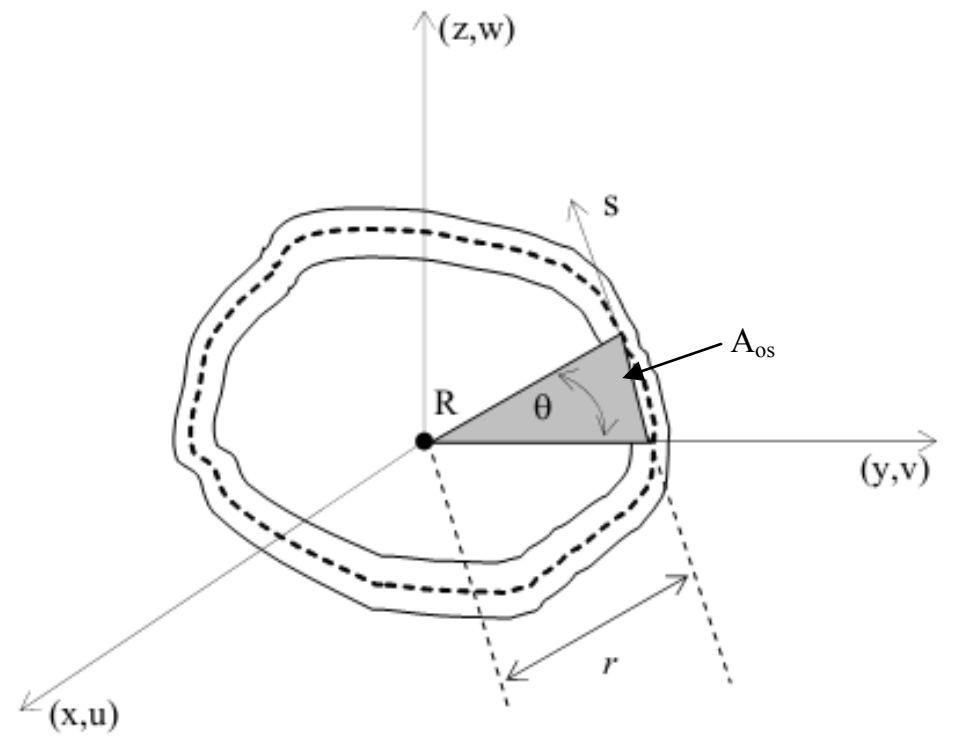

Figure 6-5: Swept Area $A_{o s}[23]$ 


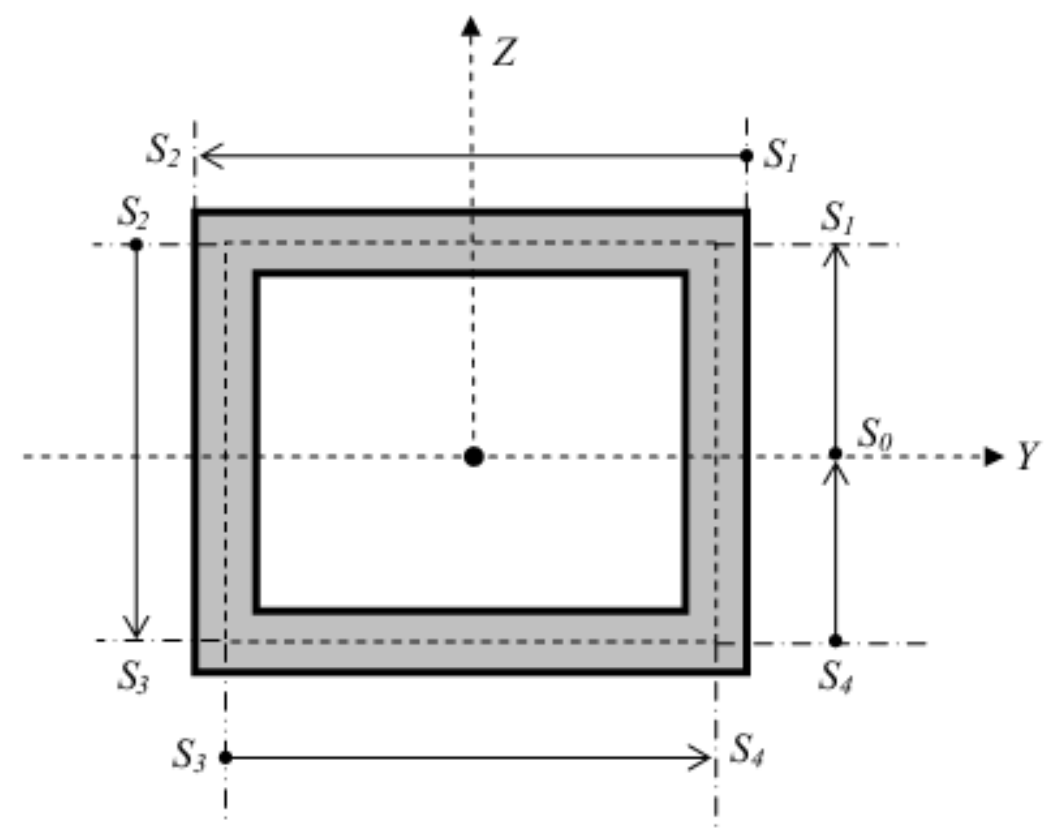

Figure 6-6: Warping Segments of a Rectangular Section [23]

For the various segments of a rectangular section shown in Figure 6-6, the warping displacements will come out to be

$$
\begin{aligned}
& \left(u_{s 1}-u_{s o}\right)=\frac{T}{8 A^{*}}\left[\frac{S_{w}}{\left[A_{66}-\frac{B_{66}^{2}}{D_{66}}\right]_{w e b}}-\frac{S_{f}}{\left[A_{66}-\frac{B_{66}^{2}}{D_{66}}\right]_{\text {flange }}}\right] \\
& \left(u_{s 2}-u_{s 1}\right)=\frac{T}{4 A^{*}}\left[\frac{S_{f}}{\left[A_{66}-\frac{B_{66}^{2}}{D_{66}}\right]_{\text {flange }}}-\frac{S_{w}}{\left[A_{66}-\frac{B_{66}^{2}}{D_{66}}\right]_{w e b}}\right] \\
& \left(u_{s 3}-u_{s 2}\right)=\frac{T}{4 A^{*}}\left[\frac{S_{w}}{\left[A_{66}-\frac{B_{66}^{2}}{D_{66}}\right]_{w e b}}-\frac{S_{f}}{\left[A_{66}-\frac{B_{66}^{2}}{D_{66}}\right]_{\text {flange }}}\right] \\
& \left(u_{s 4}-u_{s 3}\right)=\frac{T}{4 A^{*}}\left[\frac{S_{f}}{\left[A_{66}-\frac{B_{66}^{2}}{D_{66}}\right]_{\text {flange }}}-\frac{S_{w}}{\left[A_{66}-\frac{B_{66}^{2}}{D_{66}}\right]_{w e b}}\right]
\end{aligned}
$$




$$
\left(u_{s o}-u_{s 4}\right)=\frac{T}{8 A^{*}}\left[\frac{S_{w}}{\left[A_{66}-\frac{B_{66}^{2}}{D_{66}}\right]_{w e b}}-\frac{S_{f}}{\left[A_{66}-\frac{B_{66}^{2}}{D_{66}}\right]_{\text {flange }}}\right]
$$

\subsubsection{Stress Concentration Factors in Torsion [35]}

Stress concentrations factors play a very significant role in the torsional failure behavior of sections having one or more sharp edges. This phenomenon is independent of the material properties being isotropic or not. Using the notations given in Figure 6-7 (a), the stress concentration factor for a box section can be calculated as

$$
K_{t s}=\frac{\tau_{\max }}{\tau}=3.962-7.359(r / h)+6.801(r / h)^{2}-2.153(r / h)^{3}
$$

where a is 15 to 20 times larger than $\mathrm{h}$,

$$
0.2 \leq r / h \leq 1.4
$$

For an angle section, using the notations of Figure 6-7 (b), the stress concentration factor will be given by,

$$
K_{t s}=\frac{\tau_{\max }}{\tau}=6.554-16.077 \sqrt{r / h}+16.987(r / h)-5.886 \sqrt{r / h}(r / h)
$$

where

$$
0.1 \leq r / h \leq 1.4
$$

(a)

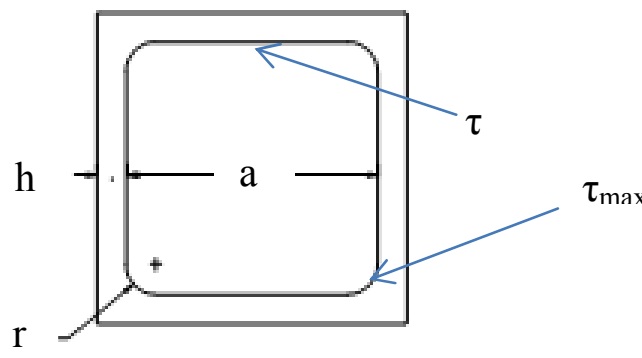

(b)

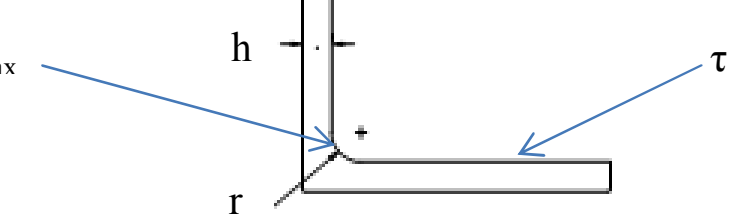

Figure 6-7: Notations of Stress Concentration Formulas in Torsion of (a) Box-Sections, (b) Angle-Sections [35] 
(a)

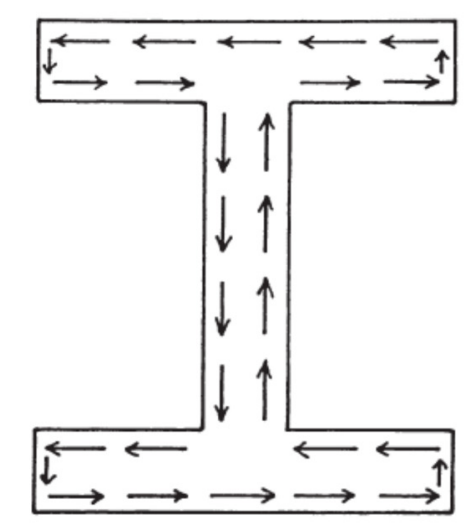

(b)
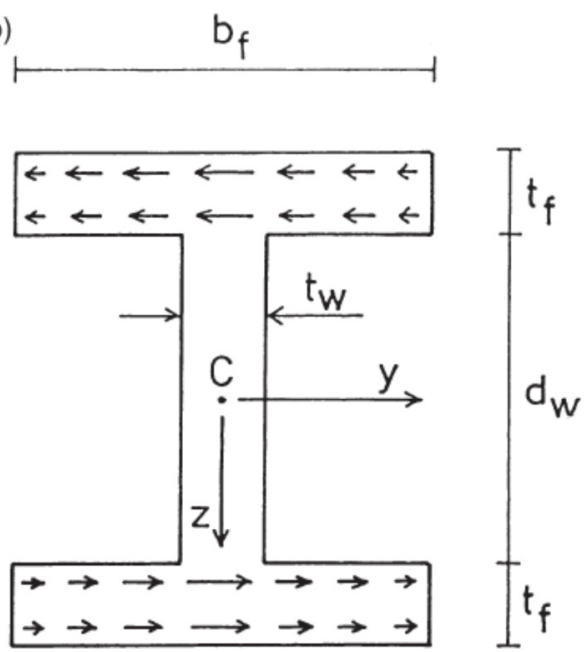

Figure 6-8: Torsional Shear Stress Distribution, (a) Saint Venant Torsion,

(b) Restrained Warping Torsion [25]

\subsubsection{Modified Timoshenko Torsion Theory}

The torsion theory of thin-walled open cross-section isotropic bars, presented by Timoshenko (1961), was extended to pultruded FRP members by Roberts et al [24-27]. According to this theory, total torque is the sum of St Venant torque and warping torque, as shown in Figure 6-8 for an I-beam. Mathematically

$$
T=T_{s v}+T_{w}
$$

Total rotation consists of rotation due to shear strain and warping rotation

$$
\theta=\theta_{s}+\theta_{w}
$$

Considering an arbitrary open cross-section of small thickness t, Saint Venant shear strain will vary linearly with distance $\rho$ from the mid-thickness. Denoting the angle of twist per unit length by $\frac{d \theta}{d x}$,

$$
\tau_{s v}=G_{s v} 2 \rho \frac{d \theta}{d x}
$$

where $G_{\mathrm{sv}}$ is the saint Venant torsional shear modulus.

Saint Venant torque will be

$$
T_{s v}=G_{s v} J \frac{d \theta}{d x}
$$


with

$$
J=\oint_{a}^{b} \frac{t^{3}}{3} d s
$$

$\mathrm{J}$ being the St Venant torsional constant. For a thin-walled I-beam, $J=\frac{2 b_{f} t_{f}^{3}+d_{w} t_{w}^{3}}{3}$

From the equilibrium of the element shown in Figure 6-9 (c),

$$
\delta(\tau t) \delta x+\delta\left(\sigma_{x} t\right) \delta s=0
$$

This, upon further solution will give

$$
\tau t=-\oint_{a}^{s} t \frac{\partial \sigma_{x}}{\partial x} d s
$$

Referring to the notations shown in Figure 6-9 (a), (b) and (c), the warping torque in the bar will be

$$
T_{w}=\oint_{a}^{b} \tau t p d s=G_{s} \Gamma \frac{d \theta_{s}}{d x}=-E_{w} C_{w} \frac{d^{3} \theta_{w}}{d x^{3}}
$$

where, $\mathrm{G}_{\mathrm{s}}$ is the torsional warping shear modulus, and

$$
\Gamma=\oint_{a}^{b} t p^{2} d s
$$

For a thin-walled I-beam, $\Gamma=2 b_{f} t_{f}\left(\frac{d_{w}+t_{f}}{2}\right)^{2}$

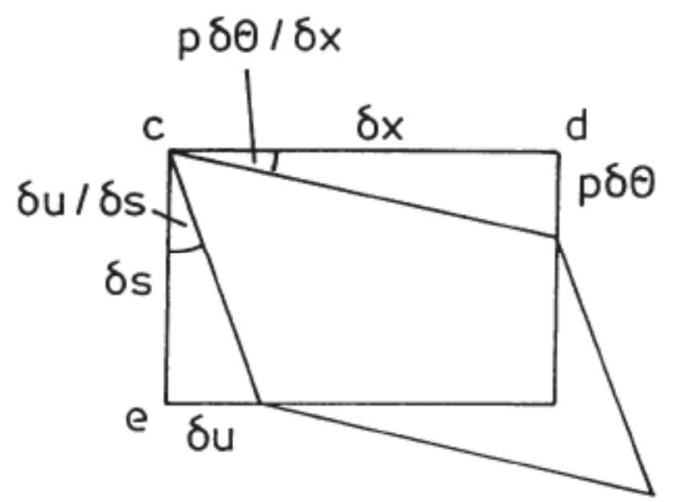

(a)

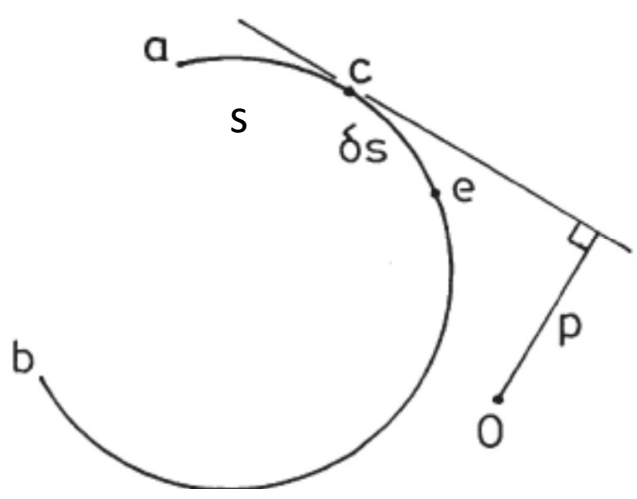

(b) 


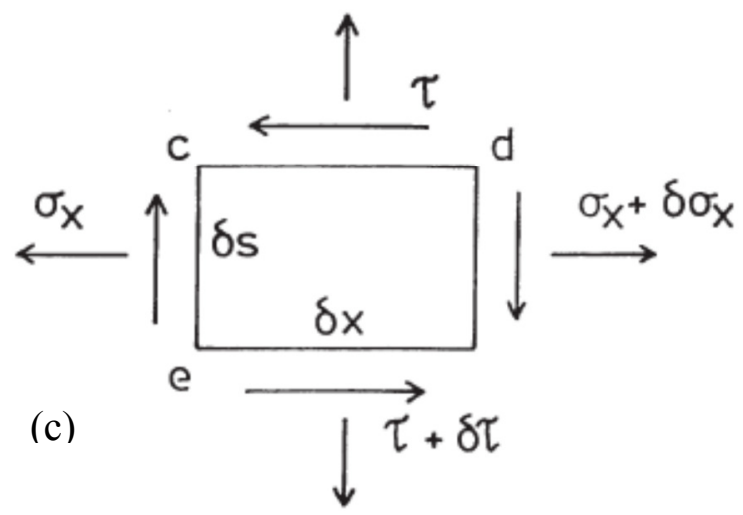

Figure 6-9: (a) Deformed Element at Bar Surface, (b) Shear Center O and Related Distances (c) Equilibrium State of the Surface Element [25]

$$
\begin{gathered}
C_{w}=\oint_{a}^{b}\left(\bar{\alpha}-\alpha_{s}\right)^{2} t d s \\
\alpha_{s}=\oint_{a}^{s} p d s, \bar{\alpha}=\frac{1}{A} \oint_{a}^{b} \alpha_{s} t d s
\end{gathered}
$$

For a thin-walled I-beam, $C_{w}=\frac{t_{f} b_{f}^{3}\left(d_{w}+t_{f}\right)^{2}}{24}=I_{z} \frac{\left(d_{w}+t_{f}\right)^{2}}{4}$

The total torque will then be

$$
\begin{gathered}
T=-E_{w} C_{w} \frac{d^{3} \theta_{w}}{d x^{3}}+G_{s v} J \frac{d}{d x}\left(\theta_{w}+\theta_{s}\right) \\
T=-E_{w} C_{w}\left\{1+\frac{G_{s v} J}{G_{s} \Gamma}\right\} \frac{d^{3} \theta_{w}}{d x^{3}}+G_{s v} J \frac{d \theta_{w}}{d x}
\end{gathered}
$$

If a bar of length $\mathrm{L}$ is subjected to equal and opposite torque at its both ends,

$$
\theta=\frac{T L}{G_{s v} J}
$$

But if the torque is applied at the center of the bar,

$$
\begin{gathered}
\theta_{\text {central }}=\frac{T}{2 G_{s v} J}\left\{\frac{L}{2}-\frac{\tanh \left(\frac{\beta L}{2}\right)}{\beta}\right\} \\
\beta^{2}=\frac{G_{s v} J}{E_{w} C_{w}\left(1+\frac{G_{s v} J}{G_{s} \Gamma}\right)}
\end{gathered}
$$




\subsubsection{Design Equations of ASCE-LRFD Pultruded Sections Draft Manual [1]}

The nominal torsional strength $\mathrm{T}_{\mathrm{n}}$ of hollow tubes according to the limit states of torsional buckling and torsional rupture shall be limited as under:

When strength governs,

$$
T_{n}=F_{n} J
$$

When stiffness governs,

$$
T_{n}=F_{c r} C
$$

with,

$$
F_{n}=\gamma G_{L T}
$$

and

$$
F_{c r}=\min \left(\frac{0.236\left(E_{T}^{C}\right)^{5 / 8}\left(E_{L}^{C}\right)^{3 / 8}}{\left(\frac{R}{t}\right)^{3 / 2}}, \frac{0.733\left(E_{T}^{C}\right)^{5 / 8}\left(E_{L}^{C}\right)^{3 / 8}}{\left(\frac{R}{t}\right)^{5 / 4} \sqrt{\frac{L}{R}}}\right) \leq F_{L T}^{v}
$$

where,

$\gamma=$ coupon specimen shear strain per unit length

$G_{L T}=$ in-plane shear modulus of elasticity

$\mathrm{J}=$ polar moment of inertia

$\mathrm{C}=$ torsional constant for rectangular tubes and wide flange beams

For circular tubes,

$$
J=\frac{\pi}{2}\left(R^{4}-R_{i}^{4}\right)
$$

For rectangular tubes,

$$
J=\frac{2 A^{2}}{\left(\frac{d_{w}}{t_{w}}+\frac{b_{f}}{t_{f}}\right)}
$$

For wide-flange beams,

$$
J=\frac{2 b_{f} t_{f}^{3}+d_{w} t_{w}^{3}}{3}
$$

For circular tubes,

$$
C=\frac{\pi t(2 R-t)^{2}}{2}
$$


For rectangular tubes,

$$
C=2 t\left(b_{r}-t\right)(h-t)
$$

For wide-flange beams,

$$
C=J / t_{f}
$$

$A=$ mean of the areas enclosed by the inner and outer boundaries

$b_{r}=$ outer width of the rectangular tube section

$b_{f}=$ width of the flange between the centers of the webs in rectangular tubes, and flange-width for T-, I- and C-beams

$d_{w}=$ the clear depth of the web

$d=$ depth of the rectangular tube section

$R=$ outer diameter of the circular tube

$t=$ thickness of the cross-section

$t_{f}=$ thickness of the flange

$t_{w}=$ thickness of the web

$\mathrm{F}_{\mathrm{cr}}=$ critical torsional buckling strength

$F_{L T}^{v}=$ in-plane shear strength. Further calculation procedures are given in the manual

$E_{L}^{c}=$ longitudinal compression modulus

$E_{T}^{c}=$ transverse compression modulus

It can be quickly realized that both of the Simplified Classical Laminate Theory (SCLT) and the design equations of ASCE-LRFD Manual are primarily based on Classical Laminate Theory (CLT), merely to simplify the calculation procedure, without a notable loss of accuracy.

\subsection{Results and Discussions}

The experimental set-up and test procedure of pure torsion of circular sections is shown in Chapter-3. The CLT/SCLT analysis of circular, square and wide-flange sections under pure torsion was performed by incorporating the laminate properties found in Chapter-4 and the results were compared with experimental results, as described below. 


\subsubsection{Optimal Orientation of Orthotropic Materials}

1. BRP-Box- $4 \times 4 \times 1 / 4$ Section,

$$
\begin{aligned}
& \sigma_{1}=56 k s i \\
& \sigma_{2}=12 k s i \\
& \sigma_{12}=12 \mathrm{ksi} \text { (assumed) } \\
& E_{1}=3.6 m s i \\
& E_{2}=1.1 \mathrm{msi} \\
& G_{12}=0.33 \mathrm{msi} \\
& v_{12}=0.33 \\
& {[S]=\left[\begin{array}{ccc}
0.286 & -0.089 & 0 \\
-0.089 & 0.937 & 0 \\
0 & 0 & 3.03
\end{array}\right]} \\
& c=S_{11}-S_{22}=-0.651 \\
& d=\frac{S_{11}-2 S_{12}+S_{22}-S_{66}}{2}=-0.8145 \\
& A=c\left(\sigma_{2}^{2}-\sigma_{1}^{2}\right)=1947.8 \\
& B=2 c \sigma_{12}\left(\sigma_{1}+\sigma_{2}\right)=-1062.4 \\
& D=d\left\{4 \sigma_{12}^{2}-\left(\sigma_{1}-\sigma_{2}\right)^{2}\right\}=1108 \\
& E=4 d \sigma_{12}\left(\sigma_{1}-\sigma_{2}\right)=-1720 \\
& \tan \theta_{1,2}=\frac{-B E \pm \sqrt{B^{2} E^{2}-A^{2} B^{2}+A^{2} E^{2}}}{A(B-A)}=1.07,-3.93 \\
& \theta_{1,2}=47^{\circ},-76^{\circ}
\end{aligned}
$$

2. BRP-Box- $6 \times 6 \times 3 / 8$ Section,

$$
\begin{gathered}
\sigma_{1}=40 k s i \\
\sigma_{2}=9.4 k s i
\end{gathered}
$$




$$
\begin{aligned}
& \sigma_{12}=11.7 k s i \\
& E_{1}=3.2 \mathrm{msi} \\
& E_{2}=1.3 \mathrm{msi} \\
& G_{12}=0.35 \mathrm{msi} \\
& v_{12}=0.3 \\
& {[S]=\left[\begin{array}{ccc}
0.32 & -0.079 & 0 \\
-0.079 & 0.79 & 0 \\
0 & 0 & 2.86
\end{array}\right]} \\
& c=S_{11}-S_{22}=-0.47 \\
& d=\frac{S_{11}-2 S_{12}+S_{22}-S_{66}}{2}=-0.796 \\
& A=c\left(\sigma_{2}^{2}-\sigma_{1}^{2}\right)=710.47 \\
& B=2 c \sigma_{12}\left(\sigma_{1}+\sigma_{2}\right)=-568.6 \\
& D=d\left\{4 \sigma_{12}^{2}-\left(\sigma_{1}-\sigma_{2}\right)^{2}\right\}=201.65 \\
& E=4 d \sigma_{12}\left(\sigma_{1}-\sigma_{2}\right)=-1054 \\
& \tan \theta_{1,2}=\frac{-B E \pm \sqrt{B^{2} E^{2}-A^{2} B^{2}+A^{2} E^{2}}}{A(B-A)}=0.78,-4.26 \\
& \theta_{1,2}=38^{\circ},-77^{\circ}
\end{aligned}
$$

\subsubsection{Pure Torsion of Circular Sections}

The circular sections represent the case of no-stress-concentrations, typically failing under strength failure.

\subsubsection{CP-Round- $2.5 \times 0.10-70$ Sample}

The torsion test results of CP-Round-2.5 $\times 0.10$ - 70 sample are summarized in Table 6-1 (a) and comparison of experimental values corresponding to the first linear trend with analytical values 
is shown in Table 6-1 (b). The graph between $\mathrm{J} \theta_{\exp }$ and TL is shown in Figure 6-10 and the mode of failure is shown in Figure 6-11. The experiment was performed with simply supported boundary conditions to facilitate any buckling under torsion. With $\theta_{\mathrm{RVIT}}$ referring to the RVIT reading and $\theta_{\mathrm{sg}}$ being found from strain gage readings with the help of Equation 6-6, a difference of $11 \%$ between the two values of $\theta$ is found. As both of the values are based on experimental data, no difference is expected. However, it should be realized that the strain gage is attached directly on the test-piece and the RVIT is attached at the back side of the torque pulley. While the torque is transferred from pulley to the sample, there is a play between the end-plug and the pulley. Concurrently, a minor slip occurs inside the bonding material between the end-plug and the sample. Due to these two factors, $\theta_{\text {measured }}$ will always be somewhat higher than $\theta_{\text {strain }}$.

Table 6-1 (a): Torsion Test Results of CP-Round-2.5 $\times 0.10-70$

\begin{tabular}{|c|c|c|c|c|c|c|c|c|c|c|c|c|}
\hline $\mathbf{L}$ & L/d & $d / t$ & \multirow{2}{*}{$\begin{array}{c}\text { Load- } \\
\text { Level }\end{array}$} & $\mathbf{P}$ & $\left|\varepsilon_{45}\right|$ & $\boldsymbol{\theta}_{\mathrm{RVIT}}$ & $\mathbf{T}$ & $\tau$ & $\gamma$ & $\theta_{\text {sg }}$ & $\mathbf{G}$ & \multirow{2}{*}{$\begin{array}{l}\text { Mode of } \\
\text { Failure }\end{array}$} \\
\hline \multirow[t]{2}{*}{ inch } & & & & lbs & $\mu \varepsilon$ & degree & lb-in & ksi & $\mathrm{rad}$ & degree & $\mathrm{msi}$ & \\
\hline & & & & & & & Eqn 6-2 & Eqn 6-1 & Eqn 6-5 & Eqn 6-7 & Fig 6-10 & \\
\hline \multirow{2}{*}{67} & \multirow{2}{*}{27} & \multirow[t]{2}{*}{25} & $0.7 \mathrm{~T}_{\max }$ & 1525 & 1700 & 11 & 9910 & 6 & 40 & 0 & 2.69 & \multirow{2}{*}{$\begin{array}{c}\text { Strength } \\
\text { Failure with a } \\
\text { Longitudinal } \\
\text { Crack }\end{array}$} \\
\hline & & & Ultimate & 2200 & 2660 & 17.63 & 14300 & 16.40 & 0.00532 & 15.87 & 2.21 & \\
\hline
\end{tabular}

Table 6-2 (b): Experimental vs Analytical Results of CP-Round-2.5×0.10- 70

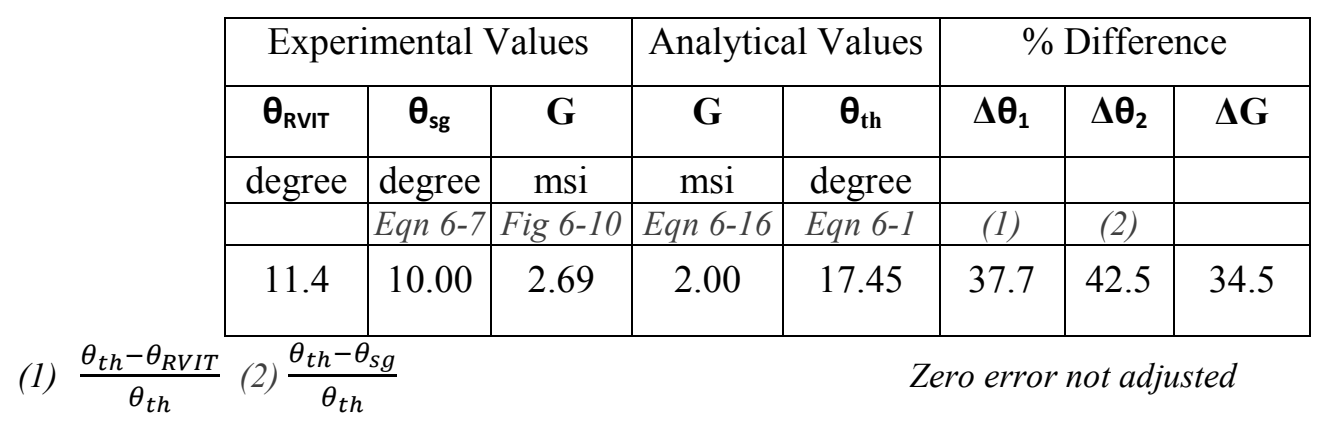

In Figure 6-10, a bilinear trend of the graph between $\mathrm{J} \theta_{\exp }$ along the abscissa and TL along the ordinate is evident. A bi- or trilinear trend is typical in torsion of FRP composite tubes, primarily attributed to the gradual ply failure under shear. As $G_{\text {exp }}$ corresponds to the slope of the straight 
trendline of the graph, two distinct values are found. The first linear trend continued till $70 \%$ of the ultimate torque due to symmetric \pm 45 carbon fibers in top and bottom layers with $\mathrm{G}_{\exp }=2.69$ msi vs $G_{t h}=2.00 \mathrm{msi}$. The second linear trend is also yields higher $G_{\text {exp }}$ than $G_{\text {th }}$ due to the same carbon fibers contribution. The higher value of $G_{\text {exp }}$ leads to smaller angle of rotation than expected theoretically, as evident from $\Delta \theta_{1}$ and $\Delta \theta_{2}$.

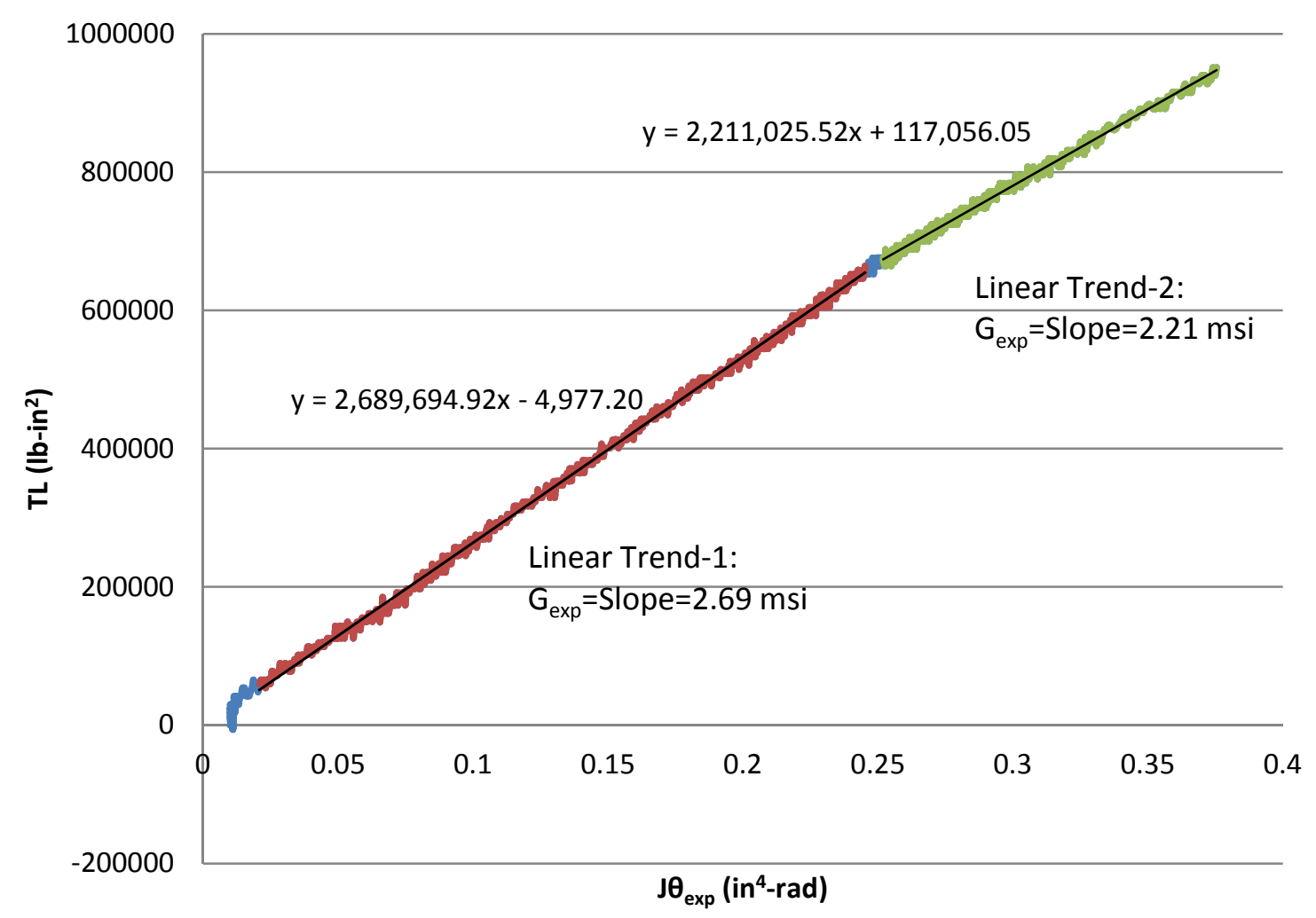

Figure 6-10: $\mathrm{J} \theta_{\exp }$ vs TL of CP-Round-2.5×0.10- 70

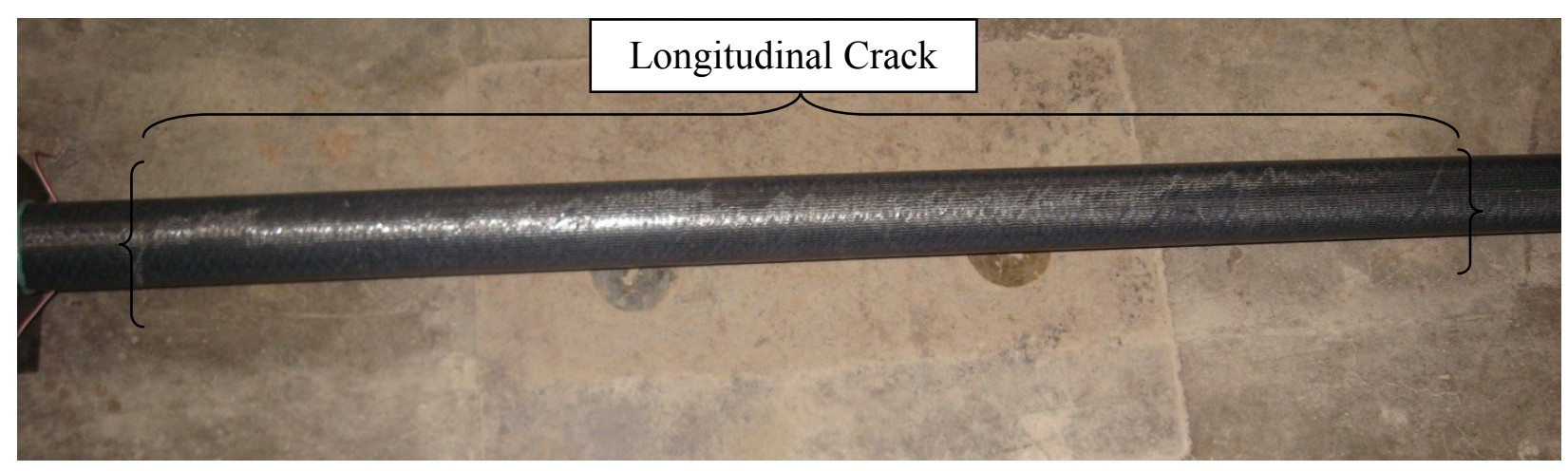

Figure 6-11: Mode of Failure of CP-Round-2.5×0.10- 70 
From the mode of failure shown in Figure 6-11, it is clearly the case of strength-failure with a continuous crack along the length of the test-specimen. The location of this type of crack is typically along the seam of a ply with the lowest strength, though it is hard to determine which one is that. The unevenness of the seam gives rise to a higher stress level as compared to the remaining part of the section leading to the failure at the seam a specific ply. Once it fails, load is transferred to the remaining plies, which in turn don't have enough strength to withstand it, hence leading to final failure.

\subsubsection{SW-Round-2.0 $\quad$ S0.125 Samples}

The SW-Round-2.0×0.125 samples with nominal lengths of 2', 6' and 12' were tested under simply supported boundary conditions to help facilitate any possible buckling due to torsion. However, as $\theta_{\text {RVIT }}$ was not measurable beyond the range of $\pm 60^{\circ}, \theta_{\text {sg }}$ served the purpose effectively.

The graphs with $\mathrm{J} \theta$ along $\mathrm{x}$-axis and TL along $\mathrm{y}$-axis, depicting the values of $\mathrm{G}$ corresponding to multilinear trendlines, are shown in Figures 6-12 through 6-14. All the three graphs represent almost similar behavior. The value of $G$ is found to decrease in every subsequent stage, indicating some permanent ply-damage taking place, hence decreasing the torsional load carrying capacity in the following stage. The first load-level is typically around $45 \%$ of $\mathrm{T}_{\max }$ during which the material has its full strength and rigidity. For all practical design purposes, load should be kept within this range, instead of the maximum value. 


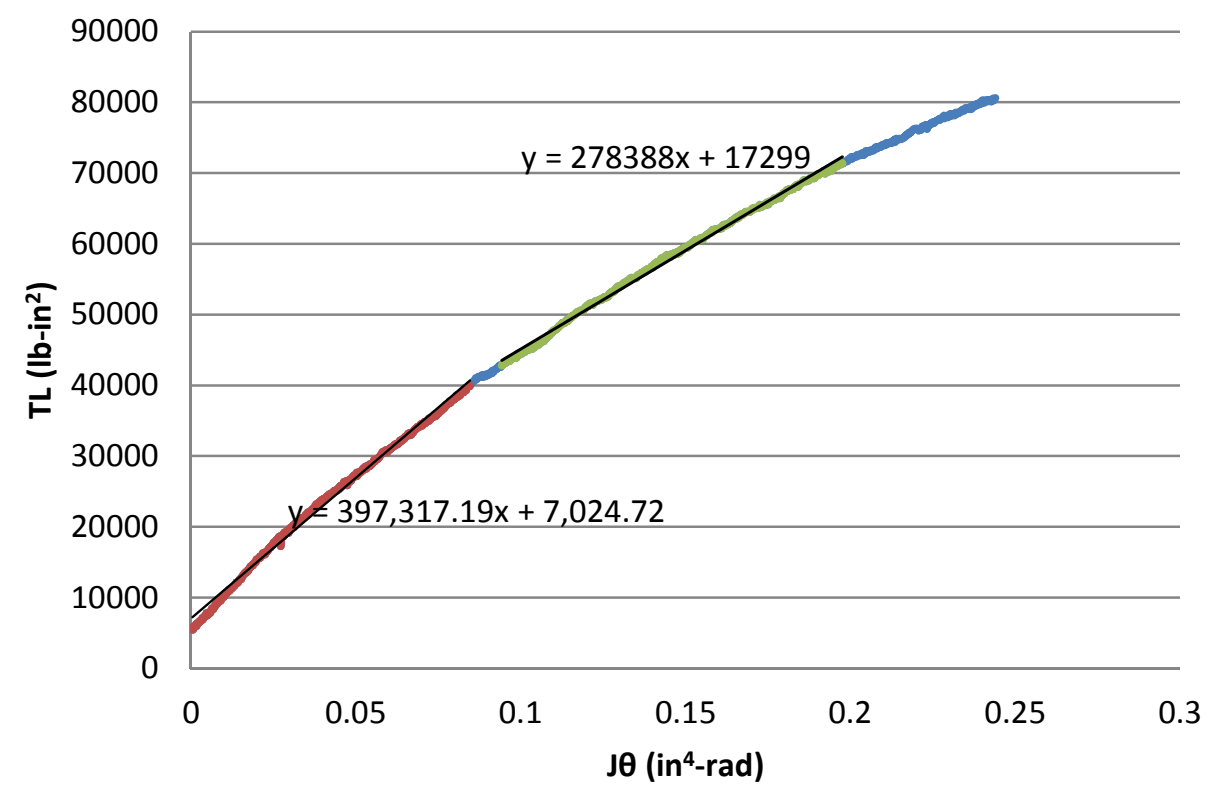

Figure 6-12: J $\theta$ vs TL of SW-Round-2.0×0.125- 24

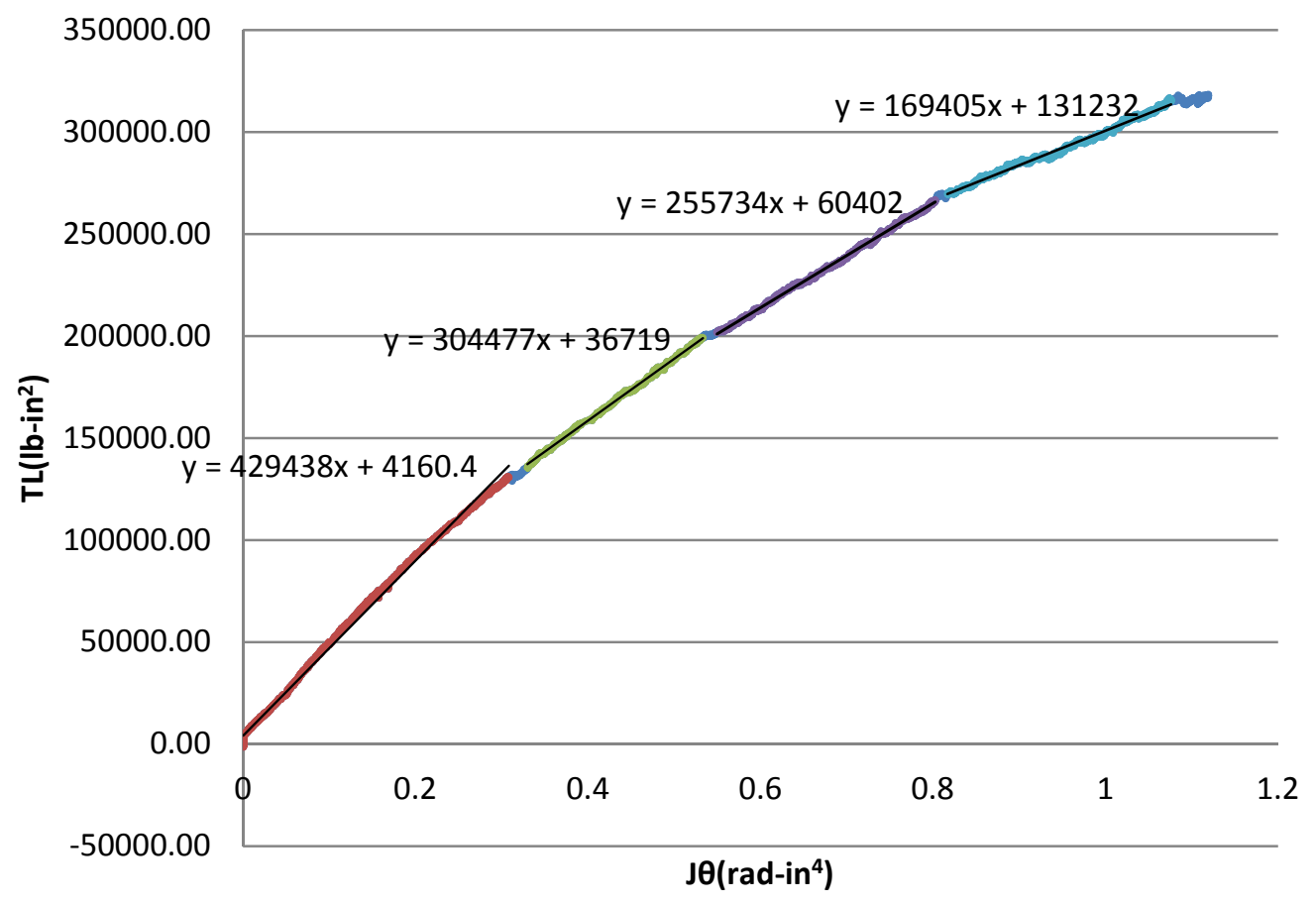

Figure 6-13: J $\theta$ vs TL of SW-Round-2.0×0.125- 70 
In Figure 6-13, a quadrilinear trend is only a matter of judgment. Stage-2 and 3 are quite close, while in the last stage the properties are too deteriorated to be accounted for

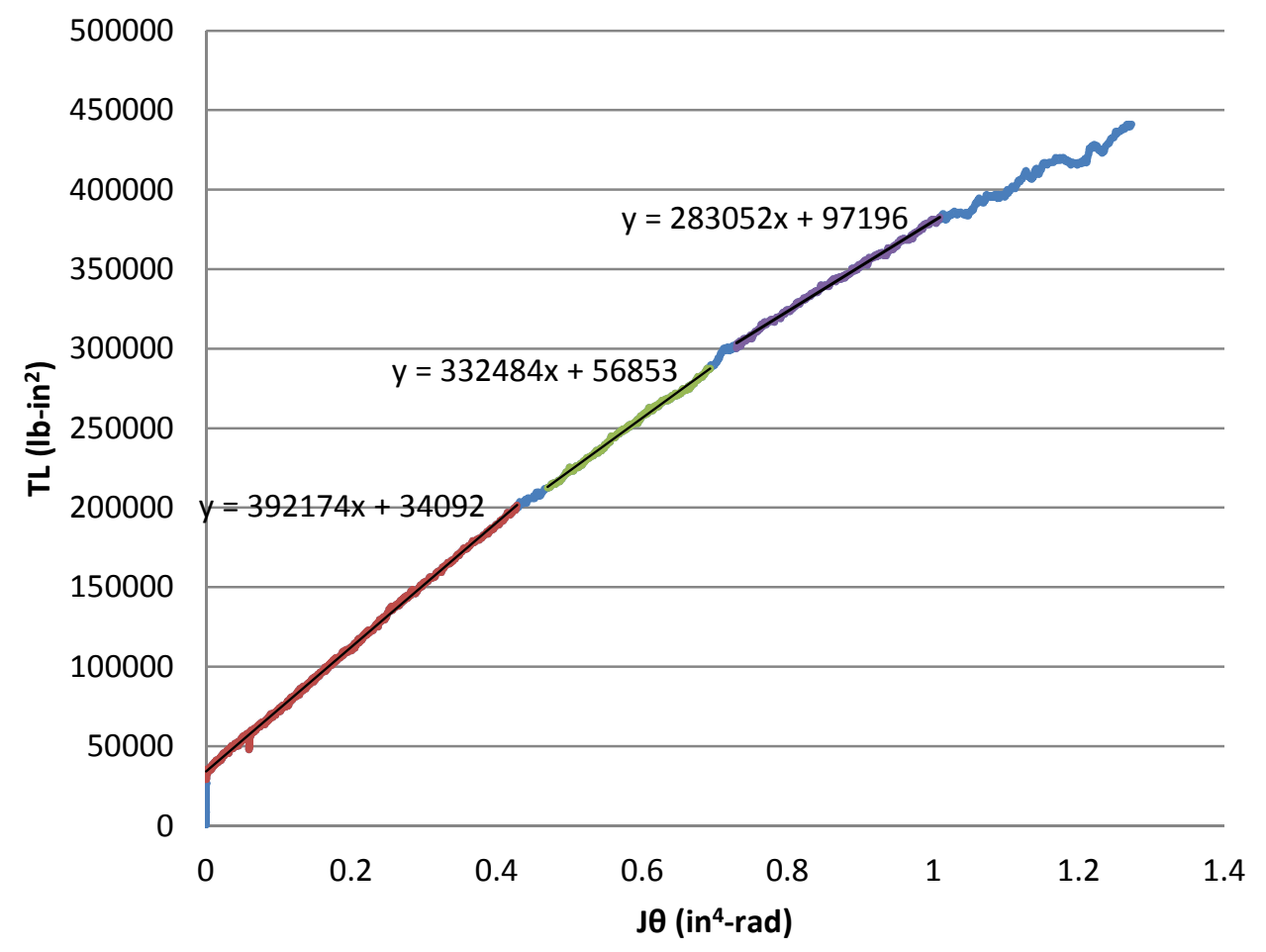

Figure 6-14: $\mathrm{J} \theta$ vs TL of SW-Round-2.0×0.125- 144

The test results of SW-Round-2.0×0.125 samples are shown in Table 6-2 (a) and the comparison of experimental and analytical values is given in Table 6-2 (b). The percent difference in theoretical and experimental values of $\theta$ ranges upto around $50 \%$ in some cases and that in $\mathrm{G}$ values is staying around $40 \%$. The main source of this error is the wrong value of $\mathrm{G}_{\mathrm{th}}=0.67 \mathrm{msi}$, controlled by $A_{66}^{-1}$, in turn influenced by $\mathrm{V}_{\mathrm{f}}$. As described in Chapter-4, $\mathrm{V}_{\mathrm{f}}$ was found through burnout test. But in FRP composite materials, the fiber concentration may vary significantly along the cross-section and if the burnout test sample is taken from a location such as the seam, some misleading results may come out.

It is evident from the experimental behavior that the $\mathrm{G}$ value is around $0.40 \mathrm{msi}$, a typical of such kind of samples. Hence $\mathrm{V}_{\mathrm{f}}$ should also not be more than $35 \%$. 
Table 6-3 (a): Torsion Test Results of SW-Round-2.0 $\times 0.125$

\begin{tabular}{|c|c|c|c|c|c|c|c|c|c|c|c|c|}
\hline $\mathbf{L}$ & $L / d$ & $d / t$ & \multirow{2}{*}{\begin{tabular}{|l|} 
Load- \\
Level
\end{tabular}} & $\mathbf{P}$ & $\left|\varepsilon_{45}\right|$ & $\theta_{\text {RVIT }}$ & $\mathbf{T}$ & $\tau$ & $\gamma$ & $\theta_{\mathrm{sg}}$ & $\mathbf{G}$ & \multirow{2}{*}{$\begin{array}{l}\text { Mode of } \\
\text { Failure }\end{array}$} \\
\hline \multirow[t]{2}{*}{ inch } & & & & lbs & $\mu \varepsilon$ & degree & lb-in & ksi & $\mathrm{rad}$ & degree & $\mathrm{msi}$ & \\
\hline & & & & & & & Eqn 6-2 & Eqn 6-1 & Eqn 6-5 & Eqn 6-7 & Fig 6-10 & \\
\hline \multirow{3}{*}{20} & \multirow{3}{*}{10} & \multirow{3}{*}{17} & $0.5 \mathrm{~T}_{\max }$ & 307 & 3500 & 7.4 & 1997 & 3220 & 0.007 & 8.0 & 0.39 & \multirow{3}{*}{$\begin{array}{c}\text { Strength } \\
\text { Failure with a } \\
\text { Longitudinal } \\
\text { Crack }\end{array}$} \\
\hline & & & $0.88 \mathrm{~T}_{\max } \mid$ & 548 & 7856 & 17.0 & 3565 & 5750 & 0.016 & 18.3 & 0.28 & \\
\hline & & & Ultimate & 620 & 10283 & 21.2 & 4030 & 6500 & 0.020 & 23.0 & 0.17 & \\
\hline \multirow{4}{*}{67} & \multirow{4}{*}{33.5} & \multirow{4}{*}{17} & $0.41 \mathrm{~T}_{\max } \mid$ & 300 & 3600 & 23 & 1960 & 3161 & 0.0072 & 27.7 & 0.43 & \multirow{4}{*}{$\begin{array}{c}\text { Strength } \\
\text { Failure with a } \\
\text { Longitudinal } \\
\text { Crack }\end{array}$} \\
\hline & & & $0.63 \mathrm{~T}_{\max }$ & 459 & 6150 & $\begin{array}{l}\text { Out of } \\
\text { Range }\end{array}$ & 2984 & 4813 & 0.0123 & 47.2 & 0.30 & \\
\hline & & & $0.83 \mathrm{~T}_{\max } \mid$ & 614 & 9276 & $\begin{array}{l}\text { Out of } \\
\text { Range }\end{array}$ & 3990 & 6435 & 0.018 & 69.0 & 0.25 & \\
\hline & & & Ultimate & 733 & 13032 & $\begin{array}{l}\text { Out of } \\
\text { Range }\end{array}$ & 4765 & 7685 & 0.026 & 100 & 0.17 & \\
\hline \multirow{4}{*}{138} & \multirow{4}{*}{69} & \multirow{4}{*}{17} & $0.45 \mathrm{~T}_{\max } \mid$ & 224 & 2463 & 32 & 1460 & 2355 & 0.0049 & 38.7 & 0.39 & \multirow{4}{*}{$\begin{array}{c}\text { Strength } \\
\text { Failure with a } \\
\text { Longitudinal } \\
\text { Crack }\end{array}$} \\
\hline & & & $0.65 \mathrm{~T}_{\max }$ & 318 & 3954 & $\begin{array}{l}\text { Out of } \\
\text { Range }\end{array}$ & 2067 & 3334 & 0.0079 & 62.5 & 0.33 & \\
\hline & & & $0.86 \mathrm{~T}_{\max }$ & 426 & 5812 & $\begin{array}{l}\text { Out of } \\
\text { Range }\end{array}$ & 2773 & 4473 & 0.0116 & 91.7 & 0.28 & \\
\hline & & & Ultimate & 492 & 6681 & $\begin{array}{l}\text { Out of } \\
\text { Range }\end{array}$ & 3200 & 5161 & 0.0134 & 106 & & \\
\hline
\end{tabular}

Table 6-4 (b): Experimental vs Analytical Results of SW-Round-2.0×0.125

\begin{tabular}{|c|c|c|c|c|c|c|c|c|c|}
\hline \multirow{2}{*}{$\mathbf{L}$} & \multirow{3}{*}{$\begin{array}{l}\text { Load- } \\
\text { Level }\end{array}$} & \multicolumn{3}{|c|}{ Experimental Values } & \multicolumn{2}{|c|}{ Analytical Values } & \multicolumn{3}{|c|}{$\%$ Difference } \\
\hline & & $\theta_{\mathrm{RVIT}}$ & $\theta_{\mathrm{sg}}$ & $\mathbf{G}$ & $\mathbf{G}_{\text {th }}$ & $\theta_{\text {th }}$ & $\Delta \theta_{1}$ & $\Delta \theta_{2}$ & $\Delta \mathbf{G}$ \\
\hline inch & & degree & degree & $\mathrm{msi}$ & $\mathrm{msi}$ & degree & & & \\
\hline & & & Eqn 6-7 & Fig 6-10 & Eqn 6-16 & Eqn 6-1 & (1) & (2) & \\
\hline 20 & $0.5 \mathrm{~T}_{\max }$ & 7.4 & 8.0 & 0.39 & 0.67 & 5.5 & -34.3 & -45 & 41.8 \\
\hline 67 & $0.41 \mathrm{~T}_{\max }$ & 23 & 27.7 & 0.43 & 0.67 & 18.1 & -27.0 & -53 & 35.8 \\
\hline 138 & $0.45 \mathrm{~T}_{\max }$ & 32 & 38.7 & 0.39 & 0.67 & 27.8 & -15.1 & -39 & 41.8 \\
\hline
\end{tabular}

(1) $\frac{\theta_{t h}-\theta_{R V I T}}{\theta_{t h}}$ (2) $\frac{\theta_{t h}-\theta_{s g}}{\theta_{t h}}$

Zero error not adjusted 
The failure behavior of the 12' long test-specimen under torsional load is shown in Figure 6-15. The crack initiated almost in the middle and longitudinally propagated towards the fixed end. This type of failure is clearly a strength failure with the crack location most likely being along the seam of the test-specimen.

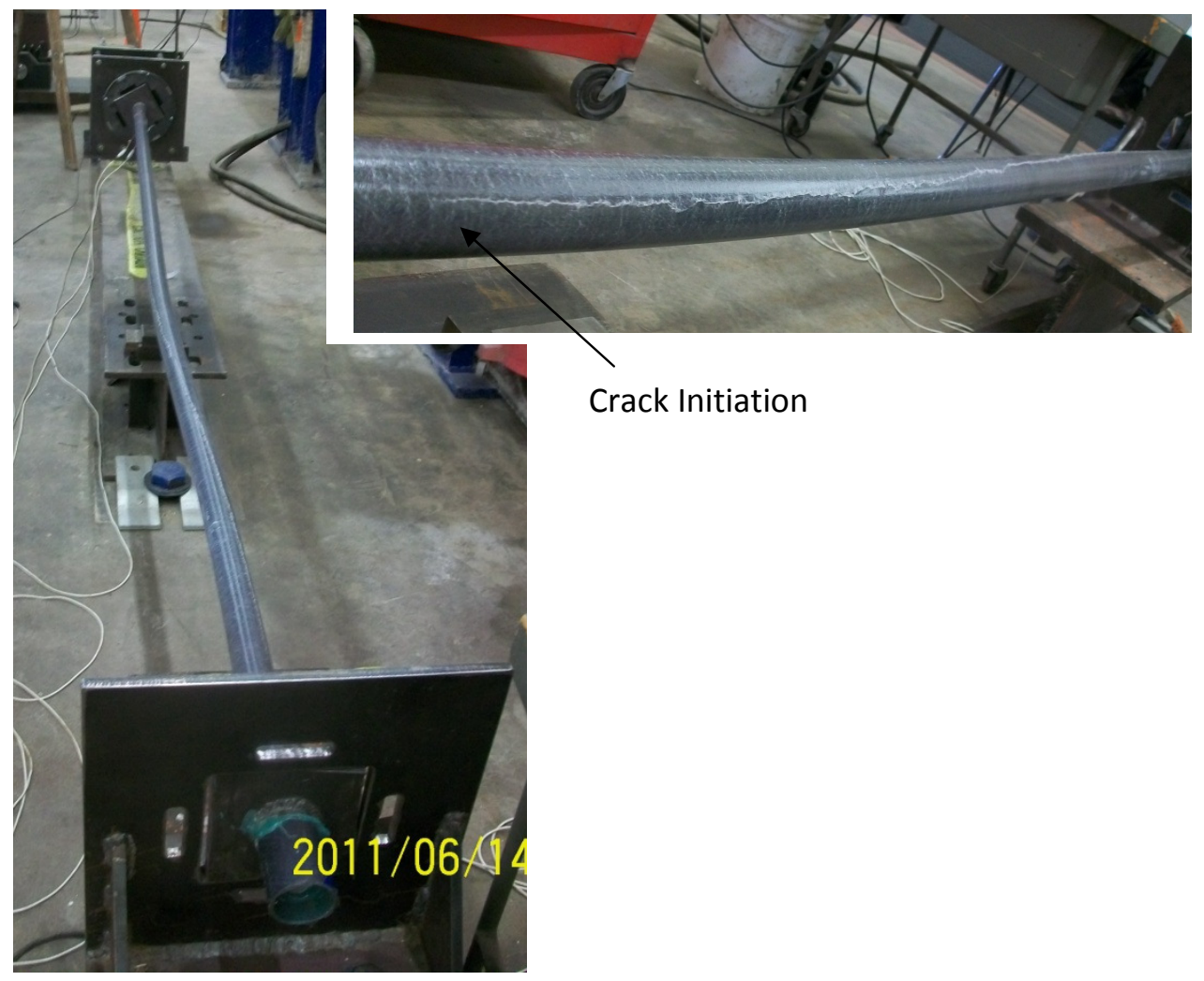

Figure 6-15: Torsional Failure of SW-Round-2.0×0.125- 144

\subsubsection{CP-Round-6.0 $\times 0.25-70$ Sample}

One CP-Round-6.0 $\times 0.25$ - 70 sample was tested under pure torsion with simply supported boundary conditions. This sample exhibited a very high torsional strength and could not be failed to rupture in the existing experimental set-up. However, from the $\mathrm{T}-\theta_{\mathrm{sg}}$ graph, as shown in Figure 6-16, a trilinear trend is evident. The slope in the second stage is less than that in the first stage, but the one in third stage is greater than that in the second stage. This behavior is non-typical, so no final conclusion can be drawn, except that the sample is far from failure. On the other hand, 
the T-ORVIT graph is showing that the RVIT was not installed properly, hence not giving useful data.

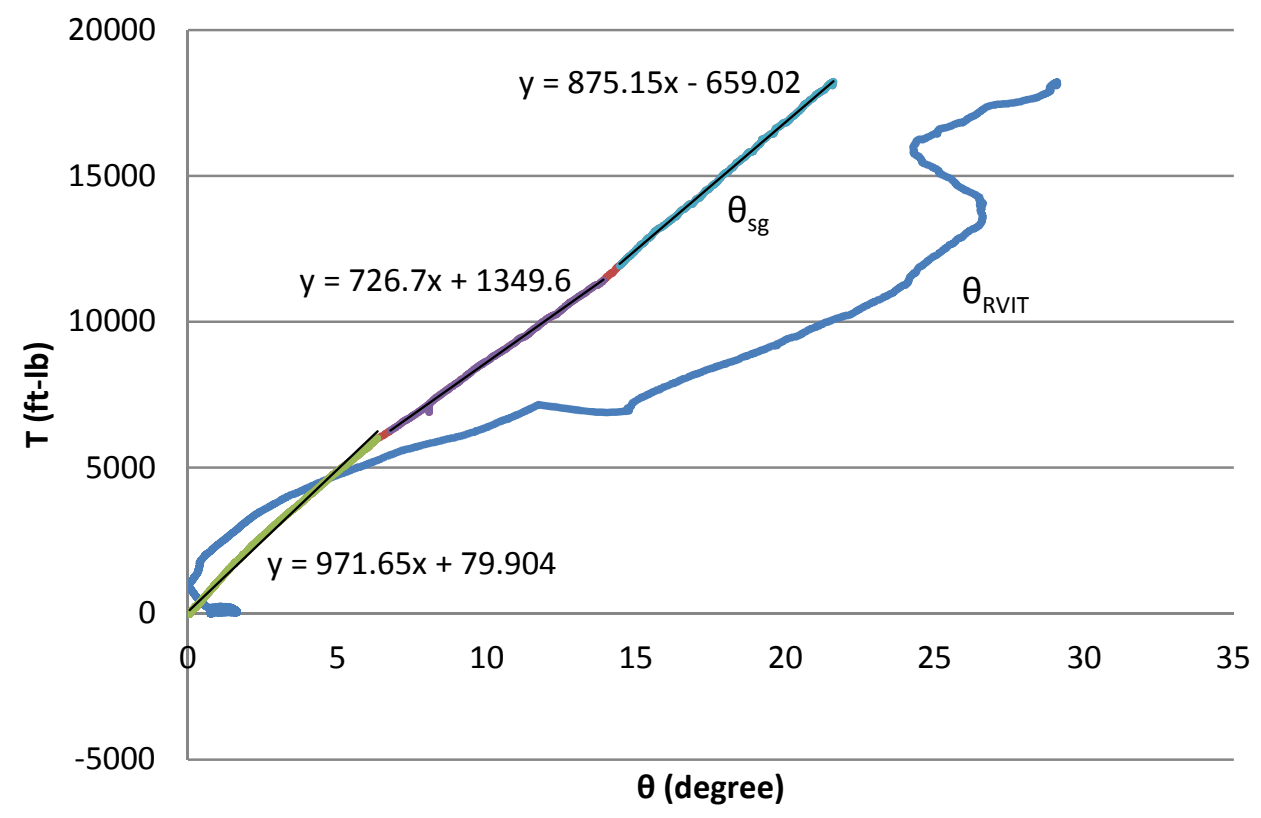

Figure 6-16: T vs $\theta$ Graph of CP-Round-6.0×0.25- 70

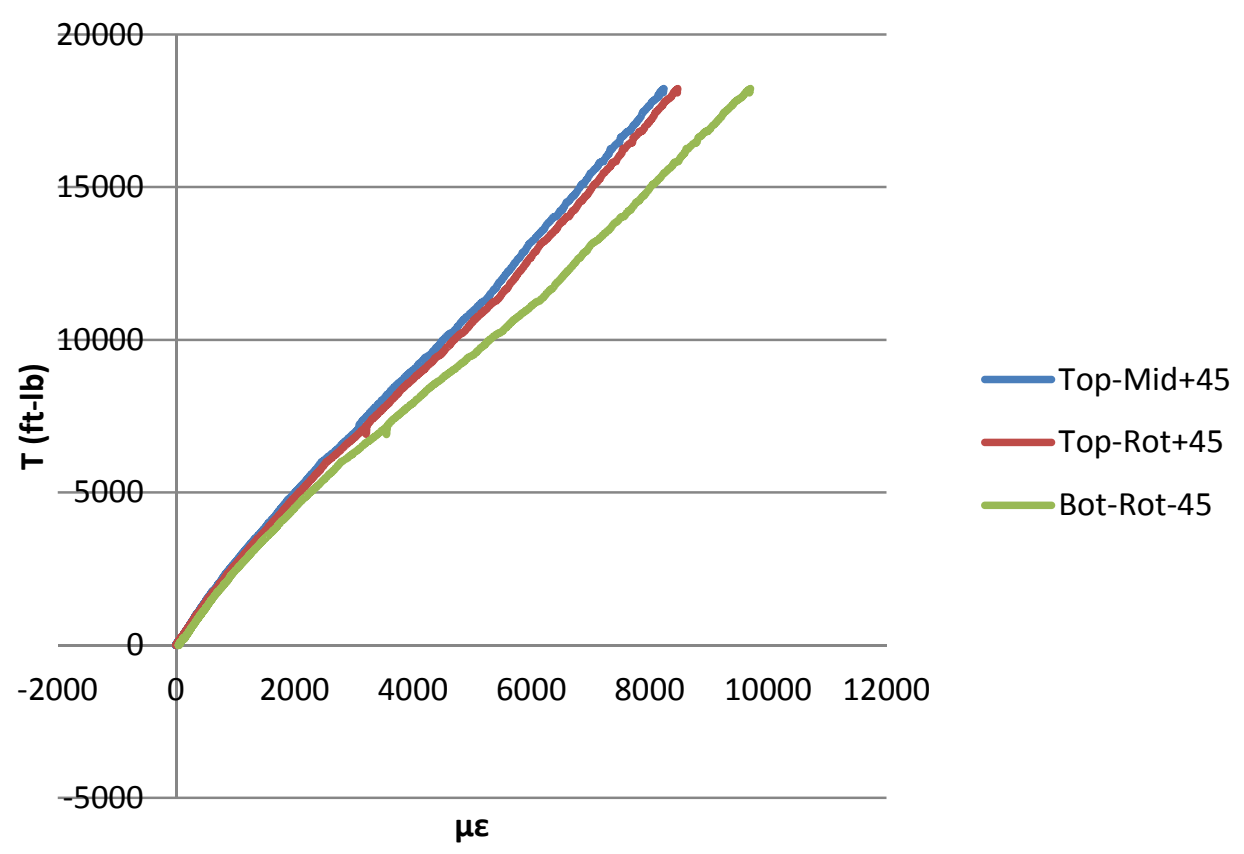

Figure 6-17: T vs $\varepsilon_{ \pm 45}$ Graph of CP-Round-6.0×0.25- 70 
The graph between torque and strains at $45^{\circ}$ is shown in Figure 6-17. The two values at the top are very close, but the one at bottom near the rotating end is little higher. From the symmetric shape and symmetric boundary conditions under pure torsion, all the three values however should be the same. Such differences in readings represent any minor variation within the material and/or data acquisition.

Table 6-5: Torsion Test Results of CP-Round-6.0 $\times 0.25-70$

\begin{tabular}{|c|c|c|c|c|c|c|c|c|c|c|c|c|}
\hline \multicolumn{3}{|c|}{ Dimensions } & \multicolumn{10}{|c|}{ Experimental Values } \\
\hline $\mathbf{L}$ & L/d & $d / t$ & \multirow{2}{*}{$\begin{array}{l}\text { Load- } \\
\text { Level }\end{array}$} & $\mathbf{P}$ & $\left|\varepsilon_{45}\right|$ & $\theta_{\text {RVIT }}$ & $\mathbf{T}$ & $\tau$ & $\gamma$ & $\theta_{\mathrm{sg}}$ & $\mathbf{G}$ & \multirow{2}{*}{$\begin{array}{l}\text { Mode of } \\
\text { Failure }\end{array}$} \\
\hline \multirow[t]{2}{*}{ inch } & & & & lbs & $\mu \varepsilon$ & degree & kip-in & ksi & $\mathrm{rad}$ & degree & msi & \\
\hline & & & & & & & Eqn 6-2 & Eqn 6-1 & Eqn 6-5 & Eqn 6-7 & \begin{tabular}{|l|} 
Fig $6-17$ \\
\end{tabular} & \\
\hline \multirow{3}{*}{64} & \multirow{3}{*}{10.7} & \multirow{3}{*}{24} & 1 & 11100 & 2790 & 8.8 & 72.22 & 5.80 & 0.0052 & 6.34 & 1.14 & \multirow{3}{*}{$\begin{array}{l}\text { The Sample } \\
\text { Did Not Fail }\end{array}$} \\
\hline & & & 2 & 21000 & 6200 & 24.1 & 137.0 & 11.00 & 0.0114 & 14.0 & 0.85 & \\
\hline & & & 3 & 33640 & 9700 & 29.0 & 218.6 & 17.50 & 0.0177 & 21.6 & 1.03 & \\
\hline
\end{tabular}

The experimental values corresponding to the trilinear trends of the unbroken sample are shown in Table 6-3, which yields a dramatically high $\mathrm{G}$ value of $1.14 \mathrm{msi}$. From coupon tests, $\sigma_{1}=72$ $\mathrm{ksi}, \mathrm{E}_{1}=5.2 \mathrm{msi}$ and $v_{12}=0.27$. If uniaxial rovings are assumed as major constituent, $\mathrm{V}_{\mathrm{f}}=47 \%$ and $\mathrm{G}_{12}=\mathrm{G}_{\text {section }}=0.45 \mathrm{msi}$. But it is obvious that the laminate of this sample consists of a welldesigned combination of $0^{\circ}, 90^{\circ}$ and $\pm 45^{\circ}$ rovings in addition to continuous strand mat.

Owing to the curvature of the coupons, neither it is possible to find $E_{2}$ from coupon transverse tension test nor possible to find $\mathrm{G}_{12}$ from coupon shear tests. It is therefore advisable to perform burnout test to effectively reveal the properties and compare with the experimental values. 


\subsubsection{Pure Torsion of Square Sections}

\subsubsection{Stress Concentration Factors Under Torsion}

The basic difference between the torsional behavior of a circular and a square section is that of the stress concentrations. Referring to Equation 6-24 and Figure 6-7 (a), the stress concentration factor under torsion $\left(K_{t s}\right)$ is calculated by taking into account the wall thickness and the inner corner radius, provided the $a / h$ and $r / h$ values are satisfied. For better accuracy, the $K_{t s}$ values were calculated from the dimensions of the pultrusion dies instead of the manufactured parts, as shown in Table 6-4. The data being unavailable for BRP-Box- $4 \times 4 \times 0.25$ sections, it is assumed to be same as BRP-Box-3.5×3.5×0.25.

Table 6-6: $K_{t s}$ Values for BRP-Box Samples

\begin{tabular}{|c|c|c|c|c|c|c|}
\hline Sample Die & $r$ (inch) & $h$ (inch) & $a$ (inch) & $a / h$ & $r / h$ & $K_{t s}$ \\
\hline BRP-Box-6×6×0.375 & 0.0313 & 0.375 & 5.25 & 14 & 0.08 & 3.40 \\
\hline BRP-Box-3.5×3.5×0.25 & 0.0313 & 0.25 & 3.0 & 12 & 0.125 & 3.14 \\
\hline
\end{tabular}

In both of the cases, $a / h$ values do not lie between 15 and 20 and $r / h$ values do not lie between 0.2 and 1.4, the calculated $K_{t s}$ values are not fully correct. It is therefore better to use even little higher value. For the sections under consideration, $K_{t s}$ can be safely taken as 3.5 to 3.6.

\subsubsection{SW-Box- $2 \times 2 \times 0.118-70$ Sample}

The effective length of this sample was 64" after excluding the end-plugs. From the TL-J $\theta$ graph shown in Figure 6-18, a trilinear trend is evident with a significant decrease in modulus of rigidity. As expected, the sample failed due to stress concentrations under torsion at the corner. However, the $K_{t s}$ value is unknown and so is the shear strength. If the fiber architecture is assumed to be same as 2 " diameter round samples, it is already established that $\mathrm{G}=0.67 \mathrm{msi}$ is incorrect. 
The shear stress at failure without $K_{t s}$ is $6.15 \mathrm{ksi}$; and as found from Iosepescu tests, the maximum shear stress of this kind of materials is typically 10 to $12 \mathrm{ksi}$. It can therefore be assumed that $K_{t s}$ is of the order of 2.

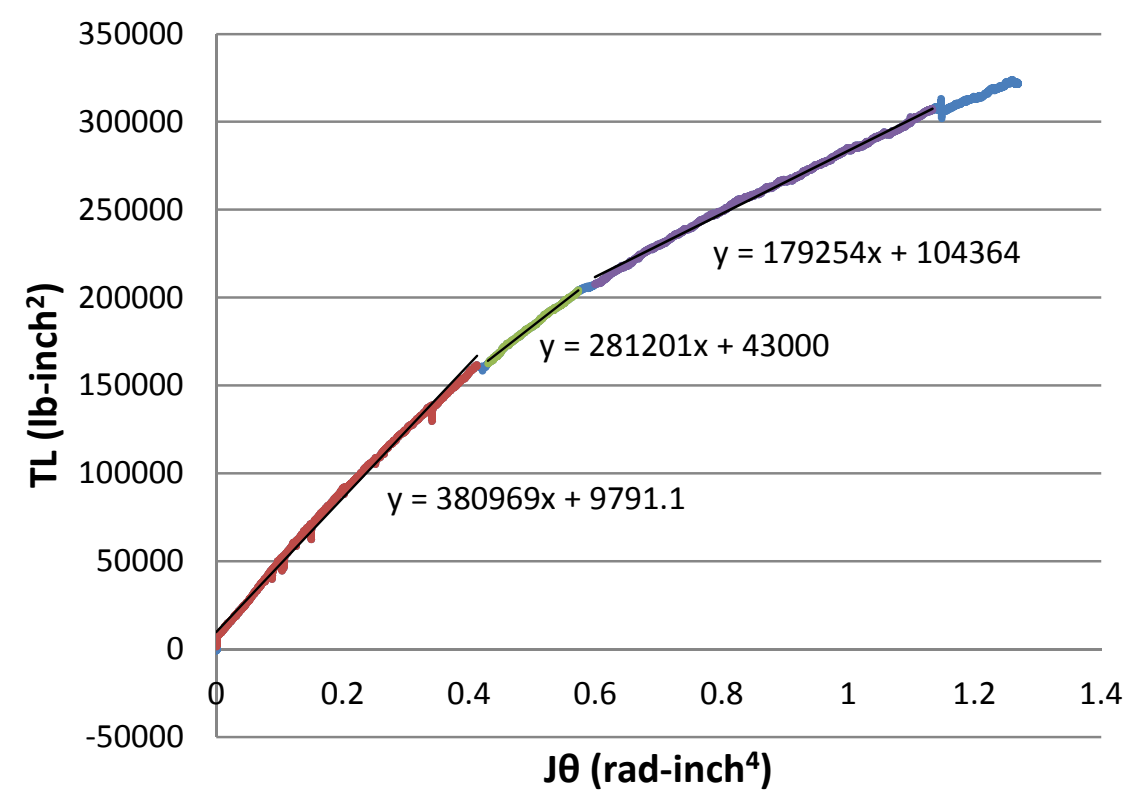

Figure 6-18: J $\theta$ vs TL of SW-Box-2.0×2.0×0.118- 70

Table 6-7: Torsion Test Results of SW-Box-2×2×0.118- 70

\begin{tabular}{|c|c|c|c|c|c|c|c|c|c|c|c|c|}
\hline \multicolumn{3}{|c|}{ Dimensions } & \multicolumn{10}{|c|}{ Experimental Values } \\
\hline $\mathbf{L}$ & \multirow{2}{*}{\begin{tabular}{|l|} 
h/b \\
$\mathrm{h}$
\end{tabular}} & \multirow[t]{2}{*}{$\mathbf{b} / \mathbf{t}$} & \multirow{2}{*}{\begin{tabular}{|l|} 
Load- \\
Level
\end{tabular}} & $\mathbf{P}$ & $\left|\varepsilon_{45}\right|$ & $\theta_{\text {RVIT }}$ & $\mathbf{T}$ & $\tau$ & $\gamma$ & $\theta_{\mathrm{sg}}$ & $\mathbf{G}$ & \multirow{2}{*}{$\begin{array}{l}\text { Mode of } \\
\text { Failure }\end{array}$} \\
\hline \multirow[t]{2}{*}{ inch } & & & & lbs & $\mu \varepsilon$ & degree & kip-in & ksi & $\mathrm{rad}$ & degree & $\mathrm{msi}$ & \\
\hline & & & & & & & Eqn 6-2 & Eqn 6-1 & Eqn 6-5 & Eqn 6-6 & Fig 6-18 & \\
\hline \multirow{3}{*}{64} & \multirow{3}{*}{32} & \multirow{3}{*}{17} & $0.5 \mathrm{~T}_{\max }$ & 386 & 3800 & 22 & 2.5 & 3.0 & 0.0076 & 28 & 0.38 & \multirow{3}{*}{$\begin{array}{c}\text { Failure at } \\
\text { Corner Due to } \\
\text { Stress } \\
\text { Concentration }\end{array}$} \\
\hline & & & $0.63 \mathrm{~T}_{\max }$ & 488 & 5200 & -- & 3.2 & 3.9 & 0.0105 & 39 & 0.28 & \\
\hline & & & $\mathrm{T}_{\max }$ & 770 & 11700 & -- & 5.0 & 6.15 & 0.023 & 86 & 0.18 & \\
\hline
\end{tabular}




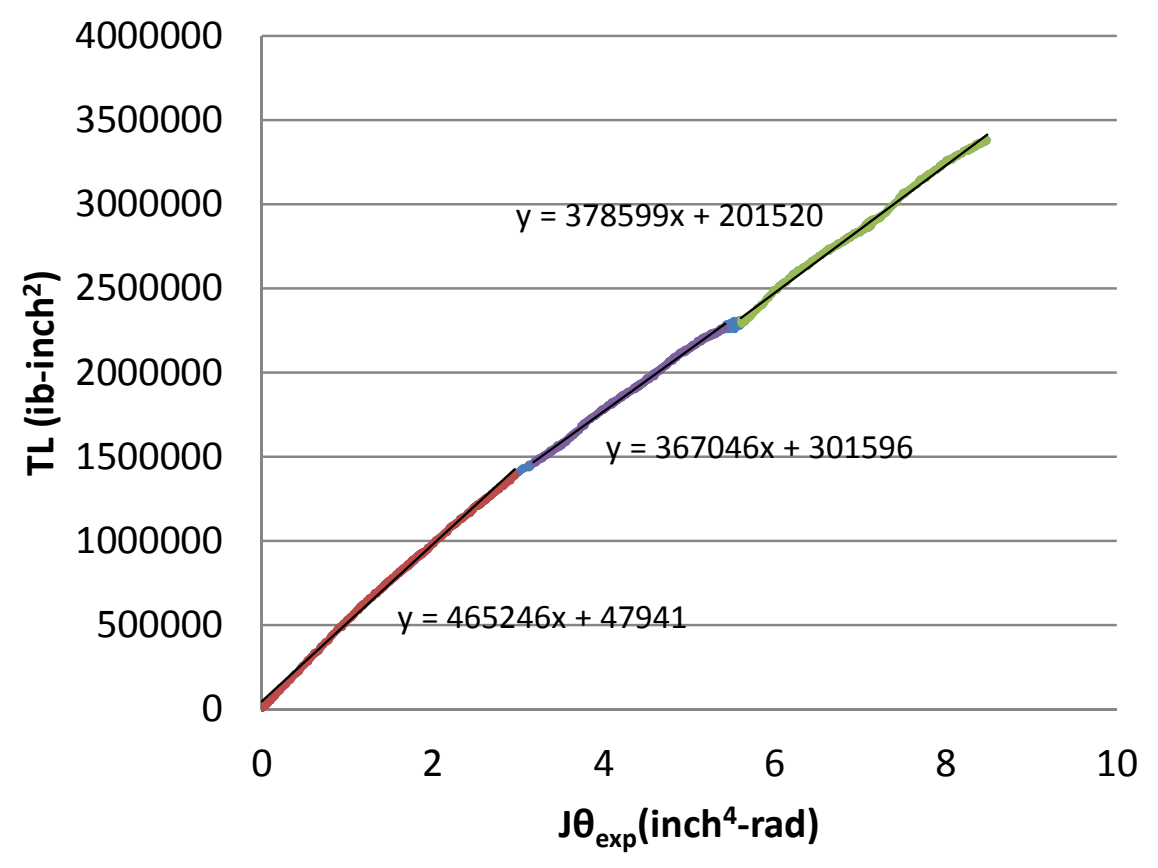

Figure 6-19: J $\theta$ vs TL of SW-Box- $4 \times 4 \times 0.25-70$

\subsubsection{SW-Box $-4 \times 4 \times 0.25-70$ Sample}

The effective length of this sample was also 64" due to end-plugs to prevent end crushing caused by torque transfer. The J $\theta$-TL graph, as shown in Figure 6-19, basically represents a bilinear trend, as the second and third lines have almost same slope. As can be seen, the first stage is upto $50 \%$ of $\mathrm{T}_{\max }$ with only $20 \%$ drop in modulus, showing good torsional load carrying capacity till failure.

The complete test results are shown in Table 6-6 (a) and comparison of experimental values corresponding to the first load-level with analytical values is shown in Table 6-6 (b). The $\mathrm{G}_{\text {th }}$ value is derived from the coupon tension test results, as given in Table 4-5, and is around 20\% less than $\mathrm{G}_{\text {exp }}$ of first stage. It refers to somewhat higher contribution of the CSM constituent towards torsional rigidity. As $\theta_{\text {th }}$ is also dependent upon $\mathrm{G}_{\text {th }}$, the similar kind of behavior can be seen in the values of $\Delta \theta_{1}$ and $\Delta \theta_{2}$. 
Table 6-8 (a): Torsion Test Results of Square Sections

\begin{tabular}{|c|c|c|c|c|c|c|c|c|c|c|c|c|}
\hline $\mathbf{L}$ & $\mathbf{L} / \mathbf{b}$ & $b / t$ & \multirow{2}{*}{\begin{tabular}{|l|} 
Load- \\
Level
\end{tabular}} & $\mathbf{P}$ & $\left|\varepsilon_{45}\right|$ & $\boldsymbol{\theta}_{\mathrm{RVIT}}$ & $\mathbf{T}$ & $\tau$ & $\gamma$ & $\theta_{\mathrm{sg}}$ & $\mathbf{G}$ & \multirow{2}{*}{$\begin{array}{l}\text { Mode of } \\
\text { Failure }\end{array}$} \\
\hline \multirow[t]{2}{*}{ inch } & & & & lbs & $\mu \varepsilon$ & degree & kip-in & ksi & $\mathrm{rad}$ & degree & $\mathrm{msi}$ & \\
\hline & & & & & & & Eqn 6-2 & Eqn 6-1 & Eqn 6-5 & Eqn 6-6 & & \\
\hline \multicolumn{11}{|c|}{ SW-Box-4×4×0.25 } & Fig 6-19 & \\
\hline \multirow{3}{*}{64} & \multirow{3}{*}{16} & \multirow{3}{*}{16} & $0.41 \mathrm{~T}_{\max }$ & 3358 & 3510 & 14.15 & 23.0 & 3.5 & 0.007 & 12.87 & 0.465 & \multirow{3}{*}{$\begin{array}{c}\text { Failure at } \\
\text { Corner Due to } \\
\text { Stress } \\
\text { Concentration }\end{array}$} \\
\hline & & & $0.67 \mathrm{~T}_{\max }$ & 5470 & 6425 & 27.34 & 35.5 & 5.4 & 0.013 & 23.56 & 0.367 & \\
\hline & & & $\mathrm{T}_{\max }$ & 8125 & 10054 & 31.9 & 52.8 & 8.0 & 0.020 & 36.90 & 0.38 & \\
\hline \multicolumn{11}{|c|}{ BRP-Box-4×4×0.25 } & Fig 6-21 & \\
\hline \multirow{3}{*}{64} & \multirow{3}{*}{16} & \multirow{3}{*}{16} & $0.34 \mathrm{~T}_{\max }$ & 1916 & 1534 & 9.10 & 12.45 & 1.9 & 0.003 & 5.55 & 0.617 & \multirow{3}{*}{$\begin{array}{c}\text { Failure at } \\
\text { Corner Due to } \\
\text { Stress } \\
\text { Concentration }\end{array}$} \\
\hline & & & $0.68 \mathrm{~T}_{\max }$ & 3832 & 3400 & 18.75 & 24.9 & 3.8 & 0.0068 & 12.6 & 0.50 & \\
\hline & & & $\mathrm{T}_{\max }$ & 5620 & 5500 & 29.15 & 36.53 & 5.54 & 0.0110 & 20.1 & -- & \\
\hline \multicolumn{11}{|c|}{ BRP-Box-6×6×0.375 } & Fig 6-23 & \\
\hline \multirow{3}{*}{64} & \multirow{3}{*}{10.7} & \multirow{3}{*}{16} & $0.50 \mathrm{~T}_{\max }$ & 7063 & 1528 & 8.41 & 45.9 & 2.1 & $\theta .0030$ & 3.8 & 0.37 & \multirow{3}{*}{$\begin{array}{c}\text { Failure at } \\
\text { Corner Due to } \\
\text { Stress } \\
\text { Concentration }\end{array}$} \\
\hline & & & $0.78 \mathrm{~T}_{\max }$ & 10895 & 2440 & 13.0 & 70.8 & 3.2 & $\theta .0049$ & 6.0 & 0.30 & \\
\hline & & & $\mathrm{T}_{\max }$ & 14000 & 3192 & 17.38 & 91.1 & 4.1 & 0.0064 & 7.92 & -- & \\
\hline
\end{tabular}

Table 6-9 (b): Torsion Test Results of Square Sections

\begin{tabular}{|c|c|c|c|c|c|c|c|c|c|}
\hline \multirow{3}{*}{$\begin{array}{c}\mathbf{L} \\
\text { inch }\end{array}$} & \multicolumn{4}{|c|}{ Experimental Values } & \multicolumn{2}{|c|}{ Analytical Values } & \multicolumn{3}{|c|}{$\%$ Difference } \\
\hline & \multirow{2}{*}{ Load-Level } & \multirow{2}{*}{\begin{tabular}{|c|}
$\boldsymbol{\theta}_{\text {RVIT }}$ \\
degree
\end{tabular}} & \multirow{2}{*}{$\begin{array}{c}\boldsymbol{\theta}_{\mathbf{s g}} \\
\text { degree }\end{array}$} & \multirow{2}{*}{$\begin{array}{c}\mathbf{G} \\
\mathrm{msi}\end{array}$} & \multirow{2}{*}{$\frac{\mathbf{G}_{\text {th }}}{\mathrm{msi}}$} & \multirow{2}{*}{\begin{tabular}{|c|}
$\boldsymbol{\theta}_{\text {th }}$ \\
degree
\end{tabular}} & \multirow[t]{2}{*}{$\Delta \theta_{1}$} & \multirow[t]{2}{*}{$\Delta \theta_{2}$} & \multirow[t]{2}{*}{$\Delta \mathbf{G}$} \\
\hline & & & & & & & & & \\
\hline & & & Eqn 6-6 & & Eqn 6-15 & Eqn 6-1 & (1) & (2) & \\
\hline \multicolumn{2}{|c|}{ SW-Box-4×4×0.25 } & & & Fig 6-19 & & & & & \\
\hline 64 & $0.41 \mathrm{~T}_{\max }$ & 14.15 & 12.87 & 0.465 & 0.39 & 16.4 & 13.7 & 21.52 & 19.32 \\
\hline \multicolumn{2}{|c|}{ BRP-Box-4×4×0.25 } & & & Fig 6-21 & & & & & \\
\hline 64 & $0.34 \mathrm{~T}_{\max }$ & 9.10 & 5.55 & 0.617 & 0.42 & 8.25 & 10.3 & 32.7 & 46.9 \\
\hline \multicolumn{2}{|c|}{ BRP-Box-6 $\times 6 \times 0.375$} & & & Fig 6-23 & & & & & \\
\hline 64 & $0.50 \mathrm{~T}_{\max }$ & 8.41 & 3.8 & 0.37 & 0.30 & 8.4 & 0 & -- & 23.0 \\
\hline$\frac{\theta_{t h^{-}}}{\theta}$ & $\frac{T}{T} \mid$ (2) $\mid \frac{\theta_{t h}-\theta_{t h}}{\theta_{t h}}$ & & & & & & 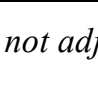 & & \\
\hline
\end{tabular}




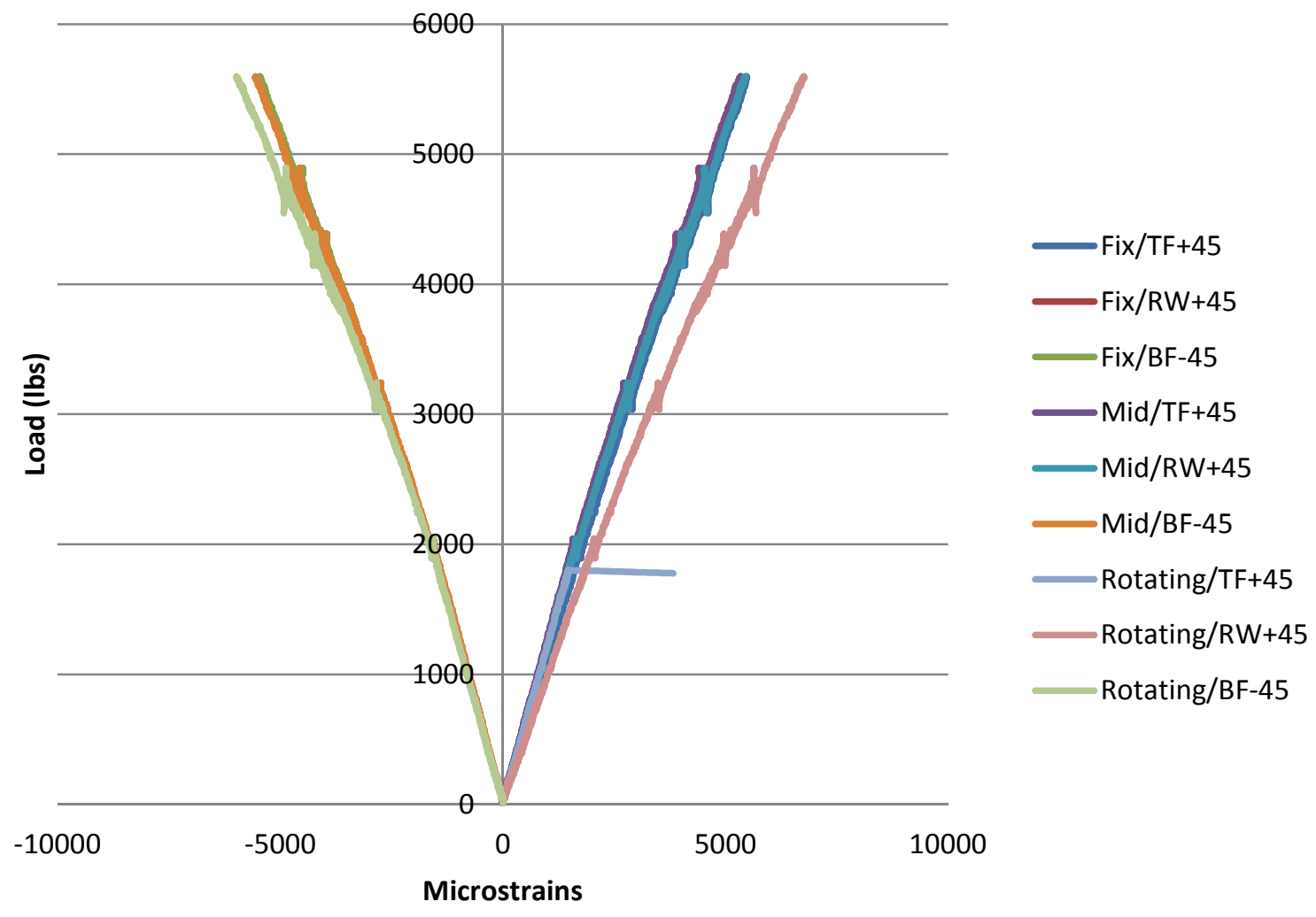

Figure 6-20: Torsional Load vs Microstrain of BRP-Box- $4 \times 4 \times 0.25-70$

\subsubsection{BRP-Box $-4 \times 4 \times 0.25-70$ Sample}

This sample was equipped with 9 strain gages: three each at the top, bottom and right web of the rotating and fixed ends plus the middle of the sample; all at $\pm 45^{\circ}$ orientations. The load vs microstrain graph is shown in Figure 6-20, which makes it very clear that the state of strain under pure torsion, hence that of stress, must be the same on all the four sides and along the whole length of a symmetric section. The minor variations are inherent to any real-material loaddeflection behavior and are inevitable. However, the strain gage is must be fixed at the middle of the face-width. Otherwise higher strains will be recorded corresponding to longer distance from the polar axis 
It can be concluded from Figure 6-20 that it should be enough to use couple of strain gages at different locations to record the torsional data, the values of which can be averaged out to use in further calculations.

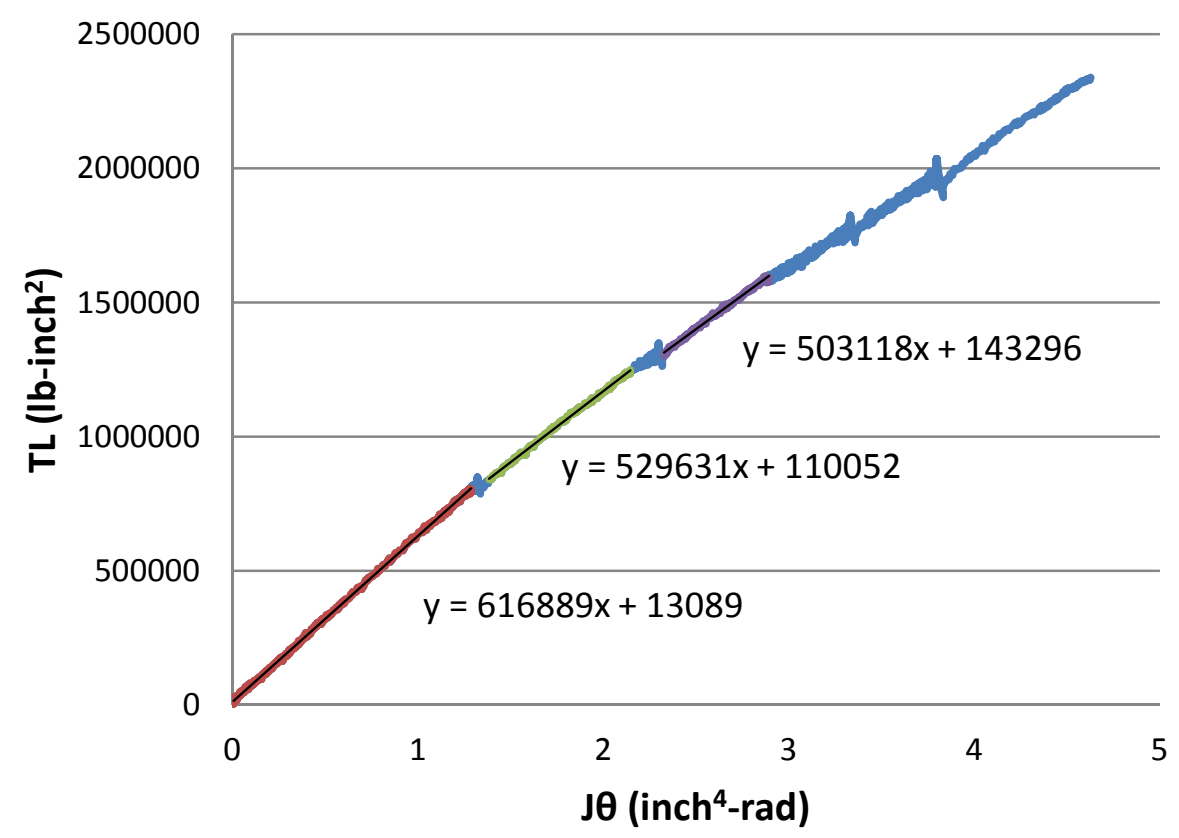

Figure 6-21: J $\theta_{\exp }$ vs TL of BRP-Box- $4 \times 4 \times 0.25-70$

The TL-J $\theta$ plot of the BRP-Box- $4 \times 4 \times 0.25-70$ Sample is shown in Figure $6-21$. The second and third trendline have almost the same slope and should considered as one stage, as given in the middle part of Table 6-6. The first stage was almost upto $35 \%$ of $\mathrm{T}_{\max }$ with only around $20 \%$ drop in modulus of rigidity. However, contrary to the SW-Box $-4 \times 4 \times 0.25-70$ Sample, the second stage did not prevail till failure, showing somewhat more degradation under applied torque.

The $\mathrm{G}_{\text {th }}$ value of this sample is around $47 \%$ less than $\mathrm{G}_{\text {exp }}$ of the first stage. As the CSM constituent is mainly responsible for torsional properties, it means that the fiber volume fraction of CSM in the laminate is higher than the generally assumed value of $25 \%$. It also reveals from Table 6-6 that there is a considerable difference between $\theta_{\mathrm{RVIT}}$ and $\theta_{\mathrm{sg}}$. As already discussed, an initial slack may occur in $\theta_{\text {RVIT }}$ value, if the sample is not properly mounted. So the $\theta_{\text {sg }}$ value is more reliable. 
Comparing torsional $\tau_{\max }=5.54 \mathrm{ksi}$ with Iosepescu test $\tau_{\max }=10 \mathrm{ksi}$, given in Table 4-, a factor of safety of the order of 2 can be approximated. This is in contrast to $\mathrm{K}_{\mathrm{ts}} \approx 3$, as given in Table 6-4. There are two possible reasons of this variation: either the corner radius of the actual 4" die is bigger than that of the considered 3.5" die, or the radius of the manufactured part increases in size after curing, hence reducing the stress concentrations. The tested sample is shown in Figure 6-22 with (a) complete length failed due to torsional stress concentrations, (b) end view of the tested sample.

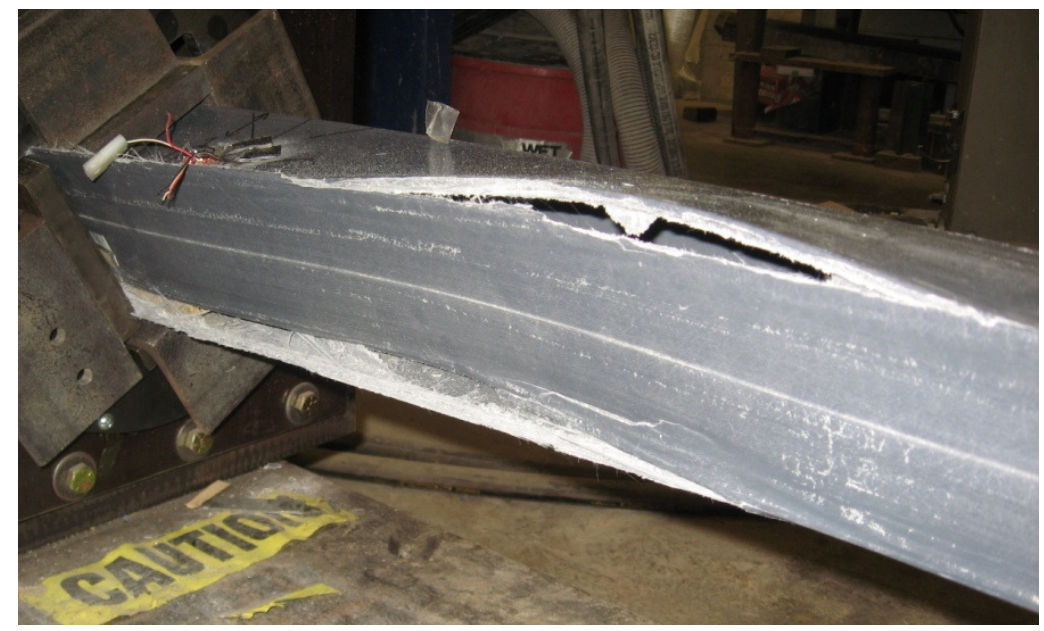

(a) Complete View of Breakage

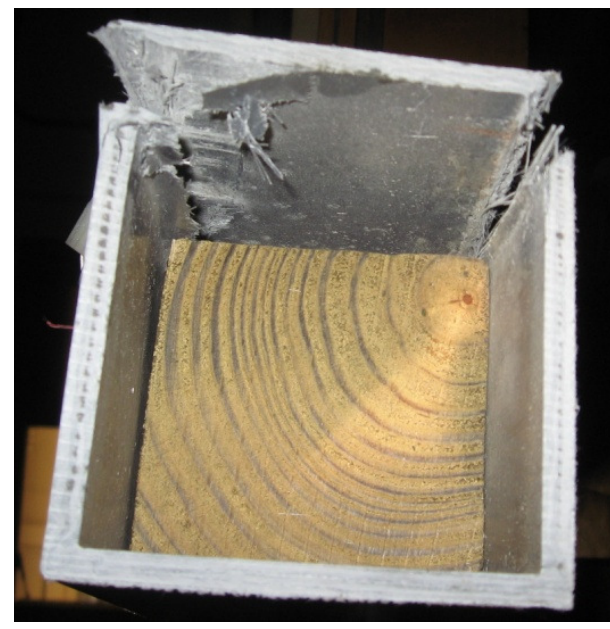

(b) Close-up from the End

Figure 6-22: Failure Behavior of the BRP-Box- $4 \times 4 \times 0.25-70$ 


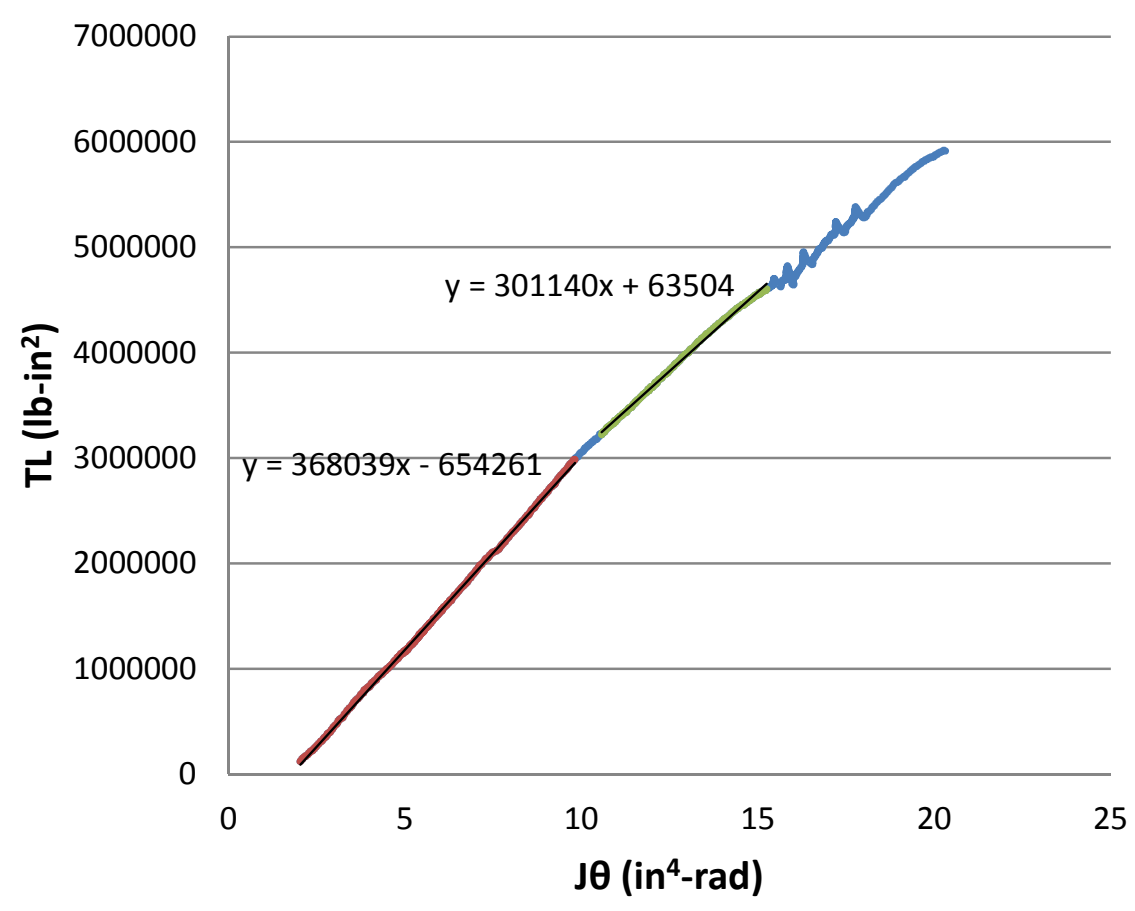

Figure 6-23: $\mathrm{J} \theta_{\exp }$ vs TL of BRP-Box- $6 \times 6 \times 0.375-70$

\subsubsection{BRP-Box-6 $\times 6 \times 0.375-70$ Sample}

The torsional behavior of this sample is shown in Figure 6-23 which resembles that of the $4 \times 4 \times 0.25$ sample. As shown in lower part of Table 6-6 (b), $\Delta \mathrm{G}$ and $\Delta \theta_{1}$ were in reasonably close range. However, there was a technical mistake, i.e., the strain gages were fixed atop the endplugs, hence not able to record the torsional data. Referring to lower part of Table 6-6, the mistaken values are presented but stricken-through, since they yield very valuable information. Assuming that the wooden end-plug and the corresponding part of the sample do not undergo torsion, the $\varepsilon_{45}$ values should have been zero. But in reality, the strain values were recorded, reflecting that the end-plug, as well as, the supported end of the sample do undergo torsion, though by a less amount. For example, $\theta_{\mathrm{sg}}=7.92^{\circ}$ vs $\theta_{\mathrm{RVIT}}=17.4^{\circ}$ suggests that almost half a torsion takes place at the supported ends.

Comparing torsional $\tau_{\max }=4.1 \mathrm{ksi}$ with Iosepescu test $\tau_{\max }=11.7 \mathrm{ksi}$, the $\mathrm{K}_{\mathrm{ts}}$ value comes out to be 2.85 . Whereas that suggested by Table $6-4$ is 3.40 , may be incorporating some factor of safety as well. 


\subsubsection{BRP-Box-3 $\times 3 \times 0.25-70$ Sample}

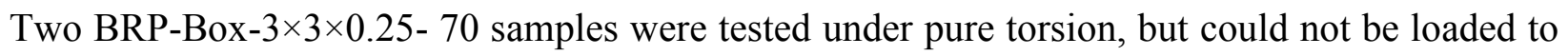
failure. However, their $\mathrm{T}-\mu \varepsilon$ diagrams gave useful information. The first sample was equipped with strain gages at $\pm 30^{\circ}$ and the second one was equipped with strain gages in the longitudinal $\left(0^{\circ}\right)$, transverse $\left(90^{\circ}\right)$ and $45^{\circ}$ directions. A comparison of microstrain values at different strain gage orientations can be made from the two T- $\mu \varepsilon$ diagrams shown in Figures 6-24 and 6-25.

For example, from Figure 6-24, at a torque of $3000 \mathrm{ft}-\mathrm{lb}$, strain at $\pm 30^{\circ}$ is around $\pm 4600 \mu \varepsilon$. From Figure 6-25, at the same torque level, strain at $-45^{\circ}$ is $-5200 \mu \varepsilon$ and that at $0^{\circ}$ and $90^{\circ}$ is negligible. Two important conclusions can be drawn from it. First, similar to isotropic materials, maximum longitudinal strain under pure torsion exists at $\pm 45^{\circ}$ in orthotropic materials. Second, as the longitudinal and transverse strains are negligible, the method of simplification of Equation 6-4 to Equation 6-5 is correct. 


\section{Torque vs srain curve}

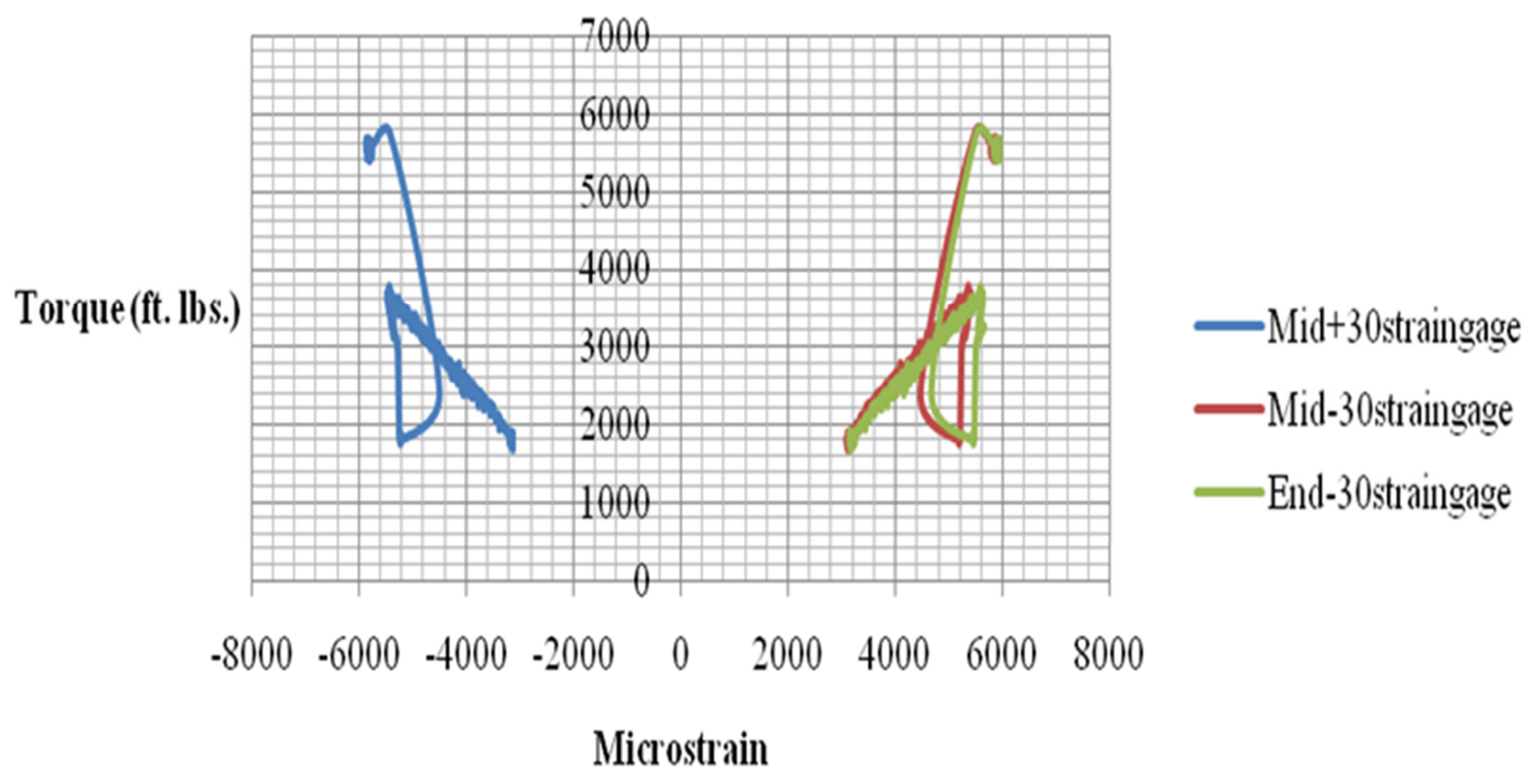

Figure 6-24: T vs $\mu \varepsilon @ 30^{\circ}$ of BRP-Box-3×3×0.25-70 


\section{Torque vs Strain for $3 \times 3$ box section}

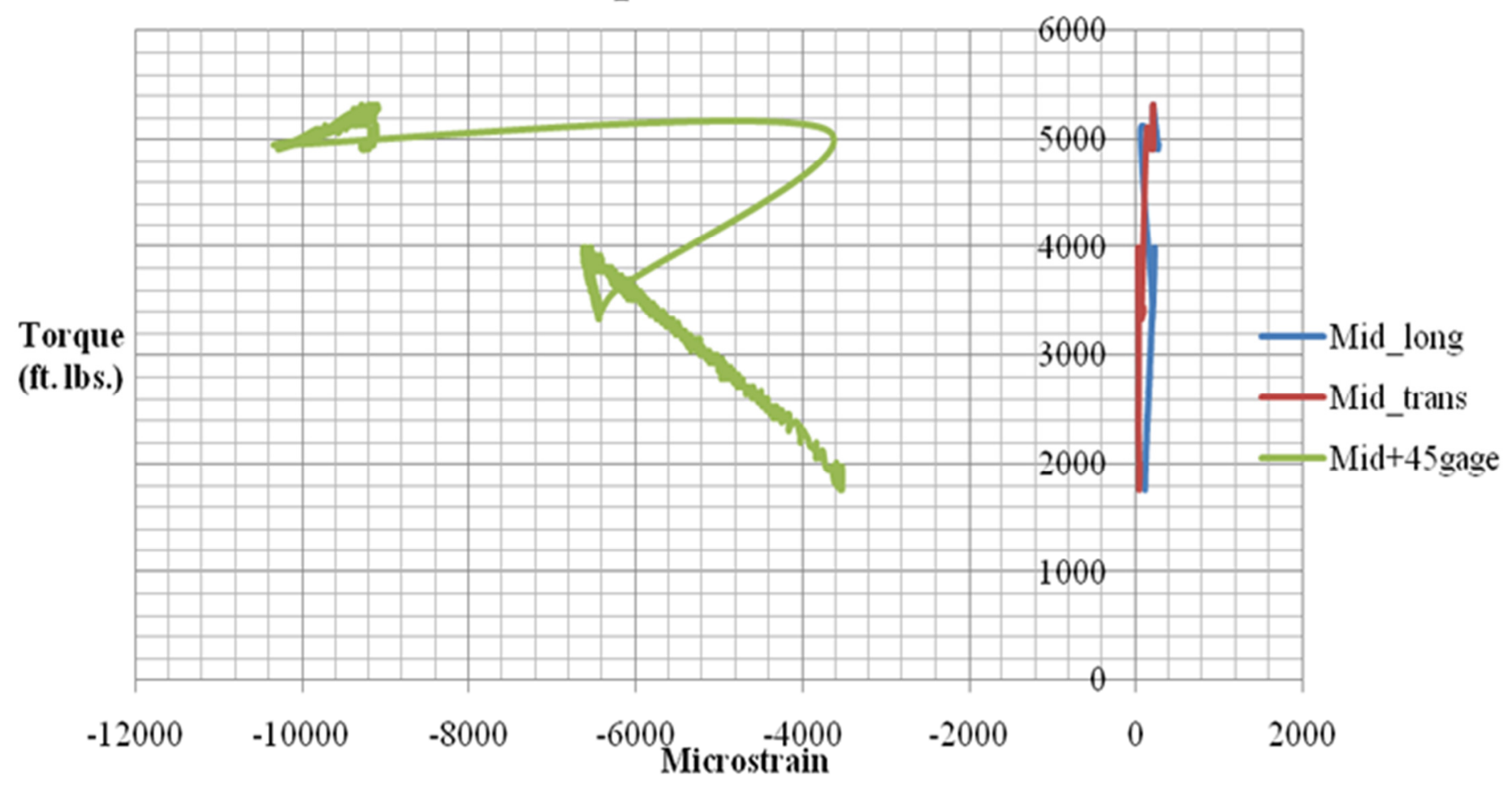

Figure 6-25: Tvs $\mu \varepsilon @ 0^{\circ},+45^{\circ}, 90^{\circ}$ of BRP-Box-3×3×0.25-70 


\subsection{Conclusions}

The samples tested under torsion consisted of round and square cross-sections, while the fiber architecture was either glass (CSM and roving) or hybrid glass-carbon (multiaxial). In all of the cases, few similar trends were clearly observed. First, the graph between J $\theta$ and TL exhibited a bilinear or trilinear trend. Second, all the samples failed under strength-failure. And third, variation in experimental and analytical results ranged different for different samples. The torsional behavior of the tested samples has been explained in the following sections.

\subsubsection{General Torsional Failure Behavior of Close-Shaped FRP Composite Members}

The failure behavior of close-shaped full-scale pultruded members under torsional loads can be understood from the analogy of their failure behavior under tension, as shown in Figure 6-24. The tension-failure starts with microcracks in the matrix while the fibers remain intact and carry load. When first ply failure occurs, the load is transferred to the remaining plies. The slope of the straight line changes and modulus of elasticity decreases. Then second ply failure takes place, hence further decreasing the modulus and so on.

On the other hand, torsion is a shear driven phenomenon. In order to understand the first ply failure under torsional shear with respect to the other plies, it is important to consider how the stacked plies have been arranged to form a section. It is found from the manufacturers' specifications that each ply, when arranged to form a closed shape, has some overlap or seam. Care is taken to distribute the seams of plies all around the cross-section to avoid staggering. Another important aspect is that the torsional strength of different types of plies is different. The plies consisting of CSM or $\pm 45^{\circ}$ rovings have much higher torsional strength than $0^{\circ} / 90^{\circ}$ rovings.

For instance, in a round section with CSM/Roving/CSM plies, the first-ply failure under torsion will take place due to warping of the rovings at the seam. Now, the load will be transferred to the remaining CSM plies and the slope of the load-deformation curve will drop. The CSM plies, having high torsional strength, will tend to carry the load. When load is further increased, one of 
them will fail under warping, not at its seam, but along the failure path of the previously failed ply, because this is where the load is being transferred. The third ply left will not be able to withstand much load and will immediately fail soon.

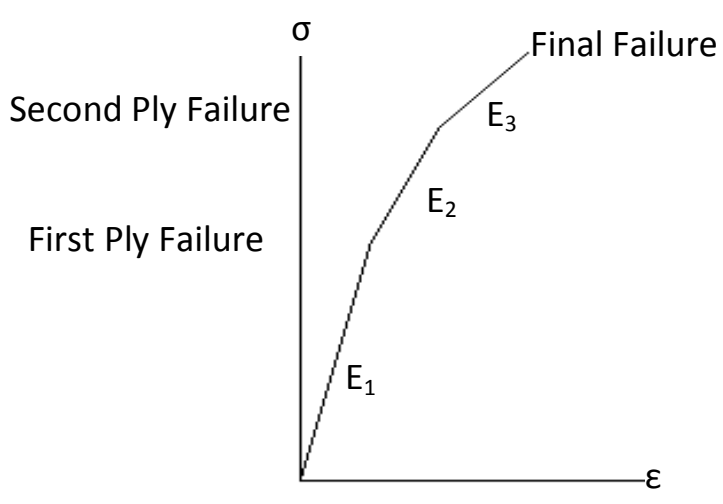

Tensile Failure

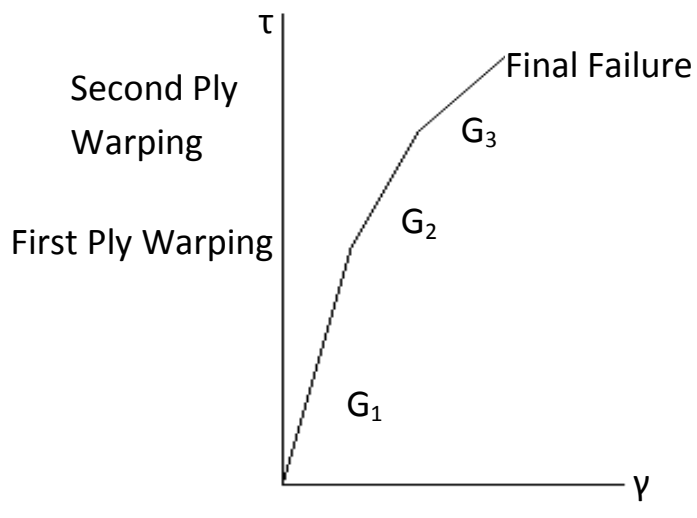

VS

\section{Torsional Failure}

Figure 6-26: Tensile Versus Torsional Behavior of Fiber Reinforced Ploymer Matrix Composites

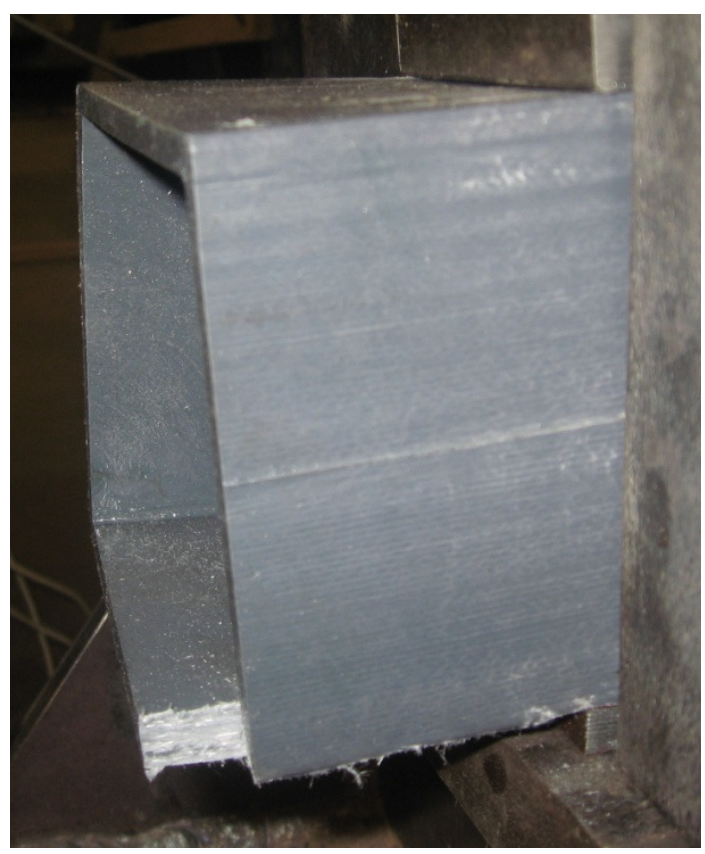

Figure 6-27: Torsional-Strength Failure of Square Cross-Section Under Warping

However, in case of a square cross-section, failure always takes place at the corners due to multiple factors, stress concentrations being the most dominant one. The torsional failure of a 
square cross-section under warping can be clearly seen in Figure 6-25, where one side of the broken corner has moved forward and the other side has moved inwards.

\subsubsection{Factors Causing Variation in Results}

As stated earlier, experimental values differ from the analytical ones in a range of more than $30 \%$. At a glance, it seems to be a big variation. But an insight through the nature of the problem reveals that this much variation can be taken as normal, owing to a number of factors, as described in the following sections.

\subsubsection{Inhomogeneous Material Structure of FRP Composites}

The fiber reinforced polymer composite materials are a typical example of inhomogeneous engineering materials. Even if they are manufactured very accurately, their load response cannot be as well-defined as that of metals, which have a highly organized crystalline structure. The pultruded members are manufactured via a continuous production-line and such a process itself cannot be much accurate.

Some of the evidences of variation in material properties are as under:

- When the cross-section of a pultruded member is viewed microscopically, the plythickness is never found to be uniform. Rather, it keeps on varying. For the analysis purpose, the ply-thickness is estimated on the basis of a number of readings. Thus the analytical results cannot perfectly represent the experimental behavior.

- The fiber volume fraction is found either by burnout test or by scanning electron micrograph. In both of the cases, the value depends upon the coupon under consideration, i.e., the fiber distribution may have some variation along the cross-section during manufacturing.

It is also found that the diameter of the glass-fiber is not constant and varies from 23 to $34 \mu \mathrm{m}$. However, it is not considered to be a source of error, because the method of finding $\mathrm{V}_{\mathrm{f}}$ takes care of the variation in diameter. 
- Fiber alignment of unidirectional fibers can never be perfect and the assumption that a fiber is able to carry $100 \%$ load in the desired direction is incorrect. There is always some loss of load associated with the variation in alignment. Similarly, the formulas used for $\bar{Q}_{i j}^{C S M}$ are only a close approximation and cannot represent the true load response of the CSM plies.

In case of noncircular cross-sections, the following additional factors should also be considered:

- Stress concentrations at the corners play an important role and are a major cause of failure of noncircular pultruded members at corners.

- Warping effect is very dominant in noncircular members, especially of open crosssections.

- The resin flow, as well as, the fiber distribution is much more uneven at the corners as compared to the location away from the corner.

\subsubsection{Behavior of End-Plugs}

Neither wooden nor mild-steel end-plugs can give perfect end-restraints. The wooden end-plugs undergo significant torsion themselves and are not advisable to use. Their only advantage is that the end-warping of the broken member can be observed clearly as shown in Figure 6.2. The mild-steel end-plugs are bonded in position with the help of an adhesive. In one of the experiments, a strain gage was installed on the testpiece atop such an end-plug and the magnitude of strain observed was about $1 / 5$ of the maximum strain observed.

\subsubsection{Frictional Losses in The Torsional Testing Rig}

The torsion testing rig consists of a metallic cylinder, housed in a frame, holding one end of the full-scale sample in its face plate. When the cable around the cylinder is pulled by the actuator, the cylinder tends to rotate in the frame, unavoidably causing friction. It assumed through a manual judgment that the frictional losses are small enough to be ignored. But actually, they contribute towards the variation between experimental and analytical results. 


\subsubsection{Rate of Application of Load}

The analytical formulas refer to the static loads only. Any dynamic effect will tend to decrease the load carrying capacity of the testpiece. When the load is applied through a microcontrolled hydraulic actuator, the feed-rate is determined automatically by the system as per load set-point. As there is no manual feed-rate option, attempt is made to vary the set-point to give a uniform feed-rate. However, it is an approximate method and any fluctuation in the rate of application of load may cause variation in results.

\subsubsection{Instrumentation Errors}

First and foremost, the strain gages should be mounted perfectly at $\pm 45^{\circ}$, because any misalignment will cause error in the recorded data. Maintaining an exact angle is not practically possible, specifically in round sample. Hence some error is always associated with the strain gage installation. In addition, all of the electronic measurement devices (strain gages, load cell and RVIT) are never $100 \%$ accurate even in the calibrated form. Inherently, there is a minute error. 


\section{CHAPTER 7 - Behavior Under Combined Bending and Torsion}

\subsection{Introduction}

In chapters 5 and 6, flexural and torsional behaviors of pultruded FRP composite sections were investigated respectively. In an attempt to investigate the behavior of such sections under combined bending and torsion, three section-types were selected, i.e., $4 \times 4 \times 0.25$ and $6 \times 6 \times 0.375$ box sections and $6 \times 0.25$ round sections, all with a nominal length of 70 ". The combined effects were created by first applying a bending load and then applying the torsional load till failure. For the first sample, bending moment was $25 \%$ of $\mathrm{M}_{\max }$, which was doubled and tripled for the following samples.

It was found that the combined bending and torsion problem of full-scale thin-walled orthotropic sections has not been solved in the contemporary research literature. Therefore, combined loading formulas of thin-walled isotropic sections were extended to orthotropic ones to establish analytical solutions and make a comparison with the experimental data.

Finally, the interactive curves were drawn with $\mathrm{M} / \mathrm{M}_{\max }$ along horizontal axis and $\mathrm{T} / \mathrm{T}_{\max }$ along vertical axis and the deviation of experimental curve from an ideal one was discussed.

\subsection{Problem Formulation}

The combined bending and torsion problem of orthotropic sections can be formulated by encompassing three main aspects, i.e., strength failure, buckling and interactive curves between bending and torsional moments, as described in the following sections.

\subsubsection{Strength Failure under Combined Bending and Torsion}

Based on the $\mathrm{L} / \mathrm{b}$ or $\mathrm{L} / \mathrm{d}$ values, the samples fall in the category of intermediate span beams, which typically fail due to inadequate resistance to strength. The state of combined bending and torsional stresses at a small element of area on the top flange is illustrated in Figure 7-1. With $\mathrm{x}-$ 
axis as the longitudinal axis and bending load acting vertically downward, the top flange is under compressive bending stress $\sigma_{\mathrm{x}}$ plus torsional shear stress, $\tau_{\mathrm{xy}}$. However, $\sigma_{\mathrm{y}}$ is negligible in this case, as was evident from the FEA results. Similarly, the local effects of load have also been excluded.

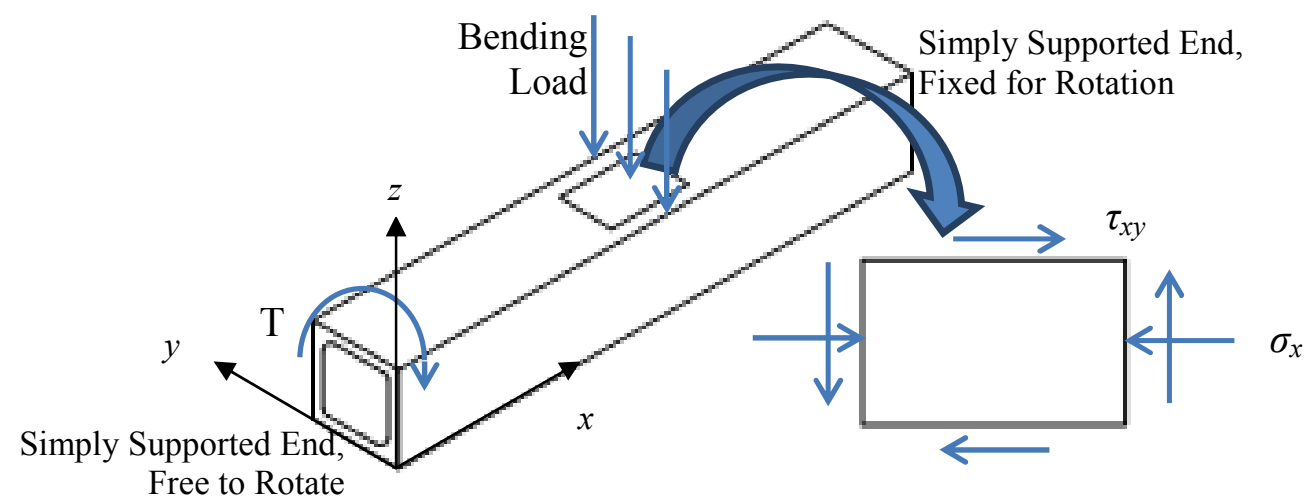

Figure 7-1: State of Combined Bending and Torsional Stresses at an Area-Element (Ignoring Stress Concentrations and Local Load Effects)

From the principles of mechanics of materials, an element of area is said to be in a state of plane stress if it is subject to $\sigma_{\mathrm{x}}, \sigma_{\mathrm{y}}$ and $\tau_{\mathrm{xy}}$ only, all the other stress components $\left(\sigma_{\mathrm{z}}, \tau_{\mathrm{xz}}\right.$ and $\tau_{\mathrm{yz})}$ being zero. Then at an angle $\theta_{\mathrm{p}}$ from the $\mathrm{x}$-axis, there exist orthogonal planes at which the normal stresses are maximum and minimum. These planes are called principal planes and the stresses are called principal stresses, as shown in Figure 7-2 and represented by Equations 7-1 and 7-2.

$$
\begin{gathered}
\tan 2 \theta_{p}=\frac{2 \tau_{x y}}{\sigma_{x}-\sigma_{y}} \\
\sigma_{\text {max } \text { min }}=\frac{\sigma_{x}+\sigma_{y}}{2} \pm \sqrt{\left(\frac{\sigma_{x}-\sigma_{y}}{2}\right)^{2}+\tau_{x y}^{2}}
\end{gathered}
$$




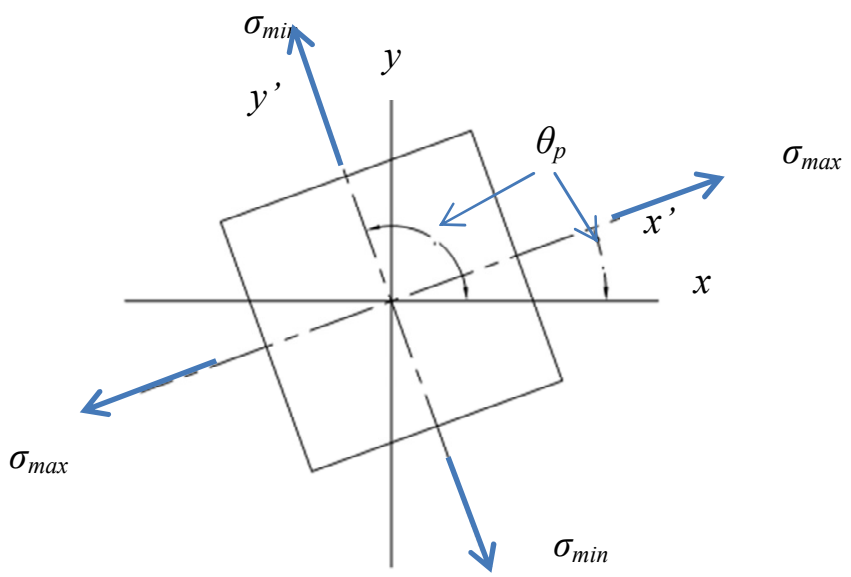

Figure 7-2: Principal Stresses at Principal Planes

Also, the planes of maximum shear stress occur at $45^{\circ}$ to the principal planes, given by the following formulas,

$$
\tan 2 \theta_{s}=-\frac{\sigma_{x}-\sigma_{y}}{2 \tau_{x y}}
$$

The maximum shear stress is then represented by

$$
\tau_{\max }=\sqrt{\left(\frac{\sigma_{x}-\sigma_{y}}{2}\right)^{2}+\tau_{x y}^{2}}
$$

Referring to combined load scenario of Figure 7-1, Equations 7-1 through 7-4 can be simplified as under,

$$
\begin{gathered}
\theta_{p}=\frac{1}{2} \tan ^{-1}\left(\frac{2 \tau_{x y}}{\sigma_{x}}\right) \\
\sigma_{\text {max } \text { min }}=\frac{\sigma_{x}}{2} \pm \sqrt{\left(\frac{\sigma_{x}}{2}\right)^{2}+\tau_{x y}^{2}} \\
\theta_{s}=-\frac{1}{2} \tan ^{-1}\left(\frac{\sigma_{x}}{2 \tau_{x y}}\right) \\
\tau_{\max }=\sqrt{\left(\frac{\sigma_{x}}{2}\right)^{2}+\tau_{x y}^{2}}
\end{gathered}
$$


Now, if the stress concentration factors for bending and torsion are taken into account, $\sigma_{\text {max }}$ and $\tau_{\text {max }}$ from Equations 7-6 and 7-8 should be comparable to the values found from coupon tests.

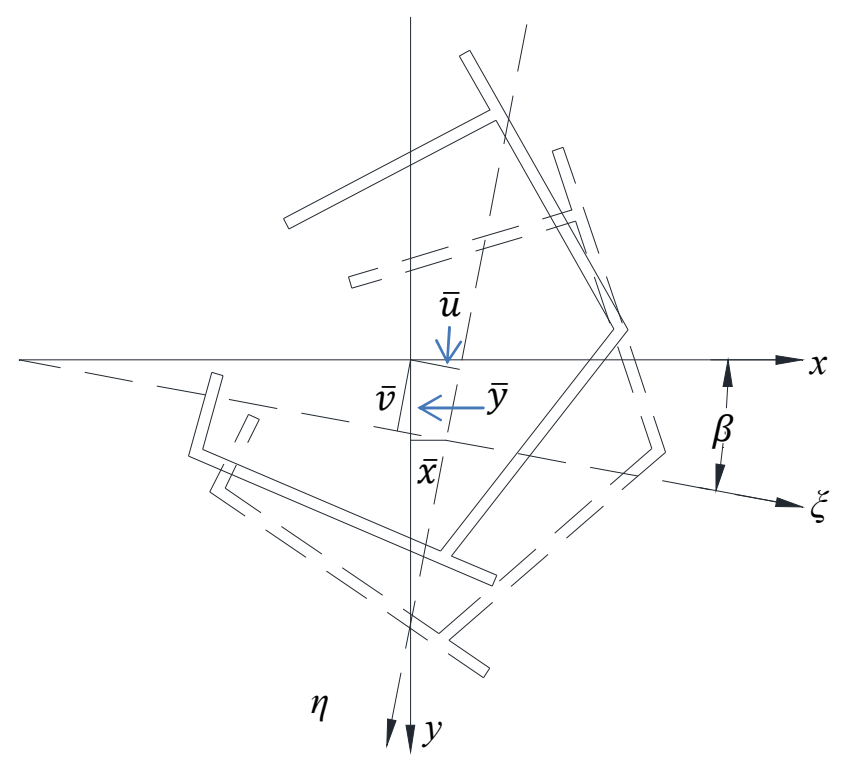

Figure 7-3: Arbitrary Open Section with Loacl and Glaobal Coordinates [5]

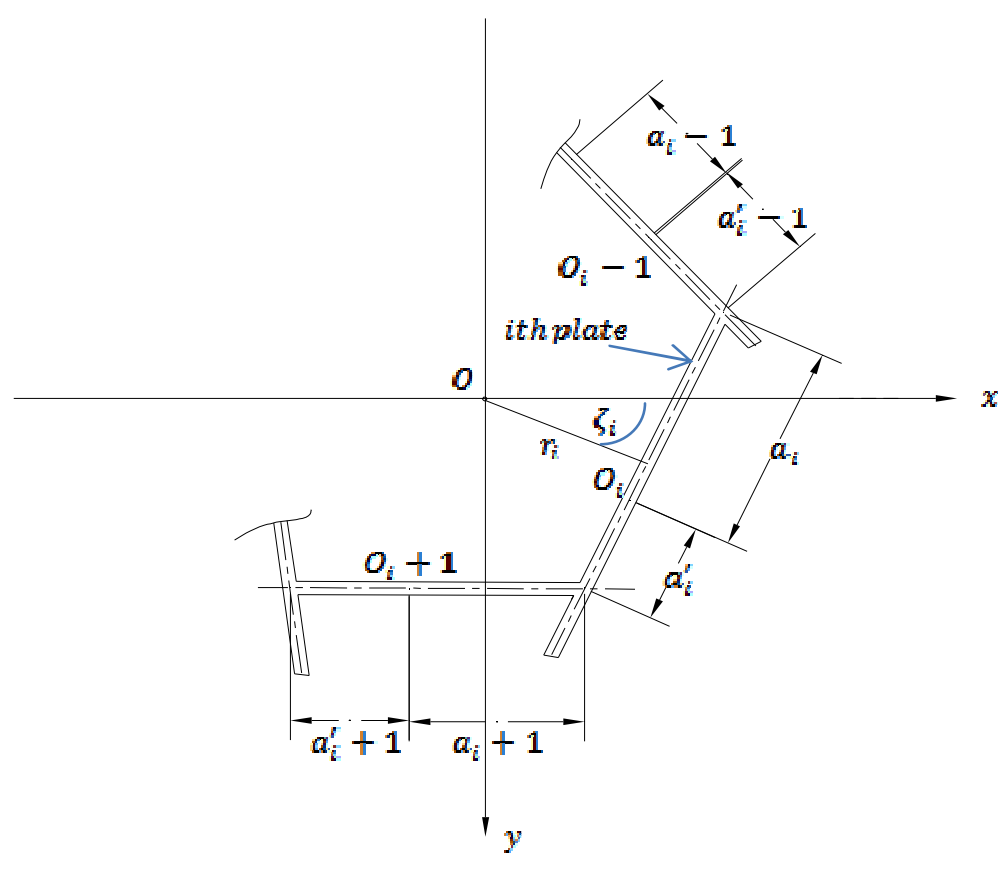

Figure 7-4: Constituent Plate System of the Open Section [5] 


\subsubsection{Buckling under Combined Bending and Torsion}

The potential energy method of bent and twisted bars of isotropic thin-walled sections was presented by Bleich et al [5]. This method has been extended to thin-walled orthotropic members of open and closed cross-sections.

As a general formula,

Potential Enerygy, $U=($ Potential Energy of External Loads)

+ (Strain Energy of Deformed Bar)

Strain Enerygy, $V=V_{1}$ Due to Longitudinal Direct Stresses under Bending

$+V_{2}$ Due to Shear Stresses under Torsion

$+V_{3}$ Due to Warping

$+V_{4}$ Due to Axial Compression

\subsubsection{Orthotropic Sections Under Combined Bending and Torsion}

A bar of arbitrary cross-section of $\mathrm{n}$ plates is shown in Figure 7-3 with $x$ and $y$ as the principal axes and $z$ as the longitudinal axis. $\xi$ and $\eta$ are attached to the center of cross-section and move as the section is displaced. This cross-section can be assumed to be made of $n$ constituent plates as shown in Figure 7-4.

The displacement of the ith plate is shown in Figure 7-5. $\beta$ being a small angle,

$$
\cos \beta=1, \sin \beta=\beta
$$

Then,

$$
\begin{gathered}
\eta_{i}=-\bar{u} \sin \phi_{i}+\bar{v} \cos \phi_{i}+\beta r_{i} \\
\frac{d^{2} \eta_{i}}{d z^{2}}=\eta_{i}^{\prime \prime}=\text { Curvature of the plate }
\end{gathered}
$$




$$
\begin{aligned}
& V_{1}+V_{2}=\frac{1}{2} \int\left(\widehat{E I_{y}} \bar{u}^{\prime \prime 2}+\widehat{E I_{x}} \bar{v}^{\prime 2}+2 E R_{y} \bar{u}^{\prime \prime} \beta^{\prime \prime}+2 E R_{x} \bar{v}^{\prime \prime} \beta^{\prime \prime}+E R_{\beta} \beta^{\prime \prime 2}+\widehat{G K} \beta^{2}\right. \\
&\left.+\widehat{A E} \epsilon^{2}\right) d z
\end{aligned}
$$

where,

$\widehat{E I}_{x}$ and $\widehat{E I}_{y}$ represent the bending stiffness of the orthotropic section

$\widehat{G K}$ represents the torsional stiffness of the orthotropic section

$\widehat{A E}$ represents the tensile stiffness of the orthotropic section

$R_{x}, R_{y}$ and $R_{\beta}$ represent the respective curvatures

The distances $\bar{u}$ and $\bar{v}$ are also shown in Figure 7-5

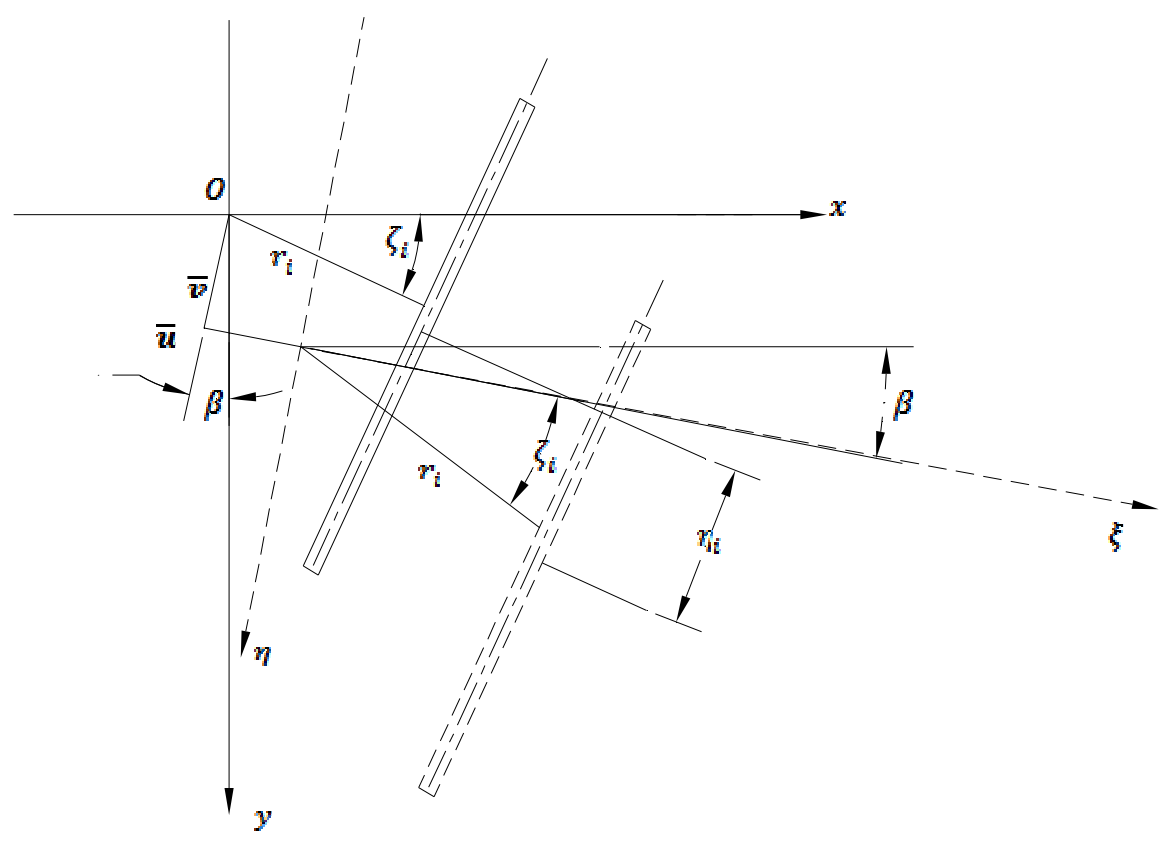

Figure 7-5: Displacement of the ith plate [5] 


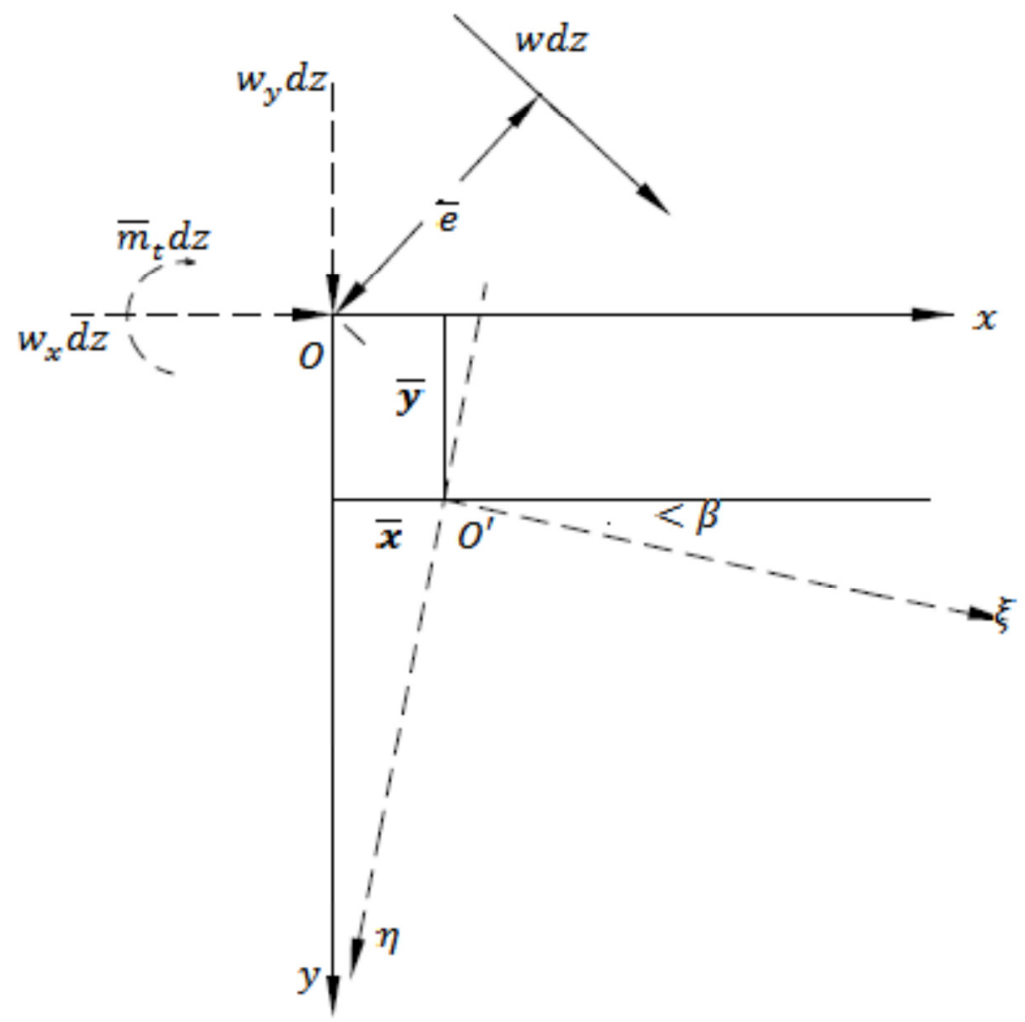

Figure 7-6: System of Forces [5]

The potential energy of this section under torsional and bending loads can be written from Figure $7-6$ as

$$
U_{w 1}=-\int\left(\bar{u} w_{x}+\bar{v} w_{y}+\beta \bar{m}_{t}\right) d z
$$

From the above equations, the following Eulerian differential equations are derived,

$$
\begin{gathered}
\widehat{E I_{y}} \bar{u}^{I V}+E R_{y} \beta^{I V}=w_{x} \\
\widehat{E I_{x}} \bar{v}^{I V}+E R_{x} \beta^{I V}=w_{y} \\
E R_{y} \bar{u}^{I V}+E R_{x} \bar{v}^{I V} \beta^{\prime \prime}+E R_{\beta} \beta^{I V}-\widehat{G K} \beta^{\prime \prime}=\bar{m}_{t} \\
\widehat{E A} \epsilon=0
\end{gathered}
$$

The above equations are simplified by re-defining the coordinate system as shown in Figure 7-7. The coordinates $u$ and $v$ are the components of the displacement of S parallel to the displaced system of axes $\xi$ and $\eta$. 


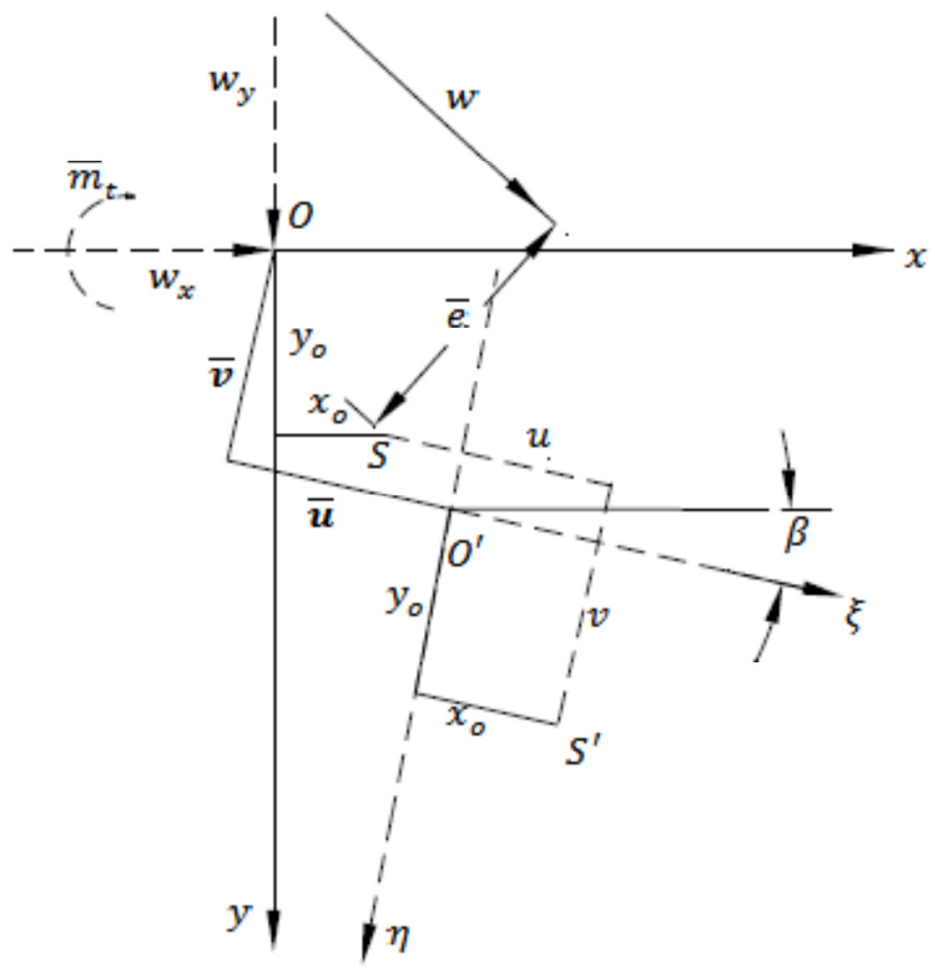

Figure 7-7:The Redefined Coordinate System [5]

$<\beta$ is small: $\cos \beta=1, \sin \beta=\beta$

$$
\begin{array}{cc}
\bar{u}=u+y_{o} \beta, & \bar{v}=v-x_{o} \beta \\
y_{o}=-\frac{R_{y}}{I_{y}}, & x_{o}=\frac{R_{x}}{I_{x}} \\
\bar{u}=u-\frac{R_{y}}{I_{y}} \beta, & \bar{v}=v-\frac{R_{x}}{I_{x}} \beta
\end{array}
$$

The strain energy of an orthotropic section will then be given by the following equation,

$$
\begin{gathered}
V_{1}+V_{2}=\frac{1}{2} \int\left(\widehat{E I_{y}} u^{\prime \prime 2}+\widehat{E I_{x}} v^{\prime \prime 2}+E \Gamma \beta^{\prime \prime 2}+\widehat{G K} \beta^{\prime 2}+\widehat{A E} \epsilon^{2}\right) d z \\
\Gamma=R_{\beta}-\frac{R_{y}^{2}}{I_{y}}-\frac{R_{x}^{2}}{I_{x}}
\end{gathered}
$$

The potential energy of the orthotropic section due to bending and torsion will become, 


$$
U_{w 1}=-\int\left(u w_{x}+v w_{y}-\left(\frac{R_{y}}{I_{y}}+\frac{R_{x}}{I_{x}}-\bar{m}_{t}\right) \beta\right) d z
$$

\subsubsection{Orthotropic Section Under Warping Effect}

The warping of an arbitrary section is shown in Figure 7-8, where

$$
\begin{gathered}
\frac{d \beta}{d z}=\theta \\
\omega=\omega_{o}+\theta \int_{0}^{s} r_{s} d s
\end{gathered}
$$

Strain energy due to warping will be

$$
\begin{gathered}
d V=\frac{d z}{2 E} \int \sigma_{z} d A=\frac{E d z}{2} \beta^{\prime \prime 2} \int\left(\omega_{1}-\overline{\omega_{1}}\right)^{2} d A=\frac{1}{2} E \Omega \beta^{\prime \prime 2} d z \\
\Omega=\int\left(\omega_{1}-\overline{\omega_{1}}\right)^{2} d A
\end{gathered}
$$

Warping strain energy for orthotropic section

$$
V_{3}=\frac{1}{2} \int E \Omega \beta^{\prime \prime 2} d z
$$



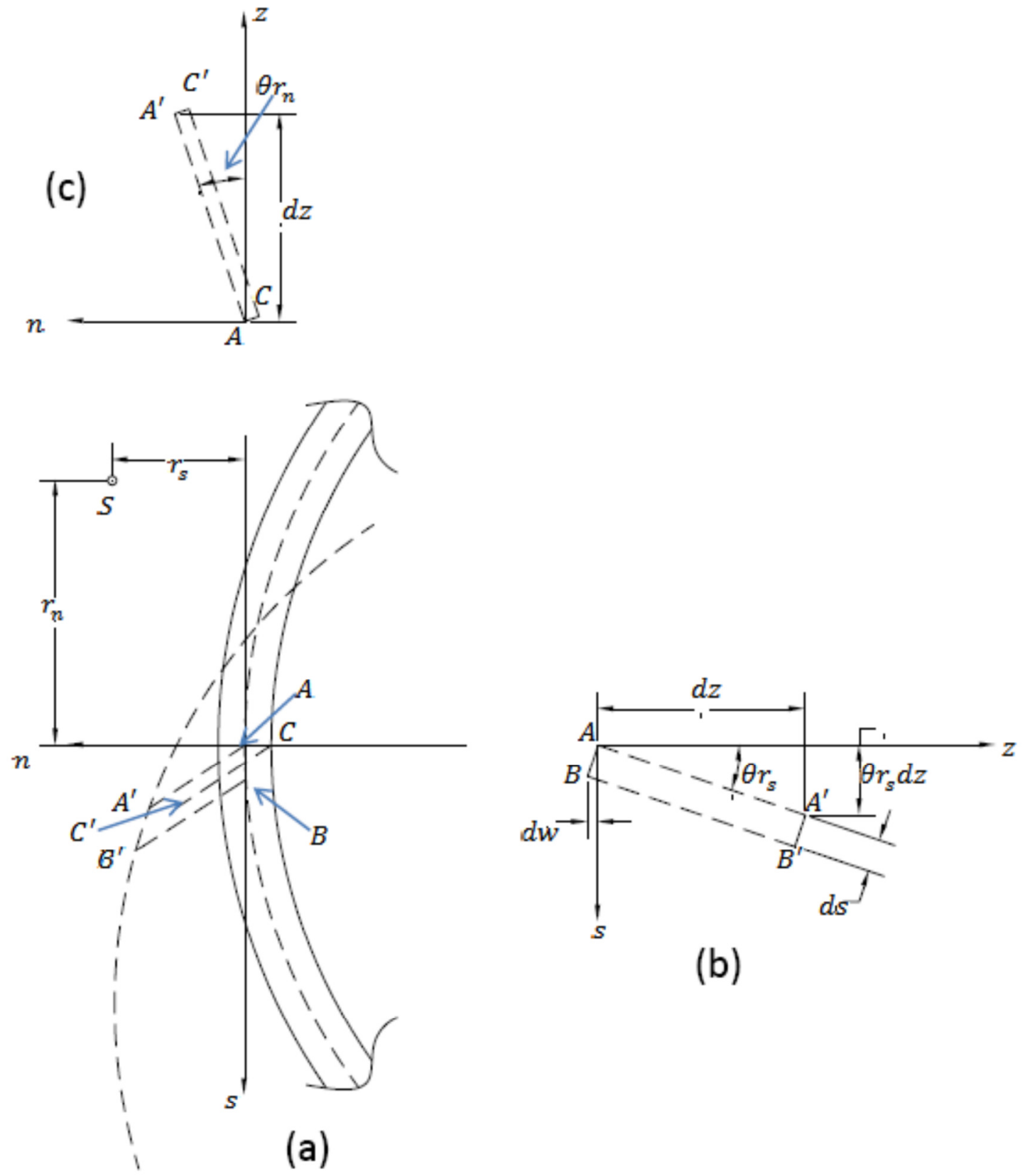

Figure 7-8: Warping of an Arbitrary Section [5] 

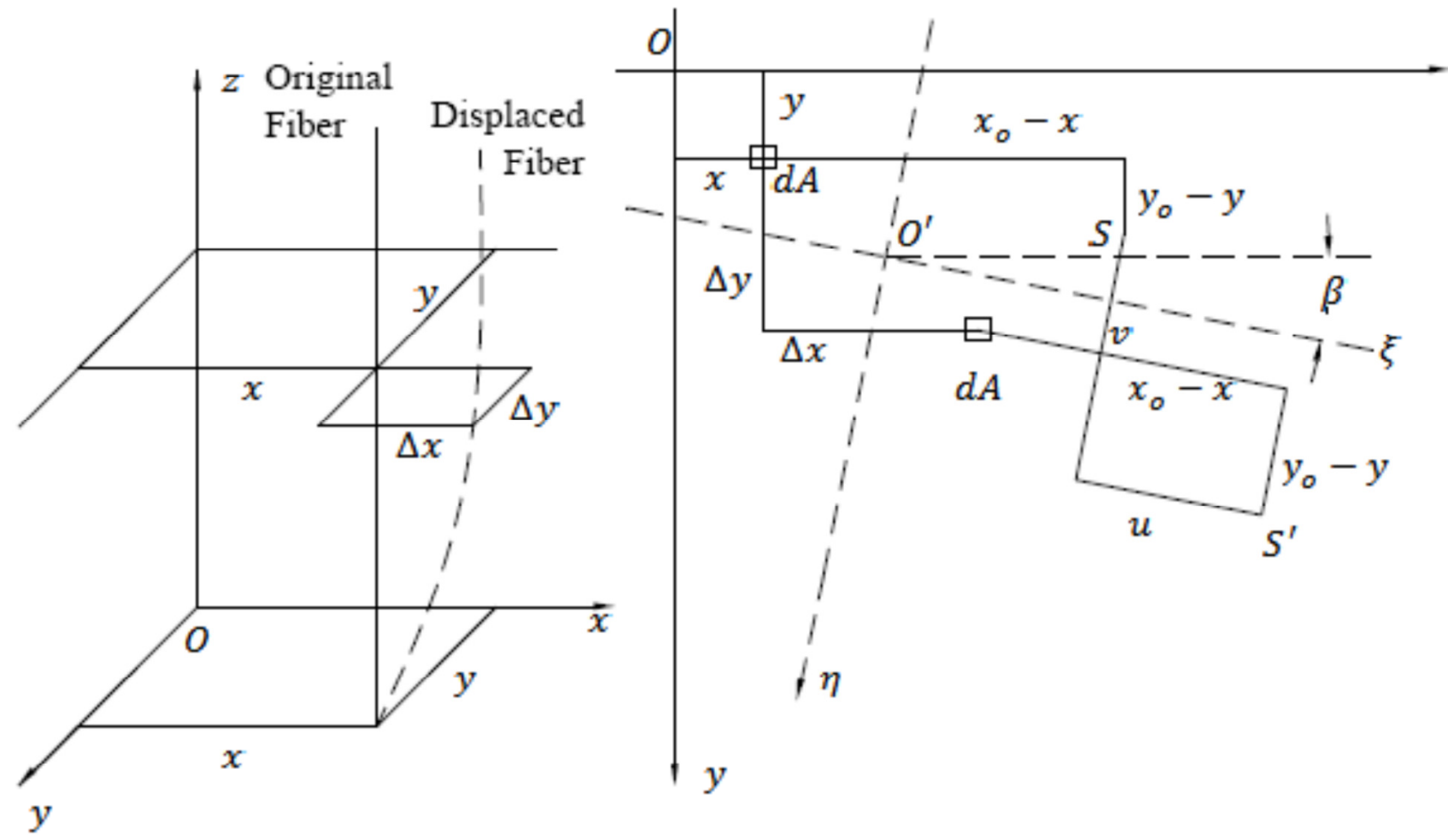

Figure 7-9: Buckled Form of an Axially Compressed Column [5]

\subsubsection{Orthotropic Section Under Compressive Axial Load}

The buckled form of an axially loaded column is shown in Figure 7-9. The strain energy of a section under a compressive axial load, acting at the center of the cross-section is given by

$$
\begin{gathered}
V_{4}=\frac{1}{2} \int\left(\widehat{E \tau I_{y}} u^{\prime \prime 2}+\widehat{E \tau I_{x}} v^{\prime \prime 2}+E \tau \Gamma \beta^{\prime \prime 2}+\widehat{G \tau K} \beta^{\prime 2}\right) d z \\
\tau=\frac{E_{t}}{E}
\end{gathered}
$$

The associated potential energy will be given by

$$
\begin{gathered}
U_{w 2}=\frac{1}{2} \int\left[-\sigma A\left(u^{\prime 2}+v^{\prime 2}\right)-2 \sigma A y_{o} u^{\prime} v^{\prime}+2 \sigma A x_{o} v^{\prime} \beta^{\prime}-\sigma I_{P} \beta^{\prime 2}\right] d z \\
I_{P}=I_{x}+I_{y}=\text { Polar Moment of Inertia }
\end{gathered}
$$


7.2.2.4 Orthotropic Section Under Combined Flexural, Torsional and Axial Loading

$$
\begin{gathered}
V=V_{1}+V_{2}+V_{3}+V_{4} \\
V=\frac{1}{2} \int\left[\begin{array}{c}
(1+\tau) \widehat{E I_{y}} u^{\prime \prime 2}+(1+\tau) \widehat{E I_{x}} v^{\prime \prime 2}+\{(1+\tau) \Gamma+\Omega\} E \beta^{\prime \prime 2} \\
+(1+\tau) \widehat{G K} \beta^{\prime 2}+\widehat{E A} \epsilon^{2}
\end{array}\right] d z \\
U_{w}=U_{w 1}+U_{w 2} \\
U_{w}=-\frac{1}{2} \int\left[2 u w_{x}+2 v w_{y}-2 \beta\left(\frac{R_{y}}{I_{y}}+\frac{R_{x}}{I_{x}}-\bar{m}_{t}\right)\right] d z
\end{gathered}
$$

$$
U=V+U_{w}
$$$$
U=\frac{1}{2} \int\left[\begin{array}{c}
(1+\tau) \widehat{E I_{y}} u^{\prime \prime 2}+(1+\tau) \widehat{E I_{x}} v^{\prime 2}+\{(1+\tau) \Gamma+\Omega\} E \beta^{\prime \prime 2} \\
+(1+\tau) \widehat{G K} \beta^{\prime 2}+\widehat{E A} \epsilon^{2}-2 u w_{x}-2 v w_{y}+2 \beta\left(\frac{R_{y}}{I_{y}}+\frac{R_{x}}{I_{x}}-\bar{m}_{t}\right) \\
-\sigma A\left(u^{\prime 2}+v^{\prime 2}\right)-2 \sigma A y_{o} u^{\prime} v^{\prime}+2 \sigma A x_{o} v^{\prime} \beta^{\prime}-\sigma I_{P} \beta^{\prime 2}
\end{array}\right] d z
$$

$$
F=\left[\begin{array}{c}
\left(\frac{1+\tau}{2}\right) \widehat{E I_{y}} u^{\prime \prime 2}+\left(\frac{1+\tau}{2}\right) \widehat{E I_{x}} v^{\prime \prime 2}+\left\{\frac{(1+\tau) \Gamma+\Omega}{2}\right\} E \beta^{\prime \prime 2} \\
+\left(\frac{1+\tau}{2}\right) \widehat{G K} \beta^{\prime 2}+\frac{1}{2} \widehat{E A} \epsilon^{2}-u w_{x}-v w_{y}+\beta\left(\frac{R_{y}}{I_{y}}+\frac{R_{x}}{I_{x}}-\bar{m}_{t}\right) \\
-\frac{1}{2} \sigma A\left(u^{\prime 2}+v^{\prime 2}\right)-\sigma A y_{o} u^{\prime} v^{\prime}+\sigma A x_{o} v^{\prime} \beta^{\prime}-\frac{1}{2} \sigma I_{P} \beta^{\prime 2}
\end{array}\right]
$$

Eulerian Equations for $u, v, \beta$ and $\epsilon$

$$
\begin{gathered}
F_{u}-\frac{d}{d x} F_{u^{\prime}}+\frac{d}{d x} F_{u^{\prime \prime}}=0 \\
F_{u}=\frac{\partial F}{\partial u}=-w_{x} \\
F_{u^{\prime}}=\frac{\partial F}{\partial u^{\prime}}=-\sigma A u^{\prime}-\sigma A y_{o} \beta^{\prime}
\end{gathered}
$$




$$
\begin{gathered}
\frac{d}{d x} F_{u^{\prime}}=-\sigma A u^{\prime \prime}-\sigma A y_{o} \beta^{\prime \prime} \\
F_{u^{\prime \prime}}=\frac{\partial F}{\partial u^{\prime \prime}}=(1+\tau) \widehat{E I_{y}} u^{\prime \prime} \\
\frac{d^{2}}{d x^{2}} F_{u^{\prime \prime}}=(1+\tau) \widehat{E I_{y}} u^{I V} \\
-w_{x}+\sigma A\left(u^{\prime \prime}+y_{o} \beta^{\prime \prime}\right)+(1+\tau) \widehat{E I}_{y} u^{I V}
\end{gathered}
$$

The same procedure to be followed for $v$ to give the following set of equations,

$$
\begin{gathered}
(1+\tau) \widehat{E I_{y}} u^{I V}+\sigma A\left(u^{\prime \prime}+y_{o} \beta^{\prime \prime}\right)=w_{x} \\
(1+\tau) \widehat{E I_{x}} v^{I V}+\sigma A\left(v^{\prime \prime}+x_{o} \beta^{\prime \prime}\right)=w_{y} \\
F_{\beta}-\frac{d}{d x} F_{\beta^{\prime}}+\frac{d}{d x} F_{\beta^{\prime \prime}}=0 \\
F_{\beta^{\prime}}=\frac{\partial F}{\partial \beta^{\prime}}=(1+\tau) \widehat{G K} \beta^{\prime}-\sigma A y_{o} u^{\prime}+\sigma A x_{o} v^{\prime}-\sigma I_{P} \beta^{\prime} \\
\frac{d}{d x} F_{\beta^{\prime}}=(1+\tau) R_{y}+\frac{R_{x}}{I_{x}}-\bar{m}_{t} \\
{\left[(1+\tau) \widehat{G K} \beta^{\prime \prime}-\sigma A y_{o} u^{\prime \prime}+\sigma A y_{o} u^{\prime \prime}+\sigma A x_{o} v^{\prime \prime}-\sigma I_{P} \beta^{\prime \prime}\right.} \\
R_{y}+\frac{R_{x}}{I_{x}}-\bar{m}_{t} \\
F_{\beta^{\prime \prime}}=\frac{\partial F}{\partial \beta^{\prime \prime}}=\{(1+\tau) \Gamma+\Omega\} E \beta^{\prime \prime} \\
\frac{d^{2}}{d x^{2}} F_{\beta^{\prime \prime}}=\{(1+\tau) \Gamma+\Omega\} E \beta^{I V} \\
\end{gathered}
$$




$$
\begin{gathered}
F_{\epsilon}-\frac{d}{d x} F_{\epsilon^{\prime}}+\frac{d}{d x} F_{\epsilon^{\prime \prime}}=0 \\
F_{\epsilon}=\frac{\partial F}{\partial \epsilon}=\widehat{E A} \epsilon \\
F_{\epsilon^{\prime}}=\frac{\partial F}{\partial \epsilon^{\prime}}=0 \\
\frac{d}{d x} F_{\epsilon^{\prime}}=0 \\
F_{\epsilon^{\prime \prime}}=0 \\
\frac{d^{2}}{d x^{2}} F_{\epsilon^{\prime \prime}}=0 \\
\widehat{E A} \epsilon=0
\end{gathered}
$$

For a doubly symmetric section,

$$
\begin{gathered}
x_{o}=0, \quad y_{o}=0 \\
R_{x}=0, \quad R_{y}=0, \quad R_{\beta} \neq 0 \\
(1+\tau) \widehat{E I_{y}} u^{I V}+\sigma A u^{\prime \prime}=w_{x} \\
(1+\tau) \widehat{E I_{x}} v^{I V}+\sigma A v^{\prime \prime}=w_{y} \\
{\left[(1+\tau) R_{\beta}+\Omega\right] E \beta^{I V}+\left[(1+\tau) \widehat{G K}+\sigma I_{P}\right] \beta^{\prime \prime}=\bar{m}_{t}} \\
\widehat{E A} \epsilon=0
\end{gathered}
$$




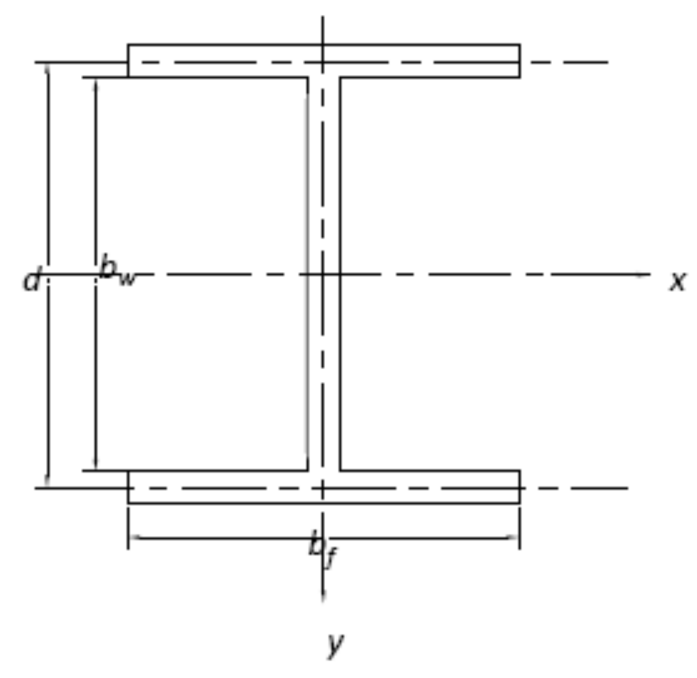

Figure 7-10: A Doubly Symmetric Open Section [5]

The relation for $\Omega$ is given in equation $7-9$, which on solving for a doubly symmetric section will yield,

$$
\Omega=\frac{\mathrm{d}^{2} \mathrm{I}_{\mathrm{y}}}{4}
$$

The torsional constant $K$ is given by

$$
K=\frac{1}{3} \sum_{i=1}^{n} m_{i} t_{i}^{3}
$$

where $m_{i}$ is the length of the middle line of a segment of cross-section and $t_{i}$ is the corresponding thickness.

The polar moment of inertia $I_{p}$ is given by

$$
I_{P}=I_{x}+I_{y}
$$

and

$$
\bar{m}_{t}=M_{z}
$$




\subsubsection{Orthotropic Doubly Symmetric Sections Under Combined Flexural, Torsional and Axial Loading}

For a doubly symmetric orthotropic section, subject to combined flexural, torsional and axial loading, equations 7-59 through 7-62 will be modified as,

$$
\begin{gathered}
(1+\tau) \widehat{E I}_{y} u^{I V}+\sigma A u^{\prime \prime}=w_{x} \\
(1+\tau) \widehat{E I}_{x} v^{I V}+\sigma A v^{\prime \prime}=w_{y} \\
{\left[(1+\tau) R_{\beta}+\Omega\right] E_{L}^{c} \beta^{I V}+\left[(1+\tau) \widehat{G I}_{t}+\sigma I_{P}\right] \beta^{\prime \prime}=\bar{m}_{t}} \\
\widehat{E A} \epsilon=0
\end{gathered}
$$

The values of $\widehat{E I}_{y}, \widehat{E I}_{x}, \widehat{G I}_{t}$ and $\widehat{E A}$ are calculated by using the standard formulas as given below,

For square cross-sections [14]

$$
\begin{gathered}
\widehat{E I_{y}}=\frac{b_{w}}{\left(a_{11}\right)_{w}} \frac{d_{f}^{2}}{2}+\frac{2 b_{w}}{\left(d_{11}\right)_{w}}+\frac{2 b_{f}^{3}}{12\left(a_{11}\right)_{f}} \\
\widehat{E I_{x}}=\frac{b_{f}}{\left(a_{11}\right)_{f}} \frac{d^{2}}{2}+\frac{2 b_{f}}{\left(d_{11}\right)_{f}}+\frac{2 b_{w}^{3}}{12\left(a_{11}\right)_{w}} \\
\widehat{E A}=\frac{2 b_{f}}{\left(a_{11}\right)_{f}}+\frac{2 b_{w}}{\left(a_{11}\right)_{w}} \\
\widehat{G I}_{t}=\frac{2 d_{f}^{2} d^{2}}{\left(d_{66}\right)_{f} d_{f}+\left(d_{66}\right)_{w} d}
\end{gathered}
$$

For wide-flange sections [14]

$$
\begin{gathered}
\widehat{E I_{y}}=\frac{b_{w}}{\left(d_{11}\right)_{w}}+\frac{2 b_{f}^{3}}{12\left(a_{11}\right)_{f}} \\
\widehat{E I}_{x}=\frac{b_{f}}{\left(a_{11}\right)_{f}} \frac{d^{2}}{2}+\frac{2 b_{f}}{\left(d_{11}\right)_{f}}+\frac{b_{w}^{3}}{12\left(a_{11}\right)_{w}}
\end{gathered}
$$




$$
\begin{gathered}
\widehat{E A}=\frac{2 b_{f}}{\left(a_{11}\right)_{f}}+\frac{b_{w}}{\left(a_{11}\right)_{w}} \\
\widehat{G I}_{t}=4\left[\frac{2 b_{f}}{\left(d_{66}\right)_{f}}+\frac{b_{w}}{\left(d_{66}\right)_{w}}\right]
\end{gathered}
$$

For round sections [14]

$$
\begin{aligned}
\widehat{E I_{y}=} \widehat{E I}_{x} & =\pi\left(\frac{R^{3}}{a_{11}}+\frac{R}{d_{11}}\right) \\
\widehat{E A} & =\frac{2 R \pi}{a_{11}} \\
\widehat{G I}_{t} & =\frac{2 R^{3} \pi}{d_{66}}
\end{aligned}
$$

The corresponding notations are shown in Figure 7-11

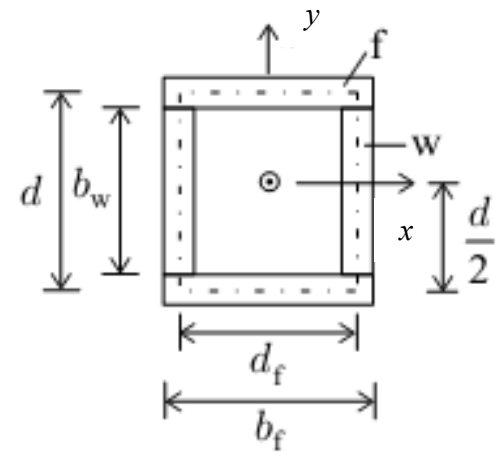

(d) Orthotropic box section

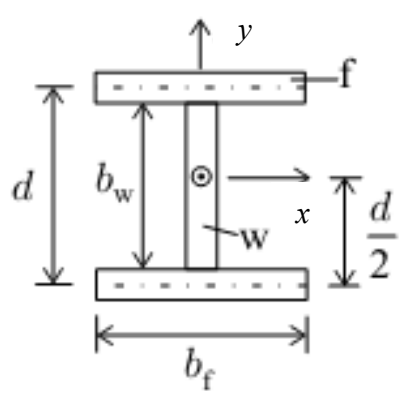

(e) Orthotropic wide-flange section (f) Orthotropic round section

Figure 7-11: Notations of orthotropic beam sections used in Equation 7-71 thru 7-81 [14] 


\subsubsection{Design Equations of ASCE-LRFD Pultruded Sections Draft Manual [1]}

According to ASCE-LRFD Draft Manual of Pultruded Sections, the interaction of torsional, flexural and axial force shall be limited by the following equation [1]

$$
\frac{P_{u}}{P_{c}}+\frac{M_{u}}{M_{c}}+\left(\frac{T_{u}}{T_{c}}\right)^{2} \leq 1.0
$$

where,

$P_{u}=$ required axial tensile or compressive strength due to factored loads

$P_{c}=\lambda \phi_{t, c} P_{n}=$ available axial tensile or compressive strength determined in accordance with the design method given in Chapters 3 or 4 of the ASCE-LRFD Draft Manual of Pultruded Sections

$M_{u}=$ required flexural strength due to factored loads

$M_{c}=\lambda \phi_{b} M_{n}=$ available flexural strength determined in accordance with Chapter 5 of the ASCE-LRFD Draft Manual of Pultruded Sections

$T_{u}=$ required torsional strength due to factored loads

$T_{c}=\lambda \phi_{T} T_{n}=$ available torsional design strength

$\phi_{t}=0.65$, resistance factor for tension

$\phi_{c}=0.7$, resistance factor for compression rupture and global buckling

$=0.8$, resistance factor for local buckling

$\phi_{b}=0.7$, resistance factor for lateral torsional buckling and web crippling

$=0.8$, resistance factor for local instability and web compression buckling

$\phi_{T}=0.7$, resistance factor for torsion

$\lambda=$ time effect factor defined in Table 2.3-1 of the ASCE-LRFD Draft Manual of Pultruded Sections

If the pultruded section is subject to combined bending and torsion, without any axial loads, Equation 7-75 reduces to

$$
\frac{M_{u}}{M_{c}}+\left(\frac{T_{u}}{T_{c}}\right)^{2} \leq 1.0
$$

For an ideal interaction curve, 


$$
\frac{M_{u}}{M_{c}}+\left(\frac{T_{u}}{T_{c}}\right)^{2}=1.0
$$

the graph of which is shown in Figure 7-12.

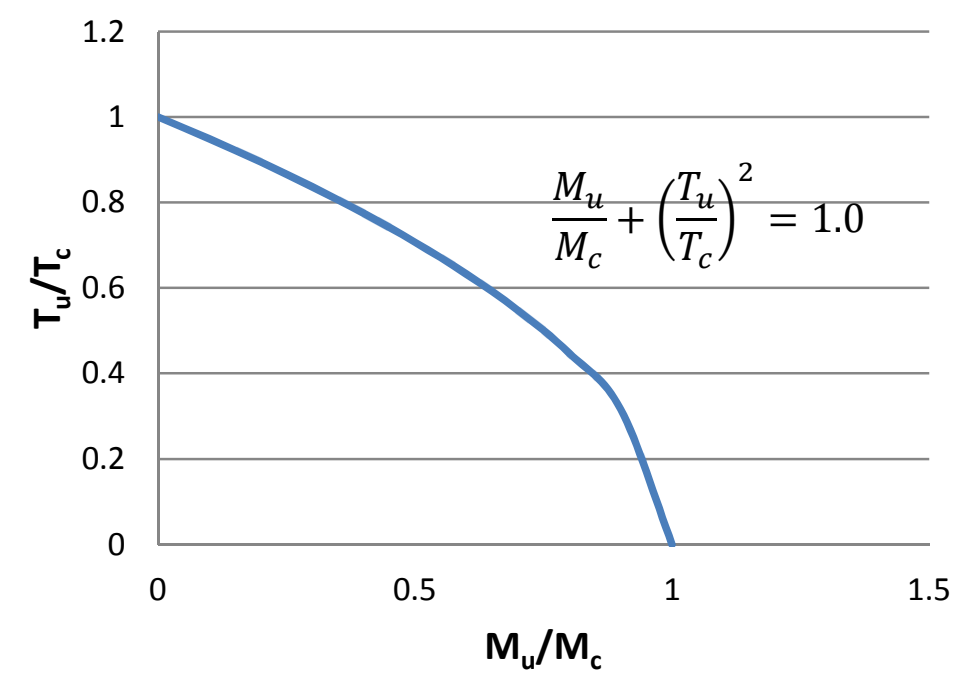

Figure 7-12: Ideal Interaction Curve of Combined Bending and Torsion

\subsection{Results and Discussions}

As mentioned earlier, three section-types were tested under combined bending and torsion with each type under three load-combinations, i.e., bending moments in the steps of $25 \%, 50 \%$ and $75 \%$ of maximum bending moment together with the torsional moment till failure. It was anticipated that at smaller bending loads, the mode of failure should be somewhat similar to that in pure torsion. Similarly, at high bending load, the mode of failure should be dominated by bending. However, when the bending load is around $50 \%$ of $\mathrm{M}_{\max }$, the principal stresses and maximum shear stresses due to combined bending and torsional stresses should be controlling. The results are presented in the following sections.

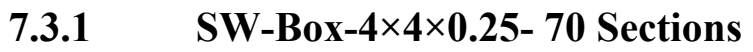

For these sections, $\mathrm{M}_{\max }=125 \mathrm{kip}$-inch, as found from 3-point bending test, and $\mathrm{T}_{\max }=53$ kipinch, as found from pure torsion test. 


\subsubsection{1. $\quad$ Sample-1: $M=0.8 M_{\max }$}

Due to the combination of bending and torsional loads, it was anticipated that strains may vary at different locations. Therefore, to record any possible strains due to these loads, this first sample was equipped with a total of 12 strain gages at $0^{\circ} / \pm 45^{\circ}$ angles, in the middle and near the ends of top- and bottom-flanges.

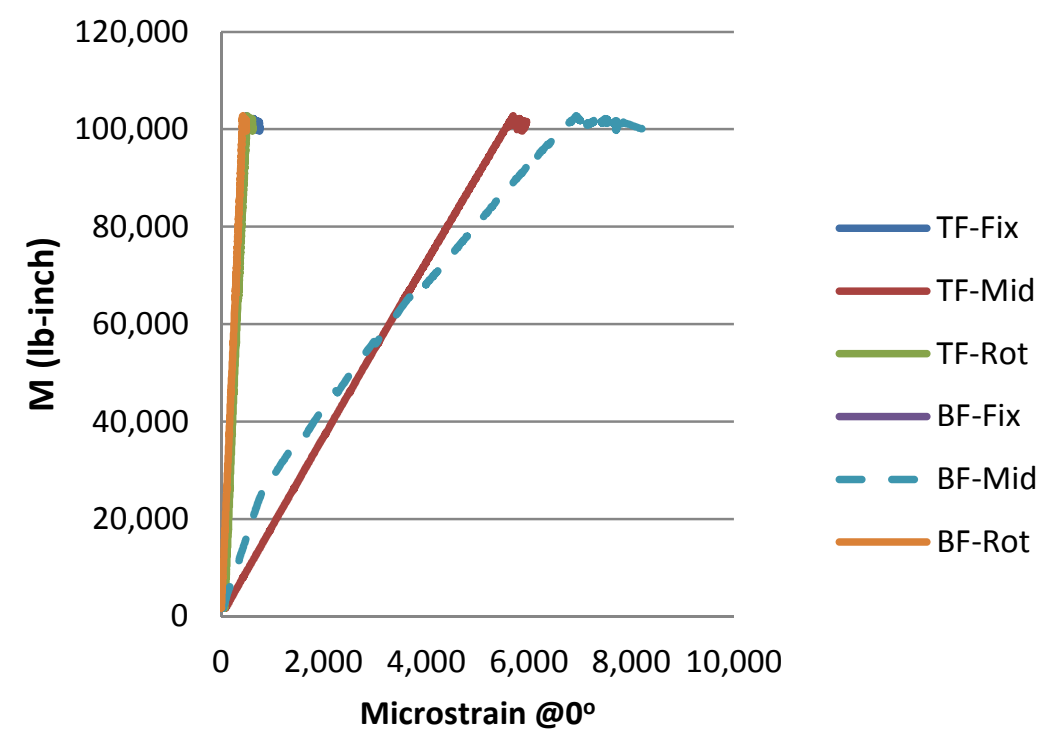

(a) BM vs Microstrains at $0^{\circ}$

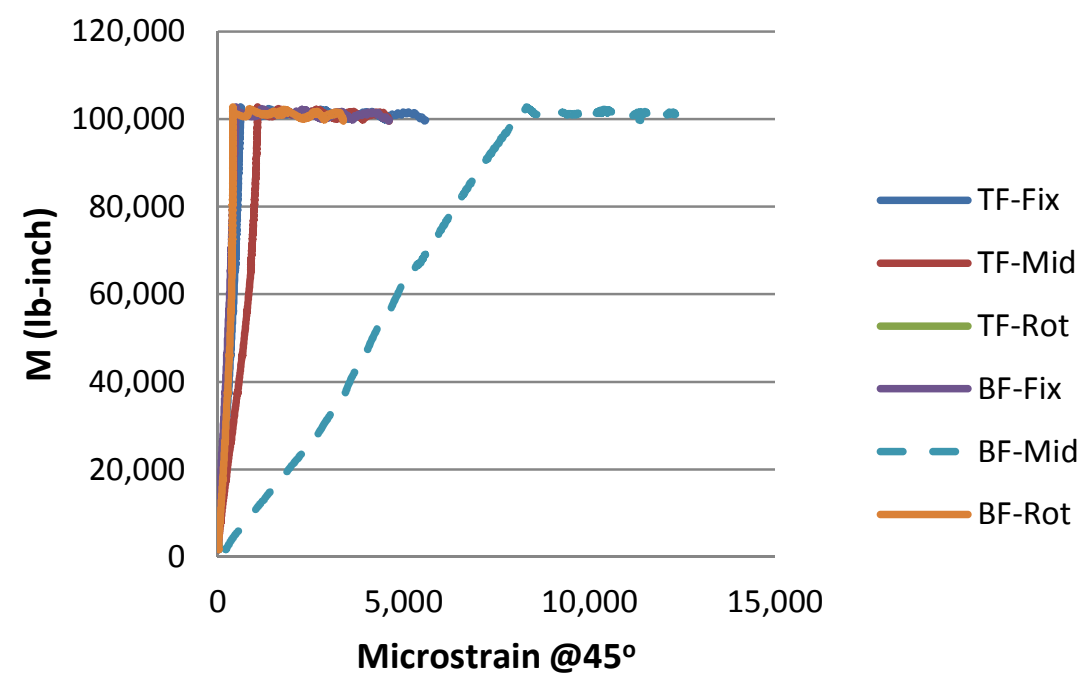

(b) BM vs Microstrains at $45^{\circ}$

Figure 7-13: BM vs Microstrains at $0^{\circ} / 45^{\circ}$ of SW-Box- $4 \times 4 \times 0.25-70\left(\mathrm{M}=0.8 \mathrm{M}_{\max }\right)$ 
For quick comparison in the moment-strain diagrams, only the absolute strain values are considered. Similarly, it was difficult to show all the strains in one figure. Therefore, the ones at $0^{\circ}$ are shown in one graph and those at $\pm 45^{\circ}$ in the other. With this methodology, bendingmoment vs microstrain curves are shown in Figure 7-13 (a) and (b).

As can be seen, the middle of the bottom flange is experiencing the highest amount of strains both at $0^{\circ}$ and $45^{\circ}$, because bending load acts at this location. In other words, this area is subject to maximum local bending stresses. From Figure 7-13 (a), the strain at $0^{\circ}$ in the middle of top flange is also very high, but the strains in the same direction near the ends are very small. From Figure $7-13$ (b), all the other strains at $45^{\circ}$ are practically non-responsive to bending moment. However, they can be seen to increase at a uniform value of $M$. This increase refers to the application of torque recorded by $\pm 45^{\circ}$ strain gages at a constant bending moment.

The torque vs strain curves are shown in Figure 7-14 (a) and (b). Referring to the microstrains at $0^{\circ}$ in Figure 7-13 (a), it is clear that strains in this direction do not respond to torsion. These were only the gages in the middle of top and bottom flange which recorded local strain due to bending and once the bending moment was constant, their values also remained constant. In Figure 7-14 (b), all the six strain values at $\pm 45^{\circ}$ are found to be very close except one, i.e., at the middle of bottom flange. For this particular case, an initial strain of around $7000 \mu \varepsilon$ was corresponding to the bending moment, as already established. If this initial strain is subtracted, the curve will be closely matching with the other ones.

From the first row of Table 7-1, the combination of bending and torsional stresses developed the principal stresses of $48.3 \mathrm{ksi}$ (compressive), as compared to coupon tension strength of $65 \mathrm{ksi}$. But the compression flange buckling strength is 29.7 and 57.84 ksi for simply supported and fixed boundary conditions, respectively. The maximum shear stress due to combined loading is around $25 \mathrm{ksi}$, while the torsional shear strength is $8 \times\left(\mathrm{K}_{\mathrm{ts}} \approx 2.2\right)=17 \mathrm{ksi}$; $\mathrm{K}_{\mathrm{ts}}$ being found from the geometry of similar BRP section. 
The tested sample is shown in Figure 7-15. The high magnitude of bending load, acting upwards at bottom flange, caused the failure pattern similar to that of 3-point bending. The sample failed due to compression flange buckling, followed by separation of flange-web junctions and finally, the post-buckling of the web.

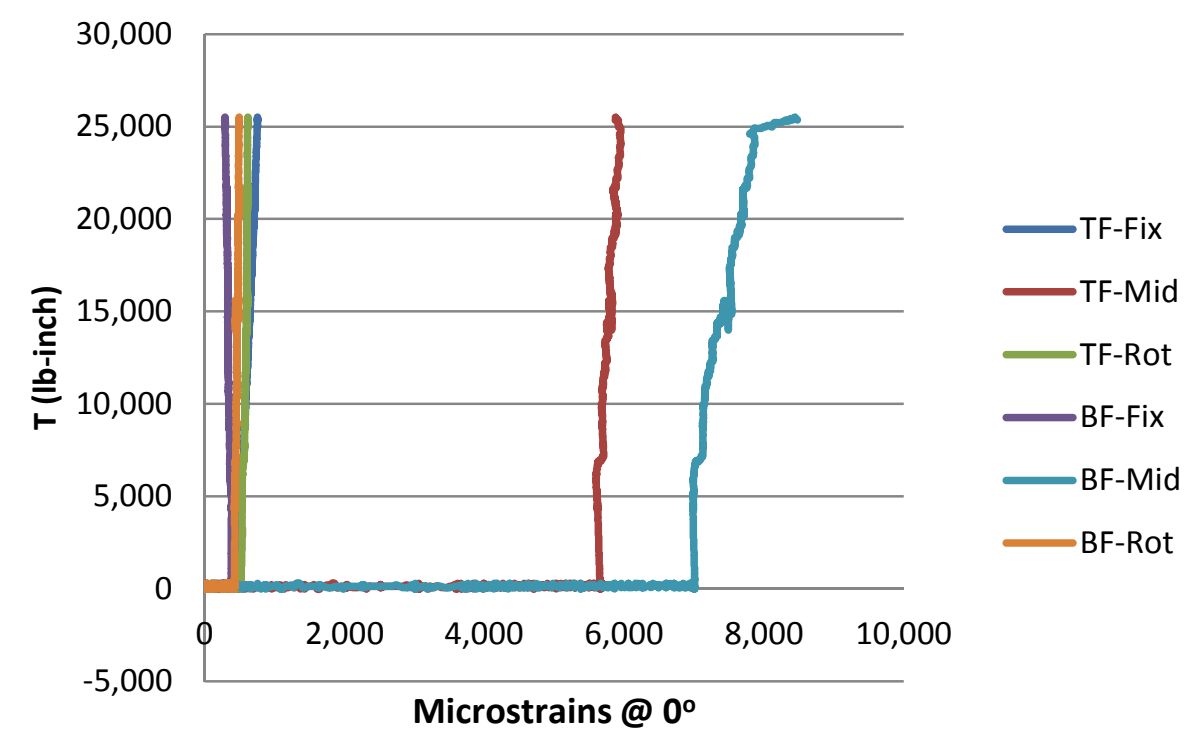

(a) $\mathrm{T}$ vs Microstrains at $0^{\circ}$

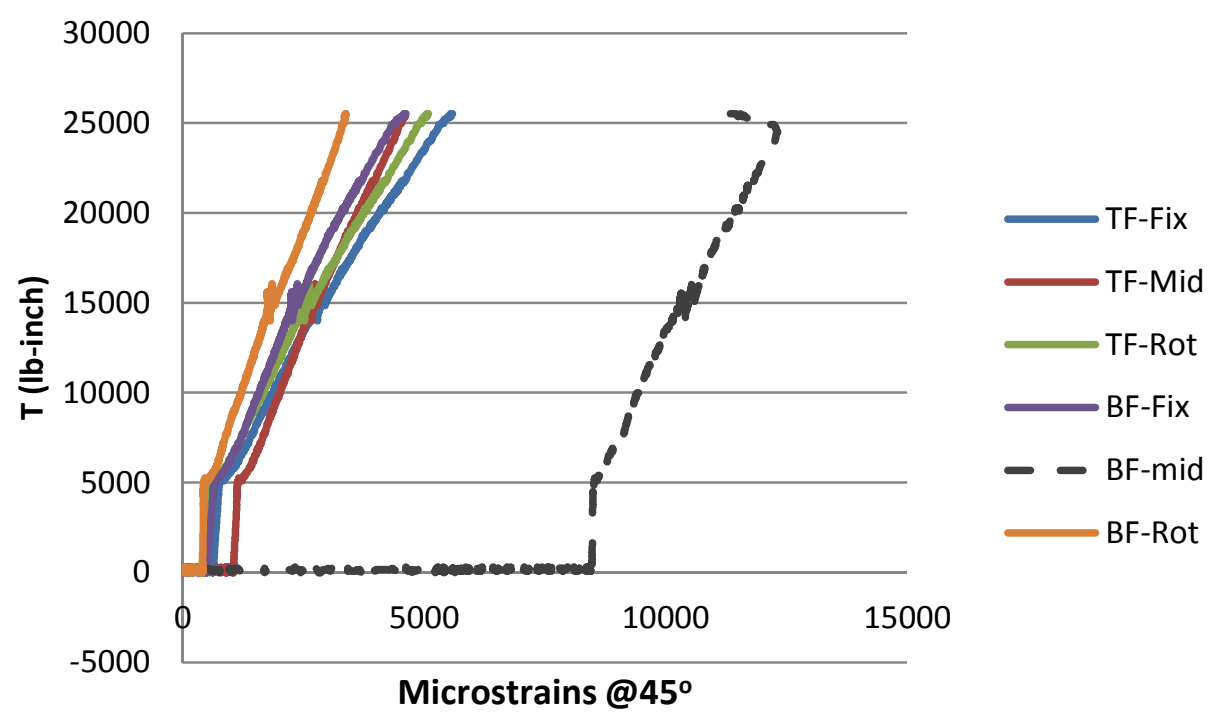

(b) $\mathrm{T}$ vs Microstrains at $45^{\circ}$

Figure 7-14: $\mathrm{T}$ vs Microstrains at $0^{\circ} / 45^{\circ}$ of SW-Box- $4 \times 4 \times 0.25-70\left(\mathrm{M}=0.8 \mathrm{M}_{\max }\right)$ 


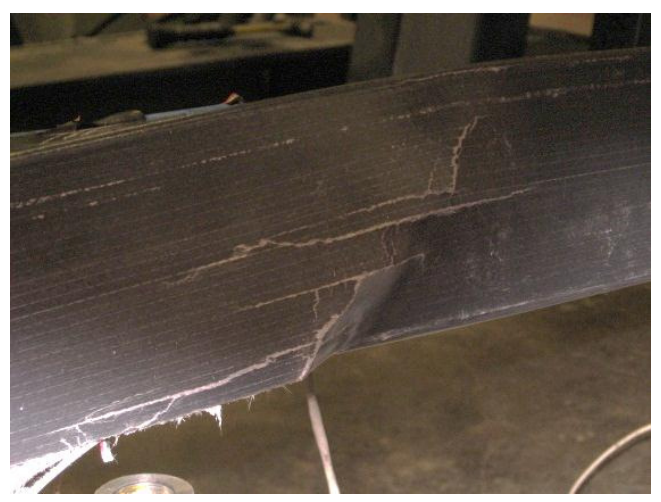

Figure 7-15: Tested SW-Box-4×4×0.25- 70 Sample $\left(\mathrm{M}=0.8 \mathrm{M}_{\max }\right)$

\subsubsection{2. $\quad$ Sample-2: $M=0.56 M m a x$}

This sample was equipped with a $0^{\circ} /+45^{\circ}$ strain gage pair at middle of top-flange, a $0^{\circ} /-45^{\circ}$ pair at middle of bottom-flange and one $+45^{\circ}$ gage near the fixed end of the top-flange. The bending moment vs microstrain and torque vs microstrain plots are shown in Figure 7-16 (a) and (b) respectively. It can be seen in Figure 7-16 (a) that the $0^{\circ} /-45^{\circ}$ pair at mid-bottom is highly subject to the local effect of bending load. The strain experienced by the gage at $0^{\circ}$ at mid-top should not have much effect of local load and the value can be taken as representative of the behavior. As already stated, the increase in strains at constant moment is due to the applied torque.

Referring to Figure 7-16 (b), the bending moment was reduced to $56 \%$ of $\mathrm{M}_{\max }$ and the sample was able to carry twice as much a torque as it did in the previous case. The torsional capacity is in fact close to maximum torsional capacity. The initial strains in this figure are due to bending moment, the values of which are correspondingly less than those in Figure 7-14 (b).

Referring to third row of Table 7-1, the principal stress value is $-40 \mathrm{ksi}$ corresponding to this combination of compressive axial stresses due to bending and torsional shear stresses, to be compared with the buckling strength of $30 \mathrm{ksi}$ (s.s.) and $58 \mathrm{ksi}$ (fix). The maximum shear stress is $23.4 \mathrm{ksi}$, well above the approximated torsional shear strength of $17 \mathrm{ksi}$. 
(a)

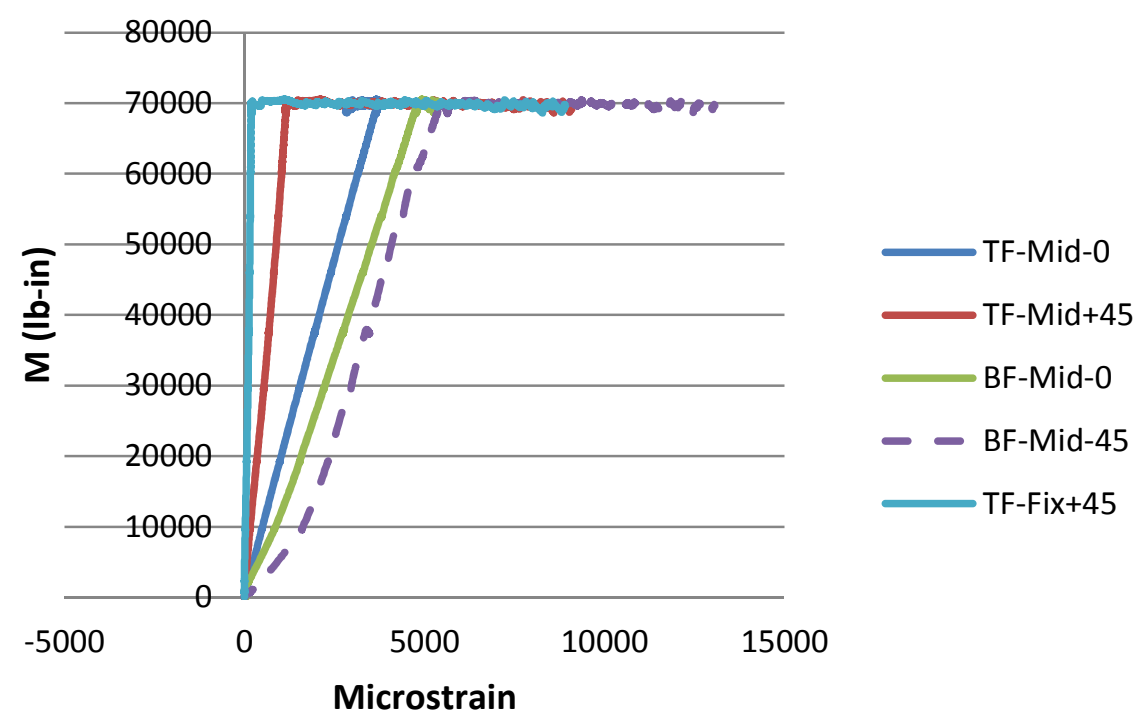

(b)

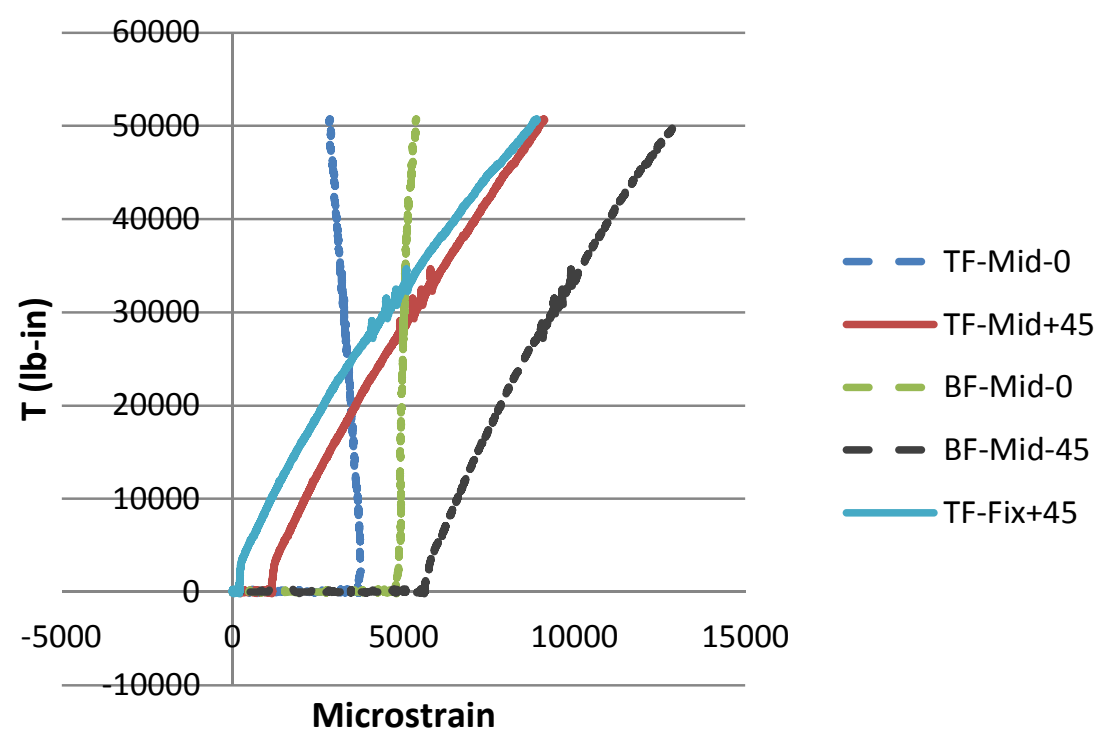

Figure 7-16: (a) M vs Microstrain, (b) T vs Microstrains of SW-Box-4×4×0.25- $70\left(\mathrm{M}=0.56 \mathrm{M}_{\max }\right)$

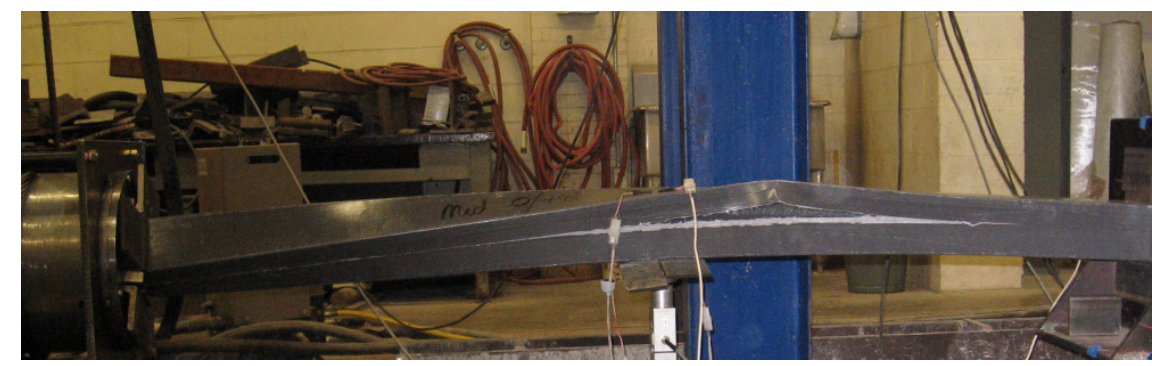

Figure 7-17: Tested SW-Box-4×4×0.25- 70 Sample $\left(\mathrm{M}=0.56 \mathrm{M}_{\max }\right)$ 
The tested sample is shown in Figure 7-17, showing a split-up at the mid-face of the web with a tendency of warping due to torsion. But the principal stresses and maximum shear stresses exist at corners. At the mid-web,

$$
\begin{gathered}
\sigma_{\text {bending }}=0 \\
\tau_{\text {total }}=\tau_{\text {torsional }}+\tau_{\text {bending }}=7.6+1.75=9.35 \mathrm{ksi}
\end{gathered}
$$

which is far less than the shear strength of the sample.

As the web-failure is not observed in any other test of this sample of other samples, it can be concluded that this failure mode is unexpected.

Table 7-1: Bending and Torsion Combinations of SW-Box-4×4×0.25- 70 Section

\begin{tabular}{|c|c|c|c|c|c|c|c|c|c|}
\hline \multicolumn{5}{|c|}{ Experimental Values } & \multicolumn{4}{c|}{ Analytical Values } \\
\hline $\mathrm{M}$ & $\sigma_{\text {bending }}{ }^{(1)}$ & $\tau_{\text {bending }}{ }^{(1)}$ & $\mathrm{T}$ & $\theta_{\text {RVIT }}$ & $\tau_{\text {torsion }}{ }^{(2)}$ & $\sigma_{\text {max,min }}$ & $\theta_{\mathrm{p}}$ & $\tau_{\max }$ & $\theta_{\mathrm{s}}$ \\
\hline kip-inch & $\mathrm{ksi}$ & $\mathrm{ksi}$ & $\mathrm{kip-inch}$ & degree & $\mathrm{ksi}$ & $\mathrm{ksi}$ & degree & $\mathrm{ksi}$ & degree \\
\hline Eqn 5-1 & Eqn 5-2 & Eqn 5-3 & Eqn 6-2 & Eqn 5-1 & Eqn 6-1 & Eqn 7-6 & Eqn 7-5 & Eqn 7-8 & Eqn 7-7 \\
\hline 100 & 46.8 & 5.0 & 25.5 & 21.2 & 8.5 & $\begin{array}{c}1.5 \\
-48.3\end{array}$ & $\begin{array}{c}80 \\
-10\end{array}$ & \pm 24.9 & 35 \\
\hline 91 & 42.42 & 4.56 & 21.83 & -- & 7.33 & $\begin{array}{c}1.23 \\
-43.65\end{array}$ & $\begin{array}{c}80.5 \\
-9.5\end{array}$ & \pm 22.4 & 35.5 \\
\hline 70 & 32.74 & 3.5 & 50.71 & 38.8 & 16.7 & $\begin{array}{c}7.0 \\
-39.8\end{array}$ & $\begin{array}{c}67.2 \\
-22.8\end{array}$ & \pm 23.4 & $\begin{array}{c}22.2 \\
112.2\end{array}$ \\
\hline 35 & 16.37 & 1.65 & 51.13 & 37.8 & 17 & $\begin{array}{c}10.7 \\
-27.1\end{array}$ & $\begin{array}{c}57.9 \\
-32.12\end{array}$ & \pm 18.9 & 12.9 \\
& & & & & & & & & \\
\hline
\end{tabular}

\subsubsection{Sample-3: $M=0.28 M \max$}

In this case, the strains at mid-bottom in $0^{\circ}$ could not be recorded due to bad gage. From Figure 7-18 (a), the value of the applied moment kept on fluctuating, thus causing experimental error. All the other strain values show the same trends as in the previous two cases, but to a smaller 
magnitude. For example, TF-Mid-0 strain is around $2000 \mu \varepsilon$, as compared to $5500 \mu \varepsilon$ corresponding to $\mathrm{M}=0.8 \mathrm{M}_{\max }$

(a)
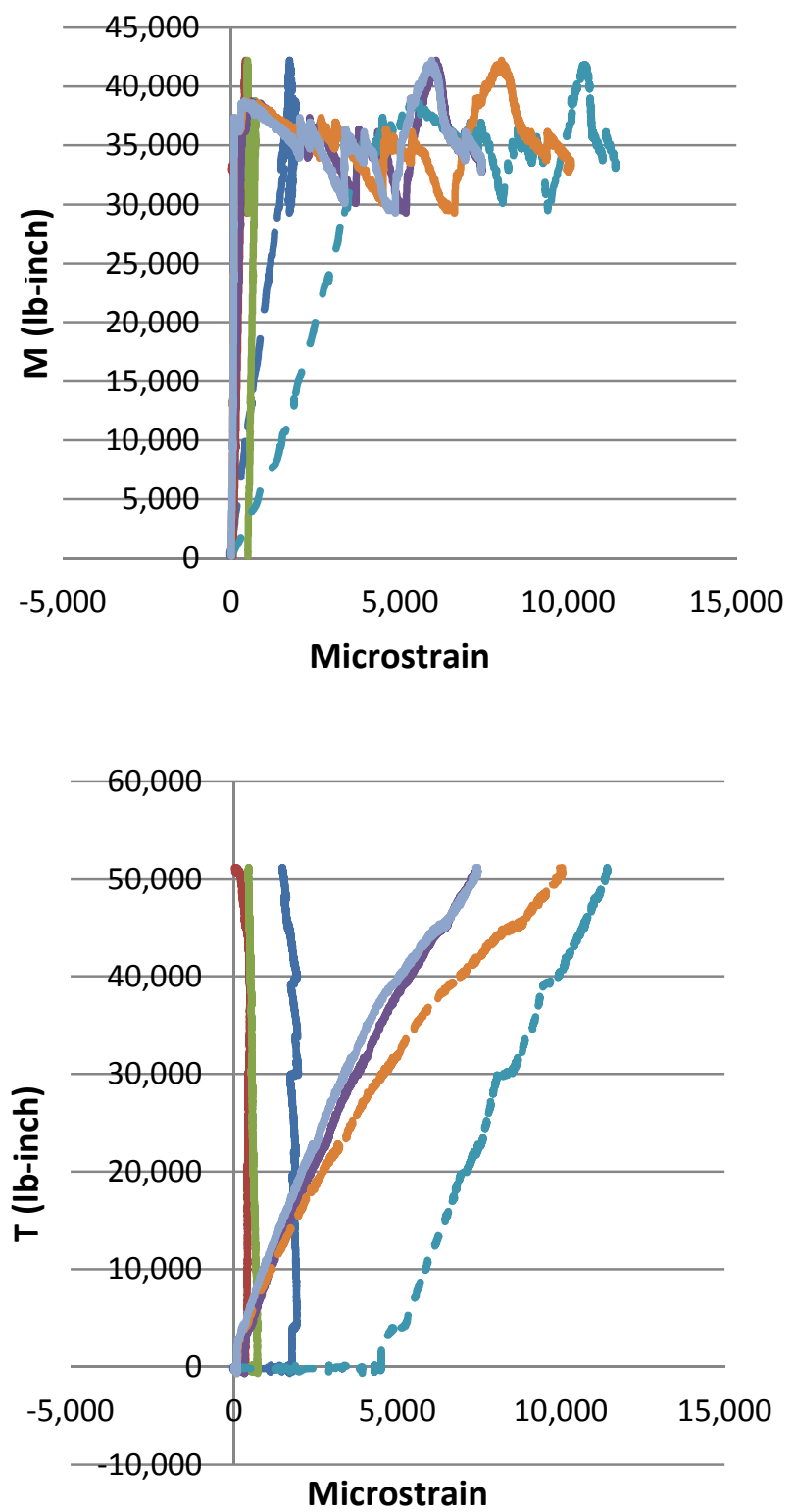

-TF_Mid_0

-TF_Rotating_0

BF_Rotating_0

$\longrightarrow$ TF_Mid+45

- BF_Mid-45

TF-Rot+45

BF_Rot-45
-TF_Mid_0

-TF_Rotating_0

-BF_Rotating_0

TF_Mid+45

- BF_Mid-45

-TF-Rot+45

BF_Rot-45

Figure 7-18: (a) M vs Microstrain, (b) T vs Microstrains of SW-Box-4×4×0.25- $70\left(\mathrm{M}=0.28 \mathrm{M}_{\max }\right)$

The T vs microstrain graph is shown in Figure 7-18 (b) with $0^{\circ}$ gages non-responsive to torsion and $45^{\circ}$ gages yielding similar net-readings. The maximum torsional moment in this case was close to the maximum torsional capacity, the mode of failure also being the same, i.e., failure at corners, as shown in Figure 7-19. 


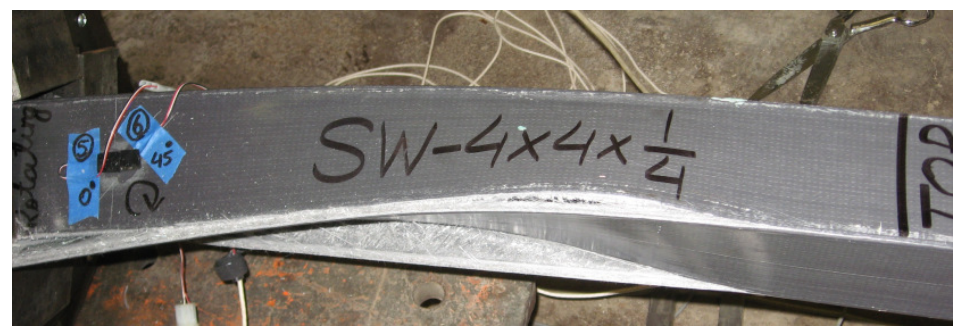

Figure 7-19: Tested SW-Box-4×4×0.25- 70 Sample $\left(\mathrm{M}=0.28 \mathrm{M}_{\max }\right)$

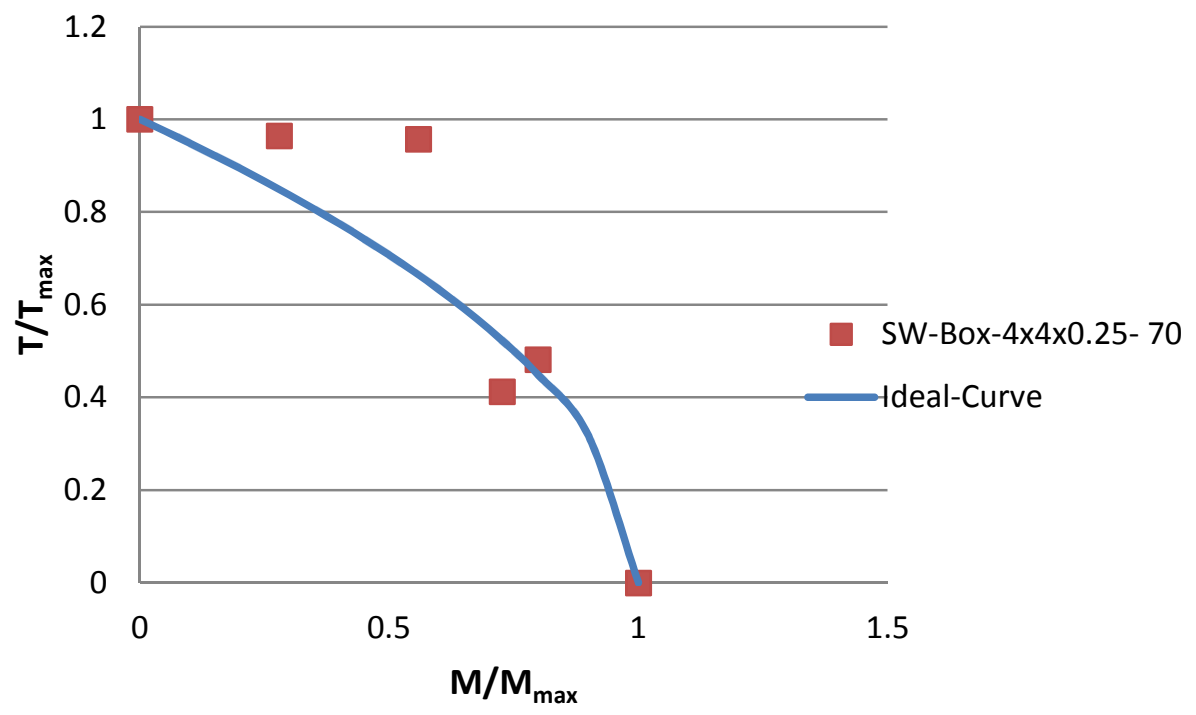

Figure 7-20: Torque vs Bending Moment Interaction Curve of SW-Box-4×4×0.25- 70

\subsubsection{The Interaction Curve}

The interaction curve between torque and bending moment is drawn with $\mathrm{T} / \mathrm{T}_{\max }$ along $\mathrm{y}$-axis and $\mathrm{M} / \mathrm{M}_{\max }$ along $\mathrm{x}$-axis, as shown in Figure 7-20. The area under the ideal curve represents the required strength. A point on the right hand side of the curve means that the actual strength at that load combination is higher than the required one. With pure torque given by $\mathrm{T} / \mathrm{T}_{\max }=1$ and 3point bending moment by $\mathrm{M} / \mathrm{M}_{\max }=1$, the four load cases given in Table7-1 are shown in small red boxes. The load case of third row does not have any strain data. The points of $0.28 \mathrm{M}_{\max }$ and $0.55 \mathrm{Mmax}$ lie well above the required strength and that of $0.8 \mathrm{M}_{\max }$ lies almost on the curve. Only one point is a little inside the curve, but this much variation seems to be acceptable. 
It can be concluded that only four data points are not enough to depict the whole combined loading behavior. For a complete picture, at least ten data points are recommended. Similarly, at least two samples should be tested for each load case. Because there is a possibility that, for example, the $0.56 \mathrm{M}_{\max }$ sample may carry relatively less torsional load in the second trial and the $0.67 \mathrm{M}_{\max }$ sample may take a higher one, hence making the data points more close to the ideal curve.

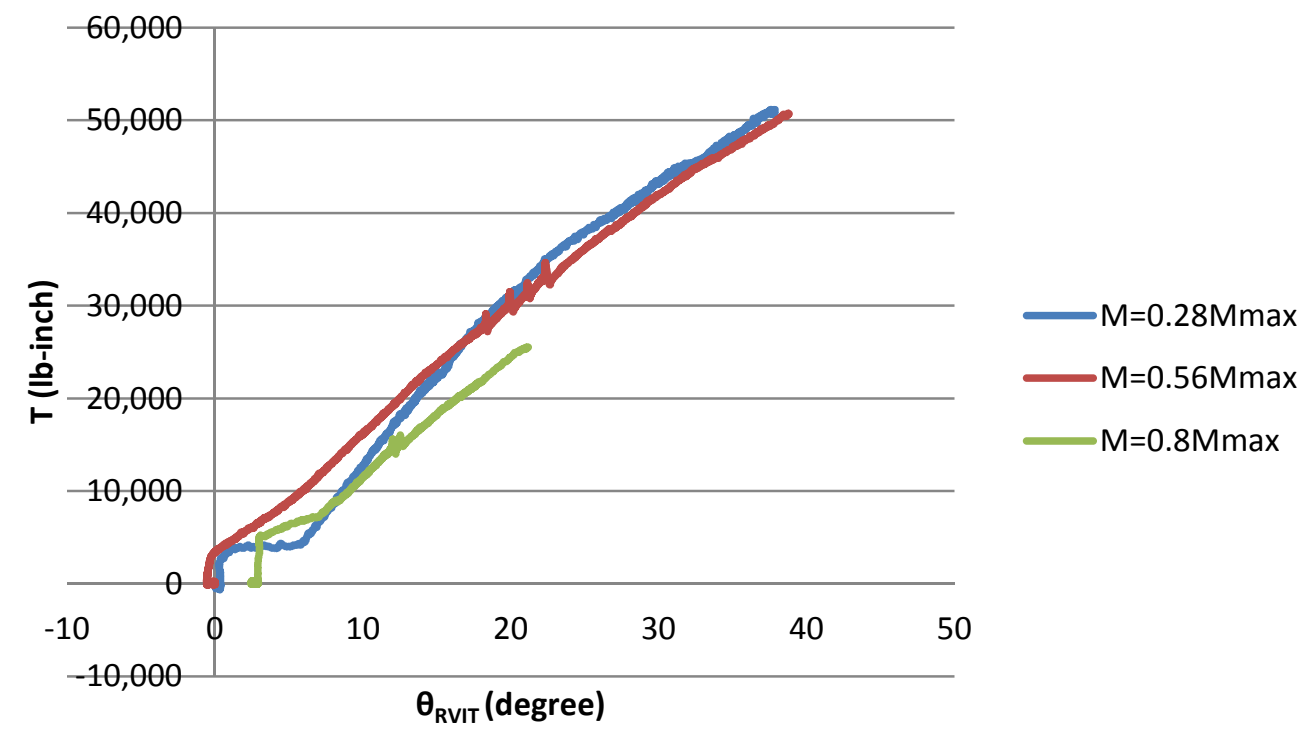

Figure 7-21: The T- $\theta$ Curve of SW-Box- $4 \times 4 \times 0.25-70$

\subsubsection{The T- $\quad$ Curves}

In the T- $\theta$ Curves shown in Figure 7-21, $\theta_{\text {RVIT }}$ has been selected instead of $\theta_{\text {sg }}$ to see what kind of experimental variations take place. Initially, applied torque does not cause any torsion because it is consumed to overcome the frictional force between the pulley and the frame caused by the bending load. In $0.28 \mathrm{M}_{\max }$ case, a rotation without increase in torque is due to a slip caused by the gap between the end-plug and the face-plate. This gap is left to maintain simply supported boundary conditions. However, the remaining part of the curves is showing the resembling bi- or trilinear trend as in pure torsion. 


\subsubsection{BRP-Box-6 $\times 6 \times 0.375-70$ Sections}

For these sample, $\mathrm{M}_{\max }=164 \mathrm{kip}$-inch as found from 3-point bending test, $\mathrm{T}_{\max }=91 \mathrm{kip}$-inch as found from pure torsion test, $\sigma=40 \mathrm{ksi}$ as found from coupon tension test and $\tau=11.7 \mathrm{ksi}$ as found from Iosepescu test.

\subsubsection{Sample-1: $M=0.9 M_{\max }$}

The $M$ vs microstrain and $T$ vs microstrain curves of Sample-1 are shown in Figure 7-22 (a) and (b) respectively. In the former figure, with no strain gage at mid-bottom- $45^{\circ}$, the maximum strain was recorded at the middle of bottom-flange at $0^{\circ}$ due to local load-effects. The top-mid-0 strain was the second highest due to tensile flexural stresses, yet little prone to local effects. The applied moment seems to remain uniform during torsion. The torsional response shown in Figure 7-22 (b) is similar to that discussed in previous cases except TF-MidEdge- $45^{\circ}$ gage.

The $45^{\circ}$ strain gage at edge of the top flange at mid-length, as shown in Figure 7-23, is not supposed to record strains due to bending, but maximum torsional strains at this location are expected. However, the recorded strain values (Figure 7-13 (b)) were almost same as other $45^{\circ}$ values. This is primarily due to the local stiffening caused by the plate through which bending load is applied.

From first row of Table 7-2, this sample withstood unusually high torque ( $93 \%$ of $\left.\mathrm{T}_{\max }\right)$. The principal stress of $25.44 \mathrm{ksi}$ well exceeded the rupture strength of $18.7 \mathrm{ksi}$ (Table 5-5) and maximum shear stress of $15 \mathrm{ksi}$ existed at $72.5^{\circ} /-17.5^{\circ}$ instead of $45^{\circ}$. This value was higher than coupon shear strength of $11.7 \mathrm{ksi}$.

The tested sample is shown in Figure 7-24 with a longitudinal crack in the middle of bottom flange. As this location is not subject to stress concentrations, $\sigma_{\max }=12.35 \mathrm{ksi}$ and $\tau_{\max }=6.6$. But the local load effects, as observed by BF-Mid-0/ \pm 45 strains, join together with these stresses to cause a shear failure along mid-face of bottom flange. 
(a)

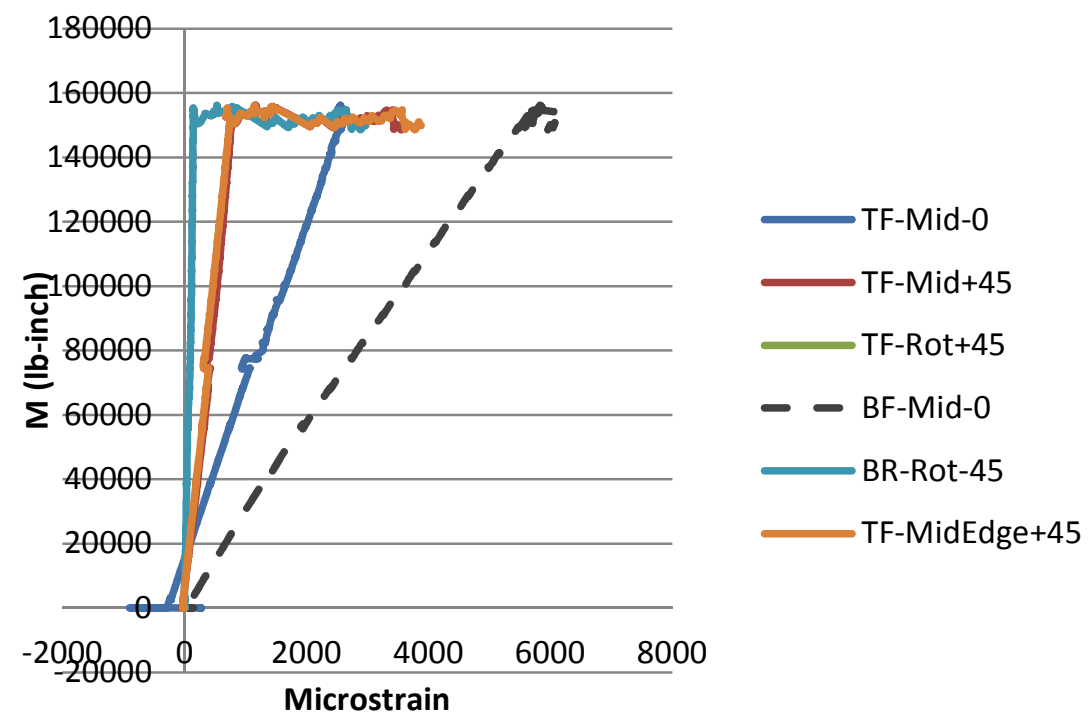

(b)
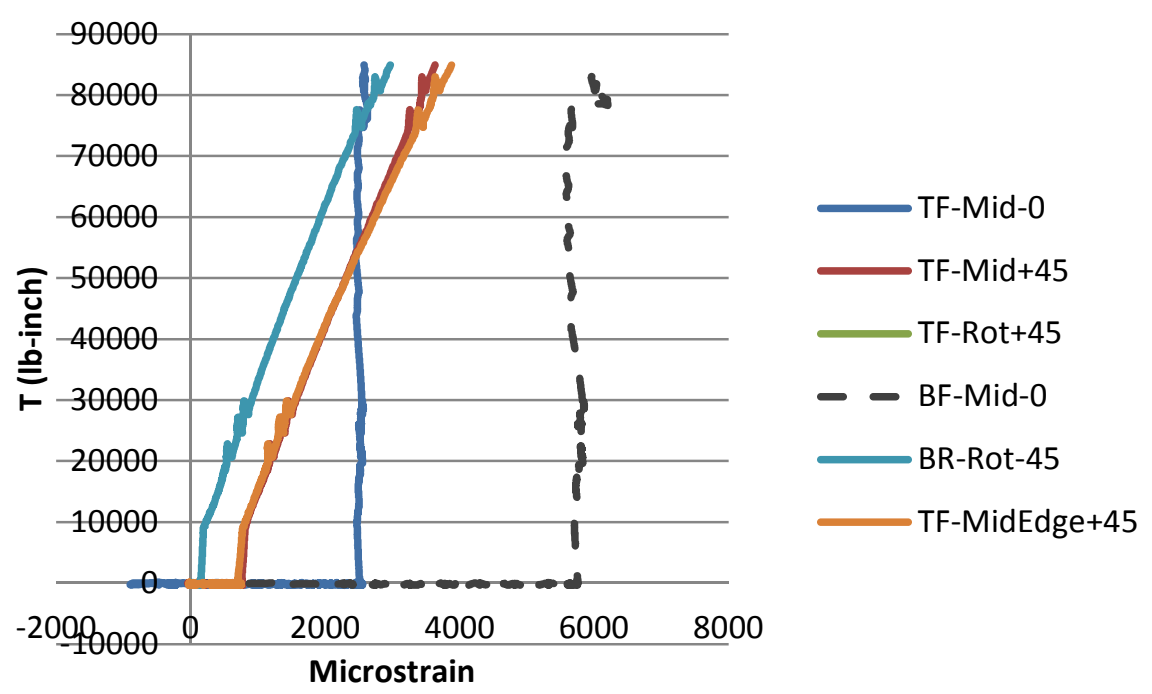

Figure 7-22: (a) $\mathrm{M}$ vs Microstrain, (b) $\mathrm{T}$ vs Microstrains of BRP-Box- $6 \times 6 \times 0.375-70\left(\mathrm{M}=0.9 \mathrm{M}_{\max }\right)$

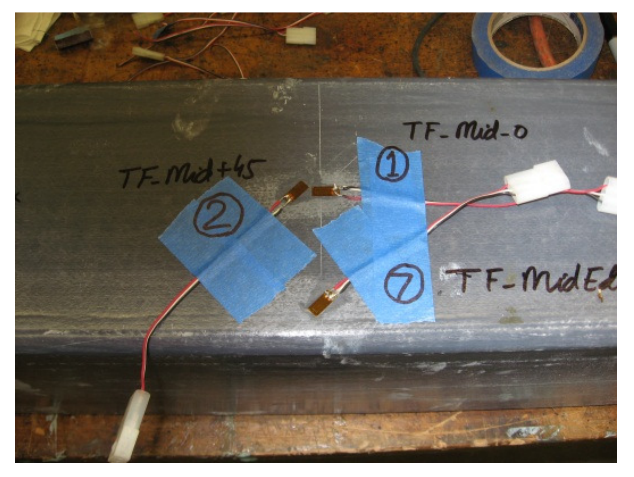

Figure 7-23: Strain Gage Locations at Top-Flange of BRP-Box-6 $\times 6 \times 0.375-70\left(\mathrm{M}=0.9 \mathrm{M}_{\max }\right)$ 


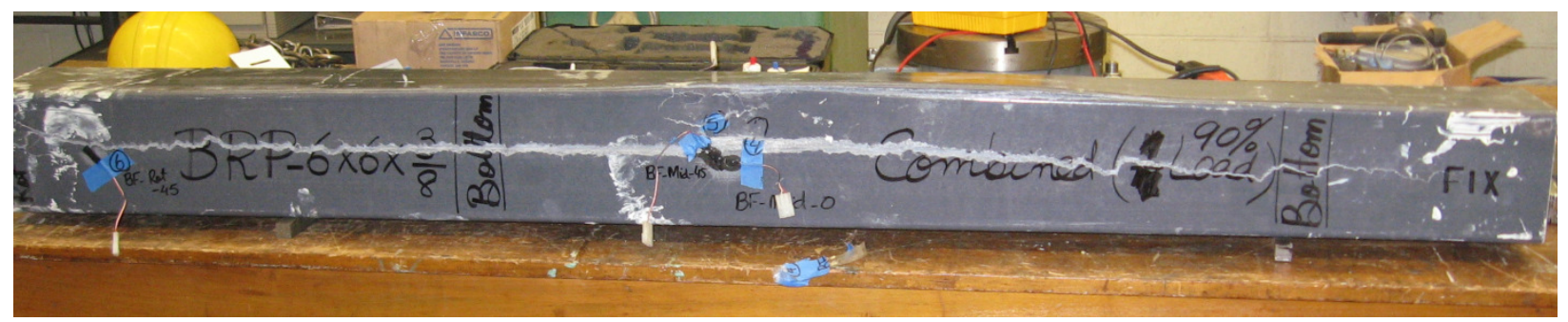

Figure 7-24: The tested BRP-Box-6×6×0.375- $70\left(\mathrm{M}=0.9 \mathrm{M}_{\max }\right)$

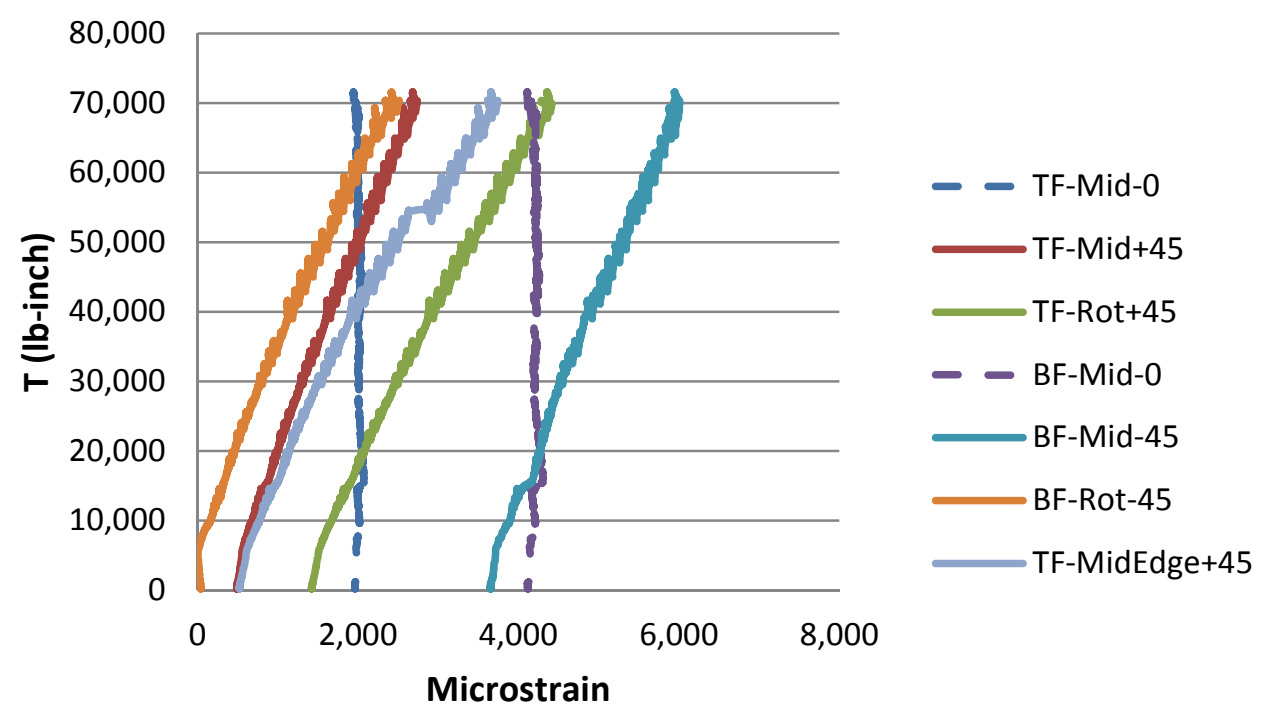

Figure 7-25: T vs Microstrains of BRP-Box-6×6×0.375- $70\left(\mathrm{M}=0.72 \mathrm{M}_{\max }\right)$

\subsubsection{Sample-2: $M=0.72 M m a x$}

As evident from T-Microstrain curve of Figure 7-25, the BF-Mid-45 strain value is maximum and the TF-MidEdge +45 strain value is less. It is important to note that when loading plate comes into contact with bottom flange, the load is initially transferred to the whole contact area, which tends to deflect. The unsupported middle part of the area undergoes deflection and yields high strain values, but the webs start acting as supports. Now the contact area between the loading plate and the web remain straight due to pressure of the plate, hence shows much less deflection or torsion. This behavior persists till final failure. 
This sample carried only 70 kip-inch torsional load as compared to 85 kip-inch in the previous case. Theoretically, it should have been the other way round. However, the principal stresses and the maximum shear stresses are still higher than the corresponding strength values. The tested sample is shown in Figure 7-26 with a corner failure.

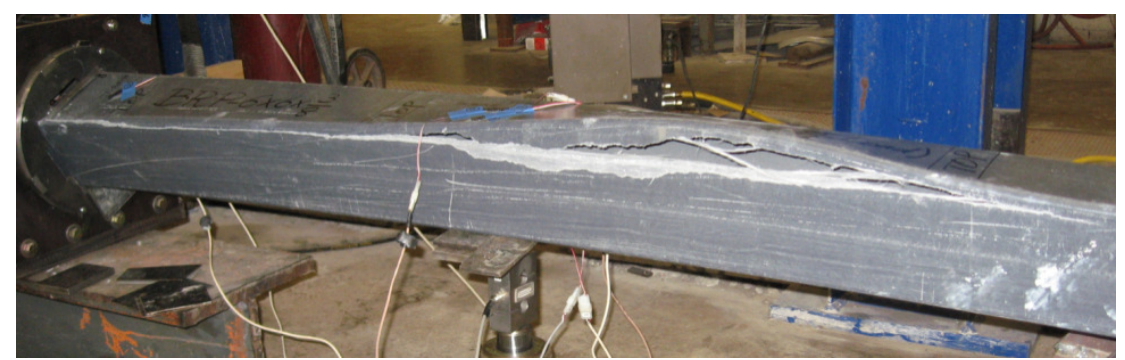

Figure 7-26: The tested BRP-Box-6×6×0.375- $70\left(\mathrm{M}=0.72 \mathrm{M}_{\max }\right)$

Table 7-2: Bending and Torsion Combinations of BRP-Box-6 $\times 6 \times 0.375-70$ Section

\begin{tabular}{|c|c|c|c|c|c|c|c|c|c|}
\hline \multicolumn{6}{|c|}{ Experimental Values } & \multicolumn{4}{|c|}{ Analytical Values } \\
\hline $\mathrm{M}$ & $\sigma_{\text {bending }}{ }^{1}$ & $\tau_{\text {bending }}{ }^{(1)}$ & $\mathrm{T}$ & $\theta_{\text {RVIT }}$ & $\tau_{\text {torsion }}{ }^{(2)}$ & $\sigma_{\max , \min }$ & $\theta_{p}$ & $\tau_{\max }$ & $\theta_{\mathrm{s}}$ \\
\hline kip-inch & ksi & ksi & kip-inch & degree & ksi & ksi & degree & $\mathrm{ksi}$ & degree \\
\hline Eqn 5-1 & Eqn 5-2 & Eqn 5-3 & Eqn 6-2 & Eqn 5-1 & Eqn 6-1 & Eqn 7-6 & Eqn 7-5 & Eqn 7-8 & Eqn 7-7 \\
\hline 150 & 20.94 & 3.57 & 84.92 & 13.35 & 10.7 & $\begin{array}{c}4.5 \\
-25.44 \\
\end{array}$ & $\begin{array}{c}117.54 \\
27.54 \\
\end{array}$ & \pm 15 & $\begin{array}{r}72.5 \\
-17.5 \\
\end{array}$ \\
\hline 118.2 & 16.50 & 2.86 & 70.37 & 15 & 9.0 & $\begin{array}{c}3.96 \\
-20.5\end{array}$ & $\begin{array}{c}113 \\
23\end{array}$ & \pm 12.2 & $\begin{array}{c}68 \\
-22\end{array}$ \\
\hline 70.9 & 9.90 & 1.70 & 75.54 & 11 & 9.5 & $\begin{array}{c}5.76 \\
-15.66 \\
\end{array}$ & \begin{tabular}{|c|}
121.24 \\
31.24 \\
\end{tabular} & \pm 10.71 & $\begin{array}{r}76.24 \\
-13.8 \\
\end{array}$ \\
\hline
\end{tabular}

\subsubsection{Sample-3: $M=0.43 M m a x$}

From the $M$ vs microstrain and $T$ vs microstrain curves shown in Figure 7-27 (a) and (b) respectively, the moment and torque response of all the $0^{\circ} / \pm 45^{\circ}$ strain gages is understandable expect TF-MidEdge+45 gage. A microstrain of 2000 does not make any sense at zero bending moment because we know that there was no other load before bending load. 
(a)

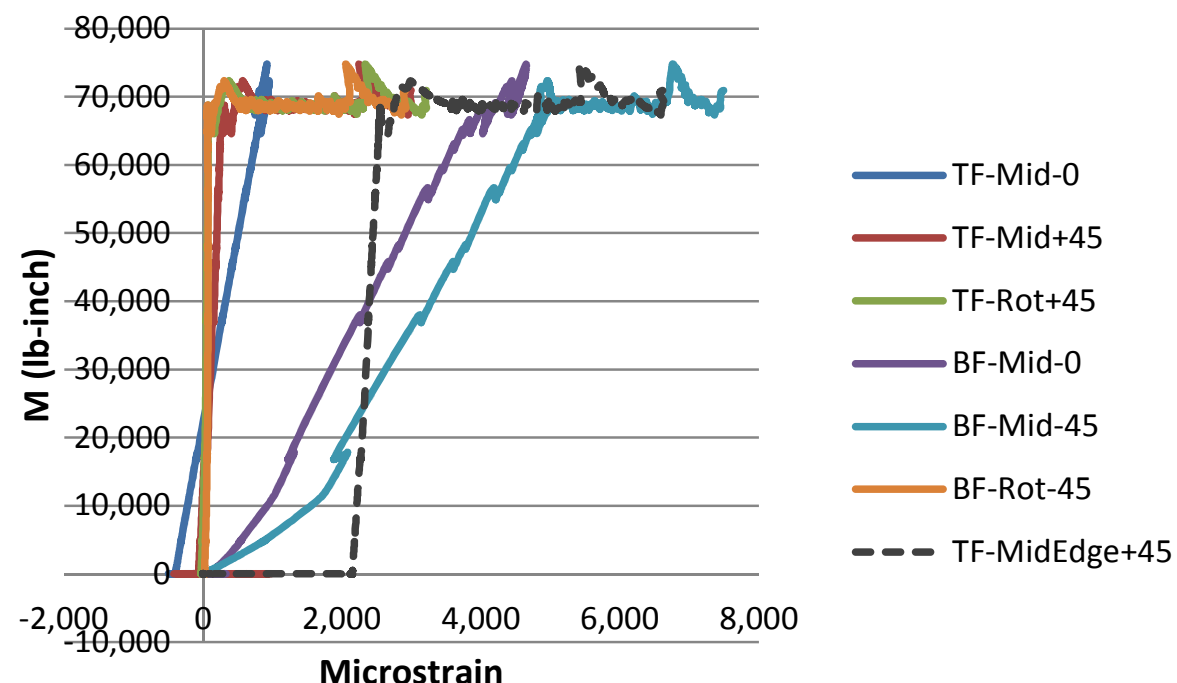

(b)

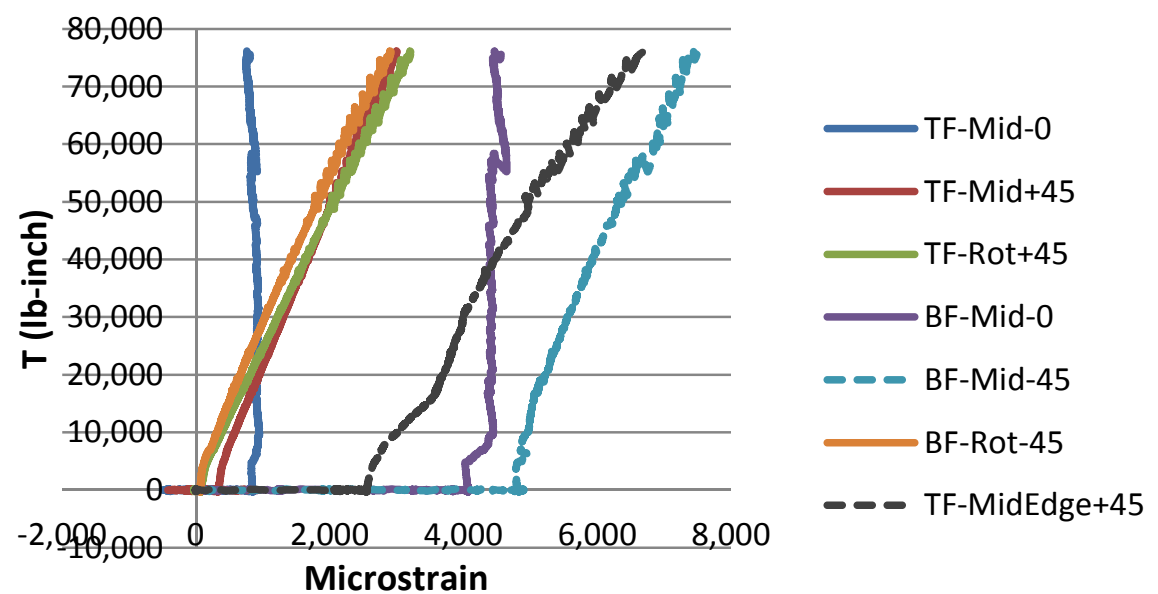

Figure 7-27: (a) M vs Microstrain, (b) T vs Microstrains of BRP-Box-6×6×0.375- 70

$$
\left(\mathrm{M}=0.43 \mathrm{M}_{\max }\right)
$$

However, if this initial strain is ignored, the remaining trend is as expected, i.e., not responsive to bending moment and the strain due to torsion is comparable to the other $\pm 45^{\circ}$ strain gages, the explanation of which is given in the preceding section.

From last row of Table 7-2, the principal stresses are less than the previous two cases because of less contribution of $\sigma_{\mathrm{b}} . \tau_{\max }$ is also somewhat less, but close to coupon shear strength of $11.7 \mathrm{ksi}$. The failure behavior is shown in Figure 7-28, with a crack along the corner. 


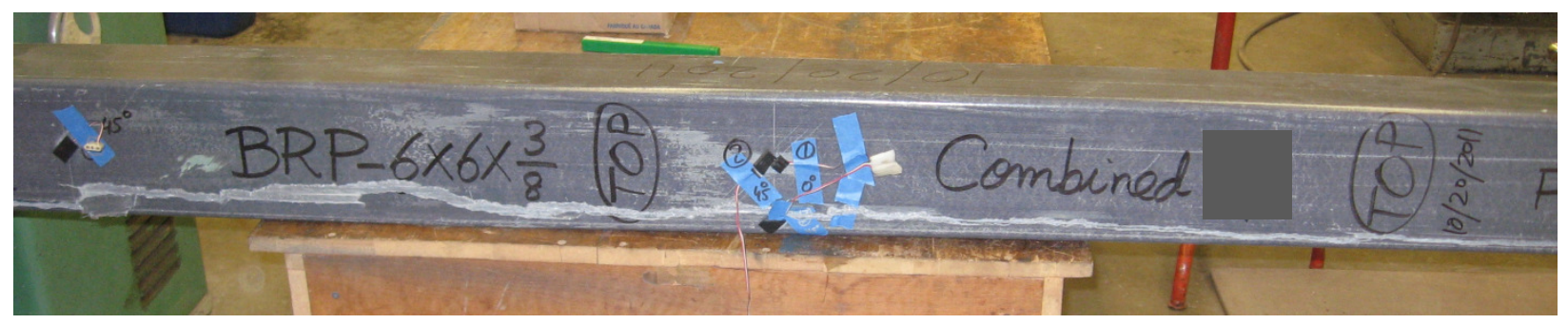

Figure 7-28: The tested BRP-Box-6×6×0.375- $70\left(\mathrm{M}=0.43 \mathrm{M}_{\max }\right)$

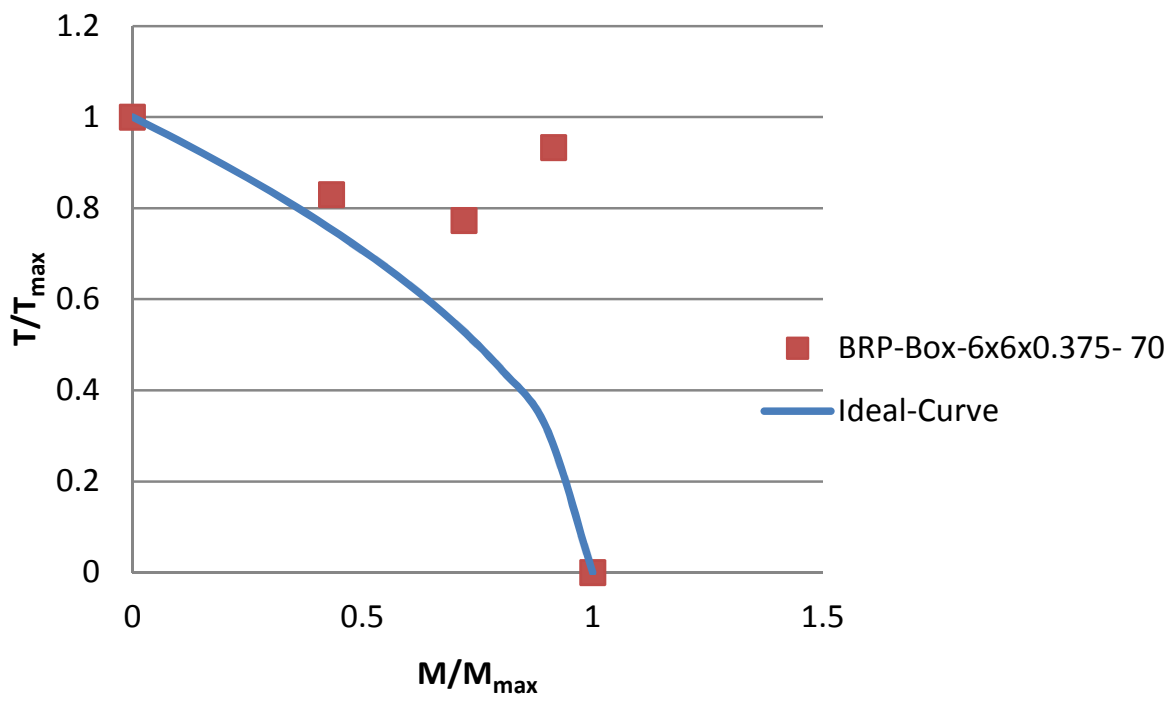

Figure 7-29: Torque vs Bending Moment Interaction Curve of BRP-Box-6×6×0.375- 70

\subsubsection{The Interactive Curve}

Following the same procedure as in Section 7.3.1.4, the interaction curve of BRP-Box$6 \times 6 \times 0.375-70$ samples is shown in Figure $7-29$, where all the data points lie well outside the ideal curve, showing that the available strength for these load combinations is considerably higher than the required strength. The load case of $0.9 \mathrm{M}_{\max }$ especially yields unusual results because at such a high bending moment, the torque capacity can be expected to be half the actual one.

The existing results again give rise to the need of larger number of data points in terms of smaller steps of bending moment and at least one repetition at each step. 


\subsubsection{The T-8 Curves}

The T- $\theta$ curves for all the three load cases are shown in Figure 7-30, where some unusual kinks in the curves are observed. Such kinks were not so prominent on the M- $\mu \varepsilon$ or T- $\mu \varepsilon$ curves. The possible reason of this behavior is that the rotation measurement device (RVIT) is either not properly fixed in its mounting bracket or not properly attached to the back face of the pulley. Similarly, it happened few times that the settings of the hydraulic actuator were not perfect and it created problems in load application. However, if the kinks are overlooked, a bi- or trilinear trend will be observed, as in all previous cases. The initial slackness behavior has been explained in Section 7.3.1.5.

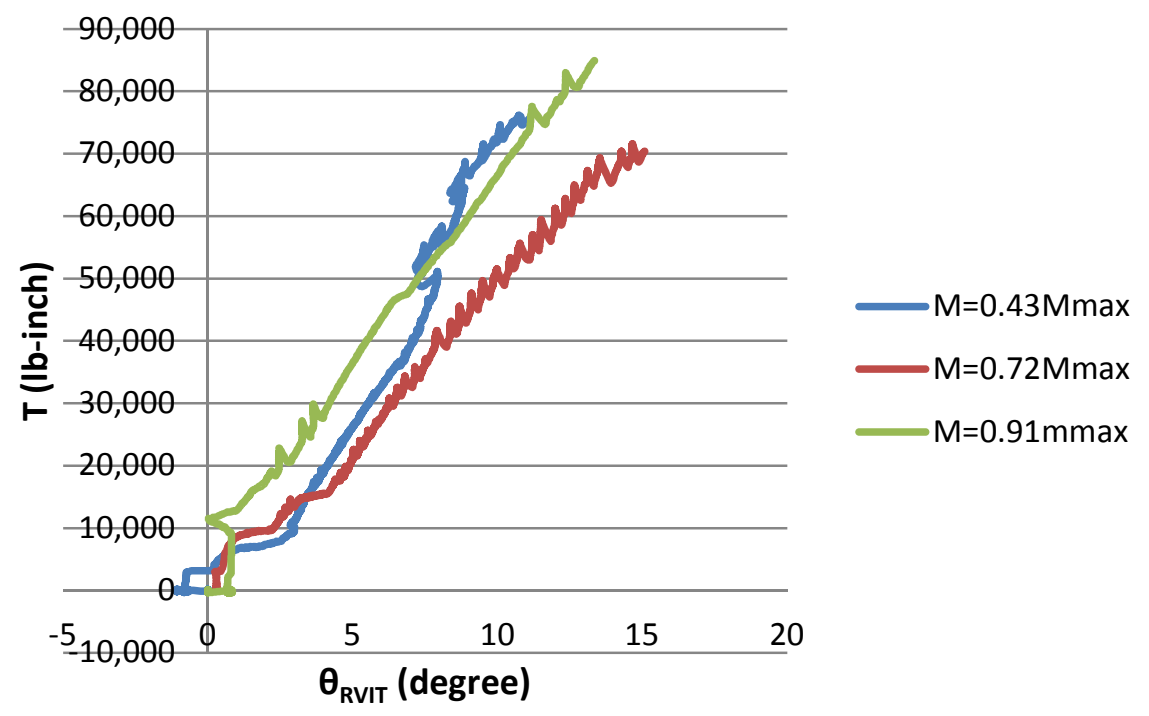

Figure 7-30: The T- $\theta$ Curve of BRP-Box- $6 \times 6 \times 0.375-70$

\subsubsection{CP-Round-6×0.25- 70 Sections}

When this sample-type was tested under 3-point bending, a metal plug was inserted in the middle to avoid local crushing with the assumption that this plug will not enhance global strength. The maximum bending moment was found to be 240 kip-inch. On the other hand, when the same sample type was tested under pure torsion, it could not be failed even at 220 kip-inch. However, in both of the load combinations presented below, the samples actually failed. 
For these samples, the coupon tensile strength was $70 \mathrm{ksi}$. However, the curvature did not allow determining the Iosepescu shear strength.

(a)

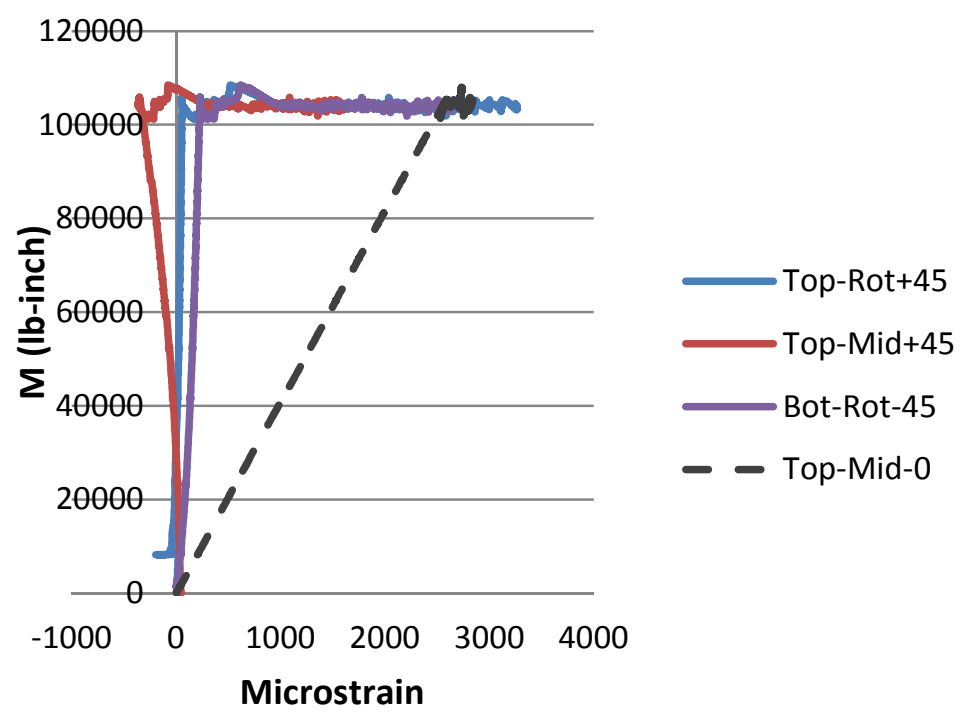

(b)

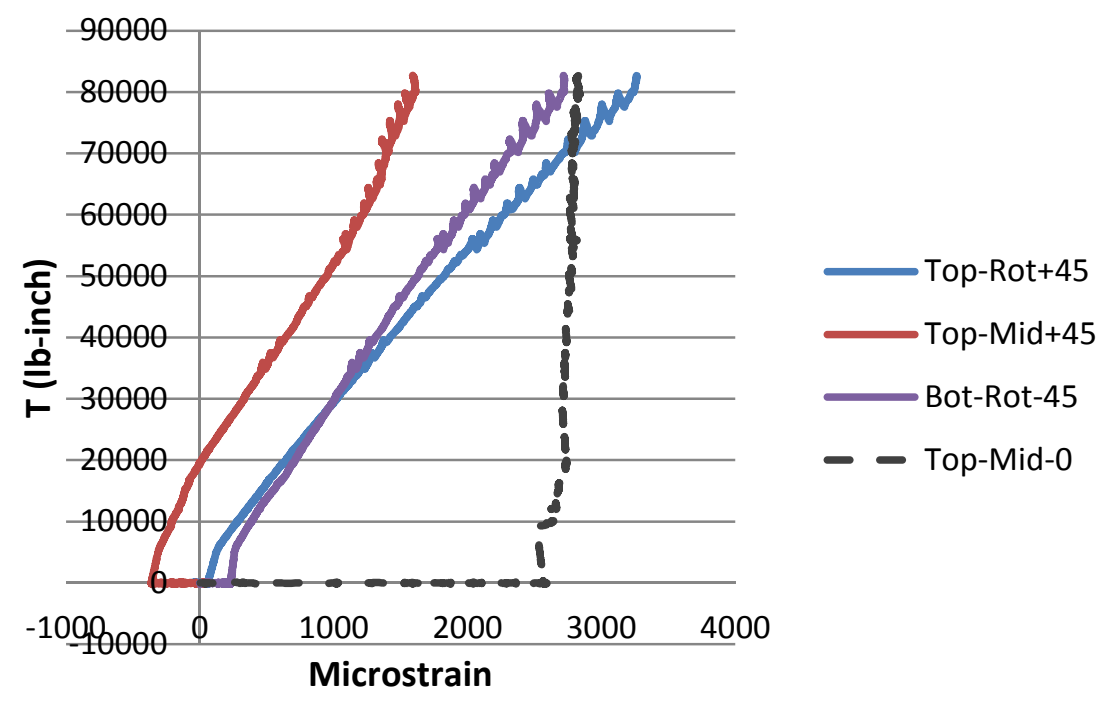

Figure 7-31: (a) M vs Microstrain, (b) T vs Microstrains of CP-Round-6×0.25- 70 (Sample-1)

\subsubsection{Sample-1}

Since $\mathrm{M}_{\max }=240$ kip-inch is somewhat questionable, $\mathrm{M} / \mathrm{M}_{\max }$ is undetermined. The $\mathrm{M}$ vs microstrain and T vs microstrain curves are shown in Figure 7-31 (a) and (b) respectively. As 
expected, the strain due to bending moment was recorded by $0^{\circ}$ strain gage only, whereas, the torque was recorded by $\pm 45^{\circ}$ gages only.

Referring to the first row of Table 7-3, the principal stresses are around $20 \mathrm{ksi}$ and maximum shear stresses are around $11 \mathrm{ksi}$. These values seem to be very low as compared to the both cases of box sections because no stress concentrations exist in this case.

Table 7-3: Bending and Torsion Combinations of CP-Round-6 $\times 0.25-70$ Section

\begin{tabular}{|c|c|c|c|c|c|c|c|c|c|}
\hline \multicolumn{6}{|c|}{ Experimental Values } & \multicolumn{4}{|c|}{ Analytical Values } \\
\hline $\mathrm{M}$ & $\sigma_{\text {bending }}$ & $\tau_{\text {bending }}$ & $\mathrm{T}$ & $\theta_{\text {RVIT }}$ & $\tau_{\text {torsion }}$ & $\sigma_{\max , \min }$ & $\theta_{p}$ & $\tau_{\max }$ & $\theta_{\mathrm{s}}$ \\
\hline kip-inch & ksi & $\mathrm{ksi}$ & kip-inch & degree & $\mathrm{ksi}$ & ksi & degree & ksi & degree \\
\hline Eqn 5-1 & Eqn 5-2 & Eqn 5-3 & Eqn 6-2 & Eqn 5-1 & Eqn 6-1 & Eqn 7-6 & Eqn 7-5 & Eqn 7-8 & Eqn 7-7 \\
\hline 104 & 17.1 & 1.44 & 82.7 & 11.82 & 6.63 & $\begin{array}{c}-19.37 \\
2.27\end{array}$ & $\begin{array}{c}-19 \\
71\end{array}$ & \pm 10.82 & $\begin{array}{c}26 \\
116\end{array}$ \\
\hline 55.9 & 9.2 & 0.773 & 154.32 & 18.3 & 12.38 & $\begin{array}{c}-17.8 \\
8.6\end{array}$ & $\begin{array}{c}-34.8 \\
55.2\end{array}$ & \pm 13.2 & $\begin{array}{c}10.2 \\
100.2\end{array}$ \\
\hline
\end{tabular}

The tested samples are shown in Figure 7-32 with broken sides rotated upwards. It can be seen that Sample-1 has a longitudinal crack from one end till middle, joining there to a circumferential crack. The longitudinal crack in a round cross-section is a classical failure pattern due to torsion. However, in this case, maximum shear stress of around $11 \mathrm{ksi}$ is due to combined loading and is significantly higher than the torsional shear of $6.63 \mathrm{ksi}$. The circumferential crack indicates that the round-shaped loading plate penetrated into the sample, most likely after the shear failure. This kind of punching effect takes place if the bending moment is significant fraction of the moment to failure. 


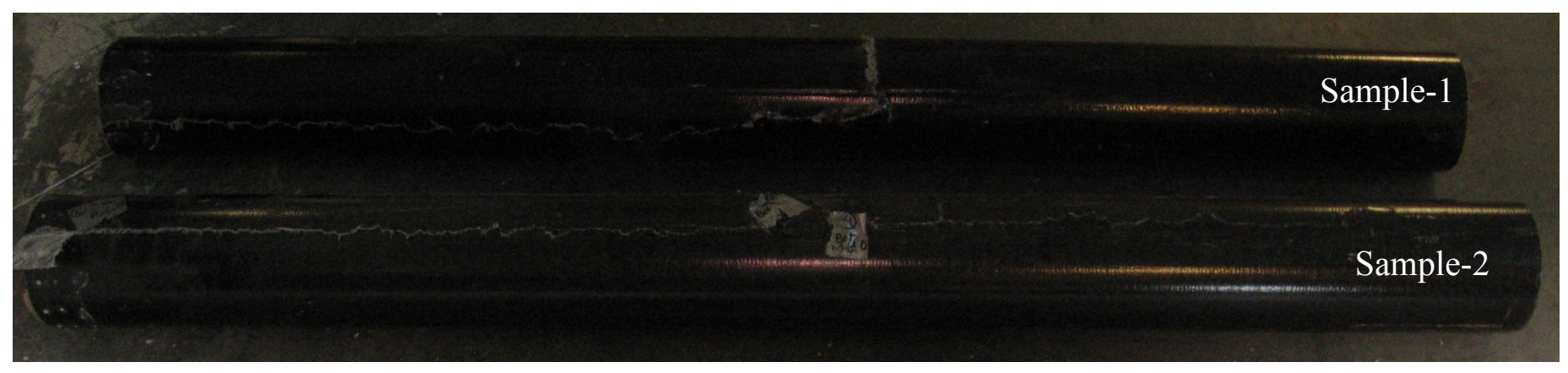

Figure 7-32: CP-Round-6×0.25- 70 Samples Tested Under Combined Bending and Torsion
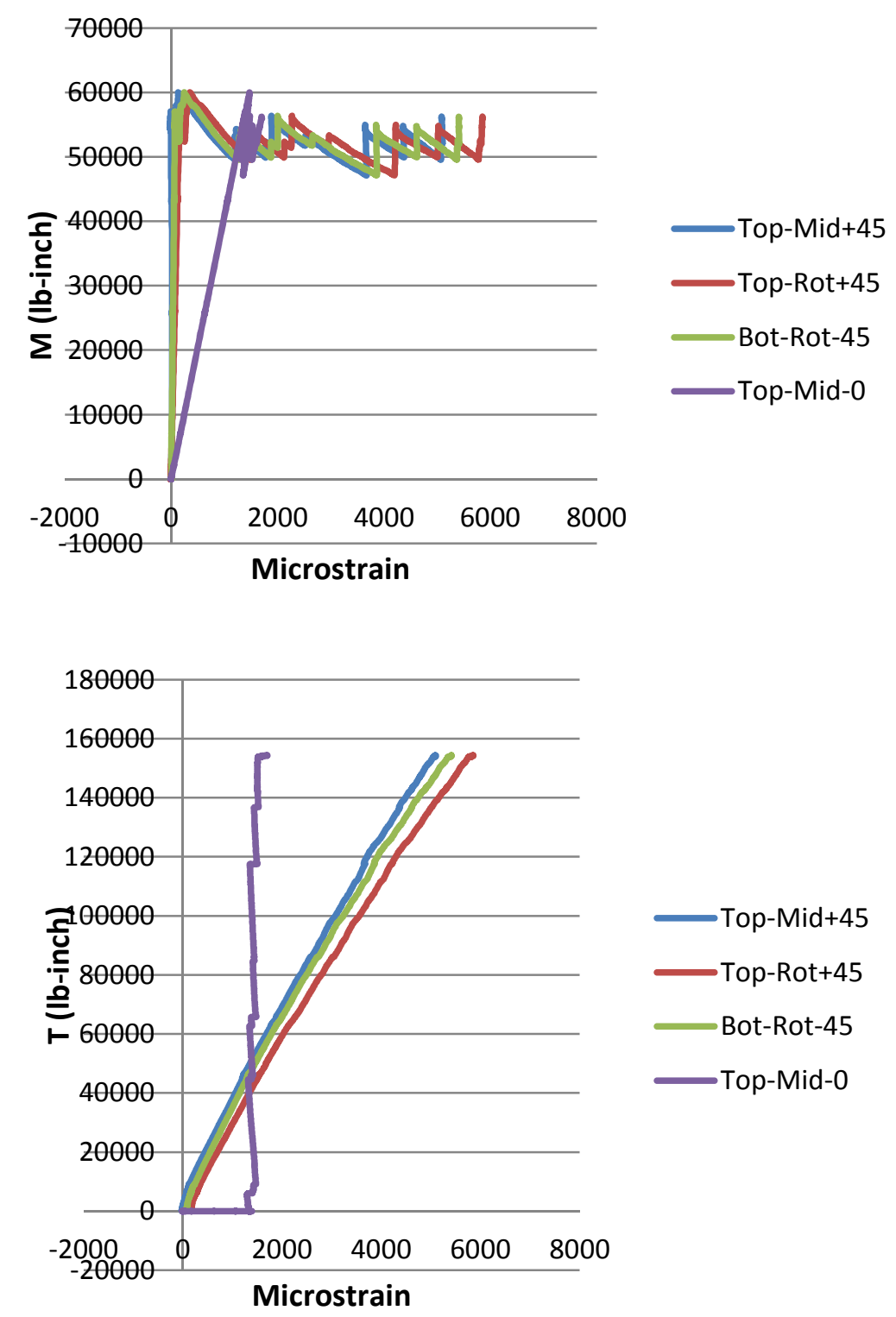

Figure 7-33: (a) M vs Microstrain, (b) T vs Microstrains of CP-Round-6×0.25- 70 (Sample-2) 


\subsubsection{Sample-2}

The $\mathrm{M}$ vs microstrain and $\mathrm{T}$ vs microstrain curves of this sample are shown in Figure 7-33 (a)

and (b) respectively. As can be seen, the applied moment was around half of the previous case, though not uniform in magnitude, while the torque to failure was around double than that. The $0^{\circ}$ gage showed linear strain due to bending and the three $45^{\circ}$ gages showed somewhat bilinear strains due to torsion, as expected.

The broken sample-2 in Figure 7-31 shows a longitudinal crack along almost the entire length due to the dominance of shear stress. Referring to second row of Table 7-3, the torsional shear stress is $12.38 \mathrm{ksi}$ and the maximum shear stress due to combined bending and torsion is 13.2 $\mathrm{ksi}$, while the principal stress is $17.8 \mathrm{ksi}$. It is interesting to see that the second load combination has half the moment and double the torque, still principal stresses and maximum shear stresses are comparable in both cases.

\subsubsection{Interaction Curve}

In order to draw the $M / M_{\max } v s T / T_{\max }$ interaction curve, we need to determine $\mathrm{M}_{\max }$ and $\mathrm{T}_{\max }$. In this regard, following findings from the experimental data are important

- The broken Sample-1 had a circumferential crack due to bending load, showing that $\mathrm{M}=104$ kip-inch should be considerably higher than $0.5 \mathrm{M}_{\max }$. In other words, if the 3point bending sample had not been reinforced in the mid-length, $\mathrm{M}_{\max }$ would have been much less than 240 kip-inch. Let us assume that for Sample-1, M/M $\mathrm{M}_{\max }$ ranges between 0.55 to 0.65 , i.e., $\mathrm{M}_{\max }$ ranges between 160 to 190 kip-inch

- Sample-2 with $\mathrm{M}=56$ kip-inch took a torsional load of 154 kip-inch to fail. Whereas, the same kind of sample did not break even at 218 kip-inch under pure torsion, which is much higher than anticipated value. It has been observed in both of the box samples that if $\mathrm{M} / \mathrm{M}_{\max }$ is even of the order of 0.5 , the torsional capacity is practically unaffected. For Sample-2, M/ $\mathrm{M}_{\max } \leq 0.35$, so $\mathrm{T}_{\max }$ should be in the range of 150 to $170 \mathrm{kip}$-inch. 
- One of the possible reasons that the sample did not break under pure torsion can be some kind of malfunctioning of the pulley and frame mechanism. If so, then the rotating head of the apparatus needs to be upgraded.

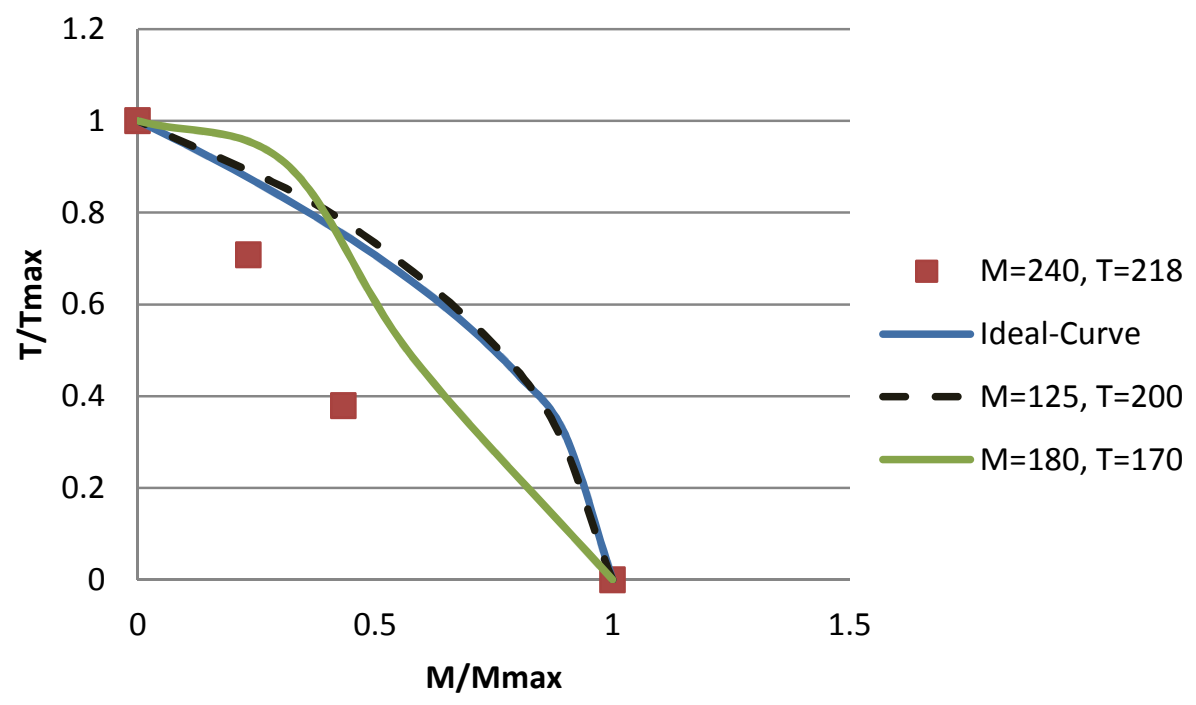

Figure 7-34: Interaction Curves of CP-Round-6×0.25- 70 Sections

The interaction curves of CP-Round-6×0.25- 70 sections are shown in Figure 7-34. When various combinations of $\mathrm{M}$ and $\mathrm{T}$ were plotted, the best fit with the ideal curve was found at $\mathrm{M}=125$ kip-inch and $\mathrm{T}=200 \mathrm{kip}$-inch. But on the basis of the discussion above, the most likely combination could be $\mathrm{M}=180$ kip-inch and $\mathrm{T}=170$ kip-inch, also shown in the figure. In the same figure, the small boxes represent the experimental points with $\mathrm{M}_{\max }=240$ kip-inch and $\mathrm{T}_{\max }=218$ kip-inch.

As a final verdict, the interaction curve seems to be more influenced by $\mathrm{M}_{\max }$ than by $\mathrm{T}_{\max }$, hence it is advisable to redo the 3-point bending test before indulging into torsional issues.

\subsubsection{The T-8 Curve}

The T- $\theta$ curves of both the samples under combined bending and torsion are shown in Figure 735. Sample-1 was acted upon by a higher magnitude of load and failed at less torque, the 
corresponding angle of twist also being less. The vice-versa conditions were true for Sample-2. The initial rotation of few degrees corresponded to slackness of end-plugs in the face-plate.

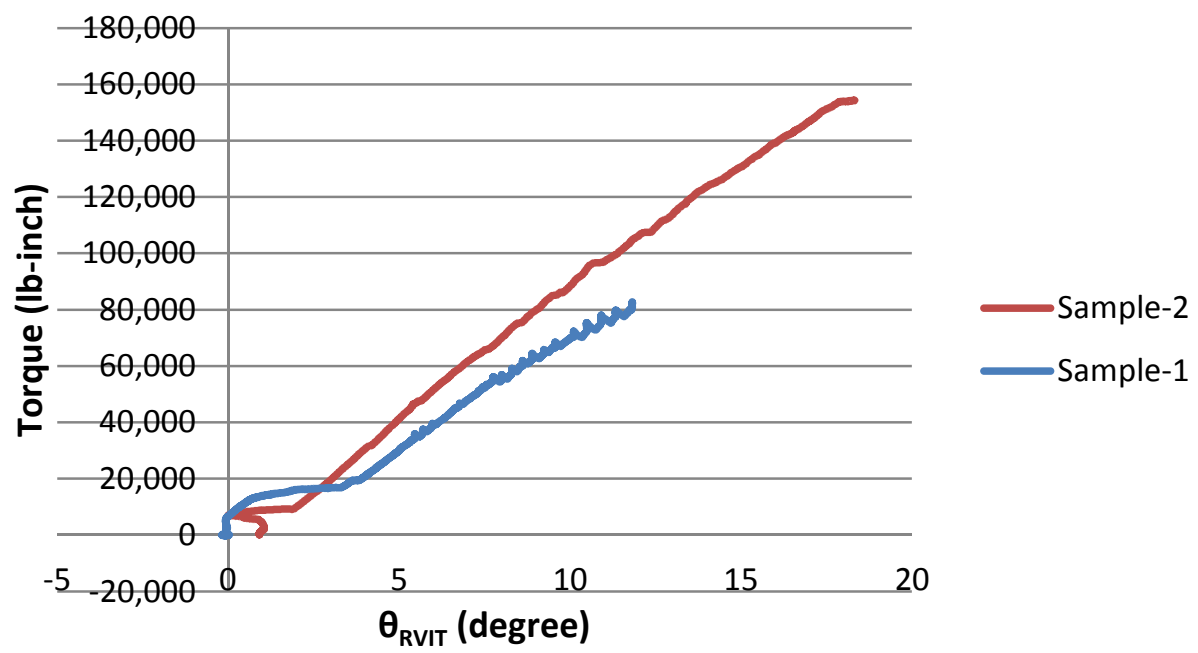

Figure 7-35: The T- $\theta$ Curve of CP-Round-6×0.25- 70 Sections Under Combined Bending and Torsion

\subsection{Conclusions}

From the behavior of square and round pultruded sections under combined bending and torsion, the following main conclusions can be drawn.

\subsubsection{Experimental Difficulties}

It has been mentioned a few times that the data points for interaction curves are too less to exhibit any conclusive trends. Hence it is advisable to have data-points corresponding to more load combinations with at least two samples tested at each stage. However, from practical standpoint, testing the full-scale samples under combined loading is much more difficult and challenging as compared to coupon testing under tension or shear. Following are some of the important issues: 
- There is no standard apparatus and test procedure for this type of testing. Design and development of such an apparatus which can hold different types and sizes of full-length samples under required boundary conditions, apply bending and torsional loads and record the corresponding deformations, needs a lot of thinking, physical work and time in addition to money.

- Extreme care is necessary in accurately mounting the sample and applying the load. After applying the bending load, when torque is applied, the bending load tends to fluctuate in magnitude. Therefore, it must be checked and adjusted all the time. At the same time, moment-torsion combination tends to create misalignment in the loosely mounted simply supported sample. If mounting is not properly balanced, even the test specimen and the loading plate can kick out of their place.

- Fixing a good number of strain gages on each sample and protecting them from being damaged needs skill and effort.

Hence it is very difficult to test big number of samples under combined bending and torsion.

\subsubsection{Response of Samples Against Combined Bending and Torsion}

\subsubsection{The Modes of Failure}

For both bending and torsion, stress concentrations occur at corners. The principal stresses due to combined bending and shear stresses must also lie at the corners, whatever be the orientation of the principal planes. The same is also true for maximum shear stresses. If the principal stresses are dominated by bending, failure mode should resemble that under pure bending, e.g., buckling of the flange under compression, web-flange separation at the area of application of load and finally, failure of the web. The SW-Box $-4 \times 4 \times 0.25$ sample at $0.8 \mathrm{M}_{\max }$ is an example in hand. If the principal stresses are dominated by torsion, the failure mode is also similar to that in pure torsion, as shown in Figure 7-19.

However, a longitudinal crack in the middle of web or flange-under-compression is difficult to explain, as shown in Figures 7-17 and 7-24. Although such a crack is due to torsional shear, yet 
it is not at the location of stress concentrations. A common aspect between the two cases is that they took unexpectedly high torsional load in the presence of high bending moments.

\subsubsection{2. $\quad$ The Interaction Curve}

Equation 7-84, representing the ideal interaction curve, seems to be an empirical relation rather than a formula derived from mechanics of composite materials. In majority of the practical load cases, the data-points lay well-beyond the interaction curve. Some of the points were even unusually high, for example, for BRP-Box- $6 \times 6 \times 0.375$ sample with $M=0.9 M_{\max }, T=0.93 T_{\max }$. Such an unexpected behavior can be explained in terms of temporal response of the sample against applied loads. It was observed that when the bending load was applied and the torsional load was picking-up, the sample was under heavy stress and likely to fail any moment. If the load were applied at a slower rate, there was a chance that the sample could break at lower rate

However, it is important to note that in many cases the samples failed as expected; the two round sections being the examples in hand. Hence, the data-points on the interaction curve did not exhibit any specific pattern. As a matter of fact, variations of such kind are not unexpected in heterogeneous materials.

In summary:

- The rate of application of torsional loads needs to be controlled in two regards (no ASTM standard test procedure):

i. the feed rate may be reduced

ii. when the sample is not failing at the expected load, the load-magnitude should be maintained for few minutes before letting it increase.

- There is need of testing more than one samples at each load-combination.

\subsubsection{Apparatus Upgradation}

As shown in Figure 4.3, the pulley is in the form of a cylinder, rotating in a frame consisting of two plates bolted on a channel section. The cylinder is made of high-strength steel and frame is 
made of mild-steel. As observed, the 6" diameter round sample did not fail even at 220 kip-inch, which is very unexpected. It is anticipated that at high-torsional load, there is some kind of interlocking between the frame and the pulley, though the mechanism is not well-understood.

One empirical solution of this problem is to upgrade the apparatus instead of getting into detailed technical analysis. This can be simply done by replacing the elements of the existing frame (plates, channel and bolts) with those of higher strength. The higher strength can be achieved either by using thicker elements of the existing material or high-strength material of the existing thickness. The best choice may be to moderately increase both the dimensions and material strength. 


\section{CHAPTER 8 - RECOMMENDATIONS}

\subsection{Introduction}

In the preceding chapters, failure behavior of full-scale pultruded GFRP composite sections was investigated under bending, torsion and combined bending and torsion; emphasis being on identification of modes of failure and determination of stress concentration factors. This investigation provides a guideline for design of different types of pultruded sections under given load conditions. Design procedures for round, square and wide-flange pultruded sections will be illustrated with the help of following illustrations.

\subsection{Illustration-I}

\subsubsection{Problem Statement}

Fiber architecture of a quarter inch thick glass-fiber reinforced polymer composite laminate is shown in Figure 8-1.

\begin{tabular}{|r|}
\hline CSM $1.5 \mathrm{oz} / \mathrm{ft}^{2}, \quad \mathrm{t}_{\mathrm{k}} \approx 0.025$ in, $\quad \mathrm{V}_{\mathrm{f}} \approx 25 \%$ \\
\hline Roving 56 Yield, $\mathrm{t}_{\mathrm{k}} \approx 0.075$ in, $\quad \mathrm{V}_{\mathrm{f}} \approx 35 \%$ \\
\hline CSM $1.5 \mathrm{oz} / \mathrm{ft}^{2}, \quad \mathrm{t}_{\mathrm{k}} \approx 0.025$ in, $\quad \mathrm{V}_{\mathrm{f}} \approx 25 \%$ \\
\hline CSM $1.5 \mathrm{oz} / \mathrm{ft}^{2}, \quad \mathrm{t}_{\mathrm{k}} \approx 0.025$ in, $\mathrm{V}_{\mathrm{f}} \approx 25 \%$ \\
\hline Roving 56 Yield, $\mathrm{t}_{\mathrm{k}} \approx 0.075$ in,, $\mathrm{V}_{\mathrm{f}} \approx 35 \%$ \\
\hline CSM $1.5 \mathrm{oz} / \mathrm{ft}^{2}, \quad \mathrm{t}_{\mathrm{k}} \approx 0.025$ in, $\quad \mathrm{V}_{\mathrm{f}} \approx 25 \%$ \\
\hline
\end{tabular}

Figure 8-1: Fiber architecture of a $1 / 4$ " thick GFRP composite laminate

Material properties of fiber and matrix are:

$$
\begin{array}{cl}
E_{f}=10.5 \mathrm{msi}, & v_{f}=0.22 \\
E_{m}=0.5 \mathrm{msi}, & v_{f}=0.38
\end{array}
$$

From coupon testing,

$$
\begin{aligned}
& \sigma_{\text {ult }}^{\text {Tension }}(\text { Laminate })=50 \mathrm{ksi} \\
& \tau_{\text {ult }}^{\text {Tension }}(\text { Laminate })=12 \mathrm{ksi}
\end{aligned}
$$


A 4" $\times 4$ " square section, a 4" $\times 4$ " wide-flange section and a 4" diameter round section are made of this laminate. Compare the design capacities of these sections under bending, torsion and combined bending and torsion.

\subsubsection{Assumptions}

1. The values of ply thickness $\left(\mathrm{t}_{\mathrm{k}}\right)$ and fiber volume fraction $\left(\mathrm{V}_{\mathrm{f}}\right)$ may have variations along cross-section. Hence approximate average values are taken.

2. Seam effects and local load effects are neglected.

3. Stress concentration factor under bending, $\mathrm{SCF}=2.0$

4. Stress concentration factor under torsion, $\mathrm{K}_{\mathrm{ts}}=2.5$

5. Properties in compression are taken to be $90 \%$ of those in tension.

\subsubsection{Laminate Properties}

From given properties, $G_{f}$ and $G_{m}$ can be found as,

$$
\begin{gathered}
G_{f}=\frac{E_{f}}{2\left(1+v_{f}\right)}=\frac{10.5}{2(1+0.22)}=4.30 \mathrm{msi} \\
G_{m}=\frac{E_{m}}{2\left(1+v_{m}\right)}=\frac{0.5}{2(1+0.38)}=0.18 \mathrm{msi}
\end{gathered}
$$

\subsection{CSM Layer}

From Equation 4-1,

$$
E_{1}=E_{f} V_{f}+E_{m}\left(1-V_{f}\right)=10.5 \times 0.25+0.5 \times 0.75=3.0 m s i
$$

From Equation 4-2,

$$
E_{2}=E_{m}\left[\frac{1+2 \eta V_{f}}{1-\eta V_{f}}\right]
$$

with $\eta=\frac{\left(E_{f} / E_{m}\right)-1}{\left(E_{f} / E_{m}\right)+2}=\frac{\left(\frac{10.5}{0.5}\right)-1}{\left(\frac{10.5}{0.5}\right)+2}=0.87$ from Equation 4-3. Then, 


$$
E_{2}=0.5\left[\frac{1+2 \times 0.87 \times 0.25}{1-0.87 \times 0.25}\right]=0.917 \mathrm{msi}
$$

From Equation 4-4,

$$
\begin{aligned}
G_{12} & =G_{m} \frac{\left(1+V_{f}\right)+\left(1-V_{f}\right)\left(\frac{G_{m}}{G_{f}}\right)}{\left(1-V_{f}\right)+\left(1+V_{f}\right)\left(\frac{G_{m}}{G_{f}}\right)}=0.18 \times \frac{1.25+0.75 \times \frac{0.18}{4.30}}{0.75+1.25 \times \frac{0.18}{4.30}} \\
& =0.287 \mathrm{msi} \approx 0.3 \mathrm{msi}
\end{aligned}
$$

From Equation 4-5,

$$
v_{12}=v_{f} V_{f}+v_{m}\left(1-V_{f}\right)=0.22 \times 0.25+0.38 \times 0.75=0.34
$$

From Equation 4-6,

$$
v_{21}=\frac{E_{2}}{E_{1}} v_{12}=\frac{0.917}{3} \times 0.34=0.10
$$

And from Equation 4-13,

$$
[Q]=\left[\begin{array}{ccc}
\frac{E_{1}}{1-v_{12} v_{21}} & \frac{v_{21} E_{1}}{1-v_{12} v_{21}} & 0 \\
\frac{v_{21} E_{1}}{1-v_{12} v_{21}} & \frac{E_{2}}{1-v_{12} v_{21}} & 0 \\
0 & 0 & G_{12}
\end{array}\right]=\left[\begin{array}{ccc}
3.1 & 0.323 & 0 \\
0.323 & 0.95 & 0 \\
0 & 0 & 0.287
\end{array}\right] \times 10^{6} p s i
$$

Equation 4-17, when solved for continuous strand mat (CSM), yields

$$
\begin{gathered}
{[Q]_{C S M}=\left[\begin{array}{ccc}
\bar{Q}_{11} & \bar{Q}_{12} & 0 \\
\bar{Q}_{12} & \bar{Q}_{11} & 0 \\
0 & 0 & \bar{Q}_{66}
\end{array}\right]} \\
\bar{Q}_{11}=\bar{Q}_{22}=\frac{3}{8} Q_{11}+\frac{1}{4} Q_{12}+\frac{3}{8} Q_{22}+\frac{1}{2} Q_{66}=1.743 \times 10^{6} \\
\bar{Q}_{12}=\frac{1}{8} Q_{11}+\frac{3}{4} Q_{12}+\frac{1}{8} Q_{22}-\frac{1}{2} Q_{66}=0.605 \times 10^{6} \\
\bar{Q}_{66}=\frac{1}{8} Q_{11}-\frac{1}{4} Q_{12}+\frac{1}{8} Q_{22}+\frac{1}{2} Q_{66}=0.569 \times 10^{6} \\
{[]_{C S M}=\left[\begin{array}{ccc}
1.743 & 0.605 & 0 \\
0.605 & 1.743 & 0 \\
0 & 0 & 0.569
\end{array}\right] \times 10^{6} \mathrm{psi}}
\end{gathered}
$$




\subsubsection{2. $\quad$ Roving 56Yield Layer}

From Equation 4-1,

$$
E_{1}=E_{f} V_{f}+E_{m}\left(1-V_{f}\right)=10.5 \times 0.35+0.5 \times 0.65=4.0 \mathrm{msi}
$$

From Equation 4-2,

$$
E_{2}=E_{m}\left[\frac{1+2 \eta V_{f}}{1-\eta V_{f}}\right]=0.5\left[\frac{1+2 \times 0.87 \times 0.35}{1-0.87 \times 0.35}\right]=1.156 \mathrm{msi}
$$

From Equation 4-4,

$$
\begin{gathered}
G_{12}=G_{m} \frac{\left(1+V_{f}\right)+\left(1-V_{f}\right)\left(G_{m} / G_{f}\right)}{\left(1-V_{f}\right)+\left(1+V_{f}\right)\left(G_{m} / G_{f}\right)}=0.18 \times \frac{1.35+0.65 \times 0.18 / 4.30}{0.65+1.35 \times 0.18 / 4.30}=0.35 \mathrm{msi} \\
{[Q]=[\bar{Q}]_{\text {Roving }}=\left[\begin{array}{ccc}
\frac{E_{1}}{1-v_{12} v_{21}} & \frac{v_{21} E_{1}}{1-v_{12} v_{21}} & 0 \\
\frac{v_{21} E_{1}}{1-v_{12} v_{21}} & \frac{E_{2}}{1-v_{12} v_{21}} & 0 \\
0 & 0 & G_{12}
\end{array}\right]=\left[\begin{array}{ccc}
4.145 & 0.388 & 0 \\
0.388 & 1.20 & 0 \\
0 & 0 & 0.35
\end{array}\right] \times 10^{6} \mathrm{psi}}
\end{gathered}
$$

From equations 4-19 and 4-22,

$$
\begin{gathered}
{[A]_{3 \times 3}=\sum_{k=1}^{n}[\bar{Q}]_{k} t_{k}=\left[\begin{array}{ccc}
A_{11} & A_{12} & 0 \\
A_{12} & A_{22} & 0 \\
0 & 0 & A_{66}
\end{array}\right]} \\
A_{11}=4\left(1.743 \times 10^{6} \times 0.025\right)+2\left(4.145 \times 10^{6} \times 0.075\right)=7.961 \times 10^{5} \\
\text { and so on } \ldots \ldots \ldots . .
\end{gathered}
$$

Then,

$$
[A]=\left[\begin{array}{ccc}
7.961 & 1.187 & 0 \\
1.187 & 3.543 & 0 \\
0 & 0 & 1.094
\end{array}\right] \times 10^{5}
$$

and

$$
[a]=[A]^{-1}=\left[\begin{array}{ccc}
1.322 \times 10^{-6} & -4.43 \times 10^{-7} & 0 \\
-4.43 \times 10^{-7} & 2.97 \times 10^{-6} & 0 \\
0 & 0 & 9.14 \times 10^{-6}
\end{array}\right]
$$

From Equations 4-20 and 4-23, 


$$
[B]_{3 \times 3}=\sum_{k=1}^{n}[Q]_{k} t_{k} \bar{z}_{k}=\left[\begin{array}{ccc}
B_{11} & B_{12} & 0 \\
B_{12} & B_{22} & 0 \\
0 & 0 & B_{66}
\end{array}\right]
$$

From the symmetry of the laminate,

$$
[B]=\left[\begin{array}{lll}
0 & 0 & 0 \\
0 & 0 & 0 \\
0 & 0 & 0
\end{array}\right]
$$

From Equations 4-21 and 4-24,

$$
\begin{aligned}
{[D]_{3 \times 3} } & =\sum_{k=1}^{n}[Q]_{k}\left(t_{k} \bar{z}_{k}^{2}+\frac{t_{k}^{3}}{12}\right)=\left[\begin{array}{ccc}
D_{11} & D_{12} & 0 \\
D_{12} & D_{22} & 0 \\
0 & 0 & D_{66}
\end{array}\right] \\
D_{11}= & 2 \times\left(1.743 \times 10^{6}\right) \times\left(0.025 \times 0.1125^{2}+\frac{0.025^{3}}{12}\right) \\
& +2 \times\left(4.145 \times 10^{6}\right) \times\left(0.075 \times 0.0625^{2}+\frac{0.075^{3}}{12}\right) \\
& +2 \times\left(1.743 \times 10^{6}\right) \times\left(0.025 \times 0.0125^{2}+\frac{0.025^{3}}{12}\right) \\
& =3846
\end{aligned}
$$

and so on ................

Then,

$$
[D]=\left[\begin{array}{ccc}
3846 & 643 & 0 \\
643 & 1913 & 0 \\
0 & 0 & 597.17
\end{array}\right]
$$

and

$$
[d]=[D]^{-1}=\left[\begin{array}{ccc}
2.755 \times 10^{-4} & -9.26 \times 10^{-5} & 0 \\
-9.26 \times 10^{-5} & 5.54 \times 10^{-4} & 0 \\
0 & 0 & 1.675 \times 10^{-3}
\end{array}\right]
$$

\subsubsection{Section Properties}

The bending stiffness of a square cross-section shown in Figure 5-1 (a) is given by Equation 5-4 as 


$$
\begin{gathered}
\widetilde{E I_{y y}}=\frac{b_{f}}{\left(a_{11}\right)_{f}} \frac{d^{2}}{2}+\frac{2 b_{f}}{\left(d_{11}\right)_{f}}+\frac{2 b_{w}^{3}}{12\left(a_{11}\right)_{w}} \\
=\frac{4}{1.322 \times 10^{-6}} \frac{3.75^{2}}{2}+\frac{2 \times 4}{2.755 \times 10^{-4}}+\frac{2 \times 3.5^{3}}{12 \times 1.322 \times 10^{-6}} \\
=26.71 \times 10^{6}{\mathrm{lb}-\text { inch }^{2}}^{2}
\end{gathered}
$$

The bending stiffness of a wide-flange cross-section shown in Figure 5-1 (b) is given by Equation 5-5 as

$$
\begin{gathered}
\widetilde{E I_{y y}}=\frac{b_{f}}{\left(a_{11}\right)_{f}} \frac{d^{2}}{2}+\frac{2 b_{f}}{\left(d_{11}\right)_{f}}+\frac{b_{w}^{3}}{12\left(a_{11}\right)_{w}} \\
=\frac{4}{1.322 \times 10^{-6}} \frac{3.75^{2}}{2}+\frac{2 \times 4}{2.755 \times 10^{-4}}+\frac{3.5^{3}}{12 \times 1.322 \times 10^{-6}} \\
=24.0 \times 10^{6}{\mathrm{ib}-\mathrm{inch}^{2}}^{2}
\end{gathered}
$$

The bending stiffness of a circular cross-section shown in Figure 5-1 (c) is given by Equation 5-6 as

$$
\begin{gathered}
\widetilde{E I_{y y}}=\widetilde{E I_{z z}}=\pi\left(\frac{R^{3}}{a_{11}}+\frac{R}{d_{11}}\right)=\pi\left(\frac{1.875^{3}}{1.322 \times 10^{-6}}+\frac{1.875}{2.755 \times 10^{-4}}\right) \\
=15.69 \times 10^{6} \mathrm{lb}-\text { inch }^{2}
\end{gathered}
$$

\subsubsection{Bending Behavior}

\subsubsection{Nominal Strength Due to Material Rupture}

From Equation 5.2.2-1 and 5.2.2-2 respectively [1],

$$
\begin{gathered}
M_{n}(\text { Tension })=\min \left[\frac{F_{L, f}^{t}\left(E_{L, f}^{a v e} I_{f}+E_{L, w}^{a v e} I_{w}\right)}{y_{t, f} E_{L, f}^{a v e}}, \frac{F_{L, w}^{t}\left(E_{L, f}^{a v e} I_{f}+E_{L, w}^{a v e} I_{w}\right)}{y_{t, w} E_{L, w}^{a v e}}\right] \\
M_{n}(\text { Compression })=\min \left[\frac{F_{L, f}^{c}\left(E_{L, f}^{a v e} I_{f}+E_{L, w}^{a v e} I_{w}\right)}{y_{t, f} E_{L, f}^{a v e}}, \frac{F_{L, w}^{c}\left(E_{L, f}^{a v e} I_{f}+E_{L, w}^{a v e} I_{w}\right)}{y_{t, w} E_{L, w}^{a v e}}\right] \\
F_{L, f}^{t}=\text { Longitudinal tensile strength of the flange }=50 \mathrm{ksi}
\end{gathered}
$$




$$
\begin{gathered}
F_{L, f}^{c}=\text { Longitudinal compressive strength of the flange }=45 \mathrm{ksi} \\
E_{L, f}^{a v e}=\frac{E_{L, f}^{t}+E_{L, f}^{c}}{2}=\text { Average of longitudinal modulus for flange } \\
=\frac{3.0+2.7}{2}=2.85 \mathrm{msi} \\
\quad I_{f}=2 A \bar{y}^{2}=2(4 \times 0.25) \times 1.875^{2}=7.03 \text { inch }^{4} \\
F_{L, w}^{t}=\text { Longitudinal tensile strength of the web }=50 \mathrm{ksi} \\
E_{L, w}^{a v e}=\frac{E_{L, w}^{t}+E_{L, w}^{c}}{2}=\text { Average of longitudinal modulus for web } \\
=\frac{3.0+2.75}{2}=2.85 \mathrm{msi}^{2} \\
I_{w}(\text { Box })=2 \times \frac{b_{w} h_{w}^{3}}{12}=\frac{0.25 \times 3.5^{3}}{12}=1.786 \text { inch }^{4} \\
I_{w}(\text { Wide }- \text { Flange })=\frac{b_{w} h_{w}^{3}}{12}=\frac{0.25 \times 3.5^{3}}{12}=0.893 \text { inch }^{4} \\
y_{t, f}=2 " \\
y_{t, w}=1.75^{\prime \prime}
\end{gathered}
$$

For box section,

$$
\begin{aligned}
M_{n}(\text { Tension }) & =\min \left[\frac{50000\left(2.85 \times 10^{6} \times 7.03+2.85 \times 10^{6} \times 1.786\right)}{2 \times 2.85 \times 10^{6}},\right] \\
& =18367 \mathrm{lb}-\mathrm{ft} \\
M_{n}(\text { Compression }) & =\min \left[\frac{40000\left(2.85 \times 10^{6} \times 7.03+2.85 \times 10^{6} \times 1.786\right)}{1.75 \times 2.85 \times 10^{6}}\right] \\
& =16530 \mathrm{lb}-\mathrm{ft}
\end{aligned}
$$

For wide-flange section, 


$$
\begin{aligned}
M_{n}(\text { Tension }) & =\min \left[\frac{50000\left(2.85 \times 10^{6} \times 7.03+2.85 \times 10^{6} \times 0.893\right)}{2 \times 2.85 \times 10^{6}},\right] \\
& =16506 \mathrm{lb}-f t \\
M_{n}(\text { Compression }) & =\min \left[\frac{40000\left(2.85 \times 10^{6} \times 7.03+2.85 \times 10^{6} \times 0.893\right)}{1.75 \times 2.85 \times 10^{6}}\right] \\
& =14856 \mathrm{lb}-\mathrm{ft}
\end{aligned}
$$

\subsubsection{Nominal Strength Due to Local Instability}

$M_{n}$ of an I, C, T or box section due to local instability is given by Equation 5.2.3-1 [1],

$$
M_{n}=f_{c r} \frac{E_{L, f}^{a v e} I_{f}+E_{L, w}^{a v e} I_{w}}{y_{c, e} E_{L, e}^{a v e}}
$$

For flange of the box-section, from Equations 5.2.3-5, 5.2.3-6 and 5.2.3-7 respectively [1]

$$
\begin{gathered}
f_{c r}=\frac{4 \pi^{2} t_{e}^{2}}{b_{e}^{2}}\left[\frac{\sqrt{\left(E_{L, e}^{c} E_{T, e}^{c}\right)(1+4.1 \xi)}}{6}+\left(2+0.62 \xi^{2}\right)\left(\frac{E_{T, e}^{c} v_{L, e}}{12}+\frac{G_{L T, e}}{6}\right)\right] \\
\xi=\frac{1}{1+\frac{4 E_{T, e}^{c} t_{e}^{3}}{5 k_{r} b_{e}}} \\
k_{r}=\frac{E_{T, a}^{c} t_{a}^{3}}{3 b_{a}}\left[1-\left[\frac{2 t_{e}^{2} b_{a}^{2} E_{L, a}^{c}}{11.1 b_{e}^{2} t_{a}^{2} E_{L, e}^{c}}\right]\left[\frac{\sqrt{E_{L, e}^{c} E_{T, e}^{c}}+E_{T, e}^{c} v_{L, e}+2 G_{L T, e}}{1.25 \sqrt{E_{L, a}^{c} E_{T, a}^{c}}+E_{T, a}^{c} v_{L, a}+2 G_{L T, a}}\right]\right] \\
k_{r}=\frac{1 \times 10^{6} \times 0.25^{3}}{3 \times 3.5}\left[\begin{array}{c}
1-\left[\frac{2 \times 0.25^{2} \times 3.5^{2} \times 2.7 \times 10^{6}}{11.1 \times 4^{2} \times 0.25^{2} \times 2.7 \times 10^{6}}\right] \times \\
{\left[\frac{\sqrt{2.7 \times 10^{6} \times 1 \times 10^{6}}+1 \times 10^{6} \times 0.34+2 \times 0.3 \times 10^{6}}{1.25 \sqrt{2.7 \times 10^{6} \times 1 \times 10^{6}}+1 \times 10^{6} \times 0.34+2 \times 0.3 \times 10^{6}}\right.}
\end{array}\right]
\end{gathered}
$$


$=1311.2$

$$
\begin{gathered}
\xi=\frac{1}{1+\frac{4 \times 1 \times 10^{6} \times 0.25^{3}}{5 \times 1311.2 \times 4}}=0.2955 \\
f_{c r}=\frac{4 \pi^{2} \times 0.25^{2}}{4^{2}}\left[\frac{\sqrt{(2.7 \times 1)(1+4.1 \times 0.2955)} \times 10^{6}}{6}\right. \\
\left.+\left(2+0.62 \times 0.2955^{2}\right)\left(\frac{1 \times 10^{6} \times 0.34}{12}+\frac{0.3 \times 10^{6}}{6}\right)\right] \\
=87532 p s i \\
M_{n}=87532 \times \frac{2.85 \times 10^{6} \times 7.03+2.85 \times 10^{6} \times 1.786}{2 \times 2.85 \times 10^{6}} \\
=32153 \mathrm{lb}-\mathrm{ft}
\end{gathered}
$$

For web of the box-section, from Equation 5.2.3-8 [1],

$$
\begin{gathered}
f_{c r}=\frac{11.1 \pi^{2} t_{e}^{2}}{12 b_{e}^{2}}\left[1.25 \sqrt{\left(E_{L, e}^{c} E_{T, e}^{c}\right)}+E_{T, e}^{c} v_{L, e}+2 G_{L T, e}\right] \\
f_{c r}=\frac{11.1 \pi^{2} \times 0.25^{2}}{12 \times 3.5^{2}}\left[1.25 \sqrt{2.7 \times 1} \times 10^{6}+1 \times 10^{6} \times 0.34+2 \times 0.3 \times 10^{6}\right] \\
=120312 \mathrm{psi}
\end{gathered}
$$$$
M_{n}=120312 \times \frac{2.85 \times 10^{6} \times 7.03+2.85 \times 10^{6} \times 1.786}{2 \times 2.85 \times 10^{6}}
$$$$
=44195 \mathrm{lb}-f t
$$

For flange of wide-flange beam, from Equations 5.2.3-2, 5.2.3-3 and 5.2.3-4 respectively [1],

$$
\begin{gathered}
f_{c r}=\frac{4 t_{e}^{2}}{c^{2} b_{e}^{2}}\left[\frac{7}{12} \sqrt{\frac{E_{L, e}^{c} E_{T, e}^{c}}{1+4.1 \xi}}+G_{L T, e}\right] \\
\xi=\frac{E_{T, e}^{c} t_{e}^{3}}{6 c k_{r} b_{e}}
\end{gathered}
$$




$$
\begin{aligned}
& k_{r}=\frac{c E_{T, a}^{c} t_{a}^{3}}{6 b_{a}}\left[1-\left[\frac{48 t_{e}^{2} b_{a}^{2} E_{L, a}^{c}}{11.1 \pi^{2} c^{2} b_{e}^{2} t_{a}^{2} E_{L, e}^{c}}\right]\left[\frac{G_{L T, e}}{1.25 \sqrt{E_{L, a}^{c} E_{T, a}^{c}}+E_{T, a}^{c} v_{L, a}+2 G_{L T, a}}\right]\right] \\
& k_{r}=\frac{1 \times 1 \times 10^{6} \times 0.25^{3}}{6 \times 3.5}\left[\begin{array}{c}
1-\left[\frac{48 \times 0.25^{2} \times 3.5^{2} \times 2.7 \times 10^{6}}{11.1 \pi^{2} \times 1 \times 4^{2} \times 0.25^{2} \times 2.7 \times 10^{6}}\right] \times \\
\left.\frac{0.3 \times 10^{6}}{1.25 \sqrt{2.7 \times 1} \times 10^{6}+1 \times 10^{6} \times 0.34+2 \times 0.3 \times 10^{6}}\right]
\end{array}\right] \\
& =719 \\
& \begin{array}{c}
\xi=\frac{1 \times 10^{6} \times 0.25^{3}}{6 \times 1 \times 719 \times 4}=0.9 \\
f_{c r}=\frac{4 \times 0.25^{2}}{1 \times 4^{2}}\left[\frac{7}{12} \sqrt{\frac{2.7 \times 1}{1+4.1 \times 0.9}}+0.3\right] \times 10^{6} \\
=11587 \mathrm{psi} \\
M_{n}=11587 \times \frac{2.85 \times 10^{6} \times 7.03+2.85 \times 10^{6} \times 0.893}{2 \times 2.85 \times 10^{6}} \\
=3825 \mathrm{lb}-\mathrm{ft}
\end{array}
\end{aligned}
$$

For web of wide-flange beam, from Equation 5.2.3-8 [1],

$$
f_{c r}=120312 p s i
$$

as already found. Then from Equation 5.2.3-1 [1],

$$
\begin{aligned}
M_{n} & =120312 \times \frac{2.85 \times 10^{6} \times 7.03+2.85 \times 10^{6} \times 0.893}{2 \times 2.85 \times 10^{6}} \\
& =39718 \mathrm{lb}-\mathrm{ft}
\end{aligned}
$$

\subsubsection{Nominal Strength Due to Lateral Torsional Buckling}

For box sections, from Equation 5.2.4-2 [1], 


$$
\begin{gathered}
M_{n}=C_{b} \sqrt{\frac{\pi^{2} E_{L} I_{y} D_{J}}{L_{b}^{2}}} \\
D_{J}=4\left[\left(b_{f}-t_{w}\right)\left(h-t_{f}\right)\right]^{2}\left[G_{L T, f} \frac{t_{f}}{8 b_{f}}+G_{L T, w} \frac{t_{w}}{8 h}\right] \\
=4[(4-0.25)(4-0.25)]^{2}\left[0.3 \times 10^{6} \frac{0.25}{8 \times 4}+0.3 \times 10^{6} \frac{0.25}{8 \times 4}\right] \\
=3707885.7
\end{gathered}
$$$$
M_{n}=1 \times \sqrt{\frac{\pi^{2} \times 3 \times 10^{6} \times 2.667 \times 3707885.7}{L_{b}^{2}}}
$$$$
\text { For } L_{b}=24 ", \quad M_{n}=108100 \mathrm{lb}-\mathrm{ft}
$$$$
\text { For } L_{b}=48 ", \quad M_{n}=54048 l b-f t
$$

For wide-flange sections, from Equation 5.2.4-1 [1],

$$
\begin{gathered}
M_{n}=C_{b} \sqrt{\frac{\pi^{2} E_{L} I_{y} D_{J}}{L_{b}^{2}}+\frac{\pi^{4} E_{L}^{2} I_{y} C_{\omega}}{L_{b}^{4}}} \\
D_{J}=\sum \frac{1}{3} G_{L T}^{i} b_{i} t_{i}^{3}=\frac{G_{L T} t^{3}}{3}\left(2 b_{f}+b_{w}\right)=\frac{0.5 \times 10^{6} \times 0.25^{3}}{3}(2 \times 4+3.5)=17968.5 \\
C_{\omega}=\frac{t_{f} h^{2} b_{f}^{3}}{24}=\frac{0.25 \times 4^{2} \times 4^{3}}{24}=2.667 \\
M_{n}=1 \sqrt{\frac{L_{b} \times 3 \times 10^{6} \times 2.667 \times 17968.75}{L_{b}^{2}}+\frac{\pi^{4} \times\left(4 \times 10^{6}\right)^{2} \times 1.125 \times 10.125}{L_{b}^{4}}} \\
=120694 \mathrm{lb}-\text { inch }
\end{gathered}
$$$$
\text { For } L_{b}=24 ", \quad M_{n}=5505 l b-f t
$$ 


$$
\text { For } L_{b}=48 ", \quad M_{n}=2259 \mathrm{lb}-f t
$$

\subsubsection{Nominal Strength Due to Material Rupture in Shear}

From Equation 5.3.2-1 [1],

$$
\begin{gathered}
V_{n}=F_{L T}^{v} A_{s} \\
F_{L T}^{v}=12000 \mathrm{psi}(\text { assumed }) \\
V_{n}(\text { Box })=12000 \times 3.75=42000 \mathrm{lbs} \\
V_{n}(W F)=12000 \times 2.875=34500 \mathrm{lbs} \\
V_{n}(\text { Round })=12000 \times 2.94=35280 \mathrm{lbs}
\end{gathered}
$$

\subsubsection{Nominal Strength Due to Web Shear Buckling}

From Equation 5.3.3-1 [1],

$$
V_{n}=f_{c r} h t_{w}
$$

Provided that

$$
\begin{gathered}
2 G_{L T, w}+E_{L, w}^{c} v_{T, w} \leq \sqrt{E_{L, w}^{c} E_{T, w}^{c}} \\
2 \times 0.3 \times 10^{6}+2.7 \times 10^{6} \times 0.10 \leq^{?} \sqrt{2.7 \times 1.0} \times 10^{6} \\
0.87<1.64 \text { оK }
\end{gathered}
$$

From Equation 5.3.3-2 [1],

$$
f_{c r}=\frac{t_{w}^{2} K_{L T} \sqrt[4]{E_{L, w}^{c}\left(E_{T, w}^{c}\right)^{3}}}{3 h^{2}}
$$

From Equation 5.3.3-3 [1], 


$$
\begin{gathered}
K_{L T}=8.1+5.0 \frac{2 G_{L T, w}+E_{L, w}^{c} \nu_{T, w}}{\sqrt{E_{L, w}^{c} E_{T, w}^{c}}} \\
=8.1+5.0 \frac{2 \times 0.3 \times 10^{6}+2.7 \times 10^{6} \times 0.1}{\sqrt{2.7 \times 1.0 \times 10^{6}}} \\
=10.747 \\
f_{c r}=\frac{0.25^{2} \times 10.747 \times \sqrt[4]{2.7 \times 10^{6}\left(1.0 \times 10^{6}\right)^{3}}}{3 \times 4^{2}}=22994.3 \mathrm{psi} \\
V_{n}=22994.3 \times 4 \times 0.25=22994.3 \mathrm{lbs}
\end{gathered}
$$

\subsubsection{Torsional Behavior}

\subsubsection{Torsional Strength Due to Web Shear Buckling}

When strength governs, from Equation 6.3-2a [1],

$$
T_{n}=F_{n} J
$$

with

$$
F_{n}=\gamma G_{L T}
$$

In the absence of shear strain $\gamma$,

$$
F_{n}=12000 p s i
$$

as assumed before

For circular sections,

$$
J=\frac{\pi}{2}\left(R^{4}-R_{i}^{4}\right)=\frac{\pi}{2}\left(2^{4}-1.75^{4}\right)=10.4 \text { inch }^{4}
$$

For a rectangular section as shown in Figure 6-4, 


$$
J=\frac{2 A^{2}}{\frac{d_{w}}{t_{w}}+\frac{b_{f}}{t_{f}}}=\frac{2 \times(3.75 \times 3.75)^{2}}{\frac{3.5}{0.25}+\frac{4}{0.25}}=13.18 \mathrm{inch}^{4}
$$

For wide-flange sections,

$$
\begin{gathered}
J=\frac{2 b_{f} t_{f}^{3}+b_{w} t_{w}^{3}}{3}=\frac{2 \times 4 \times 0.25^{3}+3.5 \times 0.25^{3}}{3}=0.6 \text { inch }^{4} \\
T_{n}(\text { Round })=12000 \times 10.4=10400 \mathrm{lb}-f t \\
T_{n}(\text { Box })=12000 \times 13.18=13180 \mathrm{lb}-f t \\
T_{n}(W F)=12000 \times 0.6=600 \mathrm{lb}-f t
\end{gathered}
$$

When stiffness governs, from Equation 6.3-2b [1],

$$
T_{n}=F_{c r} C
$$

For circular sections, $F_{c r}$ is minimum of Equations 6.3-9 and 6.3-10 as given below [1],

$$
\begin{gathered}
F_{c r}=\frac{0.236\left(E_{T}^{c}\right)^{5 / 8}\left(E_{L}^{c}\right)^{3 / 8}}{\left(\frac{R}{t}\right)^{3 / 2}} \leq F_{L T}^{v} \\
F_{c r}=\frac{0.236\left(1 \times 10^{6}\right)^{5 / 8}\left(2.7 \times 10^{6}\right)^{3 / 8}}{\left(\frac{4}{0.25}\right)^{3 / 2}}=5306.4 \text { lbs }<F_{L T}^{v}(=12000 \mathrm{psi}) \\
F_{c r}=\frac{0.733\left(E_{T}^{c}\right)^{5 / 8}\left(E_{L}^{c}\right)^{3 / 8}}{\left(\frac{R}{t}\right)^{3 / 2} \sqrt{\frac{L}{R}}} \leq F_{L T}^{v}
\end{gathered}
$$

For $\mathrm{L}=72 "$

$$
\begin{gathered}
F_{c r}=\frac{0.733\left(1 \times 10^{6}\right)^{5 / 8}\left(2.7 \times 10^{6}\right)^{3 / 8}}{\left(\frac{4}{0.25}\right)^{3 / 2} \sqrt{\frac{72}{4}}}=7835.7 \mathrm{lbs}<F_{L T}^{v}(=12000 \mathrm{psi}) \\
F_{c r}=\min (5306.4,7835.7)=5306.4 \mathrm{lbs}
\end{gathered}
$$

And 


$$
C=\frac{\pi t(2 R-t)^{2}}{2}=\frac{\pi \times 0.25(2 \times 4-0.25)^{2}}{2}=23.6 \mathrm{inch}^{3}
$$

Then

$$
T_{n}=5306.4 \times 23.6=10430 \mathrm{lb}-f t
$$

\subsection{Illustration-II}

\subsubsection{Problem Statement}

Design girts, connections with columns, and girt splices for a full supported structure in a cooling tower. Use pultruded FRP sections and stainless steel bolts. Specifically design

- Bent-line upper girts and their connections to columns. Use spacers if needed.

- Mid-bay joists using single channel, bach-to-back channel or I-beam. Mid-bay joists are laterally unsupported and may be mechanically fastened to lower girt support top flange.

- Lower girt supporting mid-bay joists and column connection.

- Splice blok and connection for transfer of bending from fill and axial load for wind.

Geometry: As shown in Figure 8.2. Each joist extends for $12 \mathrm{ft}$.

Loads: Loads will consist of

- Structural dead load

- $\quad$ Fill media dead load $=15$ psf

- Water held up by filled media (long term load) $=18 \mathrm{psf}$

- Axial force from wind load $=860 \mathrm{lbs}$ on bent-line joist and joist supporting mid-bay joists.

- Temporary service live loading $=20 \mathrm{psf}$ (not operating tower)

- Ice load $=30 \mathrm{psf}$.

- Fouling load $=30 \mathrm{psf}$ (applied to both operating and not operating tower). 
Serviceability Requirements: Limit the deflection to

- Maximum deflection $=\mathrm{L} / 180$ where $\mathrm{L}$ is the span.

- Maximum live load deflection $=\mathrm{L} / 240$ where $\mathrm{L}$ is the span.

Environment: Wet environment, $110{ }^{\circ} \mathrm{F}$ temperature, high salt content

Load duration: All dead, fill, water, and fouling loads and environmental conditions are long term.

Coverage: Combined tension or compression and bending, connections, adverse environment, and splice 


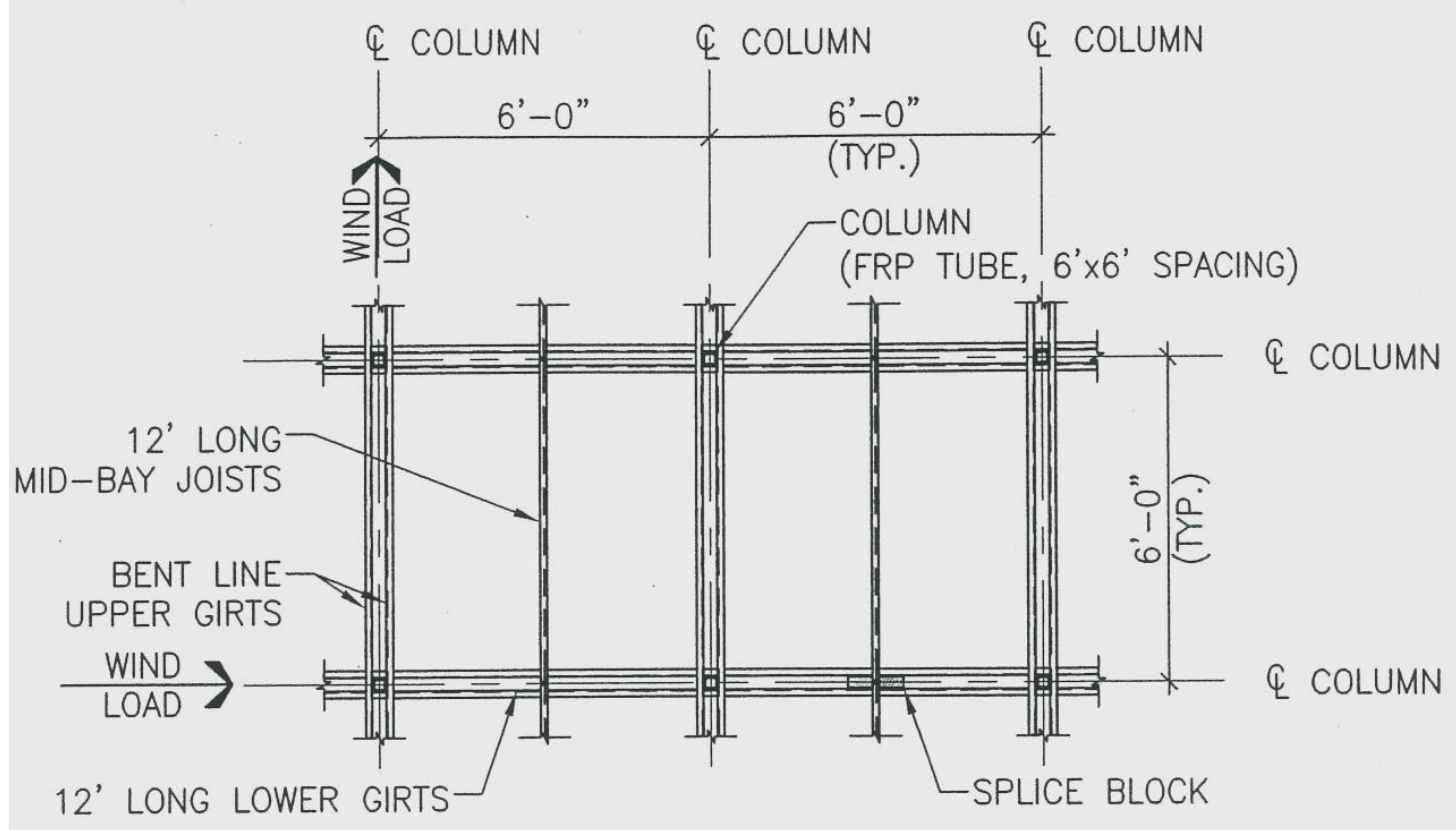

FILL SUPPORT PLAN

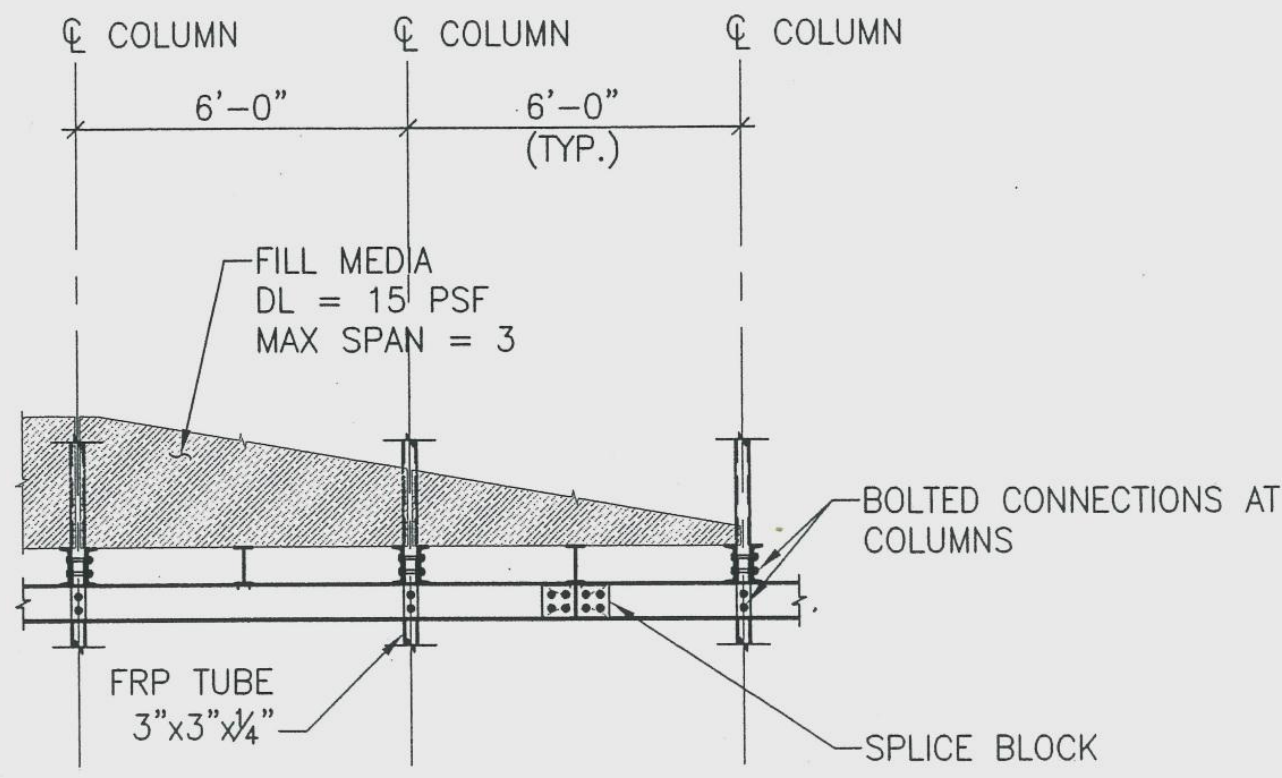

FILL SUPPORT ELEVATION

Figure 8-2: Geometry of FRP composite girts, connections with columns and girt splices in cooling tower structure 


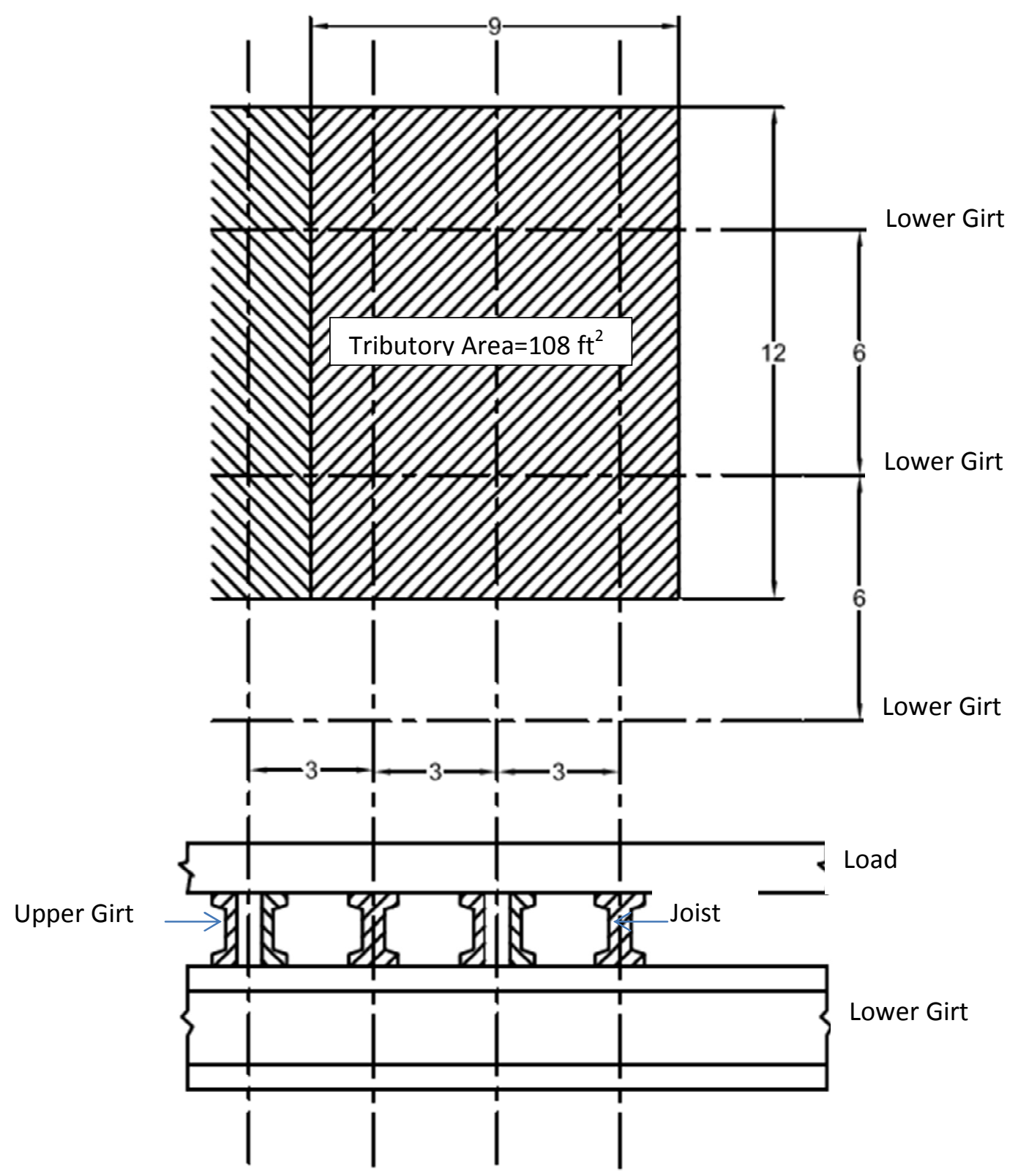

Figure 8-3: Schematic Diagram

\subsubsection{Problem Formulation}

\subsubsection{Loads and Load Combinations}

$D=$ Dead load caused by weight of permanent construction 
Assuming wide-flange beam $12 " \times 12 " \times 1 / 2 "$,

$$
W=13.25 \mathrm{lb} / \mathrm{ft}
$$

Total length from plan view $=18^{\prime}($ lower grit $)+24^{\prime}($ upper grit $)+12^{\prime}($ joist $)=54^{\prime}$

Structural dead weight $=13.25 \times 54=715.5 \mathrm{lb} \max$

$$
\begin{aligned}
& D=715.5+15 \times 108(\text { fill media })+18 \times 108(\text { water held }) \\
& \quad+30 \times 108(\text { ice })+30 \times 108(\text { fouling }) \\
& =10759.5 \mathrm{lbs}
\end{aligned}
$$

$$
\begin{gathered}
E=\text { Earthquake load }=0 \\
F=\text { Load due to fluid pressure } \\
H=\text { Load due to lateral earth pressure } \\
L=\text { Live load }=20 \mathrm{lb} / \mathrm{ft}^{2}=20 \times 108 \mathrm{lbs}=2160 \mathrm{lbs} \\
L_{r}=\text { Live load due to maintenance }=0 \\
R=\text { Rain } / \text { ice load } \\
S=\text { Snow load }=0 \\
T=\text { Self }- \text { straining force }=0 \\
\text { Wind }- \text { load }=860 \mathrm{lbs}
\end{gathered}
$$

From Equation 1.5-1 [1],

$$
1.4 D=1.4 \times 10759.5=15063.3 \mathrm{lbs}
$$

From Equation 1.5-2 [1],

$$
\begin{gathered}
1.2 D+1.6 L+0.5\left(L_{r} \text { or } S \text { or } R\right) \\
=1.2 \times 10759.5+1.6 \times 2160+0.5 \times 3240 \\
=17987.4 \mathrm{lbs}
\end{gathered}
$$

From Equation 1.5-3 [1], 


$$
\begin{gathered}
1.2 D+1.6\left(L_{r} \text { or } S \text { or } R\right)+1.0 L \text { or } 0.5 \mathrm{~W} \\
=1.2 \times 10759.5+1.6 \times 3240+2160 \text { or } 430 \\
=20255.4 \mathrm{lbs}
\end{gathered}
$$

From Equation 1.5-4 [1],

$$
\begin{gathered}
1.2 D+1.0 W+1.0 L+0.5\left(L_{r} \text { or } S \text { or } R\right) \\
=1.2 \times 10759.5+860+2160+0.5 \times 3240 \\
=17551.4 \mathrm{lbs}
\end{gathered}
$$

From Equation 1.5-5 [1],

$$
\begin{gathered}
1.2 D+1.0 E+1.0 L+0.2 S \\
=1.2 \times 10759.5+0+2160+0 \\
=15071.4 \mathrm{lbs}
\end{gathered}
$$

From Equation 1.5-6 [1],

$$
0.9 D+1.0 W=0.9 \times 10759.5+860=10543.55 \mathrm{lbs}
$$

From Equation 1.5-7 [1],

$$
0.9 D+1.0 E=0.9 \times 10759.5+0=9683.55 l b s
$$

Hence load combination of Equation 1.5-3 will govern. 20255.4 lbs load will be carried by 2 upper girts (=4 channel sections) and 1 mid-bay joist (I-section).

$$
\begin{gathered}
\text { Load } / \text { upper girt }=\frac{20255.4}{3}=6751.8 \mathrm{lbs} \\
\text { Load } / \text { channel }=\frac{6751.8}{2}=3375.9 \mathrm{lbs}=281.3 \mathrm{lb} / \mathrm{ft} \\
\text { Load } / \text { joist }=6751.8 \mathrm{lbs}=562.65 \mathrm{lb} / \mathrm{ft} \\
\text { Live load } / \text { upper girt }=\frac{2160}{3}=720 \mathrm{lbs}
\end{gathered}
$$




$$
\begin{gathered}
\text { Live load/channel }=\frac{720}{2}=360 \mathrm{lbs}=\frac{360}{6} \mathrm{lb} / \mathrm{ft}=60 \mathrm{lb} / \mathrm{ft} \\
\text { Live load } / \text { joist }=720 \mathrm{lbs}=\frac{720}{6} \mathrm{lb} / \mathrm{ft}=120 \mathrm{lb} / \mathrm{ft}
\end{gathered}
$$

\subsubsection{Selection of Flexural Members}

\subsection{Upper Girt}

$$
\begin{gathered}
\text { Load } / \text { Channel }=281.325 \mathrm{lb} / \mathrm{ft} \\
\text { Maximum deflection }=\frac{L}{180}=\frac{6 \times 12}{180}=0.4 " \\
\text { Live load } / \text { channel }=60 \mathrm{lb} / \mathrm{ft} \\
\text { Maximum live load deflection }=\frac{L}{240}=\frac{6 \times 12}{240}=0.3 "
\end{gathered}
$$

From Pultex Protrusion Design Manual [37],

$$
\text { Channel Section\#CH640 }\left(6 \times 1 \frac{5}{8} \times \frac{1}{4}\right)
$$

For $\mathrm{L}=6^{\prime}$, number of lateral restraints including ends $=4$

$$
\begin{gathered}
u d l=346 \frac{l b}{f t} @ \frac{L}{D}=180\left(>281.325 \frac{l b}{f t}\right) \\
u d l=260 \frac{l b}{f t} @ \frac{L}{D}=240\left(>60 \frac{l b}{f t}\right) \\
\text { Maximum lateral spacing }=30 "
\end{gathered}
$$

\section{Checks for Flexural Design of Upper Girt (Channel Section\#CH640)}

From Equation 5.2.2-1 [1],

$$
M_{u} \leq \lambda \phi M_{n}
$$




$$
\begin{gathered}
M_{u}=\text { Required flexural strength } \\
\phi=\text { Resistance factor for flexure } \\
\quad \lambda=\text { Time factor } \\
M_{n}=\text { Nominal flexural strength }
\end{gathered}
$$

From beam deflection formulas, for udl on fixed ended beams,

$$
M_{\max } @ e n d s=\frac{w l^{2}}{12}=\frac{281.325 \times 6^{2}}{12}=844 l b-f t
$$

From beam deflection formulas, for udl on simply supported beams,

$$
M_{\max } @ \text { mid }- \text { point }=\frac{w l^{2}}{8}=\frac{281.325 \times 6^{2}}{8}=1266 \mathrm{lb}-\mathrm{ft}
$$

Assuming 25\% fixity,

$$
M_{u}=0.75 \times 1266+0.25 \times 844=1160.5 \mathrm{lb}-f t
$$

From Equation 1.5-3, Table 2.3-1,

$$
\lambda=0.75
$$

For tensile rupture,

$$
\phi=0.65
$$

For compression rupture,

$$
\phi=0.70
$$

\subsection{Nominal Flexural Strength of Upper Girt due to Material Rupture}

From Equation 5.2.2-1 [1],

$$
\begin{gathered}
M_{n}=\min \left[\frac{F_{L, f}^{t}\left(E_{L, f}^{a v e} I_{f}+E_{L, w}^{a v e} I_{w}\right)}{y_{t, f} E_{L, f}^{a v e}}, \frac{F_{L, w}^{t}\left(E_{L, f}^{a v e} I_{f}+E_{L, w}^{a v e} I_{w}\right)}{y_{t, w} E_{L, w}^{a v e}}\right] \\
F_{L, f}^{t}=\text { Longitudinal tensile strength of the flange }=33 \mathrm{ksi}
\end{gathered}
$$




$$
\begin{aligned}
& E_{L, f}^{a v e}=\frac{E_{L, f}^{t}+E_{L, f}^{c}}{2}=\text { Average of longitudinal modulus for flange } \\
& =\frac{2.5+3.0}{2}=2.75 \mathrm{msi} \\
& I_{f}=2 A \bar{y}^{2}=2(1.625 \times 0.25) \times 2.875^{2}=6.716 \text { inch }^{4} \\
& F_{L, w}^{t}=\text { Longitudinal tensile strength of the web }=33 \mathrm{ksi} \\
& E_{L, w}^{a v e}=\frac{E_{L, w}^{t}+E_{L, w}^{c}}{2}=\text { Average of longitudinal modulus for web } \\
& =\frac{2.5+3.0}{2}=2.75 \mathrm{msi} \\
& I_{w}=\frac{b_{w} h_{w}^{3}}{12}=\frac{0.25 \times 5.5^{3}}{12}=3.47 \operatorname{inch}^{4} \\
& y_{t, f}=3 " \\
& y_{t, w}=2.75^{\prime \prime} \\
& M_{n}=\min \left[\frac{33000\left(2.75 \times 10^{6} \times 6.716+2.75 \times 10^{6} \times 3.47\right)}{3 \times 2.75 \times 10^{6}},\right] \\
& M_{n}=110.7 \mathrm{kip}-\text { inch } \\
& \lambda \phi M_{n}(\text { Tension })=0.75 \times 0.65 \times 110.7=53.96 \mathrm{kip}-i n=4497.2 \mathrm{lb}-\mathrm{ft} \\
& M_{u}(=1160.5 f t-l b)<\lambda \phi M_{n}(\text { Tension })(=4497.2 l b-f t) \quad \text { OK } \\
& \lambda \phi M_{n}(\text { Compression })=0.75 \times 0.7 \times 110.7=58.11 \mathrm{kip}-i n=4843.12 \mathrm{lb}-\mathrm{ft} \\
& M_{u}(=1160.5 l b-f t)<\lambda \phi M_{n}(\text { Compression })(=4843.12 f t-l b) \quad \mathbf{O K}
\end{aligned}
$$

\subsection{Nominal Flexural Strength of Upper Girt due to Local Instability}

From Equation 5.2.3-1 [1], 


$$
M_{n}=f_{c r} \frac{E_{L, f}^{a v e} I_{f}+E_{L, w}^{a v e} I_{w}}{y_{c, e} E_{L, e}^{a v e}}
$$

From Equation 5.2.3-2 [1],

$$
\begin{gathered}
f_{c r, f l a n g e}=\frac{4 t_{e}^{2}}{c^{2} b_{e}^{2}}\left[\frac{7}{12} \sqrt{\frac{E_{L, e}^{c} E_{T, e}^{c}}{1+4.1 \xi}}+G_{L T, e}\right] \\
t_{e}=\text { Thickness of the buckled element }=0.25^{\prime \prime} \\
c=\text { Shape constant for rotational constraint }=2 \\
b_{e}=\text { Length of the buckled element }=1.625^{\prime \prime}
\end{gathered}
$$

From Equation 5.2.3-3 [1],

$$
\xi=\text { Coefficient of restraint }=\frac{E_{T, e}^{c} t_{e}^{3}}{6 c k_{r} b_{e}}
$$

From Equation 5.2.3-4 [1],

$$
\begin{aligned}
& k_{r}=\frac{c E_{T, a}^{c} t_{a}^{3}}{6 b_{a}}\left[1-\left[\frac{48 t_{e}^{2} b_{a}^{2} E_{L, a}^{c}}{11.1 \pi^{2} c^{2} b_{e}^{2} t_{a}^{2} E_{L, e}^{c}}\right]\left[\frac{G_{L T, e}}{1.25 \sqrt{E_{L, a}^{c} E_{T, a}^{c}}+E_{T, a}^{c} v_{L, a}+2 G_{L T, a}}\right]\right] \\
& k_{r}=\frac{2 \times 1 \times 10^{6} \times 0.25^{3}}{6 \times 6} \times\left[\frac{18 \times 0.25^{2} \times 6^{2} \times 3 \times 10^{6}}{1-\left[\frac{48.42 \times 10^{6}}{11.1 \pi^{2} \times 0.25^{2} \times 1.625^{2} \times 2^{2} \times 3 \times 10^{6}}\right] \times}\right] \\
& k_{r}=706
\end{aligned}
$$

$$
\begin{gathered}
\xi=\frac{1 \times 10^{6} \times 0.25^{3}}{6 \times 2 \times 1.625 \times 706}=1.135 \\
f_{\text {cr,flange }}=\frac{4 \times 0.25^{2}}{2^{2} \times 1.625^{2}}\left[\frac{7}{12} \times \sqrt{\frac{3 \times 10^{6} \times 1 \times 10^{6}}{1+4.1 \times 1.135}}+0.42 \times 10^{6}\right]=20248.9 \mathrm{psi} \\
M_{n}=20248.9 \times \frac{2.75 \times 10^{6} \times 6.716+2.75 \times 10^{6} \times 3.47}{3 \times 3 \times 10^{6}}
\end{gathered}
$$




$$
\begin{gathered}
=63020 \mathrm{lb}-\text { inch }=5252 \mathrm{ft}-\mathrm{lb} \\
\quad \lambda \phi M_{n}=0.75 \times 0.8 \times 5252=3151 \mathrm{lb}-f t \\
M_{u}(=1160.5 \mathrm{lb}-f t)<\lambda \phi M_{n}(=3151 \mathrm{lb}-f t) \quad \mathbf{~ O K}
\end{gathered}
$$

From Equation 5.2.3-8 [1],

$$
\begin{gathered}
f_{c r, w e b}=\frac{11.1 \pi^{2} t_{e}^{2}}{12 b_{e}^{2}}\left[1.25 \sqrt{\left(E_{L, e}^{c} E_{T, e}^{c}\right)}+E_{T, e}^{c} v_{L, e}+2 G_{L T, e}\right] \\
=\frac{11.1 \pi^{2} \times 0.25^{2}}{12 \times 6^{2}}\left[1.25 \sqrt{3 \times 10^{6} \times 1 \times 10^{6}}+1 \times 10^{6} \times 0.35+2 \times 0.42 \times 10^{6}\right] \\
=53175.5 \mathrm{psi} \\
M_{n}=13781.3 \mathrm{lb}-f t \\
\lambda \phi M_{n}=0.75 \times 0.8 \times 13781.3=8268.8 \mathrm{lb}-f t \\
M_{u}(=1160.5 \mathrm{lb}-f t)<\lambda \phi M_{n}(=8268.8 \mathrm{lb}-f t) \quad \mathbf{O K}
\end{gathered}
$$

\subsection{Nominal Flexural Strength of Upper Girt due to Lateral-Torsional Buckling}

For singly symmetric sections bent about their strong axis, lateral torsional capacity shall be computed based on rational engineering analysis.

\section{Checks for Shear Design of Upper Girt (Channel Section\#CH640)}

From Equation 5.3.1-1 [1],

$$
\begin{gathered}
V_{u} \leq \lambda \phi V_{n} \\
V_{u}=\text { Required shear strength } \\
\phi=\text { Required factor for shear }=0.65 \\
\lambda=\text { Time factor }=0.75 \\
V_{n}=\text { Nominal shear strength }
\end{gathered}
$$




$$
V_{u}=\frac{w L}{2}=\frac{281.3 \times 6}{2}=843.9 \mathrm{lbs}
$$

8.3.2.2.2.4. Nominal Strength of Upper Girt due to Material Rupture in Shear

From Equation 5.3.2-1 [1],

$$
\begin{gathered}
V_{n}=F_{L T}^{v} A_{s}=7000 \times 2.12=14840 \mathrm{lbs} \\
\lambda \phi V_{n}=0.75 \times 0.65 \times 14840=7234.5 \mathrm{lbs} \\
V_{u}(=843.9 \mathrm{lbs})<\lambda \phi V_{n}(=7234.5 \mathrm{lbs})
\end{gathered}
$$

8.3.2.2.2.5. Nominal Strength of Upper Girt due to Web-Shear Buckling

From Equation 5.3.3-1 [1],

$$
\begin{gathered}
V_{n}=f_{c r} h t_{w} \\
2 G_{L T, w}+E_{L, w}^{c} v_{T, w} \leq ? \sqrt{E_{L, w}^{c} E_{T, w}^{c}} \\
2 \times 0.42 \times 10^{6}+3 \times 10^{6} \times 0.15 \leq ? \sqrt{3 \times 1} \times 10^{6} \\
1.29 \times 10^{6}<1.73 \times 10^{6}
\end{gathered}
$$

From Equation 5.3.3-2 [1],

$$
f_{c r}=\frac{t_{w}^{2} K_{L T} \sqrt[4]{E_{L, w}^{c}\left(E_{T, w}^{c}\right)^{3}}}{3 h^{2}}
$$

From Equation 5.3.3-3 [1],

$$
\begin{aligned}
& K_{L T}=8.1+5.0 \frac{2 G_{L T, w}+E_{L, w}^{c} \nu_{T, w}}{\sqrt{E_{L, w}^{c} E_{T, w}^{c}}} \\
& =8.1+5.0 \frac{2 \times 0.42 \times 10^{6}+3 \times 10^{6} \times 0.15}{\sqrt{3 \times 1} \times 10^{6}} \\
& =11.83
\end{aligned}
$$




$$
\begin{gathered}
f_{c r}=\frac{0.25^{2} \times 11.83 \times \sqrt[4]{3 \times 10^{6}\left(1 \times 10^{6}\right)^{3}}}{3 \times 6^{2}}=9009.92 \mathrm{ksi} \\
V_{n}=9009.92 \times 6 \times 0.25=13514.9 \mathrm{lbs} \\
\lambda \phi V_{n}=0.75 \times 0.65 \times 13514.9=6588.5 \mathrm{lbs} \\
V_{u}(=843.9 \mathrm{lbs})<\lambda \phi V_{n}(=6588.5 \mathrm{lbs}) \quad \text { OK }
\end{gathered}
$$

\subsection{Mid-Bay Joist}

$$
\begin{gathered}
\text { Load } / \mathrm{Joist}=562.65 \mathrm{lb} / \mathrm{ft} \\
\text { Maximum deflection }=\frac{L}{180}=\frac{6 \times 12}{180}=0.4 " \\
\text { Live load } / \mathrm{joist}=120 \mathrm{lb} / \mathrm{ft} \\
\text { Maximum live load deflection }=\frac{L}{240}=0.3 "
\end{gathered}
$$

From Pultex Pultrusion Design Manual [37]

$$
I-\text { Section\#IB640 }\left(6 \times 3 \times \frac{1}{4}\right)
$$

For $\mathrm{L}=6^{\prime}$, number of lateral restraints including ends $=4$

$$
\begin{gathered}
u d l=802 \frac{l b}{f t} @ \frac{L}{D}=180\left(>562.65 \frac{l b}{f t}\right) \\
u d l=601 \frac{l b}{f t} @ \frac{L}{D}=240\left(>120 \frac{l b}{f t}\right)
\end{gathered}
$$

\section{Checks for Flexural Design of Mid-Bay Joist (I-Section\#IB640)}

From beam deflection formulas, for udl on fixed ended beams,

$$
M_{\max } @ e n d s=\frac{w l^{2}}{12}=\frac{562.65 \times 6^{2}}{12}=1687.95 \mathrm{lb}-\mathrm{ft}
$$


From beam deflection formulas, for udl on simply supported beams,

$$
M_{\text {max }} @ \operatorname{mid}-\text { point }=\frac{w l^{2}}{8}=\frac{562.65 \times 6^{2}}{8}=2532 l b-f t
$$

Assuming 10\% fixity,

$$
M_{u}=2300 \mathrm{lb}-f t
$$

8.3.2.2.3.1. Nominal Flexural Strength of Mid-Bay Joist due to Material Rupture

From Equation 5.2.2-1 [1],

$$
\begin{aligned}
& M_{n}=\min \left[\frac{F_{L, f}^{t}\left(E_{L, f}^{a v e} I_{f}+E_{L, w}^{a v e} I_{w}\right)}{y_{t, f} E_{L, f}^{a v e}}, \frac{F_{L, w}^{t}\left(E_{L, f}^{a v e} I_{f}+E_{L, w}^{a v e} I_{w}\right)}{y_{t, w} E_{L, w}^{a v e}}\right] \\
& F_{L, f}^{t}=\text { Longitudinal tensile strength of the flange }=40 \mathrm{ksi} \\
& E_{L, f}^{a v e}=\frac{E_{L, f}^{t}+E_{L, f}^{c}}{2}=\text { Average of longitudinal modulus for flange } \\
& =\frac{4.16+3.85}{2}=4.0 \mathrm{msi} \\
& I_{f}=2 A \bar{y}^{2}=2(3 \times 0.25) \times 2.875^{2}=12.4 i n c h^{4} \\
& F_{L, w}^{t}=\text { Longitudinal tensile strength of the web }=30.3 \mathrm{ksi} \\
& E_{L, w}^{a v e}=\frac{E_{L, w}^{t}+E_{L, w}^{c}}{2}=\text { Average of longitudinal modulus for web } \\
& =\frac{3.1+3.0}{2} \approx 3.0 \mathrm{msi} \\
& I_{w}=\frac{b_{w} h_{w}^{3}}{12}=\frac{0.25 \times 5.5^{3}}{12}=3.47 \operatorname{inch}^{4} \\
& y_{t, f}=3 " \\
& y_{t, w}=2.75^{\prime \prime}
\end{aligned}
$$




$$
\begin{gathered}
M_{n}=\min \left[\frac{40000\left(4.0 \times 10^{6} \times 12.4+3.0 \times 10^{6} \times 3.47\right)}{3 \times 4.0 \times 10^{6}},\right] \\
\left.\frac{30300\left(4.0 \times 10^{6} \times 12.4+3.0 \times 10^{6} \times 3.47\right)}{2.75 \times 3.0 \times 10^{6}}\right] \\
M_{n}=200 \mathrm{kip}-\text { inch } \\
\lambda \phi M_{n}(\text { Tension })=0.75 \times 0.65 \times 200=97.5 \mathrm{kip}-\mathrm{in}=8125 \mathrm{lb}-\mathrm{ft} \\
M_{u}(=2300 \mathrm{ft}-\mathrm{lb})<\lambda \phi M_{n}(\text { Tension })(=8125 \mathrm{lb}-\mathrm{ft}) \quad \mathbf{O K} \\
\lambda \phi M_{n}(\text { Compression })=0.75 \times 0.7 \times 200=105 \mathrm{kip}-\mathrm{in}=8750 \mathrm{ft}-\mathrm{lb} \\
M_{u}(=2300 \mathrm{ft}-\mathrm{lb})<\lambda \phi M_{n}(\text { Compression })(=8750 \mathrm{ft}-\mathrm{lb}) \mathbf{O K}
\end{gathered}
$$

8.3.2.2.3.2. Nominal Flexural Strength of Lower Girt due to Local Instability

From Equation 5.2.3-1 [1],

$$
M_{n}=f_{c r} \frac{E_{L, f}^{a v e} I_{f}+E_{L, w}^{a v e} I_{w}}{y_{c, e} E_{L, e}^{a v e}}
$$

From Equation 5.2.3-2 [1],

$$
\begin{gathered}
f_{c r, \text { flange }}=\frac{4 t_{e}^{2}}{c^{2} b_{e}^{2}}\left[\frac{7}{12} \sqrt{\frac{E_{L, e}^{c} E_{T, e}^{c}}{1+4.1 \xi}}+G_{L T, e}\right] \\
t_{e}=\text { Thickness of the buckled element }=0.25^{\prime \prime} \\
c=\text { Shape constant for rotational constraint }=1 \\
b_{e}=\text { Length of the buckled element }=3 "
\end{gathered}
$$

From Equation 5.2.3-3 [1],

$$
\xi=\text { Coefficient of restraint }=\frac{E_{T, e}^{c} t_{e}^{3}}{6 c k_{r} b_{e}}
$$

From Equation 5.2.3-4 [1], 


$$
\begin{aligned}
& k_{r}=\frac{c E_{T, a}^{c} t_{a}^{3}}{6 b_{a}}\left[1-\left[\frac{48 t_{e}^{2} b_{a}^{2} E_{L, a}^{c}}{11.1 \pi^{2} c^{2} b_{e}^{2} t_{a}^{2} E_{L, e}^{c}}\right]\left[\frac{G_{L T, e}}{1.25 \sqrt{E_{L, a}^{c} E_{T, a}^{c}}+E_{T, a}^{c} v_{L, a}+2 G_{L T, a}}\right]\right] \\
& k_{r}=\frac{1 \times 1.4 \times 10^{6} \times 0.25^{3}}{6 \times 5.5} \times\left[\begin{array}{c}
1-\left[\frac{48 \times 5.5^{2} \times 3 \times 10^{6}}{11.1 \pi^{2} \times 3^{2} \times 1 \times 3.85 \times 10^{6}}\right] \times \\
0.5 \times 10^{6}
\end{array}\right] \\
& k_{r}=570
\end{aligned}
$$

$$
\begin{gathered}
\xi=\frac{1.9 \times 10^{6} \times 0.25^{3}}{6 \times 1 \times 3 \times 570}=2.89 \\
f_{\text {cr,flange }}=\frac{4 \times 0.25^{2}}{1 \times 3^{2}}\left[\frac{7}{12} \times \sqrt{\frac{3.85 \times 10^{6} \times 1.9 \times 10^{6}}{1+4.1 \times 2.89}}+0.5 \times 10^{6}\right]=26035 \mathrm{psi} \\
M_{n}=26035 \times \frac{4 \times 10^{6} \times 12.4+3 \times 10^{6} \times 3.47}{3 \times 3.85 \times 10^{6}} \\
=135121.6 \mathrm{lb}-\mathrm{inch}=11260 \mathrm{lb}-\mathrm{ft} \\
\lambda \phi M_{n}=0.75 \times 0.8 \times 11260=6756 \mathrm{lb}-\mathrm{ft} \\
M_{u}(=2300 \mathrm{lb}-\mathrm{ft})<\lambda \phi M_{n}(=6756 \mathrm{lb}-\mathrm{ft}) \quad \mathbf{O K}
\end{gathered}
$$

From Equation 5.2.3-8 [1],

$$
\begin{gathered}
f_{c r, w e b}=\frac{11.1 \pi^{2} t_{e}^{2}}{12 b_{e}^{2}}\left[1.25 \sqrt{\left(E_{L, e}^{c} E_{T, e}^{c}\right)}+E_{T, e}^{c} v_{L, e}+2 G_{L T, e}\right] \\
=\frac{11.1 \pi^{2} \times 0.25^{2}}{12 \times 5.5^{2}}\left[1.25 \sqrt{3.1 \times 10^{6} \times 1.4 \times 10^{6}}+1.4 \times 10^{6} \times 0.35+2 \times 0.5 \times 10^{6}\right] \\
=77210 p s i \\
M_{n}=33395 \mathrm{lb}-f t \\
\lambda \phi M_{n}=0.75 \times 0.8 \times 33395=20037 \mathrm{lb}-\mathrm{ft} \\
M_{u}(=2300 \mathrm{lb}-\mathrm{ft})<\lambda \phi M_{n}(=20037 \mathrm{lb}-\mathrm{ft}) \mathbf{\text { OK}}
\end{gathered}
$$


8.3.2.2.3.3. Nominal Flexural Strength of Mid-Bay Joist due to Lateral-Torsional Buckling

From Equation 5.2.4-1 [1],

$$
\begin{gathered}
M_{n}=C_{b} \sqrt{\frac{\pi^{2} E_{L} I_{y} D_{J}}{L_{b}^{2}}+\frac{\pi^{4} E_{L}^{2} I_{y} C_{\omega}}{L_{b}^{4}}} \\
D_{J}=\text { Torsional rigidity of an open section }=\sum \frac{1}{3} G_{L T}^{i} b_{i} t_{i}^{3} \\
=\frac{G_{L T} t^{3}}{3}\left(2 b_{f}+b_{w}\right)=\frac{0.5 \times 10^{6} \times 0.25^{3}}{3}(2 \times 3+5.5)=29948 \\
C_{\omega}=\text { Warping constant }=\frac{t_{f} h^{2} b_{f}^{3}}{24}=\frac{0.25 \times 6^{2} \times 3^{3}}{24}=10.125
\end{gathered}
$$

$C_{b}=$ Moment modification factor for unsupported spans with both ends braced $=1.0$

$$
\begin{gathered}
L_{b}=\text { Unbraced length }=1.75^{\prime}=20^{\prime \prime} \\
M_{n}=1 \sqrt{\frac{\pi^{2} \times 4 \times 10^{6} \times 1.125 \times 29948}{20^{2}}+\frac{\pi^{4} \times\left(4 \times 10^{6}\right)^{2} \times 1.125 \times 10.125}{20^{4}}} \\
=120694 \mathrm{lb}-\text { inch } \\
\lambda \phi M_{n}=0.75 \times 0.7 \times 120694=63364 \mathrm{lb}-\mathrm{inch}=5280 \mathrm{lb}-\mathrm{ft} \\
M_{u}(=2300 \mathrm{lb}-\mathrm{ft})<\lambda \phi M_{n}(=5280 \mathrm{lb}-\mathrm{ft})
\end{gathered}
$$

\section{Checks for Shear Design of Mid-Bay Joist (I-Section\#IB640)}

From Equation 5.3.1-1 [1],

$$
\begin{gathered}
V_{u} \leq \lambda \phi V_{n} \\
V_{u}=\text { Required shear strength } \\
\phi=\text { Required factor for shear }=0.65 \\
\lambda=\text { Time factor }=0.75
\end{gathered}
$$




$$
\begin{gathered}
V_{n}=\text { Nominal shear strength } \\
V_{u}=\frac{w L}{2}=\frac{562.65 \times 6}{2}=1688 \mathrm{lbs}
\end{gathered}
$$

8.3.2.2.3.4. Nominal Strength of Mid-Bay Joist due to Material Rupture in Shear

From Equation 5.3.2-1 [1],

$$
\begin{gathered}
V_{n}=F_{L T}^{v} A_{s}=5500 \times 2.875=15812.5 \mathrm{lbs} \\
\lambda \phi V_{n}=0.75 \times 0.65 \times 15812.5=7708.6 \mathrm{lbs} \\
V_{u}(=1688 \mathrm{lbs})<\lambda \phi V_{n}(=7708.6 \mathrm{lbs})
\end{gathered}
$$

\subsection{Nominal Strength of Mid-Bay Joist due to Web-Shear Buckling}

From Equation 5.3.3-1 [1],

$$
\begin{gathered}
V_{n}=f_{c r} h t_{w} \\
2 G_{L T, w}+E_{L, w}^{c} v_{T, w} \leq ? \sqrt{E_{L, w}^{c} E_{T, w}^{c}} \\
2 \times 0.5 \times 10^{6}+3 \times 10^{6} \times 0.12 \leq ? \sqrt{3 \times 1.4} \times 10^{6} \\
1.36<2.05
\end{gathered}
$$

From Equation 5.3.3-2 [1],

$$
f_{c r}=\frac{t_{w}^{2} K_{L T} \sqrt[4]{E_{L, w}^{c}\left(E_{T, w}^{c}\right)^{3}}}{3 h^{2}}
$$

From Equation 5.3.3-3 [1],

$$
\begin{gathered}
K_{L T}=8.1+5.0 \frac{2 G_{L T, w}+E_{L, w}^{c} v_{T, w}}{\sqrt{E_{L, w}^{c} E_{T, w}^{c}}} \\
=8.1+5.0 \frac{2 \times 0.5 \times 10^{6}+3 \times 10^{6} \times 0.12}{\sqrt{3 \times 1.4} \times 10^{6}}
\end{gathered}
$$




$$
\begin{gathered}
=11.42 \\
f_{c r}=\frac{0.25^{2} \times 11.42 \times \sqrt[4]{3 \times 10^{6}\left(1.4 \times 10^{6}\right)^{3}}}{3 \times 6^{2}}=11169 \mathrm{psi} \\
V_{n}=11169 \times 6 \times 0.25=16769 \mathrm{lbs} \\
\lambda \phi V_{n}=0.75 \times 0.65 \times 16769=8175 \mathrm{lbs} \\
V_{u}(=1688 \mathrm{lbs})<\lambda \phi V_{n}(=8175 \mathrm{lbs}) \quad \mathbf{~ O K}
\end{gathered}
$$

\subsection{Lower Girt}

20255.4 lbs load will be transferred to 2 lower girts

$$
\text { Load } / \text { lower girt }=10127.7 \mathrm{lbs}=\frac{10127.7}{9} \mathrm{lb} / \mathrm{ft}=1125.3 \mathrm{lb} / \mathrm{ft}
$$

(because the load repeats itself in 9' intervals widthwise)

$$
\begin{gathered}
\text { Maximum deflection }=\frac{L}{180}=\frac{9 \times 12}{180}=0.6^{\prime \prime} \\
\text { Live load } / \text { lower girt }=\frac{2160}{2}=1080 \mathrm{lbs} \\
=\frac{1080}{9} \mathrm{lb} / \mathrm{ft}=120 \mathrm{lb} / \mathrm{ft} \\
\text { Maximum live load deflection }=\frac{L}{240}=\frac{9 \times 12}{240}=0.45^{\prime \prime}
\end{gathered}
$$

From Pultex Pultrusion Design Manual [37]

$$
\begin{gathered}
I-\text { Section } \# \mathbf{I B 9 8 0}\left(\mathbf{1 0} \times \mathbf{5} \times \frac{\mathbf{1}}{\mathbf{2}}\right) \\
L_{b}=3.5^{\prime}=42^{\prime \prime} \\
u d l=1952 \frac{l b}{f t} @ \frac{L}{D}=180\left(>1125.3 \frac{l b}{f t}\right) \\
u d l=1465 \frac{l b}{f t} @ \frac{L}{D}=240\left(>120 \frac{l b}{f t}\right)
\end{gathered}
$$




\section{Checks for Flexural Design of Lower Girt (I-Section\#IB980)}

From beam deflection formulas, for udl on fixed ended beams,

$$
M_{\max } @ e n d s=\frac{w l^{2}}{12}=\frac{1125.3 \times 9^{2}}{12}=7595.8 \mathrm{lb}-\mathrm{ft}
$$

From beam deflection formulas, for udl on simply supported beams,

$$
M_{\text {max }} @ \text { mid }- \text { point }=\frac{w l^{2}}{8}=\frac{1125.3 \times 9^{2}}{8}=11393.7 \mathrm{lb}-\mathrm{ft}
$$

Assuming 10\% fixity,

$$
M_{u}=10000 l b-f t
$$

8.3.2.2.3.1. Nominal Flexural Strength of Lower Girt due to Material Rupture

From Equation 5.2.2-1 [1],

$$
\begin{aligned}
& M_{n}=\min \left[\frac{F_{L, f}^{t}\left(E_{L, f}^{a v e} I_{f}+E_{L, w}^{a v e} I_{w}\right)}{y_{t, f} E_{L, f}^{a v e}}, \frac{F_{L, w}^{t}\left(E_{L, f}^{a v e} I_{f}+E_{L, w}^{a v e} I_{w}\right)}{y_{t, w} E_{L, w}^{a v e}}\right] \\
& F_{L, f}^{t}=\text { Longitudinal tensile strength of the flange }=40 \mathrm{ksi} \\
& E_{L, f}^{a v e}=\frac{E_{L, f}^{t}+E_{L, f}^{c}}{2}=\text { Average of longitudinal modulus for flange } \\
& =\frac{4.16+3.85}{2}=4.0 \mathrm{msi} \\
& I_{f}=2 A \bar{y}^{2}=2(5 \times 0.5) \times 4.75^{2}=112.81 \text { inch }^{4} \\
& F_{L, w}^{t}=\text { Longitudinal tensile strength of the web }=30.3 \mathrm{ksi} \\
& E_{L, w}^{a v e}=\frac{E_{L, w}^{t}+E_{L, w}^{c}}{2}=\text { Average of longitudinal modulus for web }
\end{aligned}
$$




$$
\begin{aligned}
& =\frac{3.1+3.0}{2} \approx 3.0 \mathrm{msi} \\
& I_{w}=\frac{b_{w} h_{w}^{3}}{12}=\frac{0.5 \times 9^{3}}{12}=30.375 \text { inch }^{4} \\
& y_{t, f}=5^{\prime \prime} \\
& y_{t, w}=4.5^{\prime \prime} \\
& M_{n}=\min \left[\frac{40000\left(4.0 \times 10^{6} \times 112.81+3.0 \times 10^{6} \times 30.375\right)}{5 \times 4.0 \times 10^{6}},\right] \\
& M_{n}=1084.7 \mathrm{kip}-\mathrm{in} \\
& \lambda \phi M_{n}(\text { Tension })=0.75 \times 0.65 \times 1084.7=528.8 \mathrm{kip}-\text { in }=44067 \mathrm{lb}-\mathrm{ft} \\
& M_{u}(=10000 f t-l b)<\lambda \phi M_{n}(\text { Tension })(=44067 l b-f t) \quad \text { OK } \\
& \lambda \phi M_{n}(\text { Compression })=0.75 \times 0.7 \times 1084.7=569.5 \mathrm{kip}-\mathrm{in}=47457 \mathrm{lb}-\mathrm{ft} \\
& M_{u}(=10000 \mathrm{lb}-f t)<\lambda \phi M_{n}(\text { Compression })(=47457 \mathrm{lb}-f t) \quad \mathbf{O K}
\end{aligned}
$$

8.3.2.2.3.2. Nominal Flexural Strength of Lower Girt due to Local Instability

From Equation 5.2.3-1 [1],

$$
M_{n}=f_{c r} \frac{E_{L, f}^{a v e} I_{f}+E_{L, w}^{a v e} I_{w}}{y_{c, e} E_{L, e}^{a v e}}
$$

From Equation 5.2.3-2 [1],

$$
\begin{gathered}
f_{\text {cr,flange }}=\frac{4 t_{e}^{2}}{c^{2} b_{e}^{2}}\left[\frac{7}{12} \sqrt{\frac{E_{L, e}^{c} E_{T, e}^{c}}{1+4.1 \xi}}+G_{L T, e}\right] \\
t_{e}=\text { Thickness of the buckled element }=0.5^{\prime \prime} \\
c=\text { Shape constant for rotational constraint }=1 \\
b_{e}=\text { Length of the buckled element }=5^{\prime \prime}
\end{gathered}
$$


From Equation 5.2.3-3 [1],

$$
\xi=\text { Coefficient of restraint }=\frac{E_{T, e}^{c} t_{e}^{3}}{6 c k_{r} b_{e}}
$$

From Equation 5.2.3-4 [1],

$$
\begin{aligned}
& k_{r}=\frac{c E_{T, a}^{c} t_{a}^{3}}{6 b_{a}}\left[1-\left[\frac{48 t_{e}^{2} b_{a}^{2} E_{L, a}^{c}}{11.1 \pi^{2} c^{2} b_{e}^{2} t_{a}^{2} E_{L, e}^{c}}\right]\left[\frac{G_{L T, e}}{1.25 \sqrt{E_{L, a}^{c} E_{T, a}^{c}}+E_{T, a}^{c} v_{L, a}+2 G_{L T, a}}\right]\right] \\
& k_{r}=\frac{1 \times 1.4 \times 10^{6} \times 0.5^{3}}{6 \times 9} \times\left[\begin{array}{c}
1-\left[\frac{48 \times 9^{2} \times 3 \times 10^{6}}{11.1 \pi^{2} \times 5^{2} \times 1 \times 3.85 \times 10^{6}}\right] \times \\
{\left[\frac{0.5 \times 10^{6}}{1.25 \sqrt{3.1 \times 1.4} \times 10^{6}+1.4 \times 10^{6} \times 0.35+2 \times 0.5 \times 10^{6}}\right]}
\end{array}\right] \\
& k_{r}=2803 \\
& \begin{array}{c}
\xi=\frac{1.9 \times 10^{6} \times 0.5^{3}}{6 \times 1 \times 5 \times 2803}=2.824 \\
f_{\text {cr,flange }}=\frac{4 \times 0.5^{2}}{1 \times 5^{2}}\left[\frac{7}{12} \times \sqrt{\frac{3.85 \times 10^{6} \times 1.9 \times 10^{6}}{1+4.1 \times 2.824}}+0.5 \times 10^{6}\right]=37793 \mathrm{psi} \\
M_{n}=37793 \times \frac{4 \times 10^{6} \times 112.81+3 \times 10^{6} \times 30.375}{5 \times 3.85 \times 10^{6}} \\
=1064.8 \mathrm{kip}-\text { inch }=88734 \mathrm{lb}-\mathrm{ft} \\
\lambda \phi M_{n}=0.75 \times 0.8 \times 88734=53240 \mathrm{lb}-\mathrm{ft} \\
M_{u}(=10000 \mathrm{lb}-\mathrm{ft})<\lambda \phi M_{n}(=53240 \mathrm{lb}-\mathrm{ft}) \quad \mathbf{O K}
\end{array}
\end{aligned}
$$

From Equation 5.2.3-8 [1],

$$
\begin{gathered}
f_{c r, w e b}=\frac{11.1 \pi^{2} t_{e}^{2}}{12 b_{e}^{2}}\left[1.25 \sqrt{\left(E_{L, e}^{c} E_{T, e}^{c}\right)}+E_{T, e}^{c} v_{L, e}+2 G_{L T, e}\right] \\
=\frac{11.1 \pi^{2} \times 0.5^{2}}{12 \times 9^{2}}\left[1.25 \sqrt{3.1 \times 10^{6} \times 1.4 \times 10^{6}}+1.4 \times 10^{6} \times 0.35+2 \times 0.5 \times 10^{6}\right]
\end{gathered}
$$


$=114634.3 \mathrm{psi}$

$$
\begin{gathered}
M_{n}=269130 \mathrm{lb}-f t \\
\lambda \phi M_{n}=0.75 \times 0.8 \times 269130=161478 \mathrm{lb}-f t \\
M_{u}(=10000 \mathrm{lb}-f t)<\lambda \phi M_{n}(=161478 \mathrm{lb}-f t) \quad \mathbf{~ O K}
\end{gathered}
$$

8.3.2.2.3.3. Nominal Flexural Strength of Mid-Bay Joist due to Lateral-Torsional Buckling

From Equation 5.2.4-1 [1],

$$
\begin{gathered}
M_{n}=C_{b} \sqrt{\frac{\pi^{2} E_{L} I_{y} D_{J}}{L_{b}^{2}}+\frac{\pi^{4} E_{L}^{2} I_{y} C_{\omega}}{L_{b}^{4}}} \\
D_{J}=\text { Torsional rigidity of an open section }=\sum \frac{1}{3} G_{L T}^{i} b_{i} t_{i}^{3} \\
=\frac{G_{L T} t^{3}}{3}\left(2 b_{f}+b_{w}\right)=\frac{0.5 \times 10^{6} \times 0.5^{3}}{3}(2 \times 5+9)=312500 \\
C_{\omega}=\text { Warping constant }=\frac{t_{f} h^{2} b_{f}^{3}}{24}=\frac{0.5 \times 10^{2} \times 5^{3}}{24}=260.42
\end{gathered}
$$

$C_{b}=$ Moment modification factor for unsupported spans with both ends braced $=1.0$

$$
\begin{gathered}
L_{b}=\text { Unbraced length }=3.5^{\prime}=42^{\prime \prime} \\
M_{n}=1 \sqrt{\frac{\pi^{2} \times 4 \times 10^{6} \times 10.42 \times 312500}{42^{2}}+\frac{\pi^{4} \times\left(4 \times 10^{6}\right)^{2} \times 10.42 \times 260.42}{42^{4}}} \\
=1196668 \mathrm{lb}-\text { inch } \\
\lambda \phi M_{n}=0.75 \times 0.7 \times 1196668=628251 \mathrm{lb}-\text { inch }=52354 \mathrm{lb}-\mathrm{ft} \\
M_{u}(=10000 \mathrm{lb}-\mathrm{ft})<\lambda \phi M_{n}(=52354 \mathrm{lb}-\mathrm{ft})
\end{gathered}
$$

\section{Checks for Shear Design of Lower Girt (I-Section\#IB980)}


From Equation 5.3.1-1 [1],

$$
\begin{gathered}
V_{u} \leq \lambda \phi V_{n} \\
V_{u}=\text { Required shear strength } \\
\phi=\text { Required factor for shear }=0.65 \\
\lambda=\text { Time factor }=0.75 \\
V_{n}=\text { Nominal shear strength } \\
V_{u}=\frac{w L}{2}=\frac{1125.3 \times 9}{2}=5064 \mathrm{lbs}
\end{gathered}
$$

8.3.2.2.3.4. Nominal Strength of Lower Girt due to Material Rupture in Shear

From Equation 5.3.2-1 [1],

$$
\begin{gathered}
V_{n}=F_{L T}^{v} A_{s}=5500 \times 9.5=52250 \mathrm{lbs} \\
\lambda \phi V_{n}=0.75 \times 0.65 \times 52250=25472 \mathrm{lbs} \\
V_{u}(=5064 \mathrm{lbs})<\lambda \phi V_{n}(=25472 \mathrm{lbs})
\end{gathered}
$$

8.3.2.2.3.5. Nominal Strength of Lower Girt due to Web-Shear Buckling

From Equation 5.3.3-1 [1],

$$
\begin{gathered}
V_{n}=f_{c r} h t_{w} \\
2 G_{L T, w}+E_{L, w}^{c} v_{T, w} \leq ? \sqrt{E_{L, w}^{c} E_{T, w}^{c}} \\
2 \times 0.5 \times 10^{6}+3 \times 10^{6} \times 0.12 \leq ? \sqrt{3 \times 1.4} \times 10^{6} \\
1.36<2.05
\end{gathered}
$$

From Equation 5.3.3-2 [1],

$$
f_{c r}=\frac{t_{w}^{2} K_{L T} \sqrt[4]{E_{L, w}^{c}\left(E_{T, w}^{c}\right)^{3}}}{3 h^{2}}
$$


From Equation 5.3.3-3 [1],

$$
\begin{gathered}
K_{L T}=8.1+5.0 \frac{2 G_{L T, w}+E_{L, w}^{c} v_{T, w}}{\sqrt{E_{L, w}^{c} E_{T, w}^{c}}} \\
=8.1+5.0 \frac{2 \times 0.5 \times 10^{6}+3 \times 10^{6} \times 0.12}{\sqrt{3 \times 1.4} \times 10^{6}} \\
=11.42 \\
f_{c r}=\frac{0.5^{2} \times 11.42 \times \sqrt[4]{3 \times 10^{6}\left(1.4 \times 10^{6}\right)^{3}}}{3 \times 10^{2}}=16120 \mathrm{psi} \\
V_{n}=16120 \times 10 \times 0.5=80600 \mathrm{lbs} \\
\lambda \phi V_{n}=0.75 \times 0.65 \times 80600=39292 \mathrm{lbs} \\
V_{u}(=10000 \mathrm{lbs})<\lambda \phi V_{n}(=39292 \mathrm{lbs}) \quad \mathbf{~ O K}
\end{gathered}
$$




\section{CHAPTER 9 - RECOMMENDATIONS}

\subsection{Introduction}

The objective of this research program was to investigate the behavior of pultruded GFRP composite sections under combined bending and torsion because no such research was conducted in the past.

The complete research consisted of: (i) the laminate properties were investigated, mainly through different types of tests as described in Chapter 4 and also through CLT, (ii) flexural behavior of these members was investigated through a number of bending tests as in Chapter 5, (iii) torsional behavior of pultruded sections was investigated as described in Chapter 6, and (iv) combined bending and torsional behavior was evaluated through different combinations of bending and torsional moment values.

In many cases, the experimental behavior correlated well with mathematical and empirical formulation, primarily based on Classical Laminate Theory. However, variations were also observed in a number of cases owing to a variety of reasons. Specific conclusions were drawn and reported in Chapters 5, 6 and 7 on FRP sections under bending, torsion and combined loads respectively. Hence they are not repeated herein.

Based on experimental behavior and analysis of pultruded FRP composite sections, following recommendations can be made.

\subsection{Laminate Properties}

FRP composite sections have different properties in different directions, primarily depending upon fiber volume fraction and fiber orientation. However, during manufacturing process, alignment and distribution of fiber cannot be fully controlled, as shown in Figure 4-11 and 4-12. Therefore, the properties cannot be as consistent as in metals which have a definite crystal lattice. Therefore, it is important to conduct coupon testing under tension, bending, shear and 
torsion to establish mechanical properties including failure strengths and stiffnesses instead of relying solely on CLT

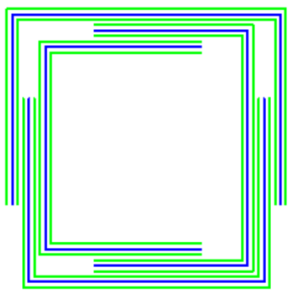

Figure 9-1: Arrangement of Laminae in the Cross-section of a Box Beam

In Figure 9-1, typical arrangement of continuous strand mat (CSM) and unidirectional rovings in the cross-section of a box beam is shown in green and blue lines respectively. It can be seen that in the middle of face, there are 6 layers of CSM and 3 layers of rovings. Near the corners, there are 4 CSM layers and 2 layers of rovings. When test-coupons are cut, harvesting location along cross section plays a key-role in determining elastic properties. Therefore, it is recommended that coupons should be cut along the whole width of at least one flange and one web. After testing, the values should not be averaged but the minimum of the two should be selected for design purpose.

\subsection{Section Properties}

It can be concluded that the test procedure of 3- and 4-point bending tests is straight forward and the test results are reliable. The torsion tests are also reliable except for CP-Round-6 $\times 0.25-70$ sample, for which a heavy duty apparatus may be suitable.

In combined loading tests, some of the samples took unexpectedly high loads. For example, the BRP-Box- $6 \times 6 \times 0.375-70$ sample at $0.9 \mathrm{M}_{\max }$ broke at around $0.9 \mathrm{~T}_{\max }$. It was found that the time for this test was only 137 seconds, as compared to 420 seconds for the other sample. Sometimes, test-samples need more time to respond to load. If load-rate of this sample were slower, there was a chance that it could fail at less load. In this research program, load rate was controlled manually, which was not uniform for all cases. It is recommended that a uniform load-rate 
should be applied to all cases. Similarly, owing to anisotropic nature of pultruded samples, it is recommended to test two samples at each load condition, though it would be a laborious exercise.

\subsection{Analytical Model}

Analytical model for combined bending and torsion of thin-walled orthotropic sections was developed by extending the one for thin-walled isotropic sections, as given in section 7.2.2. A typical approach for this kind of analysis is to identify the parameters based upon isotropic material properties and replace them with orthotropic material properties. The final solution is arrived at by solving in the form of differential equations 7-67 thru 7-70 into appropriate boundary conditions and using orthotropic section properties are given in Equations 7-71 thru 781.

It is recommended that the derived differential equations should be solved by employing appropriate boundary conditions to find the final results. 


\section{REFERENCES}

1. ASCE LRFD Manual for Pultruded Fiber Reinforced Polymer (FRP) Structures (Draft)

2. Bank, L C., "Composites for Construction", John Wiley and Sons Inc., 2006

3. Barbero, E.J., "Introduction to Composite Materials design", CRC Press, 2010

4. Barbero, E.J., "Finite Element Analysis of Composite Materials", CRC Press, 2008

5. Bleich , F., "Buckling Strength of Metal Structures", McGraw Hill Book Compay, 1952

6. Chen B. Z., and Hu, Y., "The Torsional Stiffness Matrix of a Thin-Walled Beam and Its Application to Beam Under Combined Loading", Journal of Computers and structures, 28(3), 421-431, 1988

7. Creative Pultrusions Inc., "The Pultex Pultrusion Design Manual”, Volume 4, Revision 6, http://www.creativepultrusions.com/LitLibrary/designmanual/dmv4r6.pdf, 2004

8. Davalos, J. F., Qiao, P., and Salim, H. A., "Flexural-Torsional Buckling of Pultruded Fiber Reinforced Plastic Composite I-Beams: Experimental and Analytical Evaluations", Journal of Composite structures, 38(1-4), 241-250, 1997

9. Davalos, J. F., Qiao, P., Wang, J., Salim, H. A., and Schlussel, J., "Shear Moduli of Structural Composites from Torsion Tests”, Journal of Composite Materials, 36(10), 2002

10. Davalos, J. F., Salim, H. A., Qiao, P., Lopez-Anido, R., and Barbero, E. J., “Analysis and Design of Pultruded FRP Shapes under Bending", Journal of Composites: Part B, 27B, 295305,1996

11. Salim, H. A., and Davalos, J. F., "Torsion of Open and Closed Thin-Walled Laminated Composite Sections", Journal of Composite materials, 39(6), 2005

12. Eurocode No. 3, "Design of Steel structures Part I - General Rules and Rules for Bulidings (Draft)", Commission of the European Communities, 1988

13. Gjelsvik, A., "The Theory of Thin Walled Bars", John Wiley and Sons, 1981

14. Kollar, L.P. and Springer, G.S., "Mechanics of Composite Structures", Cambridge University Press, 2003

15. Lee D. J., "The Local Buckling Coefficient for Orthotropic Structural sections”, Aeronautical Journal, 313-320, 1978

16. Lekhnitski, S.G., "Anisotropic Plates”, Gordon and Breach, 1968

17. Librescu, L. and Song, O., “Thin-Walled Composite Beams”, Springer, 2006 
18. Miracle, D.B. and Donaldson, S.N., "Introduction to Composites", ASM Handbook Vol. 21: Composites (Donaldson and Miracle, Ed.), ASM International, 2001

19. Mottram, J.T., "Lateral-torsional buckling of a pultruded I-beam”, Composites, 23(2), 81-92, 1992

20. Mottram, J.T., "Shear Modulus of standard Pultruded Fiber Reinforced Plastic Material", Journal of Composites for Construction, 8(2), 141-47, 2004

21. Nagaraj, V., and GangaRao, H. V. S., "Static Behaviour of Pultruded GFRP Beams”, Journal of Composites for Construction, 1(3), 120-129, 1997

22. Omidvar, B., "Shear Coefficients in Orthotropic Thin-Walled Composite Beams", Journal of Composites for Construction, 2(1), 46-56, 1998

23. Prachasaree, W., "Performance evaluation of FRP Bridge deck under Shear Loads", Dissertation, West Virginia university, 2005

24. Roberts, T.M. and Al-Ubaidi, "Flexural and Torsional Properties of Pultruded Fiber Reinforced Plastic I-Profiles”, Journal of Composites for Construction, 6(1), 28-34, 2002

25. Roberts, T.M. and Al-Ubaidi, "Influence of shear deformation on restrained torsional warping of pultruded FRP bars of open cross-section", Thin-Walled Structures, 39, 395-14, 2001

26. Roberts, T.M. and Masri, H.M.K.J.H., "Section Properties and Buckling Behavior of Pultruded FRP Profiles", Journal of Reinforced Plastics and Composites, 22(14), 1305-13, 2003

27. Roberts, T.M., "Influence of Shear Deformation on Buckling of Pultruded Fiber Reinforced Plastic Profiles", Journal of Composites for Construction, 6(4), 241-48, 2002

28. Salim, H.A., "Modeling and Application of Thin Walled Composite Beams in Bending and Torsion", Dissertation, West Virginia University, 1996

29. Salim, H.A., and Davalos, J.F., "Torsion of Open and Closed Thin-Walled Laminated Composite Sections", Journal of Composite Materials, 39(6), 497-28, 2005

30. Timoshenko, S.P. and Gere, J.M., "Theory of Elastic stability”, McGraw-Hill Book Co, 1961

31. Whitney, J.M., "Structural Analysis of Laminated Anisotropic Plates", Technomic Publishing Company, 1987

32. Cowper, G.R., “The Shear Coefficient in Timoshenko's Beam Theory”, Journal of Applied Mechanics, 33, 335-340, 1966 
33. Cowper, G.R., "On the Accuracy of Timoshenko's Beam Theory", Proceedings of ASCE EM6, 94, 1447-1453, 1968

34. Beer, F.P. and Johnston, E.R., "Mechanics of Materials", McGraw Hill Book Company, 2003

35. Pilkey, W.D., "Peterson's Stress Concentration Factors", John Wiley and Sons, Inc., 1997

36. Prachasaree, W., GangaRao, H.V.S. and Shekar, V., "Performance Evaluation of FRP Bridge Decks Under Shear Loads", Journal of Composite Materials, 43(4), 377-395

37. Pultex Protrusion Design Manual, www.creativepultrusions.com/LitLibrary/designmanual/dmv4r6.pdf

38. Carlsson, L.A. and Pipes, R.B., "Experimental Characterization of Advanced Composite Materials", Technomic Publishing Company, 1997

39. Gea, H.C. and Luo, J.H., "On the Stress-based and Strain-based Methods for Predicting Optimal Orientation of Orthotropic Materials", Structural and Multidisciplinary Optimization, 26, 229-234, 2004

40. Tan, S.G., "Stress Concentrations in Laminated Composites", Technomic Publishing Company, 1994 


\section{APPENDIX-A: Classical Laminate Theory (CLT)}

Basic features of the Classical Laminate Theory can be summarized as under:

From rule of mixtures, the longitudinal modulus of elasticity $\mathrm{E}_{1}$ is

$$
E_{1}=E_{f} V_{f}+E_{m}\left(1-V_{f}\right)
$$

where $E_{f}$ and $E_{m}$ refer to the moduli of elasticity of the fiber and the matrix respectively and $V_{f}$ refers to the fiber volume fraction.

The transverse modulus of elasticity $\mathrm{E}_{2}$ is calculated by the following empirical formula

$$
\begin{gathered}
E_{2}=E_{m}\left[\frac{1+2 \eta V_{f}}{1-\eta V_{f}}\right] \\
\eta=\frac{\left(E_{f} / E_{m}\right)-1}{\left(E_{f} / E_{m}\right)+2}
\end{gathered}
$$

Finding $E_{1}$ and $E_{2}$ by coupon tension testing and taking the standard properties of glass fiber and vinylester/polyester matrix, $\mathrm{V}_{\mathrm{f}}$ can be calculated from the above relations. The modulus of rigidity can then be determined as

$$
G_{12}=G_{m} \frac{\left(1+V_{f}\right)+\left(1-V_{f}\right)\left(G_{m} / G_{f}\right)}{\left(1-V_{f}\right)+\left(1+V_{f}\right)\left(G_{m} / G_{f}\right)}
$$

Similarly,

$$
\begin{gathered}
v_{12}=v_{f} V_{f}+v_{m}\left(1-V_{f}\right) \\
v_{21}=\frac{E_{2}}{E_{1}} v_{12}
\end{gathered}
$$

Experimentally,

$$
v_{12}=\frac{\varepsilon_{2}}{\varepsilon_{1}}
$$

where, $\varepsilon_{1}$ and $\varepsilon_{2}$ are the strain-values found in longitudinal and transverse directions in a coupon under a tensile load.

The constitutive equations of 3-dimensional anisotropic materials can be expressed in the general matrix form as [2],

$$
\{\varepsilon\}_{6 \times 1}=[S]_{6 \times 6}\{\sigma\}_{6 \times 1}
$$


Conversely,

$$
\{\sigma\}_{6 \times 1}=[C]_{6 \times 6}\{\varepsilon\}_{6 \times 1}
$$

where $[S]_{6 \times 6}$ and $[C]_{6 \times 6}$ represent the compliance matrix and the stiffness matrix respectively, such that

$$
[C]=[S]^{-1}
$$

For orthotropic materials, the compliance matrix is given by

$$
[S]=\left[\begin{array}{cccccc}
\frac{1}{\mathrm{E}_{1}} & -\frac{v_{21}}{\mathrm{E}_{2}} & -\frac{v_{31}}{\mathrm{E}_{3}} & 0 & 0 & 0 \\
-\frac{v_{12}}{\mathrm{E}_{1}} & \frac{1}{\mathrm{E}_{2}} & -\frac{v_{32}}{\mathrm{E}_{3}} & 0 & 0 & 0 \\
-\frac{v_{13}}{\mathrm{E}_{1}} & -\frac{v_{23}}{\mathrm{E}_{2}} & \frac{1}{\mathrm{E}_{1}} & 0 & 0 & 0 \\
0 & 0 & 0 & \frac{1}{\mathrm{G}_{23}} & 0 & 0 \\
0 & 0 & 0 & 0 & \frac{1}{\mathrm{G}_{13}} & 0 \\
0 & 0 & 0 & 0 & 0 & \frac{1}{\mathrm{G}_{12}}
\end{array}\right]
$$

The 2-dimensional approximation involves, $\sigma_{3}=0, \sigma_{4}=\tau_{13}=0, \sigma_{5}=\tau_{23}=0$. Hence,

$$
\left\{\begin{array}{l}
\varepsilon_{1} \\
\varepsilon_{2} \\
\varepsilon_{6}
\end{array}\right\}=\left[\begin{array}{ccc}
\frac{1}{E_{1}} & -\frac{v_{12}}{E_{1}} & 0 \\
-\frac{v_{12}}{E_{1}} & \frac{1}{E_{2}} & 0 \\
0 & 0 & \frac{1}{G_{12}}
\end{array}\right]\left\{\begin{array}{l}
\sigma_{1} \\
\sigma_{2} \\
\sigma_{6}
\end{array}\right\}
$$

or,

$$
\{\varepsilon\}_{3 \times 1}=[S]_{3 \times 3}\{\sigma\}_{3 \times 1}
$$

Then, 


$$
[Q]=[S]^{-1}=\left[\begin{array}{ccc}
\frac{E_{1}}{1-v_{12} v_{21}} & \frac{v_{21} E_{1}}{1-v_{12} v_{21}} & 0 \\
\frac{v_{21} E_{1}}{1-v_{12} v_{21}} & \frac{E_{2}}{1-v_{12} v_{21}} & 0 \\
0 & 0 & G_{12}
\end{array}\right]
$$

Stress transformation matrix $\left[\mathrm{T}_{\sigma}\right]$ and strain transformation matrix $\left[\mathrm{T}_{\varepsilon}\right]$ are used to transform stress / strain from load-axis (off-axis) to material-axis (on-axis) and are given by,

$$
\begin{gathered}
{\left[T_{\sigma}\right]=\left[\begin{array}{ccc}
m^{2} & n^{2} & 2 m n \\
n^{2} & m^{2} & -2 m n \\
-m n & m n & m^{2}-n^{2}
\end{array}\right]} \\
{\left[T_{\varepsilon}\right]=\left[\begin{array}{ccc}
m^{2} & n^{2} & m n \\
n^{2} & m^{2} & -m n \\
-2 m n & 2 m n & m^{2}-n^{2}
\end{array}\right]}
\end{gathered}
$$

where $\mathrm{m}=\cos \theta$ and $\mathrm{n}=\sin \theta, \theta$ being the angle between off-axis and on-axis.

The off-axis compliance and stiffness matrix are then given by,

$$
\begin{aligned}
& {[\bar{S}]=\left[T_{\varepsilon}\right]^{-1}[S]\left[T_{\sigma}\right]} \\
& {[\bar{Q}]=\left[T_{\sigma}\right]^{-1}[Q]\left[T_{\varepsilon}\right]}
\end{aligned}
$$

The constitutive equation of a general (unsymmetrical) laminate, consisting of $\mathrm{n}$ unidirectional layers of thickness $t_{k}$ each, is written as

$$
\left\{\begin{array}{c}
N_{x} \\
N_{y} \\
N_{x y} \\
M_{x} \\
M_{y} \\
M_{x y}
\end{array}\right\}=\left[\begin{array}{ll}
{[A]} & {[B]} \\
{[B]} & {[D]}
\end{array}\right]_{6 \times 6}\left\{\begin{array}{c}
\varepsilon_{x o} \\
\varepsilon_{y o} \\
\gamma_{x y o} \\
\kappa_{x} \\
\kappa_{y} \\
\kappa_{x y}
\end{array}\right\}
$$

where $\mathrm{N}$ and $\mathrm{M}$ refer to loads and moments, $\varepsilon$ and $\nu$ refer to strains, $\mathrm{k}$ refers to curvature, $\mathrm{x}$ an $\mathrm{y}$ refer to the axes, and o stands for the mid-plane.

In-plane stiffness matrix 


$$
[A]_{3 \times 3}=\sum_{k=1}^{n}[\bar{Q}]_{k} t_{k}
$$

Laminate coupling stiffness matrix

$$
[B]_{3 \times 3}=\sum_{k=1}^{n}[\bar{Q}]_{k} t_{k} \bar{z}_{k}
$$

Laminate bending stiffness matrix

$$
[D]_{3 \times 3}=\sum_{k=1}^{n}[Q]_{k}\left(t_{k} \bar{z}_{k}^{2}+\frac{t_{k}^{3}}{12}\right)
$$

$$
\bar{z}_{k}=\text { distance from middle of laminate to middle of } \mathrm{k}^{\text {th }} \text { lamina }
$$

For orthotropic laminates

$$
\begin{aligned}
& {[A]=\left[\begin{array}{ccc}
A_{11} & A_{12} & 0 \\
A_{12} & A_{22} & 0 \\
0 & 0 & A_{66}
\end{array}\right]} \\
& {[B]=\left[\begin{array}{ccc}
B_{11} & B_{12} & 0 \\
B_{12} & B_{22} & 0 \\
0 & 0 & B_{66}
\end{array}\right]} \\
& {[D]=\left[\begin{array}{ccc}
D_{11} & D_{12} & 0 \\
D_{12} & D_{22} & 0 \\
0 & 0 & D_{66}
\end{array}\right]}
\end{aligned}
$$




\section{APPENDIX-B: Finding the Fiber Volume Fraction $\left(V_{f}\right)$}

Fiber volume fraction of a fiber reinforced polymer composite material can generally be found by any of the following methods [38]:

1. Chemical Dissolution

2. Burnout Test

3. Scanning Electron Microscopy
a. Area Method
b. Line Method

The SEM line method is illustrated in Figure B-1. On the scanning electron micrograph, a number of lines were randomly drawn. For each line, length occupied by the fiber was measured and its ratio with the total line length gave the fiber volume fraction; the final value being the average of all the calculated values.

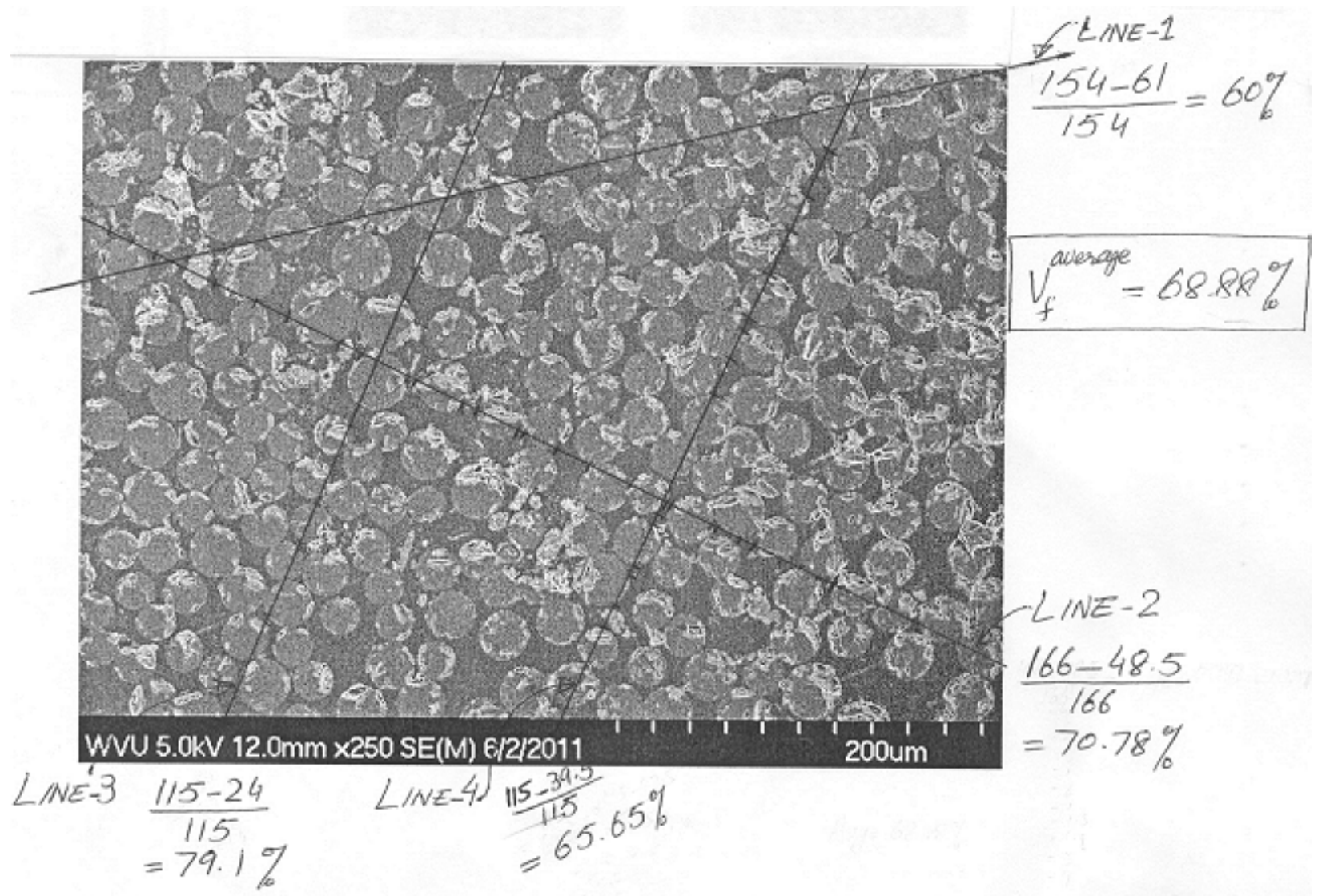

Figure B-1: SEM Line Method of finding fiber volume fraction 


\section{APPENDIX-C: FEA Results of Local Load Effects}

\section{Specimen: BRP-Box-6x6x3/8- 36}

Specimen portion under consideration: Central portion, 3" wide

Applied load $=1 \mathrm{Lb}$ at the center of the beam

\section{Stress Values at Nodes at Right- and Left-Web}

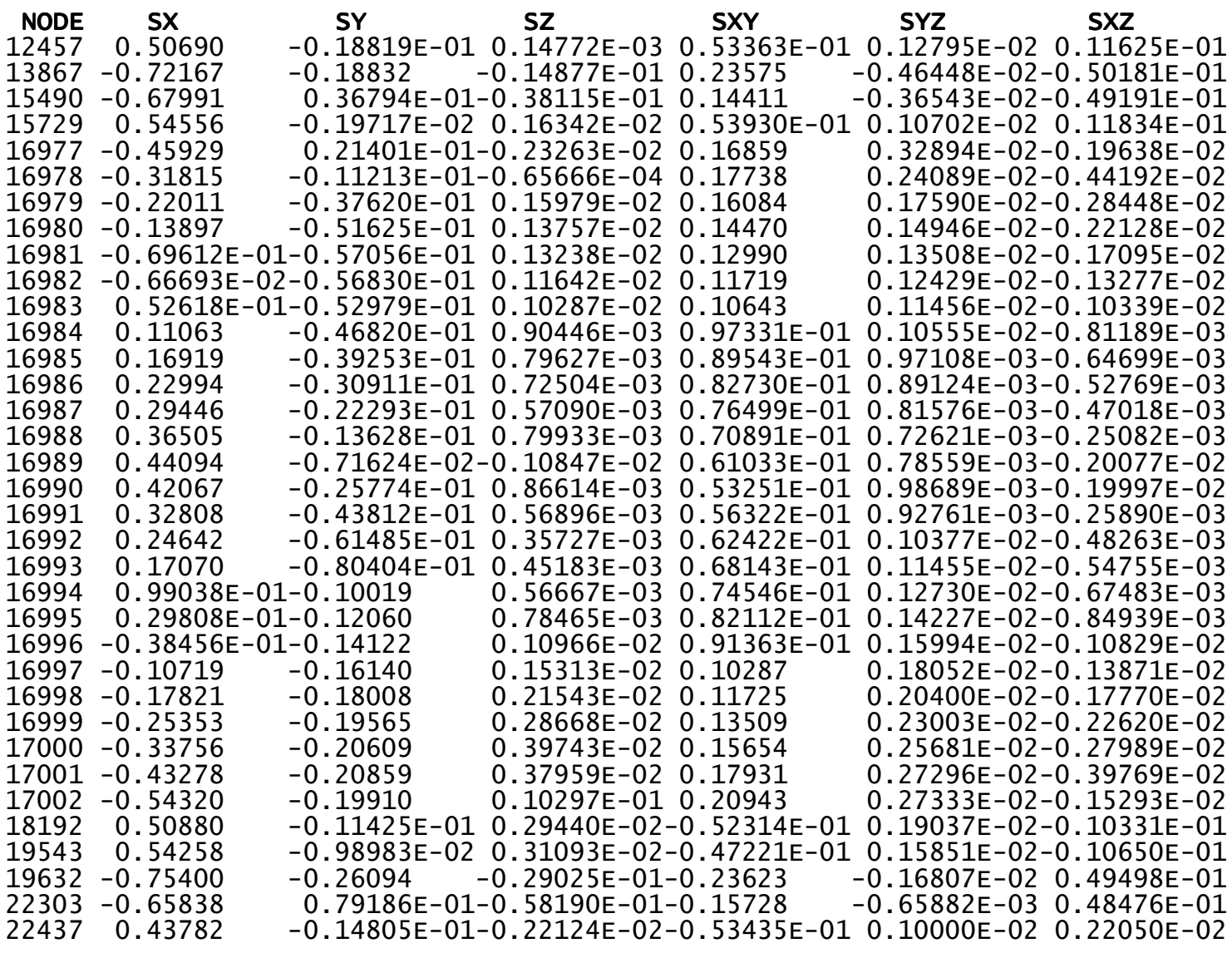

\begin{tabular}{rllllcc} 
NODE & \multicolumn{1}{|l}{ SX } & SY & SZ & SXY & SYZ & SXZ \\
22438 & 0.36404 & $-0.20442 \mathrm{E}-01$ & $0.57066 \mathrm{E}-03-0.62575 \mathrm{E}-01$ & $0.97109 \mathrm{E}-03$ & $0.38878 \mathrm{E}-03$ \\
22439 & 0.29552 & $-0.28536 \mathrm{E}-01$ & $0.21786 \mathrm{E}-03-0.67907 \mathrm{E}-01$ & $0.10643 \mathrm{E}-02$ & $0.50500 \mathrm{E}-03$ \\
22440 & 0.23362 & $-0.36642 \mathrm{E}-01$ & $0.51211 \mathrm{E}-03-0.73986 \mathrm{E}-01$ & $0.11592 \mathrm{E}-02$ & $0.44497 \mathrm{E}-03$ \\
22441 & 0.17597 & $-0.44545 \mathrm{E}-01$ & $0.65591 \mathrm{E}-03-0.80789 \mathrm{E}-01$ & $0.12669 \mathrm{E}-02$ & $0.43864 \mathrm{E}-03$ \\
22442 & 0.12114 & $-0.51682 \mathrm{E}-01$ & $0.86854 \mathrm{E}-03-0.88726 \mathrm{E}-01$ & $0.13962 \mathrm{E}-02$ & $0.46200 \mathrm{E}-03$ \\
22443 & $0.67633 \mathrm{E}-01-0.57319 \mathrm{E}-01$ & $0.11241 \mathrm{E}-02-0.98196 \mathrm{E}-01$ & $0.15562 \mathrm{E}-02$ & $0.52382 \mathrm{E}-03$ \\
22444 & $0.13911 \mathrm{E}-01-0.60338 \mathrm{E}-01$ & $0.14412 \mathrm{E}-02-0.10967$ & $0.17640 \mathrm{E}-02$ & $0.63500 \mathrm{E}-03$ \\
22445 & $-0.42054 \mathrm{E}-01-0.58972 \mathrm{E}-01$ & $0.19294 \mathrm{E}-02-0.12367$ & $0.20517 \mathrm{E}-02$ & $0.81328 \mathrm{E}-03$ \\
22446 & -0.10259 & $-0.50247 \mathrm{E}-01$ & $0.23863 \mathrm{E}-02-0.14074$ & $0.25000 \mathrm{E}-02$ & $0.11141 \mathrm{E}-02$ \\
22447 & -0.17305 & $-0.29584 \mathrm{E}-01$ & $0.37575 \mathrm{E}-02-0.16061$ & $0.32894 \mathrm{E}-02$ & $0.16498 \mathrm{E}-02$ \\
22448 & -0.26104 & $0.85502 \mathrm{E}-02$ & $0.12163 \mathrm{E}-02-0.18254$ & $0.47909 \mathrm{E}-02$ & $0.35801 \mathrm{E}-02$ \\
22449 & -0.39585 & $0.58582 \mathrm{E}-01$ & $0.43316 \mathrm{E}-02-0.17977$ & $0.67062 \mathrm{E}-02$ & $0.21450 \mathrm{E}-02$ \\
22450 & 0.42041 & $-0.19560 \mathrm{E}-01$ & $0.84683 \mathrm{E}-03-0.53593 \mathrm{E}-01$ & $0.12386 \mathrm{E}-02$ & $0.21250 \mathrm{E}-02$ \\
22451 & 0.32655 & $-0.39457 \mathrm{E}-01$ & $0.12142 \mathrm{E}-02-0.58387 \mathrm{E}-01$ & $0.11578 \mathrm{E}-02$ & $0.41687 \mathrm{E}-03$ \\
22452 & 0.24328 & $-0.59150 \mathrm{E}-01$ & $0.69748 \mathrm{E}-03-0.65731 \mathrm{E}-01$ & $0.12872 \mathrm{E}-02$ & $0.51307 \mathrm{E}-03$
\end{tabular}




$\begin{array}{lll}22453 & 0.16595 & -0.80197 \mathrm{E}-01 \\ 22454 & 0.92433 \mathrm{E}-01-0.10234 \\ 22455 & 0.21045 \mathrm{E}-01-0.12544 \\ 22456 & -0.49834 \mathrm{E}-01-0.14927 \\ 22457 & -0.12184 & -0.17344 \\ 22458 & -0.19706 & -0.19735 \\ 22459 & -0.27788 & -0.22008 \\ 22460 & -0.36886 & -0.24071 \\ 22461 & -0.47101 & -0.25717 \\ 22462 & -0.58297 & -0.26600\end{array}$

$0.74805 E-03-0.72466 E-01 \quad 0.14127 E-02 \quad 0.46754 E-03$ $0.74212 \mathrm{E}-03-0.79603 \mathrm{E}-01 \quad 0.15727 \mathrm{E}-02 \quad 0.46837 \mathrm{E}-03$ $0.84566 \mathrm{E}-03-0.87602 \mathrm{E}-01 \quad 0.17733 \mathrm{E}-02 \quad 0.50360 \mathrm{E}-03$ $0.10185 \mathrm{E}-02-0.96963 \mathrm{E}-01 \quad 0.20310 \mathrm{E}-02 \quad 0.57988 \mathrm{E}-03$ $0.12668 \mathrm{E}-02-0.10823 \quad 0.23667 \mathrm{E}-02 \quad 0.70685 \mathrm{E}-03$ $0.16631 \mathrm{E}-02-0.12199 \quad 0.28147 \mathrm{E}-02 \quad 0.90164 \mathrm{E}-03$ $0.18892 \mathrm{E}-02-0.13882 \quad 0.34328 \mathrm{E}-02 \quad 0.11955 \mathrm{E}-02$ $0.28129 \mathrm{E}-02-0.15888 \quad 0.42847 \mathrm{E}-02 \quad 0.16311 \mathrm{E}-02$ $0.81748 \mathrm{E}-03-0.18036 \quad 0.52277 \mathrm{E}-02 \quad 0.30403 \mathrm{E}-02$ $0.12926 \mathrm{E}-01-0.20948 \quad 0.61438 \mathrm{E}-02 \quad 0.16856 \mathrm{E}-02$

MINIMUM VALUES

NODE 19632

VALUE -0.75400

\section{2}

$-0.26600$

22303

19632

$-0.58190 \mathrm{E}-01-0.23623$

13867

$-0.46448 \mathrm{E}-02-0.50181 \mathrm{E}-01$

MAXIMUM VALUES

NODE $\quad 15729$

22303

22462

13867

22449

19632

VALUE

0.54556

$\begin{array}{lll}0.79186 \mathrm{E}-01 & 0.12926 \mathrm{E}-01 & 0.23575\end{array}$

$0.67062 \mathrm{E}-02 \quad 0.49498 \mathrm{E}-01$

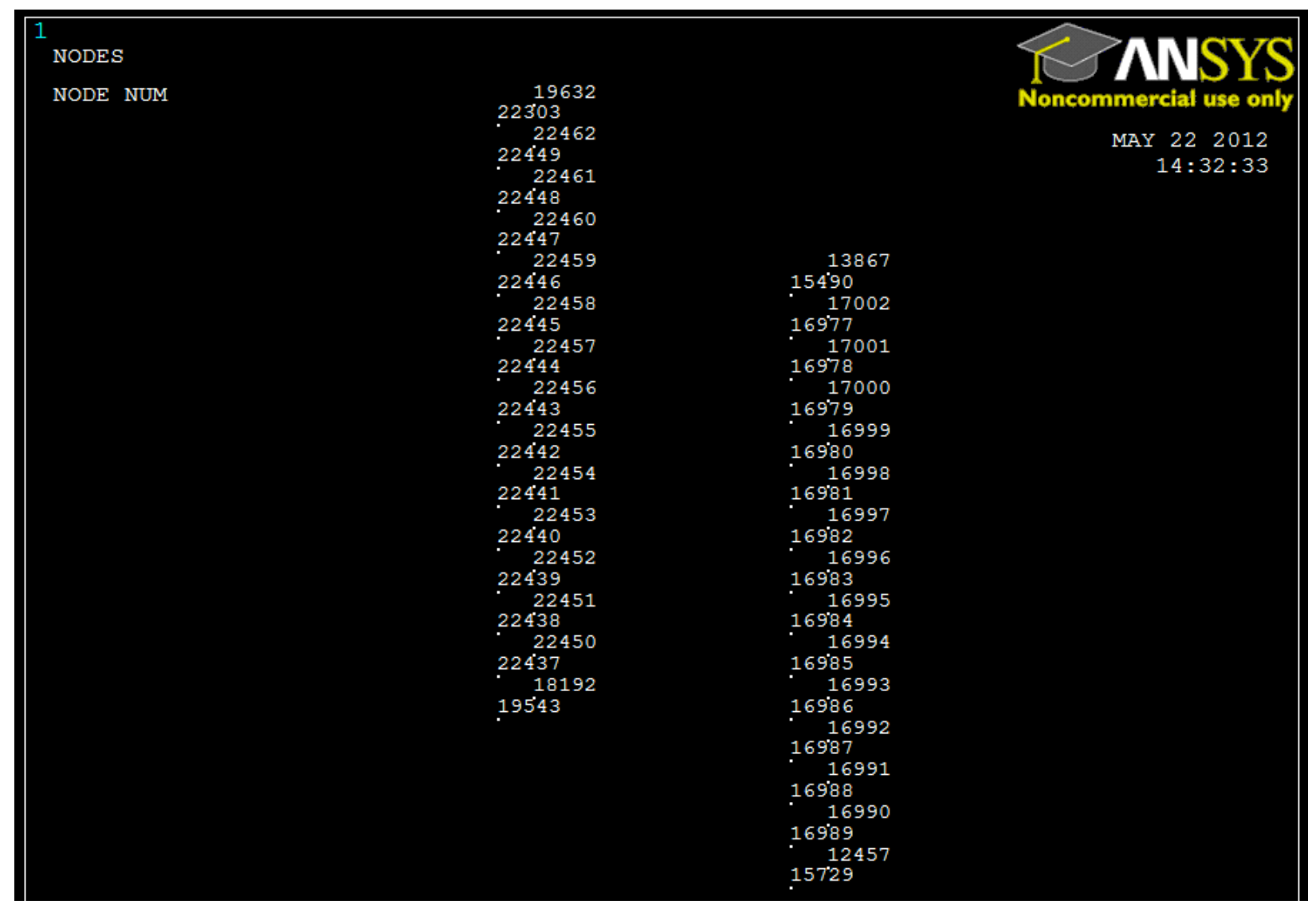

Figure C-1: Nodal points at right- and left-webs 


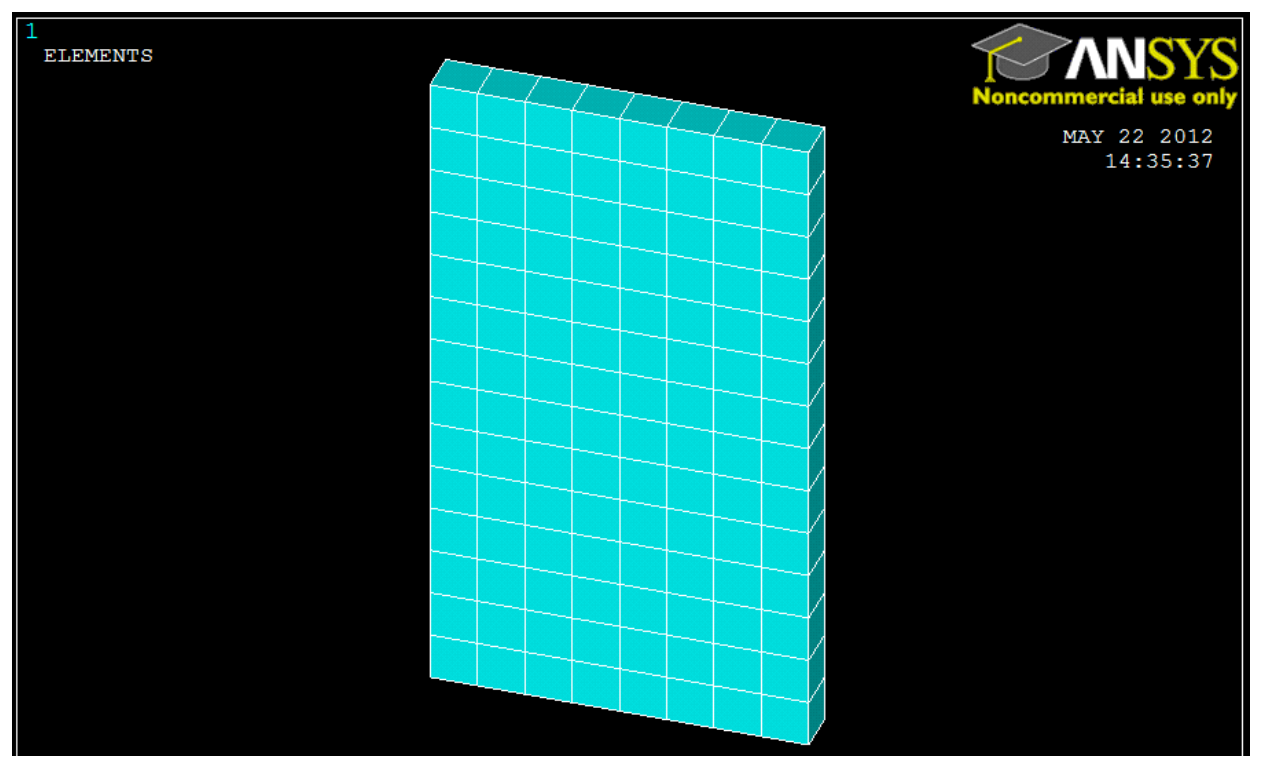

Figure C-2: 3" wide web portion 


\section{APPENDIX-D: Torsional Behavior of a Wide-Flange Section}

As the open FRP sections have very low torsional strength, a wide-flange section cannot be tested under torsion in the same way as a box section is tested. For this purpose, the load cell and metallic cable around the cylinder were replaced by a nylon rope and a hanger, as shown in Figure D-1.

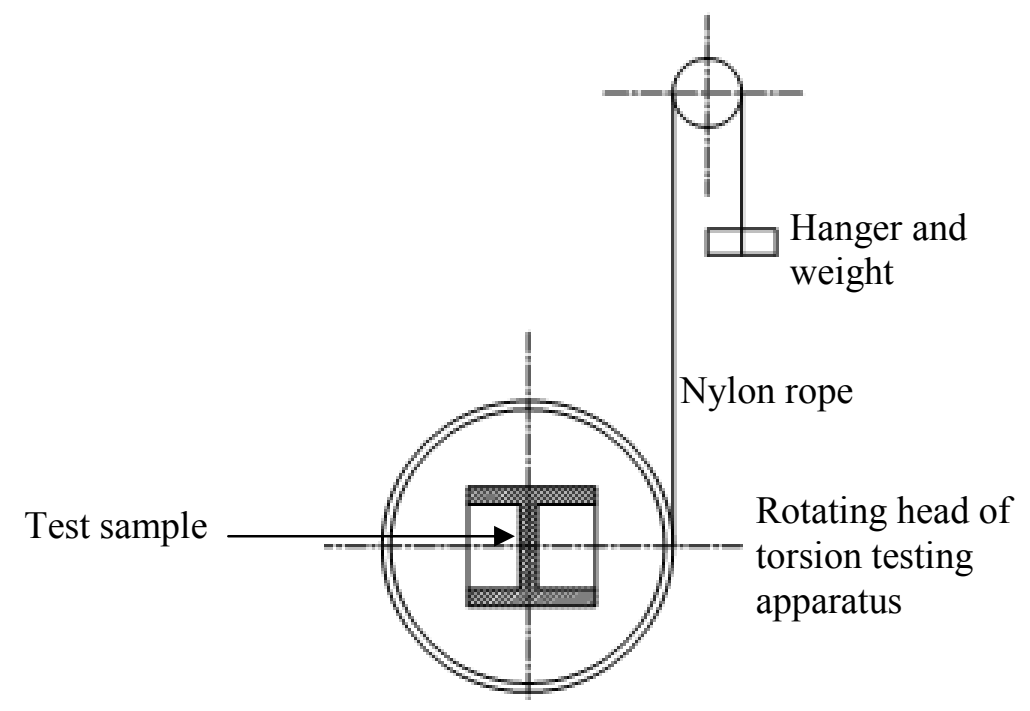

Figure D-1: Torsion Test Setup of Wide-Flange Section

When a $6 \times 6 \times 0.25$ wide-flange section was tested under torsion under this arrangement, the sample started twisting at

$$
T=15(l b s) \times 6.5(i n c h)=97.5 l b-i n c h
$$

It can be therefore be concluded that for any practical purpose, the torsional strength of an open FRP section is negligible. 